THE RELATIONSHIP BETYEEN FOAD ACCIDEITSS END UPBAN

\title{
STPICTURE
}

M.D. HODGKINSOH BSC

(A Thesis submitted for the degree of Doctor of Philosophy)

Department of Ciril Engineering

University of Salford

Hay, 1974 


\section{LIST OF FIGURFS}

1.1.1. The growth in the volume of vehicles in

G.B. 1912 - 1972 .

Page

1.1.2. Population, road notor vehicles, traffic, accidents and casual ty rates 1934 to 1970 (Pord Accidents 1970).

3.2.1. Tro routes to scientific explanation. 21

5.4.1. The road accident systens. 68

6.2.1. The Police Stats 19 Form. 91

7.2.2 Contrasts based on different eizes of collecting units.

8.1.1. Flon diogran of methodological approach.

8.3.1. Possible locations for dezired factors with orthogonal and oblique rotation metiods.

8.6.1. Diagrammatic representation of three trend surfaces.

9.3.5. Three possible residual graph plot abnomalities. 232

9.3.6. Plot of residuals from TC70 ageinst NETT.

9.3.11. Plot of TCPP70 against the regression restauls. 245

9.3.15. " "томито

9.3.16.

9.4.5. Linear trend surface for TC70. 281

9.4.6. Cubic " "TC70. 282

9.4.7. Sixth order trend surface for TC70. 283

9.4.3. Deviations from the cubic trend surface for TC70. 287

9.4.9. Cubic trend surface for TDRC70. 293

9.4.10. The road network system of England and Wales. 294

9.4.11. Deviations from the cubic trend surface for
IDRC70. 


\section{LIST OF FIGURES Contd.....}

9.4.12. Sixth order trend surface for TDRC70. 298

9.4.13. Cubic trend surface for TAPP70. 300

9.4.14. Deviations from the cubic trend surface for TAPP7O.

302

9.4.15. Sixth order trend surface for TAPP7O. 304

9.1.16. Deviations from the sixth order trend surface for TAPP7O.

305

9.4.17. Fifth order trend surface for PEDIT70.

308

9.4.18. Deviations from the fifth order trend surface for PEDiTT70.

9.5.12. Plot of road casual to growth retes (1966 - 1970) against 1966 population.

9.5.14. Plot of standardised group road casual ty grovith rates, means and standard doviations.

9.5.16. Map of the spatial distribution of group standardised road casual to growth rates. 


\section{LIST OF TABLES}

2.2.1 The growth of road casualties 1960 - 1970 (G.B.). $\frac{\text { Page }}{7}$

2.3.1. The growth of pedestrian casualties $1960-70$ (G.B.). 9

2.3.2. The number of pedestrians killed and seriously injured by age groups 1960 - 1970 (G.B.).

2.3.3. Intemational comparison of pedestrian casualties by age groups (1969).

2.6.1. Cost of road accidents $1969-1970$.

4.1.1. The 100 sanpled urban areas.

5.4.2. Correlation matrix for the 22 independent varlables (1970).

6.1.1. List of 22 independent variables (1970).

6.1.2. List of 45 dependent variebles (1970).

6.3.1. Volume of work joumeys as a percentage of total trips, as given by various recent Trensportation Survegs.

6.3.2. Traffic (growth) volume correction factors 1960 1970 using 1966 as the correction base year.

6.3.3. Comparison of some standard shapes using the Haggett Shape Index, and the Blair-BIlss Index.

7.2.1. The "Scelling dorn" method used for Cumbernauld N.T., and some other comparable towns.

7.2.3. Urban population densities under alternative census boundaries.

8.2.1. Normality Tests for the 22 independent variables 1970.

9.2.1. The Variance Ranking for the 100 urban areas 1970. 174

9.2.2 Correlation values between the desired Promax factors $(k=4) 1970$.

9.2.3. Oblique factor pattern inatrix ( 100 Areas, $k=4)$ 1970 - Values $> \pm 0.1$.

9.2.4. Oblique factor structure matrix for 100 urban areas $1970(k=4)-$ Values $> \pm 0.1$. 
9.2.6. Original correlation matrix between variables and principal components - Primary Factor loadings matrix.

9.2.7. Interpretation of derived factors $1966-1970$.

9.2.8. Ilst of 51 count borough areas wi thin the sampled 100 areas.

9.2.9. The basic statistics for the 22 independent variables disaggregated according to type of urban area and including the transformed $\left(\log _{10}\right)$ variables.

9.2.10. The rarlance ranking for the 51 counts borough areas 1970.

9.2.11. Count borough areas factor correlation matrix. $\quad 196$

9.2.12. C.B.S. Oblique factor pattem matrix.

9.2.13. C.B.S. Oblique reference structure matrix.

9.2.14. Interpretation of derived factors 1966 - 1970 for count borough areas.

9.3.1. Composition of the 120 regression equations.

9.3.2. Results of the basic 45 regression equations (1970). 204

9.3.3. Factors included within the 45 regression equations 1970.

9.3.4. Regression ranking for $\mathrm{TC} 70$.

9.3.7. Significent factors within regressions and their 236 comparable transformed variables.

9.3.8. Significent factors within regressions and their comparable coun to borough regressions.

9.3.9. Regression ranking for TA70.

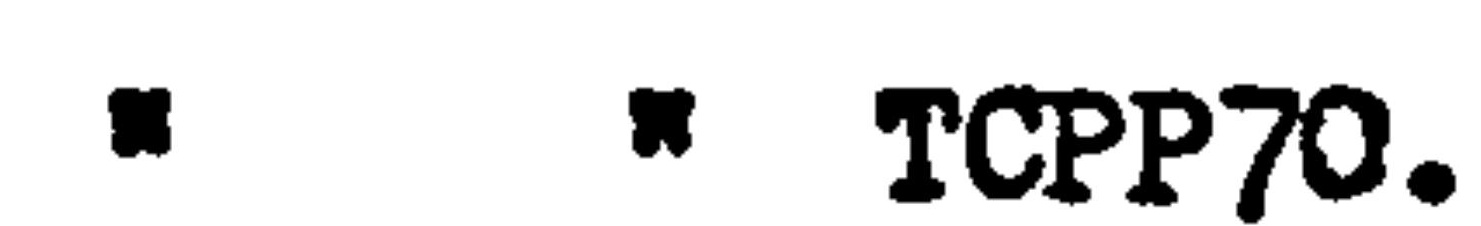


9.4.1. List of the 20 Variables used in the Trend

9.4.2. The explenation level for each order surface of the $\geq 0$ Trend Surface Analyses.

9.4.3. Significance tests for the individual surfaces of the Trend Surface Analysis (F. Values).

9.4.1. Significance tests for the compound surfaces, of the Trend Surface Analysis (F. Values).

9.4.19. Mean Safety Index groupings for TC70.

$\begin{array}{lllllll}9.4 .20 & \text { n } & \text { n } & \text { n } & \text { n } & \text { " TFS70. } \\ 9.4 .21 . & n & n & n & n & \text { n } & \text { TPED70. } \\ 9.4 .22 . & \text { n } & \text { n } & \text { n } & \text { n. } & \text { " TCVM70. } \\ 9.4 .23 . & \text { n } & \text { n } & \text { n } & \text { n } & \text { n } & \text { TPEDET70. }\end{array}$

9.5.1. Time series analysis for simple and transformed variables in relation to Total Casualties.

9.5.2. Confidence intervals for the $b$ coefflcients within the time series analysis of total casualties.

9.5.3. Variation in the influence of the indezendent variable ETT in respect to total casualties 1966 1970. (Significent difference fron zero).

9.5.4. Time series analysis for simple and transformed variables in relation to Total Casualties per 10? population.

9.5.5. Confidence intervals for the $b$ coefficients within the time serles enalysis of total casualties per 103 population.

9.5.6. Time series analysis for simple and transformed variables in relation to total casualties per $10^{6}$ vehicle miles.

9.5.7. Confidence intervals for the $b$ coefficients within the time series enalysis of total casualties per $10^{6}$ vehtcle miles.

9.5.8. Results for the analysis when the level of road accidents in one year is regressed ageinst the level of road accidents in some preceding year. 
9.5.9. Results for the regression modal when the growth in road casualties is regressed ageinst the total volume of road casualties at that time.

9.5.10. Calculated basic statistics for the ennual gro:th rates in road casualties for the 100 urban areas.

9.5.11. Results of $t$ test used to test the significance of the difference between the mean growth rate values for the years 1966 - 1970 .

9.5.13. The grouped urban areas with their orfiginal and standardised growth rates.

9.5.15. Results of the student's $t$ test used in order to test for any significant difference betwecn the growth rate means for different urban groups $(1966-1970)$

10.2.1. The Meen Safety Indices for dependent variables relating to the Hew Town Areas (1970).

10.3.1. Growth rates for the New To:n Areas $(1966$ - 1970) • 374 


\section{CONTENTS}

\section{List of Flgures}

Page

List of Tables

Chapter 1. Introduction

1.1 The Growth in Traffic Volumes

1.2 Effect upon Urban Areas

Chapter 2. The Present Road Accident Situation

2.1 Introduction

2.2 Aggregated National Statistics

2.3 Disaggregated National Statistics

2.4 The Urban Foad Accident Problem

2.5 The New Town Developments

2.6 The Application of Costing Techniques

Chapter 3. Road Accident Analysis - Past and Present 21

3.1 Introduction 21

3.2 Problems within Poad Accident Analysis 21

3.3 Possible Future Developments in Poad Accident Analysis

Chapter 4. The Aims and Scope of the Study 46

4.I Introduction 46

4.2 Research Aims 46

4.3 Spatial Studies - Limitations and Use 51

4.4 Scope of the Study 53

4.5 Sumary of Research Aims 60 
$\checkmark$ Chapter 5. The Road Accident Systern 62

5.1 Introduction 62

5.2 Accident Definitions 62

5.3 Defining and Urban Area 66

5.4 A Suggested Road Accident System Kodel 67

$\checkmark$ Chspter 6. The Data 87

$\begin{array}{lll}6.1 \text { Introduction } & 87\end{array}$

6.2 Dependent Variables 87

6.3 Independent Variables 102

Chepter 7. Methodology I 126

7.1 Introduction $\quad 126$

7.2 "Scaling Down" Method 127

7.3 Application of Probabilits Models 135

VU Chapter 8. Methodology II - Multiole Regression Analysis

8.1 Introduction 143

8.2 The Multiple Regreseion Model . 143

8.3 Princlpal Components Analysis 152

8.1 The Step-kise Regression Hodel 157

8.5 The Study of Festduals 160

8.6 Trend Surfece Snslysis 163

8.7 Temporal Variation Enalysis 167

8.8 Sumnary of Methodology 170 
$\checkmark$ Chapter 9. The Inalysis and Presentation of Results 172

9.1 Introduction $\quad 172$

9.2 The Principal Components Analysis 172

9.3 Multiple Regression Analysis 201

9.1 The Spatial Variation Analysis 273

9.5 Time Series Analysis . 323

9.6 The Study of the Growth of Road Accident
Casualties $1966-1970$
340

Chapter 10. The New Town Areas - A Case Assesswent 364

10.1 Introduction $\quad 364$

10.2 Assessment of the Mean Safety Indices 365

10.3 Assessment of the Growth Rates for the

Hew Town Areas $1966-1970372$

10.4 Summary of the New Torn Response Rates. 378

$\sqrt{ }$ Chepter 11. Conclusions and Possibilities for

Future Research

11.1 Conclusions 377

11.2 Future Research Developments 381

References

Appendix I The Town Classification Index

Appendix 2 Significant Trend Surfece Maps

Appendix 3 Multiple Regression Results

Acknowledgmente 


\section{Chepter I INTFONOCTIOI}

The development of the motor-vehicle as $\varepsilon$ merns of transport has had a distinctly dichotomous impect upon our present soclety. Whilst it has helped to resove the naturel obstructions of distence end space for eny individuel, it has elso created meny problcis, especielly within the urban envirannent, for which there secms to be no imediate solution. If such solutions are to be forthccing In the nerr rutare, it nccessitetes several immedicte courses of action, oll of which in their own turn demend a Ereater emount of reser.rch and consequently a greater understending of the problems Involved.

\subsection{THE GFOHTE III TPAFFIC FOLU:IFS}

The most obvious ceusel factor in regerd to these urben cociel end economic problens is the growth in the number of rotor-velifcles end the conseguent increase in the volune of traffic, as measured by the ennual vehicle milerge.

Since the first motor-vchicle was introouced in to Britein in 1888, the number of vehlcles has fisen at a phenominal rate of growth. (FIE. 1.1.1). From a figure of approximetely 400,000 vehicles in 1914, the number of vehicles increased to 3.0 aillion in 1946, and 14.5 million in 1970. (FMSO 1972). That represents en increese of almost 500\% in under 25 jears, (1946-1970). 


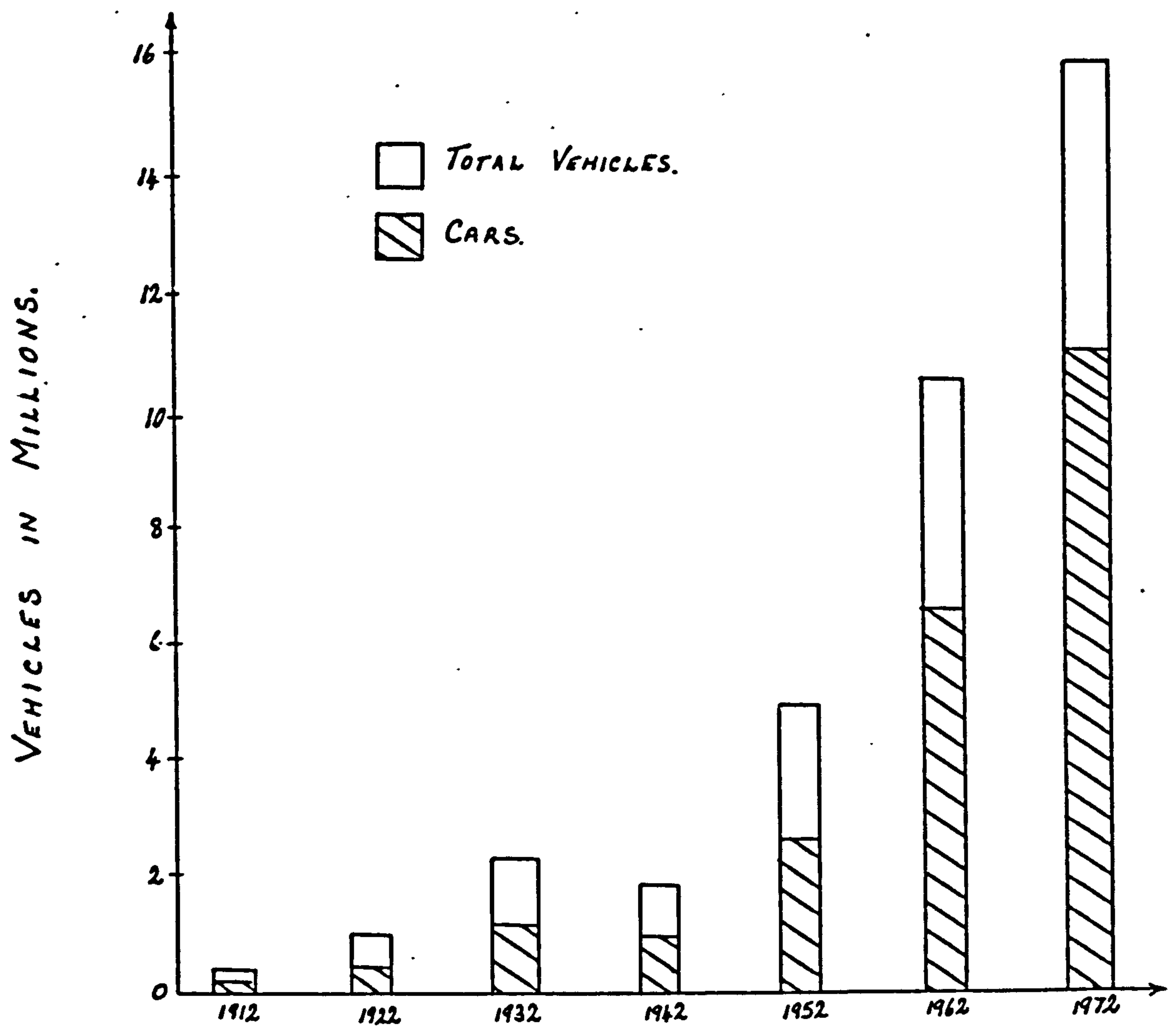

Fig. 1.1.1. THE GROWTH IN THE VOLUME OF VEHICLES IN G.B. 1912 - 1972 . 
A similer increase can also be noted in the growth of vehicle mileage. These flgires are based on the regular traffic cencus returns of the Department of the Environment and the Transport and Road Research Laboratory (TFFL). If one takes the index of vehicle mileage for motor traffic in 1949 as being equal to 100, the compareble index for 1970 is 444. (FIE. 1.1.2).

\subsection{EFFECT UPON URBAN AFFAS}

As already mentioned, the areas where these rapid growth rates have had the most striking effect have tended to be the larger centres of population and urban areas in generel. The problem can be simply generelised by stating that most urban structures are the result of slow evolution since the time of the post-industrial revolution, to the present day, with the consecuent result that most of these developed structures are unable to accommodate the increased traffic volumes, nor are they able to alter repicly enough to create a satisfactory alternative environnent. For this reason, most of the present urban environments can be vlewed as inadequate to deal with the present urban transportation problem. This inadequacy cen be seen in two ways. Firstiy it is epitomised by the varying degrees of urban blight and sociel deprivation evident in áll urban areos, especially where the conflict between the development of the trensport network and the need for greater socinl awareness is most pressing. Secondly it is also epitomised by the high degree of failure within the urban transport system, as indicated by the high level of urban traffic conflicts or casualties. Conceptualised in this vay, road 
(Logaritumic Scanes.)

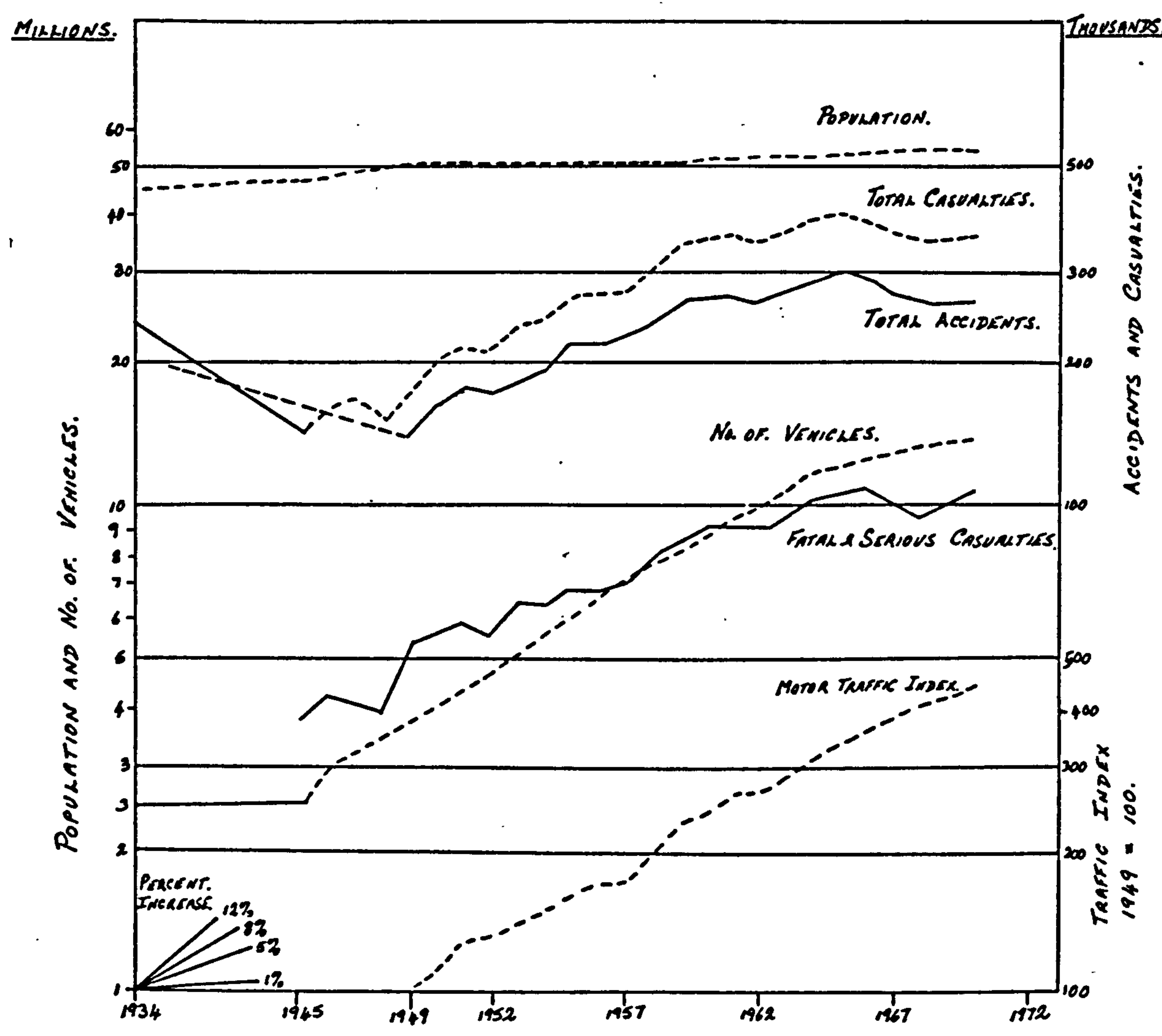

FIg. 1.1.2. POPULATION, POAD MOTOR VEHICLES, TPAFFIC, ACCIDENTS AND CASUALTY RATES 1934 - 1970 (ROAD ACCIDENTS 1970) 
accidents can be seen to be system fallures, or the fallure of the urban structure system to chenge sufficiently to acconmodate the urban traffic system. Consequently, it can be argued that the level or degree of fallure of any one individual area is a function of the degree of change within the urvan structure systen, elther in physical, social or economic tarns. By identifying these ralationships it should then be possible to postulate the optinum lines of research, and intemal modification of the various systens, for the future. However, before this point can be reached, it is necessary to docurnent and classify the degree of fajlure of the various Individual systems, and also the national system as a whole. To achieve this one has initially to look at the present rosd accident situation noting both the present trends and also any anomalies. 


\section{Chapter 2 THE PRESFNT ROAD \&CCIDFNT SITUATION}

\subsection{INTRODUCTTON}

In order to gain some insight into the road accident situation in Britain at present, this chapter atterapts to present the arailable road accident statistics (1970) both at the aggregrated level, and the disaggregated level. A further sub-division is effected by referring to urban road accident statistics, whtch Indicate the serfousness of the problem in built-up urben areas.

\subsection{AGGREGATED NATIONAL STATISTICS}

If one considers the aggregated national statistics in the first instance, it cen be seen that there has been a consistent overall increase in the number of raad casualties, such that in 1960 there were approximately 348,000 people killed or injured on all the roads in Great Britain. (Table 2.2.1). By 1970 the comparable statistic had risen to approximately 365,000 . Perhaps a more meaningful way of representing these flgures is by comparing then to one or other basic variables. For example, if the casualties are related to the motor vehicle mileage index, it can be shown that whilst the number of casualties has doubled orer the last twent years, the index shows that orer the same time period, vehicle mileage has trebled. However, if casualties are related to the Increase in population, the picture is not so good. Road deaths have increased by $57 \%$ over a period when the total population has increased by only 10\%, and therefore the probability of an individual losing his Iife on the rosds has shortened from 150 to 1 , to 100 to 1 . 


\begin{tabular}{|c|c|c|c|c|c|}
\hline \multicolumn{2}{|c|}{ CASUALTIES FROM ROAD ACCIDENTS $\left(10^{3}\right)$} & $\begin{array}{c}\text { ACCIDENTS } \\
\left(10^{3}\right)\end{array}$ \\
\hline YEAR & KILLED & SERIOUS & SLIGHT & TOTAL & \\
\hline 1960 & 7.0 & 84 & 256 & 348 & 272 \\
1961 & 6.9 & 85 & 258 & 350 & 270 \\
1962 & 6.7 & 84 & 251 & 342 & 264 \\
1963 & 6.9 & 88 & 261 & 356 & 272 \\
1964 & 7.8 & 95 & 282 & 385 & 292 \\
1965 & 8.0 & 98 & 292 & 399 & 299 \\
1966 & 8.0 & 100 & 285 & 392 & 292 \\
1967 & 7.3 & 94 & 269 & 370 & 277 \\
1968 & 6.8 & 89 & 254 & 349 & 264 \\
1969 & 7.4 & 91 & 255 & 353 & 262 \\
1970 & 7.5 & 93 & 262 & 363 & 267 \\
& & & & & \\
\hline
\end{tabular}

(ROAD ACCIDENTS 1970)

TAELE 2.2.1. THE GROWTH IN ROAD GASUALTIES 1960-1970 (G.B.) 
When disaggregated, the national statistics also provide some pertinent information. During 1970 there were 85,370 pedestrian crsualties, which was an increase of 18\% since 1960. (Table 2.3.1). When related to total casualties, these pedestrian casual ties account for $24 \%$ of all casualties. In Great Britain. The nost significant feature hovever, of these statistics can only be shown when the number of pedestrian casualties are broken down into a relevant age distribution. (Table 2.3.2). This distribution shows that tro groups of the populatIon, those aged 15 years or less, and those aged 65 years or more, account for approximately $62 \%$ of all pedestrian casual ties, and the young pedestrians almost $50 \%$ of all pedestrian casualties on their own.

. If these pedestrian statistics are put into a European context It can be seen that pedestrian casualties per 1000 population are the highest in the 5- 14 years age group in all countries except for Sweden and Ireland. (Table 2.3.3). Studying this table even furtier, It can be seen that Great Britrin has in fact the highest pedestrian rate in all of Western Europe. Although this can possibly be explained by the variation in such variables as level of urban development and population densito, it still points to the necessito for a better understanding of the problen, and therefore hopefully, more solutions whlch thay help reduce the problem.

The other major group of road users, drivers and passengers, has a similar problen to those described above for pedestrians. During 1970, 205,245 drivers and passengers were injured, about 56,6 of all casualties. However, as with pedestrians, almost a third of these casualties occurred within one age group, the elght year period 


\begin{tabular}{|c|c|c|c|c|}
\hline \multirow{2}{*}{ YEAR } & \multicolumn{4}{|c|}{ PEDESTRIANS } \\
\cline { 2 - 5 } & KILLED & SERIOUS & SLIGHT & TOTAL \\
\hline 1960 & 2708 & 19831 & 49675 & 72214 \\
1961 & 2717 & 19880 & 49702 & 72299 \\
1963 & 2681 & 20062 & 49498 & 72241 \\
1964 & 2740 & 20838 & 51551 & 75129 \\
1965 & 3105 & 23714 & 58248 & 85067 \\
1966 & 3153 & 24786 & 57684 & 85623 \\
1967 & 2964 & 24472 & 56843 & 84279 \\
1968 & 2762 & 24440 & 56449 & 83651 \\
1969 & 2955 & 24267 & 56486 & 83708 \\
1970 & 2925 & 24875 & 57570 & 85370 \\
\hline
\end{tabular}

TABLE 2.3.1. THE GROWTH OF PEDESTRIAN CASUALTIES 1960-1970 (G.B.) 


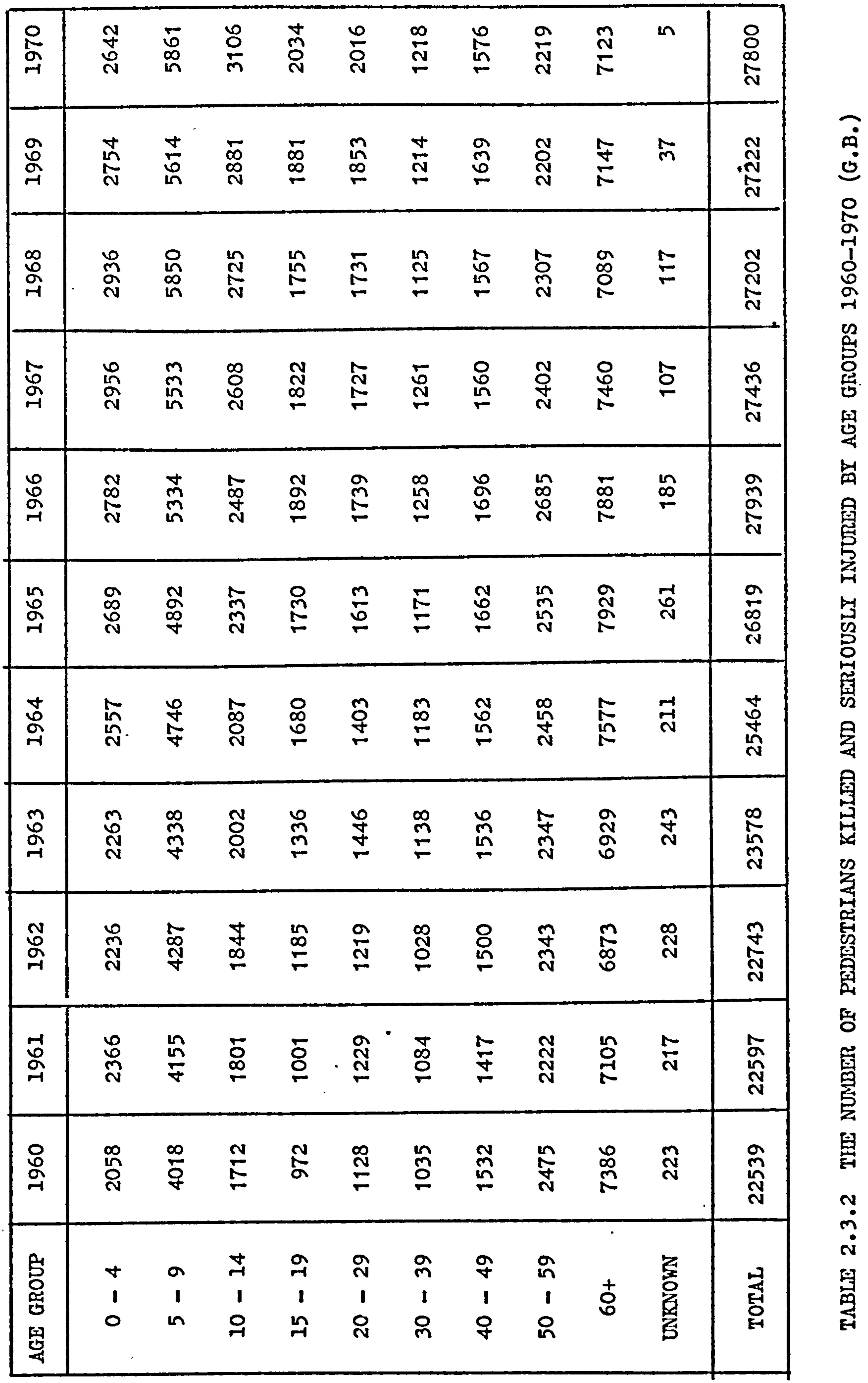


between 17 and 25 years, indicating once again the vulnerability of young drivers, although the degree of exposure of this group must obviously be taken into account before any such definitive statenent can be categorically accepted.

\subsection{THE URBAN ROAD ACCIDENT PROBLEI}

So far this account has only described the situation in all of Great Britain. Howerer, since this research attempts to look at the distribution of road accilents in urben areas, it is also necessary to look at the situation related solely to these areas, as defined by roads having a speed limit of $40 \mathrm{mph}$ or less.

The major problem in uriben areas 1s, and has been, the conflict betreen pedestrians and road traffic. In fact what Sifft wrote in the "Tatler" in 1710 could almost be applicable to present day conditions, some two hundred and flftj years later:-

"We are very glad to watah an opportunity to whisk across a passage, very thankful that we are not run over for interrupting the machine that carries in it a person neither more handsome, wise nor vallant than the meanest of us."

Similarly, Stone (1914) who was describing the situation at the turn of the century, also put most of the blane on the motor-rehfele:-

"It is practically impossible for the pedestrian to gauge the speed of a motor car approaching end on .... And with its elasticits, 


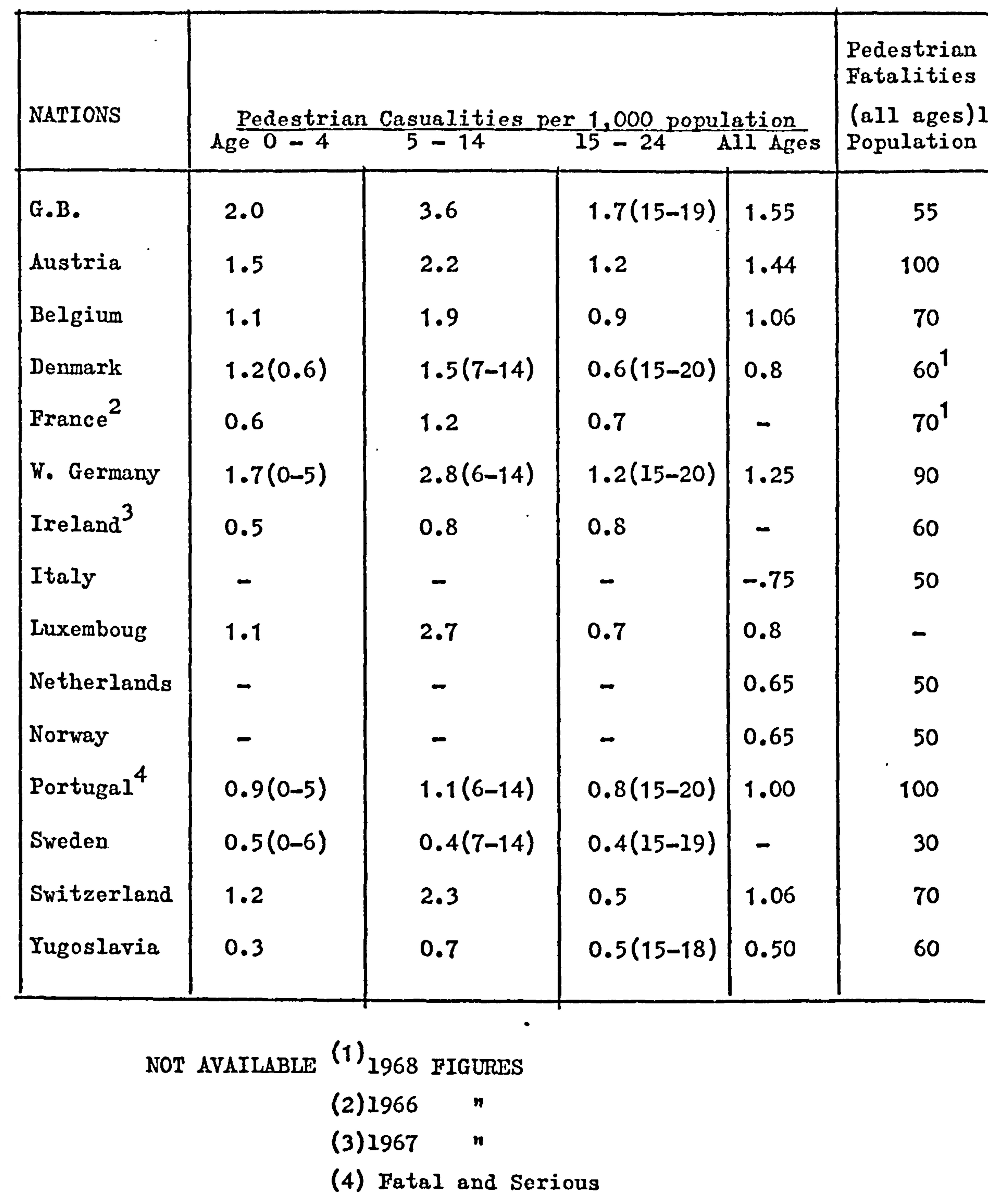

TABLE 2.3.3. INTERNATIONAL COMPARISON OP PEDESTRIAN CASUALITIES BI AGE GROUPS (1969) 
even a judgenent of pace would be of littio use, since cars can varg their speed between say, 4 and $40 \mathrm{mph}$ in the length of a few yards. This alone, therefore, throws the entire responsibility for accidents on the car and not the pedestrian." (Stone 1914).

Although this is perhaps a harsh judgenent against the motor vehicle, the actual pedestrian casual ty flgures for urben areas do emphasise the vulnerability of the pedestrian, against the more solidly constructed automobile. Thus in 1970, 262,553 road casualties occurred in urban areas accounting for $72.7 \%$ of the total number of casualties in Great Britain. Similarly, pedestrian casualties in urban areas accounted for $30.8 \%$ of all urban casualties, giving a figure of 80,751 pedestrian casualties in urban areas, which in turn is almost $95 \%$ of all pedestrian casual ties in Great Britain.

Perhaps one of the major difficulties related to this pedestriantrafflc conflict has been the dichotomous approach usually used, and spotlighted in the Buchanan Report. (Buchanan et al 1963). On the one hand there are the needs of the driver sub-system, who demand increased network access, and hlgher speeds etc., whllst on the other hand, there is the pedestrian (and dwellers) sub-system who demand greater safety and freedom from traffic. Now although both of these two groups are not mutually exclusive, in most instances the reaction of an indiridual reflects his actual morement within either of the groups at any one point in time. Consequently, there has to be some balancing of suggestions and proposals to accommodate both sub-groups, and the advantage has usually gone to the group which could exert the greatest pressure. Until recently this has tended to be the motor- 
vebicle "lobby" with the result that recent developments have tended to aid the movenent of vehicles around our urban areas, through increased capacities, or new constructions, all at the expense of our environisint in terns of noise, safety and pollution. It is for this reason that little, if any, action had been taken as regards road safety proposals, until the environmentallst "lobby" had also started appljing pressure.

This neglect of the pedestrian-traffic conflict can perheps be best illustrated by the fact that most of the solutions traffic engineers are now suggesting for pedestrian safet in modem town, such as shopping precincts, elevated pedestrian walkways, and subways etc., were all suggested many years ago, and in some cases centuries ago. Thus in 1500, Leonardo da Vincl proposed a schene for ground level pedestrian-ways with the vehicular traffic ruming in tunnels. Similarly the Pantiles in Tunbridge Wells built in the 17 th century are an exemple of an eariy pedestrian precinct.

Basically most of tine approsches aimed at satisfying the pedestrian-traffic conflict all contained some degree of pedestrientraffic segregation. Thus as Stane says, "If absolute safety for pedestriens is required, it is attainable only by the overbridge or subway, so that all interference is avolded...... That the overbridge has not becone a feature of our own English cities is curious, when we consider the stringent regulations imposed on railway conpanies with regard to level crossings." (Stone 1914). A similar point was made by H.A. Tripp, an Assistant Comissionor of Police at Scotland 
Yard, some twents five years later:- "If we could segregate pedestrians completely from the wheeled trafflc, we should of course abolish pedestrian casualties. Complete segregation cannot, however, be achieved........ so one has to concentrate on the major roads, and there the problem is definitely soluble." Tripp then continues by pointing out that, "where heavy through trafflc invades old age towns and villages, one shall have to build roads exclusively for motor traffic and by-passing the centre of population. In places where pedestrians and heary streans of traffic must still use the same thoroughfare, resorts must be had to either place-segregation (e.g. overbridges) or time-segregation (i.e. traffic signals)." (Tripp 1942).

Thus Tripp appears to understind the basic problem of road safet when he says that complete segregation is totally impossible. Although this would seen to be the Utopian 1deal, only in very exceptional circumstsnces would it be at ell possible and this would have to be within the fremework of some new development. But as Tripp realises, the major problem concerns the older, more established towns, where modification is only something which can be completed in a plece-meal manner, therebs precluding the idea of total segregation, and restricting any segregation to very limited "isolated" areas.

\subsection{THE NEN TOIN DEVELOPIENTS}

Whilst the older towns provided obviously the greatest problems, It was hoped that the development of the New Town Ideal would create 
new environments which would be in themselves safer, whilst at the same time alleviating some of the pressures in the other older areas. Although some work had been started on New Torms, espectally those Garden cities adrocated by Ebenezer Howard, at Letchworth and Welwy, little progress was really made until the post-1945 period. In fact Sir Patrick Abercrombie, one of the leading figures in the New Town movement after 1945, wrote in 1933 that - "It is interesting to speculate what might have been done if three or four million people out of the sixteen million who have been provided with detailed local residential planning in the country, had their housing made the subject of a really comprehensive plan. A hundred real new towns in different parts of the country would have been more constructive, if also more adventurous than a multitude of garden suburbs. In fact this post-war (post World War 1) housing as regards a general theory of civic planning, does not show much adjance upon the Victorian muddle." (Abercrombie 1933).

The post 1945 developments, both first and second generation, New Towns seem to meet most of these criticisms, jet it is interesting to note that whilst the majority of these towns were built and planned explicitiy with road safety in mind, the amount of research into the results of these experiments is very limited. Surely if money is to be spent it ought to be possible to deternine whether this money is being used to a good purpose. With this thought in mind it is usefur to compare the response of these entirely different urban systems within a road casual to context, with other less-planned urban areas. 


\subsection{THE APPLICATION OF COSTIIIG TFCHITCNUS}

The present road accident problem can be put into context in meny weys, es already inoicated. One method which seems to be becoming more applied of late is that of cost-benefit analysis, and other related techniques. Wohl in a recent article concerning the analysis and evaluation of traffic safet measures, has formulated his argument somewhat in these terms. (Wohl 1969). He starts from two basic propositions -

11) Safety measures that provide increased benefits (or reduced costs) to someone which, when totaled, outweigh the sum of Increased costs to someone, should be adopted........

2) Safety measures that provide increased aggregate net benefits, but cause segments of the community to bear increased costs in excess of their increased benefits, should be "voted on" by society through its political process, and perhaps foregone."

He then continues:- "The traffic safety problem is to determine a) the eggregate levels of benefft and cost associzited with the adoption of one safety measure or enother, b) who will benefit and how much, end c) who will pay end how much. It is simply not good enough to say that "society as a whole will benefit" or that "safety will improven if we adopt a certain safety measure."

Whilst one does not have to ggree with the suggestions and arguments in Wohl's paper, it does Indicate the present trend towards costing of various alternative proposals, and therefore the need for a vast increase in our knowledge about the results and implications 
of any improvement procedure. Without this knowledge such costing procedures would appear embiguous at least, and meaningless at worst. Therefore it kould appear to be a reasonable argument that until sufflcient research has been completed upon road safety, the application of cost-benefit techniques would seem presumptuous and totally restrictive, especially in the short term. However, having made this observation it must be pointed out that the costing of road accidents to the community as a whole can help to indicate the serloumess and the degree of urgency needed to reciuce the problem.

Every road accident is ultimetely impossible to cost in terms of pain, grief and suffering to the individuals concerned, but it is possible to represent each accident as a quantifieble loss to the community in economic terms. Such costings have been studied both at the Ministry of the Environment and the Trensport and Roed Research Laboratory. The work at the TRRL was carried out by Dawson (1971), who estimated that the total number of accidents in Great Britain, cost the community approximately £3l8 million in 1970. These costs were mainly derived from costs leading to a diversion of current resources, and the gross loss of future output.

The work by the Hinistry of the Euvironment, meanwhile, as published in the EMSO publication "Boad Accidents 1970," arrived at the greater figure of $£ 346$ million (1970). (Table 2.6.I). They also calculated that the average economic cost of a fatal accident was 113,000 , the arerege serious injury accident cost $£ 700$, and the avergge slight injury cost $£ 250$, and the averege accident involving 


\begin{tabular}{|c|c|c|}
\hline & $\begin{array}{l}1970 \\
\text { Em }\end{array}$ & $\begin{array}{l}1969 \\
\text { fm }\end{array}$ \\
\hline Medical treatment, ambulance and funeral costs & 17 & 15 \\
\hline Police and Administration costs & 28 & 26 \\
\hline Damage to vehicle and other property & 198 & 183 \\
\hline \multirow[t]{3}{*}{ Lost output } & 103 & 96 \\
\hline & 346 & 320 \\
\hline & & \\
\hline
\end{tabular}

TABLE 2.6.1 CCST OF ROAD ACCIDENTS (1969 AND 1970) 
only damaged vehicles and property £lca. They then continue by stating that, "on averege road accidents result in an economic loss of approaching $\mathrm{fl}$ million a day on top of the personal suffering caused by the daily toll of more then $20 \mathrm{kIlled}, 250$ seriously injured, and 700 slight ty injured. These figures provide the facts behind 'a problem inf ch mast be the concern not only of the Goverrment and safety organisations, but elso of all roed users"(HISO 1972). 
Chapter 3. ROAD ACCILENT ANALYSIS - PLST AND PRESENT

\subsection{INTPONOCITON}

Since road accident analysis is a relatively young subject, it can be compared with meny of the other embryonic social-science subjects such as sociology, economics, geography etc., all of which havo their orn related technical problems, and generel overall, methodological Iimitations. However, when compared to these other disciplines, road accident enalysis would seem to have been more restricted in its type end rate of development. This section tries to account for this apparent slowmess in development whilst also suggesting approaches which may be more beneficial in the future.

\subsection{PROBLFNS WITHIN POAD ACCIDENT ANATYSIS}

The reasons for the dearth of development within road accident analysis can perhaps best be understood by referring back to the subject matter itself. Whilst the other sociel sciences have tended to. develop through the use of increased "scientific" rigour, and the greater use of statistical techniçues necessary for hypothesis testing, road accident anelysis has been restricted by three simple failings.

In the first instance, road accident anelysis has been beset by the need for practical solutions to irmediate problems, and therefore the development of any theoretical fremework has been severly restricted. That is to say, road accident enalysis has tended to develop as a method of program evaluation, where very often, evaluation is merely a formelity after the program has been 
implemented. There has been little, if any, effort to understand the problems involved in any accident situstion, and the most emphasis has been leid on reaching an empirically satisfactory solution. Yet such en understanding and hypotbesis testing is essentiel in any approach to scientific explenation. Thus as Likert (1960) has pointed out, there are two functions of statistics in the process of evaluation:-

a) To provide information on the state of the system "statistical measurements which reveal the current situation of the nation or economy, such as population date, price indices, etc."

b) To provide information on the nature of the system "the basic conceptual model which serves as a guide to tell what dimensions of the nation should be interpreted in making decisions."

Whilst both of these points are importent in pointing out the need for a more scientific approach in road accident anelysis, the second point is perhaps the more pertinent one here since it explicitly indicates the need that there should be statistics avallable wich can provide information on, or help build a "basic conceptual model." The implication of such a strtement is simply that, without the basis of some theoretical understanding, the evaluation of any procecure, or progrem, is of very limited value. For this reason it is obvious that to progress, road accident analysis will have to move further in the direction of scientiflc explenstion and theoretical conceptualisation. Before leaving this point, it would perhaps be worthwhlle to point out that there are 
two basic routes used in scientific explanation, each of which has some advantages, depending upon the subject and the subject materlal being used. Therefore, since it is being suggested that road accident analysis should develop its level of scientiflc explenation, these tro routes ought to be introduced and the differences noted. The tho routes are generally known as inductive 'and decuctive explenation.

(1) INDUCITVE EXPLANATION - Inductive explenation can be clessifled as the classic model of scientific explenation as propounded by Frencis Bacon. By this method, the scientist moves from a collection of perceptual experiences which when transformed Into some language, forms a mass of poorly ordered statements into some kind of grouping or classifactory system. As Harvey points out:-

"In the early steges of scientific development, such ordering and classification of date may be the main activity of science, and the classifications so developed may have a weak explenatory function." (Harvey 1969).

Furtber study of these groupings, and the interkctions between these groups may lead to the discovery of certain regulerities, which through inductive inference may suggest the formulation of certain empirical (inouctive) laws and ultimately postuleted unirersal laws from the structuring of the empirical laws, into some theoretical framework. This mode of scientific explenation is shoun dirgramatic ally in (FIE. 3.2.1). 
The problem with the inductive method of explenation is "the assumption that the processes of ordering and structuring date are somehow independent of the theory ultimately constructed." (Harvey op. cit). Thus as Churchmen has argued, "lacts, measurements and theories are methodologically the same." (Churchmen 1961). Therefore, if one creates. on $n_{a}$ priori" classification system to a set of date, it may be regarded identical to postulating an "a priori" theory.

(11) DEDUCITE FXPLENATICN - Deductive explanation meenwhile explicitiy includes the "a prior" nature apparent in most scientific research, through the creation or formulation of some "a priori" model. The perceptual experiences are input into this theoretical model generating hypotheses, which can be then tested, according to some degree of confidence, by various statistical techniques. As (FIg. 3.2.1) shows, the process is cyclical in nature, only allowing the construction of laws and theories once the "a priori" model has been verified to a satisfactory degree. It will also be noted that classification only occurs once the "a priori" model and resultent hypotheses have been postulated. In this way the classiflcation system is based on a hypothetical fremework which can be tested and, therefore, ultimately accepted or rejected before further theoretical work is attempted. In this form the deductive approach to sclentific explanation would appear to be the most satisfactory, especielly in the field of sociel sciences where very complex systems, with a high degree of inter-relationships are encountered, and where the original data cannot be controlled in some experimentel situation. 
Whilst such an approach has been edopted freely in most of the other sociel science disciplines, in road accident enalysis, this has not been the case, even where there has been an attempt at any coherent explenatory fremework.

The problems indicated above pin-point the second major friling of road accicent analysis. Iike most social science subjects, advanced research has been restrlcted by the complex inter relationships which must be studied and understood within any meeningful model. However, within rosd accident analysis, most models which have been dereloped have tended to be more simplistic in nature than realistic, basically because these models can be handled nore easily by the researcher, and also beceuse they circument the numerous data problems. Although some of these models appear to work reasonably well, it must be remembered that they are merely $:$ abstracted models which have Iittle, if any, meaning when applied to a real world situation. That is not to say such models or relationships have no relevance whatsoever, but the extent of their limitatlons must be realised. One aspect of this debate in the Iiterature has concerned the formula suggested by Smeed to predict the number of deaths from road accidents in various different nations (Smeed 1949). Smeed's work was "illustretive of a type of statiatical modelling in considersble use today in various sociel sciences, where a limited number of varicbles are linked in a functional relationship without there being any available expla nation of causality. Thus:-

$$
\frac{D}{N}=0.003\left(\frac{N}{P}\right)^{-\frac{2}{3}}
$$


where: $D=$ deaths; $N=$ number of vehicles; $P=$ population,

remains as predictively valid (1.8. current date fits the curve), and as uninterpreted today as it did 20 years ago." (Katz 1971). This lack of interpretation was taken up by Peranio (1970) in a general discussion on the. use of formulae in traffic engineering and road safety, and the Smeed fomula in particular. He argued that all useful formulae must have certain attributes, and that wi thout these attributes, and derived complex models, the possibility of useful formulae in road safety was very lo\%. Thus, be states that in road safety topics, "Hunans of varging characteristics play key roles. Varlables include all aspects of the hunan highway users, vehicles, highways, and the physical and sociological environment. Whereas engineers woris routinely..... with errors of about I per cent, those dealing with humans operating in open systens are fortunate If they can roughly predict what will happen....... In general, it Is safe to say that when an obviously simple formula purports to describe a complex phenamenon in an open systea, one can without trepldation question its validity or practical usability." (Peranio 1970).

Smeed replied to these criticisms by pointing out that what Peranio sald was undeniable, but that it did not mean that even where one had to question the validity and practical usability of a formula, one necessarily had to reject that formula. (Smeed 1972). Simllarly, Smeed also pointed out that any formula with any valldity at all, "is almost bound to throw light on the phenomena it describes, 
even if it does not fully explain thein." (Smeed op. cit.). Thus in the case of Smeed's formula, he argues that several possible reasons can be put forward to explain the tendencies revealed. These include the increased probability of being involved in a rosd accident with increases in the volume of motor traffic, and also the influence of some major counterbalancing factors; "as the population accident rate becomes higher the urge to do something about it becones greater, and that something is in fact done. In addition, as the number of motor vellicles increases, which is in practice as time goes on, people are growing up and beconing more used to dealing with the situations wilch motor-traffic causes." (Smeed 1949). In a way, Katz puts this argunent more succinctiy whon he states that, "Despite this critical lack of interpretation one important historical propert of the systen - the increase in safety attendant to systein expansion - has been demonstrated." (Katz 1971).

It rould seem that the crux of this argument revolves around the ultimate aim, and degree of progress desired by each of the writers. Peranio would appear to want to create some kind of complex model which enables both explanation and interpretation, even tiough he recognises the multitude of problens to be overcome before this becones possible. Smeed on the other hand seems to be arguing that anj model, even if it adds verg little to our understending of the sitaation, is better than nothing, especially in the short tern, whilst the subject is still in the early stages of derelopment. 
Whilst both argunents carrg some conviction, it would seem reasonable to argue that if raad accident analysis is to develop and create some methodological framework, there would seen to be more hope for the future in the ambiguous proposals of Peranio. Hoverer, it must be emphasised tinat both proposals are complementery, rather then as usually portrayed, supplenentary. For this reason, both approaches should be encouraged and the relevant prosress noted.

The third major problen which road accident analysis has had to overcome, has been that until recently, it has had no acadentic core or base. Although this is less a philosophical problem and more a practical and organisational problem, it has caused many related problems within the subject natter. Until recently, when road accident analysis has tended to becone a more coherent subject, the normal situation was to find road safety research being done by isolated individuals within entirely different, and therefore independent,academic disciplines. The result has been that interdisciplinary comparisons have been severely complicated, the collection of all relevent material restricted, and the construction of a satisfactory all-embracing methodological subject framework, prevented.

Howerer, even though development within the subject has been severely restricted for the above reasons, some progress has been made and recent developments suggest that the major advances will be made along three basic lines of research. 


\subsection{POSSIBLE FUTURE DFVELOPHFNTS IN FOAD ACCIDFNT ANALYSIS}

(1) MODEI, BUIIDING:- It was pointed out earlier in this section that models developed within road accident research had tended to be simplistic in nature end therefore restricted in use. However, one of the major trends of recent years has been the creation or formulation of a much more meaningful group of models, with a much higher degree of mathomatisation. Similarly, associated with this increased use of mathematical models, there has been an increase in the application of statistical techniques and, therefore, objective hypothesis testing.

Since models have many different functions, dependent upon the alm of any piece of research, it is virtially impossible to define a model except in terms of its relevent function. However, Ackoff (1962) has tried to circumvent this problem by suggesting that a model can be conceptualised as being an niderlised representation of reality in order to demonstrate certain of its properties, " and then continues by advocating a breakdown of models into three types:iconic, analogue, and symbolic, in which each stage represents a higher degree of abstraction than the last. However, for the purpose of this discussion, it would appear more meaningful to use Lowry's classification of models based on function. (Lovry 1965).

Before looking at Lowry's classiflcation in more deteil, it is relevant at this point to ask the question, "Why do we bother creating models rather then study the facts themselves directiy?n The answer lies in the ineritebility, the econong and the stimulation 
of model building.

a) Model bullding is inevitable because there is no flxed dividing line between facts and beliefs; in Skilling's tems, nbeltef in a universe of real things is merely a bellef... a bellef with high probability certainly, but a belief none the less." (1964). Models are theories, laws, equations, or hunches which state our belief about the universe we think we see.

b) Hodel building is economical because it allows us to pass on generalised infornation in a highly compressed forn. Like all rules there may be exceptions, but this does not in itself reduce the importance of the model as a first approximation in the learning process.

c) Hodel building is stimulating in that through its very overgeneralisations, it makes clear those areas where improvement is necessary. Thus the building and testing of any model is of paramount importance in any subject, since each step leads onto further research and modifications. In other words, as has already been enphasised, model building and theoretical conceptualisation of any problen is a basic stage in any method of scientific explanat1on.

Returning, therefore, to Lowr's classification, one can see how the three classes; descriptive, predictive, and planning, all perform a different, but essential function in understanding any research problem. 
(1) DESCRIPTIVE MODETS

According to Lowry, a descriptive model is one which replicates the "relevent features of en existing urban environment or of an already observed process of urban change. ${ }^{l}$ (Lowry op.cit). The importence of such models are numerous, and for this reason should be the first models derived within any field of research. In the first instance, such models reveal much about the structure of any system and recuces the complexity of the real world into the more coherent and rigorous language of mathematical relationships. At the same time, descriptive models provide concrete evidence on the inter-relationships of the systems processes. Thirdly these models cen also generate reliable values for "hard-to-messuren variables from input data consisting of "easy-to-measure" vuriables. Unfortunately, bowever, it is impossible for descriptive models to predict future relationships or situations, or to evaluate between different progrems. These are the tasks of the other tho classes of models proposed by Lowry.

(2) PREDICTIVE MODEES

When building a predictive model it becomes necesse.ry to have an understanding of the relationship between form and process. Whilst it was sufficient in a descriptive model to note that two varlables $X$ and $I$ are co-verient, in a predictive model it becomes necessary to be able to specify a causal sequence. "If one is able to postulate the direction of causation knowledge of the future value of the "cause" enables one to predict the future value of the "effect." end administretion. 
(Lowry op. cit.). Therefore, when bullding a predictive model, the researcher has to satisfy tro conditions. In the first place, he has to estajlish a logical franework where the variables of Interest are at the end of a causal sequence rather than the beginning. Secondly, he must be certain that any "causal" variables can be thenselves predicted as far into the future as necessary. This second condition can be dropped if one is interested in a "conditional" prediction. That is where one is interested in the consequence that should be expected to follow a specified exogonous impact (change in variable $X$ ), if the environnent were otherwise undisturbed. In road accident analysis, such an interest could be identified with the imposition of a speed limit on urban roads, and its consequent result upon the level of road accidents etc.

(3) PLANIING WODETS

A planning model is one which incorporates the method of conditional prediction and relates the outcome to the researcher's aims or goals. That is, the planning model is an evaluatory model for deciding betwean different alternatives proposed by the researcher during any review of the environuent or system.

Theso three classes of models as described by Lowry, therefore, necessitate the model builder to progress tarough three complementary stages of analysis. He must begin with the identification of persistent relationships among relevant variables, move on to the study of 
causal sequences and ultimately develop a logical framework for the model. In so doing he should develop or borrow from relevant theories postulated at an earlier date. It is at this point that model building in rosd accident research is severely restricted and the lack of any theoretical understanding of the road accident system underlined. For al though the terms "model" and "theory" are often used interchangeably to denote a logico-mathenatical construct of interrelated variables, a clear distinction should be drawn. Unlike the reverse situation, the model builder is dependent upon the theorist, since he is explicitly applying theoretical constructs to empirical situations, and where the theorist can be satisfied with vague logically coherent statenents, the model builder has to deal with exact functional relationshlps in order to generate enpirically-relevant output from enpiricallybased input. For this reason it can be argued that the growth of relevant model building in road accident research will only increase following the expansion of our theoretical understanding of the raad accident problen as a whole.

Therefore, in tho context of road accident analysis, most of the models so far developed fall into the descriptive category, with perhaps the exception of some modifled regression models which have tried to postulate some kind of functionel relationship. This family of descriptive models include both the Smeed model already described, the various probability models, and also the vurious behavioural models such as the accident proneness model. Ultimately, of course, one would hope to be able to produce planning or evaluatory 
models, but at present it must be emphasised once again that a basic need is the further development and understending of the various significant functional relationships.

It ras pointed out at the beginning of this section, that assoclated with the increase in model building, there had also been an equivalent increase in the use of statistical techniques, especially for simple hypothesis testing and program evaluation. Unfortunately, some of the results of these tests have not been exactly what they appeared. In this context it is useful to discuss one technique which has been applied quite extensively in road accident analysis, since it has several implications which are relevant both to road accident research in general, and this research problen in particular. The technique referred to involves the application of Chi square analysis in the evaluation of road accident improvements, and is generally knom as a "Before and After" study.

Before and After studies are usually associated with the removal of road accident "black spots" or high accident location treatment. The technique was described by Tanner (1958):-

"To estimate the effect of a change in road conditions at a particular site on the frequency of accidents there, the usual procedure is to obtain detalls of accidents at the site in convanient periods before and after, and to compare the ratio after to before with the corresponding ratio for a large control area. The latter may be the whole of the Police district in which the 
site lies, or some other area fron which trends due to external factors can be reliably assessed. The significance of the alfference between the tiro ratios can be tested in the usual way by means of $x^{2}$ with one degree of freedom."

Mthough this technique has been used extensively, it is necessary to point out two severe theoretical Iimitations. The first relates to the contral area and the problem of allowing for unlnown variables which may influence the road accident level, whilst the second relates specifically to the purpose of the technique, and the areal unit used. This second criticism needs to be expanded since it is relevant to the main body of this research.

An importent study in relation to the above mentioned criticisa, was carried out by Thomson (1968) when be Iooked into the value of traffic management in central London. The basic aim of traffic wanagement is to make "the best use of the existing street system." Its techniques range from the micro to the macro level, involving such actions as roadray markings, one-way streets, new roundabouts and flyovers etc. "A program of traffic management In a large city consists of hundreds, perhaps thousands, of small individual actions over the course of a year, which it is believed wlll add up to progress in better and safer vehicle flow." (Katz 1971). Unfortunately, the results of Thonson's wor's led him to two conclusions:-

(I) "The true (road-speedflow) capacity of Central London has 
becn falling as a result of traffic management, as supported by varlous statistics of travel volumes, flows, and speeds," and,

(2) "Comparisons of accident rates do not reveal any improvenents wich might be attributed to traffic management." (Thomson op. cit).

Whilst these conclusions have been debated at some length in the relevant literature, (e.g. Ridley et al 1968; Stott 1968) the most importsnt point to be raised in Thomson's analysis was that whilst measurenent of the local effects of individual changes on capacity was positive, measurement of network effects were ei ther non-existent or negative. The implication here is that a bad traffic situation is cured at one location simply by moving the problem to one or more other points on the road network system. As Katz points out, "If these conclusions are correct, and are transferred to safety work, then they have obvious and importent consequences for high accident location treatinent, indicating the need to deal in wider areas of system improvenent. For measurement work the implications are that conclusions about progress must not be drawn from too small an area or from data on individual treatments alone." (Katz 1971).

Although such observations and comnents are not new, they have usually been dealt with inplicitly rather than explicitly as should have been the case. These facts, along wi th the reluctence of most researchers to assume that individual improvenents within a system (urban area) will automatically lead to an improvenent in the overall system performance, makes it imperative that some morenent is made 
to the formulation of some model or system of models, which can take into account the complex inter-relationships evident in road accident enalysis.

(ii) MICRO-LEVET STUDIES

The second major line of development in road accident analysis has been the increase in micro-level studies. The pieces of research which fall into this group attempt to study some set of Isolated or locel incidents (accidents) at the point of occurrence and try and derive some trend from these individual findings. Although such studies involve a partial Inductive mode of reasoning, this approach can be queried by asking whether it is statistically meaning ful to generalise from specific incidents, which are neither randomly selected nor the follow up work to anomalies discovered in a more general overall study.

An example of this tope of study is the "Causes and Effects of Road Accidents" carried out by the Department of Transportation and Envi ronmental Planning at Binningham Universitj. (1969). Once again, al though this study provided considerable useful background material essential for any road accident analysis, it would be hard pressed to justify any universal generalisations which would be applicable to any area in Great Britain, without considerable extensive work being carried out, along the same lines, in other areas. For this reason it would seem that the micro-level approach is subservient in usefulness to the third line of development, which can be described as the application of systems aralysis. 


\section{(iii) APPLTCATION OF STSTHIS ANALISIS}

The third method of development and the one adrocated in this research is the conceptualisation of the problen as a complex interlocking system, allowing the application and use of the techniques of systems analysis. Without moving too far into the realms of systems analysis, it is necassary to deel with this point in more detail in order to comprehend the advantiges of the approach and the considerable amount of work still needed before the technfques can be applied with any adrantage.

Systens analysis is not foolproof nor is it a complete researci methodology. It is merely a helpful set of research ideas, procedures, and techniques which have been dereloped by investigators to assist in the formulation of policy. Considered in this way, oystems analysis can be associated uf th the "planning models" adrocated by Losry.

The simplest way of defining a system is through the use of set theory. Following KIir and Valach (1967), the set of objects (identified by a set of attributes of objects) contained within some system $S$ may thus be represented as a set of elements:-

$$
A=\left\{a_{1}, a_{2}, a_{3} \ldots \ldots a_{n}\right\} \text {. }
$$

To this one may add an extra element $a_{0}$ to represent the environment. One then introduces a set:-

$$
B .=\left\{a_{0}, a_{1}, a_{2} \ldots \ldots a_{n}\right\}
$$


which includes all the elenents within the system plus an element that represents the environent. The interactions and relationships between these elements can then be examined. If rif represents the relationship between any elenent $a_{1}$ and $a_{j}$ (the case where $\mathrm{HIj}=0$ would be the case where $a_{i}$ has no effect upon $a_{j}$, then we can denote the set of all rij $(1, j=0 \ldots \ldots . n)$ by $R$. The definition of a system is then contalned in the statement that every set

$$
S=(A, R)
$$

is a system.

Having defined a system, the first step in the process is to develop as clear a statement of the problen to be tackled as possible. Lack of a clear problem statement is a major source of imperfection In decision making. In particular, there is a danger of inadvertently adopting one solution to a problem as the problem itself. For example, one could do a careful imaginative study of how to accommodate an additional desk in an office so that an extra secretary could be hired, when actually the problen is how to increase the typing output of the office, which may be more easily, cheaply and permanently solved by electric typewriters and duplicating machinery.

In the context of road accident analysis, this statement of problem could take many forns, and it is ossential in any piece of work to describe exactiy the ultimate aim of that stads. For example, one statenent of problem could be, given our present level and type of urban development, how can we reduce the number of road accidents to a minimum level? Alternativels, it would be possible to postulate an opposite statenent of problem such as, 
what form of urban development in the future would give us the optimum level of road accidents? of course in some cases it may even be desirable to have a reduction in the type of accident as the statement of problem. For instance, one could propound the statement, "how can the cost of road accidents to the community be reduced by decreasing the severt ty of road accidents?n

It is obvious that all these statenents of problem are realistic and, therefore, pertinent in different situations, and the need to define the relevant statement 1s, therefore, fairly obvious and as indicated, must be the initial operation in any systens analysis.

Given a clear statanent of objectives, the next step is to develop en eppropriate model of the phenomena which are being studied. During the modelling process, a dellberats attempt is made to broaden the study so that important variables and relationships are not onitted. At this time, the thinking of the researcher should not be constrained by problems of data collection, measurement difficulties, computational difficulties, saall budget, or any other real world constraints. He must try to force hinself to think about an ideal, totally unconstrained solution to the problem in which all important phenomena and relationships are considered. In addition, an attenpt is made to structure the problem by specifying the nature and direction of the relationships between the phenornena which Ideally should be included in the stady.

Developing a systens model provides a framework in which one 
can perceive important variables and relationships which are being omlted. The output of an investigation should be as thoroughls mathonatised as possible. However, the information avallable to do so is limited. To develop a systen model based merely upon presently avallable infornation tands to perpetrate both pleceneal studies with narrow results and the status quo with regard to information avallability.

There is a feedback between the statenent of the problem and the system modelling. The statement of the problem should be constently revlewed to ensure that the model is appropriate to the problem. Alteratively, as the model develops and existing knowledge about phenomena being studied is organised, the statcment of problen should be evaluated for correction. Eventually, through an Iteratire process, the statenent of problem and the systen model become balanced and the researcher feels little is to be gained by trying to expand the basic systen model and time, manpower and phosical facility resources are allocated to the following actirit1es:-

1) Mathematising and calibrating the basic model.

2) Establishing criteria for evaluating performance.

3) Testing and evaluating the given system.

4) Designing alternative solutions.

5) Testing and evaluating performance of the existing system and alternative.

Mathenatising and callbrating the basic model involves devising appropriate measuring strategies, collecting information, and then 
reducing the data to the various relationships specified in the basic model. As this work proceeds, results are fed back into the statement of problen, the basic systems model and resource allocation and, if necessary, modifications can take place.

At the time that the basic model is being calibrated and revised, consideration should be given to establishing criteria by which the performance of existing and future systans and system components can be evaluated. Criteria for design and evaluation are also fed back into the statement of problem and the basic model. The criteria must conform to the goals of the study. Comparing criteria with the problen and the model gives the researcher an opportunity not only to evaluats the criteria, but also to expand or modify the problem and the basic model.

Perfornance of the given systein and its conponents are evaluated after criteria for performance are established. The criteria for performance are established not only in terns of what the existing systems can do, but also in terms of the basic problen and what a system should or could do. Thus it may be discovered that ths given system does not perform at all in terms of one or more of the standards which have been set.

The next step is to design alternative systens which improve poor performances and provide additicnal performance properties where none existed before. Inperfections end lack of performence in the existing system do suggest kinds of innovations to be made. If the initial statement of the problem is correct, likely innovations will not be arbitrarily excluded. 
The costs of alternetive systems are determined as a part of the process during which, elternetive solutions are designed. The perfornence of each of the alternatives is compared with that of the others ond with the exlsting system. Durlng this phase, the mathomatisation of the given system yields great benefits. Using simulation models provides the best method to date for eralueting alternetives without ectualiy building them.

The evaluation stratag takes two forms. First, with a given budget, one may ask which alternative gives the highest performance. Second, with a given level of :performance needed, one may ask which alternative costs the least. Both questions are eppropriate depending on the nature of the problem. After alternatives are eveluated and one is selected, it only remains to implement the decision that has been made.

The application of such \& methodological fremework, or some similar framework, cen be argued to be of paremount importence In the development of road accident enalysis, for once the level and type of relationships between different elements has been recognised, the eveluation of a set of renedial procedures Immediately becomes more cbjective than under eny other epproach. However, tefore this type of approech can be applied, one other problem must be settled. This involves what elements to include In the system, or how the system should be "bounded." Although It is possible to trace inter-relationships between everything and everything else, if eny system is to be studied effectively, 
boundaries for the study have to be established. A system should be bounded in order to incluae all. of the entities and activities which are meaningfully related, and which are relerent to the problem statement. Mathematically this problem poses no difficulties, since the boundaries are given by deflnIng certain elcmonts as being in the system and other (relevent) elements as belonging to the environment. However, in order to use the mathematical properties of system analysis, it is necessary to have some operational method of defining boundaries. In most instences, this has to be done subjectively and boundaries are imposed at points where the researcher believes the problem statement is being satisfied.

Although the use of systems analyols has many inherent practical difflculties, not least of which is the vast enount of research necessary before it can be made productive, it is suggested here that in the long term, it is by far the best and most meaningful approach at present evaileble. For this reason, the basic need in road accident analysis now should be the formulation of mathematical relationships between the various elements of the road accilent system and a greater understending of the problem, (possibly through better modelling) in general. 


\section{Chapter 4 THE AINS AND SCOPE OF THE STUIY}

\subsection{INTFODUCTION}

Having described in the previous two sections the past end present situation regaras the growth in road mileage, and therefore road accidents and casualities, it is necessary at this point to elucidate the aims of this research in more detell, end place them in context within the road accident problem as a whole.

\subsection{RESFARCH AIMS}

It bas elreaco been pointed out that there are two basic Iimitations within present road accident research; the lack of a sultable methodological framework and the sparseness of suitable background information, which would allow the formulation of satisfectory functional relationships between variables under stucy. Therefore, the essential need at present in road accident analysis is to try and overccme these present limitations, both theoretically and empirically. This situation is well described by Mackay et al (1969):-

"The fallure to apply rational causation fremeroriss to accidents has, therefore, led to "common-sense" evaluations of often complex multi-factorial sequences being treated with more importance than they deserve. Thus, not only drivers and bystenders feel competent enough to present their own solutions 
for the couse and prevention of accidents, but often the police, locel authorities and other public bodies have accepted such "common-sensen approaches......"

Noting these observations, the aims of this research can be summed up within two categories. On the one hand it has tried to review and criticise the major approaches in road safety enalysis to date, whilst ultimately suggesting systoms analysis as a suftuble methodological framework. On the other hend meanuhile, and perheps of more immediate impact, this research has tried to look at the relationship between road accidents and urben structure by studying the variation in the rolume of road accidents between different urban areas. This vias done by observing the calculated variations for each urban area between some derived "expected" number of accidents or "norn" and the actual observed number of road accidents for that same urban area. The logic behind this approach is that if tokns have different responses to the same set of controls, then it should be possible to identify further influential factiors which have not so far been considered, and group (classify) touns according to their varying response rates. This clessiflcation process besides being essential in any theory building, elso enables individual tokns to be taken and used as representative of their particular group. The importance of this is shown by the fact that further investigation of these towns should present representative problems, and perhaps solutions unique to their group. In other rords, classiflcation 
accepts that different urban areas will have different types of road accident problems for which "national" or even "regional" solutions might prove useless.

The structure of eny urban area was defined by means of 18 independent variables which included variables describing the physicel structure, sociel structure, end socio-economic structure of all urben areas. However, since these variables are described later ${ }^{I}$ in this report no more explenation will be made at this point.

These structural veriables were chosen because it is often clatmed that the only real solution to the road accident problem in urban areas is that of total traffic-pedestrian segregation. Whilst this is almost possible in the new planned toms, especielly the second generation new toms such as East Kilbride and Cumbernauld, it is virtually impossible in the older more established urban areas. For these towns, if anything more than piece-meal redevelopment is required, some compromise solution becomes necessary, and it would seem that this means some manipulation of one or more of these structural variables.

Similerly in road accident analysis, there are two basic Iines of thought. One group argues that the quickest way to solve the road accident problem is through the improvement of the physical environment, and the greater application of engineering measures in general. The second group meanwhile, 
clain that the road accident problem is the result of humen psychological deficiencies. Thus one of the arguments put forvard by some researchers (e.g. Nader 1965, Cohen and Preston 1968) is that eny improvement to a stretch of road etc. through engineering measures, whllst making that stretch of road "physically" safer, will merely entice the motorist to lower his own responsibility, and therefore possibly maintain the same level of road accidents as was noted before the Improvement. As Preston stetes, "It would seem that given safer conditions, some drivers will increase speed until the denger is as great as it was before." (Cohen and Preston op.cit.). If this is true, then this "feedback" mechani am between the road standard and the humen psychological beheviour Is of paremount importance and interest.

This dichotomous approach to the effect of roed safety improvements is perhaps epitomised by the book of Cohen and Preston mentioned above. Because of this difference of opinion, the authors found themselves unable to complete one plece of work and instead settled for "two distinct vierpoints side by side." (op. cit.). Cohen's approach revolves around the need to study the psychological aspects of road safety, especially in relation to the study of the "motorist as a cantaur" and the fusion of man and machine into some kind of "Bio-robot model." That is, Cohen belleves that the practice of sub-dividing the system into individual sub-gystems, especially those relating to the vehicle and the driver, has confused the issue rather than simplified it, due to the fact that the responso of the newly created bio-rotot is not 
equal to the sum of the two wholes! It is therefore necessary, Cohen argues, to study and understend the responses of this twentileth century creature before eny improvement can be made in the road accident problen. Implicit in this argurnent, however, is the contention that until this "bio-rokot" is totally understood, no improvenents in the road accident system will have any northwhile effect upon the ultimate list of road casualties.

Conversely, Preston puts forward the argument that although the solution to the road accident situation as a whole is through the increased understending of various aspects of the system, short term improvements can be, or will be, beneficial if the more urgent problems are given concentreted attention. Accordingly she indicates nine areas where Improvements could lead to immediate orerall recuctions in casualties ${ }^{2}$. Attempting to quantify these reductions she states, "If all these measures were carried out, then instead of nearly 8,000 people killed in a year there would be ebout 2,250, that is, somemere in the order of 5,750 lives a jear could be saved." (Cohen and Preston op. cit.).

Because of this divergence in opinion, exemplifled above, It becomes necessary, therefore, before going any further into the psychological factors affecting driving beheviour, to determine which of these.two lines of thought appear to be the more acceptable.

2 Preston's nine ereas of improvement were:- (1) Use of Seat Belts, (ii) Drink and Driving legislation, (iii) Enforcement of speed limits, (iv) Training and other safoty measures for rotor cyclists, ( $\nabla)$ Parking restrictions, ( $\nabla i)$ Safety helmets for pedel cyclists, (vii) Surveiliance of stendards of goods vehicles, (viii) Provision of pedestrian facilities, (ix) Enforcement of road safety legisletion. 
In the case of environment and engineering measures, the enswer to this question is of the utmost importence and relevance to future planning proposals. This is so because a lot of new town developments have been planned and dereloped with explicit aspirations to roed safety through partial or total segregation. Thus if the physical stiucture of an urben area is importent in causing road accidents, then these new towns should have a distinctly better road accident record than other comparable non-plenned urban areas. If, however, such a situation is found to be non-existent then there must be some doubt as to whether the avaflable capitsl has been expended in the optimum monner.

\subsection{SPATILI STUDIES - LIMITETTONS AND USE}

As stated, the relationship between road accidents and urban structure was studied both sprtielly and temporally in this research by noting the variations in the volume of road accidents between different urban areas. Whilst this is not a new approach, most studies which havattempted to study areal variotions in the rolume of road accidents have tended to use national units. (Smeed 1949, Pfundt 1969, Bull 1969 etc.). However, most of these studies have met considerable difficulties due to the varying definitions used by different nations. An obvious example here is related to the definition of fatal road accidents, where the "time period" for a road accilent varies from, "at the scene of the accident or Immediately afterwaràs" in Portugal, to "within thirty days of the accidentin Great Britein. Unfortunately, even if this problem 
can be overcome, there are several other probable difflculties. Thus Pfundt (1969) has pointed out that "a truly scientific verdict on the relative risk of accidents in different countries can only be made by comparing the accident rates on roads of simflar type in two or more countries. $n$ The problem with this kind of approsch, however, is that eny results obtalned are only applicable to a diseggregated section of the various nations' road networks, and are meaningless as regards overall aggregate compartsons.

What Pfundt is really suggesting, therefore, is that several variables cannot be used experimentally, and should in such an Instance be held constant, whilst the influence of other variables can be assessed independently. Although this cen only be done in a controlled experimental situation, it can be closely approximated in various statistical technicues where the variables are held "stetistically" constant, allowing verietions only in the specifled rariables 3 .

Some other researchers have tried to overcome this problem by reducing the scale of the observation units from international comparisons to intra-national comparisons. Unfortunately, these types of comparisons have largely been restricted to inter-state comparisons in the USA, and in many ways these are limited by the same restrictions as the national studies. The intention in

3 The technique of "step-wise regression" allows this function and this was one of the reasons for applying this technique in this research. 
reducing the size of the unit is to maintein the level of certain national factors constant. Thus in this research, when comparing the response rates of different urban areas in Great Britain, such variables as vahicle inspection, road speed limits, etc. could be ignored, or at leest, deemed to be held constant since such variables are imposed equally overall by decree of the national government. The result is that in any such intra-national study, fewer variables heve to be incorporated in any model which attempts to describe or explain the road accident situaticn, than would be necessary in any internaticnal comparison.

Another spatial study which indicates further the problems which can arise, was an inter-state comparison study made by Colton et al (1968) when they set out to answer the question, "Do states with compulsory motor-rehicle inspection exhibit lower motor-vehicle accident mortality rates then non-inspection states?" Whilst this study could be generalised as a "cause present" and "cause absent" situation, it is perhaps marginally more sophisticated statistically then earlier studies, (e.g. Coverdale et al 1967), since it does attempt to account for variation in other independent rariables (which could otherwise have affected the flnal results) through the use of a "weighted co-variance enalysis." Hovever, even with the application of this technicue to remove the influence of these disturbing variables ${ }^{4}$, the authors had to accept in their

4 These disturbing variables which Colton took account of in this study were:-

1) Log population density,

2) Per capita income,

3) Other accident mortality rates. 
conclusions that "The evidence on the role of inspection in motor vehicle accident mortality in this report is retrospective and circumstanticl. Further investigation is needed to classify this association." (Colton et al 1968).

The conclusion to be dram from this study, therefore, is that in any areal comparison study, the necessity to control all variables which may "disturb" the actual relationship being studied, is paramount in importance. This is especially true where the areal units being used have been chosen quite subjectIvely. Once again this point is stressed very strongly by Colton (op. cit.):-

"In examining the role of inspection in motor vehicle accident mortality, it is importent to recognise that the inspection states are a self selected group. Hence, the comparison of mortalities In inspection and non-inspection states should account for the possibility that the inspection end non-inspection states may be very different in several ways other than inspection, and that perhaps these other variables explain the observed mortality difference." (Coltin op cit)

In most of these inter-state studies, the main eim has been, therefore, to discover the influence one variable has upon the volume of road accicents. That is, there has always been an Implicit causal approach, coupled with the need for some evaluatory technique, to test the effect of any one counter-measure proposel. Thus most studies using motor vehicle inspection as 
their causal voriable, have consistently tried to evoluate the effect upon the volume of road accidents of the introduction of compulsory inspection at the national level. However, because of the complexities of the road accident system, noted above, such evaluations have proved Impossible leaving the results of these studies as minor indicative trends.

One way in which this evaluation process could be simplified is by introducing some intervening performence criterla, which has to be satisfied if the countermeasure introduced is to have ang effect upon the road accicient volume in the long term. For example, where the influence of motor vehicle inspection is being studied, the intervening criteria could be the improvament in the mechanical condition of the vehicle population. If this criteria is not satisfied, then it is obvicus that the difference say between a non-inspection state and an inspection stete is caused by some variable other than that of motor vehicle testing. (See McCutcheon et al 1969).

Since it has been shown that areal studies have several Inherent problems, it could be asked what point is there in such studies. Essentially comparisons of geo-political units serve two functions. Not only do they reveal the nature and underlying structure of the accident generating system, but they also help spotlight differences betiveen one area and another with the evental purpose of initiating beneficial changes. In other words, spatial comparisons can be viewed as a search procedure for new relationships within the road accident system, whilst 
at the sane time observing the actual perfomance of the various Individual systems, and the relative effectiveness of countermeasure treatneints.

The classic piece of work on the effectiveness of countermeasure treatwent was that by Recht (1965). In this piece of work, whilst he accepted that most studies on road accident analysis had been aimed at explaining the causes of road accidents, he enphasised that his research was aimed at studying the Influence of various activities which should directly or indirectly contribute to accident prevention. Thus, by rejecting the implication of causality, Recht was able to look at the consequence of various counterneasures which had been introduced in the American states under observation. Using multiple regression he introduced 218 progran and non-progran items into the model, where progran factors were introduced safety counterneasure activities, and non-progran factors were those relating to the environmental and physical conditions of the states. In arriving at his conclusions, Recht derived 110 regression equations with varjing combinations of progran and non-progran itens. The principal findings of the research was that the major proportion of the differences in accident experiance is associated with the differences in the non-progran factors, particularly vehicle density, age of population etc. Howerer, when the fatality experience was adjusted for the non-program factors, there were many program activities that were significantly associated with the death rate. 
The results of this piece of woris by Recht are verg important to thils research, sinco most of Recht's "non-progran" factors are included within the present research's structural variables, seemingly indicating the importence within the road accident systen of these such variables.

Summarising, therefore, the study of spatial variations from one area to another can be an essential sethod in the analysis of the road accident problen. Such studies are, "well adapted to reveal the effects on accident generation of differences in environment, geography, and transport arrangenents, that exist between areas. Once these structural factors are identified that is a model exists - then they can be put under statistical control in order to compare the changes in accident and injury from year to year, in the same geo-political area." (Katz 1971).

As has been pointed out previously, most spatial studies have been concerned with the macro-level, or national level, but this does not mean to say that comparison between snaller units is unacceptable. In fact in many ways the spatial com- . parison of urban areas within one nation has several advantages over the larger units. For example, it can be argued that within one nation several variables are going to ramain reasonably constant, thereby reducing the probleins of experinental control. Indicetive of these variables are; traffic laws, vehicle laws, social characteristics etc., all of which would theoretically have to be controlled in any international study. 


\subsection{SCOPE OF THE STUDY}

This study of the spatial variation in road accidents between different urben areas in England, Scotland and Wales was effected by sampling a hundred urbon areas with a population level greater than 20,000 (1969). An urban area was defined for practical purposes as that area contained within the relevant local government kuthority. In England and Wales, this included County-Boroughs, Non-Countj-Boroughs and Urban District Councils. In Scotland, the relevant authorities were the Large and Sinall Burghs.

In all, these urban areas produced a "total population" of 412 urban areas, from which the 100 sampled areas produced a sample size of approximately 25\%. Because of the positive skewed distribution associated with the population level of these urban areas, a random-stratified sampling technique was applied, using the population levels of 100,000 and 50,000 as strata limits. The resultent list of a hundred urban areas is shown in Table (4.4.1).

In addition to this study of the spatial varistion in road accidents, a temporal analysis was also used in order to study the influence of the relevant structural variables over time. Originally, it had been hoped that it would be possible to use a ten year period for observation 1960 - 1970. However, due to the lack and incompatibility of the data, this intention proved impossible. Instead the influence of the structural variables 

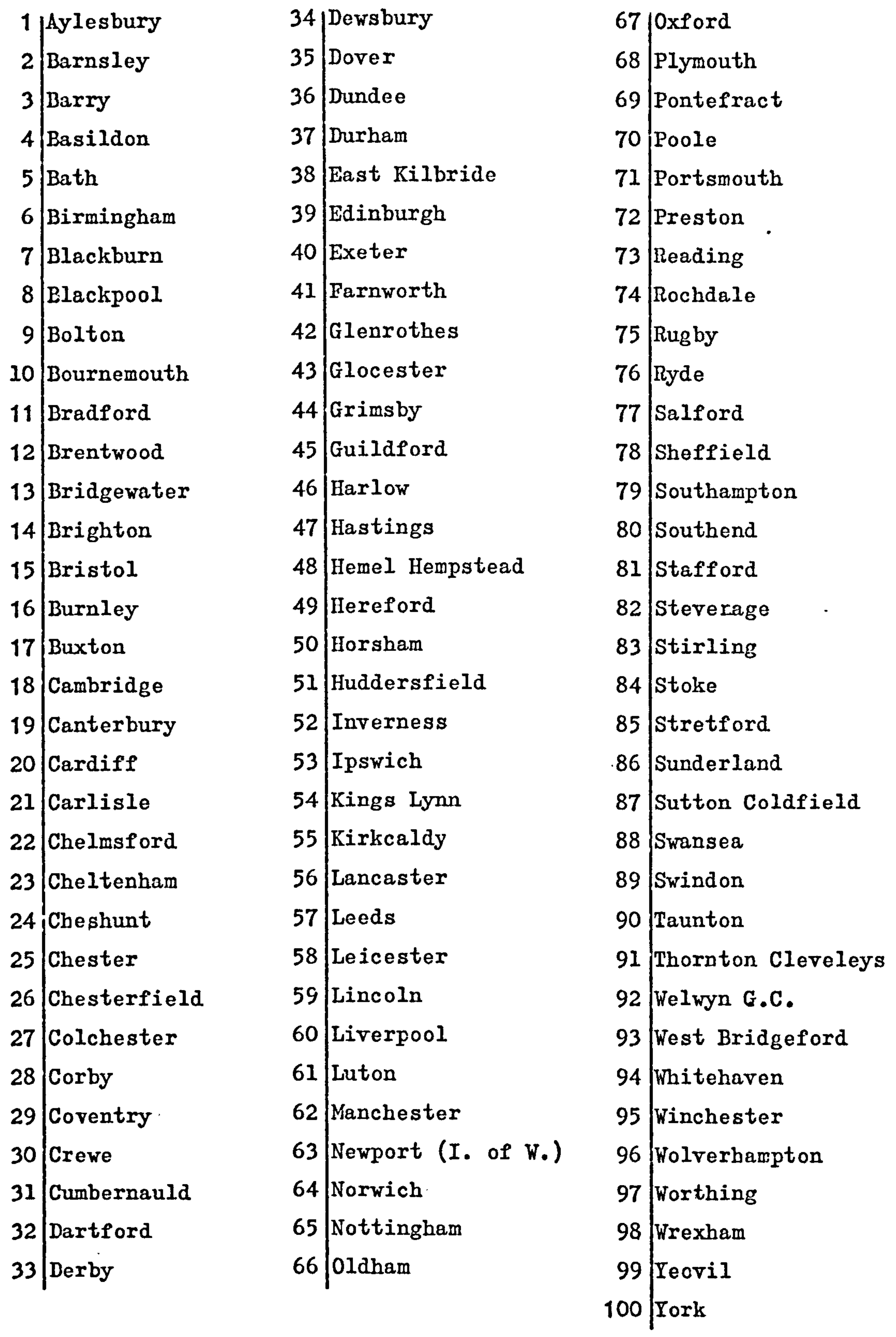

TABLE 4.4.1. THE 100 SAMPLED URBAN AREAS. 
was stidied only orer the five year period 1966 - 1970, with disaggregation possible only for the two years 1969 and 1970.

\subsection{SUMMARI OF RESFARCH AIISS}

Before moving into the main text of this report, it would seen advantageous to draw together in a concise form all the aims and intentions so far mentioned. These aims can be classified under 6 headings, and are given below:-

(i) To review the present methodology used in Road Accident Analysis, suggesting the use of systems analysis as one of the more encouraging developments for the future.

$\rightarrow$ (ii) Through the technique of multiple regression to calculate, en expected level of road accidents for each urban area, and therefore the corrected spatial variation in road accidents.

$\rightarrow$ (iii) To discover which structural variables account for the greatest variation in the spread of road accident volumes.

(iv) To test to see if individual urban areas can be class ifled according to their response rate to the road accident problen, and therefore to discover any "group" problens, or "group" solutions.

(v) To observe the spatial spread of the residuals from the proposed "model" and discover any further varlables which nay appear important or relevant. 
$\rightarrow$ (vi) To study the importance of the various structural varlables over tine, in order to see how these variables react to different stimuli.

These then are the major aims of this research and in the reaaining sections of this report they are elucldated in much more detall, along with the conclusions which can be drawn from the relevant results. 


\section{Chepter 5 THE POAD ACCIDENT SISTEM}

\subsection{INTPODTCTTON}

It has been areued in previous sections of this report, that the application of systems analysis provides the nost hopeful trend for the development of the subject in the near future. If this is so, it becomes necessary to define and describe what is meant by the road accident systen. That is, one has to know what elements are defined within the system, and wat type and direction of relationships exist between these elements. Although it is impossible to do this in any detail at the present level of road accident research, this section does attempt to give a simple postulated systen which can serve as a first approximation for the eventual true road accident systen. Initially however, several definitions, relerant to tints section and the main body of the research in general, are expounded.

\subsection{ACCIDEIT DEFINIITONS}

The definition of what constitutes an accident is one of the major operational difficulties in any research dealing with the subject. A dictionary definition of an accident is, n... an event without apparent cause,....unexpected, unintentional act." However, in the instence of road accidents, the majority of such events are neither unexpected nor without cause. In fact, it is usually true to state that a large number of road accidents could 
be aroided by greater design control of the environment, and more self control by the human beings involved. For this reason, various authors have proposed that an accident should not be defined as a unitary concept, but that a "range" as opposed to a "class" definition should be adopted. (Suchman 1961, McFarland 1963). Thus Suchman suggested that the followIng criterla should be adopted in definition:-

(1) Degree of expectedness - the less anticipated an erent is the more likely it is to be labelled an accident.

(11) Degree of aroidability - the less the event could be aroided, the more Ifkely it is to be described as an accident.

(iii) Degree of intention - the less the event involves deliberate action, the more the event is accidental.

Accordingly Suchman defined an accident as nan event characterised by a low degree of expectedness, avoidability and intent." This definition is an interesting one since it emphasises the precedent factors leading up to an event and eliminates any factors relating to damage or injurg. It is, therefore, applicable to studying near misses as well as events involving damage or injury.

However, Barmack (1962) has suggested that it is not known what definitions provide the basis for obtaining the most useful Information for understanding and preventing accidents, nor is it known what groups or classifications of accidents can best max- 
Imise the possibility of Identifying common factors or combinations of factors.

For these reasons, most researchers have had to use a definition of an accident which has provided a practical range of possibilities for carrying out the particular piece of research under study. Thus Mackay et al (1969) defined a road accident as:-

"A traffic incident involving moving vehicles which results in danage to those or other vehicles, or road furniture, or results in injury to road users."

Similarly the definition used in this research bears many similarities to the above definition; however, since nost of the accident data was provided by the Trensport and Road Research Laboratory, the definition used is related to that suggested by the Ministry of the Environinent in "Road Accidents" 1970. (HMSO 1972). Thus an accident is defined as:-

"An event in which at least one motor vehicle is involved in a collision on the public highway, and which results in one or more persons being injured."

Therefore, within the limits of this research, only personal injury accidents are considered, basically because most of the data on damage only accidents is incomplete.

Although such a definition leaves much to be desired, it is perhaps the most functional one available at present. Similarly as Suchman has also pointed out, "as our knowledge of causal factors increases we are more likely to describe an event in terms 
of those factors and less likely to label it as an accident." (Sucliman 1961). A similar point is also argued by MoGlade et al (1965) wihen they state that nfor human causation research purposes, an 'accident' must be defined as a predictable event subject to human control and therefore avoldable." The relevant fact therefore is whatever definition may be used, as the subject develops so must the definition, and therefore what is sultable for one piece of research may be totally inadequate for another. For this reason, functional definitions as used above would appear to be the most practical in such a piece of research as studied here.

Other accident definitions, relating to the severity of a road accident are also the same as those used by the Department of the Environment:-

(1) FATAL ACCIDEIT: - is an accident in which one or more persons die within 30 days of that accident.

(ii) SERTOUS ACCIDENT: - is an accident in which a person is injured such that he (or she) has to be detained in hospital as an "in-patient," or suffers any other serious injury (fractures, concussion, internal injuries, crushings, severe cuts and lacerations) whether or not the individual is detained in hospital.

(1ii) SLIGHT ACCIDENT:- is an accident in which a person receites an injury of only minor significance such as a sprain, or a bruise. 


\subsection{DEFTNING AN URBAN AREA}

The problems inherent in the definition of any urban area have been well discussed by geographers for many years, and as such will not be argued at length in this report. (See Childe 1936, Weber 1958, Tisdale 1942, Dickinson 1947, Smailes 1947, Berry 1968. etc.). However, in the philosophical literature there has been a consistent growth in concem about "entitation." That is "any attempt to establish or explore relationships needs first to specify the objects which are to be related in some appropriate manner and the test of whether the definition is appropriate is that it should be meaningful in terms of the function and the perfornance of the objects." (Robson 1973). The stringency of this need is greatest when functional relationships are under study, and less so when the study is solely concerned with description. Unfortunately, the opportunities for such satisfactory definitions of urben areas are very limited and once again the problem is usually solved by movement to some operational definition. However, even with this approach there are numerous difficulties. For example, Dickinson's "spheres of influence" (1947) are restricted by the fact that any urban area has many such spheres dependent upon which function of the urban area is used as the relevant yardstick. Similarly Berry's attenpt to define an "urban field" in place of the more familiar "urban arean, using journes to worix data in the USA (1968), merely complicated the situation even further from the

point of view of definitions. Based on these calculations Berry 
showed that $96 \%$ of the total population of the USA lay within the urban regions which he produced, against only $67 \%$ within the census-defined Standard Metropolitan Statistical Areas.

It is obvious therefore that no definition of an urban area is going to be totally satisfactory although some will obviously be better than others. Although this problem is discussed further in relation to the problems of scale $e^{l}$ in this report, suffice it to say that the definition used in this research was a simple operational one. An urban area was defined as that area lying within a relevant urban local authority area. In England and Wales these included County Boroughs, Non-Oounty Boroughs and Urban District Councils, and in Scotland the relevant areas were large and small Burghs.

\subsection{A SUGGESTED POAD ACCIDENTT SYSTEM MODEL}

It has already been stated that it is possible to postulate a simple road accident system model which could act as a simple first approximation model. Such a model can predict the direction of relationship between entities within the system, and also define what entities should be "closed" wi thin the system. It cannot however go into more detail about these relationships as regards type and strength. The systern presented in (FIg. 5.4.1) is such a simple model, and is the one used throughout this piece of work.

1 See page 129. 


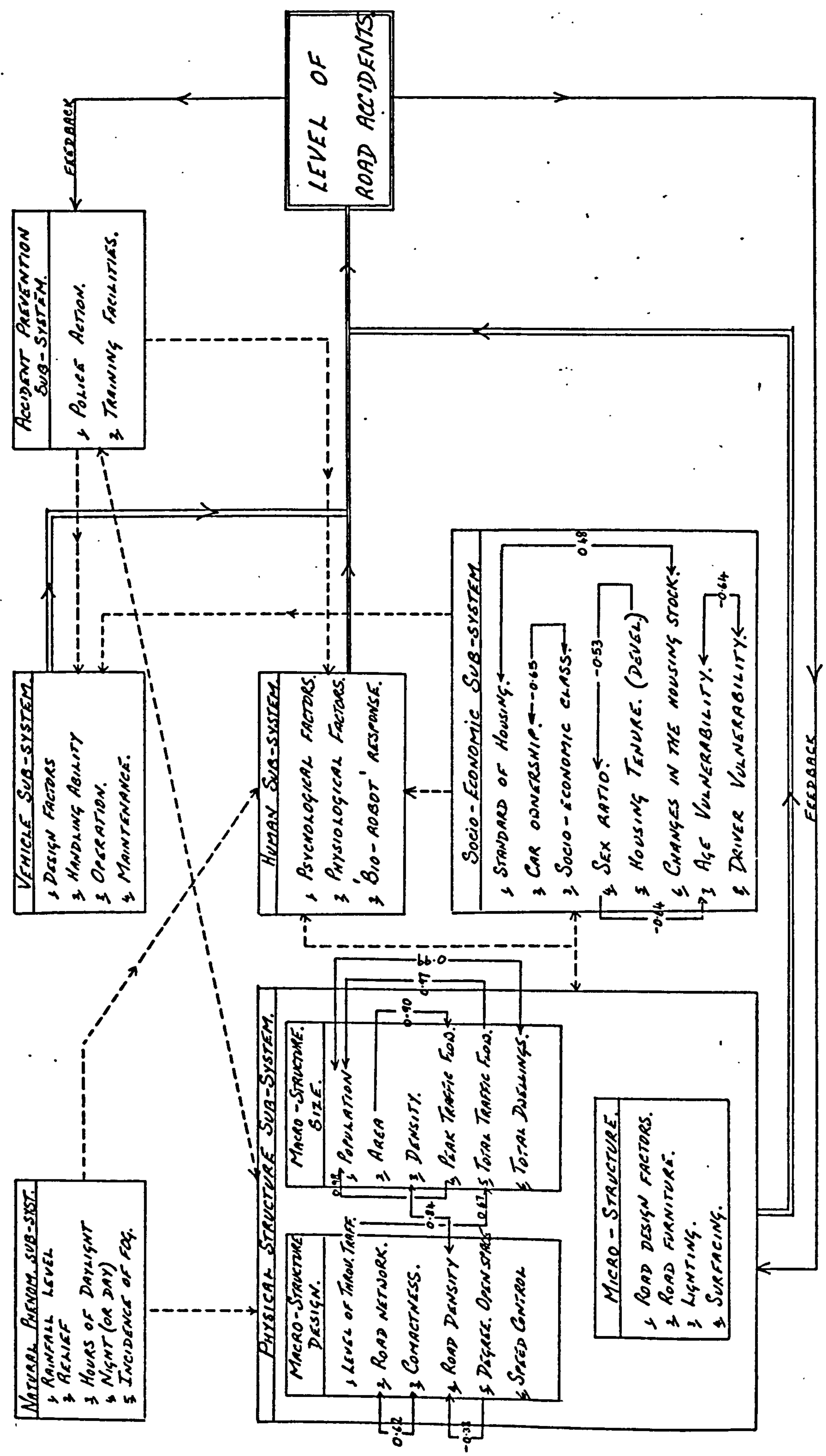

Fig. 5.4.1. THE TOAD ACCIDENT SYSTEA 
In many ways this systen approximates the model suggested by Gordon (1949) who was one of the adrocates of an epideniolog1cal approach to accident analysis, with the application of techniques and methods available for the study and control of mass diseases. Thus Gordon found that when data on accidental injuries were analysedin a standard epidemiological manner, Injurles appeared to follow related biological principles. The distribution of infuries showed characteristic variations in regard to age, sex and type of accldent etc. Accidents occurred at different rates, and in relation to different agents and circumstances among different groups of the population.

By considering accidents as an ecological problem and by using the concept of causation "as a combination of forces from at least three sources - the host, the agent and the environment in which host and agent find themselves" Gordon (1949) was able to recognise patterns in the distribution of otherwise seemingly chance events.

The host, agent, environment model suggested by Gordon, approximates the proposed system most in its specification of Its environment factors. Gordon splits his "environnent" into three relevant sections:-

(1) Physical environment which relates to matters of weather, season and any physical features which can be natural or man made, concerning the world where man lives and drives or travels. 
(ii) Blological environment - which included all living things connected with man excluding himself, and

(iii) Socio-economic environment which is the sphere of the environment where man is affected by the relevant interactions with other men.

It will be noted that in the case of road accident analysis, whilst such a sub-division is theoretically workable, the physical and socio-economic environments are by far the more important of these three sub-sections. Therefore in the system model described below, the biological environment is ignored.

It can be seen that the road accident model proposed here has been split into six different sub-systoms, where a sub-system can be defined as a collection of closely related elements. However, of these six sub-systems, it will be noted only three directly Influence the level of road accidents. The remaining three subsystams operate upon this accident level through one or more of the other sub-systems.

In order to explain clearly this proposed model, it has been disaggregated into its relevant sub-systens, each of which will be described below. However, before that can be comnenced, it must be pointed out that this model is a model which is only related to the "urban" road accident system. Obviously there will be an equivalent "rural" road accident system, which whilst consisting of the same basic sub-systems, must have different 
levels and directions of relationships between the different elements. Similarly, if an overall road accident system is to be built, these tro models, rural and urben, will have to be combined and the complete pattern studied.

(1) PHYSICAL STPUCTURE SUR-SYSTFM

Since the basic aim of this research was to look at the relationship between road accidents and urbanstructure, this sub-system, along with that relating to the socio-cconomic structure, are the two sub-systems studied in some detafl. Thls physical stricture sub-system can in actual fact be sub-divided even further into three smaller units:-
a) MACRO-STFUCTURE - DESIGN
b) MACMO-STRUCTURE - SIZE
c) MICPO-STPUCTURE

Although the third component - micro-structure - is obviously importent in the overall road accident study, this research was more concerned with the macro factors. Accordingly, there is no detail from this research available concerning this facet of the system. However, research has been conducted in this area by other researchers and one study by the U.S. Bureau of Public Roads (BPR) is of particular significance.

This BPR study which elucidates many aspects of multi-fector modelling, was intended as an "Analysis and Modelling of Relationships Between Accidents and the Geometric and Traffic Character- 
Istics of the Interstate Highway System" (Cirillo et. al 1969). In other words, the study tried to measure the effect of various geometric design features on accidents, and also evaluate different interchange designs.

The model used in this BPR study was a standard multiple regression model, and 75 independent variables were introduced in the first stoge of the analysis, being recuced to 20 factors in the final enalyses. Besides pure geometric design features (shoulder width, curveture etc.) the independent variebles also covered such features as traffic variables, (average dajly traffic etc.), road features (IIghting etc.), end environmental factors (pollce hours etc.). Although such variebles were therefore mainly traffic and road variables, 5 of the final 20 , and 10 of the original variables were concerned with "other" items such as the percentage of commercial vehicles, the number of reedable information signs, end if the location was rural or urben.

The major fincings of this research, whilst being important In the main body of road accident research, has this to say about the importence of geometric design factors (micra-structure features),

"Geometric and traffic variables together account for only a fraction of the veriance in accidents. The remaining portion is presumed to be accounted for by major factors not covered in this study, such as driver, vehicle and weather conditicns." (Cirilio op. cit). 
On these lines it is interesting to note that when the BPR stucis looks at the distribution of traffic end accidents over the 24 hours of the day, it points out that the time perlod from midnight to 4 a.m., el though having the lowest average daily triffic of the day, has the highest rates of accidents per mile of trevel. Obviously, road geometry has not changed during this period of time and also, since the traffic variables have been controlled statistically, it must be that driver end vehicle variables had not yet been accounted for, whlst logic, as well as knowledge of the work by Temburis (1969), Indicate that the interaction of specific geometric design features with driver charecteristics mey well be of considerakle significance in elucidating this dilemma. Thus as Katz states:-

"It is an open question whether the BPR study has in fact, "expressed the signiflcant relationships betwecn the design and traffic characteristics and.....accident experience" as claimed or whether the truly significant relationship between these varlables isn't still to be found in the interaction with the "major" variables not included in the investigation." (Katz 1971).

In the light of these reservations, therefore, perhaps the most that can be said about the study is that considerable further information has been added to road accident research, data which when linked with additional similar information in other sections of the road accident system, will serve as the basis for the creation of more advanced and sophisticated models in this field of research. 
Returning to the macro features of this sub-system, the relationships between these various variables will be discussed In the mein boog of this report, although certain superficiel points can be made at this stage in the discussion.

The first point to be made is the high degree of correlation that is present between the two components as well as withs.n each component. In the diggram (Fig. 5.4.1) the highest correlation coefficient is show between any two variables, along with the direction of the relationship. Thus the degree of open spece variable bas its highest correlation coefficient with the density variable $(r=-0 . j)$ whilst the density variable has its highest correlation coefficient with the Foad. Density Index (which is an indicator of road junction density) where $r=+0.84$. As stated, this diggram only shows the highest correlation coefficient between variables, and al though this gives some indication of the relationships present, it is much better if all the correlation coefficients are shown. Therefore, Table (5.4.2) presents the correlation matrix for $\varepsilon 11$ the 22 variables studied and used in this system model.

The second ferture to note about the macro components and the physical sub-system in general, is the way it is postulated to influence the level of road accidents. Not only is it postulated that they directly influence the rolume of road accldente, through the degree of interaction realised ut thin an urban area, and the nature of the acturl road network, but 


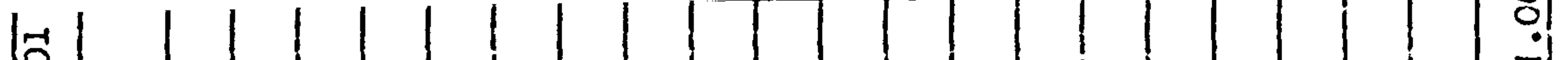

粮

चू

a

承

造

i

崫

이다.

定

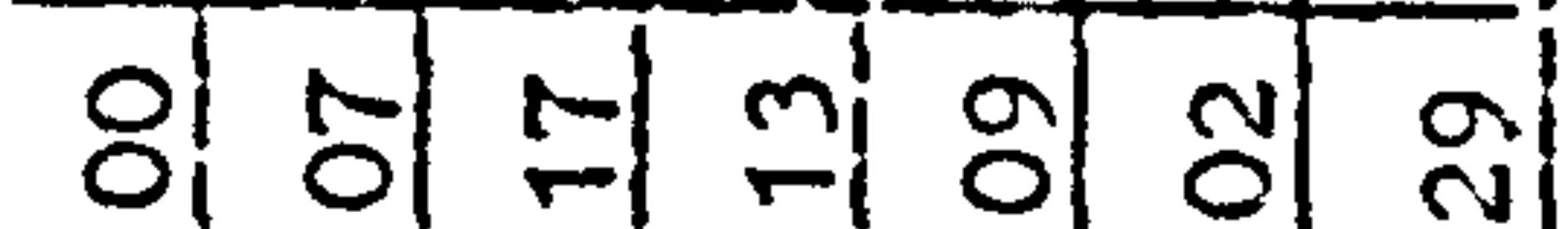

宫

安

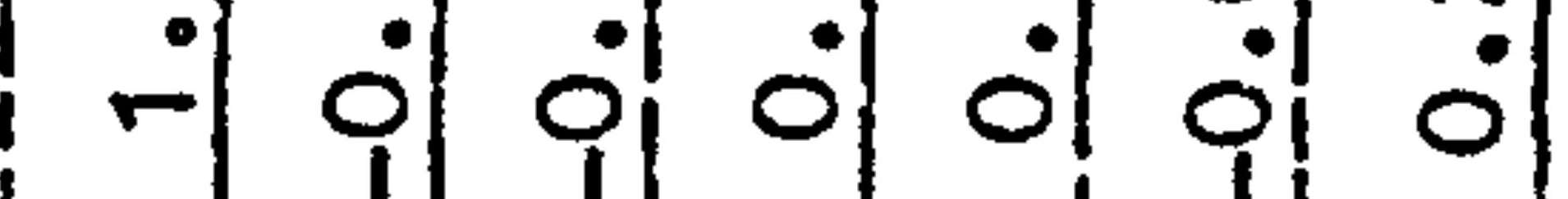

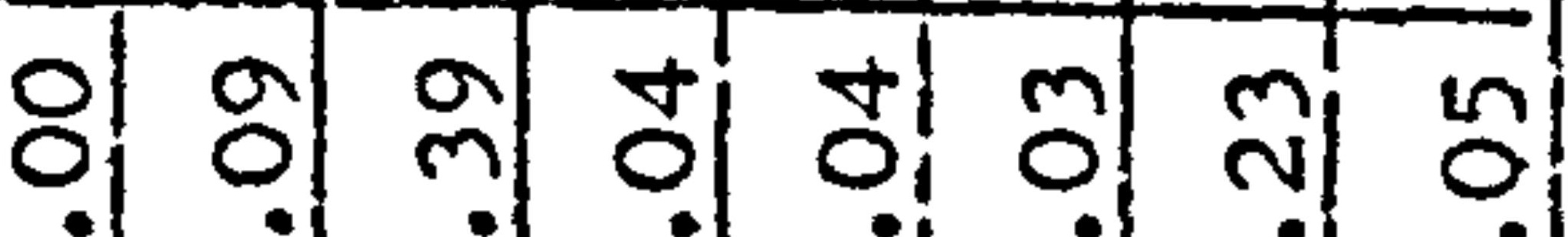

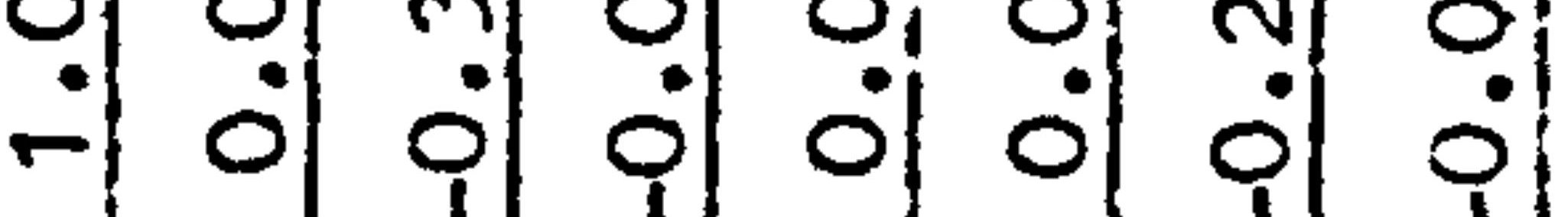

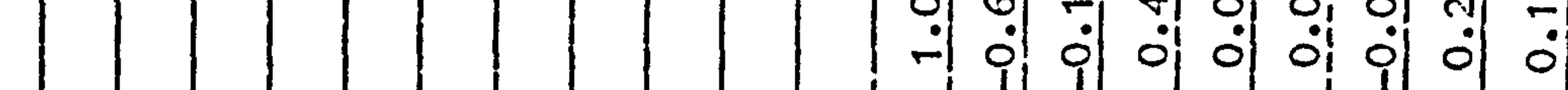

要

O

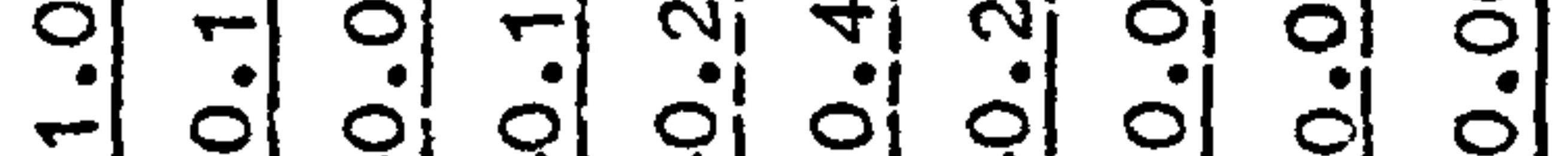

r2

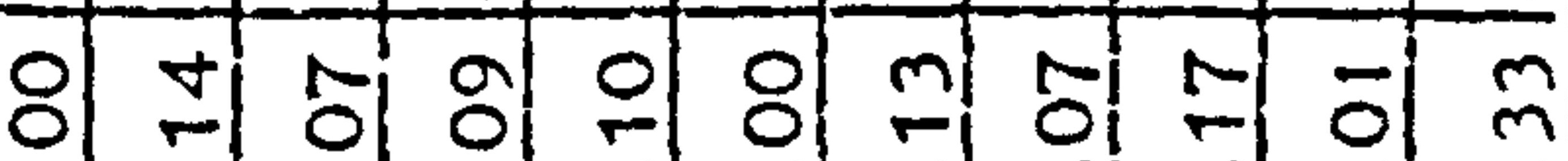

$\because$ 일

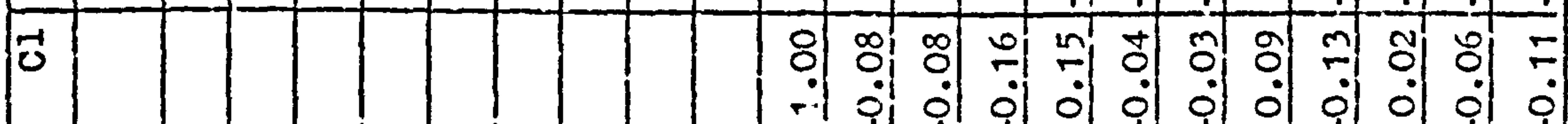

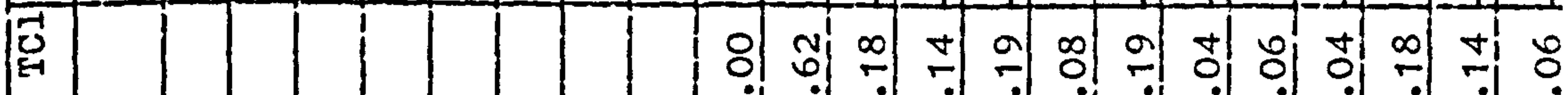

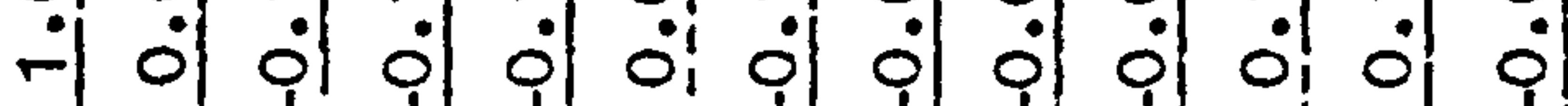

魚

이 이

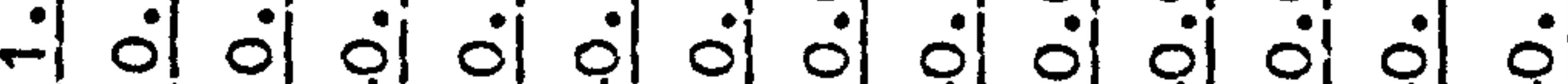

每

이

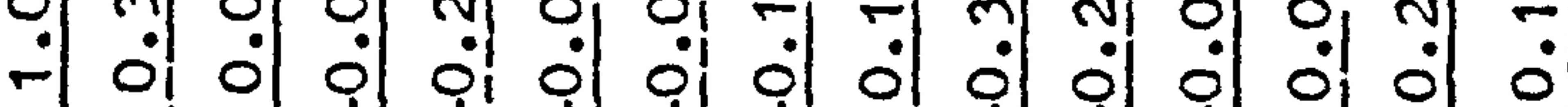

0

이 대

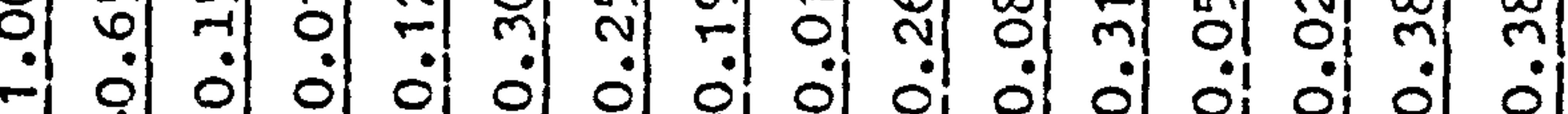

武

$\infty-\infty$ a $-1+0$
이

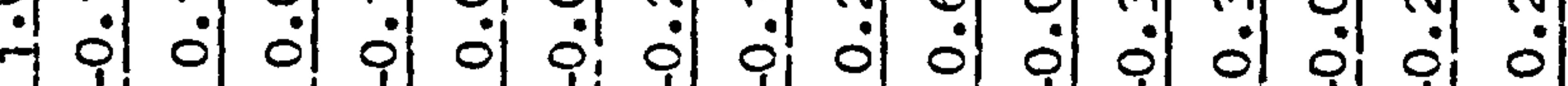

(4)

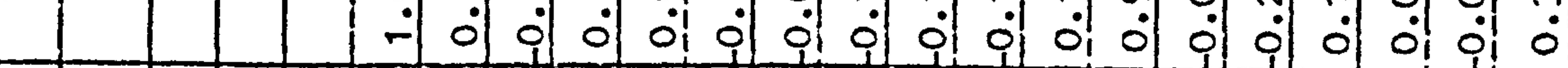

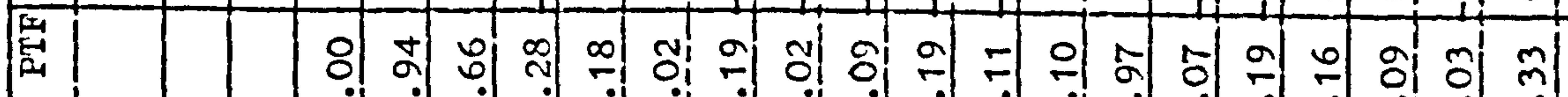

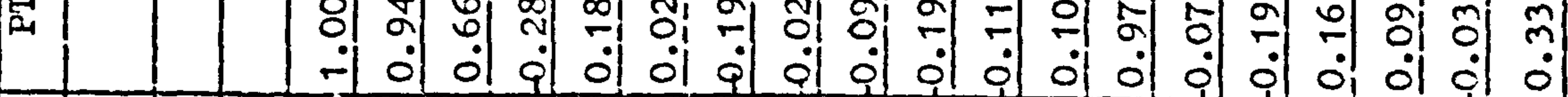
居

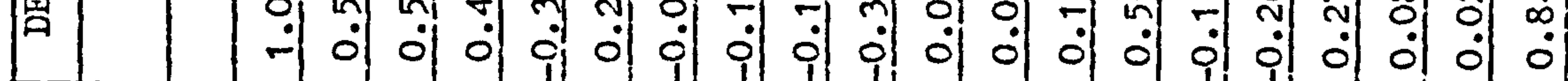

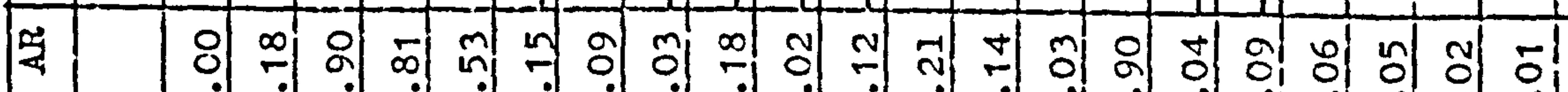

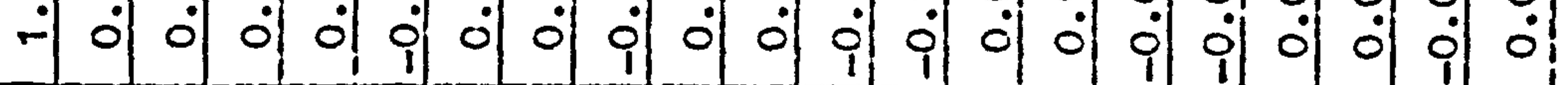

a 8 일

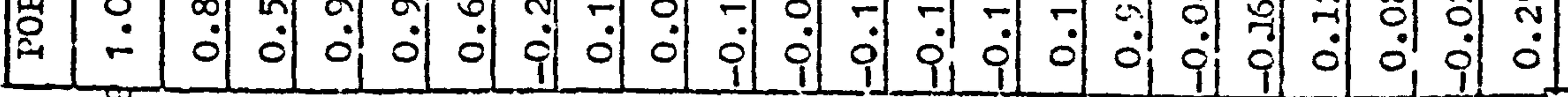

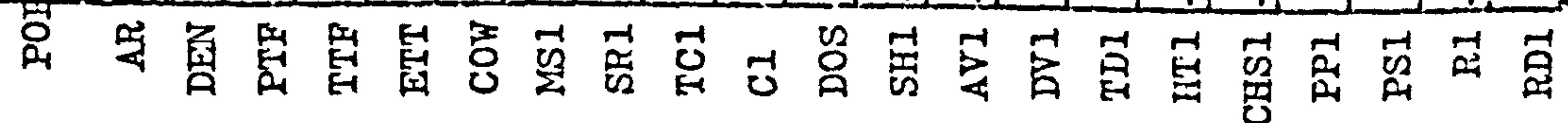


it is also postulated that they are causel variables as they interact with other sub-systems. The most obvious interaction of this kind is through the humen sub-system where it is presumed that the psychological attitude of the driver is influenced by such factors as traffic density, type of road, congestion etc. which in turn, will influence the driver's attitude to "risk taking" and ultimately, therefore, the volume of road accidents.

The thiri point to make meanihile, is the direct "feedback" link between the actual level of road accidents and the "control". of the physical structure sub-gystem of any urbon area. Since one can conceive of the road accident system as being a "controlled system"2 this "feedback" mechenism is of vital importence, since in one wey it indicates a certain "tolerancen level within society, whilst at the some time, it acts as a motivator in reconstruction within the physical environment. Thus it can be argued from this point, that this feedback mechanism is essential in determinIng the level of road accidents (or costs) that any society is liable to deam acceptable, when related to the actual cost of physical improvement and/or redevelopment. The understending

2 There are usually deemed to be four types of systems:(1) HOHAEOSTETIC SYSTEY:- This is a system that maintains "a constent operating environment in the face of rendom externel fluctuations." (Rosen 1967). Such systems resist any change in envijonmental conditions and gre dually return to en equilibrium or steady state beherlour after any such change. A spring is a good analogy for this kind of system. 
of such a feedback mechanism can only come, however, at a much later date in the rodelling of the road accident system, when the relationships between all the elements are more clearly understood. When that situation has been reached, the feedback mechanism becomes a type of eveluatory process.

\section{(2) SOCTO-ECONCIIC STPLICTURE SUB-SYSTEM}

It can be seen that this sub-system is basically made up of social status and housing variables. Once again since these variables were studied in this research, the highest correlation links are shown both by value and direction.

Although it is postulated that this sub-system does not directly influence the volume of roid accidents, it was deemed signiflcent in affecting the ultimate level of accidents through other sub-systems. Thus the level of car ounership will affect the traffic volumes in the physical structure sub-system, and the sex ratio will affect the humen sub-system, because of the different accident potterns and rates, noted for male and female drivers. (See HcKay 1969, Fobertson et al 1966 etc.). A similar argument can be put forvard for the tro age distribution variables.

2 contd. (1i) ADAPIIVE SYSTIN:- is a systen for which there exlsts for each possible input a set of one or more preferred stetes, or outputs. The system is also such that if at any time the system is not in a preferred state, then the system will so act as to alter the stete until one of the prefcrred ones is achieved. The study of such systems obviously involves the concept of "goal seeking." The concept of a feedbccl: mechanism is obviously vitel in these types of system changing the rerious states by dirictly affecting the condition of the environment or by altering the peremeters of the system itself. 
The other major sub-system linked with the socio-economic sub-gystem is the vehicle system. The line of reasoning here is that the socio-cconomic level of an urban area, will directiy influence the type, age and therefore level of maintencnce, of the vehicles used in that area. The lower an area is socielly, the higher the proportion of "second-hand" and old cars one would expect to find in the total vehicle population. On these Ines, if any confidence can be placed on the tentative results of the motor vehicle inspection studies mentioned previously, then one would elso expect a relatively higher degree of road accidents in these areas.

\section{(3) VHHCLE SUR-SYSTFY}

of all these sub-systems within the roed accident system, the vehicle sub-sjstem has perhaps comended in the past, the major amount of reseerch in this field. Unfortunately, this sub-system is complicated by the fact that it cen influence road accidents both in the "pre-collision circumstences" and also in the "post-collision circumstences," and as such they ought to be deslt with individually.

2 contd. (iii) DYNMIC SISTHIS:- are systems through which the feedback mechanism keeps the system moving through a sequence of unreperted states usually termed the trejectory or line of behaviour of the system. Implicit in such systems is the leaming process where the feedback may cause new preforred states to be identified. Exemples of such systems include economic growth models etc. 
Post collision investigations can be generelised under the heading of protective devices; their use and degree of success in the post-crash condition. Such investigations have therefore studied the use of safety belts and the energy absorbing steering column etc. Although these devices could be tested experimentally in the laborktory, the true degree of their success can only be statistically demonstrated in the field, since in the case of the safety belt there was considerable scepticism as to what hould be the belt's real contribution to the overell traffic safety progress.

A good example of the resultent studies, end one which helps to indicate the influence of ather variables end subsystems, upon the vehicle sub-system is the study completed by Bohlin (1967) who looked at 28,000 accidents involving Volvo vehicles in Sweden 1965 - 1966.

The flrst and perhaps most significant finding was that only 25\% of the vehicles with seat belts, actually used them with the result that any effect of seat belts on overall injury

2 conto.. (1v) CONTPOLLED SYSTFMS: - are those where the operetor has some degree of control over inputs. Systems control theory is therefore very important when desling with these systems. Controlled systems are most frequently found in the fielcis of planning, end government policy were some inputs are controlled in order to achieve some desired level of output. For further reading on these systems see (hosen 1967, Ashby 1966, 1963). 
must be very limited. Returning to the main findings of the stuóy meenwhile, using a "cause present" and "cause absent" group technique, Bohlin was able to study these two groups and see if there vas any significance in the serloumess of injurles sustained. However, before uncritically rccepting the findings of this study, which conclusively showed the effectiveness of seat belts as a crash injury reducing agent, It must be pointed out that the two groups used exhibited significant differences in composition. For example, as regards age, in the total group of 37,511 injured front eat occupents, the author states that $n$ the substantial part were the very young drivers oged 18 - 24." On the other hand, since belt usage varied from 176 in the 20 - 25 gears ege group, to 376 in the 45 - 55 years age group, it is obvious that the distribution of ages in the 9569 injury cases who vore seat belts is entirely different from that in the remaining 27,952 cause absent, non-belted group. If this is coupled with the assumption that people who wear safety belts might prove to be more "careful" persons overall (Morgan 1967) it can be seen that the actual influence of these rehicle variables cannot truly be assessed until the interactive influence of other variables (age, speed, sex, carefulness, etc.), has setisfactorily been accounted for end studied.

Similarly, the studies which have tried to investigate the influence of vehicle factors on the pre-crash concitions, have also been restricted by severel difficulties. The major hypothesis 
here has been to try and detemine whether changes in the handling, and performence characteristics of different vehicles, can in any way be a factor in the causation of road accidents. Thus a typical study was thet by Comell Aeronautical Leboratory which attempted, "to find out to what extent power steering cars might differ frcm standard steering cars in injury preducing accldents." (Gensler 1966). Their enelysis sub-divides the "wl th" end "wi thcut" groups according to weight of car, age and sex of driver, time end type of eccident, impact speed, area of impact, direction of force, roll-over violence and two car - single car configuration. These observations led to two major conclusions.

(i) Power steering cars have more object collisions as contrasted to rehicle collisions, and,

(ii) Power steering cars have more rear end involvement as contrasted to frent involvement etc.

However, the complext ty of such studies, and therefore this part of the vehicle sub-system as a whole, can be best illustrated by cuoting from the Correll study:-

"None of the findings cen be related to the steering mechenism. There is no obvious way by which power steering could be thought to cause object collisions rather than vehicle colijsicns ....etc. ..... Yet these tendencies are statistically significant.... The interpretation of these findings is made problenatic if not inpossible by the fact that the data contain no information on 
the exposure of the two groups of cars..... It may be that power steering cars are on the road ......under different traffic conditions.....Preponderence of object collisions could be expected if power steering cars did more rurel highway driving.... These explanations of the observations must remain quite speculative." (Gensler op cit.).

The major conclusions to be drewn from both types of study described above, (those looking at pre-crash conditions, and those concerried with post-cresh conditions) is that al though one cen determine several relationships, the relationships betreen vehicle factors and other variables cannot be explicitiy stated wi thout further data and further study. However, it can be concluded that tile vehicle sub-systen is definitely affected by the socioeconoulc sub-system and the prevention sub-systen (through police survelllance and control) even though the type, level and direction of these influences cannot be specifically stated at this point in tims.

(4) NATURAL PHFROIIETA SUB-SZSTFI

Although the influence of this sub-systen in Britain on the level of rosd accidents (in urbsn areas) cen be postulated as being minimal, it should not be discounted altogether.

There are two ways suggested in which this sub-system can influence the volune of accidents. In the first instance it can work through the micro-features of the physical structure sub- 
systen, whereby it makes "normally" safe physical features "less" safe under bad natural conditions. Thus the degree of satisfaction concerning surfacing work can vary according to the level of such things as rainfall, ice, relief etc.

Similarly the natural phenomena sub-systen can be influsnced due to its interaction with the human system. It should be realised there are two climatic conditions, one inside the vehicle as well as one outside the vehlcle. The interior conditions within a vehicle can therefore be important in determining the physiological condition of the driver etc., and therefore the way in which he responds to any incident.

In this research, because of data difficulties, the only variable included from this sub-systein was that of rainfall. Although its correlation with the other variables is shown in Table (5.4.2) it would sppear that these are rather neaningless, since the above mentioned intermediary variables are not included and therefore the postulated important interactions unavaileble.

\section{(5) PREVEVTION SUB-STSTEI}

Once again this sub-systen can be very influancial in detenining the level of road accidents in any area through one or other of the various sub-systens. It would appear that this sub-systen can be split into two separate sections which can influence the accident level in different ways.

One section can be described as tine police action section. This includes the action of the police in relation to car mainten- 
ance, traffic control, and also motoring offences. Thus this section can influence the level of road accidents by means of its interaction with the vehicle, physical and human sub-systens respectively. For exanple, it can be argued that where a police force is well known for its "unsympathetic" attitude to motoring offences, this should affect the attitude of individual drivers, through the human psychologicel sub-system. It is interesting to note here that the naximun correlation coefficient for the Police Prosecution Index used in this research is $r=0.38$ and links this variable with the level of through traffic, in the physical structure sub-systen. This could indicate perhaps one of tro hjpotheses. Either it could be argued that police action tends to be more stringent in traffic control where there is a high degree of through traffic and therefore, possibly traffic congestion, or altematively it could be argued that where a police force follows a stringent line on motoring offences, the number of police prosecutions is related directly to the volume of through triffic and therefore the volume of strangers through on area who are not conversant with the local police attitude. Whichever argurnent is accepted however, it is obvious that the police action is definitely interacting with one or more of the other sub-systens.

The second section within this sub-systen can be looked upon as a training section. That is, the action of such people as road safety officers, and driver trainer bodies. This section therefore obviously interacts with the human sub-systen by troing 
to alter the psychological attitude of both driters and pedestrians of all ages, by increasing the level of knowledge and understanding of these people.

Before leaving this sub-systern, it should be pointed out once again, the direct feedback link between the actual level of road accidents and the prevention sub-systern. The logic behind this is that the prevention organisations are the implenentors of the "tolerance" level of sociaty to the volune and cost of road accidents. Thus it can be seen that there is a direct relationship between the volume of road accidents and polics action as regards motoring incidents.

\section{(6) HUMAN SUB-SISTEI}

Basically this sub-system is related to the poychological end physiological response of the hunan individuals to any situation. The importance of this sub-systen cen be seen by the fact that it is influenced by every other sub-systen within the rod accident system, and can therefore perhaps be regarded as the central core of the whole systen. Unfortunately the intermal oper ation of this sub-systen is also the least understood and any studies which have been attenpted in this direction have been of verg little success. It can be argued, however, that before this sub-system cen be satisfactorily "opened" the relevant interactions of the other sub-systeras will have to be known, and the understanding of the hunan systen will be the last clue in the problen. 
Studies which have tried to look at this sub-oystem in isolation, have tended to revolve around the virious early theoretical models of road accident causation, such es accident proneness and highway hypnosis. Consequently, as these theories have become less acceptable, so have the results of these studies, although once again importent background information way have been collected. However, it is still true to state that very little is still knom about this sub-systen and further advanced work by pertaps psychologists is one of the major necessities in roud accident analysis at present.

This chapter has therefore attenoted to postulate a simple road accident system, and the various internal sub-systens, which can serve as a first approximation to the final road accioent systen. It must be enphasised this model only suggests the varlous directions of the interrelationships and therefore no mathematical functions can be put forward at this time. These functional relationships can only be obtained by further detalled wors into the nature of each of the sub-systems. Accoraingly, this research has used the suggested framewors and has atteinpted to look at two of these sub-systens; the physical structure subsysten and the socio-economic sub-system, the analysis and results of which, are given in the following sections of this report. 
Cheipter 6 DATA

\subsection{INTPODUCTION}

Since the aims of this research involved the study of the spatial and temporal variation in road accident statistics in England end Wales, various sources had to be used for the extraction of the relerant data points. Similarly it was necessarg to collect two sub-sets of data, one relating to the dependent variables (road accident statistics) and another relating to the independent or explanatory variables. The source and definition of these variables will be expounded in more detall in the following sections of this report. Nunerically twenty two independent variables (Table 6.1.1) and fort five dependent variables (Table 6.1.2) were assertalned for each of the one hundred areas sampled. In order to elucidate the explanation of these two sets of variables, each will be referred to individuelly within each relevant sub-set.

\subsection{DEPENDEIT VAPIABLES}

The major source for this sub-set of variables was obtained from the TRFi's computerised output of the Police Stats 19 forn. Use of this source of data enabled uniformity of data spatially, whilst unfortunately restricting the temporal analysis due to the variation in the svallability of the same data population for different jears. Because of this difficulty, it was only possible to attain heavily disagsregated data for the years 1969 
1. POP:- POFULATION LEVEL

2. AR:- AREA OF URBAN DISTRICT

3. DEN:- DENSITY OF POPULATION

4. PTF:- PEAK TRAFFIC FLOW

5. ETT:- ESTIMATE OF THROUGH TRAFFIC

6. TIF:- TOTAL TRAFFIC FLOW

7. COW:- CAR OWNERSHIP

8. MSI :- NEAN SOCIAL INDEX

9. SRI:- SEX RATIO INDEX

10. TCI:- TOWN CLASSIFICATION INDEX

11. CI:- COMPACTNESS INDEXX

12. DOS:- DEGFEE OF OFEN SPACE

13. SHI:- STANDARD OF HOTISING INDEX

14. AVI:- AGE VULNERABILITI INDEXX

15. DVI:- DRIVER VULNERABILITY INDEX

16. TDI:- TOTAL DWELLING INDEX

17. III:- HOUSING TENURE INDEX

18. CHSI - CHANGE O1 HOLSING STOCK INDEX.

19. PPI:- POLICE PROSECUTION INDEX

20. PSI:- POLICE SEVERITY INDEX

21. RI:- RAINFALL INDEX

22. RDI:- ROAD DENSITY INDEX

TABLE 6.1.1. IIST OF 22 INDEPENDENT VARIABLES (1970) 
1. TC70:

2. TA70:

3. TFS70:

4. TPED70:

5. TMC70:

6. TPCY70:

7. TLRC70:

8. TCFED70:

9. TYDR70:

10. TJUN70:

11. TPDCR70:

12. TTPN70:

13. TET70:

14. TTJN70:

15. TIJN70:

16. TXJN70:

17. TUCRD70:

18. TCRD70:

19. TCPP70:

20. TAPP70:

21. TFSPP70:

22. TCVM70:

23. TAVM70:

24. TFSVM70:

25. SR70:

26. CFEDCR70:

27. IDRCR70:

28. TVNAR70:

29. PDCRAR70:

30. TAYNC70:

31. TAMC70:

32. RTAR70:

33. TJNAR70:

34. IJNAR70:

35. XINAR70:

36. TFEDPP70:

37. PEDCR70:

38. PCINT70:

39. PEDNT70:

40. PCIAR70:

41. MCAR70:

42. TJTIN70:

43. DRCR70:

44. TCTA70:

45. TJNAR70:
Total Casualties

Total Accidents

Total Fatal and Seri ous Casualties

Total Pedestrian Casualties

Total Motor cycle Accidents

Total Pedal cycle Accidents

Total Driver and Rider Casualties

Total Child Fedestrian Casualties

Total Young Driver and Rider Casualties

Total Junction Accidents

Total Accidents at Pedestrian Crossings

Total Accidents due to a

Total Accidents at Roundabouts

" $n$ at Tunctions

" $"$ at $I$ "

$" n$ at $X$ n

Total Accidents on Unclassified Roads

" " Classified Roads

Total Casualties per $10^{3}$ population

n Accidents n " n

Total Fatal and Serious casualties par $10^{3}$ population

Total Casualties per 106 Vehicle Miles

"Accidents " " n "

Total Fatal and Serious casualties per $10^{6}$ Vehicle Miles

Fatal and Serious casualties/Total Casualties.

Child fedestrian casualties/Total pedestrian casualties

Young driver and rider casualties/Total driver and rider casualties.

Total turning accidents/Total acciaents

Total accidents at pedestrian crossings/Total accidents

Total accidents on unclassified roads per mile of unclassified road.

Total accidents on classified roads per mile of classified road

Total roundabout accidents/Total junction accidents

Total T Junction "

$n \quad n \quad n$

$" x n$.

"

Total pedestrian casualties per $10^{3}$ population

Total pedestrian casualties/Total casualties

Total pedal cycle accidents/pedal cycle work trips (103)

Pedestrian casualties/Total walk work trips $\left(10^{c}\right)$

Total pedal cycle accidents/Total accidents

Total motor cycle accidents/Total accidents

Total driver and rider.casualties per $10^{6}$ Vehicle miles

Total dr:ver and rider casualties/Total Casualties

Total Casualties/Total Accidents

Total Junction accidents/Total Accidents.

TABLE 6.1.2. LIST OF 45 DEFENDENT VARIABLES 1970. 
and 1970. However, the temporal analysis was extended for three of the basic dependent variables; total casualties, total casualties per thousand of population and total casualties per vebicle mile $\left(10^{6}\right)$, for the years 1966 - 1970. Such variables related to all accidents involving fatal, serious and slight casualties for each of the sampled local authority areas. Data prior to 1966 was only available for fatal and serious accidents thereby restricting the use of these years in any extended, or meaning ful temporal analysis. Therefore it is important to note that the 45 disaggregated dependent variables obtained from the Stats 19 form, are essentially only related to the two year period 1969 and 1970 .

The Pollce Stats 19 form has been operative for many yeare, but the data used in this research came from the 1968 revised form. This forn which has to be completed by the pollce for every personal injury accident, contains extended information ranging from the type and class of casual ties to attendant road and manoeurre circunstances. (Fig. 5.2.1). The computerisation of these forms in 1967 by Harris (1971) at the TRRL at Crowthorne, enabled the extraction of the necessary data to take place for the relevant local authority areas. This allowed a greater disaggregating of the data than would otherwise have been possible. The definition of the various disaggregated dependent variables is given below:-

Iol TOTAL CASUALTIES: (TC 70) the total number of fatal, serious and slight casual ties reported by the pollce for each relevant local eutinority. 


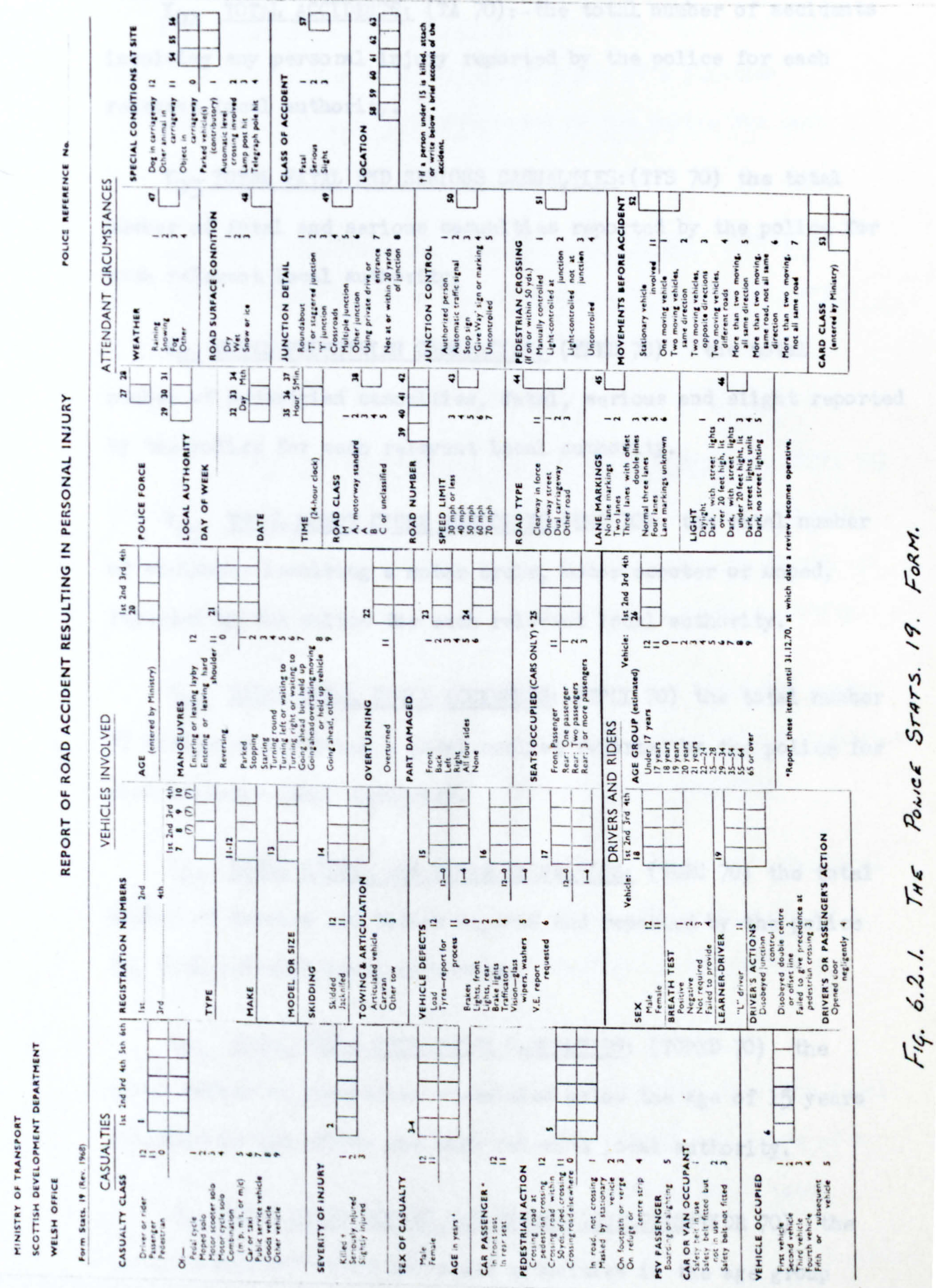


Yo2 TOTAL ACCIDENTS: (TA 70):- the totel number of accidents Involving any personal injury reported by the pollce for each relevant local authorits.

Y03 TOTAL FATAL AND SERTOUS CASUALTIES: (TFS 70) the total number of fatal and serious casualties reported by the police for each relevant local authority.

$\mathrm{Y}_{04}$ TOTAL PEDESTRIAI CASUALTIFS: (TPED 70) the to tal number of pedestrian casualties, fatal, serious and slight reported by the police for each relevant local authority.

$Y_{05}$ TOTAL MOMR CRCLE ACCIDFNTS: (TIC 70) the to tal number of accidents involving a motor cycle, motor scooter or moped, reported by the police for each relevant local authority.

Y06 TOTAL PFDAL CYCLE ACCIDENTS: (TPCT 70) the to tal number of accidents involving a pedal cyclist reported by the police for each relevant local authority.

Y07 TOTAL DRIPER AND RIDER CASUALTTES: (TDRC 70) the total number of drivers and riders injured and reported by the police for each relevant local authority.

\section{I08 TOTAL CHILD PEDESTRLAN CASUALTIES: (TCPED 70) the} total number of pedestrian casualties below the age of 15 years reported by the pollce for each relevant local authority.

YOg TOTAL YOUNG DRIVER AND PIDER CASUALTIES(TYDR 70) the total number of driver and rider casualties in the age group 16 - 25 years reported by the police for each relevant local authority. 
I $_{10}$ TOTAL JUICTION ACCIDENTS: (TJINI 70) the total number of accidents occuring at or within 20 yards of a function involving personal injury and reported by the police for each relevant local authority.

$I_{11}$ TOTAL ACCIDENTS AT PEDESTRTAN CPOSSINGS: (TPDCR 70) the total number of accidents occurring at or within 50 yards of a crossing involving personal injury and reported by the police for each relevent local authority.

I12 TOTAL ACCIDENTS INVOLVING A TUPNING MOVEMENIT: (TTRR 70) the total number of injury accidents involving a vehicle turning round, turning left or weiting to, or turning right or waiting to do so, reported by the police for each relevant local authorito.

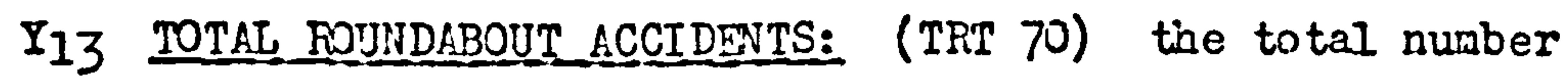
of infury accidents occurring at, or within 20 yards of a roundabout reported by the police for each relerant local authority.

$Y_{14}$ TOTAL ACCIDEITS AT ' $I^{\prime}$ JUNCTIONS: (TIJN 70) the total number of injury accidents occurring at or within 20 yards of a ' $T$ ' junction or staggered junction, reported by the police for each relevant local authoritj.

Y $_{15}$ TOTAL ACCIDENTS AT IYI JUNCTIONS: (TTJN 70) the total number of injury accidents occurring at or within 20 yards of a 'I' junction, reported by the police for each relevant local euthorits. 
$Y_{16}$ TOTAL ACCIDENTS AT CRDSS-POADS: (TXIN 70) the total number of injury accidents occurring at or within 20 yards of a cross-roads junction, reported by the police for each relevant local authority.

$I_{17}$ TOTEI ACCIDEATS ON UNCLLSSIFIFD ROADS: (TUCRD 70) the total number of personal injury accidents occurring on urban roads graded as class $C$ rosds or unclassified roads, reported by the police for each relevant local authority.

$I_{18}$ TOTAJ ACCIDENTS ON CIASSIFIED PDADS: (TCRD 70) the total number of personal injury accidents occurring on urban roads graded as class $M, A / H, A$ and $B$, reported by the police for each relevant local authority.

\section{Y $_{19}$ TOTAL CASUALIIES PER THOUSAND OF POPUT,ATION: (TCPP 70)} the total number of road casualties reported by the police for each relevent locel authority, divided by the population (000s) for that local authority area.

I20 TOTAI, LCCIDENTS PER THOUSAND OF POPULATION: (TAPP 70) the total nurber of personal injury accidents, reported by the police for each relevant local authority, divided by the population (000s) for that local authority area.

\section{$I_{21}$ TOTAL FATAL AND SERIOUS CASUALTLES PER THOUSAND OF} POPULATION: (TFSPP 70) the total number of fatal and serious casualties, reported by the police for each relevent local authority, divided by the population (000s) for that local authority area. 


\section{$I_{22}$ CASUALTY RATE, PER MILLION VFHICLE MILES: (TCVM 70)}

the total number of casualties reported by the pollice for each relevant local authority, divided by the number of million vehicle miles calculated for that local authority area. ${ }^{1}$

\section{I $_{23}$ ACCIDEIT PATE PER MILLION VEHICLE MTLES: (TAVH 70)} the total number of personal injury accidents reported by the pollce for each relevant local authorits, divided by the number of million vehicle miles calculated for that local authority area.

\section{$I_{24}$ FATAL AND SERTOUS CASUALTL RATE PER MILLION VEHICLE MILES:}

(TFSVI 70) the total number of fatal and serious casualties reported by the polfce for each relevant local authorits, divided by the number of million vehicle miles calculated for that local authoritg area.

$I_{25}$ SEVEPITI RATE: (SR 70) the total number of fatal and serious casualties reported by the police for each relevant local authority, divided by the total number of casualties reported by the police for each relevant local authority.

1 Vehlcle milerge is defined as:-

$$
\nabla m_{1}=T T F_{1} \cdot R M_{1}
$$

$$
\text { where } \begin{aligned}
& \mathrm{TTF}_{1}= \text { Total traffic flow for } \text { area }_{1} \\
& \text { (see notes on independent } \\
& \text { varlables) }
\end{aligned}
$$


$I_{26}$ CHILD PEDESTRTAN CASUALTT RATE: (CPEDCR 70) the total number of pedestrian casualties below the age of 15 years reported by the police for each relevant local authorits, divided by the total number of pedestrian casualties reported bJ the police for each relevant local authority.

\section{$Y_{27}$ YOUNG DRTVER AND RIDER CASUALTT RATE: (YDRCR 70)} the total number of drivers and rider casualties in the age group $16-25$ jears reported by the police for each relevant local authority, divided by the total number of driver and rider casualties reported by the police for each relevent local euthority.

I28 TURING ACCIDENTRATE: (IUNAR 70) the total number of personal injury accidents resulting from a turning menoeurre ${ }^{2}$, reported by the police for each relevant locel authority, divided by the total nuraber of personal injury accidents reported by the police for each relevant local authority.

\section{I $_{29}$ PEDESTRIAN CPOSSTVG ACCIDENT RATE: (PDCRAR 70) the} total number of personal infury accidents occurring at or within 20 yards of a pedestrian crossing reported by the police for each relevant local authorlty, divided by the total number of personal injury accidents reported by the police for each relevent local authori ty.

2 Actions included in a turning manoeurre are:-

1) Turning round in the roadway.

2) Turning left or waiting to tarn.

3) Turning right or waiting to turn. 
$T_{30}$ ACCIDENTS PER MILE OF UNCLASSIFIED RDAD: (TASTC 70) the total number of personal injurg accidents occurring on unclassified roads reported by the police for each relevant local authority, divided by the mileage of unclassified roads 3 in that local authority area.

\section{$Y_{31}$ ACCIDEITS PER MITE OF CLASSIFIFD ROADS: (TAMC 70)} the total number of personal injury accidents occurring on classifled roads reported by the polfce for each relevant local authority, divided by the mileage of classified roads 3 in that local authority area.

$I_{32}$ FOUNDABOUT ACCIDENT RATE: (RTAR 70) the total number of personal injury accidents occurring at or within 20 gards of a roundabout reported by the police for each relevant local authority divided by the total number of personal injury Junction accidents reported by the police for each relevant local authority.

I33 'T' JUNCTIOI ACCIDENT RATE: (TJNAR 70) the total number of personal injury accidents occurring at or within 20 yards of a ' $T$ ' or staggered junction recorted by the police for each relevent local euthority, diviced by the total number of personal injury eccidents occurring at or within 20 yards of a junction, reported by the police for each relerent local authority.

3 Supplied by the Ministry of the Envirorment end the Scottish and Welsh Offices. 
$Y_{34}$ IY' JUNCTION ACCIDEIT RATE: (YJNAR 70) the total number of personel injury accidents occurring at or within 20 yards of a ' $Y$ ' juncticn, reported by the police for each relevent locel euthority, divided by the total number of personal injury accidents occurring at or within 20 yards of a junction reported by the police for each relevent locel Euthority.

$Y_{35}$ CROSS-FOAD JUNCTION ACCIIENT PUTE: (IJNAR 70) the total number of personal injury accidents cccurring at or within 20 yards of a cross-road juncticn, reported by the police for each relevent local authority, difided by the total number of perscnal injury accidents occurring at or within 20 yaris of a junction, reported by the police for each relevent local authority.

\section{$\mathrm{Y}_{36}$ TOTIL FEDESTFI LN CISUALTIES PEP TYOUSLND OF PCPULATICN:} (TPEDPP 70) the total nunber of pedestrikn casuel ties reported by the police for exch relevent local authority, divided by the population (000s) of that local euthority area.

$I_{37}$ PEDESTRI EN CASUALTI PATE: (PEDCR 70) the total number of pedestrian casualties reported by the pollce for each relevent local authority, divided by the totel number of casual ties, reported by the police for each relevent locel authorfty.

$Y_{38}$ TOTAL PEDAL CYCLE ACCIDFNTS PER THOUSAND PEDAL CYCLE WORK TFIPS: (PCYVT 70) the totel number of pedal cycle injury 
accidents reported by the police for each relevent local authority, divided by the estimated pedal cycle work trips 4 for that local euthority area.

\section{$I_{39}$ TOTAL PEDESTETAN CASUALTIES PER HONDFED WOPK WLLK}

IRIPS: (PEDWT 70) the total number of pedestrien casuelties reported by the police for each relevent local authority, divided by the estimated work walk trips ${ }^{4}$ for that local authority area.

$Y_{40}$ PEDAL CYCLE fCCIDENT PATE: (PCIAP 70) the total number of personal infury accidents involving pedal cycles, reyorted by the police for each relevent local euthority, divided by the total number of personal injury accidents reported by the police for each relevent local authority.

$I_{41}$ MOTOR CICLE ACCIDENT PLTF: (MCAR 70) the total number of personel injury accidents involving a motor cycle reported by the police for each relevent locel authority, divided by the total number of personal injury accidents reported by the police for each relevant locel authority.

\section{$I_{42}$ TOTAL DPIVER AND RUDER CASUAJTIES PER MIIIION VFHICLE}

MIJES: (TIKNM 70) the total number of driver end rider casualties reported by the police for each relevent local authority, divided by the number of million vehicle miles calculated for that local authority area.

4 Both the pedal cycle work trips $\left({ }^{Y} 38\right)$ end the totel valk work trips ( $Y_{39}$ ) were obtuined from the "Journey to Work" tables presented in the 1966 census returns. These estinates were included to try and obtain soine degree of exposure of these two diseggregated eccident variables. 
$I_{43}$ DRIVER AND RIDER CASUALTY FETE: (DRCR 70) the total number of driver end rider casual ties reported by the police for each relevent local authority, diflded by the total number of casualties reported by the police for each relevent locel authority.

$\mathrm{I}_{44}$ CASUAITI RATE: (TCTA 70) the total number of casuel ties reported by the polfce for each relevent local euthority, divided by the total number of personal injury accidents reported by the police for esch relevent locel authority.

$I_{45}$ JUNCTION ACCIDINT RATF: (TJNAR 70) the total number of perscinal injury accidents occurring at or within 20 yards of a function reported by the police for each relevent local authorlty, divided by the total number of persenel injury accidents reported by the police for each relevent locel authority.

As will be obvious from the list of cependent variables used, their nature and type are very diverse, some are absolute figures, whilst others are compound variables. Wi thin the road accident Iiterature, there has been some, but not enough discussion, as to what type of variable is the best kind of safety indicator. (Katz 1971 Rapoport 1967). Following Katz it can be argued that there are two groups of indicators, one which measures how intense or prevalent accidents are vithin a given population, and another which measures the emount of eccident incidence in relation to a related measure of exposure to that activity. Thus the first group which Katz calls the "static" or "population" femily includes 
such indicetors as:-

(1) accidents per 1,000,000 persons

(ii) accidents per 1,000 vehicles

(iii) accidents per mile of road

(iv) accidents per 1000 male drivers etc.

The second group meanthile, which can be called the "exposure" or "activity" femily of indicators, includes:-

(1) accidents per mile of bus travel

(ii) o.ccidents per mile of ennual driving

(iii) accidents per number of pedestriens crossing the road

(iv) accidents per mile of travel of road length etc.

The distinction between these tro groups is both relevant to this research, end also any future research, since of the two, the exposure indicators are by far the more meaning ful cnes yet to date such information is either scarce cr non-existent, and when epplied to sub-netionel geographicel areas, open to considereble error values due to the dearth of accepted information collection and derivation. Therefore of the 45 dependent variables used in this research, only 6 can be said to be of the exposure group whilst the remainder belong to the static femily of indicators. The reason for preferring the exposure indicators is due to the Iimitation inherent within the static indicators, which reflect both the emount of activity and the degree of danger associated wth that actirity, within one stetistic. Thus where one is 
trying to measure the effectiveness of some colntermeasure action, such indicators would appear menningless. However, where one is trying to study spatial variations about some declared "norm" of accoptability, es in this research, whilst the static indicators may not be the optimum ones, they do have considerable relevence and are therefore meeningfur in relation to consequent conclusions.

\subsection{INDEPENDENT VARIABLES}

Onlike the dependent variables, there was no one source of data for the indenendent variables, al though in several instences the 1961, 1966 and 1971 censuses provided the major components. of the 22 independent variables 8 were constent during the period of the study, whilst the remainder veried from year to year. A description and the derivation of each of these variables is given in the following section.

$X_{1}$ POPULATTON:- (POP 70) The incidence of road accident conflict is obviousiy related to the size of an urben area. Therefore data of the relevent population levels viere obteined from the 1961, 1966 and 1971 census returns for Englend, Weles and Scotiend. The data for the intervening years wes taken from the Registrar General's annual estimates of population.

\section{$\mathrm{X}_{2}$ APFA OF AN UFBAN AFFA:- (AR 70) Once egein this} information was obteined fron the respective census returns. Additional information was also obtained from the data given 
WI thin the Hunicipal Year Book, end the annual reports of the New Town corporations, where relevant. The area of an authority was measured in acres.

$\mathrm{I}_{3}$ POPULATION DENSITI:- (DEN 70) This variable was a combination of the previous two variables and can be defined as

$$
D_{i t}=\frac{P_{i \cdot t}}{A_{i \cdot t}}
$$

where $D_{i . t}=$ the density of population area 1 at time $t$

(persons per acre)

$$
\begin{aligned}
& P_{1 . t}=\text { the population of area } 1 \text { at time } t \\
& \text { H.t }_{1 . t}=\text { the area of an area } i \text { at time } t \text { (acres) }
\end{aligned}
$$

$\mathrm{X}_{4}$ PEAR TRAFFIC FIOW:- (PTF 70) During the period 1964 1966 the Foad Research Laboratory made a study of raad traffic flows crossing cordons around the control areas of eight tows of varying population size. One of their conclusions was; "The peak $\frac{3}{4}$ hour flow a.m. or p.r. in passenger car units was found to vary with population $p$ as-

$$
\text { f.p.c.u }=6 p^{a \cdot 6} \text { p.c.u/h (Munt et al 1968)n }
$$

Accordingly this formule was used in this research as an estimator for the peak traffic flow, for each of the relevent urben areas, and for each year under study.

$I_{5}$ TOTPS, TRAFFIC FLOH:- (TTF 70) Because of the possibility of error in the previous veriable it was deemed expedient to introduce a second traffic variable which could be calculated 
from en entirely different source. Although some date on traffic How was available from the numerous Traffic and Transportation studies alreacy published, due to differing methods of collection and estimation, comparisons between different areas was deemed unaccepteble. Similarly whilst at one stage it was originally intended to relate total traffic flow to a calculated total capacity for that urban area following Tanner, (Tenner 1966) this wias also eventually rejected. This line of reasoning kas due to the fact that any such capacity level rould necessitate a high degree of calculated estimation, and that this would create a high level of inaccurecy within any such derived index. Therefore the eventual index that was derived was both simple and nationally comparable, but $\in$ even so it must include a substintial error term due to the method of estimation. However, it was assumed that this error term would vary only slightly from one area to another, thereby enabling some confidence in the areal veriations.

The data scurce used was therefore the 1966 Sample Census, "Workplace and Transport Tables," which gives the number of . "person-kork-trips" by mode of trensport, end plece of destination. Three categories of destination are given:-

(1) Persons resident and working in the area,

(ii) Persons working in the area but resident elsewhere,

(iii) Persons resident in the area but rorking elsewhere.

The first two groups indicate person moversent into the city area, whilst the third gives movement out of the city area: Thus 
during the vork period, all three groups are golng to be involved In some kind of "work-transport-journey" within the total urban area.

The mode of trensport is also givenin six categories:-
(i) Bus
(ii) Car
(iii) Goods
(iv) Motor Cycle
(v) Pedal Cycle
(vi) On foot.

The first five categories will give some indication of the number of vehicles upon the roed network during the "work-treveln period, whilst the last category, if included, gives some indication of the number of pedestriens around the road netrork during the same time period. To relate the data presented in these returns to some kind of traffic volume index, certein extra assumptions had to be made. In the first instance the figure giving the number of people going to vork by car coes not give the number of those nho are car passengers. If the number of cars being used is to be calculated, en assimption concerning car occupency rates has to be made. Similarly the number of buses is dependent upon an expected bus occupency rate. Tanner (Tanner 1966) whilst estimating the total capacity of urban areas used the two occupency rates of 1.45 people per car and 42.5 people per bus. These rates were based on 1966 
empirical observations in London and other urben areas. It was noted however that the two rates were altering, the forner increasing and the latter decreasing. Therefore for the purpose of this research the two occupancy rates used were 1.5 , and 40.0 respectively. Using these rates it was then possible to calculate the total number of vehicles used in the journey to work, and also the traffic flow in terns of passenger car units. The p.c.u. values used were those recomended by the former Ministry of Transport for urban areas:-

$$
\begin{aligned}
& \text { (i) Bus }=3.0 \text { p.c.u. } \\
& \text { (ii) Car }=1.0 \text { p.c.u. } \\
& \text { (iii) Motor Cycle }=0.75 \text { p.c.u. } \\
& \text { (iv) Pedal Cycle }=0.33 \text { p.c.u. }
\end{aligned}
$$

The calculated p.c.u. figure is therefore an estimated figure of the number of vehicles used in the joumey to work. By doubling this figure a two-way work journey figure can be assumed. From empirical observations recorded in the various Land Use and Transportation studies available, it can' be seen that the volume of work journgys ranges between 28 - $35 \%$ approxinately, of all joumeys, during the 24 hour day. (6.3.1). If the previously calculated figure is multiplied by a factor of 3 , one then has some estinats of the Annual frerage Daily Flow. This calculated Annual Average Daily Flow (AADF) was the figure used for the Total Traffic Flow variable for 1956. Taking this figure as the base figure, variations from year to year were estinated by using 


\begin{tabular}{|l|c|c|c|}
\hline SURVEY & TAR WORK TRIPS \\
LEICESTER & AS \% & $\begin{array}{c}\text { WORK TEIPS AS } \\
\text { \% ALL TRIPS }\end{array}$ & ALL CAR TRIPS \\
W. MIDLANDS & 1963 & 40.51 & 35.03 \\
M.A.I.T.S. & 1964 & 54.40 & 51.67 \\
S.E.L.N.E.C. & 1966 & 39.70 & 29.70 \\
EXETER & 1966 & 43.60 & 27.60 \\
BELFAST & 1965 & 30.24 & 31.57 \\
L.T.S. & 1964 & 18.00 & 21.00 \\
NORWICH & 1967 & 24.00 & 34.00 \\
E. CEN. SCOT. & 1966 & 32.00 & 43.00 \\
CAMBRIDGE & 1969 & 38.00 & 32.00 \\
WINLSCR & 1968 & 26.00 & 32.00 \\
\hline
\end{tabular}

TABLE 6.3.1. VOLUNE OP WORK JOURNEIS AS A PERCENTAGE OF TOTAL TRIPS AS GIVEN BY VARIOUS RECENT TRAN SPORTATION SURVEYS. 
the ennual indices of vehicle travel for all urban roads, (Dunn 1970) attined from the various traffic census returns of the Ministry of Trensport. These annual correction factors are given in (Table 6.3.2). The totel traffic index can therefore be defined as below:-

$T T F_{i t}=6\left(\sum_{j=1}^{3} B_{i j} / 0.075\right)+\left(\sum_{j=1}^{3} c_{i j} / 1.5\right)+\left(\sum_{j=1}^{3} M_{i j} / 0.75\right)+\left(\sum_{j=1}^{3} P_{i j} / 0.33\right) c_{t}$

where:-

$$
\begin{aligned}
T_{i t}= & \text { Total Traffic Flow in area } i \text { for year } t \text { (p.c.u.) } \\
B_{i j}= & \text { The number of people going to work by bus in cetegory } \\
& \text { of destination } j, \text { in area } 1 . \\
C_{i j}= & \text { The number of people goirg to work by car or goods } \\
& \text { in category of destination } j, \text { in area } i .
\end{aligned}
$$

$H_{i j}=$ The number of people going to work by motor cycle in category of destination $j$, in area $i$.

$P_{i j}=$ The number of people going to work by pedal cycle in category of destination $j$, in Erea 1 .

$$
c_{t}=\text { Correction factor for year } t
$$

$\mathrm{X}_{6}$ ESTIMATF OF THE LFVH OF THROUGH TFLFFIC: $($ ETT 70) Since It was only possible to obtain "rough" stutistics of the volume of through traffic for some of the larger urban areas from individual 


\begin{tabular}{|c|c|c|c|c|}
\hline \multirow[b]{2}{*}{ YEAR } & \multicolumn{2}{|c|}{ TRUNK RCADS $(A L L)^{1}$} & \multicolumn{2}{|c|}{ ALL ROADS (URBAN) ${ }^{2}$} \\
\hline & $\begin{array}{l}\text { TRAVEL } \\
\text { INDEX }\end{array}$ & $\begin{array}{l}\text { CCRRECTION } \\
\text { FACTOR }(1966)^{3}\end{array}$ & $\begin{array}{l}\text { TRAVEL } \\
\text { INDEX }\end{array}$ & $\begin{array}{l}\text { CORRECTION } \\
\text { FACTCR }(1966)^{3}\end{array}$ \\
\hline 1960 & 100 & 0.62 & 100 & 0.66 \\
\hline 1961 & 109 & 0.68 & 108 & 0.72 \\
\hline 1962 & 117 & 0.73 & 114 & 0.76 \\
\hline 1963 & 125 & 0.78 & 122 & 0.81 \\
\hline 1964 & 140 & 0.87 & 135 & 0.89 \\
\hline 1965 & 153 & 0.95 & 143 & 0.95 \\
\hline 1966 & 161 & 0 & 151 & 0 \\
\hline 1967 & 169 & 1.05 & 155 & 1.03 \\
\hline 1968 & 172 & 1.07 & 157 & 1.04 \\
\hline 1969 & 172 & 1.07 & 161 & 1.07 \\
\hline 1970 & 178 & 1.11 & 166 & . \\
\hline
\end{tabular}

${ }^{1}$ Used for Through Traffic growth.

${ }^{2}$ Used for internal Traffic growth.

${ }^{3} 1966$ is the base year for the correction factor.

TABLE 6.3.2. TRAFPIC (GROWTH) VOLUME CCRRECTION FACTCRS 1960-1970 USING 1966 AS THE CORRECTION BASE YEAR. 
trafflc surveys some other estimate had to be derived to validate this rariable. It vas assumed that if traffic was to be classed as through trafflc, then it would be proportional to the amount of traffic entering an urban area on the main arterfel roads of the national transport netrork. Thus using data published by the Ministry of Transport (MMSO 1967), the volume of traffic along each of the major roads, arcund each of the relevant urban areas, was calculeted, and the resultant figure was deemed to be the volume of through traffic 1966. The correction factor used for other years was once egain taken from the annual Indices of motor vehicle travel on ell trunk roads. (Dunn 1970). Corroborkting evidence was elso obtained fron the Atlas of Great Britein and N. Irelend (196Z) and further census returns of the Ministry of Trensport.

$X_{7}$ DEGREF, OF CAR CNNEFSHIP:- (COW 70) The original source of date for this veriable vas once again the 1966 Census County Reports, which provide information on "Household by number of cars," for each relevant urban area. Al though it would have been desireble to extrepolate these figures, end update them to 1970 because of the lack of data for non-county borcugh areas, this proved impossible. It could have been possible to extrapolate for county borough areas using the estimates given by Herrern (Hermenn 1968). However, in the first instance, these estimetes were based on different indices (vehicles per head of pozulation), ond secondly even the author puts little reliability on the extrepolated flgures due to the lack of locel knowledge. Thus 
the outhor stetes; "Therefore 1t must be stated that the forecasts given here are not given in the belief that the figures are a close epprosimation to what is Iikely to heppen. Their purpose is rather to indicate the local implications that may follow from the nationsl forecasts that are currently accepted, $n$ and "It is suggested therefore that the forecasts given here for any particuler area should only be given eng acceptance if no forecasts have been made for that area on the basis of better local knowledge." (Hermenn 1968). Because of these limitations it was decided that this variable would be held constant during the period of study, solely using the 1966 observations.

\section{$\mathrm{X}_{8}$ MELN SOCIfI INDFX:- (MSI 70) This index was celculated} in the seme manner as that used in the recent Birminghem Road Accident Survey. (McKay et. al. 1969). The index is based on the social class totals given in the County Reports of the 1966 census returns. These retums list five groups of sociel cless, based on Socio-economic groupings, and gives the number of people in each group. The variable cen be defined therefore es below:-

$$
H S_{i}=\frac{\sum_{j=1}^{5}\left(K_{i j} \cdot N_{i j}\right)}{\sum_{j=1}^{5:} N_{i j}}
$$

where,

$$
\begin{aligned}
\mathrm{MSI}_{1}= & \text { the mean social index for area } 1 \\
\mathrm{~K}_{1 j}= & \text { the number of the } j \text { th social class in area } 1 . \\
\mathrm{N}_{i j}= & \text { the number of people in the } j \text { th social class } \\
& \text { in area } 1
\end{aligned}
$$


Obviously the index will have a renge between the values 1 and 5 , but as was found in the Birminghem survey, the Index tends to oscillate between 2.20 and 4.50 , which proved en eren greater ronge than in this research because of the larger areal units used. The index is such that as the value increases, the lower the social grouping of the area. Once again becouse of the lack of data, and also because of the very small variance In this index, this variable was held constant during the period of study.

\section{$X_{9}$ SEX RATIO INDEX: (SFI 70) This variebIe which} measures the relative distribution of males and females within a population is important in the context of road accident analysis for tro reasons. In the first instance the two groups have totally different response rates to the road accident situation (Nickay 1969), whilst secondly; the two groups exist within different exposure "sets" during the working day. Data for this variable was obtained from the census returns since 1961, with interpretation between these standard years. The variable can simply be defined as:-

$$
S R I_{1}=\frac{M_{1}}{F_{1}}+1
$$

where,

$$
\begin{aligned}
\mathrm{SRI}_{i} & =\text { the sex ratio index for area } 1 . \\
\mathrm{M}_{1} & =\text { the number of males in area } 1 . \\
F_{1} & =\text { the number of females in area } 1 .
\end{aligned}
$$

Thus as the value of the sex ratio index increases the proportion of nalos relative to fenales also increases. 
$X_{10}$ TOiN CI,LSSTFLCATION INDEX:- (TCI 70) This index was designed such that it gave some indication of the structural shape of the urban area, both in respect to the actual shape and the developed road net:sork systen. Although these two sections are treated as one within the final index to facilitate ease of explanation, the two sections will be dealt with independently in this account.

Geographicel literature has often expounded the problens of finding a satisfactory mathematicel representation of the shape of any one ares, (Bunge 1966, Haggett 1965 etc. ) yet even with these probleins, several such indices have been developed and used. In this tom classification index hovever, it was thought that no great advantage would be geined by using one of the more intricate techniques, and a simple measure of shape by Haggett (Haggett 1965) was eventually employed. Haggett's shape index can be represented as:-

$$
S h_{i}=\left(1.27 A_{i}\right) / I_{i}^{2}
$$

where,

$$
\begin{aligned}
& S h_{1}=\text { the shape index for area } i . \\
& A_{1}=\text { the area in sq. lons. of area } 1 . \\
& I_{1}=\text { the lengti of tine long axis }(\mathrm{kn}) \text { for area } 1 .
\end{aligned}
$$

This index gives a range of values between zero and one. Values near zero indicate extrene elongation, whilst those near one tend to circularity. Intemediate values, calculated by Haggett are; triangles $=0.42$, squares $=0.61$ and hexagons $=0.83$. (Table 6.3.3). 


\begin{tabular}{|c|c|c|c|}
\hline SHAFE & HAGGETTS INLFX & DAG. REF. & BLAIR/ELISS INTEXX \\
\hline CIRCLE & 1.000 & & 1.000 \\
\hline $\begin{array}{l}\text { POLIGCN } \\
\text { (10 SIDED) }\end{array}$ & 0.935 & & 0.999 \\
\hline $\begin{array}{l}\text { HEXAGCN } \\
(6 \text { SIDED })\end{array}$ & 0.827 & & 0.996 \\
\hline $\begin{array}{l}\text { EQLILATERAL } \\
\text { TRIANILE } \\
\text { (3 SIDEDD) }\end{array}$ & 0.413 & & 0.909 \\
\hline $\begin{array}{l}\text { SQLARE } \\
\text { (4 SIDED) }\end{array}$ & 0.637 & & 0.977 \\
\hline $\begin{array}{l}\text { ELONGATION } \\
(1 \times 7.5 \\
\text { UNITS })\end{array}$ & 0.167 & 7.5 & 0.500 \\
\hline
\end{tabular}

TABLE 6.3.3. CCMPARISON OF SOMF, STANDARED SHAFES USING TEE HAGGETT SFAFF INCEX AND THE BLAIR-BLISS INLEX. 
The calculation of the netior's spacing was based on work by Dacey, (Dacy 1967), who used a randon walk technique in testing the network spacing of different river drainage patterns. The random walk is constructed by locating an originating point fron a pair of randon co-ordinates. Fron this point a vector is constructed by selecting a real number from the range zero to tiro. The vector terminates where it intersects the nost distent line of the netark systen. From this point a second randomly-orientated vector originates; it terainates once again at the point at which it intersects the most distant line under investigation. The walk continues until the number of intersections is equal to the sample size desired, which in. this research was deened equal to 60 intersections. Earlier work by Clark (Clark 1956), has shown that in a random spacing of points along a long traverse line $\frac{2}{3}$ rds of the points have a reflexive (first) nearest neighbour, and the proportion of points which have a reflexive nearest neighbour of order $n_{n} n=\left(\frac{2}{3}\right)^{n}$. When the percentage of points having $n^{\text {th }}$ order nearest neighbours is significantly greater than $\left(\frac{2}{3}\right)^{\mathrm{n}}$ the lines are positively grouped as in the Manhattan Grid. Conversely when the proportion of points having $n^{\text {th }}$ order nearest neighbours is significantly less than $\left(\frac{2}{3}\right)^{\mathfrak{n}}$ the lines are negatively grouped as in the Redial Grid. This technique of studying networis spacing produces a range of zero to one, if the propurtion of reflexive points to the total number of points is used. 
Combining these tro previously mentioned indices, the Town Classification Index can now be formulated based both on shape and netrork density. This index can be defined as below:-

$$
\mathrm{TCI}_{1}=\left(\frac{\mathrm{I}_{1.27 \mathrm{~A}}}{l_{1}^{2}}\right) \cdot\left(\begin{array}{c}
1-\mathrm{r}_{1} \\
\mathrm{~N}
\end{array}\right)
$$

where $\mathrm{TCI}_{1}=$ the tom classification index for area 1.

$$
\begin{aligned}
& A_{1}=\text { the area in sq. kms. of area } i . \\
& f_{i}=\text { the length of the longest exis (kms) for area } 1 . \\
& r_{1}=\text { the number of reflexire first-order nearest } \\
& \text { neighbour points in area } 1 . \\
& N=\text { total number of sampled intersections on the } \\
& \text { random walk traverse (60) }
\end{aligned}
$$

Thus the index will have a range of zero to one with a circular town with a radial network having a value approaching one, and an elongated to:m with a Manhattan grid having a value approacing zero. Besides allowing the calculation of the torm classification index, the above inentioned approach and results gave some interesting insights into the structure of the sampled urban areas. This point is developed more in Appendix (I). Data for the calculation of the town classification index was obtained from the Ordinance Survey $6 n$ maps of Great Britain. 


\section{$X$ COMPACTNESS INDEX: (CI 70) Unlike the Town Class-} Ification index just described, the compactness index purely related to the shape and circularity of the various urban areas, and no account was taken of the internal mad networs systen. The index used in this research was the "Blair-Bliss" compactness index (Blair et al. 1967) which is defined by the formula:-

$$
C I_{1}=\frac{A_{1}}{\sqrt{2 \pi \int_{a} R^{2} d x d y}}
$$

where,

$$
\begin{aligned}
C I_{1}= & \text { the compactness index for area } i . \\
A_{1}= & \text { area of urban area } 1 \text { (sq. kms.) } \\
\text { a }= & \text { radial axes from gravi ty centre to } \\
& \text { sinall area, } 2(\mathrm{~km} .)
\end{aligned}
$$

The index values vary from between zero and one, with values approachin one indicating a high degree of compactness and circularity. Because the Blair-Bliss index is more related to areal spread around tine centroid of an urban area, the range of values experienced with this index, as compared with those obtained from Haggett's shape index, is substantially reduced. For exanple, the values calculated in this resesch for each of the administrative units had a range of only 0.339 , varying from 0.645 to 0.934 . 
$X_{12}$ DEGREE OF OPEN SPACE:- (DOS 70) Because of the lack of data this was another veriable which was held constant during the period of study. The original data was obtained from the 1967 Municipal Yeär Book which published returns fron a questionnalre sent to all local authorities in $1964-65$. The retums gave infornation as ts the total acreage of public open space, and also the proportion of totel acreage, per 1000 population. It was this last figure which was used as the degree of open space variable in this research.

$$
\mathrm{X}_{13} \text { STANDARD OF HOUSING INDEX:- (SHI 70) This variable }
$$
attempts to provide infornation as to the relative standard of the housing stock in different urban areas. The source of the data was the consus returns since 1961, which provide tables for all local authorities, of the number of dwellings which do not provide the basic anenities of hot and cold water, inside W.C. and a bath etc. It was therefore possible to ascertain two sets of figures from these census returns; the number of dwellings with these basic necessities, and those without. The index derived tierefore can be defined as:-

$$
\mathrm{SH}_{1}=\mathrm{B}_{1} / \mathrm{C}_{1}
$$

where

$$
\begin{aligned}
\text { SHI }_{i}= & \text { Standard of Housing Index for area } 1 \\
B_{i}= & \text { The number of dwellings with basic } \\
& \text { necessities in area } 1 . \\
C_{1}= & \text { The number of dwellings without basic } \\
& \text { necessities in area } 1 .
\end{aligned}
$$


Obviously therefore the higher the value of this index, the better the stendard of housing in that area.

\section{$\mathrm{X}_{14}$ AGE VULNERABILITI INDFX:- (AVI 70) The two most} vulnerable sections of the population as far as pedestrien accidents are concemed, involve the two age groups, 0 - 14 years and over 65 years. It is therefore importent to know the potential vulnerability of an area, as regards these two groups. Data on the actual numbers within these tro ege groups was obtrined from the Census returns, county reports. These numbers were then expressed in relation to the total population of that area. Thus,

$$
A V I_{i}=A_{i} / P_{i}
$$

where,

$$
\begin{aligned}
A V I_{1}= & \text { the age vulnerability index of area } i . \\
A_{1}= & \text { the number of people under } 14 \text { years of age } \\
& \text { and over } 65 \text { years of age in area } i . \\
P_{i}= & \text { the total population of area } i .
\end{aligned}
$$

The higher the index the more vulnerable the orea is, especielly in reletion to pedestrien accidents.

$\mathrm{X}_{15}$ DFIVER VULIJERABILITI INDEY:- (IVI 70) This variable vas Included to supplanent the previous age vulnerebility index. It is generally assumed that the most vulnerable ege group for drivers occurs within 5 to 10 years of learning to drive. In most instances this involves people in the age group 16 years to 25 years. Hovever 
because of the limitations of the available data in the relevant Census returns, the age group used for this veriable renged between 15 years and 25 years, for each relevent area. As before the numbers in this oge group were related to the total population of the area such that,

$$
D V I_{1}=D_{1} / P_{1}
$$

where,

$$
\begin{aligned}
D V I_{1}= & \text { the driver vulnerability of area } i . \\
D_{1}= & \text { the number of people between the eges of } \\
& 15 \text { years and } 25 \text { years in area } i . \\
P_{1}= & \text { the total population of area } i .
\end{aligned}
$$

The higher the index, the more vulnerable is any aree, especielly in relation to the number of driver accidents.

\section{$X_{16}$ TOTEL DWELIING INDFX:- (TDI 70) Data on the total} number of dwellings within any urban area was agein obtrined from the relevant Census returns, and also the Housing returns for Englend and Vales and also those for Scotland. Such a variable although obviously related to the population size of an area, was included as another indicaticn of the nagnitude of the urben area, ond the resultant impact upon the road accident situation.

$$
X_{17} \text { HOUSING TENURE INDEX:- (HTI 70) It was postuleted }
$$
that the type of urtan development betreen public and private might cause verying responses within the road accident system. 
An indication of these tho types of development cen be obtained by comparison of the number of people living in local authority owned direllings end the number of people living in privete housing. Data was obtained for this index from the relerant Census returns, with additional annual information from the HMSO publications, "Local Housing Statistics for Englend and Wales," and "Housing returns for Scotland." The index cen be defined as,

$$
\mathrm{HTI}_{i}=\mathrm{Pr}_{i} / \mathrm{Pb}_{i}
$$

where,

$$
\begin{aligned}
\mathrm{HTI}_{i}= & \text { the housing tenure index for area } i . \\
\mathrm{Pr}_{i}= & \text { the number of dwellings of private origin } \\
& \text { in area. } i . \\
\mathrm{Pb}_{i}= & \text { the number of council o:ned dwellings in } \\
& \text { area } i .
\end{aligned}
$$

The lower the value of the inder, the more the area has been developed by the relevant local, or public authority, and therefore the more likely the area is to have been subject to controlled comprehensive plenning. The lowest index values in this research obviously occurred therefore within areas containing Nen Town Developments.

\section{$\mathrm{X}_{18}$ CHANGF OF HOUSIIG STOCK:- (CHSI 70) Where the} structure of an urben erea is changing repialy one vould tend to expect a proportional response rate in observed road accicents. One ray of measuring this structural change is by cbserving 
the change in the housing stock. Once egain data was obtained for this index from the Census returns and Elso the HaSO publications of Housing Returns, and the resultent index cen be defined as below,

$$
\mathrm{CHSI}_{i \cdot t}=\left(\begin{array}{lll}
\mathrm{I}_{i \cdot t} & \times 100 \\
\mathrm{~T}_{1-1} &
\end{array}\right)+10
$$

where,

$$
\begin{aligned}
\text { CHSI }_{i \cdot t}= & \text { the change of housing stock index for year } t \\
& \text { in area } 1 . \\
I_{1 \cdot t}= & \text { the absolute increase in the housing stock } \\
& \text { during the year } t, \text { in area } 1 . \\
I_{1} t-1= & \text { the total number of dwellings in area } 1 \text { for } \\
& \text { the year } t-1 .
\end{aligned}
$$

Thus areas with a high level of change in the housing stock would be characterised by an index value considerably above 10.

$$
X_{19} \text { POLICF SEVERITI IIIDEX:- (PSI 70) This index along }
$$

with the folloning variable was introduced to study the possible impact of police action within the various urban aress. The main problen encountered however, centred around the fact tilat data was only available accorijing to Police Force Areas. Similarly, the various re-organisations of the police forces since 1956 have made it very difficult to obtain comparable area statistics. The first of these problens was overcome by assuning that the influence and/or attitude of a police force would be approximately constant over all the constituent parts of that area. This is reinforced by the fact that in areas where the attitude may hove been different, in areas of high population densit $t_{j}$, thess aress tend to have their 
own police force. At the same time, to solve the problern of lacis of temporal data both of these police variables were held constant over time.

The police severitj index was designed to show the change in the attitude of a police force in any area from 1958 - 1970. The index can be defined as giving the proportional change in the rate of prosecutions per thousand of population 1968 - 1970 . These prosecutions concern "offences relating to motor vehicles" as published by the (HMSO). The index was equal for all urban areas falling within the same police force area, and can therefcre be defined such:-

$$
\text { PSI }_{1}=\left(P_{\text {ci }} / P_{\text {si. }}\right) \times 100
$$

where,

$$
\begin{aligned}
P_{i}= & \text { the police severity index for area } i . \\
P_{c i}= & \text { the increase in number of prosecutions } \\
& \text { per thousend population } 1968-1970 \\
& \text { in area } i . \\
P_{S 1 \cdot 70=} & \text { the nuraber of prosecutions per thousand } \\
& \text { population } 1970 \text { in area } i .
\end{aligned}
$$

$X_{20}$ POLICE PROSECUTION INDEX:(PPI 70) finilst the previous index attanpted to show the dynanic attitude of the police forces, the prosecition index simply shows the absolute attitude of any police force within its area. The data source and apilication to individual urben areas, is exactly the sane as in the previous 
variable, and can be defined simply as the number of prosecutions (relating to motoring offences) per thousand of population within the police force area in 1970:-

$$
\operatorname{PPI}_{i}=\mathrm{P}_{\mathrm{si}} / \mathrm{P}_{\mathbf{i}}
$$

where,

$$
\begin{aligned}
\mathrm{PPI}_{i}= & \text { the police prosecution index for area } i . \\
P_{s i}= & \text { the number of police prosecutions within } \\
& \text { area } i(1970) \\
P_{i}= & \text { the population within the area } i \text { in } \\
& \text { thousands }(1970) .
\end{aligned}
$$

$X_{21}$ PATNFALI IYDFX:- (FI 70) the mean annual rainfall for the Jears 1916 - 1950 obtained from the "Atlas of Britein and N. Irelandn (D.P. Bicirmore et al 1953) was the data used for the rainfall index in this reseerch, and obviously this variable was constant for the period studied.

$X_{22}$ FOED DFISITI INDEX:- (RDI 70) Defined as the mileage of roads per acre, this variable is useful on two counts. In the first instance, it helps to show the density of the road network within an urban area, and in the second instance it also gives a measure of the road junction density. This follows the wors of Borchert (Borchert 1961) on the road pattern in the twincities of Minneapolis - St. Pauls, which showed that there was a verg high degree of correlation between the density of road junctions and the total road langth (+0.99). The data for this variable was obtained from Highwey Statistics (HMSO) for county 
borough areas, end the Ministry of Transport for non-county boroughs.

This then completes the list of independent variables used in the body of this research. A sumnary of thrm is given in (Table 6.1.1) along with some of the more relevant descriptive statistics for 1970. 
Chapter ? METHODOLOGY: I

\subsection{INTRODOCTION}

In order to compare the various road accident statistics spatially and temporarliy, it is necessary to hold the effect of various variables constent. Wh thout this precaution eny derived index would be spatially incomparable. Since the theme of this research is to study the vuriations from some acceptable "norm" the index to be used is one which reflects an "expected" number of rosd accidents for en urben area, to those which actually occurred in that same urben area. The essential problen then was $t=$ decide upon the method by wich these "expected" nurber of accidents, per urban area could be derived. Three such groups of methods were studied starting from a simole scaling procedure to the more complex statisticsil modelling of probability theory and multiple regression. Although it is often true that the simplest models are often the most useful in practlcel application, it must be pointed out that as far as the researcher is concerned he is rore intent upon modelling as clearlj as possible tho real world in order to understend and explain that very world. Very often the simpler approsch is pursued to the detrinent of meaningful results. As regards spatial comparisons such an opinion was expressed by some of tine participants at the recent O.E.C.D. Symposium held at Crowthorne, (O.E.C.D. 1969) followine the session on International Comparisons. If this is true at the macro level it must also be true at the micro level. Complexity is not an end result in itself, but it is more likely to produce more realistic explenations in the long run. With this thought 
In mind the progress and direction of this research was not deterred by the increasingly complex techniques used, and often the simpler approach was rejected because of the low level of reality.

Before progressing on to the methodology used, it is useful to explain the other approaches considered and point out the reasons for their rejection.

\section{2 "SCALING DOINN METHOD}

The simplest approach studied was that of scaling down of national data and applying these rates to individual urban areas. An example of this aporoach was that used by Cumbernauld Development Corporation to compare the response of Cunbernauld with other new torms, and older established towns. (Cum. Dev. Corp. 1967). Using national data on the number of accidents, it was possible to derive a Mational Average rate of Accidents per thousand of Population" for each year under observation. Once this national average had been computed it was an easy step to apply it to individual urban areas, knowing their population levels. In this way an expected number of accidents could be calculated for all areas and compared with the actual number of accidents (Table 7.2.1). Although this method produced instent practical results, it has several severe limitations, which together could invalidate any conclusions derived from such a method. Flrstly it would seen verg naive to assume "a priori" that only one variable, (population) is responsible for all road accident variations. Similarly one could argue as to kitich one variable to accept. In most instances 


\begin{tabular}{|c|c|c|c|c|}
\hline & $\begin{array}{c}1966 \\
\text { POPULATION }\end{array}$ & $\begin{array}{c}\text { TOTAL POSSIBLE } \\
\text { ACCIDENTS DURING } \\
\text { THE FIVE YEARS } \\
1962 / 1966\end{array}$ & $\begin{array}{c}\text { TCTAL ACTLAL } \\
\text { ACCIDENTS DCRING } \\
\text { THE FIVE TEARS } \\
1962 / 1966\end{array}$ & $\begin{array}{l}\text { TOTAL ACTUA } \\
\text { EXPRESSED A } \\
\% \text { OF TOTAL } \\
\text { POSSIBLE } \\
\text { ACCIDENTS }\end{array}$ \\
\hline CTMBERNAULD & 16.640 & 330.73 & 77 & 23 \\
\hline NEHTCN AYCLIFEE ${ }^{1}$ & 17,202 & 504.82 & 128 & 25 \\
\hline CLIBERNAULD ${ }^{2}$ & 19,640 & 249.45 & $91^{3}$ & 36 \\
\hline GLENROTHES $^{1}$ & 21,830 & 572.73 & 248 & 43 \\
\hline HȦTFIELD & 24,800 & 338,60 & 235 & 69 \\
\hline CWMBRIAN $^{2}$ & 38,000 & $1,126.93$ & 709 & 63 \\
\hline WELWTN GD. $\operatorname{CITY}^{2}$ & 42,600 & $1,314.90$ & 1,071 & 81 \\
\hline $\mathrm{CCRBY}^{2}$ & 45,065 & $1,397.75$ & 948 & 68 \\
\hline STEVENAGE ${ }^{1}$ & 48,000 & $1,418.28$ & 918 & 65 \\
\hline EAST KILBRIDE ${ }^{1}$ & 48,952 & $1,138.66$ & 614 & 54 \\
\hline BASILDON $^{2}$ & 66,700 & $1,619.35$ & $1,122^{6}$ & 69 \\
\hline HARLOW ${ }^{7}$ & 70,800 & $2,160.08$ & 1,506 & 77 \\
\hline ALLOA ${ }^{8}$ & 15,000 & 473.64 & 310 & 65 \\
\hline GPANGEMOUTH $^{8}$ & 21,000 & 665.91 & 544 & 82 \\
\hline
\end{tabular}

NOTES: 1 Accidents occurring on roads developed by the Corporation.

2 Accidents occurring on all roads within the designated area.

3 Covers year 1965/66 only.

5 Covers years 1964/66 only.

6 Covers years 1962/65 only.

7 Accidents occurring on all roads within Harlow Urban District

8 Existing towns not developed as New Towns.

TABLE 7.2.1. THE 'SCALING IOWN' METHOD USED FOR CUMRERNAULD NT., AND SOME OTHER CCMFARABLE TOWNS. 
dependent upon which variable is chosen, one could prove any hypothesis. The most obvious approach is one which applies varlous variables, testing each individually, whilst holding the other voriables statistically constant.

The second and perhaps most daining criticisin of this type of approach, involves the so called "problens of scale." Such problems have received increased attention from geographers since the work of McCarty (Hiclarty et al 1956) and Duncan (Duncan et al 1961). Both of these pieces of research indicated similar probleas, which can be simply expounded by stating that in each case the type and direction of results was dependent upon, and varied with the size and level of the areal unit used. Thus Duncan who was studying the simple question of what is the population density of an area of doxntorn Chicego, cane up with two sets of figures, one of which was twice as large as the other, derived from toro different definitions of vicinity. Extending the problen to comparisons of different cities, Duncan also shors that the comparisons are entirely dependent upon the areal defintion of these cities. This variation is shom in (Fig.7.2.2) for two citles Chicago and Detroit. Still more striking contrests are also sho:n with comparisons over time where the population of the USA appears to be becoming more concentrated on the evidence of the counties, but were dispersed on the evidence of the states. (Table 7.2.3). A simflar development of this scale problem has been noted by Harvey. "Similar problems of comparability and 


\begin{tabular}{|l|c|c|c|}
\hline AREAL DEFINITION & $\begin{array}{c}\text { CHICAGC (C)* } \\
\text { (POP/SQ. ML.) }\end{array}$ & $\begin{array}{c}\text { DETROIT (D)* } \\
(\text { POP/SQ. ML.) }\end{array}$ & $\begin{array}{c}\text { RATIO } \\
(\mathrm{D} / \mathrm{C})\end{array}$ \\
\hline CITI & 17,450 & 13,249 & 0.76 \\
URBANISED AREA & 7,713 & 6,734 & 0.86 \\
$\begin{array}{l}\text { ST,METKGFOLITAN } \\
\text { AREA }\end{array}$ & 1,519 & 1,535 & 1.01 \\
\hline
\end{tabular}

SOLKCE: DENCAN, CUZZORT \& DCACAN 1961

* 1950

TABLE 7.2.3. UREAN POPULATION DENSITIES UNLER ALTERNATIVE CENSUS BOLATARIES.

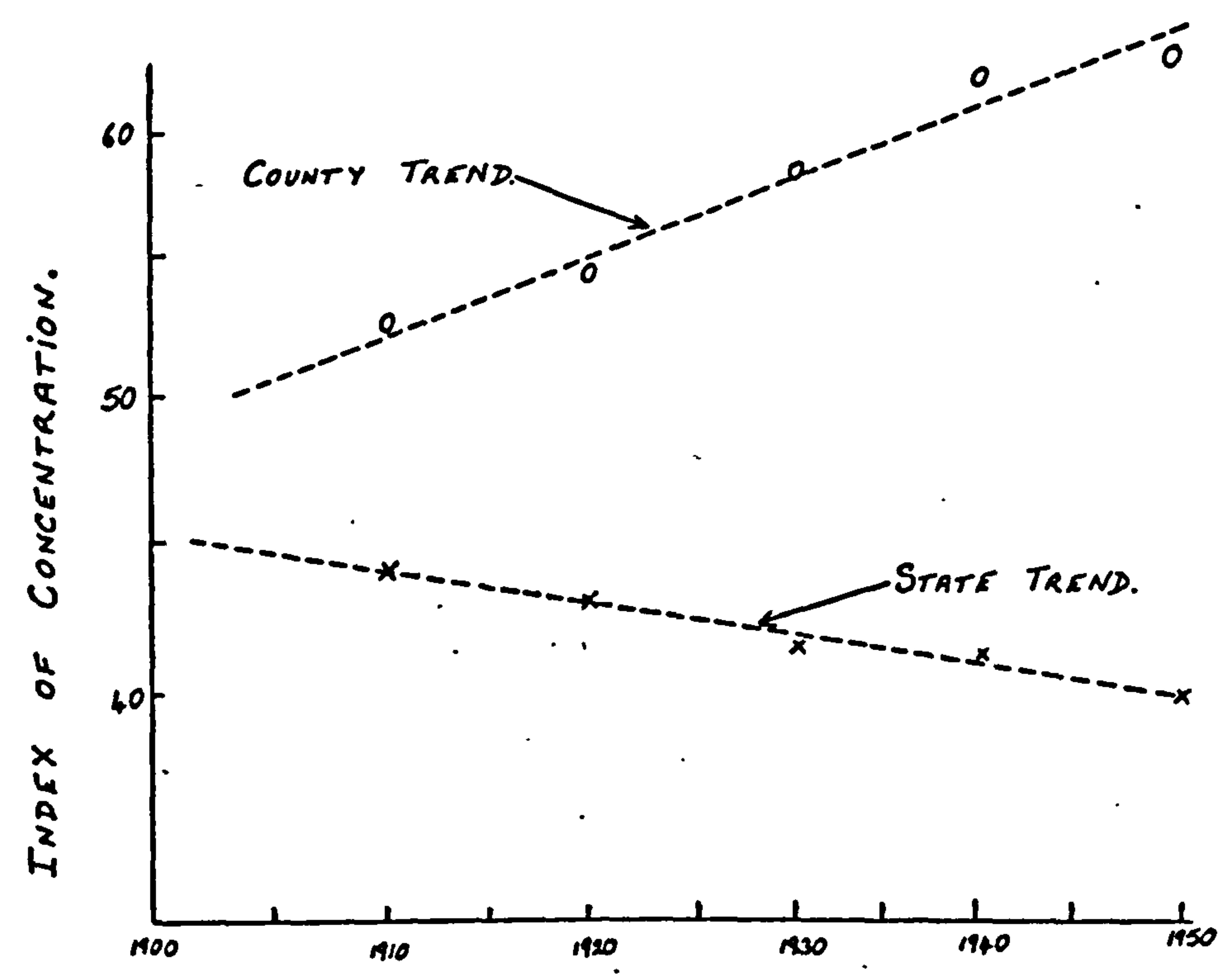

PIG. 7.2.2. CCNTRASTS BASED ON DIFFERENT SIZES CF COLLECTING CNITS. 
inference exist when different levels in the hierarchy are simulteneousls studied..... We shall begin by considering the special case in which distinct steps in the hierarchy of areal units can be recognised, 1.9. areal units at one level can be included in areal units at the next level. In such a "nested" hierarchical situation it should be observed that comparisons can only be made between similar individuals, (1.e. Individuals at the same level in the hierarchy) and that inferences made about relationships at one level cannot be extended, wi thout making strong assumptions, to any other level. This is not to say that conditions at one level are irrelevant to conditions at another. It does indicate that the nature of the analysis is contingent upon whether the individuals being compared or analyscd are at the saine or different levels." (Harvey 1969 p.352). Harvey then continues by pointing out that where continuous data is being used areal units can be "imposed" spatially in order to create a hierarchical situation within which comparison is possible. However, in most situations such assumptions can prove to be groundless. For example, whilst adninistrative units mej be regarded as singular areal individuals from the point of view of administrative structure, it is unreglistic to continue comparability to other variables, especially if these are cantinuous variables. "In such a situntion there is nothing natural in the way the data are aggregated and it mey well be that the administrative units are not "similar" or comparable from the point of view of the data aggregated within them." (Harvey 1969, p. 353). The main problem therefore is 
that since most areal data is only available for territorial units, and will probably remain so for the next few decades, (except in the case of computer grid mapping techniques) how can one attempt to overcome these areal scale problens? Theoretically there are perhaps three different types of solution, but once again they all include their own inplicit limitations. Robinson suggested that one solution was to "weight" the various parameters by the size of the areal unit. (Robinson 1956). Thus he suggested modified equations for the standard deviation, and regression co-efficient as below,

$$
\begin{aligned}
& \sigma_{A}=\sqrt{\left\{\left(\Sigma A X^{2}\right) / \Sigma A\right\}-(\Sigma A X / \Sigma A)^{2}} \text { and } \\
& b_{A}=\left\{\sum A_{i} \sum A_{1} X_{1} Y_{i}-\left(\sum A_{i} X_{1}\right)\left(\sum A_{i} Y_{i}\right)\right\} /\left\{\sum A_{i} \sum A_{i} X_{i}^{2}-\left(\sum A_{1} X_{i}\right)^{2}\right\}
\end{aligned}
$$

where $A_{i}$ was the area of the ith observation.

However, such modifications will only in very special circumstances remove the size effect from areal comparison studies, as was pointed out by Thomas and Anderson (1965).

Another attenpt by Robinson to overcome this same problem suggested the use of regular hexagons as the unit of study in preference to irregularly sized counties. (Robinson et al 1961). For each hexagon he interpreted a standardised value. However, as King has pointed out such a solution is neither practical nor in many cases, very useful. (King 1969). "The interpolation is not only time-eonsuming and arduous, but there is no guaran tee 
that it will not introduce as much error, perhaps even more, as would result from the use of the original county data." (King 1969 p.155).

The work by Thomas and Anderson (1965) tries to solve the problen through the notion of statistical inference, making a distinction between a population as the total set of outcones or events from which a sample may be drawn and a universe which is "a more abstract group" containing "all events as they happened and as they might have happened if everything else had remained the same but the random shocks." Thus it follows that "the data for each of ...... several study areas may be treated as a random sanple from some hypotheticel universe of possible values al though each is in fact, a population." (Thomas et al 1965). However once again this approach involves severely limiting assumptions and as Curry has pointed out, the distinction between a population and universe is very tenuous. (Curry 1966). He further concludes that "the real problems in the study of areal associations are not statistical but rather the dearth of theory on the process producing the association."

The conclusions to be drawn from the above discussion are therefore tatally inconclusive, and the best that can be said at present is that given our acceptance of these areal data limitations, one can only proceed as before, but with increased caution. The one glimer of hope is provided by Harvey who folloring his critique on the use of non-euclidean date collection units, comes to this 
tentative conclusion. "It may seem reactionary to defend the crazy patchwork of adrinistrative units of different sizes which have traditionally been used to record data, but such units have tended to be adaptable in the face of temporal change and tend to be much smaller in areas of great social and economic activity than ther are in areas of little economic activitj. In some cases It may be, therefore, more appropriate to use data collected in old-style adninistrative units than data collected in the rew-style uniform Euclidean cell.n (Harvey 1969 p.355).

The above discussion on the problems of scale has been dealt with in some detail beceuse of its importance not only as a criticism of the "national rate" method used by Cumbernauld, but also wi thin the bounds of this present research. As regards the first point, the "national rate" method is a perfect example of the cross-hierarch1cal comparlson that Harrey was discussing, and as such would seem to be dealing with much too many implicit assumptions, and has therefor little reliability. The present research meanwhile has atterpted to explicitiy avold this problem through various mesns. Initially, one hieratchical level is taken, that of sub-national local authorits divisions, even though it is accepted that these divisions are arbitrarily imposed, and must therefore contain the resultant restrictions mentioned previously. Similarly the difference between the units in tems of size, shape etc. have been acknowledged by introducing these terns as independent varlables in to the multiple regression equations. Finally, since it has been theorised that 
road accidents in urban areas occur within an urban and road accident system it would seen reasonable to accept these units as equally c:mparable units. However, even having argued these points, it must be mentioned that the limitations of the various date sources is well recognised and al though some modiflcation would have been destrable, this has proved impossible, due to the vast quantities of data utilised. Thus one nust remember that for this reason any conclusions and results nust be tempered with caution. A good example of this problem is the differing results obtained by this research and that mentioned above, by the Cumbermauld Development Corporation. This diversity of results can almost totally be explained by the fact that two different areal units were used. One dealt with that area under the aegis of the Development Corporation, whilst the present research has dealt with the whole Cumbernauld District Council. Once again therefore, caution must be emphasised in interpretation of the results of this research if comparison is necessary with other studies using different areas. The only solution to this problem and the problem of scale in general is furtiner microlevel analysis, say at the individual urban area level, but before this can be contemplated the furtiher necessary theoretical, and classifactory research must be completed at the macro level.

\subsection{APPLTCATTOI OF PFOBABILITY MODELS}

The second major methodological approach contemplated, in order to calculate on "expected" level of road accidents for 
each urban area, involved the use of probability models and techniques. The use of probability models in road accident analysis is quite extensive, and al though many of the different purpose models overlap considerably, up to the present there is no sultable "general purpose" model. Thus any study using these models must develop its own specialised model.

The use of probability models and various poisson models In particular, can be justified if a road accident is considered to be the consequence of a combination of a large number of circuistances, where each circumstance (or event) has a small probability of leading to an accldent. Following Erlander (1971) this can be demostrated statistically, quite simply if one considers a Poisson nodel for the number of accidents experienced by on individual. If we let the outcome of an event 1 be $x_{1}$ and $\begin{aligned} \text { define } x_{i} \text { such that } X_{i}= & (1 \text { if event } 1 \text { results in an accident } \\ & \text { (0 otherilse }\end{aligned}$ then, $\quad s_{n}=\sum_{i=1}^{n} x_{1}$

denotes the total number of accidentis experfenced in connection with $n$ events. If we assume that the outcone of events are mutualiy independent, (1.e. that the rendom variables $X_{1}$ are mutually independent) and that the probability of an accident at event 1 equals $P_{1}$ then the outcome of the successive events represents a sequence of "Bemoull Trials" with varlable probabilities. It is known that as $n \rightarrow \infty$ the probabilities $P_{1}$ depend on the 
number of erents $n$ in such a way that the largest $P_{1}$ tends to zero and the sum,

$$
\sum_{i=1}^{n} P_{i}=\lambda
$$

remains constant, then $S_{n}$ has in the limit the Poisson distribution

$$
P\left(S_{n}=k\right){\frac{\lambda}{k !} e^{-\lambda}}_{k !}^{k} \quad \text { as } n \rightarrow \infty
$$

Hence for lerge $n$ the distribution $S_{n}$ can be epproximated by the Poisson distribution.

The intultire appeal of such a model for road accident occurrence is due to three principal reasons. Firstly the number of events that may lead to accidents is very great. Secondly the outcome of different events seens to be falrly independent, although problems arise here over fatel and serious accidents which of course interrupt the flow of events for the particular individual concemed. Thirdly the probability of an accident in any specific event is very small. Thus the major assumptions of the Poisson model seen to be satisfled by the observed characteristics of road accidents.

Whilst it is also possible to use other probability distributIons to describe road accidents, especially some kind of weighted poisson distribution, where it is assumed that the parameter $\lambda$ 
is itself a rendom variable with distribution function $G(\lambda)$, (this allows account to be taken of the differing risk levels of different individuals) the added complications are not justified by much improvenent in the empirical results.

The Poisscn model described above will predict the number of accidents experienced by one individual but it is also possible to apply the model to a collective of incividuals, such as those living in any one urben area. The sum of independent Poisson veriebles is poisson distributed and, similarly the superposition of independent poisson processes is itself a poisecn process. fill that is necessary is to sum the parameter values. Assume that there is a collective consisting of $\mathbb{N}$ indivicuels who experience $X_{1} \ldots .$. . X $X_{N}$ accidents during the time period (0.T). Sssume further that for ung randomly chosen individual the occurrence of accidents can be described by a poieson process, then the total number of accidents for the whole population of $N$ incividuels $x+1$ al so be a poisson process. Hence

$$
\rho\left(\sum_{i=1}^{N} x_{i}=k\right)=\int_{0}^{\infty} \frac{(\lambda I)^{k}}{k !} e^{-\lambda T}
$$

When studring the whole population of $\mathrm{N}$ indivicuols the ordinary folsson process with fixed but unknown paremeter velue will usuelly be more preferable than the use of the veighted distribution $G(\lambda)$. 
The mejor adventage of the use of probabilistic models lies to a great extent in their copacity to treat quantitativels, events, which have a common structure but differ in meny detalls. Unfortunately they also have the disedrentige of 1Enoring and vesting eny veluable background data which may be aveilable other than the total number of accldents, end in some cases the time. For this reason, other types of models hich attempt to study the influence of verlous variables on the number of accidents, are freferable, especielly those using the technique of multiple regression analysis. However, this is not to denigrate the use of all probability models. Various researchers have attemeted to combine such models with the technique of multiple regression. Although such models are perheps the most satisfactory at the present tine they are usually only possible when dealing with very limited areel units such as a certain stretch of road etc., and are therefore limited in use when dealing with urben eystems end the resultent spatial comparisons. Even so, the potential of these compromise models is $v \in r y$ great, end this can perheps be demenstrated most rewardingly by looking at $\varepsilon$ recent model developed by Jorgensen of the Danish Council of Poad Safety Research, in order to eveluate the traffic safety implications of different choices of construction stages of a new notorway scheme in Jutlend. (Joreensen 1969).

If one assumes that the density of road accidents (d) is some function of the traffic flow, such that, 


$$
a=f(N)
$$

where $\mathrm{N}$ is come estimate of traffic flow. If the data is disaggregated into different road classes vif thin a unit area, then a relationship can be assumed as below,

$$
\mathrm{d}=\mathrm{a} \cdot \mathrm{N}^{\mathrm{p}}
$$

where $a$ and $p$ are constents characterising that raad class and $N$ is some observed measure of ennual everage daily traffic.

If one now assumes that the annuel number of accidents on a certain road section is a Poisson distributed variable then it is possible to extend the simple model postulated above. Let $U_{1 j}$ be the number of accidents in a certain year on section number $j$ of road class $i$. It is assumed that $U_{i j}$ is a poisson varikble such that,

$$
E\left(U_{i j}\right)=a_{i} \cdot N_{i j} P_{1} \cdot L_{i j}=a_{i} \cdot I_{i j}
$$

where $\quad Y_{i j}=N_{i j} P_{1} \cdot L_{i j}$ and

$$
L_{i j}=\text { the length of road section (ij) }
$$

Thus the distribution is,

$$
P_{r}\left(U_{i j}=u\right)=\frac{\left(z_{i} \cdot Y_{i j}\right)^{u}}{u} e^{-a 1 \cdot Y_{i_{j}}}
$$

$N_{i j}$ and $L_{i j}$ are known from observed datk and the only uninowns are a and p. Although it is imposstble to estinate these paremeters 
using the stendard least squares method, velues can be derived using an iterative process by setting $P_{1}$ at chosen volues end estirating for $\varepsilon_{1}$ from the equation,

$$
a_{i}=\frac{\sum_{j} U_{1 j}}{\sum_{j} Y_{1 j}}=\frac{U_{1}}{I_{i}}
$$

The $p_{1}$ value chosen is the one at wich the sum of squares of the deviations $S\left(P_{i}\right)$ ketween the estimated curve given by (I) end the cbserved velues $U_{i j}$ is minimised.

The application of these two mentioned parameters is very Important for, since they charccterise the different road classes, and cen also be derived for different areal units, they can be compared to the $\beta$ coefficients of multiple regression, and used as indicators of the spatiel variation of road accidents end other related veriables.

This model by Jorgensen is not therefore a simple standerd probability model since it is necessary to know beforehend the original relationship between the number of road accidents and the relevent variables. In this instence it was assumed for simplicity sake that $d=a \cdot N^{p}$, but this must be verified using some other statistical technique, usually regression or correlation, before the model can be reasonably applied. Consecuently, such models are perhaps more useful once the emount of information and theories about the basic properties of road accidents have been 
greatly increased. For this reason such a model was not fursued in this research, but the technique acranced vas that of multiple regression. 
Chapter 8. METYODOLOGY II: MULTIFLE PEGFESSION ANALYSIS

\subsection{INTPOLUCTION}

Although the methodology used in this research can be generelised as a multiple regression analysis, in practice the method involved the use of several other statistical techniques and so as on aid to comprekension, a flow diagrim, showing the relevant techniques and approech is shorn in (Fig. 8.1.1). The main purpose of this chapter is to elucidate and explain this Now olagram, whilst explaining the methodology used in this rescerch, end also pinfointing the limitztions inherent in eny such epproach.

\subsection{THE NULTIFLE RIGFESSION MOLFI}

of all the techniques used in road accident enalysis, that of multiple regression has proved the most fopular end also the most rorthwhile. This is so because of the complex nature of the road accident situation and the multitude of veriables which have to be considered in eny realistic model. Similerly, the use of the multiple regression nodel also enables the inclusion of bacl:ground information whenever it beccmes eveileble.

There are several exmples in the litercture of the use of multiple regression models in road accident enalysis, but since these are mainly dealt with in other sections of this report only three simple uses will be mentioned here. 


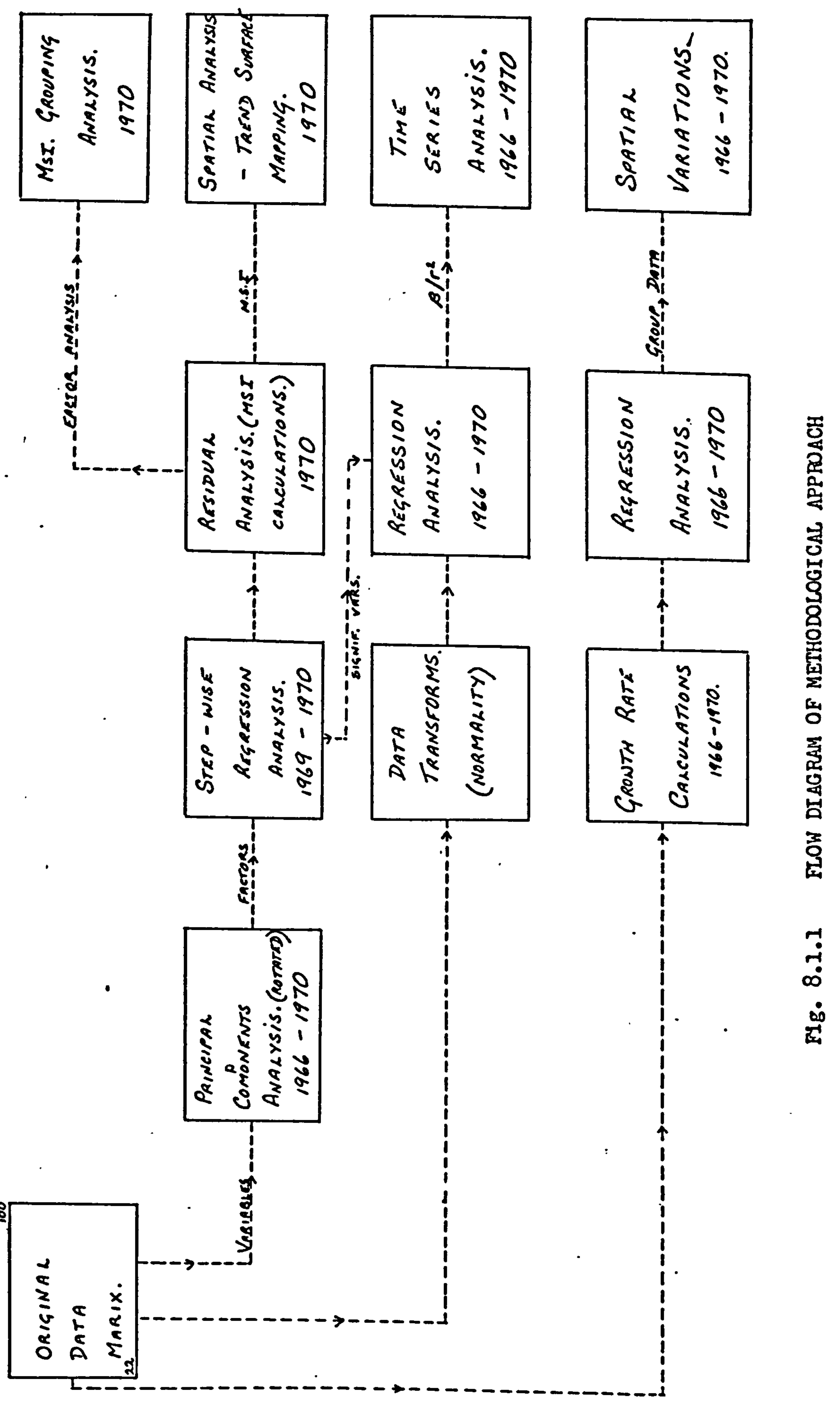


The model developed by Smeed (1949), whilst studying the variation in road accident volumes in 20 different countries, was baslcally a modifled regression model. Using 1938 accident data he derived an equation which related the number of deaths In road accidents in any one year to the number of licenced motor vehicles and the population level. A line corresponding to the formula,

$$
D=0.0003\left(\mathrm{NP}^{2}\right)^{\frac{2}{3}}
$$

where,

$$
\begin{aligned}
& N=\text { the number of licenced motor } v \in \text { hicles } \\
& P=\text { the population level } \\
& D=\text { the number of road accident deaths, }
\end{aligned}
$$

was found to be the best fit line for the collected date.

Along vith the rork by Rempler end Blomçuist (1956) in their study of road accidents in Sweden, the Smeed study used compound variables such as the volume of traffic, but it would seem more meeningful to diseggregate such deta and perhaps divide traffic variebles emong the different traffic elements. A good exemple of this kind of diseggregation can be seen in the work of fiempler end Viestergren (1966). In the present research, such disaggregation was also attempted, but the possibilities proved very Iimited due to the size and nature of the areal units used.

As steted previously, the mein aim of the methodological approach in this research was to predict an "expected" number of 
road accidents per urten area. In stetistical terms and within the multiple regression model used, this is knovn as point estimation. To understend how the multiple regression model is able to provide this point estimation, it is best to describe the regression model as simply as possible. The multiple regression model attempts to fit a linear surface to a set of variable data points, such that the sum of the squared deriations from that surface is minimised. The model can be represented by

$$
Y=a+\sum_{i=1}^{k} b_{i} x_{i}+e
$$

where, I is the dependent variable

$X_{1}$ is the $k$ independent variables

$a$ and $b_{1}$ are the regression coefficients, representing the paremeters of the model for a specific population. e is a stochastic disturbance term.

When the number of independent variables is above five or six the calculation of the various paremeters becomes very complex, and some standardising procedure is necessary, and very often the formulation in terms of matrices is the cne preferred since it is the method most easily applied in computer baseà solutions. Before leaving this point of the discussion it is importent to note that the computed $b$ velues of the regression are know as "partial regression coefficients." These coefficients each give the rate of change in the dependent variable for $a$ unit change in the 
independent variable while the remaining independent variebles are held statistically constent. However, beceuse the partial regression coefficients are not independent of the particular metrics used for the variables, it is meeningless to attempt to compare directiy the megnitudes of the $b$ values, as in any way indicative of the relative importance of the different variebles in the regression equation. The solution to this problein is to standardise the partial regression coefficients in such a way to enable direct comparisons. The normal method used is to calculate the bete values $\left(\beta_{j s}\right)$ which are dimensionless terms. They can be derived as follows:-

$$
\beta_{j}=b_{j}\left(s_{j} / s_{o}\right)
$$

where,

$$
\begin{aligned}
\beta_{j}= & \text { the standardised beta value } \\
s_{j}= & \text { the standard deviation of the independent } \\
& \text { variable } \\
s_{0}= & \text { the stendard deviation of the dependent } \\
& \text { variable. }
\end{aligned}
$$

The use of this model in this research is importent on two accounts. In the first instance the best-fit regression plene allows the calculation of a value for $Y_{\text {oi }}$ for any set of $X_{i}$ independent variables. In other nords, for every urben area a value relating to the number of road accidents can be calculated from the relevent independent (structural) variable values. Thus the regression plene can be conceptualised as the "nom" from which to study spatial variations. Secondly the $\beta$ coefficients 
allows one to study and compare the influence of each of the structural variables upon the level of road accidents. Additionally, over time, the $\beta$ coefficients will show the variation in the Influence of any one independent varieble over time. Sumarising therefore the multiple regression model enables the calculation of en "expected" number of road accidents for each urben area; the comparison of the influence of different structural variables upon the level of road accidents and finglly the $\beta$ ccefficients allow the study of the influence of these variables over time. model

Unfortunately, the multiple regression/is based upon vurious Implicit assumptions which must be satisfied if the results atteined are going to have eny realistic interpretation. There has been considerable discussion within the geographical literature as to whether these assumptions have received enough, if any attention. (King 1969, Harves 1969, Tobler 1966 etc.). A recent paper by Poole et.al. (1971) has pointed out that there are seven basic assumptions which must be satisfied if enything more than pointestimation is desired. As regards the present research three of these problems proved difficult to accept, end are discussed below.

The most limiting assumption was that of multi-colinearity. This assumption states that $n$ the independent variables, $X_{1}$ are IInearly independent of each other." (Poole et. al 1971) That is the correletion between the independent veriables is minimel. Obviously in this research such an assumption was untenable since 
several of the variables introduced had high correlation values with other variables. The correlation matrix for these independent variables is shown in Table 5.4.2.

A second limiting assumption is that of autocorrelation. The relevent assumption states that the error terms in the regression model are independent and normally distributed. When the least squares technicque is used to estimate $b$ in the regression equation $\Sigma e_{1}^{2}$ is minimised. Therefore $\operatorname{if} \sum e_{i}{ }^{2}$ is 0 or neer to zero, then there is no autocorrelation problen, end all the relevant variables have been included. Similarly if $\Sigma e_{1}^{2}$ is relatively large the problem can be tiofold. There maj be a sompling error or a specification error, whereby the wrong relationship has been postuleted in the model. However, in both instences if the sample size is increased $\Sigma e_{i}{ }^{2}$ does not tend towards zero. Therefore it is possible to test for the occurrence of autocorrelation simply by increasing the sample size and noting whether the value of $\Sigma e_{1}{ }^{2}$ is reduced or increased. Whilst most of the discussions on eutocorrelation have revolved around time-series data, it is obviously just as importent in the analysis of spatial data, where one refers to cross-sections through time. Spatial autocorrelation which occurs when desling with contiguous areas is probably more complex and therefore more difflcult to accomodate then time-series autocorrelation, because the time-series data involves only one dimension whilst spatialautocorrelation can involve many more dimensions. One of the methods used for testing/spatial autocorrelation is the Cliff-ord Statistics (CIiff 1970). However, in this research, because the 
areas dealt with were in most instances non-contiguous, the problem of spatial autocorreletion was not explicitly tested for, but the eutocorrelation in the regression residuals was stadied by means of the trend surface enalysis.

The third limiting assumption is that of normality of data. flthough this assumption is of little importance as regards point estimation, it is important if any inferential statements are to be made of the regression as a whole, or the various parameters. Normality can be tested by using the formule proposed by Lembe (1967) which is given as:

$$
\left|\frac{\eta}{6}-0.7979\right|<\frac{0.4}{\sqrt{N}}
$$

where,

$$
\begin{aligned}
& \eta=\text { the mean deriation } \\
& 6=\text { the stenderd deriation } \\
& N=\text { the nunber of observations. }
\end{aligned}
$$

The results of this test on all the independent variebles is shown in Table (8.2.1). A study by Anderson et. al. (1968) tested this assumption of normality amongst the number of accidents in Sweden, by studying the derived trends and autocorrelations, using histogrems of the standerdised residuals, and correlogrems. In each case, the deviation was small and tended to zero, and although the semple size was too small to make any definite conclusions, it sears plausible to accept that the assumptions of normall ty and 


\begin{tabular}{|c|c|c|c|}
\hline VARIABLE & $\begin{array}{l}\text { LAMBE } \\
\text { TEST }\end{array}$ & KURTOSIS & SKEWRESS \\
\hline POPULATION & 0.158 & 12.765 & 3.155 \\
\hline AREA & 0.084 & 5.055 & 2.108 \\
\hline DENSITY & $0.029 *$ & 0.700 & 0.458 \\
\hline P.T.F. & 0.073 & 4.561 & 1.936 \\
\hline TTF & 0.202 & 16.074 & 3.592 \\
\hline ETT & $0.031 *$ & 2.428 & 1.320 \\
\hline COW & $0.012 *$ & 0.768 & -0.324 \\
\hline MSI & $0.009 *$ & 0.428 & -0.531 \\
\hline SRI & 0.101 & 3.791 & -1.249 \\
\hline TCI & $0.016 *$ & -0.254 & 0.060 \\
\hline CI & 0.049 & 1.961 & -1.450 \\
\hline DOS & 0.207 & 20.644 & 3.967 \\
\hline SHI & 0.362 & 30.536 & 5.284 \\
\hline AVI & 0,187 & 14.203 & 2.482 \\
\hline DVI & 0.167 & 7.373 & 1.787 \\
\hline TDI & 0.157 & 11.696 & 3.033 \\
\hline HTI & 0.186 & 12.635 & 3.015 \\
\hline CHSI & 0.200 & 13.221 & 2.907 \\
\hline PPI & 0.081 & 2.461 & 1.142 \\
\hline PSI & $0.055=$ & 3.452 & 1.574 \\
\hline RI & $0.039 *$ & 1.352 & 1.213 \\
\hline$R D I$ & $0.042 *$ & 1.115 & 0.573 \\
\hline
\end{tabular}

* indicates a normal distribution (80.04)

KURTOSIS - is given by the formula:-

$$
K=\frac{\sum_{i=1}^{n}\left(\frac{x_{i}-\bar{x}}{s}\right)^{4}}{N}-3
$$

SKEWNESS - is given by the formula:-

$$
S=\frac{\sum_{i=1}^{n}\left(\frac{x_{i}-\bar{x}}{s}\right)^{3}}{N}
$$

TABLE 8.2.1. NORMALITY TESTS FOR THE 22 INDEPENDENT VARIABIES 2970. 
independency of the residuals, can generelly be accepted.

\subsection{PRINCIPAL COMPONENTS ANALYSIS}

Beceuse of the extent of these vurious limitations, it was decided that the original data ought to be transformed. This was cone by applying a principel components analysis upon the original data matrix of 18 variables. Principal components analysis cen be conceptualised as a technique which is capable of collapsing a set of intercorrelated veriables into a smaller number of basic dimensions, or "composite variables." What is more important however, is that these basic dimensions are such that they are totally uncorrelated one to another (orthogonal). The solution, moreover, is such that the first dimension extrected accounts for the highest proportion of the total variance present vit thin the original data matrix.

The interpretation of these resultant basic dimensions is one of the major problems of eny research project, and this is done by reference to the "loading coefficlents." In practice these loadings are simply the correlation coefficients between the original variables and the derived components. However, very often eny one component will have a high loading with severel of the original variables mating any interpretation difficult, especially when dealing with the higher order components. For this reason it is common practice to rotate the components, in order to recuce the number of high loadings on eny one component. 
Mathematically, rotation cen be viewed simply as the result of the indeterminacy of the principal component analysis, since an infinite number of locetions could have been derived for the various axes, and the problen is which location is to be preferred. (FIg. 8.3.1). The most common rotation used is the Varimax rotation. This method attempts to simplify the columns of the factor loadings matrix, by a series of orthogonal transformations of pairs of factors. (See Harmen 1960). Thus the varimax solution can be simply described as an iterative procedure aimed at finding en optimun solution for the location of rotatedfactors. Two limitations of this solution are that the pattern of loadings obteined may change considerably if additional factors are included in the solution, and also the solution is not very useful in cases where there is a dominant general factor. (Lawley et al 1971). For this reason $1 t$ was decided to use an oblicue ratetional method wihich whilst useful in alcing interpretation of the various factors, suffers from the loss of ortrogonality. The oblique solution methods were first studied by Thurstone (1947) and Thomson (1951), who both used a graphical solution. However, these solutions "involve the researcher inmery arbitrary decisions ebout the choice of factors." (Lawley et al 1971), and so further research was directed inte the discovery of enalytical criteria that could be used to produce unique and less subjective solutions. The earliest kork in this field was carried out by Carroll (1953), Kaiser and Diclman (1959) and Hendrichison end thite (1964), who evolved the "Promex Solution." It was this solution which was used 


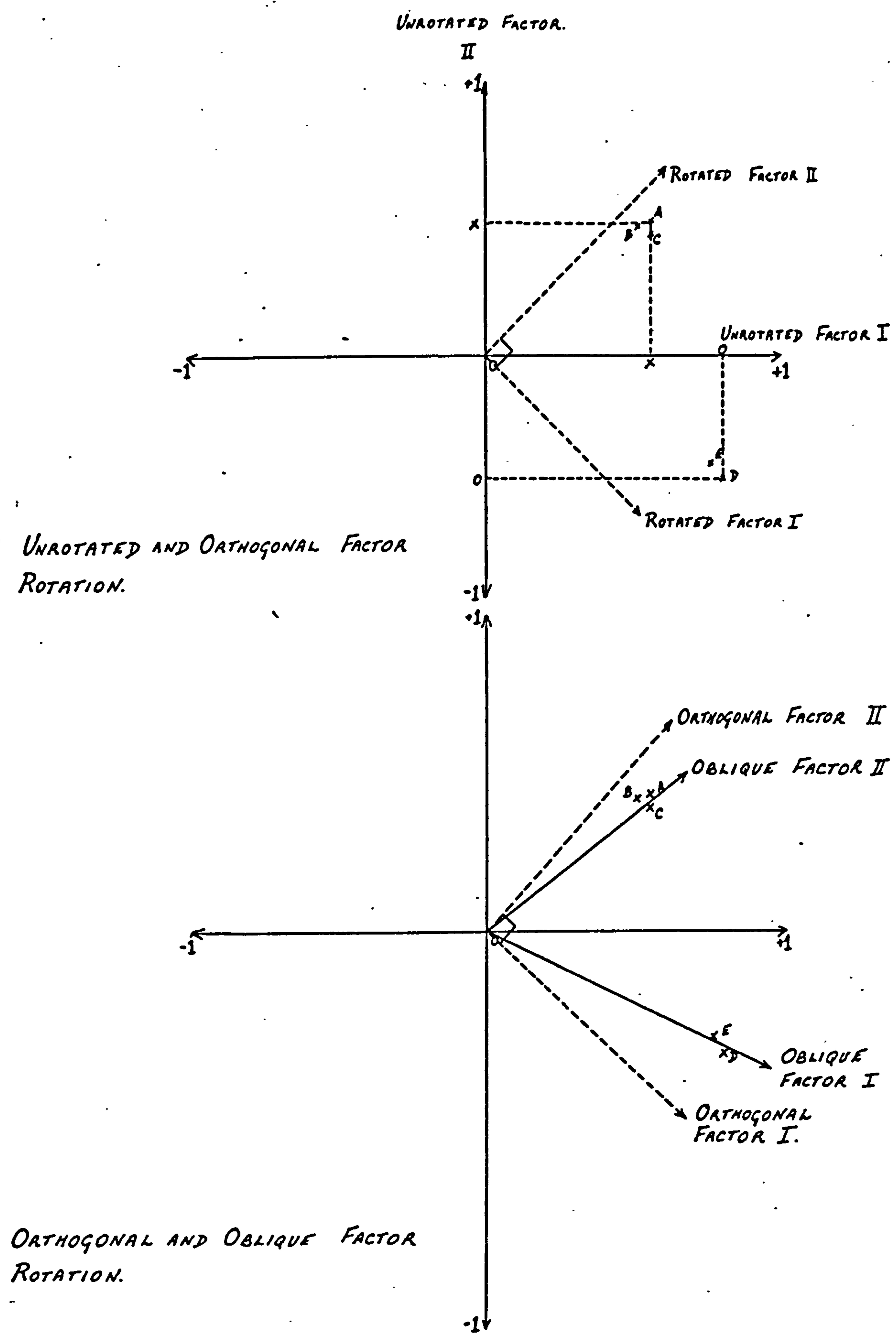

Fig. 8.3.1. POSSTBLE LOCATIONS FOR DERIVED FACTORS WITH ORTHOCONAL AND OBLIQUE RDTATION METHODS. 
in this research necessitating only the one subjective decision, that of what velue to use for " $\mathrm{m}$ " in the simplification of the "pattern matrix." This value for " $m$ " determines the degree of oblicieness desired in the solution, and consequently therefore, the level of correlation betwean the various factors. It is generally accepted that velues upto $\mathrm{m}=4$ will simplify the pattern of loadings by increasing the absolute magnitude of relatively large loadings whilst decreasing those with relatively small loadings. However, where $m>4$ the usefulness of the simplified pattern loading matrix may be overcome by the high level of correlation produced between the various factors. For this reason a velue of $m=4$ was used in the present rotation.

The use of a principal components solution in a ntro-stage regression" is quite extensive and has been reviewed at some length by Massey (1965), but only a few have actually used a rotated solution (Wong 1953, Hodge 1965) mainly because of the "commanality" problem which is associated with any factor enalysis solution. However, it can be argued that if the communalities are held to be equal to one, then the metrod used here remains a principel components solution, with rotation being used merely as en aid to icientification. In the context of a two stage regression approach, the results from such an analysis would appear clearly acceptable, especially since there is the added bonus that derived scores input into the regression are standardised with a mean of zero and a standard deviation of one. 
Thus the use of this analysis was useful in satisfying most of the assumptions of the multiple regression model, whilst allowing some observation of the urten structure system through the icentification of the various derived components. This line of discussion will be continued at a later point in this report, (Chapter 9). Before leaving this discussion on principal components cnalysis and its use in a tro-stage regression analysis, one further point must be elucidated, concerning the number of components to be introduced into the regression. This problem arlses because of the very small amount of variance explanation, provided by the higher order components. Very often such components are deemed insignificant and thereby ignored. Altematively some test is performed upon them to test for their actual significance. These include those tests suggested by Bartleit (1950) or Jeffers (1967) who suggests that in general, it is satisfactory to disregard all components with a varience of less than 1 . However, It is suggested that when the components are to be used as regressors in a regression analysis, it is not necessarily true to maintain that just beccuse a component explains an insignificant anount of the total variance in the originnl data matrix, it is also going to be insignifleent in "explaining" the variation in some other variable. If this point of view is to be accepted then the obvious conclusion must be tihat all the components ought to be available for the regression enalysis, and their significance determined accordingly. This was the approach of this research and the significance of each component was deternined by using a "Step-inise regrassion model" rather then the traditional multiole regression nodel. 


\subsection{IHE STIP-XISE REGRESSION MODEL}

When the simple multiple regression nodel is utilised, all the available variables are introduced in to the model at the sane time. This is satisfactory when the relationship between all the variables is know and when one is not interested in further research hjpotheses, but as is generally the case, most research problens necessitate the selection of an optimun callection of variables, fron all the avallable variables, adding only variables which significantly affect the explanation $l=v e l$ of the regression, whilst the other variables are held statistically constant. Essentially therefore, the problen is to derive and select the "best" regression equation. Unfortunately, since there is no statistical procedure which csil guarantee on "optinum" solution, or an "optimun" group of variebles, some compronise algorithnic technique has to be used. Although there are several such algorithnic procedures, the one used in this research was the "step-rise" procedure.

The step-wise regression nethod recursively constructs a prediction equation one independent variable at a tine. The first step is to choose the single variable which is the best predictor. The second independent variable to be added to the regression equation is that which provides the best prediction (level of explanation) in conjunction with the first variable. One then proceeds in this recursive fashion, adding variables step-by-step until the desired number of independent variables has been achieved, or until no other variable will make a sig- 
nificant contribution to the prediction equation. It is importent to note at tinis point that such a procedure, besides dictating the selection and therefore addition of the independent variables, also dictates the renoval of variables from the regression equation. This is essential because a viriable which may have been the best single variable to enter at an early stage may, at a later stage, be superfluous because of the relationship between it end other variables now in the regression. To checis on this, the partial $F$ criterion for each variable in the regression at any stege of calculation is calculated and compared with a preselected percentage point of the appropriate $F$ distribution. This provides a judgenent on the contribution made by each variable as though It had been the most recent variable entared, irrespective of its actual point of entry into the model. Any variable for which the calculated $F$ value is less than the preselected acceptance value, and which therefore provides a non-significent contribution, is renoved fron the model. This process continues until no moro variables can be added or removed from the regression equation.

Step-wise regression is based upon a common method of solving the systen of linear equations in multiple regression, that is Gauss elimination with row and colunn interchanges. This corputational method is also useful since it provides the tio pieces of information necessary in the selection process. The first is the nornalised reyression-coefficient value $b$ that the prospective independent varisble would have if it were brought in to the equation on the next step. It is the value of this coefficient 
which is tested by the F statistic during the selection process, and as already indicated, if $F$ is too small, there is little reason to add that independent variable to the regression equation.

The second piece of information used in the selection process is the pirot elenent which would be involved in bringing that variable into the equation. This value is known as the tolerance level. If the tolerance is small then that variable is nearly a linear combination of variables already in the equation. If it is really a linear combination of independent variables already In the equation, then the tolerance value will be zero. A large tolerance indicates that a new "dimension" is being added to the prediction equation. The tolerance has a value range of zero to one. The anount of additional variance expleined by adding the new variable is the product of the normalised regression coefficient b squared and the tolerance. Thus, even if the prospective b is large, a small tolerance value vill negate the value of that variable being added to the equation. Consequently, the step-wise procedure never enters a variable into the equation if the tolerance is below a specified minimum. This is, therefore, another way in which the computational accuracy of the program is upheld.

This step-rise procedure described above, was the model used In this research to derive the desired regression planes, and the resultent level of road accidents in any one urben aree ascertained. The program used was the standard BMD step-inse regression progran which was converted from the original Fortran II program, to 360 Fortran IV(H-Level) at Salford University. 
The confidence interval used to obtain the inclusion and deletion values for the $F$ statistic was the $\alpha=0.1$ level which gave $F$ values of 4.00 for inclusion and 3.92 for deletion. Similarly the default value of 0.001 for the tolerance level ras used, although in most instances this was never called into consideration.

\subsection{THE STUDF OF RESTIUALS}

Ilaving obtained the necessary "expected level" of road accidents, the next problex was then how to relate these values to the actual number of road accidents in any urben area. In a way this problen can be generalised as that of how to deal with the "residuals" from regression analysis. That 1s, the researcher is interested in the difference between observation and theory. Because of the complext of spatial variations there is obviously considerable unexplained variation and the residual values can be conceptualised as reflecting in part, the effect of other possibly unknown variables, and as such can be used to gain a greater insight into the behaviour of particular phenomenon. For example, John Stuart Mill in a "Systen of Logic" (1874) presents the "methods of residues" as the fourth Canon, and consistently praised it as a highly respectable research tecinique. Thus, "Subduct from any phenomenon such part as is knoxn by previous inductions to be the effect of certain antecedents, and the residue of the phenonenon is the effect of remaining antecedents." Similarly, whilst speaking generally of tine method of residues, "Of all the nethods 
of investigating laws of nature, this is the most-fertile and unexpected result; often informing us of sequences in which neither the cause nor the effect were sufficiently conspicuous to attract of themselves the attention of the observers. The agent $C$ may be an obscure circumstance, not likely to have been perceived unless sought for, nor likelf to have been sought for until attention had been awakened by the insufficiency of the obrious causes to account for the whole of the effect." (MiII 1874). Thus in a way, Mill's Method of Residues is simply a search procedure used in the analysis, for the discoverg of further important variables or oren new theoretical concepts. As such this approach has developed into the more modem "deviantcase analysis" which is importent because as Horst points out, " the most interesting and useful parts of a pradiction study should be the investigation of the cases which have been incorrectly predicted in the new sample." (Horst 1941).

Whilst there has been a rapid increase in the use of " residual analysisn one of the major problens encountered has been the forn of the residual index. Thomas identifies four of the more common forns used, favouring the standardised residual,

$$
\left(x_{01}-x_{1}\right) / s_{01}
$$

$$
\text { where, } \quad \begin{aligned}
& X_{0 i}=\text { the computed value for ares } 1 \\
& Y_{1}=\text { the observed value of } I \text { for area } 1 \\
& S_{01}=\text { the stendard error of estinate }
\end{aligned}
$$

but there are many other forms which are viable and cun only really 
be determined by the individual research project. Thus Tarfe et al (1963) in their study of the trensport development in Nigeria and Ghana ysed the simplified, non-stendardised residuals,

$$
\left(X_{0 i}-Y_{1}\right)
$$

and yet the mapping end study of these residuals led the authors to suggest five additional factors, which they had previously not considered and which ultimately added further findings concerning the transport systems within those tro nations.

The form of the residual used in this research relates to the third forn as mentioned by Thomas (1960) and is given as the magnitude of the observed value for the 1 th unit as a proportion of the computed value for that area. When multiplied by 100 this residual was used as the value for the Mean Safety Index for each area at time $t$,

$$
\mathrm{MSI}_{1 \cdot t}=\left(\mathrm{I}_{1 t} / \mathrm{X}_{\mathrm{oi}} \mathrm{t}\right) \times 100
$$

where,

$$
\begin{aligned}
M_{1 \cdot t} & =\text { the mean safety index for area } i \text { at time } t . \\
Y_{i \cdot t} & =\text { the observed value for area } i \text { at time } t \\
X_{\text {oi.t }} & =\text { the computed value for area } i \text { at time } t
\end{aligned}
$$

As Thomas points out howerer, this, "is not a residual according to the strictest of definitions" due to the fact that the difference between the tro values is ignored in preference to the measure of their relative values. Howerer, since this index is closely related to the more common forn of residual $\left(X_{01}-Y_{i}\right) / Y_{i}$, the maping of such an index is obviously useful in the study of 
unexplained variance.

The derived meen safety index is therefore designed such that it gives a variation about 100. Where the index exceeds this base value, the observed value is greater than the computed value, and the "response" of that urban area is rorse than would be expected given the present set of independent variables. Similarly when the index is less then 100 the observed value is Iess than the computed and therefore the "response" of that urban area is better then theorised.

\subsection{TREID SURFACV ANALISIS}

Whilst the Hean Safety Index is meaningful in its own right, as already suggested, much more can be achleved by mapping this Index and by creating some "continuous" surface which can possibly predict the relationship in other "unsampled" urben areas, and also for suggesting new variables which ought to have been taken Into account. Although such mapoing procedures as simple isopleth maps are useful, the problem of discontinuous data can prove a serious problem; for this reason a further stage was added to this research approach by means of the application of Trend Surface Analysis techniques.

Trend surface analysis is simply an extension of the multiple regression model into a third dimension. It is a method of fitting progressively higher order polynomial equations to a set of $X, Y$ and $Z$ observations in which the $X$ and $Y$ values are co-ordinate data 
and the $Z$ values are observations of some variable. This type of analysis has been used extensively in the varlous "earth sciences" where the problen has been mainly extrapolation of existing data or the reconstruction of surfaces from fragnentary date (as in the "ghost stratigraphies" of whitten (1959). However, trend surface analysis has also been used in order to extract regional trends and examining the deviations from these trends. Thus Krumbein and Grajsbill (1965) define trend surface analysis "as a procedure by which each map observation is divided into two or more parts: some associated with the "larger-scalen" systematic changes that extend from one map edge to the other and the others associated with "snall-scale" apparentiy non-systematic fluctiations that are imposed on the large-scele patterns." (p.32I). In other words therefore one of the main aims of trend surface analysis is to differentiate between the broad regional distribution of variability, from the non-systematic, local and chance variations. In terns of road accident enalysis, this shows the differentiation between those factors which necessitate national attention and those which must be dealt if th at the local level.

With the derivation of computer-based solutions to the problem of fitting the various polynonial surfaces, Trend-surface analysis has been applied in many other fields other than those simply related to geology. Obviously the usefulness of Trend Surface mapping is greatest where continuous data is avallable, and regularly spaced sampling points are used. However, the latter problem can be overcome, al though the solution of the polynomial 
equations becones much more complex, and the former problem has been discussed by Chorley et al (1965). They argue that surfaces need not be continuous and that "population, like light may be profitably regarded either as a series of discontinuous quanta or as a continuum." The fitting of trend surfaces to social and economic data may provide then a "useful yardstick for describing geographical patterns." (Chorley et al 1965). Subsequent work has followed these suggestions with trend surfaces being applied to such diverse subjects as spatial perception studies, (Gould 1966), the location pattern of urban services among a set of towns (Fairbaim et al 1967) and the growth of urban areas in England and Wales, (Robson 1973).

The formulation of the trend surface equations is given below for a first order surface (linear) and a second order surface (Quadratic).

$$
\begin{aligned}
& Z=a+B X+c Y \text { (Ist order), } \\
& \text { and, } Z=a+b X+c Y+d X^{2}+e X I+f Y^{2} \text { (2nd order) } \\
& \text { where, } Z=\text { the value of the research variable. } \\
& X \& Y=\text { two grid co-ordinates } \\
& a, b, c, d, e, f=\text { paraneters. }
\end{aligned}
$$

The shape of the various surfaces upto the quartic surface are shown in (Fig. 3.5.1.). Thus the trend surface model is derfied by creating a hierarchs of mathenatical surfaces which are fitted to the original data, and the explained portion of the observed variability, conventionally expressed as the per 
centage recuction in the total sur of squares, may then increase with surfaces of successively higher degree. In most instences, however, the lower order surfaces have been preferred since they tend to indicate the regional trend, whilst surfaces which exceed the 6th order tend to become very complicated, and are near Epproximations to the original complex distribution. Therefore In this research, surfaces were produced for twenty dependent variables (1970) all of which extended at least as far as the 6 th order surface, but none exceeded the 7th order (Appendix 2).

\subsection{TEAPORAL VARIATION NVALISIS}

So far this enalysis of the methodology used in this research has been limfted to the stucy of the spatial variation in road accidents. Tuming to the problem of temporal variation, one has to retum to the multiple regression model. As already indicated, the nultiple regression model is useful in two ways when studying the chonge In road accident characteristics over time. In the first instance, the amount of the total variation in a dependent variable, that is explained by a set or group of independent variables can be studied over time simply be reference to the $R^{2}$ value. If the impact of these indepondent variables is constant over a given time period, then one would also expect the level of explanation by the model, also to remain constant. Variation in either statistic therefore suggests a changing relationship. Secondly the influence or relationship between the dependent variable and the individual Independent variables can also be studied over tife by recourse to the standardised $\beta$ coefflcients. Unfortunately since the 
transformation of the original data matrix by means of the principal components analysis, was completed individually for each year, the various derived components also varied year by year. Therefore it was necessary to return to the original data matrix. To escape the problems noted previously in the use of untransformed data and multi-colinearity etc. a new regression equation was developed for each dependent variable used in the time analysis, which included only thoseindependent variables which were shown to be significent by the step-wise regression during the spatial analysis. Where a component was heavily loaded on more than one variable, the variable vith the highest loading was the one entered into this section of the enalysis. Once these modifications had been completed the time analysis was completed as described above. However, since the road accident datz was very difficult to obtain prior to 1966 and because the disaggregation of the data was very limited, it was only possible to conduct this time analysis for three dependent variables. Total casualties, total casualties per thousand population, and total casualties per vehicle mile $\left(10^{6}\right) \cdot 1966$ - 1970.

Becruse of the Iimitations posed by the lack of data, it was deened useful to look at the temporal variation in another way, basically through the growth rate in the number of road accident cesualties from 1966 to 1970. The hypothesis put forward was, how much was the level of road accidents in tine $t+1$ the response of the level of road accidents in time $t$. Altamatively, do towns of different size and therefore different road accident levels have accldent growth levels which are proportionally equivalent. This 
hypothesis can be tested by the regression equation,

$$
x_{t+1}=a+b x_{t}+e
$$

where,

$$
\begin{aligned}
x_{t} & =\text { the number of casualties at time } t . \\
a, b, & =\text { constants } \\
e & =\text { normally distributed error term. }
\end{aligned}
$$

If the absolute growth of road accident casualties is proportionate and independent of the original level of road accident casualties, then one would expect $b=1.0$, with 'a' representing the overall growth in road accident casual ties for all the urban areas studied. Obviously where the value for b is less than 1.0 the areas with a siall road accident casualty level must be growing at a faster rate than those with an original high level. Of course one must also take into account the effect of the error term which should be at a minimal level if any significance is to be put on the consequent results.

A second hypothesis which was postulated was whether the actual growth rate in road accident casualties was a function of the original road accident casualty level. If the growth rate in road accident casualties is defined as,

$$
G \cdot A_{t . t+1}=\left(T C_{t_{+1}}-T C_{t}\right) \cdot\left(\frac{T C_{t+1}+T C_{t}}{2}\right)^{-1}
$$

where,

$$
\begin{aligned}
\mathrm{GA}_{t . t+1}= & \text { the growth rate in casualties from } \\
& \text { time } t \text { to } t+1 \\
\mathrm{TC}= & \text { the total number of casualties at time } t
\end{aligned}
$$


then this second hypothesis which can be equated as,

$$
G_{t . t+1}=f\left(T C_{t}\right)
$$

can be tested by the simple regression equation,

$$
G_{t \cdot t+1}=a+b T C_{t}+e
$$

These two hypotheses and their consequence to road accident analysis will be developed further in the following discussion on the results obtained during this research. At present it is sufficient to mention the problem and the methodolog used without delving any further into the respective consequences.

\subsection{SUMYPPY OF METHODOLOCY}

The last two sections of this report have attempted to explain the methodology used in this research. Beckise of the complexity of the epprosch it would seem best to simply sumarise the methodology before moving on to the results obtained.

As regards the spatiel analysis, the methodologlcel epproach can be conceptualised as a five stege analysis. (Fig. 8.1.1). These steges are listed below:-(1) Collection and manipuletion of the orfiginal data matrix. (ii) Transforration of the original data matrix by meens of en "oblique" (promax) rotation principel components enalysis. (iii) The input of the derived principel component scores into a "step-wise" regrescion anelysis if th a 10\% conflaence intervel. (iv) The celculation of the mean safety indices from the residuals given by the "step-uisc" regression analysis.

(v) The input of the mean safety indices 
Into a trend surface analysis to stucy the spatiel variations.

Parallel to this enalysis the tamporal enalysis used the variables designated by the step-wise regression (from the originel data matrix) end input them into a separate regression model in order to derive the $\beta$ (standardised) coefficients, and the level of explanation $\left(R^{2}\right)$ for the years 1966 to 1970. At the same time the absolute increase in road accident casualties, end the grorth rate $(1966$ - 1970) in road accident casualties were studied according to their initiel road accident casualty level.

This then was the methodologicel epproach used and the consequent results are given in the following sections of this report. 
Chapter 9. THE ANALYSIS AND PFESFNTATICN OF FFSULTS

\subsection{INTPOLUCTION}

The results obteined in this reseorch, using the methodologicel approach cutlined in the previous section of this report are presented in this chepter. In order to facilitate ease of comprehension, the presentation of these results will be disaggregated, dealing with different sections of the approech individualy. Once such a presentation has been effected, it will be possible to draw these results into a suitable form in order to reach some meaningful conclusions, as regards this piece of research.

\subsection{THE PAIRCIPSL COMPONENTS ANALYSIS}

Although the principel components analysis ras inftially introcuced as a meens of reducing the multi-colinearity emongst the explanatory variables, through use of this technique several other edvantages were attalned as well as further interesting information, e.s regerds the inter-rclationship of the varicus sub-systems of the road accident system. For example, if the compontint scores are introduced into the regression equation, not only is the problem of multi-colinearity recuced, but elso these scores are stendardised with a mean of zero, end varience of one. Adiitionally these component scores have the further adventege of being elmost normel. Thus by this means most of the limitations previcusly mentioned, inherent in multiple regression analysis, have been satisfactorlly removed. 
The principal components analysis was carried out on the $18^{1}$ initiel explanatory variebles. The importance of the rotated components in explaining the total variation of the explanatory variables is shown in Table (9.2.1) which lists the components according to their variences in declining order. (1970). As a simple means of reference this listed ranking of components will be known as the "Varience Panking."

It will be noted from the varience ranking that only 6 components have en eigenvelue exceeding 1.0. However, it should also be noted that these six components also account for $81.755^{\circ}$ of the total variation within the list of explanatory variebles. This in fact incilcates one of the mejor properties of P.C.A. The variances (elgenvalues) of the higher number components are very small and such components are often disregarded as non-significant, especielly when they are used in a two-stage regression analysis. In some instences meenrhile, it mas be totelly fallecious to excluce components from the regression enalysis for this reason. It could, for example, be true that a component which may be nonsignificant when judged by the proportion of the total variance It explains, may nonetheless still be significent when used in a regression constructed to explain veriation within some other verieble. Accordingly, all the derived components within this

1 The four explanatory variables; Police prosecution Index, Police Severity Index, Rainfall Incex and Road Density Index, were not included in this initial PCA because they vere not principally related to the urban structure of the 100 sampled urben areas, or in the case of the Road Density Index, because of lack of data available for the 49 non-county borough areas 


\begin{tabular}{|c|c|c|}
\hline $\begin{array}{l}\text { CONPONENT } \\
\text { NUMBER }\end{array}$ & $\begin{array}{l}\text { COMPONENT (VARI- } \\
\text { ANCE) EIGENVALVE }\end{array}$ & $\begin{array}{l}\text { COMULATIVE EXPL. } \\
\text { VARIANCE }(\%)\end{array}$ \\
\hline 1 & 5.863 & 32.570 \\
\hline 2 & 2.733 & 47.751 \\
\hline 3 & 2.019 & 58.968 \\
\hline 4 & 1.777 & 68.838 \\
\hline 5 & 1.298 & 76.048 \\
\hline 6 & 1.034 & 81.795 \\
\hline 7 & 0.731 & 85.856 \\
\hline 8 & 0.593 & 89.151 \\
\hline 9 & 0.464 & 91.731 \\
\hline 10 & 0.399 & 93.949 \\
\hline 11 & 0.327 & 95.767 \\
\hline 12 & 0.287 & 97.360 \\
\hline 13 & 0.216 & 98.562 \\
\hline 14 & 0.137 & 99.325 \\
\hline 15 & 0.091 & 99.829 \\
\hline 16 & 0.016 & 99.917 \\
\hline 17 & 0.011 & 99.976 \\
\hline 18 & 0.004 & 100.000 \\
\hline
\end{tabular}

TABLE 9.2.1. THE VARIANCE RANKING FOR THE 100 URBAN AREAS 1970. 
analysis were treated as potential independent variables in the regression analysis.

Because the results of the P.C.A. were rotated using a Promax rotation with $k$ being assigned the value of 4 , the derived conponents were not orthogonal, as is usually the case in a simple P.C.A. Instead there was $\varepsilon$ degree of correlation noted between the components, end these correlations are show in Table (9.2.2.). (1970). From this table it can be seen that there are only 9 significent correlations where the level of correlation is above the velue $r= \pm 0.50$. There is however one correlation which reaches the high value of $r=-0.76$, but since this is between the last two derfied components ( 17 and 18 ), the restrictions due to this fact are cnly marginal, espectally when matched egeinst the increased feasibility of interpretation of the derived components.

The importence of the interpretation (and therefore rotaticn of) the derived components in a piece of research cannot be overemphasised. If eny meaning ful interpretetion is to be given to the results of the regression analysis, then it is obvious that one must be able to identify the varicus inputs into the model, which in this instence are the independent veriables. In nost instences, the P.C.A. Wi thout rotation is unable to satisfy this need, end as Kendal (1957) states, "In many cases our principal

1 contd. included within the semple. However when the multiple regression nodel was used, these indices were included as explanatory verieliles. In order to equate them to the Factor scores used from the P.C.h., these variebles were also stendardised using the formula,

$$
z_{1}=\frac{x_{1}-\bar{x}}{6 x}
$$




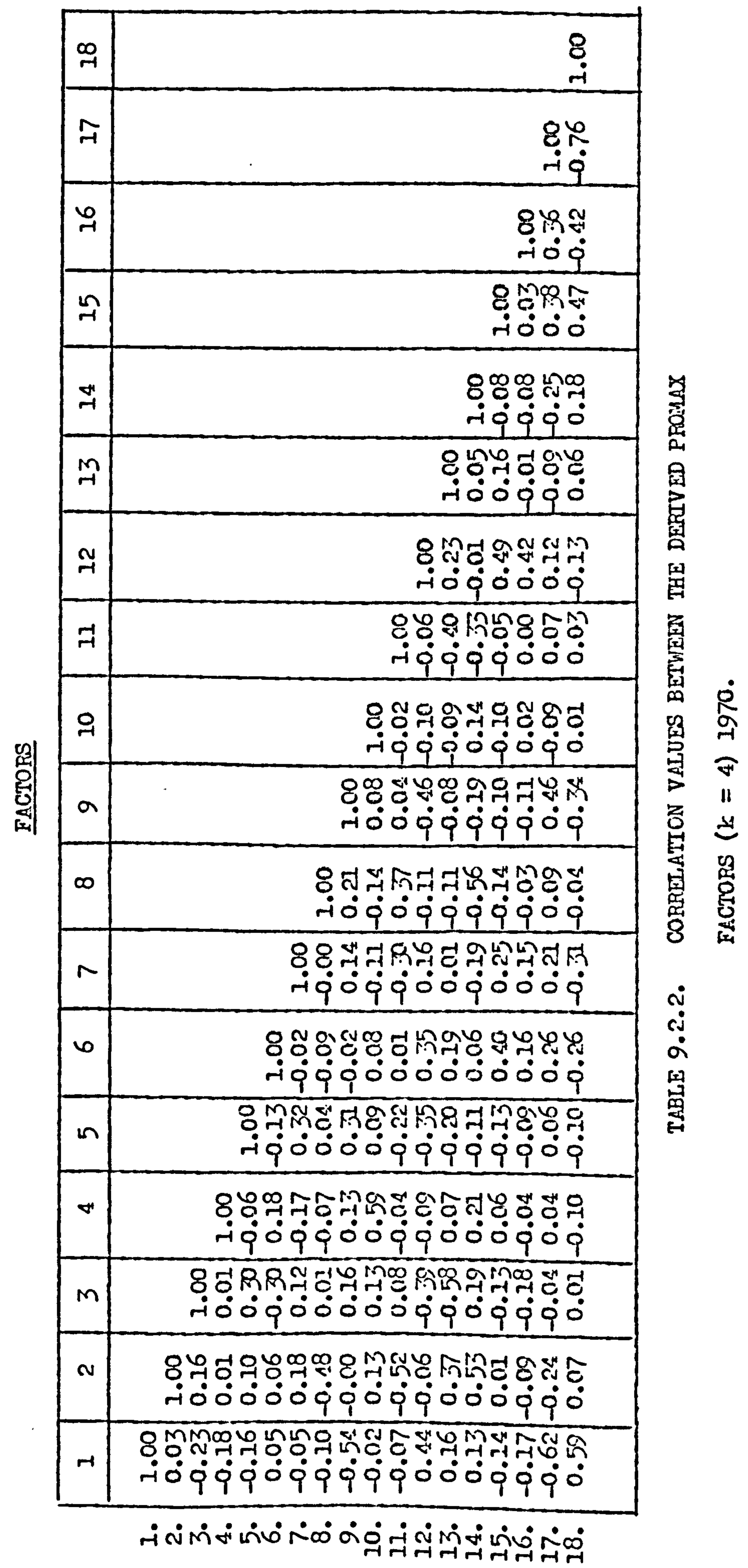


components do not have an identifiable separate existence and are to be regarded as convenient mathematical artefacts." Dhrymes (1970) also makes the same point when he argues, "In generel, one does not or cannot interpret principal components in an intuitively meening ful way. They are best regarded as the outcome of a statistical technique that handles certain types of problems efficientiy."

In this research similar problems were encountered as those described above. Hovever, following the use of the Promax rotation, it was possible to put some meaning ful interpretetion on almost all of the derived components and these are described below.

When one is trying to put some interpretation upon a derived component there are two sources of information:-

(1) FACTOR PATTEEN MATRIX - to factor analyse means to express a variable as a linear combination of indepondent variables, either defined or inferred. The Factor pattern inatrix contains the regression weights of the common fecturs end therefore, tells the researcher the composition of a variable in terms of hypothstical factors. The oblique fector pattern matrix obtained for 1970 is given in Table $(9 \cdot 2.3)$

1 contd.. where $Z=$ the stendard deviate score for area 1 , $\begin{aligned} \sigma_{\mathrm{X}} & =\text { the standard deviation of variable } X, \\ \bar{X} & =\text { the mean of variable } X,\end{aligned}$

such that each variable had a transformed mean value of zero and a stendard deviation of $l$. 


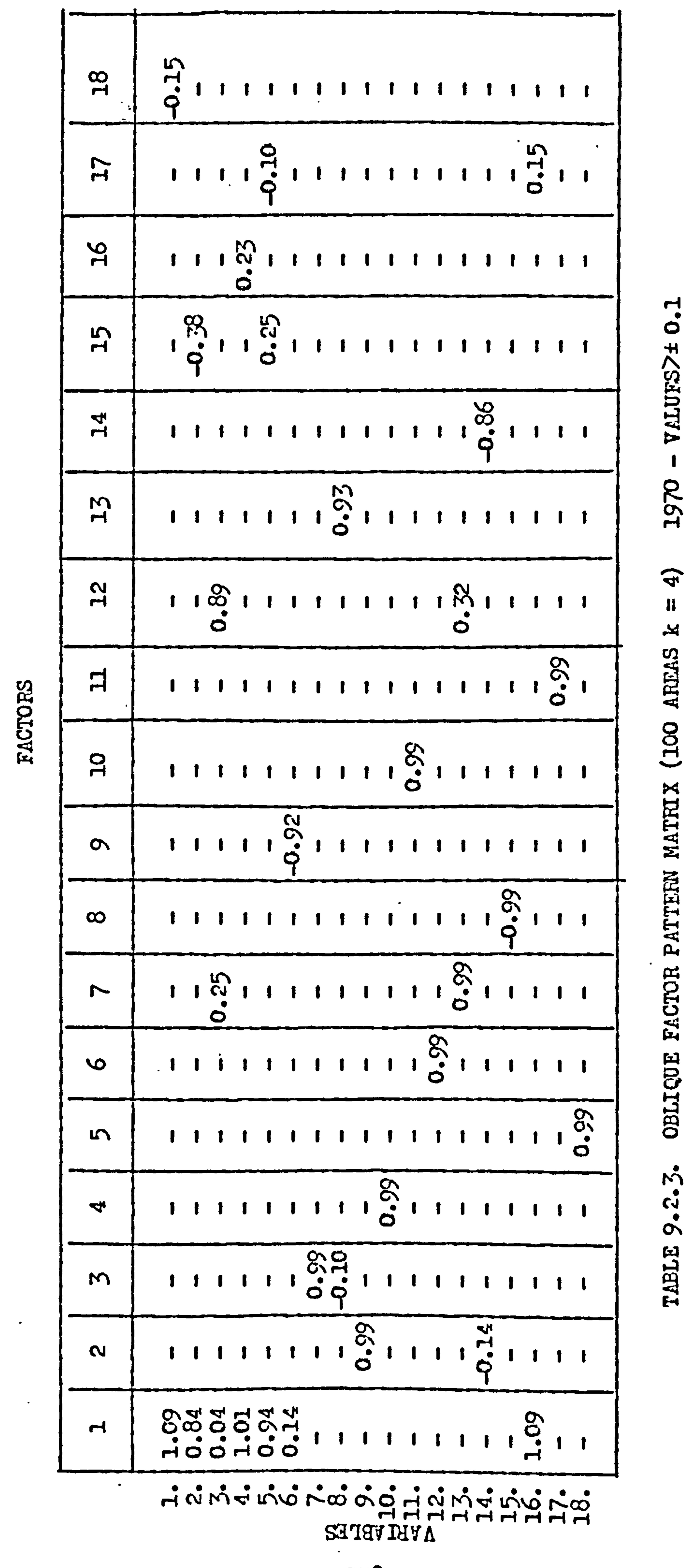


(ii) FACTOR STRUCTUEE MATPIX - this second source of Information relating to the composition of the derived components is eimply a matrix of correlation coefficients between each variable and each factor. In many ways this factor structure is more useful than the pattem matrix because not only does it indicate the important associations and their direction, but it also gives some indication of the strength of the association betreen components and variatles. The correlation between a component and its constituent variables becomes weaker es the components are taken seriatim in variance ranking. The effect of the rotation of the factors can also be seen by the fact that the resultant correlations of any significence on each component, is limited to very few variebles. The Factor structure matrix is shown in Table (9.2.4). (1970).

From this structure matrix it can be seen that for components I - II, there is always some variable which has a high correlation coefflcient $(2 \pm 0.60=r)$. However, for hlgher order components, the ease of interpretation is drastically reduced with the result that the maximum correlation coefficients for the 17 th and 18 th components are $r=0.07$ and $r=-0.08$ respectively. Except for

1 contd. Similariy, the level of correlation between these stendardi sed variables and the derived components was not sufficient to invoke the problem of multi-colinearity which hed been one of the major reasons for using the P.C.A. in the first instance. 


\begin{tabular}{|c|c|}
\hline$\stackrel{\sim}{\infty}$ & 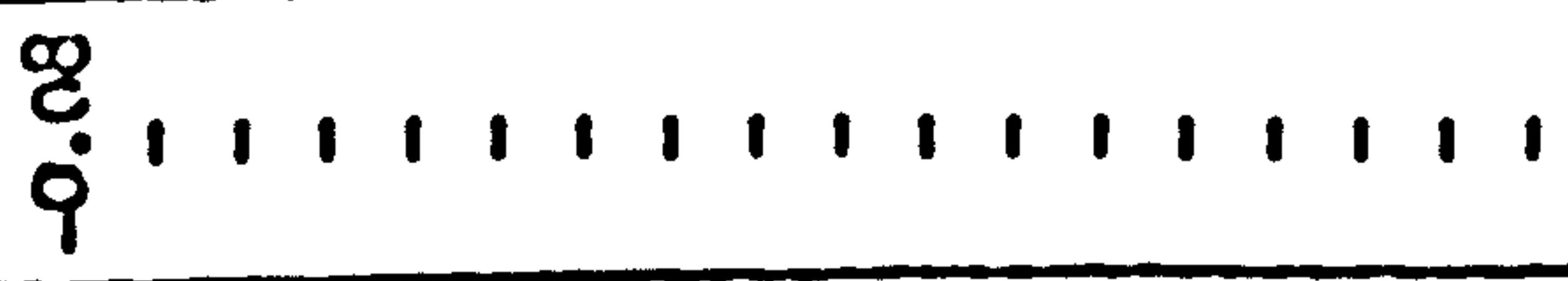 \\
\hline$\tilde{A}$ & 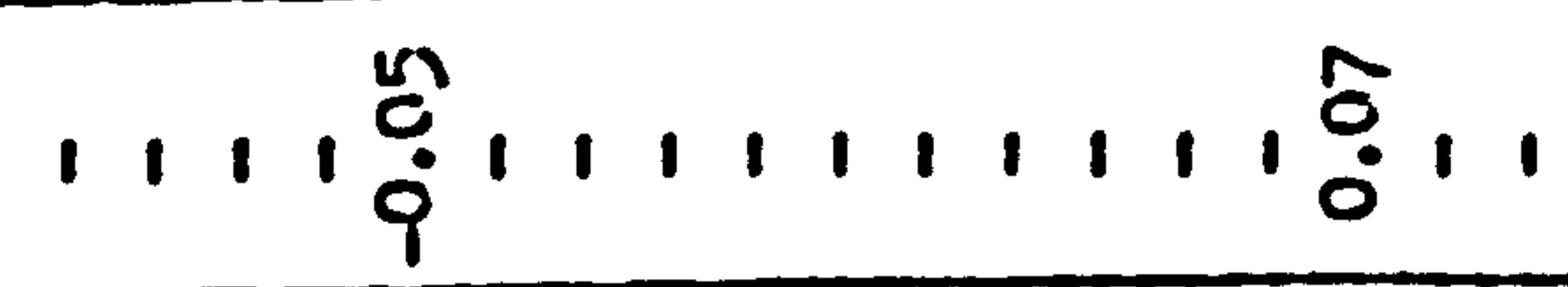 \\
\hline$\stackrel{\bullet}{\mathscr{r}}$ & 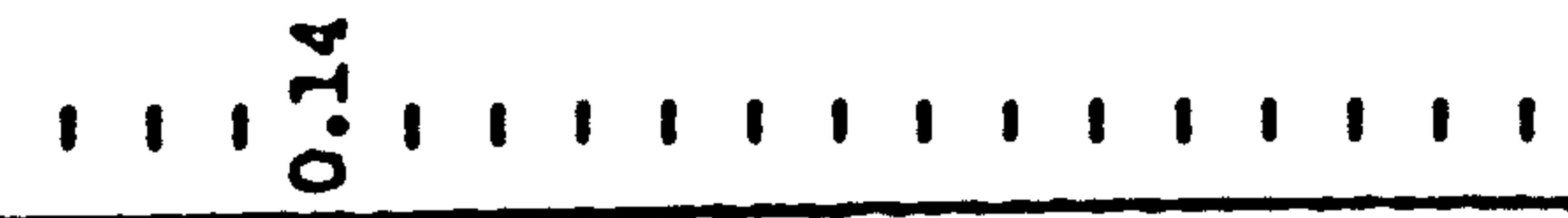 \\
\hline$\stackrel{n}{n}$ & 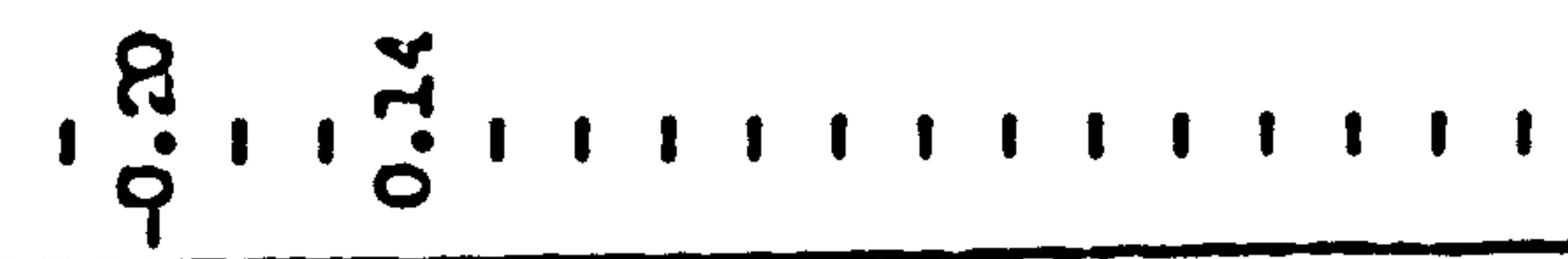 \\
\hline$\stackrel{+}{\sim}$ & 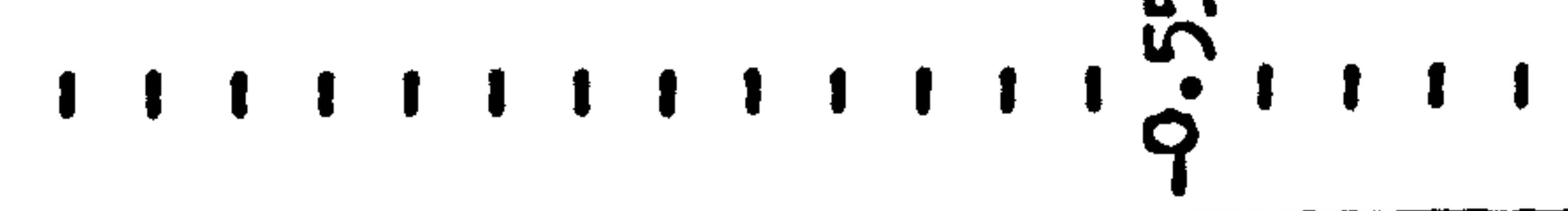 \\
\hline$\stackrel{m}{m}$ & $\begin{array}{llllllllllllllll}1 & 1 & 1 & 1 & 1 & 1 & 0 & 1 & 1 & 1 & 1 & 1 & 1 & 1 & 1 & 1\end{array}$ \\
\hline 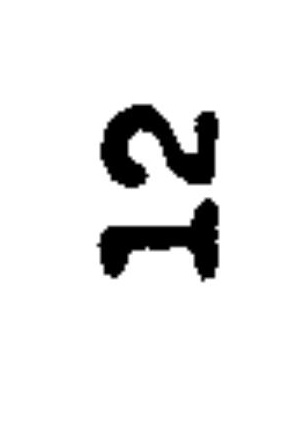 & 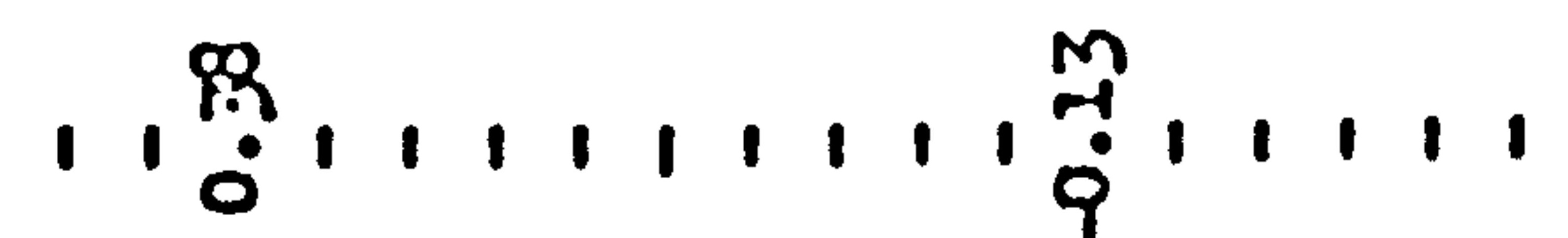 \\
\hline A & $\begin{array}{lllllllllllllllll}1 & 1 & 1 & 1 & 1 & 1 & 1 & 1 & 1 & 1 & 1 & 1 & 1 & 1 & 1 & 1 & 0 \\
\end{array}$ \\
\hline 욱 & 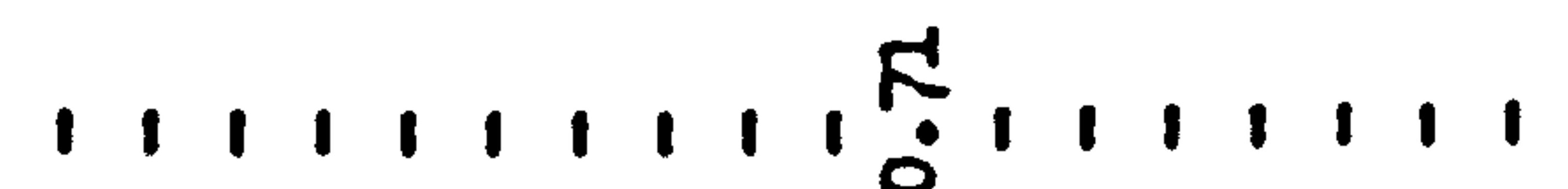 \\
\hline$a$ & 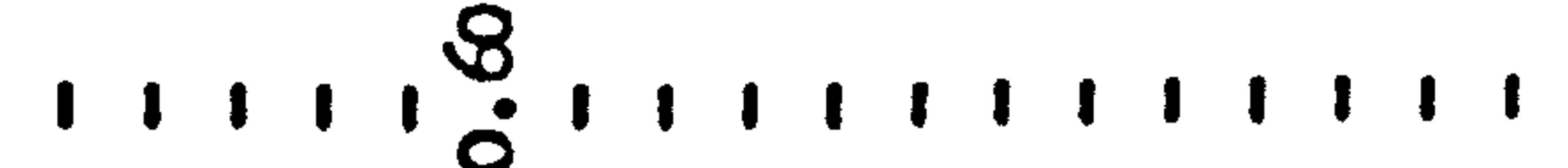 \\
\hline$\infty$ & $\begin{array}{llllllllllllllllll}1 & 1 & 1 & 1 & 1 & 1 & 1 & 1 & 1 & 1 & 1 & 1 & 1 & 1 & 0 & 1 & 1 & 1\end{array}$ \\
\hline$r$ & 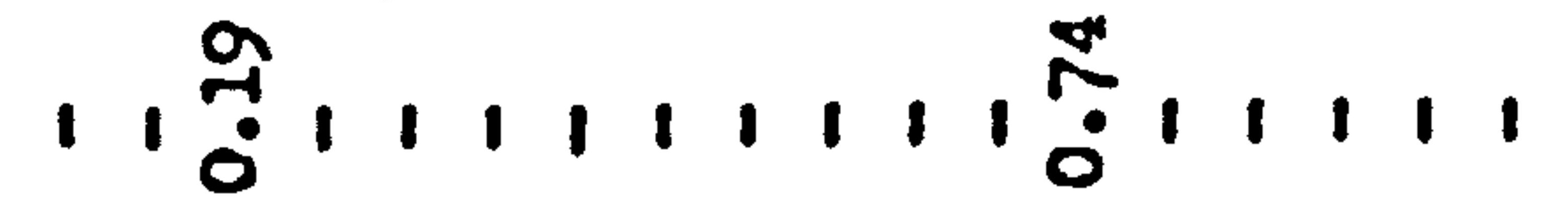 \\
\hline $\boldsymbol{0}$ & 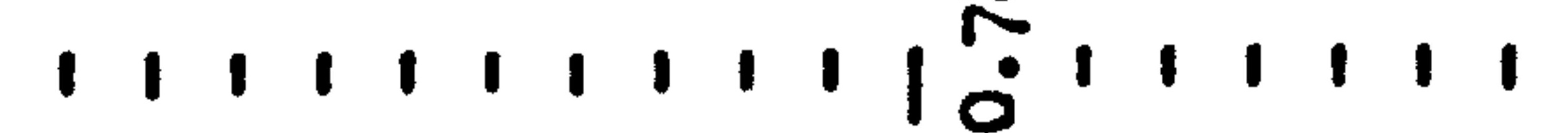 \\
\hline in & $\begin{array}{llllllllllllllllll}1 & 1 & 1 & 1 & 1 & 1 & 1 & 1 & 1 & 1 & 1 & 1 & 1 & 1 & 1 & 1 & 0 & 0 \\
\end{array}$ \\
\hline$\nabla$ & $111111111 \frac{0}{0} 11,111111$ \\
\hline$m$ & 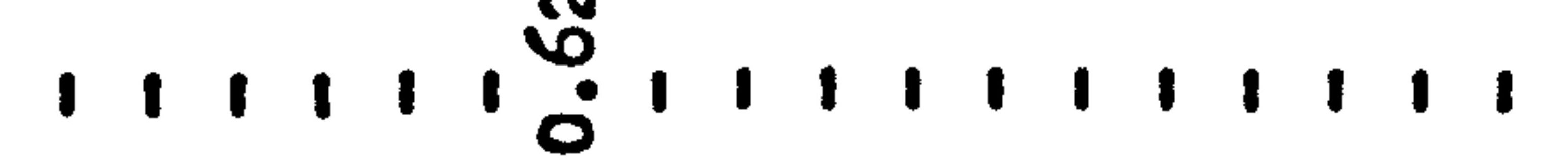 \\
\hline N & 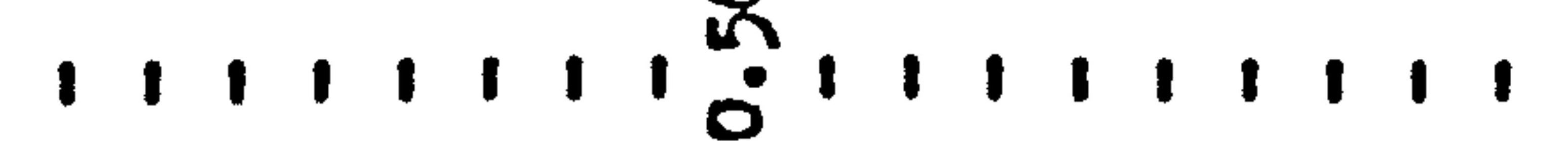 \\
\hline$r$ & 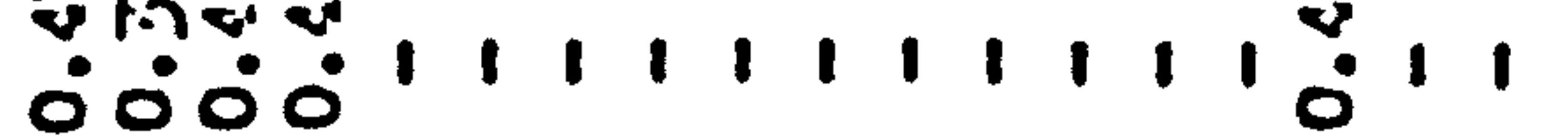 \\
\hline
\end{tabular}

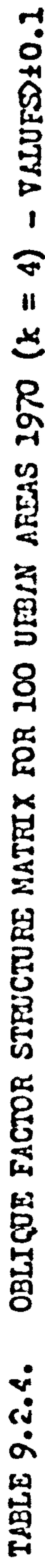

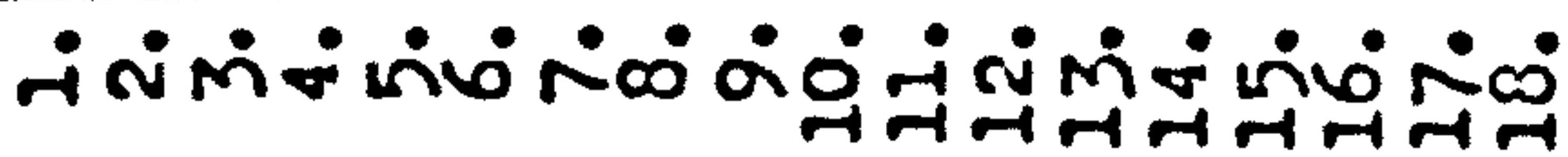


the first component therefore, the interpretation of the derived components yas based on the highest recorded ' $r$ ' value, or a combination of ' $r$ ' values in the higher components. In the Instance of the first component, however, it was found that there were five variables with high correlation coefficients, these were; Population, Area, Totel Traffic Flow, Peak Traffic Flow, ond Total Dwelling Index. It can be seen that these variables are all related to the size and trafflc flow level within any urban area. For this reason this component was interpreted as a "Size/Interaction" dimension of the urben areas, accounting for approximately $32 \%$ of the total variation within the original data matrix. Other interpretations are given in Table (9.2.5).

The importance of the promax rotation can once again be readily appreciated if the figures in Table (9.2.6) are studiec. This table shows the major correlation coefficlents between variables and derived components, following the initial P.C.A. That is, before eny rotation had teken place, and using the original factor lcadings matrix. From this teble two conclusions cen immediately be made:-

(i) Most of the derived components had reascnably high correlations with a fair number of original variables. Following rotation of the components however, this multiplicity of correlation is repleced by a severely reauced "setn of significant variables, usurlly with higher individuel correlation coefficients.

(ii) Before rotation, the interpretation of the derived components is inhibited due to the regular appesrance of certuin variables 


\begin{tabular}{|c|c|c|}
\hline FACTOR & INTERPRETATION & $\begin{array}{l}\text { NAXIMUM CCRRELATION } \\
\text { WITH VARIABLES }\end{array}$ \\
\hline 1 & INTERACTION VARIABLE & 0.472 \\
\hline 2 & SRI & 0.558 \\
\hline 3 & $\mathrm{COW}$ & 0.619 \\
\hline 4 & TCI & 0.682 \\
\hline 5 & CESI & 0.790 \\
\hline 6 & NEG.DOS & -0.782 \\
\hline 7 & SHI & 0.741 \\
\hline 8 & NEG .DVI & 0.719 \\
\hline 9 & NEG .ETT & -0.603 \\
\hline 10 & CI & 0.715 \\
\hline 11 & HTI & 0.707 \\
\hline 12 & DEN & 0.375 \\
\hline 13 & MSI & 0.556 \\
\hline 14 & $\mathrm{NEG} \cdot \mathrm{AVI}$ & -0.516 \\
\hline 15 & $\mathrm{NEG} \cdot \mathrm{AR} / \mathrm{TTF}$ & $-0.203 / 0.137$ \\
\hline 16 & PTF & 0.143 \\
\hline 17 & NEG .TIF/TDI & $-0.046 / 0.073$ \\
\hline 18 & $\mathrm{NEG}$ 。POF & -0.082 \\
\hline 19 & PPI & N.A. \\
\hline 20 & PSI & N.A. \\
\hline 21 & RI & N.A. \\
\hline 22 & $\mathrm{RDI}$ & N.A. \\
\hline
\end{tabular}

TABLE 9.2.5. INTERPRETATION OF DERIVED FACTORS (1970) 


\begin{tabular}{|c|c|c|}
\hline$\underset{\sim-1}{\infty}$ & 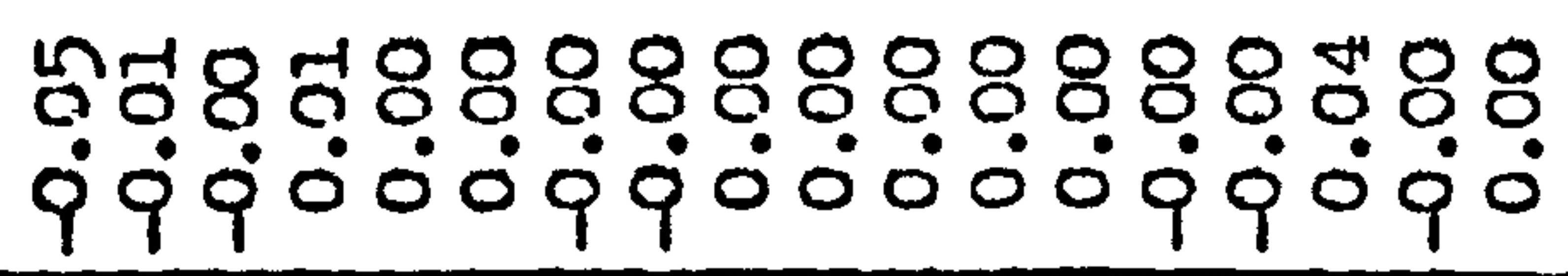 & \multirow[b]{5}{*}{ 互 } \\
\hline$\stackrel{\sim}{H}$ & 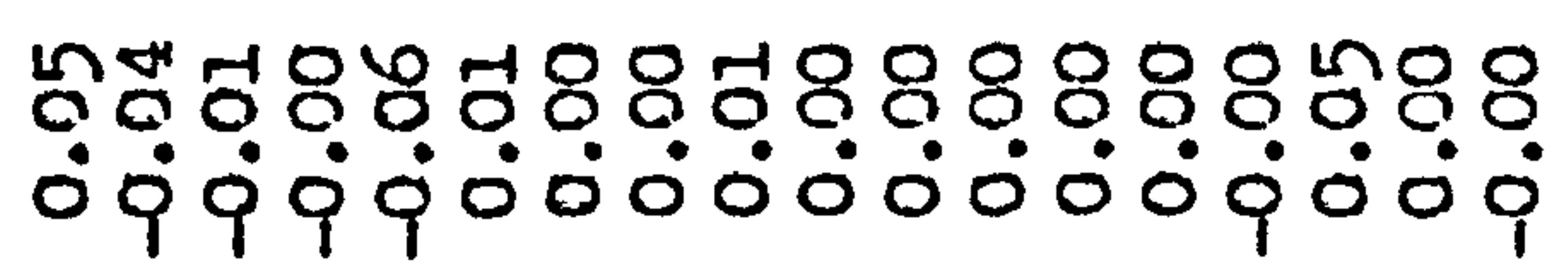 & \\
\hline$\underset{-1}{0}$ & 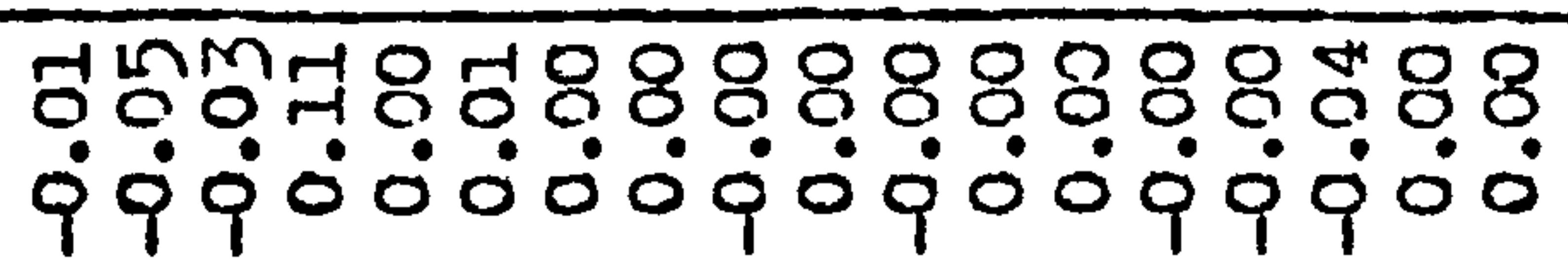 & \\
\hline$\underset{r}{n}$ & 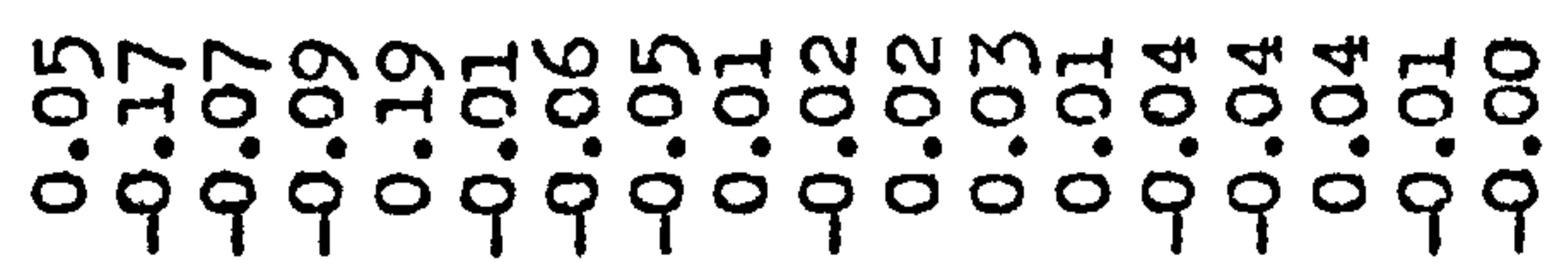 & \\
\hline$\stackrel{\sim}{\sim}$ & 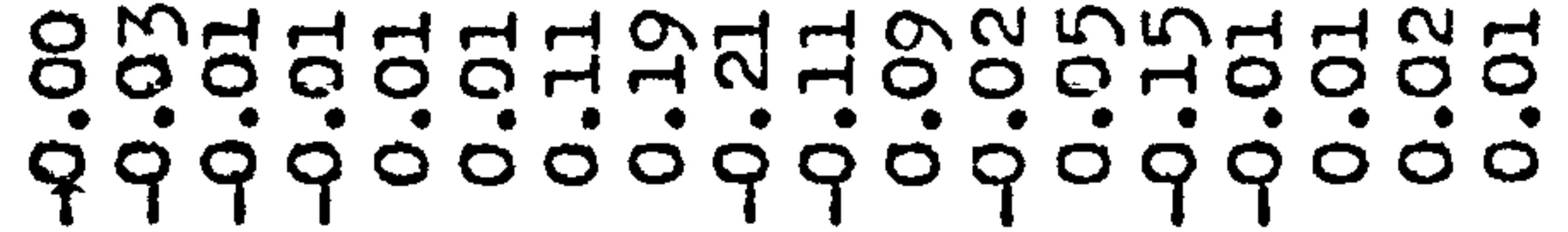 & \\
\hline$\underset{M}{M}$ & 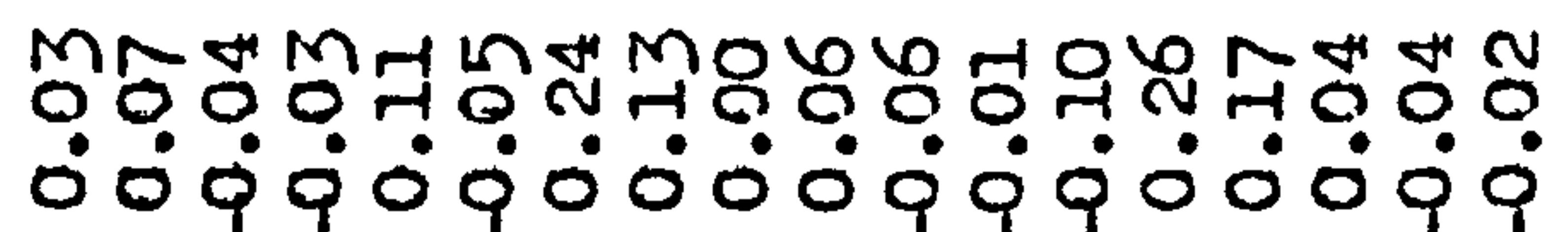 & 龺 \\
\hline$\underset{\sim}{\stackrel{N}{*}}$ & 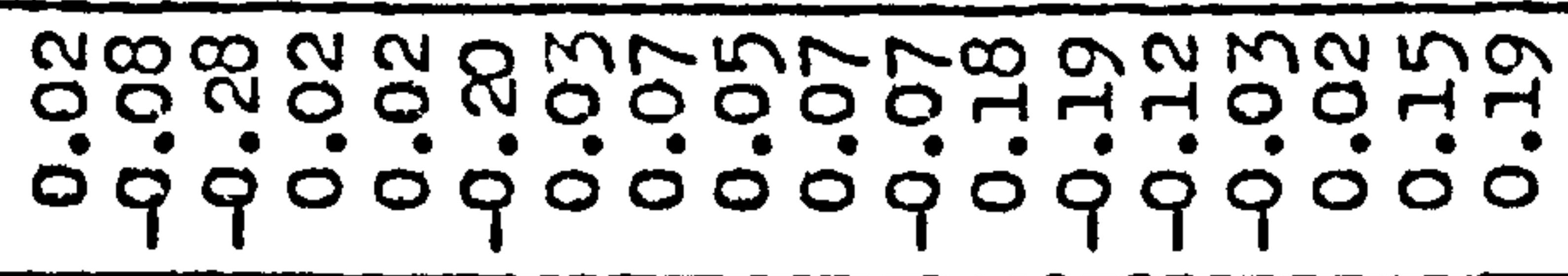 & 夏 \\
\hline$\vec{F}$ & 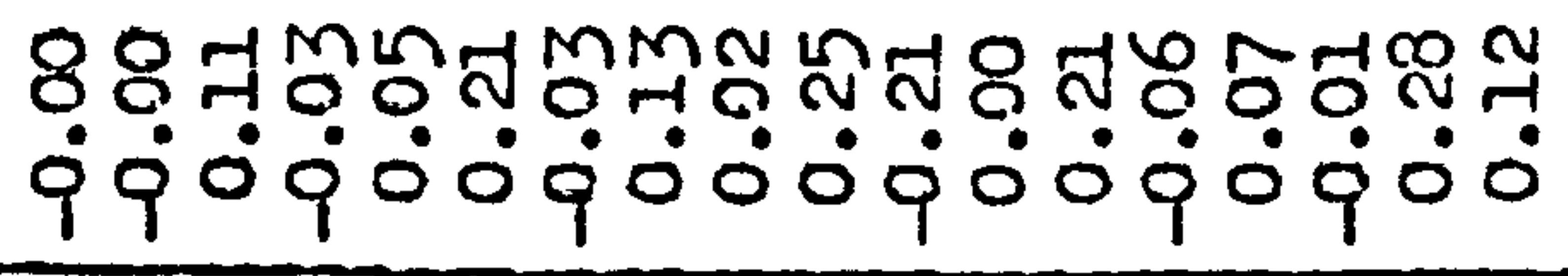 & 䁂 \\
\hline 욱 & 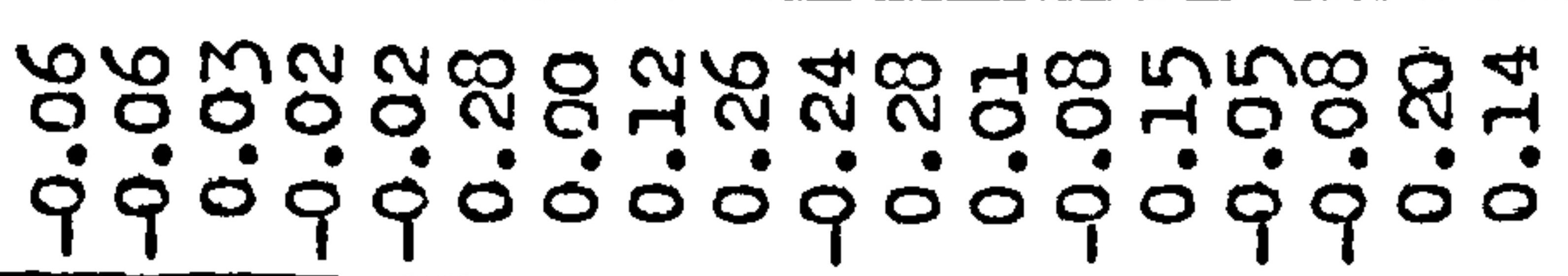 & 远 \\
\hline$a$ & 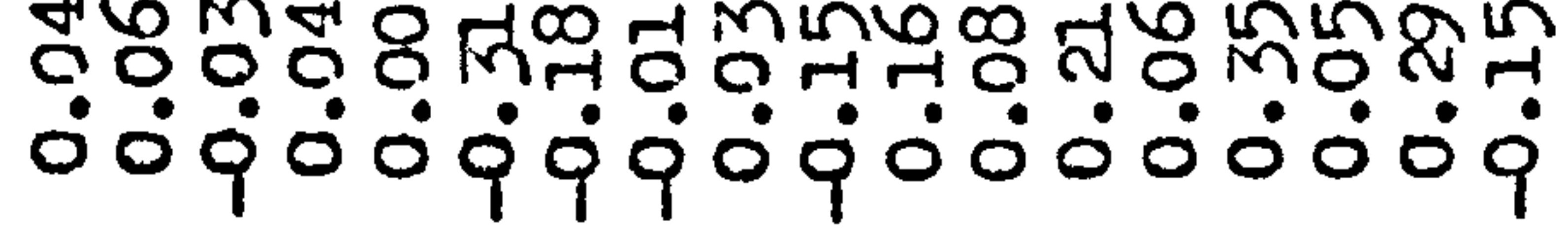 & 军 \\
\hline$\infty$ & 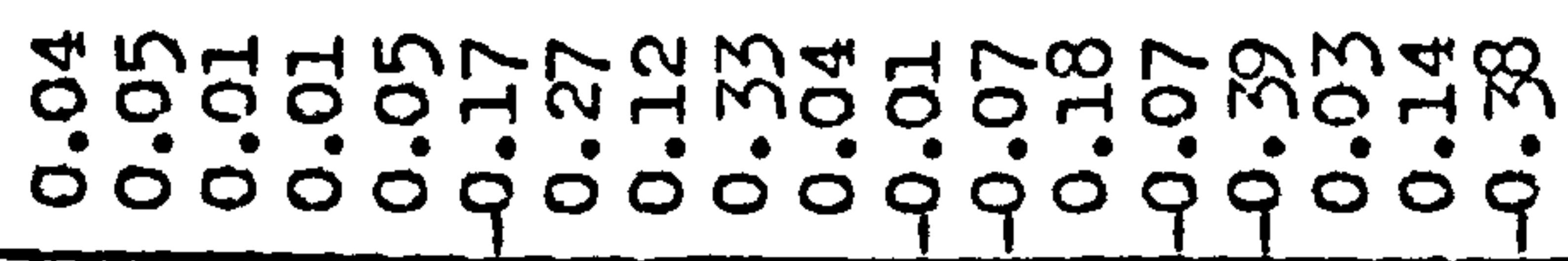 & 是 \\
\hline$r$ & 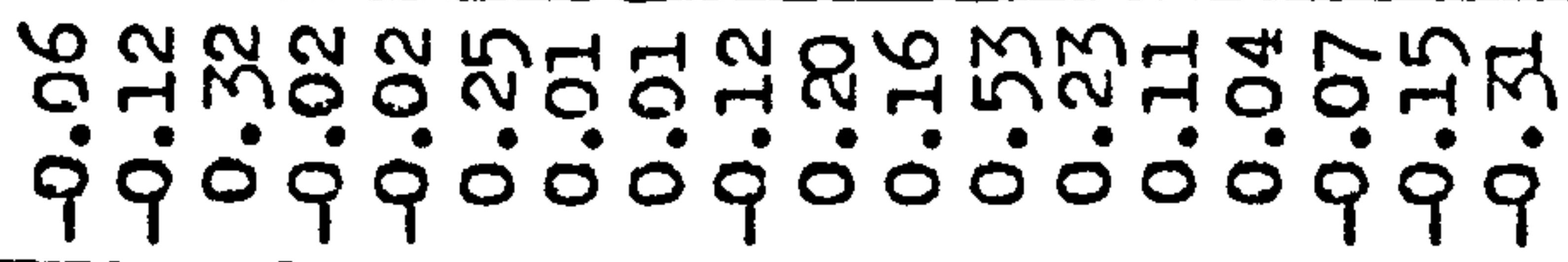 & 或 \\
\hline 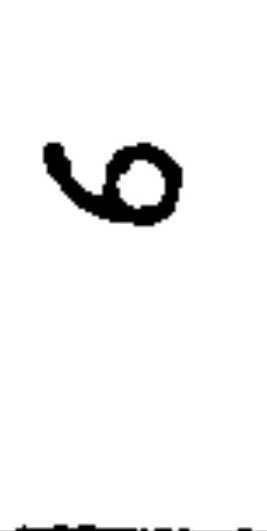 & 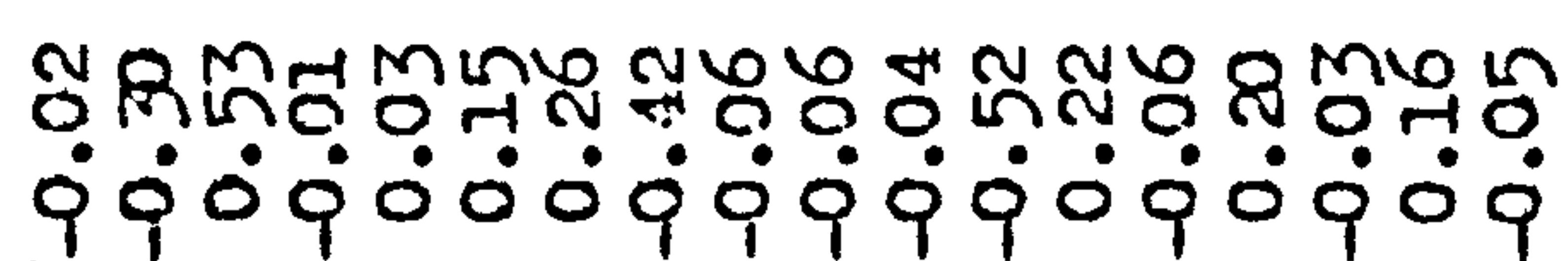 & $\dot{\dot{\varphi}}$ \\
\hline in & 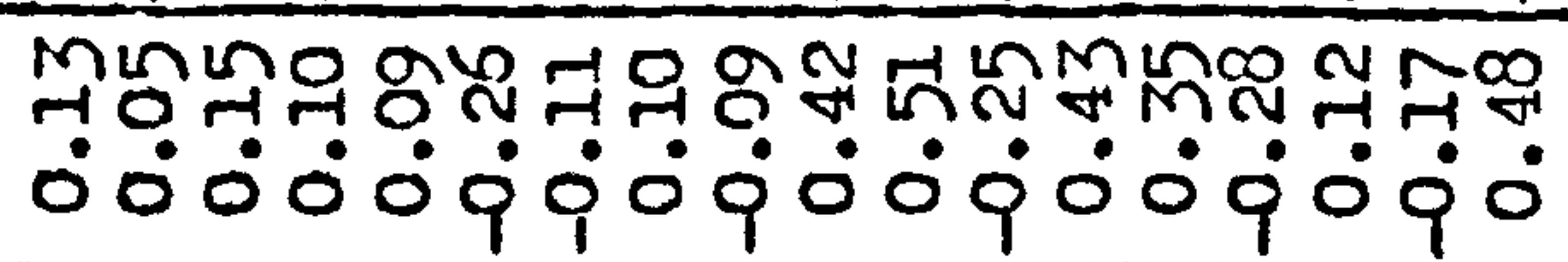 & 四 \\
\hline$\nabla$ & 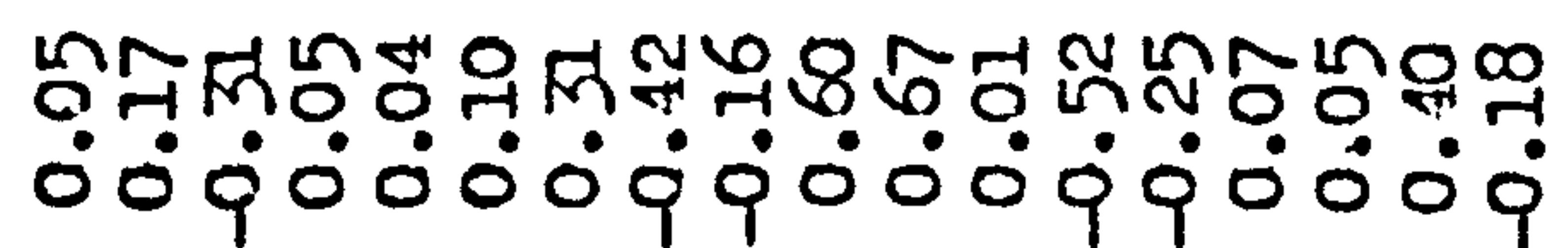 & \\
\hline$m$ & 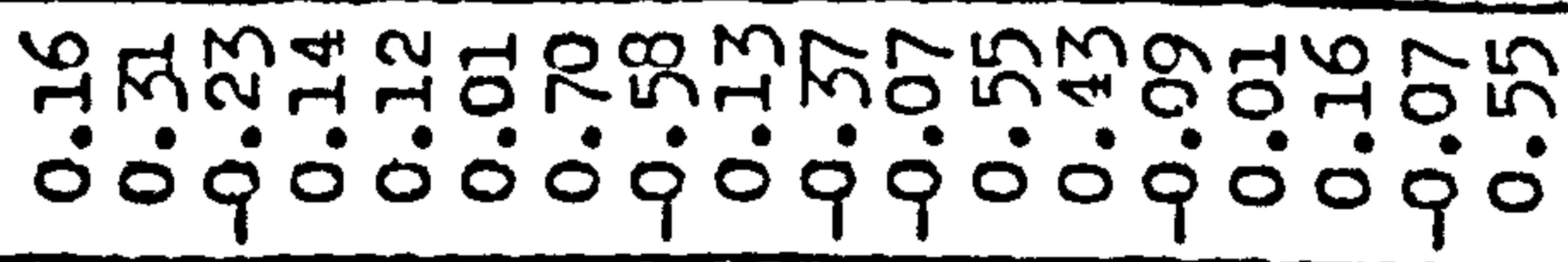 & \\
\hline N & 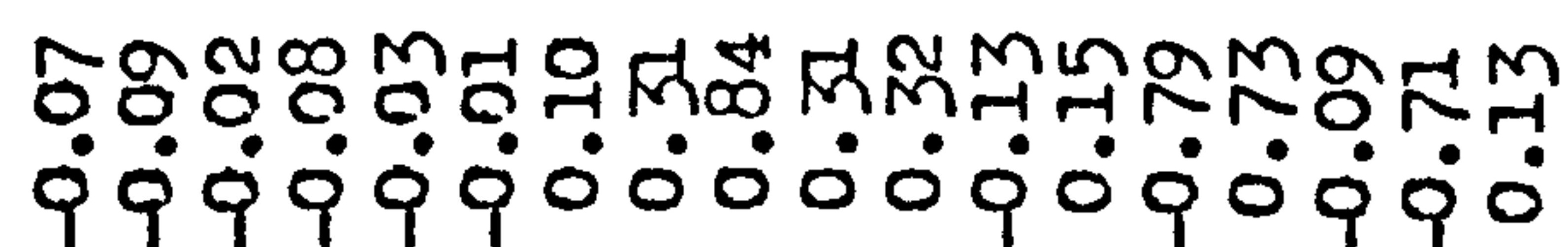 & \\
\hline$H$ & 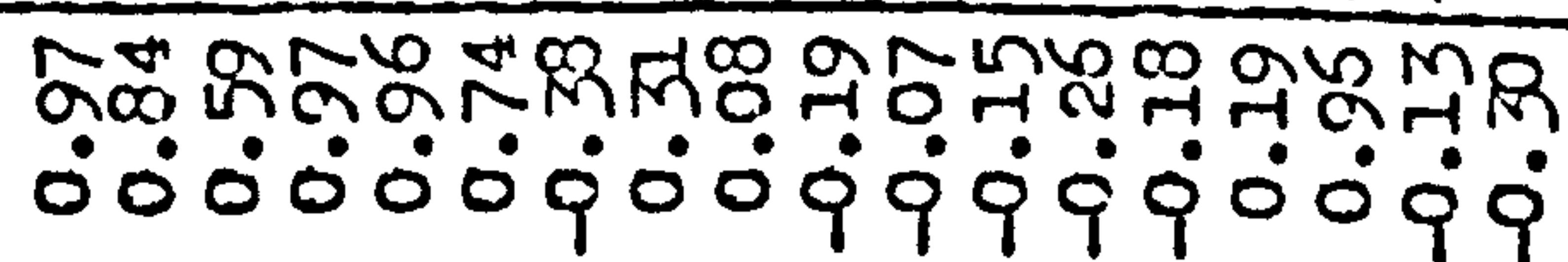 & \\
\hline
\end{tabular}


of varying significance ( $r$ value) in different components. That is, the same variables appeared in nearly all the factors, only in different renked orders. After rotation however, this problem was removed by the fact that in generel, every oblique factor was only correlated highly with one variable, and also each variable was only correlated strongly with one oblique factor, except in the higher variance rankings where there were very few correlations of any significance at all.

A further point of interest related to the P.C.A. was the degree of stability of the derived components for the time period 1966 - 1970. An independent P.C. A. was conducted on the original data matrices for each year 1966 - 1970. Yet as can be seen from Table (9.2.7), the derived components for each year were almost identical as regards; the derived eigenvalues, the percentage of total explenation and ranking of interpreted components. The degree of association between the annual interpretation of components was tested using Spearman's Rank Correlation Coefficient, which is given by the equation,

$$
r_{s}=1-\frac{6 \sum_{i=1}^{n} D_{i}^{2}}{N\left(N^{2}-1\right)}
$$

where,

$$
\begin{aligned}
D_{1}^{2}= & \text { the sum of squares of difference between } \\
& \text { any pair of renkings } \\
N= & \text { the number of components }=18
\end{aligned}
$$




\begin{tabular}{|c|c|c|c|c|c|}
\hline \multirow{2}{*}{$\begin{array}{l}\text { FACTOR } \\
\text { NUMBER }\end{array}$} & \multicolumn{5}{|c|}{ YEAR } \\
\hline & 1970 & 1969 & 1968 & 1967 & 1966 \\
\hline 1 & INTACT & INTACT & INTACT & INTACT & INTACT \\
\hline 2 & SRI & SRI & NSRI & NSRI & SWVI \\
\hline 3 & $\mathrm{COW}$ & $\mathrm{COH}$ & $\mathrm{COW}$ & NTCI & $\mathrm{NCOW}$ \\
\hline 4 & TCI & CI & CI & $\mathrm{CCW}$ & NSRI \\
\hline 5 & CHSI & SHI & SHI & SHI & CI \\
\hline 6 & NDOS & NDOS & CHSI & DOS & NLOS \\
\hline 7 & SHI & CHSI & NDOS & CHSI & CHSI \\
\hline 8 & NDVI & DEN & $\mathrm{DEN}$ & DEN & DEN \\
\hline 9 & NETT & DVI & NDVI & NDVI & NSHT \\
\hline 10 & CI & NHTI & ITI & NCI & HTI \\
\hline 11 & HTI & NTCI & TCI & $\mathrm{HTI}$ & NTCI \\
\hline 12 & DEN & ETT & NETT & ETT & ETT \\
\hline 13 & MSI & AVI & AVI & $A V I$ & AVI \\
\hline 14 & NAVI & MSI & MSI & $\mathrm{MSI}$ & MSI \\
\hline 15 & $\mathrm{NAR} / \mathrm{TTF}$ & NAR/TTP & NAR/TTF & $\mathrm{NAR} / \mathrm{TTF}$ & NAR \\
\hline 16 & PTF & PTF & PTF & NPTP & PTF \\
\hline 17 & TDI & TDI & TDI & POP & NTTP \\
\hline 18 & NPOP & NPOP & NPOP & TDI & NPOP \\
\hline 19 & FPI & PPI & PPI & PPI & PPI \\
\hline 20 & PSI & PSI & PSI & PSI & PSI \\
\hline 21 & $R I$ & $R I$ & RI & $R I$ & RI \\
\hline 22 & RDI & $R D I$ & $\mathrm{RDI}$ & $\mathrm{RDI}$ & RDI \\
\hline
\end{tabular}

INTACT $=\mathrm{POP} / \mathrm{AR} / \mathrm{PTF} / \mathrm{TTF} / \mathrm{TDI}$

TABLE 9.2.7. INTERPRETATION OF DERIVED FACTCRS 1966-1970. 
This correlation coefficient has a range of +1.0 to -1.0 , being +1.0 when the rankings are in perfect agreement, and -1.0 if they are in perfect disagreement, end zero if there is no relationship whatsoever. The correlations so calculated are given below and it can readily be seen that the lowest value is $r_{s}=+0.85$ between 1970 and 1966.

$\begin{array}{llllll} & 1970 & 1969 & 1968 & 1967 & 1966 . \\ 1970 & 1.00 & 0.87 & 0.88 & 0.96 & 0.85 \\ 1969 & & 1.00 & 0.99 & 0.90 & 0.89 \\ 1968 & & & 1.00 & 0.89 & 0.88 \\ 1967 & & & & 1.00 & 0.90 \\ 1966 & & & & & 1.00\end{array}$

Although it is only to be expected that the correlation between the two marginal years will be the lowest value calculated, the stability of the relationship can be seen by the fact that if one tests the null hypothesis that there is no linear relationship in the population, 1.e. $p=0$, using an $F$ test such that,

$$
F(1, N-2)=\frac{r^{2}}{1-r^{2}}(N-2)
$$

where $F=$ the tabled $F$ value with $I$ and $(N-2)$ degrees of - freedom, at some specified $\propto$ level. $r=$ the correlation coefficient. $N=$ the number of observations. 
the test is found to be significent even at the $99.0 \%$ level. 2

The significence of this stability of the various components over the time period 1966 - 70 is important in practical terms as well as in the ebove mentioned statistical terms. The implications are that, the urban structure, as measured by these 18 variables, has altered very little since 1966, with the same significant "dimensions" being present, and just as significent, at each time period. Once again, therefore, the resistance of the urben structure to repid and essential change appears to have been highlighted by this P.C.A. In terns of this research howerer, the static rature of the urban structure has proved very useful, since it could consequently be argued when involved in the temporal analysis, that any voriation in the significence of the various independent variables, could not be due to significent chenges in the variables themself, but rather to interaction with other factors within the road accident system, or a temporel fluctuation in the significance of that variable itself as regards road accident csusation.

The 100 sempled areas can subjectively, be disaz̃ regated in to tiro groups, county borough ereas (large burghs in Scotland) and non-county borough areas (small burghs). It can be argued that these txo groups are distinct according to the degree of responsib-

$2 F(1,16: \alpha=0.001)=16.2$

$$
\frac{r^{2}}{1-r^{2}}(N-2)=\frac{0.723}{0.277} \cdot 16=41.76
$$

Therefore since the calculated value is greater than the tabled value the $H_{0}$ can be rejected and the hypothesis accepted that $P \neq 0$ at $\alpha=0.001$ level. 


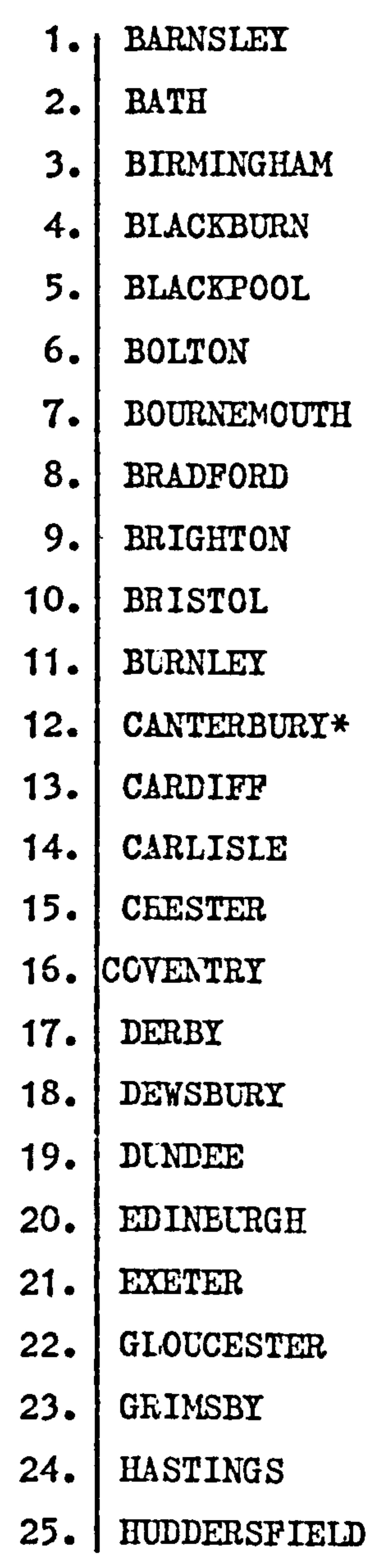

\begin{tabular}{|c|c|}
\hline 26 & IPSWICH \\
\hline 27 . & KIRKCAIDDY \\
\hline 28. & LEEEDS \\
\hline 29. & LEICESTER \\
\hline 30 & LINCCIN \\
\hline 31. & LIVERFOOL \\
\hline 32. & LUTON \\
\hline 33. & MANCEESTER \\
\hline 34. & NORWICH \\
\hline 35. & NOTTINGHAM \\
\hline 36. & OIDHAM \\
\hline 37 . & OXFORD \\
\hline 38. & PLIMOUTH \\
\hline 39. & PORTSMOUTH \\
\hline 40 & PRESTCN \\
\hline 41. & READING \\
\hline 42. & RCCEDALE \\
\hline 44. & SALFORD \\
\hline 44. & SHEFP IELD \\
\hline 45. & SOUTHAMPTON \\
\hline 46. & SOCTHEND \\
\hline 47. & STOKE \\
\hline 48. & SUNDERLAND \\
\hline 49. & SWANSEA \\
\hline 50. & WOLVERHAMPTCN \\
\hline 51. & YORK \\
\hline
\end{tabular}

TABLE 9.2.8. LIST OF 51 CCUNTT BCROUGH AREAS WITHIN THE SAMPLE 100 AREAS. 
ility they hold over their own environment. Thus in non-county boroughs, the authority which is the responsible highway authority is the relevent County Council office. For this reason, therefore, an indivicual P.C.A. was carried out upon the 5.1 county borcugh areas, for each of the years 1966 - 1970, in order to assess any differing response which may arise from the isolation of these areas. A list of the 51 areas used is shown in Table (9.2.8), whilst the basic statistics for the three groups of urben areas are show in Table (9.2.9). variable by variable for 1970. -

Before moving on to study the results of the County Borough P.C.A., it would be relevant to observe Table (9.2.9) in some more detail in order $t=$ see where the three groups differ markedly.

The first impressions from this table are the marked differences in the means of the size variables for the Ccunty Borcugh areas (CBs) and the Non-County Borough areas (NCBs). Thus just taking the population variable it can be seen that the difference between the mean values is $163,318.00$, which is over three tines larger than the original mean value $(49,998.73=\bar{X})$ for the rCBs.

Howerer, besides this expected variation in the size varisbles, there are significent differences in some of the other variable statistics, which could explain any different "response rates" for the various groups of urban areas. Using the "tn statistic it was possible to show that there was a significant difference between the $\overline{\mathrm{X}}_{\mathrm{CB}}$ and $\overline{\mathrm{X}}_{\mathrm{NCB}}$ for 12 veriables at the $\alpha=0.01$ prob- 


\begin{tabular}{|c|c|c|c|c|c|c|}
\hline \multirow{2}{*}{ VARS. } & \multicolumn{2}{|c|}{ ALL } & \multicolumn{2}{|c|}{ CBS } & \multicolumn{2}{|c|}{ NCBS } \\
\hline & $\overline{\bar{x}}$ & 6 & $\bar{x}$ & 6 & $\overline{\bar{x}}$ & 6 \\
\hline 1. $\mathrm{POP}^{*}$ & 133199.11 & 160016.73 & 213316.73 & 191821.25 & 49998.73 & 25031.84 \\
\hline 2. $A R^{*}$ & 10810.32 & 9268.16 & 14874.10 & 10644.63 & 6580.67 & 4829.91 \\
\hline 3. $\operatorname{DEN}^{*}$ & 11.56 & 4.58 & 13.78 & 4.17 & 9.25 & 3.80 \\
\hline 4. $\operatorname{PTF}^{*}$ & 6269.83 & 3970.16 & 8655.49 & 4263.11 & 3786.80 & 1112.28 \\
\hline 5. $\mathrm{TIF}^{*}$ & 405194.04 & 530277.68 & 653619.57 & 649785.24 & 146628.69 & 79553.56 \\
\hline 6. $\operatorname{ETT}^{*}$ & 21.71 & 16.69 & 29.25 & $17 \cdot 72$ & 13.87 & 11.14 \\
\hline 7. $\mathrm{MST}^{*}$ & 2.59 & 0.16 & 2.64 & 0.13 & 2.54 & 0.17 \\
\hline 8. SRI & 1.94 & 0.05 & 1.93 & 0.05 & 1.94 & 0.06 \\
\hline 9. TCI & 0.18 & 0.06 & 0.18 & 0.06 & 0.19 & 0.06 \\
\hline 10. $\mathrm{CI}$ & 0.90 & 0.07 & 0.89 & 0.06 & 0.90 & 0.07 \\
\hline 11. DOS & 8.11 & 8.24 & 6.69 & 4.25 & 9.58 & 10.81 \\
\hline 12. $\mathrm{SHI}^{*}$ & 9.06 & 24.28 & 2.32 & 0.94 & 16.09 & 33.41 \\
\hline 13. AVI & 0.61 & 0.06 & 0.61 & 0.04 & 0.61 & 0.07 \\
\hline 14. DVI & 0.18 & 0.03 & 0.18 & 0.03 & 0.18 & 0.03 \\
\hline 15. $\operatorname{TDI}^{*}$ & 42997.58 & 50611.27 & 68756.59 & 60212.20 & 16187.18 & 8231.25 \\
\hline 16. HTI & 2.51 & 2.22 & 2.42 & $1.4 \epsilon$ & 2.59 & 2.83 \\
\hline 17. $\mathrm{CESI}^{*}$ & 11.29 & 1.71 & 10.84 & 1.03 & 11.75 & 2.11 \\
\hline 18. PPI & 20.83 & 6.08 & 21.63 & 6.79 & 19.95 & 5.17 \\
\hline 19. PSI & 0.86 & 13.16 & 2.00 & 15.29 & -0.32 & 10.51 \\
\hline 20. RI & 31.07 & 6.70 & 31.65 & 7.23 & 30.46 & 6.13 \\
\hline 21. $\mathrm{RDI}^{*}$ & 18.03 & 6.51 & 20.72 & 6.02 & 15.23 & 5.84 \\
\hline 22. $\mathrm{COW}^{*}$ & 0.48 & 0.21 & 0.42 & 0.09 & 0.54 & 0.13 \\
\hline 23. $\mathrm{POP}$ & 4.93 & 0.39 & 5.20 & 0.32 & 4.65 & 0.21 \\
\hline 24. SRI & 0.29 & 0.01 & 0.29 & 0.01 & 0.29 & 0.01 \\
\hline 25. CHSI & 1.05 & 0.06 & 1.03 & 0.04 & 1.06 & 0.07 \\
\hline 26. SHI & 0.57 & 0.44 & 0.33 & 0.18 & 0.81 & 0.49 \\
\hline 27. DCS & 0.76 & 0.44 & 0.76 & 0.22 & 0.76 & 0.59 \\
\hline 28. DVI & -0.75 & 0.07 & -0.75 & 0.06 & -0.76 & 0.08 \\
\hline 29. AVI & -0.22 & 0.04 & -0.22 & 0.03 & -0.22 & 0.05 \\
\hline 30. HTI & 0.26 & 0.40 & 0.33 & 0.22 & 0.18 & 0.52 \\
\hline 31. PPI & 1.30 & 0.12 & 1.32 & 0.12 & 1.29 & 0.12 \\
\hline 32. PSI & 0.36 & 0.56 & 0.92 & 0.61 & 0.33 & 0.51 \\
\hline
\end{tabular}

* INDICATES SIGNIFICANT DIFFERENCE BETWETEN $\overline{\mathrm{X}} \mathrm{CB}$ and $\overline{\mathrm{X} N C B}$ $\alpha=0.01$ (USING ' $T$ ' STATISTIC)

TABLE 9.2.9. TEE BASIC STATISTICS FOR THE 22 INDEFENDENT VARIABLES DISAGGREGATEC ACCCRDING TO TYPE OF URBAN AREA, AND INCLUDING TEE TRANSFORMED (LOGIO) VARIABLES. 
ability level. 3 of these variables perhaps the more importent ones are, Density, Degree of Through Treffic, Mean Social Index and Car Ormership.

The variable with the greatest statistically significent difference between $\bar{X}_{C B}$ and $\bar{X}_{N C B}$ was the density variable. As can be seen from the table $\overline{\mathrm{X}}_{\mathrm{CB}}=13.78$ conpared to 9.25 for $\mathrm{X}_{\mathrm{NCB}}$, Giving a calculated $t$ value of $t(98) \alpha=0.01=7.12$. Therefore, it can be statistically assuraed that non-county boroughs have a much lover density of population than the county borough areas. Now this is of some relevence, since this research has tried to limit its observations and enalysis to solely "urban areas," because the difference between rural accident patterns and urben acciaent patterns has often been emphasised in the relevent literature. For this reason it is necessarg to observe the degree of response for this variable between the different groups, when introduced into the regression model, so as not to bias or inveliagte the findings of the major regressicn analyses, when using the full 100 sampled urben areas.

A further variable which exhibits a similar divergence between the tr:o groups is the Degree of Car Omership variable, $\left(t_{(98)} \alpha=0.01=\right.$ 5.40). From the table it cen be seen that the IrCBs have a significantly higher level of car ownership than the CEs vihich would presumably affect the level of trafflc and vehicle mileage within these groups. Thus once agein this variable has to be considered carefully when introduced into the regression model.

3 The significence velue for $t(98) \propto=0.01$ is 2.62 . 
Another variable which has to be treated with considerable caro is the one of Estimated Through Traffic $\left(t_{(93)} \propto=0.01=5.23\right)$. It will be noted that the level of through traffic in the NCBs is considerably lower then in the CB areas. Obviously if the impact of through traffic upon the level of road accidents in eny urban area, is as importent as hypothesised, then once again this difference between the two groups should be appreciated and the results modified accordingly.

Before leaving this line of argunent one further variable which ought to be elucidated further is the Change in Housing Stock Index. Once again this variable is shom to be statistically higher for NCBS $(t(98) \propto=0.01=2.72)$ and this could be importent in one or two ways, especially as regards the temporal enalysis. This higher value for the NCBs could imply one of two hypotheses,

1) That the NCB urban areas are groving at a more rapio rate than the $C B$ areas.

2) That because of the lower densities sho:m to exist in these NCB aress, these areus can nodify their urban structure to neet present needs, at a much faster rate. That is, the response in these NCB aress as regards their urben structure systen, is much higher and quicker in meeting the deteriorating standards of the road traffic and accident systens, then in the $C B$ areas. If this is true one would expect tine NCB areas to have a slower roed accideat growth rate, then the $C B$ areas, if all other variables are held constant. This point will be left until later however, 
when the results of the teinoral analysis are presented in some more detail.

Before the original data matrix for the CB areas wos modified through the P.C.A., three additional variables were added wich were only available for these aress. These variables were; an Ethnic Index, Vehicle Registration Index, and the Road Density Index.

\section{1) ETHIIC INDEX}

Faniliarity with an area is a factor generally accepted as helping to reduce road accidents. Where unfaniliarity exists, and especially where it is exaggerated by different habits and custons, this can often significently affect the level of road accidents in en urban area. Several studies in the USA have tentatively concluded that as there is a different road accident pattem between the sexes, so there may be betireen the races, (e.g. Colton et al 1963). Therefore it was thought reasonable to introduce an ethnic index which would attenot to relate the

level of the innigrant $t^{4}$ population onthin an urbsin area, to the total population of that area. The data for this index was obtained from the 1956 Sample Census Feturns (ifigration Tables) The index is defined as,

$$
E_{i}=\frac{I_{m i}}{\left(P_{i} / 1000\right)}
$$

where, $\quad E_{1}=$ the ethnic index for area $i$

4 An innigrant is defined as belng any person living in tie Britisin Isles who was not born there. 


$$
\begin{aligned}
& I_{m i}=\text { the imnigrant population for area } i . \\
& P_{i}=\text { the total population of area } i
\end{aligned}
$$

\section{2) VEHICLE REGISTRATION INDEX}

This index was introduced simply as a supplenent to the traffic variables and the degree of car ownership. The absolute level of the number of motor-vehicles registered for each urban area was the value used. The data was obtained from the annual publication of the Ministry of Transport, "Highiay Statistics."

\section{3) FOED DENSTTY IYDEX 5}

This index is the sane one as described previously in the Data Chapter. (See page 124 ).

The mean and standard deviation of these variables for the $51 \mathrm{CB}$ areas are given below for 1970.

\begin{tabular}{rrr} 
& \multicolumn{1}{c}{} & $\sigma x$ \\
EI & 33.34 & 17.17 \\
VRI & 52510.00 & 43022.93 \\
RDI & 20.72 & 6.02
\end{tabular}

When the original date matrix for the CB areas was subjected to the P.C.A., there were 51 cases and 21 veriables. The results of this analysis are shoun in a comparable form to those for the full 100 urben areas, in Tables (9.2.10) to (9.2.14). 


\begin{tabular}{|c|c|c|}
\hline $\begin{array}{l}\text { CCMPONEWT } \\
\text { NLNBER }\end{array}$ & $\begin{array}{l}\text { CCNFONENT } \\
\text { EIGENVALUE }\end{array}$ & $\begin{array}{l}\text { CUMULATIVE } \\
\text { EXPLANATION }\end{array}$ \\
\hline 1 & 6.879 & 32.76 \\
\hline 2 & 3.572 & 49.76 \\
\hline 3 & 2.534 & 61.83 \\
\hline 4 & 1.596 & 69.43 \\
\hline 5 & 1.419 & 76.19 \\
\hline 6 & 1.033 & 81.11 \\
\hline 7 & 0.866 & 85.24 \\
\hline 8 & 0.681 & 88.48 \\
\hline 9 & 0.506 & 90.89 \\
\hline 10 & 0.466 & 93.11 \\
\hline 11 & 0.428 & 95.14 \\
\hline 12 & 0.330 & 96.71 \\
\hline 13 & 0.242 & 97.87 \\
\hline 14 & 0.168 & 98.67 \\
\hline 15 & 0.115 & 99.22 \\
\hline 16 & 0.068 & 99.54 \\
\hline 17 & 0.057 & 99.81 \\
\hline 18 & 0.020 & 99.91 \\
\hline 19 & 0.013 & 99.97 \\
\hline 20 & 0.004 & 99.99 \\
\hline 21 & 0.003 & 100.00 \\
\hline
\end{tabular}

TABLE 9.2.10 THE VARIANCE RANKING FOR THE 51 COUNTI BOROUGH AREAS 1970. 


\begin{tabular}{|c|c|}
\hline $\bar{N}$ & $\stackrel{1}{\circ}$ \\
\hline i & $\stackrel{\substack{+: \\
\hdashline}}{0}$ \\
\hline$q$ & \begin{tabular}{lll}
8 & 0 \\
0 & 0 \\
\hdashline & 0 \\
$i$ & 0 \\
$i$
\end{tabular} \\
\hline$\stackrel{\infty}{\stackrel{0}{2}}$ & 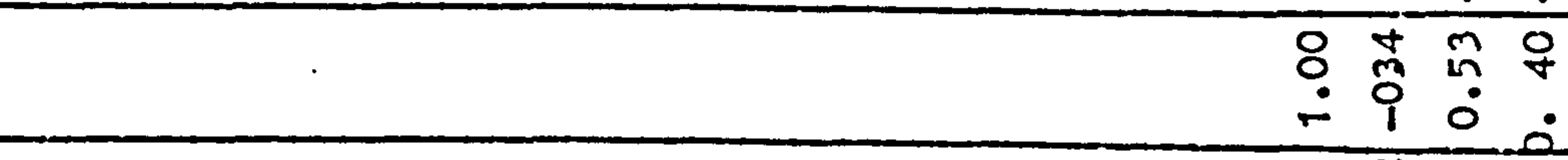 \\
\hline 5 & 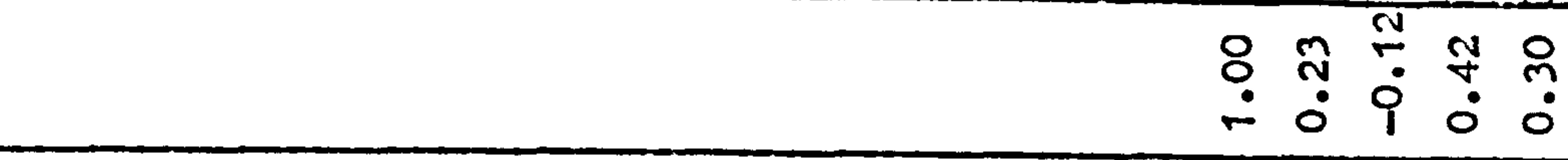 \\
\hline$\stackrel{\circ}{\circ}$ & 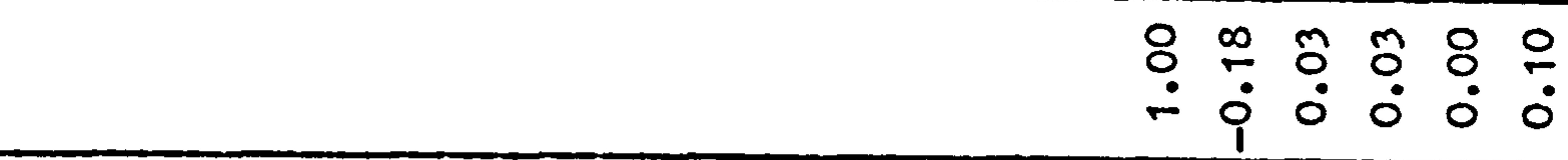 \\
\hline$\stackrel{n}{n}$ & 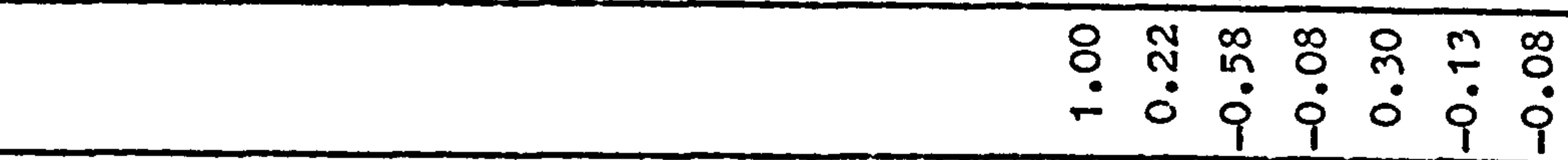 \\
\hline \pm & 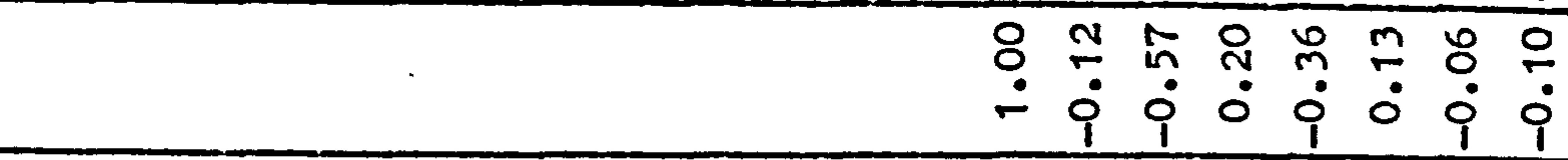 \\
\hline 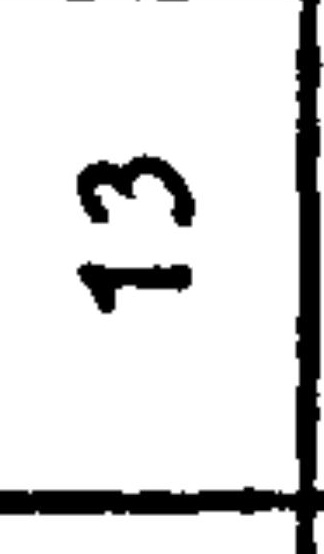 & 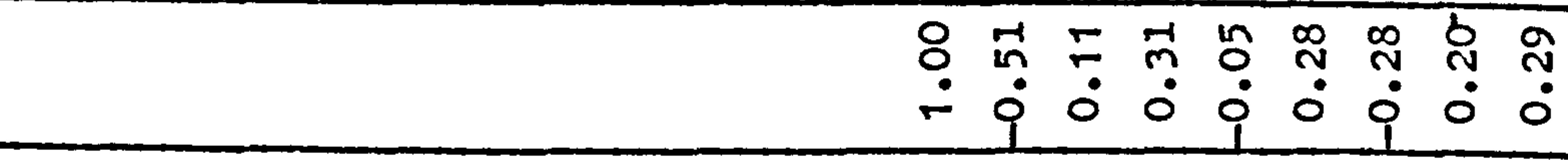 \\
\hline I & 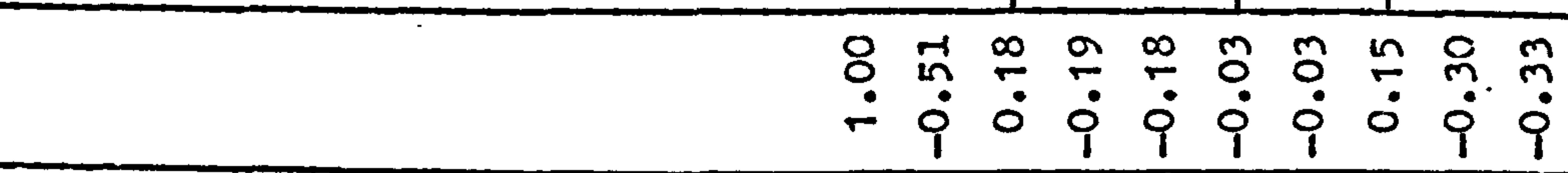 \\
\hline 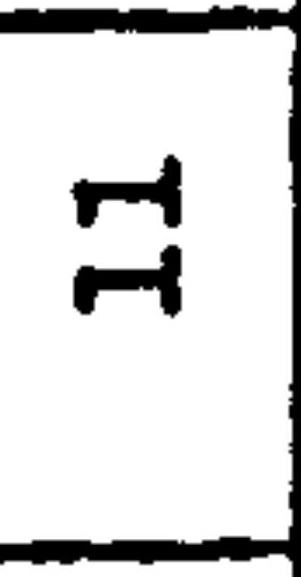 & 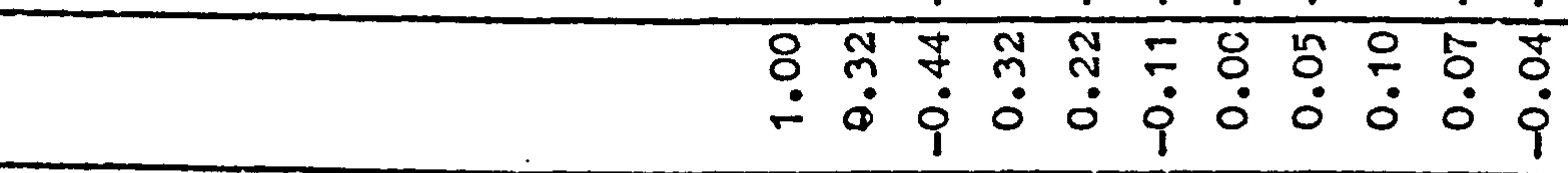 \\
\hline 음 & 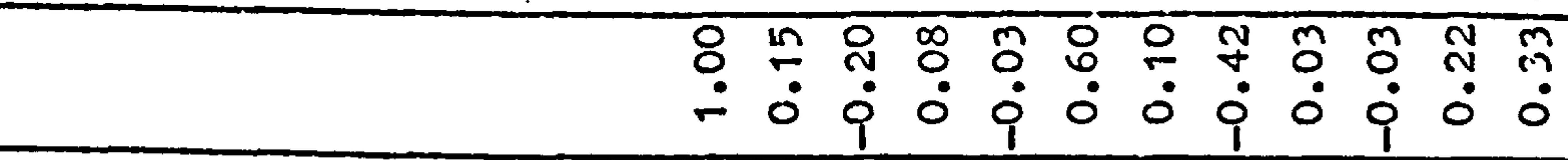 \\
\hline$\sigma$ & 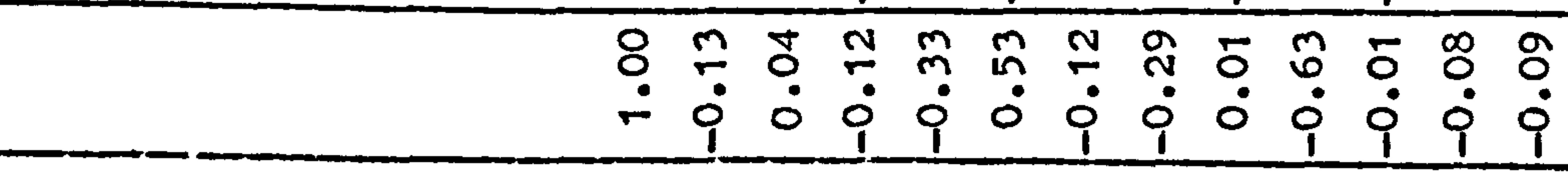 \\
\hline$\infty$ & 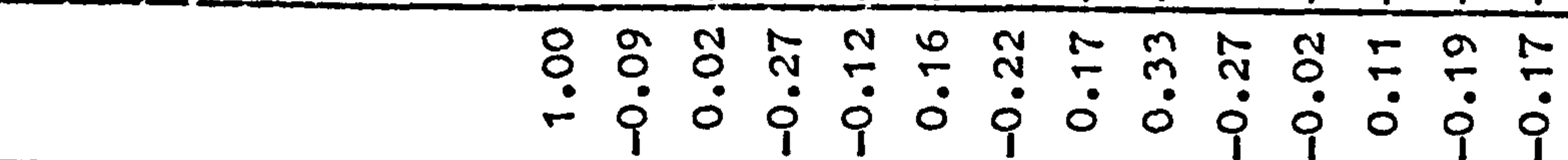 \\
\hline$r$ & 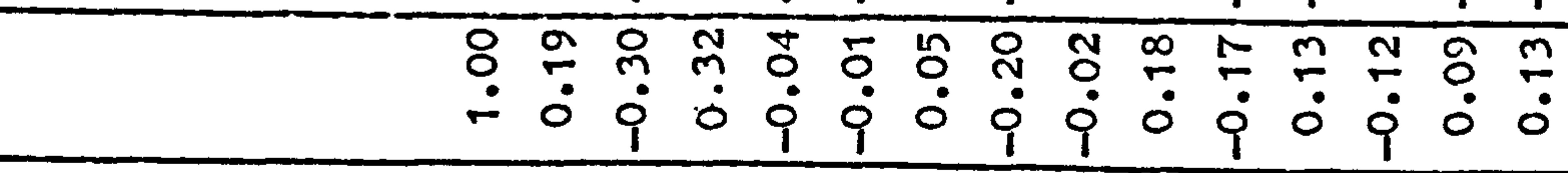 \\
\hline 0 & 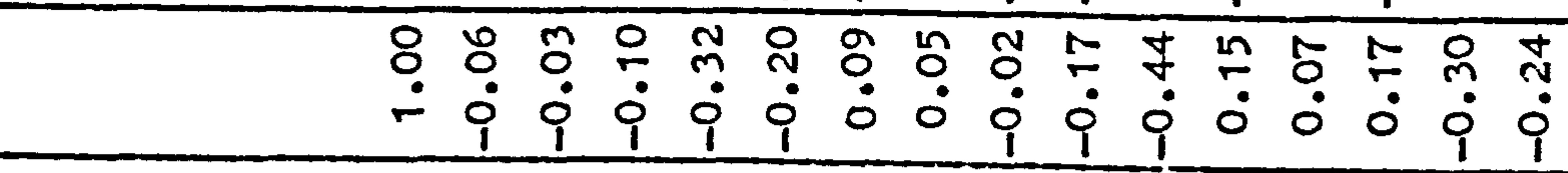 \\
\hline in & 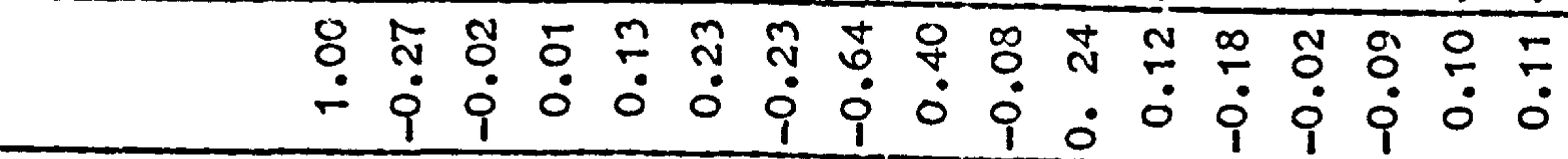 \\
\hline$\checkmark$ & 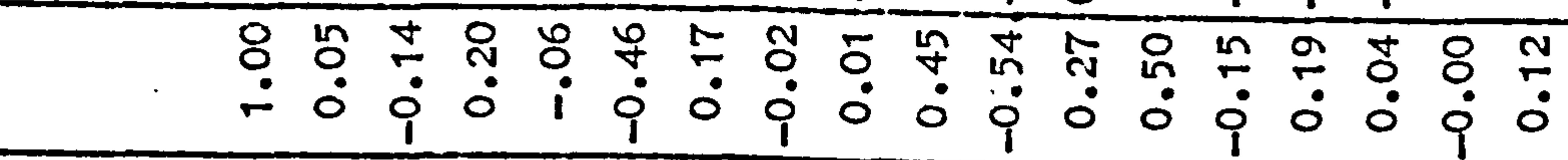 \\
\hline m & 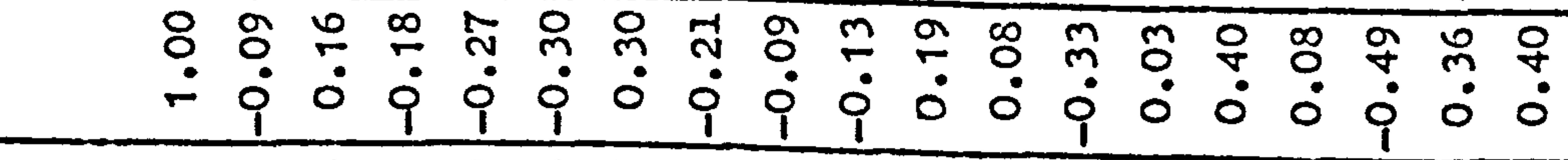 \\
\hline N & 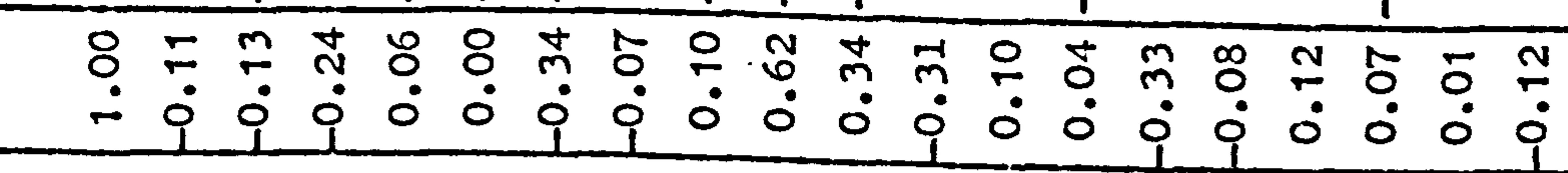 \\
\hline- & 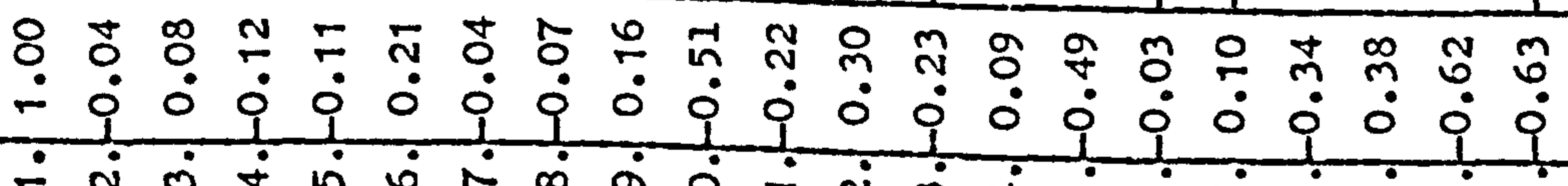 \\
\hline
\end{tabular}




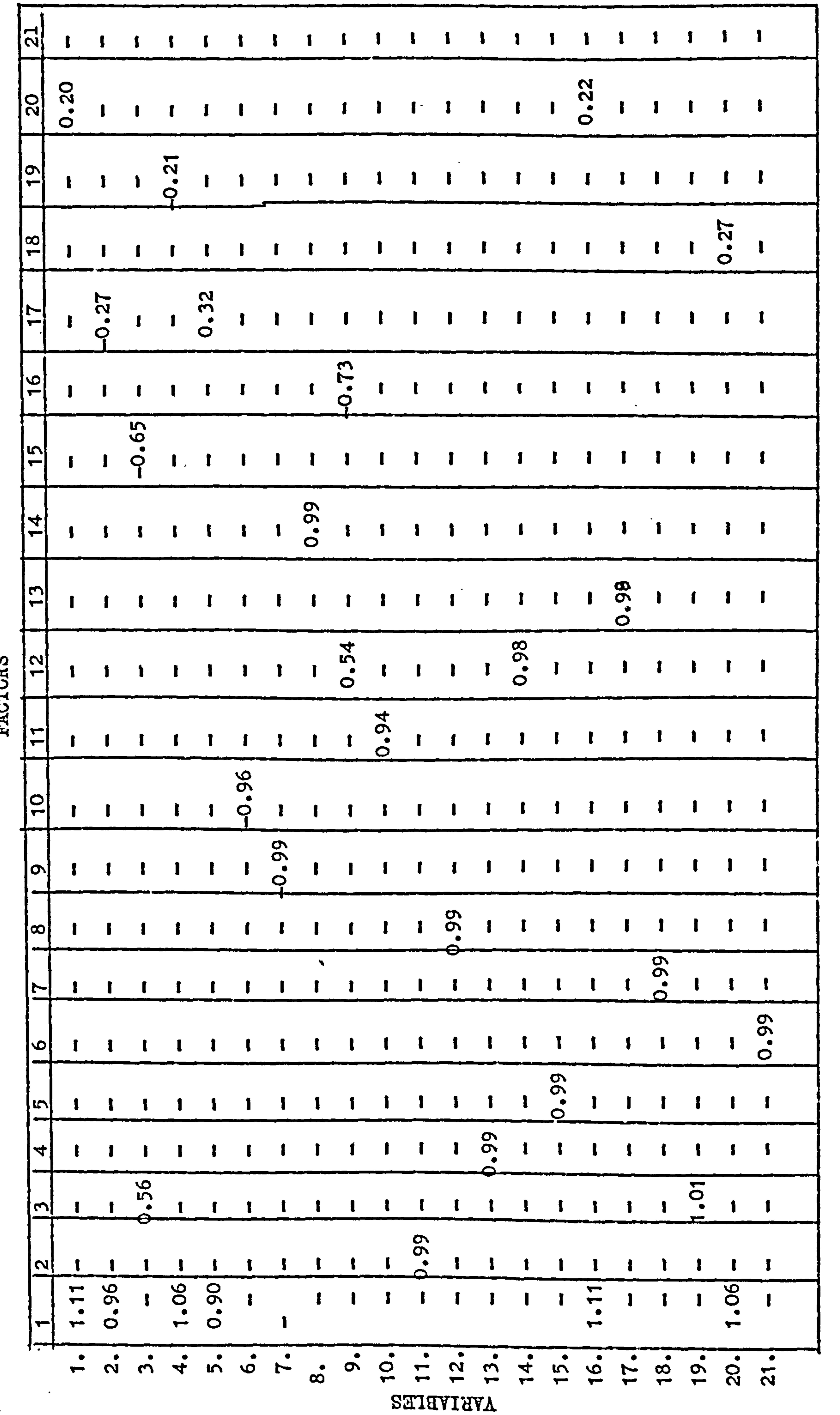

197 


\begin{tabular}{|c|c|c|c|c|c|c|c|c|c|c|c|c|c|c|c|c|c|c|c|c|}
\hline ㄱ. & 11 & 1 & 1 & 1 & 1 & 1 & 1 & 1 & 1 & 1 & I & I & I & I & & & & I & 1 & 1 \\
\hline 이 & $\begin{array}{ll}5 & 1 \\
\dot{0} & \end{array}$ & 1 & 1 & 1 & 1 & 1 & 1 & 1 & 1 & 1 & I & 1 & I & I & & 1 & I & 1 & 1 & 1 \\
\hline$a$ & 11 & 1 & 웅 & 1 & 1 & 1 & 1 & 1 & I & 1 & 1 & 1 & I & 1 & & 1 & I & 1 & 1 & I \\
\hline$\stackrel{\infty}{\infty}$ & 11 & 1 & I & 1 & 1 & I & I & 1 & I & 1 & 1 & 1 & I & I & & 1 & 1 & 1 & I & $\frac{t}{0}$ \\
\hline 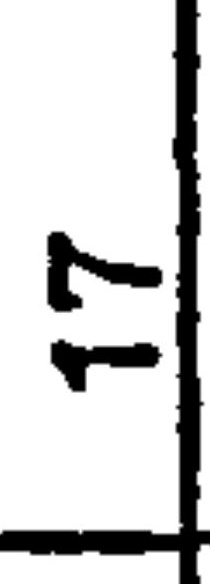 & $1 \stackrel{ \pm}{0}$ & 1 & 1 & $\stackrel{0}{0}$ & 1 & 1 & I & 1 & 1 & 1 & I & 1 & i & 1 & & I & 1 & 1 & 1 & 1 \\
\hline 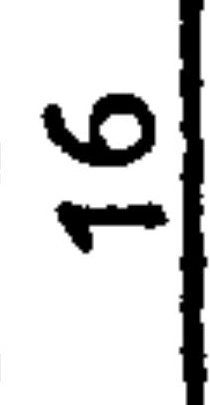 & 11 & 1 & 1 & 1 & 1 & 1 & I & 8 & I & 1 & 1 & 1 & 1 & I & & 1 & 1 & 1 & 1 & 1 \\
\hline$\stackrel{n}{=}$ & 11 & ì & 1 & 1 & 1 & 1 & 1 & 1 & I & 1 & I & 1 & I & 1 & & I & 1 & 1 & 1 & 1 \\
\hline \pm & 11 & 1 & 1 & 1 & 1 & 1 & in & 1 & 1 & I & I & I & I & 1 & & I & 1 & 1 & 1 & 1 \\
\hline$m$ & 11 & 1 & 1 & 1 & 1 & 1 & 1 & 1 & 1 & 1 & I & 1 & I & 1 & & 1 & 1 & 1 & 1 & I \\
\hline 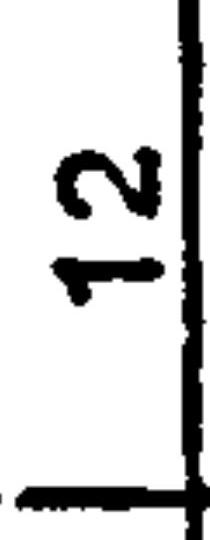 & 11 & 1 & 1 & 1 & 1 & 1 & 1 & c & 1 & 1 & I & I & $\begin{array}{l}\text { nn } \\
\text { ? } \\
\text { i }\end{array}$ & 1 & & $\hat{\tilde{\beta}}$ & I & 1 & 1 & I \\
\hline$=$ & 11 & 1 & 1 & 1 & 1 & 1 & I & , & ڤే & 1 & I & I & 1 & 1 & & 1 & 1 & 1 & 1 & 1 \\
\hline 의 & 11 & 1 & 1 & 1 & in & 1 & 1 & & 1 & 1 & I & 1 & I & I & & I & 1 & 1 & 1 & 1 \\
\hline a) & 11 & 1 & 1 & 1 & 1 & : & I & & 1 & 1 & 1 & I & 1 & 1 & & 1 & 1 & 1 & 1 & I \\
\hline$\infty$ & 11 & 1 & 1 & 1 & 1 & I & 1 & & 1 & I & $\stackrel{N}{N}$ & 1 & 1 & 1 & & 1 & 1 & 1 & 1 & 1 \\
\hline- & $\begin{array}{ll}1 & 1\end{array}$ & 1 & 1 & I & I & I & I & & 1 & I & I & 1 & I & 1 & & 1 & : & 1 & 1 & 1 \\
\hline$\omega$ & 11 & 1 & 1 & 1 & 1 & I & 1 & & 1 & I & 1 & I & I & 1 & & I & 1 & 1 & 1 & $\begin{array}{l}\tilde{n} \\
\dot{0}\end{array}$ \\
\hline in & 111 & 1 & I & 1 & 1 & I & 1 & & 1 & I & 1 & I & 1 & 8 & & 1 & 1 & 1 & 1 & 1 \\
\hline$\nabla$ & 11 & 1 & 1 & 1 & I & 1 & 1 & & 1 & I & 1 & $\ddot{0}$ & 1 & 1 & & 1 & 1 & 1 & 1 & 1 \\
\hline$m$ & $\begin{array}{ll}1 & 1\end{array}$ & ஸ் & 1 & 1 & I & 1 & I & & 1 & 1 & I & 1 & 1 & 1 & & 1 & 1 & $\begin{array}{l}\infty \\
\stackrel{\infty}{+} \\
0\end{array}$ & 1 & 1 \\
\hline
\end{tabular}

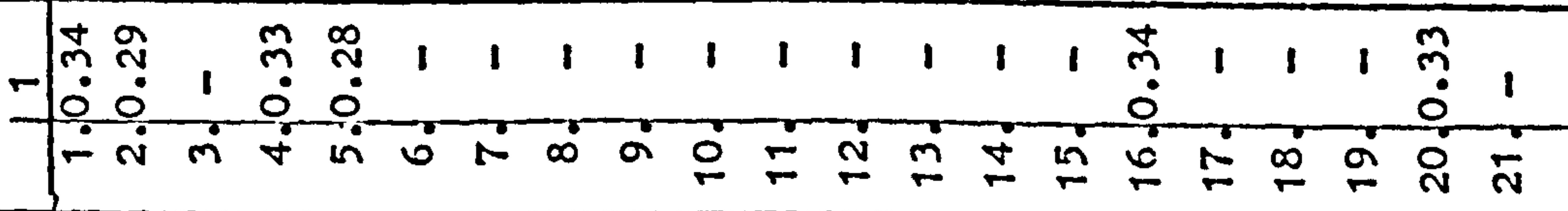
SGIबTरण 


\begin{tabular}{|c|c|c|c|c|c|}
\hline \multirow{2}{*}{$\begin{array}{l}\text { FACTOR } \\
\text { NUMBER }\end{array}$} & \multicolumn{5}{|c|}{ YEAR } \\
\hline & 1970 & 1969 & 1968 & 1967 & 1966 \\
\hline 1 & INTACT & INTACT & INTACT & INTACT & INTACT \\
\hline 2 & CI & NAVI & DVI & NAVI & NAVI \\
\hline 3 & RDI & NCCW & NCOW & $\mathrm{NCOW}$ & NCHSI \\
\hline 4 & SHI & NRDI & RDI & RDI & NPDI \\
\hline 5 & NDVI & CI & NDOS & CI & $\mathrm{CI} / \mathrm{TCI}$ \\
\hline 6 & EI & EI & EI & EI & EI \\
\hline 7 & CHSI & DOS & CHSI & CHSI & NSHI \\
\hline 8 & DOS & CHSI & CI & DOS & RETT \\
\hline 9 & NCOW & ETT & NETT & ETT & NCON \\
\hline 10 & HETT & SHI & SIII & SIII & NECS \\
\hline 11 & TCI & MSI & MSI & MSI & MSI \\
\hline 12 & NAVI & HTI & AVI & NDVI & SRI \\
\hline 13 & HIII & DVI & HTI & HTI & HTI \\
\hline 14 & MSI & SRI & DEN & NSRI & TCI. \\
\hline 15 & NDEN & TCI & NTCI & NTCI & DVI \\
\hline 16 & NSRI & NDEN & SRI & NDEN & $\mathrm{NAR} / \mathrm{TTF}$ \\
\hline 17 & $\mathrm{NAR} / \mathrm{TTF}$ & NAR/TTP & NAR/TTF & $\mathrm{NAR} / \mathrm{TTF}$ & DEN \\
\hline 18 & VRI & VRI & VRI & VRI & VRI \\
\hline 19 & NPTF & NPI? & NPTF & NPTP & PTF \\
\hline 20 & POP & $T D I$ & POP & POP & NITP \\
\hline 21 & TDI & NPOP & TDI & TDI & NPOP \\
\hline 22 & PPI & PPI & PPI & PPI & PPI \\
\hline 23 & PSI & PSI & PSI & PSI & PSI \\
\hline 24 & RI & RI & RI & RI & $\mathrm{RI}$ \\
\hline
\end{tabular}

TABLE 9.2.14 INTERPRETATION OF DERIVED FACTORS 1966-1970 FOR CCUNTY BOROUGH AREAS. 
It will be seen from these tables that the tup sets of results are very similar in many details. Once again only six distinct "dimensions" are recognised with an "eigenvalue" of more than one, accounting similarly for approximately 81,5 of the total variation within tise total explanatory variables. One difference that can be noted, however, is that interpretation of the higher order derived components is nuch more difficult with only the first 9 components having high factor loadings ( $r \geqslant \pm 0.60)$. Similarly those low order components which can be interpreted produced a different set of variables (Table 9.2.14), although this was only to be expected considering the differences between the original variables discussed above. It will be sho:n hoverer, that these differences did not seeningly alter the results of the regression analysis, when the derived components in both groups were used as independent variables.

As regards the nature of these derived components over time, using the same technique as employed in the 100 aree P.C.A. (Speanuan's Renh), it cen be seen below, that al though the correlatfons between the gears was lower as a whole than for the 100 areas, they were all still significant $\left(F_{1,19} \alpha=0.001\right)$ at the $99.9,0$ level? This indicetes that the static nature noticed in the full sample

\begin{tabular}{llllll} 
& 1970 & 1969 & 1968 & 1967 & 1966 \\
1970 & 1.00 & 0.82 & 0.90 & 0.85 & 0.82 \\
1969 & & 1.00 & 0.87 & 0.91 & 0.88 \\
1968 & & & 1.00 & 0.89 & 0.84 \\
1967 & & & & 1.00 & 0.85 \\
1966 & & & & & 1.00 \\
\hline
\end{tabular}

6 The table value for $F_{1,19} \alpha=0.001=15.08$. Therefore ang $r$ value $\geqslant 0.67$ is significent at the $99.9 \%$ level. 
selection appears to renain true when only the $C B$ areas are studied. In fact it would seen reasonable to conclude that the results achieved by the two P.C.A. produced results which vary only marginally, although the importence of eny such differences will only sho: itself in the regression analysis, shich is described in the following section of this report.

\subsection{MULTIPLE REGRESSION AVALYSIS}

Using the factor scores and derived components from the two groups of P.C.A., as the input variables in the regression model 120 regression equations were derived. Of these,90 related to the 45 dependent variables described in the data section of this report for the years 1969 and 1970. The renainder consisted of 19 regressions relating only to Counts Borough areas (1966/70); 7 regressions for 1970 with transforned dependeint variables; and 4 regressions relating to the Jears 1966 and 1961. This composition of variable regresslons is shown in Table (9.3.1).

Because of the magnitude of these regressions it is obviously impossible to describe each result in detail, even though all results are presented in Appendix (3). Therefore, the aim of this section of the report will be to present an overall view of the result of these regression models, and also deal with several of the dependent variables in some more detail, whilst reserving most attention for the 8 variables listed below:-

1) Total Casualties.

2) Total Accidents 


\section{REGRESSION}

Number

$1-45$

$46-90$

91

92

93

94

95

96

97

$$
98-100
$$

$101-102$

$103-104$

105 - 107 Count.y Borough

$108-109$ Areas Only

$110-111$

$112-114$

$115-116$

117

118

119

120

\section{REGRESSION DEPENDENT}

\section{Variables}

45 Basic regressions 1970

45

1969

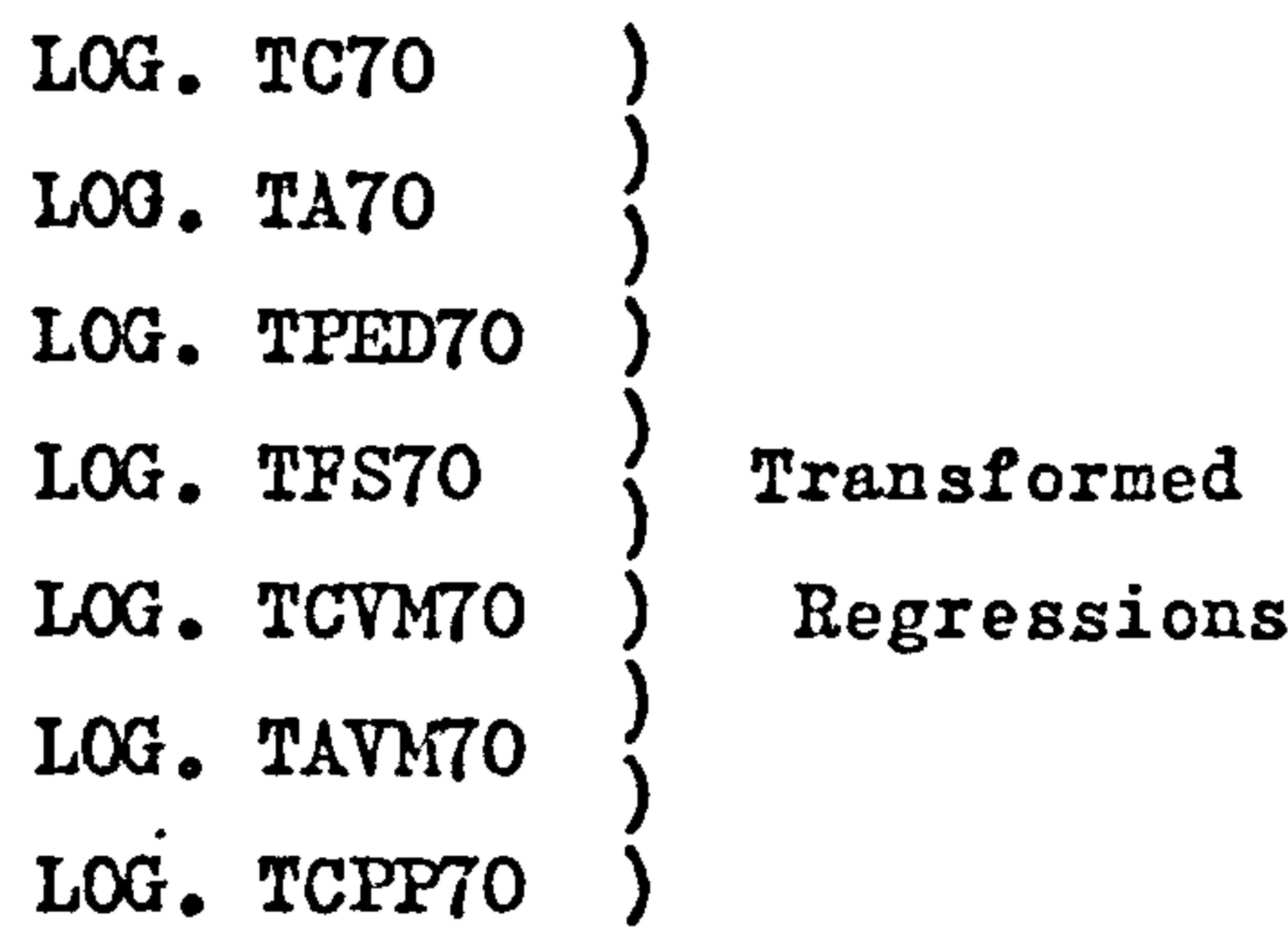

Total Casualties 1966, 1969, 1970

Total Accidents 1969, 1970

Total Pedestrian Casualties 1969, 1970

Total Casualties per $10^{3}$ Population 1966, 1969, 1970

Total Accidents Per $10^{3}$ P0pulation 1969, 1970

Total Ped. Cas. n n

Total Casualties Per $10^{6}$ Vehicle Miles, $1966,1969,1970$

" Accidents per $10^{6}$ Vehicle Miles, $1966,1969,1970$

Total Casualties Per $10^{3}$ Population 1966

Total Casualties 1966

Total Casualties Per $10^{6}$ Vehicle Miles 1966

Fatal and Serious Casualties 1966

TABLE 9.3.1. COMPOSITION OF THE 120 REGRESSION EQUATIONS. 

3) Total Casualties/000 population
4) Total Accidents/000 population
5) Total Pedestrian Casualties
6) Total Casual ties/Vehicle mileage
7) Total hccidents/Tehicle mileage
8) Total Pedestrian Casualties/000 population

As a simple approximation the results of the regression analyses can be studied in tro ways:- 1) Significance and level of explanation of each derived regression equation, 2) Analysis of the variables entered into each regression equation at the $10 \%$ confldence level $(F(\alpha=0.1)=2.79)$.

Taking the first analysis mathod and observing the results of the 45 basic regression equations, it can be seen in Table (9.3.2) that there is a large variation in the level of explanation and "goodness of fit" of individual regressions. These two measures are indicated bo the coefficient of mul tiple determination $\left(R^{2}\right)$, and the estimated stendard deviation about the regression expressed as a percentage of the mean response, respectively. This second statistic periaps needs some further explanations. In any rezression calculation the residual mean square $S^{2}$ is an estimate of $\sigma_{Y . X}^{2}$, the variance about the regression. The square root of this value therefore (S) is obviously equivalent to the stendard deviation about the regression. Exainination of this statistic indicates that the smaller it is, the better; that is, the more precise will be the predictions. This statistic is generally referred to as the "Standard error of Estinate." When, comparing different 


\begin{tabular}{|c|c|c|c|c|c|c|}
\hline Yo & CODING & $\mathrm{R}^{2}$ & $\bar{I}$ & S.D. & S.E.E. & $\vec{Y} \%$ of $S_{0}$ E.E. \\
\hline 1 & TC70 & 0.986 & 804.43 & 1015.21 & 123.32 & 15.3 \\
\hline 2 & TA70 & 0.987 & 636.72 & 808.17 & 98.06 & 15.4 \\
\hline 3 & TFS70 & 0.960 & 223.75 & 281.57 & 57.57 & 25.7 \\
\hline 4 & TPED70 & 0.988 & 257.41 & 369.55 & 41.69 & 16.2 \\
\hline 5 & TMC70 & 0.901 & 72.80 & 84.11 & 27.48 & 37.7 \\
\hline 6 & TPCY70 & 0.641 & 86.73 & 81.03 & 49.50 & 57.1 \\
\hline 7 & TDRC70 & 0.959 & 329.04 & 362.64 & 76.26 & 23.2 \\
\hline 8 & TCPED70 & 0.967 & 120.75 & 177.06 & 33.01 & 27.3 \\
\hline 9 & TYDR70 & 0.938 & 166.04 & 180.16 & 45.56 & 28.0 \\
\hline 10 & TJN770 & 0.961 & 431.16 & 557.98 & 115.62 & 26.8 \\
\hline 11 & TPDCR70 & 0.878 & 18.93 & 33.81 & 12.12 & 64.0 \\
\hline 12 & TTRN70 & 0.907 & 156.42 & 145.77 & 45.82 & 29.3 \\
\hline 13 & TRT70 & 0.851 & 21.06 & 26.72 & 10.54 & 50.0 \\
\hline 14 & TTJN70 & 0.950 & 227.86 & 269.18 & 61.82 & 27.1 \\
\hline 15 & TIJN70 & 0.731 & 14.30 & 19.90 & 10.48 & 73.3 \\
\hline 16 & TXNN70 & 0.954 & 124.10 & 209.16 & 46.63 & 37.6 \\
\hline 17 & TVCRD70 & 0.972 & 290.50 & 376.20 & 63.68 & 21.9 \\
\hline 18 & TCRD70 & 0.921 & 347.63 & 440.91 & 129.03 & 37.1 \\
\hline 19 & TCFP70 & 0.292 & 5.74 & 1.102 & 0.95 & 16.6 \\
\hline 20 & TAPP70 & 0.285 & 4.49 & 0.879 & 0.78 & 17.4 \\
\hline 21 & TFSPP70 & 0.162 & 1.59 & 0.530 & 0.49 & 30.9 \\
\hline 22 & TCVMTO & 0.784 & 18.48 & 13.140 & 6.38 & 34.5 \\
\hline 23 & TAVI70 & 0.739 & 14.47 & 10.450 & 5.67 & 39.2 \\
\hline 24 & TFSVIT0 & 0.594 & 5.21 & 4.410 & 2.89 & 55.4 \\
\hline 25 & SR70 & 0.059 & 0.28 & 0.077 & 0.08 & 29.0 \\
\hline 26 & CPEDCR7O & 0.569 & 0.48 & 0.099 & 0.07 & 14.7 \\
\hline 27 & YDRCR70 & 0.202 & 0.51 & 0.064 & 0.06 & 11.9 \\
\hline 28 & TUNAR70 & 0.408 & 0.27 & 0.075 & 0.06 & 22.0 \\
\hline 29 & PDCRAR70 & 0.262 & 0.03 & 0.040 & 0.04 & 142.9 \\
\hline 30 & TAMUC70 & 0.414 & 1.70 & 0.607 & 0.47 & 27.7 \\
\hline 31 & TAMC70 & 6.356 & 7.75 & 3.220 & 2.64 & 34.1 \\
\hline 32 & RTAR70 & 0.259 & 0.05 & 0.037 & 0.04 & 78.4 \\
\hline 33 & TJNAR70 & 0.348 & 0.57 & 0.101 & 0.08 & 13.9 \\
\hline 34 & YNNAR70 & 0.131 & 0.04 & 0.028 & 0.03 & 78.9 \\
\hline 35 & XJNAR70 & 0.544 & 0.23 & 0.098 & 0.07 & 30.8 \\
\hline 36 & TPEDPP70 & 0.640 & 1.67 & 0.444 & 0.28 & 16.8 \\
\hline 37 & PEDCR70 & 0.581 & 0.29 & 0.068 & 0.04 & 13.7 \\
\hline 38 & PCIWT70 & 0.407 & 31.06 & 22.740 & 17.97 & 57.9 \\
\hline 39 & EEDWT70 & 0.599 & 1.92 & 0.686 & 0.45 & 23.5 \\
\hline 40 & PCIAR70 & 0.302 & 0.18 & 0.115 & 0.10 & 55.6 \\
\hline 41 & MCAR70 & 0.301 & 0.12 & 0.042 & 0.04 & 32.5 \\
\hline 42 & TERVMTO & 0.718 & $.8: 73$ & 6.770 & 3.71 & 42.5 \\
\hline 43 & DRCR70 & 0.547 & 0.45 & 0.084 & 0.06 & 13.4 \\
\hline 44 & TCTA70 & 0.423 & 1.27 & 0.085 & 0.07 & 5.51 \\
\hline 45 & TNRAR70 & 0.474 & 0.65 & 0.093 & 0.07 & 10.8 \\
\hline
\end{tabular}

TABLE 9.3.2. RESULTS OF THE BASIC 45 REGRESSION EQUATIONS 1970. 
regression equations the actual value of $S$ is obviously related to the metric, and size of the dependent variable. Therefore in order to have some means of comparing such regression equations, the standard error of estimate is often related to the mean vilue of the dependent variable, in terms of a percentage value. The lower this percentage value, the better the goodness of $\mathrm{fit}$, end the lover the defiations from the actual regression plane.

From the table $(9.3 .2)$ it can be seen that according to the derived $\mathrm{R}^{2}$ values, there would appear to be two groups of regression equations. The first group involves the absolute casualty figures diseggregated according to location or the mode of the persons involved. Of these 18 regression equations all have in $R^{2}$ value greater than 0.50 and only 4 have a velue of less than 0.90 . hlso as is true for 81145 regression equations, all regressions are significant at the 95. confidence level, as indicated by the calculated value of the $F$ test statistic. That is, one can say that these derived regression equations end relationships could not have occurred by chance at the $95^{\circ}$ confidence limit. Unfortunately, however, when the deviations from the regression planes are studied It can be seen that several regression equations have very high percentege values, with the smallest value being 15.39 for TC7 70 . The indications are therefore that, whilst this group of regression equations account for a large amount of the totel sum of squares, the actial variance about the regression planes is relatively large.

The second group of equations meanwile has a much more varied set of results. As regards the $\mathrm{K}^{2}$ values it cen be seen that these range betiveen $0.059(\mathrm{SR} 7 \varnothing)$, and $0.784(\mathrm{TCV} N 7 \%)$ wi th a predominence 
of values at the lower levels. It is interesting to note, however, that the exposure dependent variables have most of the high $R^{2}$ values. Thus, TCVI $7 \varnothing=0.784$, TAVI $7 \varnothing=0.739$, TFSVM $\not \varnothing=0.594$, PCIWT $\varnothing=0.107$, PEDIT7 $\varnothing=0.599$, and TDFM $=0.718$. In terms of understanding the road accident situation from these regression models, this previous fact is of very great importence since it means that both of Xatz's fanilies of dependent variables show high explanation levels when dealing with structural variables, and therefore the importance of these variables are noted accordingly.

Turning to the deviation of this second group of regression equations, once again the general level ( $(p)$ is higher than would seen desirable with a minimum value of $5.51 \%$ for TCTA7 $\varnothing$ and a maximum value of $142.3 \%$ for PDCRAR7\%. The variation within this range would also appear random, with no seeming relationship between this velue and any other statistic related to the regression. It is important to point out neanwhile that the percentage values for the 6 "exposure" regressions all appear fairly high with PCIUT7 $\varnothing$ having a velue of 57.96. Thus becouse of this high degree of deviation, allied with reasonable levels of explanation, these exposure regressions are deserving of further enalysis, which will be completed later in this report.

Within this second group of regressions there are several other dependent variables which produce certain interesting results. For example within this group there is a sub-set of 4 rearessions which have as their dependent variable some statistic related to the population level (103) of each urban area. These four varlables 
are TCPP7 $\not$, TAPP7 $\not$, TFSPP7 $\not \varnothing$ and TPEDPP7 $\not$. What is of interest here is that the first three seen to exhibit different tendencies fron the fourth regression. Thus whilst the first three exhlbit low $\mathrm{R}^{2}$ values $(0.292,0.285$, and 0.162 respectively), the regression explaining the variation within the number of pedestrian casualties per $10^{3}$ population, produces the reasonable $R^{2}$ value of 0.640 . The implication from this would seen to be that the total number of casualties or accidents in any urban area, are influenced by factors other than those describing that urban structure. Therefore it could be argued that perhaps the number of pedestrian casualties per 103 population, is a better indicator of the perfornance of any urban area than any one of the other three variables. Conversely the other three varlables would seem to be good indicators of how any urban area deals with its extemal factors such as the level of through traffic, and regional comercial attraction.

The second method of generalising about the results of the regression analysis, mentioned previously, is by regarding the varlables introduced into the various regressions. The variables included in all 45 regressions (1970) are given in Table (9.3.3). From this table it cen be seen that the most important variable is $X_{1}$ which was interpreted as an interaction variable, and which appears in 30 out of the 45 regression equations. Although the significance of this varieble wlll be dealt with later when Individual regressions are studied, some explanation should be made at this point.

One of the fundaiental questions within this research is whether it is possible to reduce road accidents within urban 


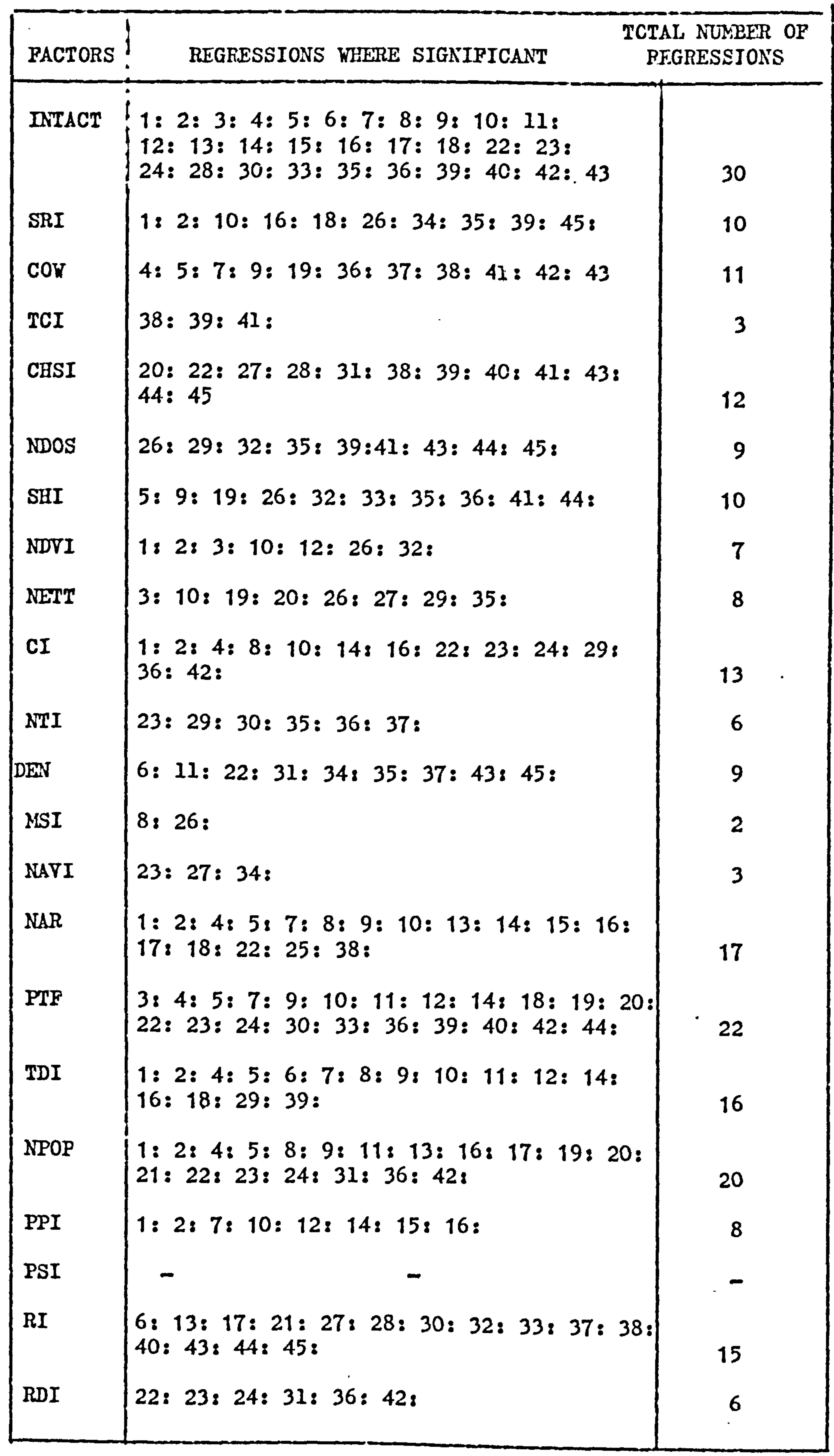

TABLE 9.3.3. FACTORS INCLUDED WITHIN THE 45 REGRESSION EQUATIONS 1970 
areas through the modification of one or more structural variebles? That is, is the road accident problen predominantly an engineering problem or predoninantly a psychological problem? Although it is obvious that the level of road accidents will increase with the increased size of an urben area, and also the level of interaction within each area, one would not expect variables which describe such conditions to dominate the regression equation, if the road accident problen was predominantly an engineering problem. Therefore wheneve such variables do occur in a regression both their statistical significance and the size of their $b$ coefficient should be studied. In a general summary such a study cannot be accurately completed, however it is very signiflcant that the variable $X_{1}$ should appear in 30 regressions. Similarly three other variables, wict are related to the peak traffic flow (PTF) number of dwellings (TDI) and the population (NPOP) of each urben area, also occur in 22, 16, and 20 respectively, of the regression equations.

Although these four variables appear most often within the regression equations, other variables appear falrly often, end shed further light on the road accident problem. Accordingly these variables will be discussed below.

\section{(1) $\mathrm{x}_{2}: \operatorname{sRI} 7 \varnothing-$}

This variable which is related to the relative presence of males and fenales within an urben area is present within ten of the regression equations. In 8 of these equations the $b$ coefficlent is negatively signed, end therefore it would seen that as the proportion of males increases, the response of these 
dependent variables is reduced. Since this variable is significent witinin both regressions, $T C 7 \varnothing$ and TA7 it can be maintained that both total casualties and total accidents will decrease where the proportion of males increases. In some ways, this inverse relationship is somewhat surprising since it is generally considered that females are safer with respect to both driving and walking. However, this seeming discrepancy can perhaps be explained with regard to relative exposure. That is to say, won are more exposed to traffic conflicts during the hours whilst the majority of menfolk are at work, both as regards vehicle end pedestrian conflicts. This could be the result of more and more wonen having the use of the family car during these hours for both recreation and shopping actirities. Similarly the activities of women as pedestrians, especially on shopping expeditions, also exposes then to increased danger. Perhaps a further explanation could be that on excess of males in any population will tend to reduce the number of young inhabitants associated with that area. Since the accidents to persons under the age of 15 years accounted for some $47 \%$ of all pedestrian accidents in 1970, this could be a verg important feature. of these two basic possible explanations the first one seems to be a little lacking since if it was true that increased exposure for women leads to more accidents, then one vould also expect SRI $7 \varnothing$ to be significant both in total pedestrian casualties and also total driver and rider casualties. Since this is not so, one must consider this explanation with some degree of uncertainty. However, it should be noted here that SRI $7 \varnothing$ does eppear significent 
In PEDiT7 which relates pedestrian casualties to the number of pedestrian work trips in each urbon area, but even with this qualiflcation, the conclusion reached above would seem to remain valid. The second possible explanation meanwhile seems to be invalidated by the fact that SPI $7 \varnothing$ is positively related to CPEDCR7 in that regression. Thus as the relationship between child pedestrian casualties and total pedestrian casualties increases, (i.e. child pedestrian casualties account for a larger proportion of total pedestrian casualties) the SRI $7 \varnothing$ also increases. If the postulated explanation was to have been correct then this relationship would have to be inverted. Consequently all that can be really stated about this variable is that there is an inverse relationship between the sex ratio index and the number of total casualties and total accidents in enj urben area. The exact reason for this can only be discerned by further research and stady.

\section{(.2) $x_{3}: \cos : 7 \phi$}

This variable is significant in 11 of the derived regression equations. Its importsnce seems to lie more in the fact that it disaggregates between the various tjpes of accidents rather than affecting the absolute total number of accidents and/or casualties. Thus, COW7 seens to be positively related to those accidents involving driver and rider casualties and motor-cycle casualties, and negatively related to those casualties involving pedestrien and pedal cycle casualties. The implications here are that the general level of accidents can be fairly well pre- 
determined, but the disaggregation of the types of road accidents cen only be determined with respect to various internal factors such as $\operatorname{cotr} 7 \phi$.

\section{(3) $x_{5}: \operatorname{CHSI7}$}

Since this variable gives some indication of the amount of chenge whin an urban area, it can also indicate what effect this change has had upon the road accident situation. In some ways it could be argued that it should also point out the impact of modern comprehensive planning. With these thoughts in mind It is interesting to note that the variable is found to be significent in 12 of the derived regression equations, not one of rhich appears emongst the 18 absolute dependent variables. Therefore once again it would seen that CHSI $7 \varnothing$ hes not helped in reducing the total number of casualties and/or accidents, but has determined how the are distributed about the total population.

of the 12 significent regressicns 8 have inverse relaticnships with CHSI7 $\varnothing$, incluoing the traffic dependent variables such as,

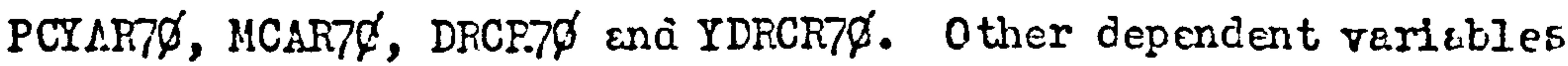
with inverse relationships are elso of interest. For example, TCTA79 is inversely related, thereby indiceting either that the car occupancy rate is lower in these ereas, end therefore nost accidents involve only one cesualty, perheps cne pedestrien. Alternatively because of the improved environment, more people could be travelling on foot, end therefore when involved in an accident, fewer people are involved in each conflict situetion. This ergunent rould seem to be supported by the direct relation- 
ship betveen CHSI7 $\not \varnothing$ and PEDWT7 $\not \varnothing$. This relationship vould seen to suggest that more pedestriens are exposed to conflict situations in newer or more planned areas. Two other interesting regressions with direct relationships with CHSI $7 \varnothing$ are TCVII $7 \varnothing$ and TIMC7 $\phi$, both of which suggest that the improved road netrorks in these areas have also tended to increase the number of accidents per degree of exposure.

Summarlsing therefore, this varikble seems to incick.te 6 conclusions which nay be drann, as regards these newer, more chenged, urben arees:-

1) The CHSI7 $\not \varnothing$ variatle has no effect upon the overall level of roed eccidents.

2) The CHSI7 $\not \varnothing$ variable cen influence the distribution of road accidents betreen the type of accidents.

3) Any increase in the CHSI7 7 variable can increase the number of pedestrien casual ties when related to degrees of exposure.

4) Where there has been extensive redevelopment the number of casualties per degree of exposure on the roads has also increased, possibly as a result of an increase in the number of pedestriens or altematively beckuse of a reduction in the miletge of unclassified roads in these arets.

5) Redevelopment has tended to reduce the number of eccidents 
caused by tuming menoeurres, and those located at roed juncticns.

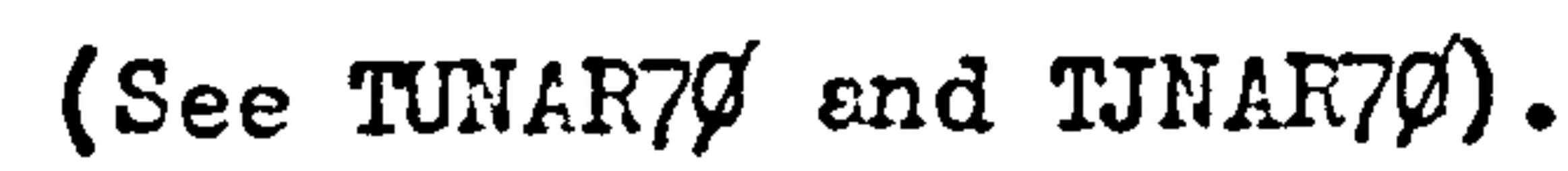

6) Where the velue of CHSI $7 \varnothing$ increases the number of casualtics related to the number of accidents (i.c. the casualty rate per accident) is reauced.

(4) $x_{8}: \operatorname{NDVI} 7 \varnothing$

Since this factor is negatively related to the variable IVI7 $\not \varnothing$ all relationships derived from the regression equaticns (i.e. signs of the b coefficients) kave to be inverted to arrive at the correct relationship. For this reason all relationships will be presented here in terms of the originel DVI7申 verieble.

The IVI7 $\not \varnothing$ variable is significent in 7 of the derived regression equations, of wich 5 relate to absolute dependent varicbles, ell of which have $\varepsilon$ positive relaticnship. Thus the number of people in any urban area, in the age group 15 years 25 years, directly influences the level of road accidents, cesurities etc. In that urban area. It should be noted however, that this varieble is not significant emongst any of the exposure depcrient variables. The impication here therefore is that the increase in the total number of accidents etc. is not ciue simply to the absolute number of people in this age group, but more Iikely to the fact that this group has a higher exposure rate. This seens to vindicate the presumed conclusions of recent research, which has tenced to suggest that this age group is no more potentially vulnerable or likely to be involved in road accidents, then any other age group. 
The only dependent varieble with a negative (inverse) relationship is CPEDCR/ $7 \varnothing$ wich in meny rays is only to be expected. The reason being that as DVI7 increases, other ege groups must be relatively reduced. Therefore, the absolute number of people within the child age group must also be substantially recuced, and there should be a related reduction in the number of accidents occurring to people in this age group.

\section{(5) $\mathrm{Z}_{9}: \operatorname{NETT} \varnothing$}

Once egain since this factor is negctively related to the variable ETT7 the areunents and conventions put forrard above are once egain used in relation to this factor.

Although this veriable ETT7 is found to be significent in 8 of the derived regression equations, beceuse of the varying direction of the relationships, it proves very difficult to interpret within the road accident fremework. However, the most important result is that there is a positive relationship betreen ETT7 $\varnothing$ and both TCPP $\varnothing \varnothing$ and TAPP7 $\varnothing$. It would seem from these two regressions that the low levels of explanation obtained with these regressions, $\left(R^{2}=0.202\right.$ and 0.285 respectively) could be explained by the underestimation of the impact of the amount of through traffic. The absolute number of casualties etc. is related to the situation present within an urben area at any one point in time and with no explicit regard to extemal factors. When the number of casualties/accidents per thousard of population is regarded however, the impact of externel egents, in the guise 
of through traffic, obviously must play some very importent part. If this is so, then the inpact of through traffic upon the road accident situation should not be underestimated.

Other reletionships between ETT7 $\not$ end the significent depandent variables are very difficult to interpret, with any degree of certeinty. For exemple, there is on inverse relationship between ETT7 and TFS7\%. In other words as the degree of through traffic increases then the total number of fatal and serious casuelties decreases. At first such a relationship mey eppear to be the reverse of what rould be expected. However, this result can perheps be explained by the fact that ebsolute Ievels of through traffic are usually associated positively with the population size of each urban area. That is, the emount of through traffic is a function of the nodality of any urban area; the level of trade and regionel commercialism is a function of the nodality of any urban area; the growth of an urban area is a function of the comercial and trading capacity of that urban area due to its focal nodality; therefore, the present size of any urben area is a function of the nodality, expressed in terms of the emount of through traffic. Extending this reasoning a stage further the size of an urban area has a positive relationship with the degree of traffic congestion, end therefore traffic speeds. Thus if the absolute number of fatal and serious cesualties is a positive function of traffic sfeed, then it can be seen just how there is en inverse relationship between ETT7 $\varnothing$ and TFS7 $\varnothing$. 
Another interesting feature of this veriable is the negative reletionship betreen ETT7 $\varnothing$ and the number of child pedestrien casualties as a proportion of all pedestricn cesurlties. The most reasonable explanation for this relationship would seem to be that as the volume of through traffic increases further modifications are mede to accommodate this unwented traffic. (Ping roads etc.). As a result unwented treffic is removed from pedestrian and living erees of the urben environment.

\section{(6) $\mathrm{x}_{10}: \operatorname{CI} 7$}

This compactness index was found to be significant in 13 of the derived regression equations within which all relationships were found to be invorse. That is, as the shepe of the urben area beceme more compact (circular) there was a corresponding decrease in the set of dependent vuriables. Since this set of dependent varlables included 7 of the absolute veriabies, end TC7 $\phi$, TAT $\not \varnothing$ and TPEDT in particuler, the importance of this varieble becomes obvious. In fact of the 22 variables used in this research, CI7 was cne of the few which has a negative response upon the absolute level of roed accidents. More importent CI $\not \varnothing$ along with PPI7 were the only tro viriobles which can ectively be menipulated to reduce the accident level. In the instence of CI 79 it ney prove that the link between urban shepe and the level of road eccidents is not a direct link. For example it mey prove that the link goes through treffic movement and traffic congestion values, since it is usually presumed that circuler towns have radial network systems, which thereby tend to increase congestion as one moves towards the 
urban centre. Whatever the reascn however, the fact renains that from the road accident situation, the more compact an urben area the lower the level of road accidents, casuelties etc.

Further justification for these conclusions is also given by the other regressions within which CI7 $\varnothing$ is also significant. These include the 4 exposure variables related to the vehicle

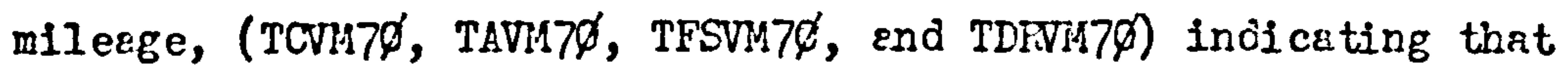
not only are the absolute levels of road accident conflicts reduced, but also that the level of conflicts related to degree of exposure is also reduced.

The discussion of this variable is very importent then one considers the 7 New Torn Areas, included in this research. These areas and their calculated CI7 $7 \varnothing^{\prime}$ values are given below, olong

\begin{tabular}{|c|c|c|c|c|}
\hline URBAN ARFA & CI $7 \varnothing$ & DEVI\&TION & $\begin{array}{l}\text { FACTOR } \\
\text { SCORE } \\
\end{array}$ & DEVIITION \\
\hline CUIBEPNAULD DC & 0.876 & $-0.3 \hat{<} 8$ & -0.306 & -0.3 \\
\hline EAST KILBFIDE LB & 0.950 & +0.776 & 0.791 & 0.79 \\
\hline GLENEDTHES DC & 0.689 & -3.119 & -3.103 & -3.10 \\
\hline HAFLON & 0.896 & $-0.0=0$ & -0.025 & -0.03 \\
\hline HEMEI HEMPSTEAD & 0.945 & +0.701 & 0.692 & 0.69 \\
\hline STEVENAGE & 0.912 & +0.209 & 0.652 & 0.65 \\
\hline WFLI:YN GC & 0.970 & $= \pm 1.075$ & 1.046 & $=2.05$ \\
\hline 100 A.EFES MEAN & 0.898 & $=$ & 0.000 & \\
\hline 100 FFAS SD & 0.067 & - & 1.000 & \\
\hline CUNBFENAULD NT & 0.800 & -1.463 & -1.4 .48 & -1.45 \\
\hline EAST KILBRTDE NT & 0.858 & -0.597 & -0.568 & -0.57 \\
\hline GLENPOTHES NT & 0.955 & +0.851 & 0.852 & 0.85 \\
\hline
\end{tabular}


wh the derived factor scores, and their deviations from the orerall means. The significance of this table lies in the fact that of these new towns the three which are most recent, Cumberneuld, E. Kilbride and Glenrothes, tend to have a volue below the overell meen of the 100 sampled areas. For Cumbernaula this remains true independent of the authority unit used. (Local goverment or Hew Toum). However, with both East Kilbride and Glenrothes whether the deviation value is positive or negative depends upen the unit used. Thus East Kilbride is negative if the new tom area is used and positive if the local authority area is used. As it has been poirted out that the higher the CI7 value, the lower the $l \in v \in I$ of rad accidents, it would apper that these new towns are not making the optimun use of the shape of the urben area as regards road accidents. It should be remembered however that road safety is only one aspect of new town plennirg proposals.

\section{(7) $\mathrm{X}_{11}: \operatorname{HTI} 7 \varnothing$}

This varieble witch measures the relative type of housing tenure between private and public, vas found to be significant in 6 of the derived regression equations. The index was so calculeted that high velues of HIT7 indicates a predominance of private tenure and construction, whilst the opposite indicates a predominance of local autrority development.

The results of these relevent regression equations once again provided some interesting observations. Of the 6 regressions, 4 proved to heve an inverse reletionship; these were, TAVM7 $\phi$,

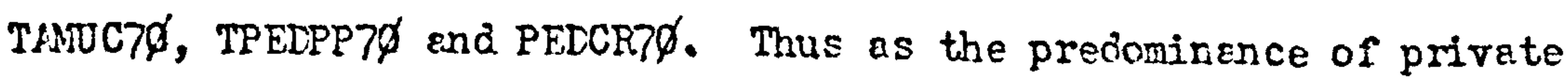
ownership increased, so the volume and velues of these dependent 
variables decreased. Although this seems to indicate at first glance that private development is "safer" then public developments, this mey not be so once certein other factors have been considered.

In the first instance it should be noted that only accident rates are affected, and not casualty rates. Therefore if there has been an increase in the accident rate, there must have been some compensating reduction in the number of casuelties per accident, thereby indicating that there had been an increase in one casuelty accidents, which is the usual feature of pedestrien accidents. This assumption seems to be supported by the fact that as HIT $7 \varnothing$ increases, there is a reduction in the tro pedestrien casurlty rates. The conclusions to be drawn here therefore are thet HTI $7 \varnothing$ seens to affect road accidents by means of the nuraber of pedestrian casualties, ond that public developments have higher pedestrien casualty rates. Meenuhile, it should not be concluded that this relationship is causel in nature. For example, the types of development and ownership contrined within HTI7 $\varnothing$ are usuelly associnted with different types of social cless, which in turn have different accident response rates, especially emongst child pedestrien casualties. 7 Therefore the relationship between housing tenure end road accident levels may work through the social cless variable, which has not been included within the causal link frefrework. The only way in wich this relationship, end the impact of HTI $7 \varnothing$ in general, can be correctly understcod is by further deteiled local study into statistically comparable ereas. 


\section{(8) $\mathrm{X}_{12}:$ DEN7Ø}

Once again this variable, (which was significent In 9 of the derived regression equations) secms to be cne which allocates the number of accidents and casurlties, within any urbsn aren, into groups indicating the type of accicient, rather than the volume. Thus as DEN7 increases, so does the pedestrien casialty rate, with a compenseting reduction in the Driver and Pilder casualty rete, end pedal cycle accidents. Similarly, DEN7 79 seems to affect the location of accidents, with positive relation-

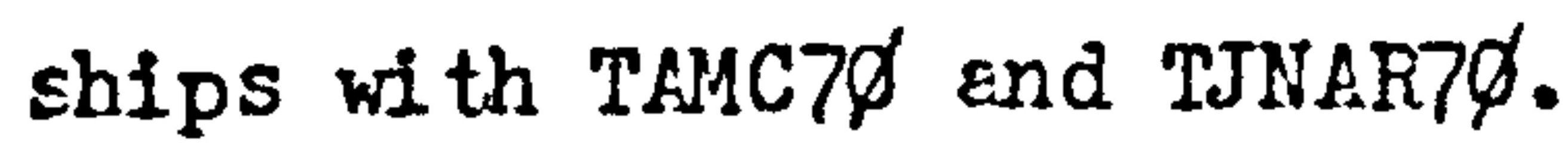

\section{(9) $\mathrm{X}_{13}: \operatorname{MST} 7$}

Although this varieble was significent in only 2 of the derived equations its impact in these was very strong. Both regressions were releted to child pedestrien casuelties; TCPELT $\varnothing$ and CPELCR7 $\varnothing$.

The MSIT $\varnothing$ variable was calculated such that as the value increases the social class composition of that area, decreases. In both regressions the derived relationships were positive, thereby indicating that as social class increases, the number of child pedestrien casualties is reduced. The reason for this relationship could be due to many factors such as degree of supervision, access to play areas, including spacious gardens, end as was mentioncd previously, type and standard of housing develcpment. Whatever the reason ${ }^{8}$ however, this relationship

8 If one studies the tivo regression equations to find out which other variables are significent, TCPEDT reverls very little, thilst CPFDCR7 9 elso

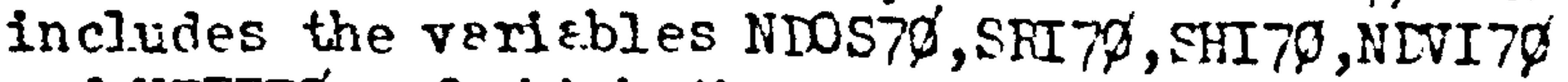
end NETT7 $\varnothing$, of which the most importent appers to be SRIT 
is obviously an integrel feoture of the overell road accident situation.

(10) $X_{19}$ PPI $7 \varnothing$

Two variebles were included in this reserch which geve some indication of police activity as regards motor law enforcement, PPI7 $7 \varnothing$ and PSI7 $\not$. Of these PPI $7 \varnothing$ was found to be significant in 8 of the derived regressions, vhilst PSI7 $7 \varnothing$ did not eppesr in eny.

The importance of lnoxing the actual impect of the police enforcement is well illustrated by the following guote which is trying to answer the question, "What can be done?"

"However good our present or future safety legislation may be, it will not save lives if it remains pigeonholed and urenforced. It seems likely that if detection was increased by increasing the police $\varepsilon v a i l a b l e$, if punishments were admiristered more speedily, and were more effective, so that the fear of them became $\varepsilon$ deterrent to treffic viclators, then even with our present legialation, about $30 \%$ of the present road deaths and casualties could be prevented. This would mean that about 2,400 lives end nearly $£ 90$ million a year could be saved." (Cohen and Preston 1968).

Wi thout substantiation however, such statements, of which meny abound, cen have little meaning. Consequently, the fect that PPI $7 \varnothing$ hes en inverse relationship with all the dependent variebles, where significant, is of the utmost importence. Similerly, since the list of significent regressions include both 
TUZ and TA7 $\varnothing$ it would seen that perhaps the savings in both Iife and money mentioned by Preston (above) mey be totally substentiated. Thus it would eppear that the results of this research, and the national casualty trends since the introduction of the 1967 Road Safety Act ${ }^{9}$ (Legislation on Drink and Driving) both indicate the edvantages to be attained by increased police activity within the field of road safety. The problem however, is thet with the continued shortage of manpower within the police forces, what is desirable end wat is practical, are two ontirely different features. Perhaps the only solution here is to increase the pover of some subsidiery force, such es the present traffic. wardens, but even this would be only satisfactory if this new body commanded the same influence, both on the streets and in the courts, as the police do at present.

(11) $\mathrm{x}_{21}: \operatorname{RI} 7 \emptyset^{\circ}$

One of the major conclusions from the work by Recht (1965) was that $n$ the major portion of the differences in accident experience is associated with differences in the non-progrem fectors....particulerly vehicle density, kind of trevel, ege of population and weather." (Fecht op.cit). In this research this reinfell index was representative of this last group of non-progrem factors. Recht used as his rainfall index, the amount of precipItetion in inches, and derived a strong negative relationship

9 Accorcing to the information produced by the Department of the Environment in Foad fccidents, 1969, following the 1967 Foad Safety let, the level of total casualties was down epproximately 10,6 on pre-Act level despite a $4: \mathrm{rise}$ in the volume of motor traffic. 
betpreen this vorieble and his "Totel death Ratio." However, in the present research of the 15 significant regressions, 9 had positive relctionships, end the only absolute dependent veriables included were TPCY $\not \varnothing$ and TUCRDT $\not \varnothing$. Basically the results from this variable were all totally inccnclusive with only some brief generallsations being possible. This could be due to the fact that the varietion noted within this variable is mainly due to spatial variation and should therefore be really studied in context, with the overall spatial variation in the volume of rood accidents, casualties etc. However, what tentative conclusions that cen be made, are given in the follow $n$ :-

(i) The volune of pedal cycle accidents positively releted to the emount of rainfall in any one area. That is where there is a higher rainfall incidence both $T P C Y 7 \varnothing$ and $P C Y A R 7 \varnothing$ increase proportionally.

(i1) There is a positive increase in the volune of road eccidents occurring on unclassified roads relative to a rise in the amount of precipitation. This could be indicative of the relative stanciard of surfacing on these roads, or alternatively due to the reduction in visibility in these less well lit roads.

(11i) There would seem to be a positive relationship betricen the level of rainfall and the number of fatal and serious accidents occurring within a given volume of population, (TFSPP7Ø).

(iv) Since there is a positive relationship between $\mathrm{FI} 7 \%$ and YDRCR7 $\varnothing$ it would seen to suggest that in inclement weather 
conditions the inexperience of some young drivers and riders can account for the variation in road accidents in any given urban area. One further variable which could perhaps be relevent here is the attendent speed in such accidents.

(v) Finally the incidence of all driver and rider casual ties as a proportion of ell casualties is positively related to the level of precipitation.

(12) $\mathrm{X}_{22}: \mathrm{RDI} 7 \varnothing$

This variable which describes the road density in any area and which was pointed out earlier to be highly correlated with junction density was found significant in 6 of the regression equations. Of these 4 related to the exposure variables, TCVN $7 \varnothing$,

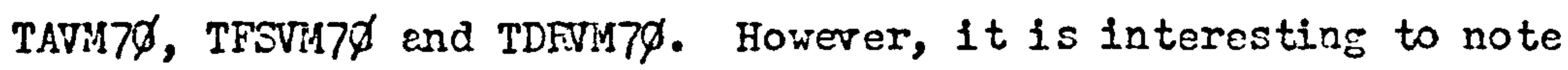
that PDI 77 was not significant in any of the junction dependent variables, which suggests that whilst road density increases the relative accident/casualty response, this increase does not occur at road junctions themselves. Perhaps this could be explained by increased psychological frustration due to the slower progress rates caused by greater junction "stopoing and starting."

of the reaaining variables which have not been explicitly exanined here, ei ther no distinct relationship can be found or alternatively they appear to be related to the inpact of other veriebles which are more significant or powerful. For example, SHI $7 \varnothing$ would eppear to be highly similar in influence to CHSI7\% and NAVIT to NDVI7\%. For these results one is referred back to Table (9.3.3) and Appendix 3 . 
Having given so far a generalised account of the results of 45 (1970) rezression equations it now becomes necessary to look at some of the regression equations in more detail. This will be completed comencing with the major 8 regressions listed previouslJ. 10

\section{1). TOTAL CASUALTIES 1970 (TC7D)}

During the discussion on the results of the principal conponents analysis, reference vas made to the"variance Ranking" which listed the components according to their variances in declining order (Table 9.2.1). A comparable ranking systan is the "Regression Ranking." For each dependent varisble there is a possibility of three different models, the composition of which is detemined by the three significance levels ( $F$ values) used as entry limits for the independent variables. The three F levels for inclusion in the regression model are $0.1,2.79$ and 4.00 respectively, and the three models derived for TC7\% are show in Table $(9.3 .1)$.

The most obvious result from this teble is the difference between the two ranking systems, thus showing that whilst a component may accuunt for a large portion of the varience in the original date natrix, it does not have to account for a significant variable when attenpting to explain the variation in some depeindent variable. Thus in the rezression raniing for TC7P only one of the first five variables has a varlance rank of less then 10 and that is the first variable itself. 


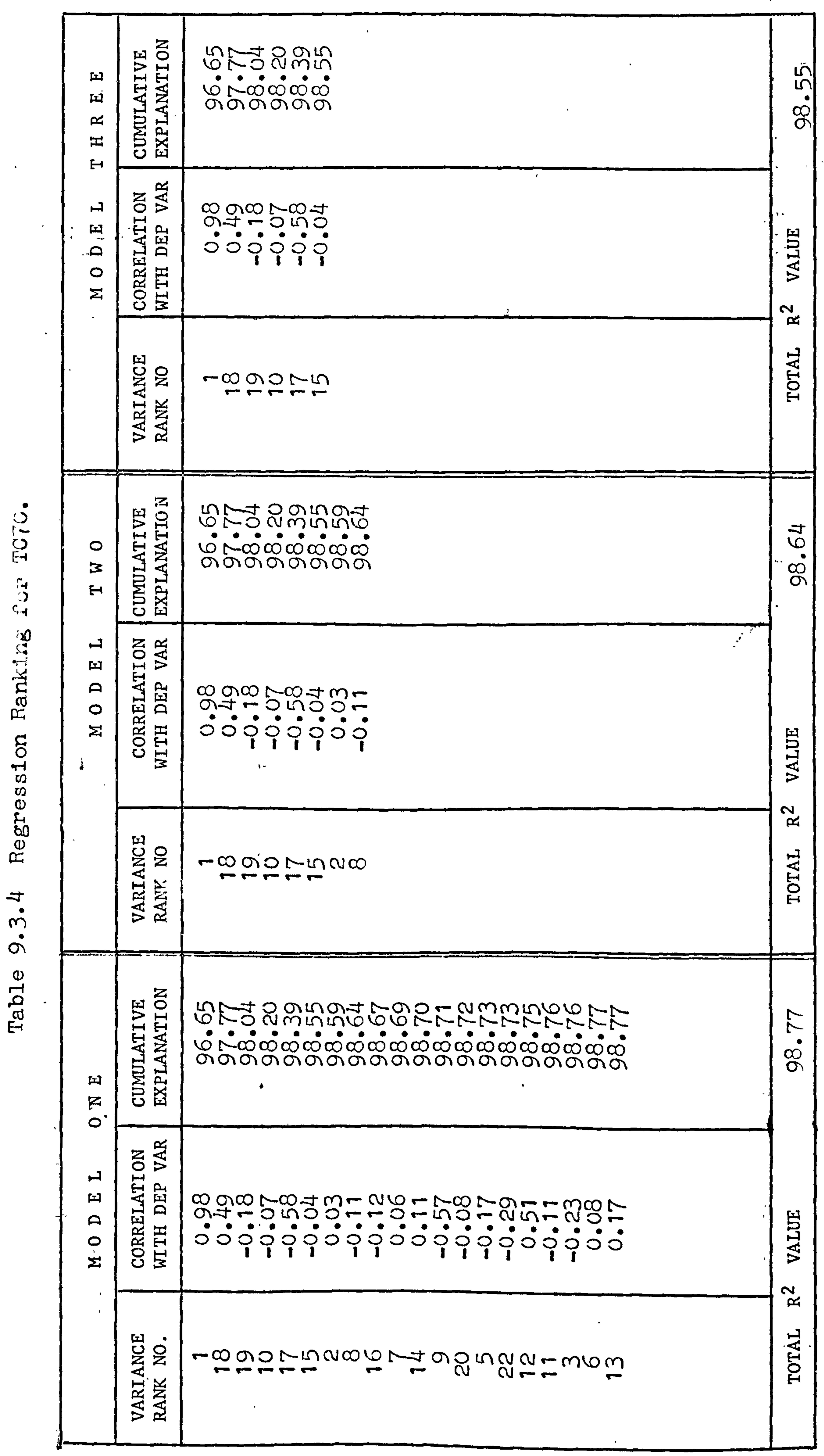


When looking at the regression equation and attempting to explain them, the second model is the one used, since this Includes variables, which are significant at the $10 \%$ confidence level. In the instance of TC7 $\varnothing$ this model included 8 independent variables and is given by the equation;

$$
\begin{aligned}
Y_{i}= & 779.1+1011.3 X_{1}-35.2 X_{2}-25.67 X_{8}-44.02 X_{10}-45.52 X_{15} \\
& -92.94 X_{17}-157.9 X_{18}-38.4 X_{19} \quad(1970)
\end{aligned}
$$

This model accounts for $99, \%$ of the variation in the dependent variable $\left(r^{2}=0.936\right)$, with a Standard Error of Estimate (S.E.E.) expressed as a percentage of the man response of 15.36

The inportance of the individuel variables in the regression equation can be assessed in t:ro different ways. In the first instance one can observe the increase in the regression percenteze explanation associated with each independent variable. Secondly, since the independent variables are standardised with a mean of zero and a standard deviation of one, the $b$ coefficients $c \in n$ be simply related to the beta $(\beta)$ coefficients and therefore compared directly according to their magnitude. Thus the larger the coefflcient the greutor that variable's influence upon the dependent variable.

A further piace of infornation which is important in each regression is the statistical significance of the value of the $b$ coefficient. Although this information is implicit in the step- 
wise regression procedure, an independent assessnent is of great practical value.

Using the Student's $t$ test it is possible to test the null hypothesis $\left(H_{0}\right)$ that $b_{i}=b_{10}$, where $b_{10}$ is a specified vulue which can be $\phi$ or any other value, against the test hypothesis $\left(H_{1}\right)$ that $b_{1}$ is different from $b_{10} \cdot\left(H_{0}: b_{1}=b_{10}\right.$ versus $\left.H_{1}: b_{i} \neq b_{i O}\right)$. If $H_{0}$ has to be accepted then it must be assumed that the $b$ value could have occurred by chence, and the independent variable moy not significsntly affect tise dependent variable. The test statistic is given by,

$$
\begin{aligned}
t & =\frac{\left(b_{1}-b_{10}\right)}{\text { est.se }\left(b_{1}\right)} \\
& =\frac{\left(b_{1}-b_{10}\right)\left\{\Sigma\left(x_{1}-\bar{x}\right)^{2}\right\}^{\frac{1}{2}}}{s}
\end{aligned}
$$

where,

$S=$ Standard Error of Estimate and the confidence interval is given by $t\left(n-2 ; 1-\frac{1}{2} \propto\right)$

The calculated t values are also given in Table $(9 \cdot 3.4)$.

As regards the regression equation $\mathrm{TC} 7 \phi$, it becomes obvious that the entire model is dominated by the one variable $x_{1}$ : INTACT 79 . This one variable accounts for 96.76 of the variation in TC7 and has a $\beta$ value of +1011 .3. That is, since these are partial regression coefficients, a chenge of $I$ in the variable $X_{1}$ will increase the value of the dependent variable by 1011.3, if the 
remaining independent variables are held constant. The only other variable which increases the percentage explanation by more then one per cent is $\mathrm{X}_{18}: \operatorname{NPOP} 7 \phi(1.126)$.

This dominance of INTACT7 $\$$ is in fact a feature of all the regression equations dealing with absolute dependent variables, and can be interpreted in one of two ways. In the first instance it could simply be stating that as urban areas increase in size, there is a corresponding increase in the number of road accidents. Altematively it could be argued tinat the level of road accidents is detennined less by the urban stracture of an area but more by the actual level of interaction, within that area. In other words it would seein to be suggesting that the road accident problen is a psychological one rather than an engineering one. If this is true then it would seen to support the conclusions of Cohen (1963), that there is a need for a better understending of the hunan driver and his psychological attitudes. This is further supported by the significance of PPI7\%.

Although the variation in TC7 $\varnothing$ was highly accounted for, the acturl varlance about the regression plane was relatively high e.s given by the S.E.E. Therefore in order to look further in to this problen three additional observations were nade.

1) The restduals from the predicted ragression plane were plotted both against the dependent variable, and each of the indezendent variables, in order to search for eny non-random irregularities. 
ii) The variable TC7 was regressed against the independent variables relating only to the County Borough areas (51).

11i) The dependent variable (TC7D) was transformed where necessary and regressed once again against the independent variables.

The plotting of the residuals against the total rariables used in the regression is a simple method of observing enomalies, and discovering unsuitability within the regression model used. The diagrams in Fig. $(9.3 .5)$ show three of the more comon abnornalities revealed by residual plots. The interpretation of the abnornalities is dependent upon the variables being used in the plotting. However, when plotting against the independent variables the three anomalies shown in Fig. (9.3.5) can be interpreted as follows:-

1) Variance not constent; need for weighted least squares or a preliminary transfornation on the I's.

2) Error in calculations; linear effect of $X_{j}$ not renoved.

3) Need for extra teras, for example, a quadratic tern in $X_{j}$ in the model or a transforation on the $Y^{\prime} s$.

When the residuals are plotted against the $Y_{1}$ meanwile the interpretation for the three same enomalies is slightly different.

1) Variance not constant as assumed; need for weighted least squares or a transformation on the observations $Y_{1}$ before making a. rezression analysis. 


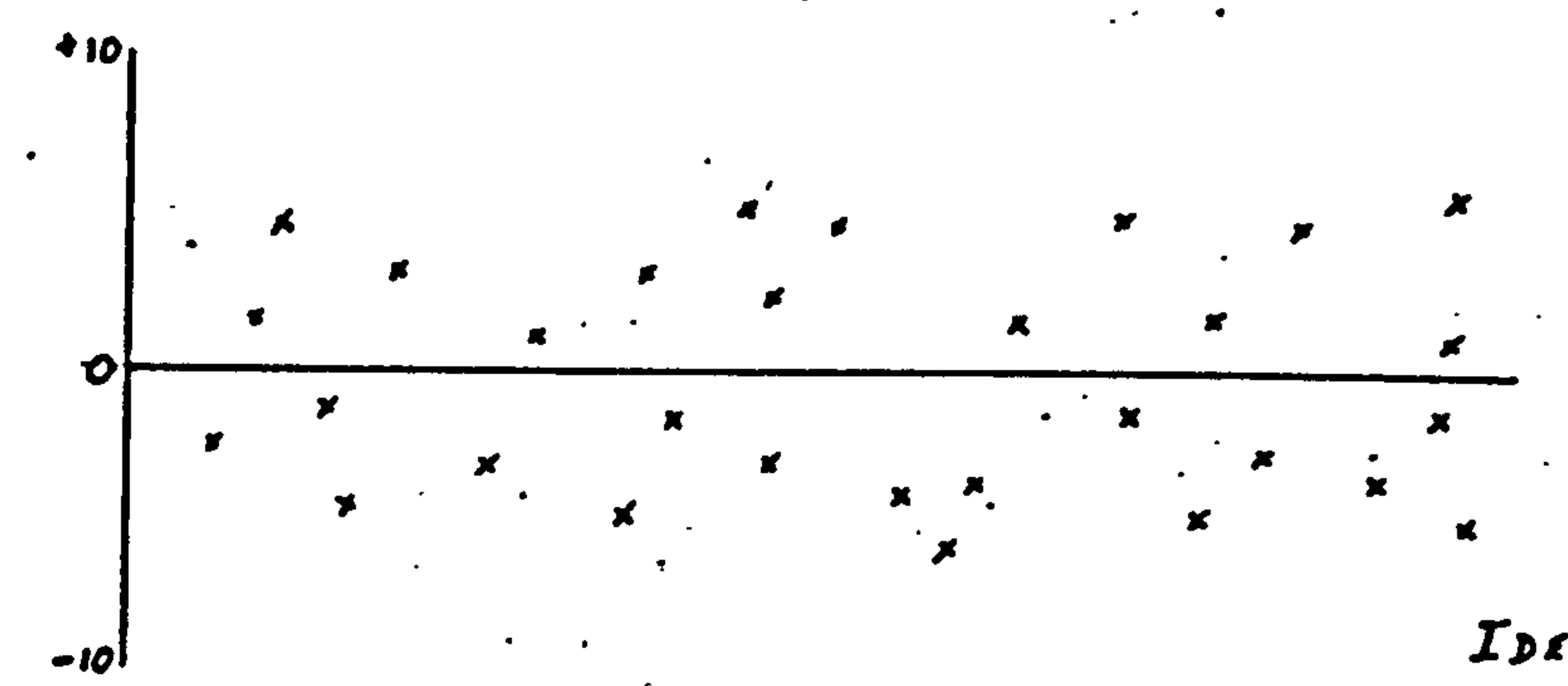

IDEALISED DISTRIBUTION.

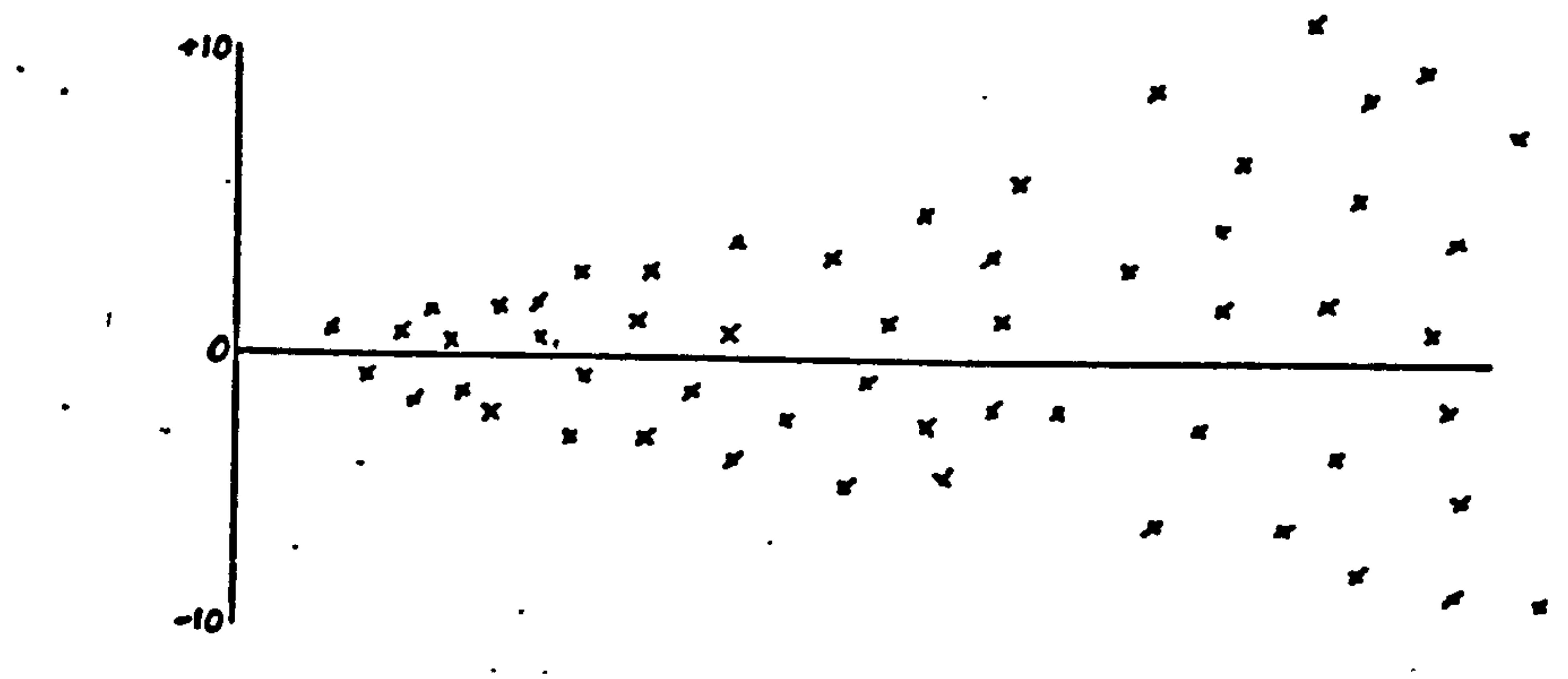

Varying VariancE.

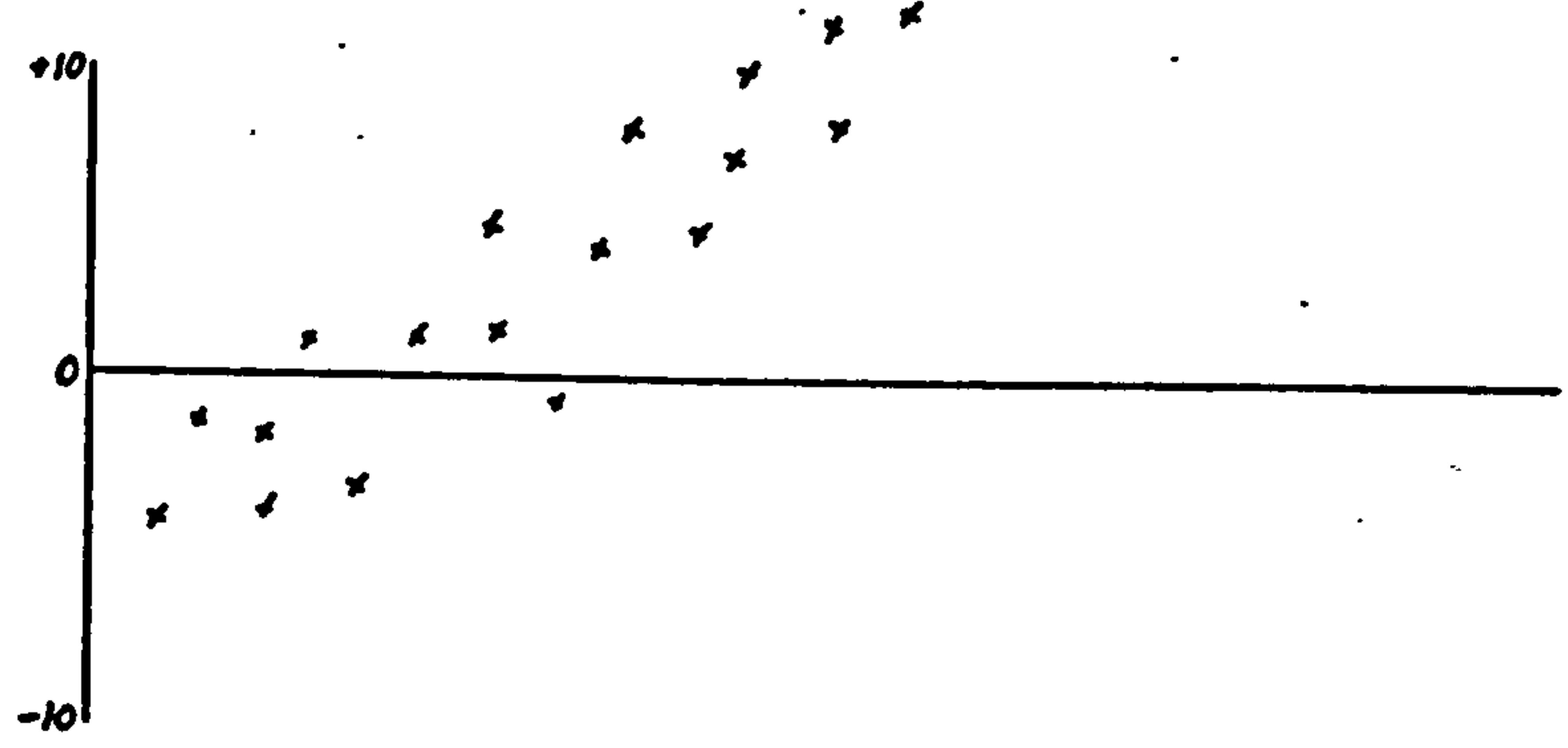

LINER TREND.

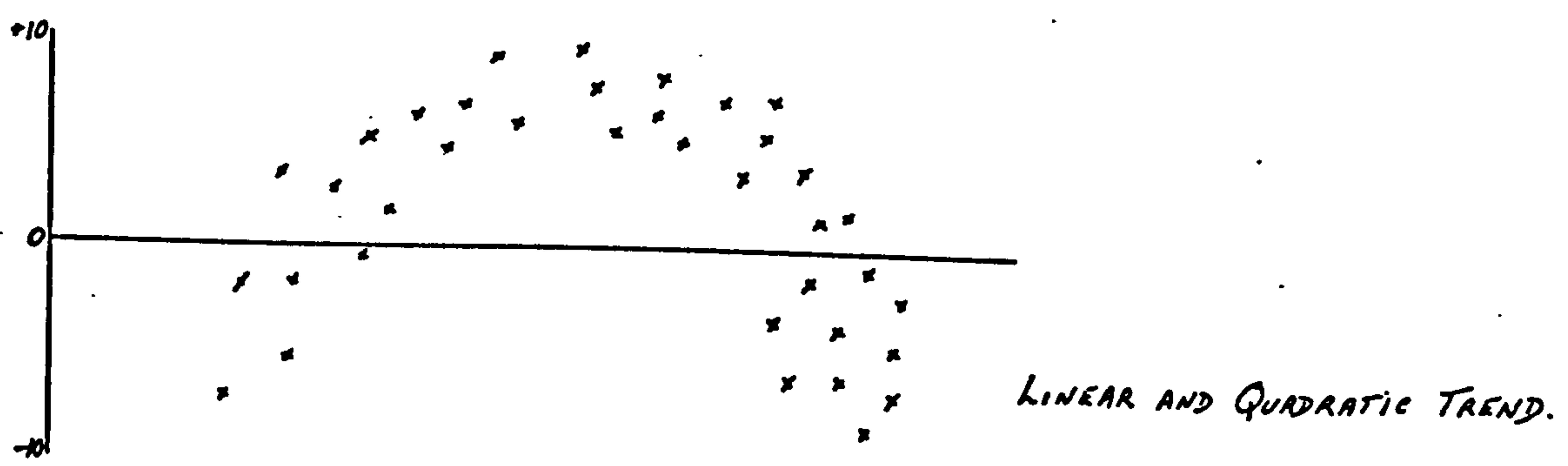

Fig. 9.3.5. THREE POSSIBLE RESIDOAL GRAPH PLOT ABNORMALITIES.

232 
2) Error in onalysis; the departure from the fitted equation is systematic. Negative residuals correspond to low $Y_{S}$ and positive residuals to high $Y_{S}$. The effect can also be caused by omitting the $\beta_{0}$ term in the model.

3) Model inadequate - need for extra terns in the model (e.g. square or cross-product tenas) or need for a transfornation on the observations $Y_{i}$ before analysis. (After Draper et al 1966).

In most of the regressions studied there were very few which proved to heve abnormal plots, and therefore for this reason, these residual plots will only be mentioned where relevant in the following accounts.

As regards $T C 7 \not$ the only plot which apoears any thing like abnornal is the one between the residuals and $X_{9}$ : NETT. (FIg. 9.3.6). Remenbering that this factor is negatively related to the amount of through traffic variable, it can be seen from tinis graph that the regression equation is overestlmating the number of casualties when the volume of through traffic is high, and underestimating the number of casualties when the volume of through traffic is at, and around its mean value. The indication here once again is that the actual impact of this variable is still not understood sufficientiy nor modelled correctly. It would seem therefore that the relationshio between TC7 $\varnothing$ and ETT $7 \varnothing$ is el ther logarithic or some polynomial function, rather then the linear function postulated in this model. As a result, the influence of the amount of through traffic, which is not 


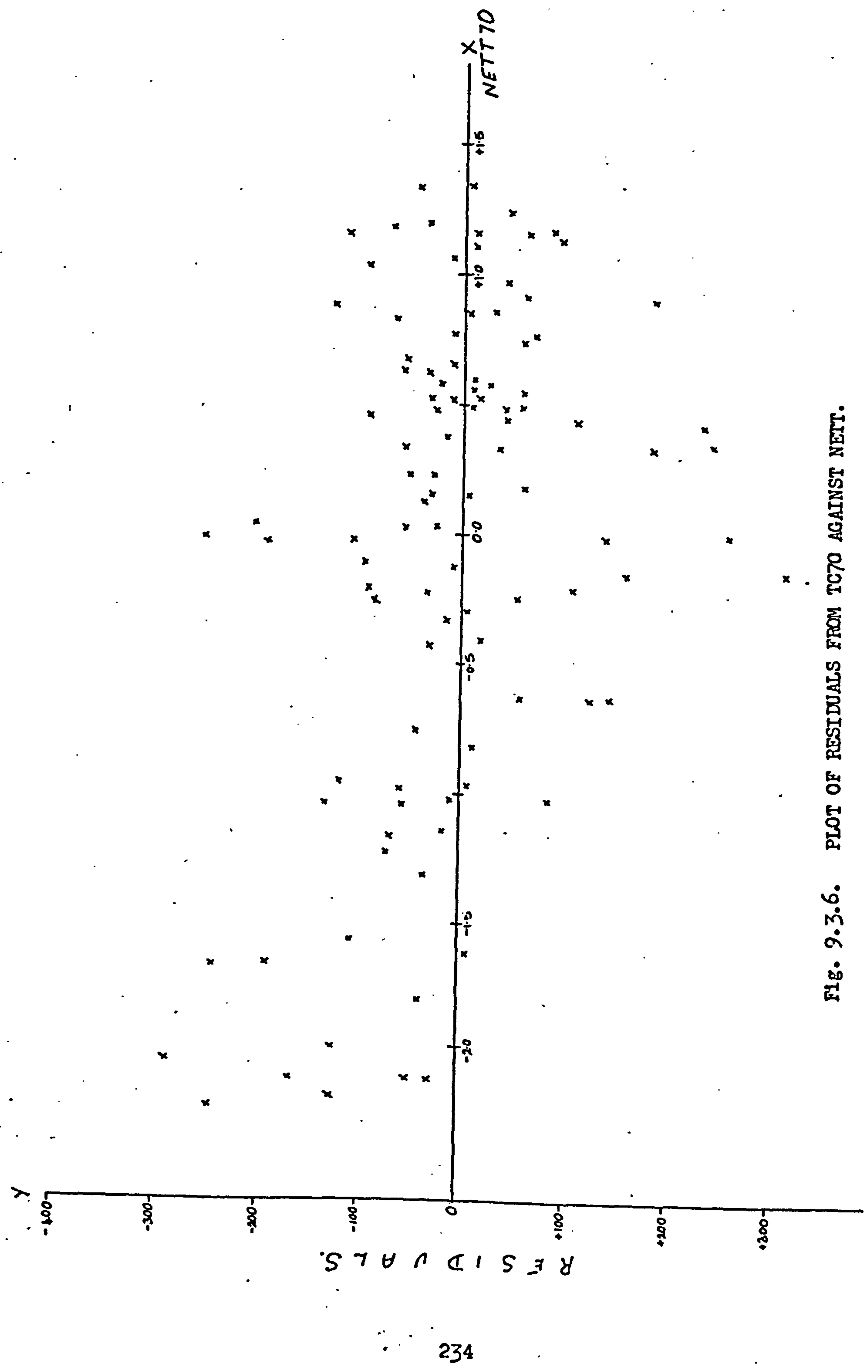


significant in TC7 $\varnothing$, could heve been seriously underestimated, as has been suggested from other results in this research. Consequently the dependent variable TC7 was logarithmically transformed and a new regression equation derived.

The results of this new regression equation are given in Appendix (3) and the variables found to be significsnt are shown in Table (9.3.7). Although there was a similar number of variables in the new equation, the actual variables differed, and the new equation was as below:

$$
\begin{aligned}
\log I_{1}= & 2.67+0.32 x_{1}+0.02 X_{3}-0.02 x_{4}-0.05 x_{7}-0.02 x_{9} \\
& -0.02 X_{11}+0.23 x_{16}+0.10 X_{18}
\end{aligned}
$$

Fron this it can be seen that whilst all the size and traffic varlables are positively related to INTC79, there is a degree of Iimitation imposed bo the inverse relationships between LNTC7\% and the three significant structural variables, TCI $7 \varnothing$, SHI $7 \varnothing$ and HTI7\%. Thus in this form the dependent varieble LNTC7\% would appear to be influenced by both humail and structural variebles, with the latter being able to reduce or restrict the level of log. road casualties. However, it should be also noted that only three variables substentially increase the percentege level of explanation, and all of these are size or interaction variables. (Table 9.3.7).

A further feature of this regression equation for LWTC7P was that whilst the variation about the regression plane was 
reduced (S.E.E. $\not=3.2 \%$ ), the overall regression explanation level was also reduced to $r^{2}=0.963$. Thus whilst certain features have been improved by this transformation, other features have been restricted and it might well be asked what is the advantige of a furtiner complication of the regression model through the addition of a logarithmic transformation, when the overall explanation level is reduced. The only real justification is if the model is wanted for accurate predictive purposes. In this research this is not so, elthough in terms of future research such models could be useful.

When the dependent variable TC7 7 was regressed against the independent variables relating only to the 51 county boroughs areas, the two sets of results proved very sinilar, and the derived regression equation was given as:

$$
\begin{aligned}
\mathrm{I}_{\mathrm{CB}_{i}}= & 1306.7+1248.4 \mathrm{X}_{1}-87.5 \mathrm{X}_{2}+19.20 \mathrm{X}_{17}-48.0 \mathrm{X}_{19}+244.1 \mathrm{X}_{20} \\
& -124.5 \mathrm{X}_{21}-55.7 \mathrm{X}_{22} 11
\end{aligned}
$$

The comparable signiflcant variables are given in Table (9.3.3).

The removal of the non-county borough areas, which was to see if there was a disaggregated dichotomous response between the list of sampled areas, had the effect of maintaining the percentage explenation level $\left(r^{2}=0.987\right)$ whilst at the sane time reducing the S.E.E. \% response $(11.6,0)$. Thus it can be concluded that the non-county borough areas whilst having a similer casual ty pattern as county borough areas, also have a wider variation in their deviations from the regression plane. In some way this is only County Borough areas only, given in Table (9.2.14). 


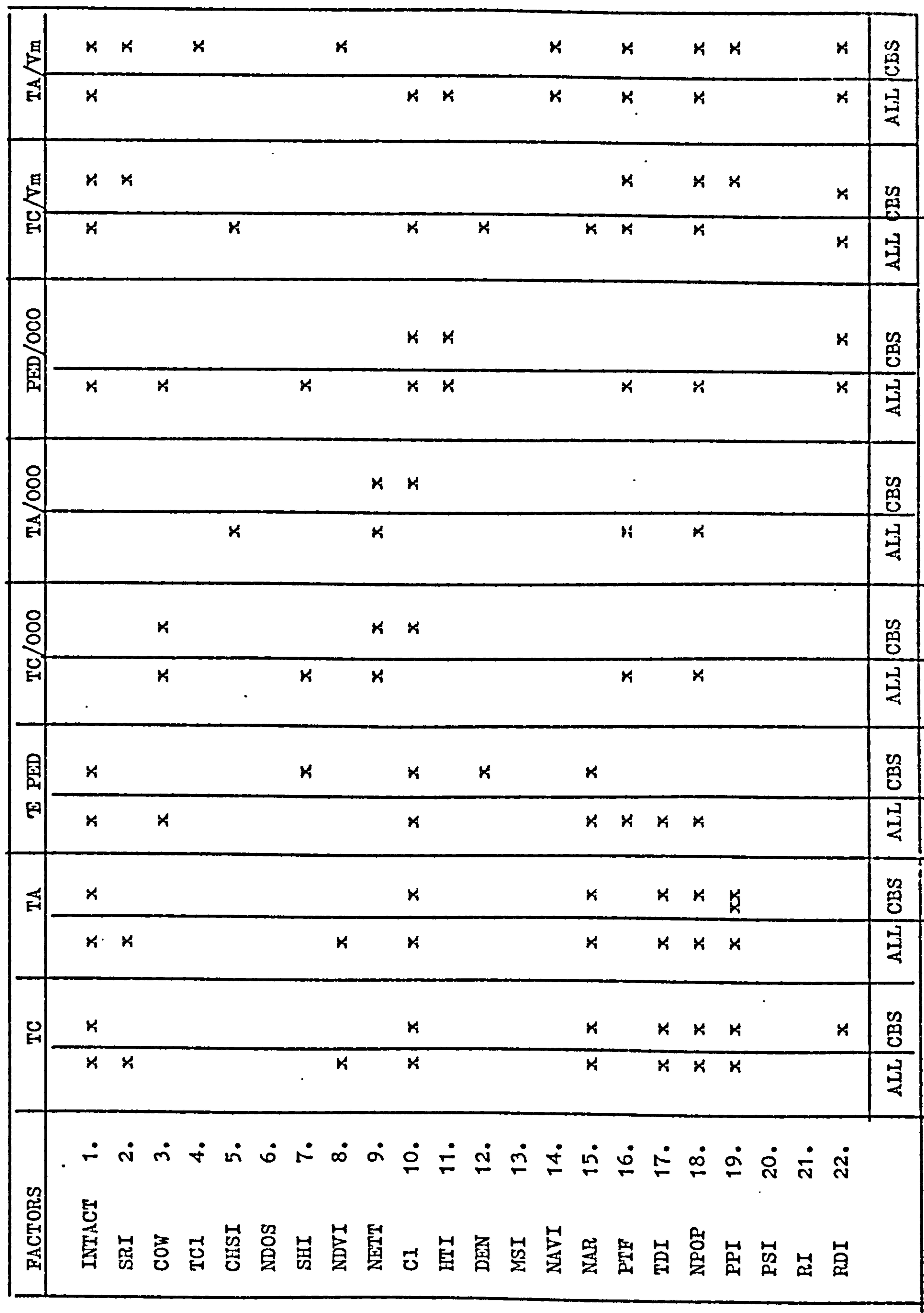


to be expected from the varying nature of these non-count borough areas, as well as their greater size range.

Summarising therefore, TC7 $\varnothing$ secms to be mainly explained by the level of interaction within any urban area, as well as the actual size of that urben area. Similarly although the introduction of the transformed variable LNTC7 $\$$ reduces the variation about the regression plane, end therefore enables more accurate prediction, it also reduces the overall level of explanation.

Finally when the county-borough areas only are considered verg little difference is noted in both the regression equation variables and also the level of explanation, although the variation about the regression plane is reduced slightly. Consequently the relationships noted above would appear to remain consistent for ell types of erea, and therefore practically efficient for spatial comparisons.

\section{2) TOTAL ACCIDENTS (1270) TA7Q}

Most of the results obtained for this dependent variable are directly comparable to those obtained for TC7 $\varnothing$ and therefore discussion of this variable is somewhat limited.

The regression ranking for TA7ð is given in Table (9.3.9) and the eventaral derived regression equation was as below:

$$
\begin{aligned}
Y_{1}= & 616.8+812.2 x_{1}-31.7 x_{2}-26.9 x_{8}-32.5 x_{10}+34.5 x_{15} \\
& -68.5 x_{17}-i 35.1 x_{18}-31.3 x_{19} .
\end{aligned}
$$




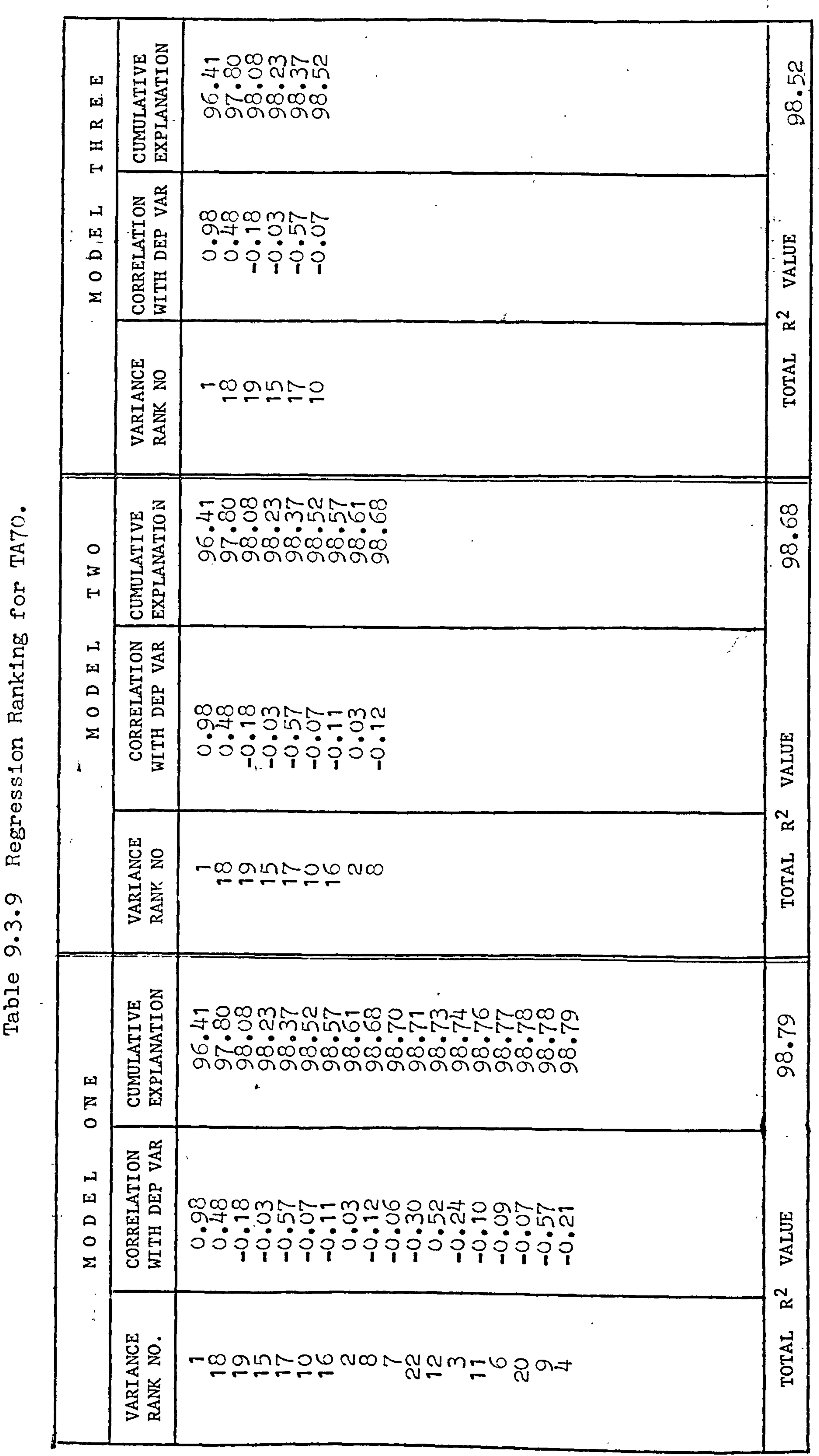


The equation accounted for over $98 \%$ of the total variation wi thin the dependent variable and the deviation about the regression plane was approximately 15:7 (S.E.E. $=15.4,0)$. Once again as was the case with TC7\%, over 96\% of the overall explanation level is accounted for by the single variable $x_{1}$ :INTACT7P, with only the one other varieble $X_{18}$ : NPOP7 $\varnothing$ accounting for more than 17 of the explanation.

Since a similar graph plot was noted for the residuals from TAT $\not$, and NETT7 $\not \varnothing$, the dependent variable was once again transforned logarithrically. The regression equation thus derived is given as,

$$
\begin{aligned}
\log Y_{1}= & 2.56+0.27 X_{1}-0.03 X_{5}+0.04 X_{3}+0.22 X_{16}+0.13 X_{18} \\
& +0.04 X_{2 l}
\end{aligned}
$$

and once again the $r^{2}$ value $\left(r^{2}=0.950\right)$ was reduced at the some time as the regression deviation (S.E.E. $=3.9 \%$ ). However, there is one basic difference between these results and that for INTC7 In that in this equation there are none of the structural variebles which had been present in the INTC7 $\varnothing$ regression, and once again the emphasis.is retrined with the psychological and human aspects of the road accident situation. This comparison of significant variables is shown in Table $(9 \cdot 3 \cdot 7)$.

When the original dependent variable was regressed against the county Borough areas (C.B.S.) the situation was again shown to be static over space, with the explanation level renaining almost constant $\left(r^{2}=0.385\right)$ and the regression deviation being slightly 
reduced (S.E.E. $=12.17)$. The derived CBS regression equation is the one given below, and it can be seen from this and Table (9.3.8) the similarit between the sets of significant variables for both of

$$
\begin{aligned}
Y_{1}= & 1040.8+1009.2 x_{1}-65.8 x_{2}+54.9 x_{17}+37.0 x_{18} \\
& +206.4 x_{20}-79.7 x_{21}-45.9 x_{22} .
\end{aligned}
$$

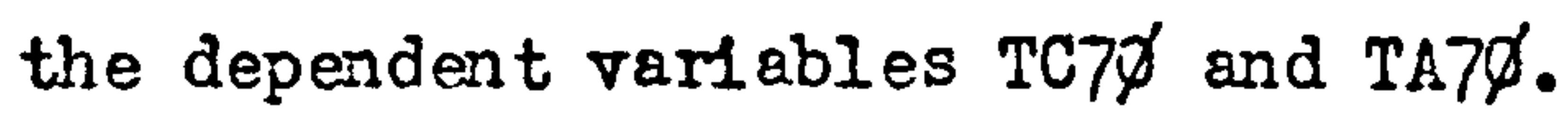

\section{3) TOTAL CASUALTTES PER 103 POPULATTON 1970 (TCPP7ஜ)}

It was indicated in the discussion upon the regression equation derived for the dependent variable TC7 $\varnothing$, that the dominence of the independent variable INTACT7 in explaining the variation in TCTף could simply be related to the fact that the volume of road casualties increases as does the size of the urben area being studied. If this assumption was correct then one would also expect TCPP7 to be virtually constant for all the urban areas studied. Yet the mean value for 1970 was 5.744 with a standard deriation of 1.102. The relevant question therefore is once the population factor has been held constant (admittedly in a linear manner) what other factors account for the remaining variation. Theoretically it would appear that whatever factors are found to be significant, would be the structural ones which can perhaps be modified so as to allow beneficial changes to take place. Unfortunately the derived regression equation for TCPP7ף was found to account for only aporoximately 30 : of the 


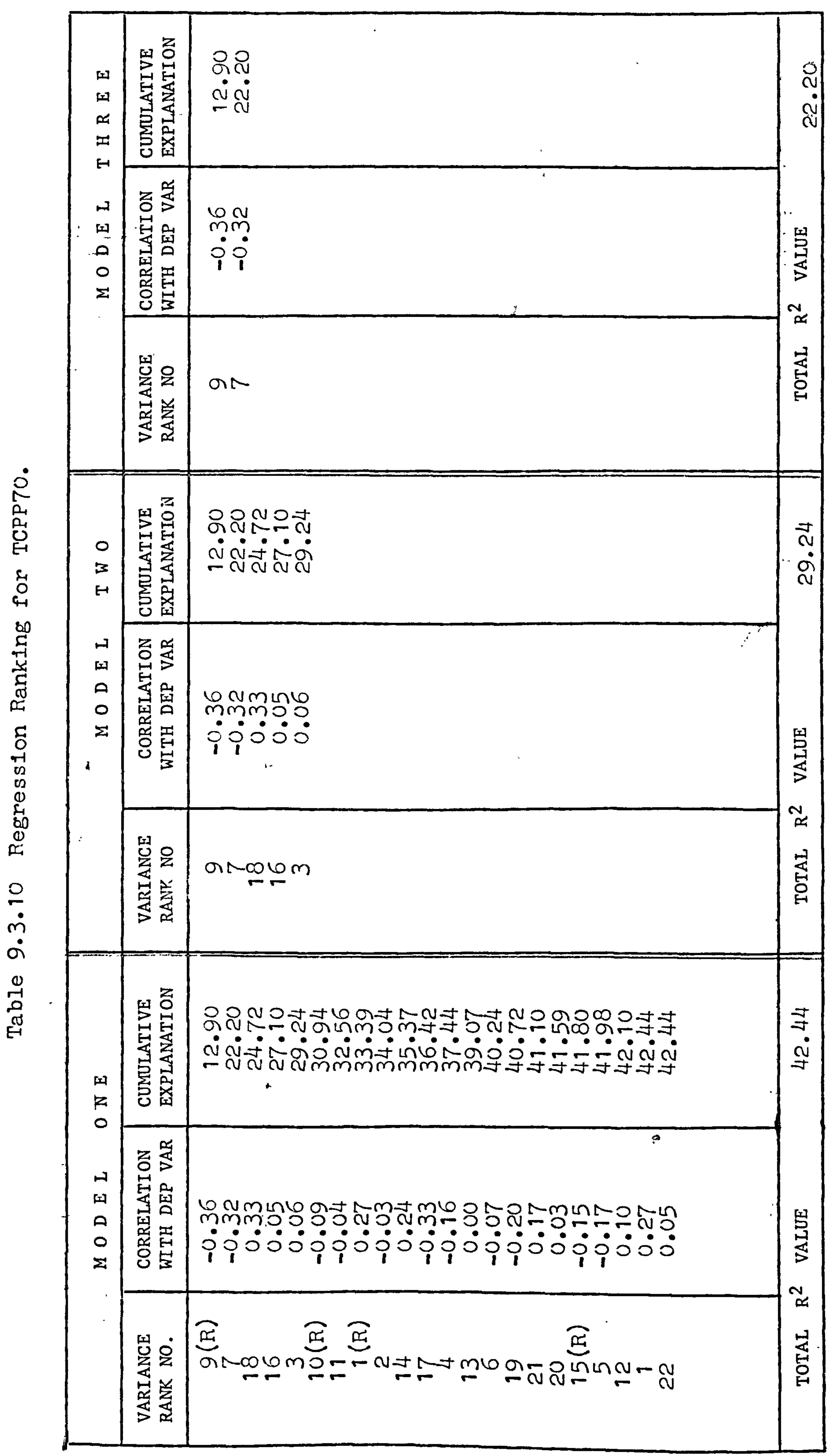


variation in the dependent variable $\left(r^{2}=0.292\right)$, whilst the regression variance was also relatively high. (S.E.E. $=16.6 \vec{b}$ ). However, the regression as a whole with an $F$ value of 7.77 and 5 and 94 degrees of freedom was significant even at the 0.001 probability level. The derived regression was given as,

$$
Y_{i}=5.68+0.167 X_{3}-0.416 x_{7}-0.292 x_{9}+0.222 x_{16}+0.279 X_{18}
$$

Comparing this equation with the regression ranking for TCPP7D given in Table (9.3.10) it can be seen that the two most important variables are $X_{7}:$ SHI $7 \varnothing$ and $X_{9}:$ NETT $7 \phi$, with $X_{7}$ accounting for almost 9,6 of the total variation and $x_{9}$ almost 130. The importance of the level of through traffic would once again appear to have been demonstrated, whilst SHI $7 \varnothing$ would also seen to indicate the advantages to be obtained from modernisation and perhaps redevelopment. It should however, be remembered that only $30 \%$ of the variation in the dependent variable has been accounted for by this regression.

A study of the residual graph plots complicates the matter further since as can be seen in Fig. (9.3.11), the plot between $e_{i}$ and TCPP7D reveals a systematic error. The derived regression equation is obviously over-predicting the lower casualty rates and under-predicting higher rates. Consequently the dependent variable was given a logarithmic transfornation to see if this error could be removed and whether the overall explenation level increased. The results along with the significant variables are given in Table (9.3.7). From this it can be seen that there is still virtually 





no change in the explanation level with $r^{2}=0.300$ and the regression equation being defined as below,

$$
\log I_{1}=0.75-0.02 x_{4}-0.04 x_{7}-0.03 x_{9}+0.01 x_{14}
$$

Similarly since the systematic error still remoins, one must conclude that the structural variables on their okn still do not explain this rariation and in the context of the rosd accident system one must look at the other sub-systems in order to explain this variation. Once again the sub-system which would seem to be the most relevant in this context would be the hunan sub-systen and the different psychological response related to different levels of congestion and interaction, with strcss ctc. being much higher in those more congested (larger) urban areas.

However, in such a situation one vould expect that the level of explanation associated solely with CBS areas vould be higher. Unfortunately the derived regression equation for these areas given below, whilst having a lower variation about the

$$
Y_{C B i}=6.00-0.225 X_{2}-0.204 X_{9}-0.251 X_{10}
$$

regression plane (S.E.E. $=12.1, b)$ does not have a better explenation level with $x^{2}=0.231$. Meanwhile it is relevant that the $\mathrm{X}_{0}$ value for this regression is considerably higher than for all the 100 sampled areas: 6.00 compared to 5.58 .

The conclusion that must be drawn therefore conceming this regression equation is that given the present level of infornation we are unable to account for the observed variation with any 
certainty, but it is postulated that perheps the solution could be found within the human psychological sub-system.

\section{4) TOTAL ACCIDEITS PER 103 POPUTATION 1970 (TAPP7D)}

Once again the results for this regression are very similar to the equivalent casualty variable described above, and consequently the arguments put forward for that variable (TCPP7 $\phi$ ) are also applicable within this regression.

The explanation level for TAPP7ף was once again found to be very low $\left(r^{2}=0.285\right)$ and with a high regression variance.(S.E.E. = 17.46). The derived regression equation is given as below.

$$
I_{1}=4.47-0.20 \dot{x}_{5}-0.22 x_{9}+0.21 x_{16}+0.23 x_{18}
$$

If this equation is compared with the equivalent regression for TCPP7 $\varnothing$ it will be seen that the only difference in variable inclusion is that this regression (TAPPTD) has replaced variable $X_{7}$ : SHI7 7 , with a varikble $X_{5}$ : CHSI7\%. However, es can be seen from the regression ranking given in Trble (9.3.11) the matter is further confused by the fact that it would appear that these two variables are interchangeable. As a result the inclusion of one seems to lead to the exclusion of the other end vice-versa.

Due to the similarity between TAPP $7 \varnothing$ and TCPP7 $7 \varnothing$ it ras deemed unnecescary to test this regression with any trinsformation, even though the systematic error noted above wes also present in the TAPP7 graph plots. There was however, \& comparison with 


\begin{tabular}{|c|c|c|c|}
\hline \multirow{3}{*}{ 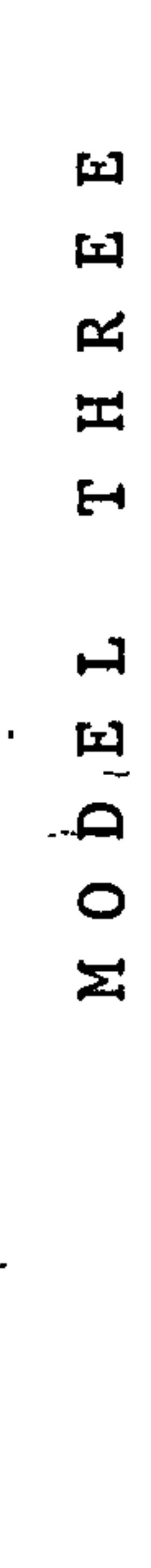 } & 舅总 & 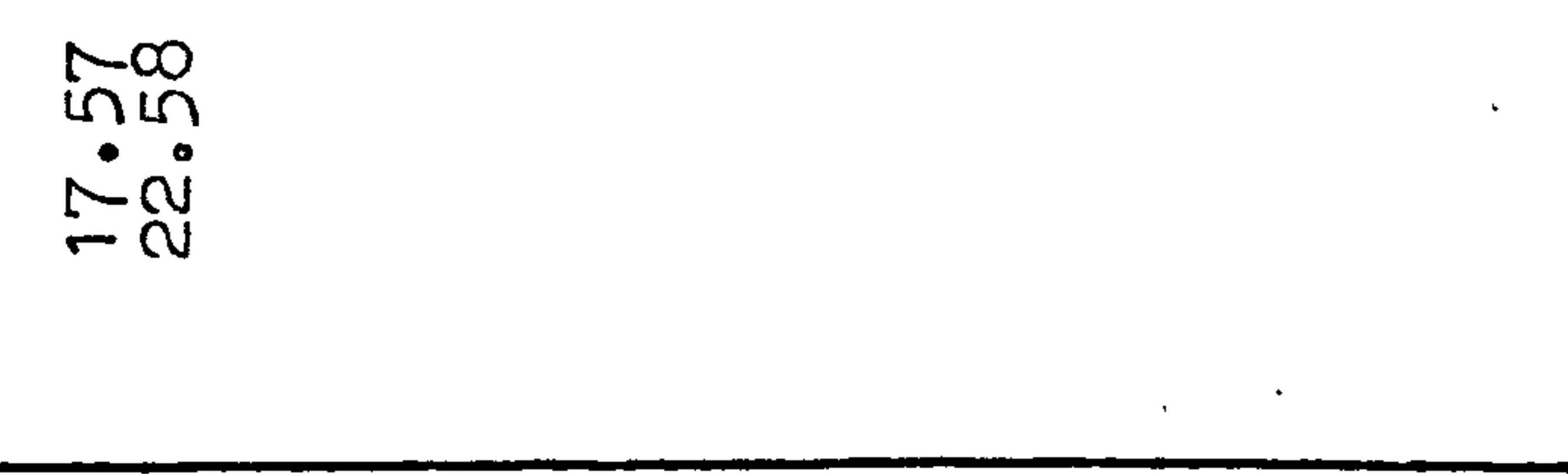 & 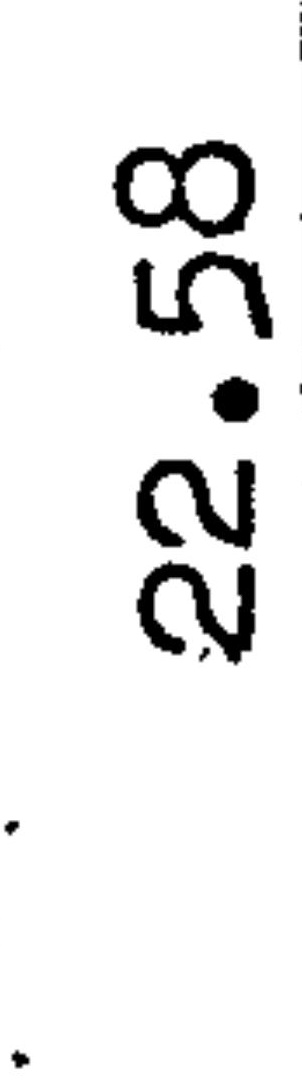 \\
\hline & 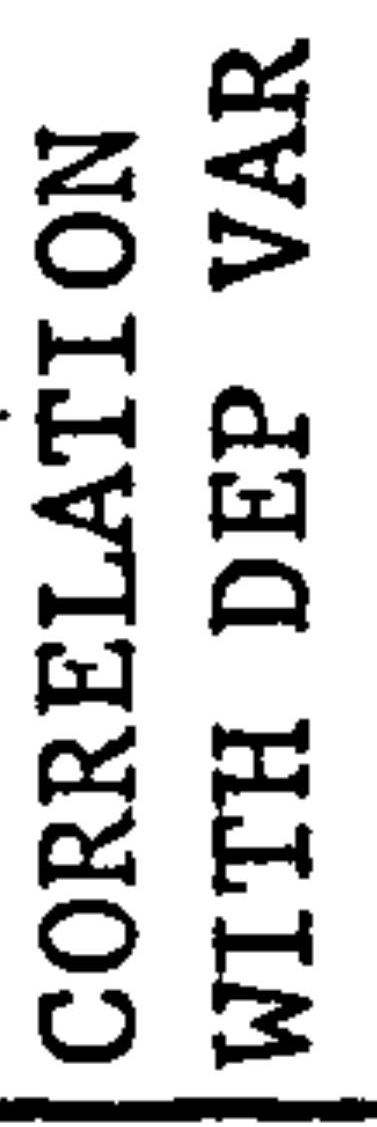 & 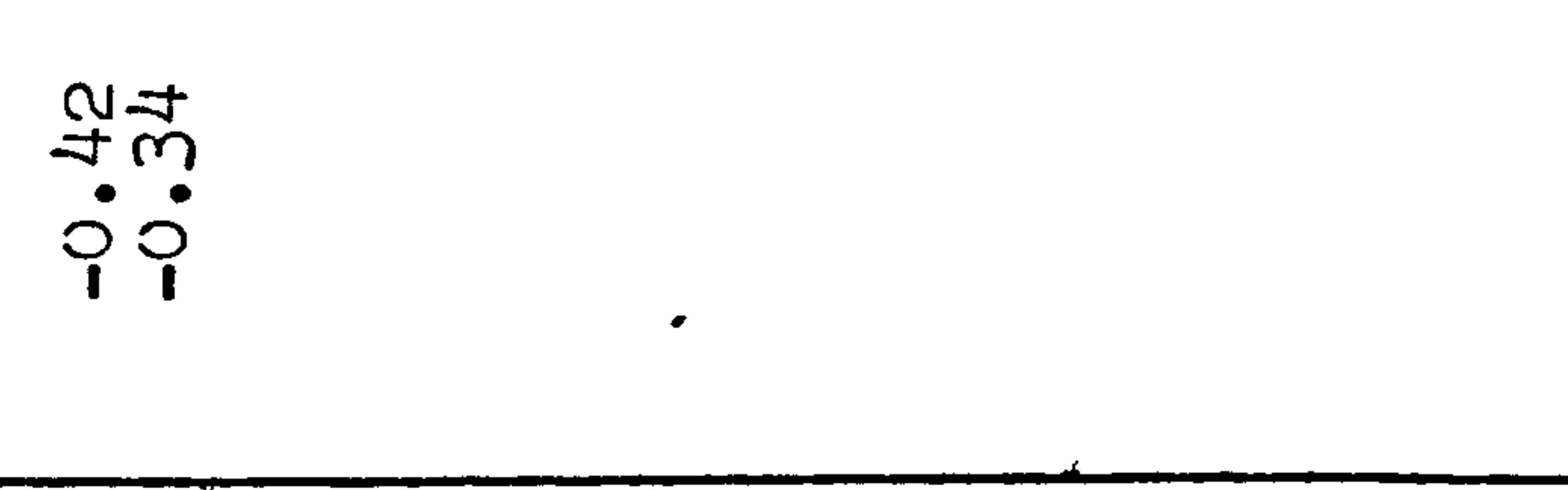 & \multirow{2}{*}{ 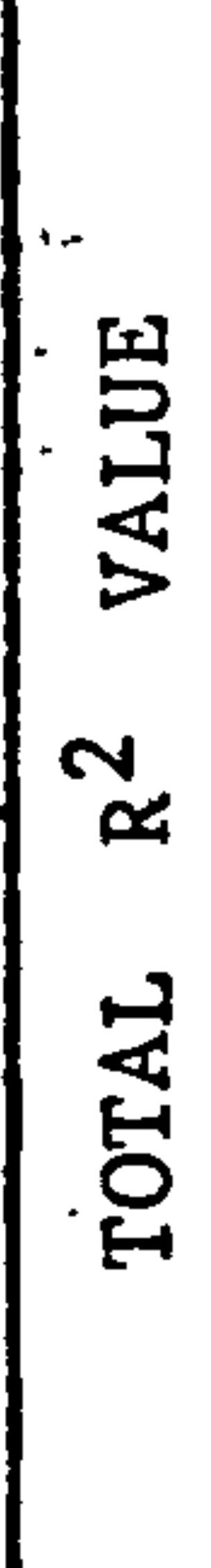 } \\
\hline & 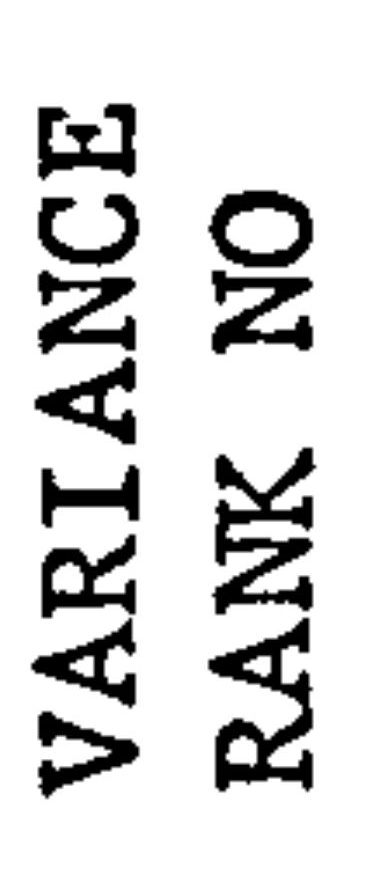 & aLn & \\
\hline \multirow{3}{*}{$\begin{array}{l}0 \\
3 \\
H \\
1 \\
1 \\
0 \\
0 \\
\Sigma \\
\Sigma\end{array}$} & 留总 & 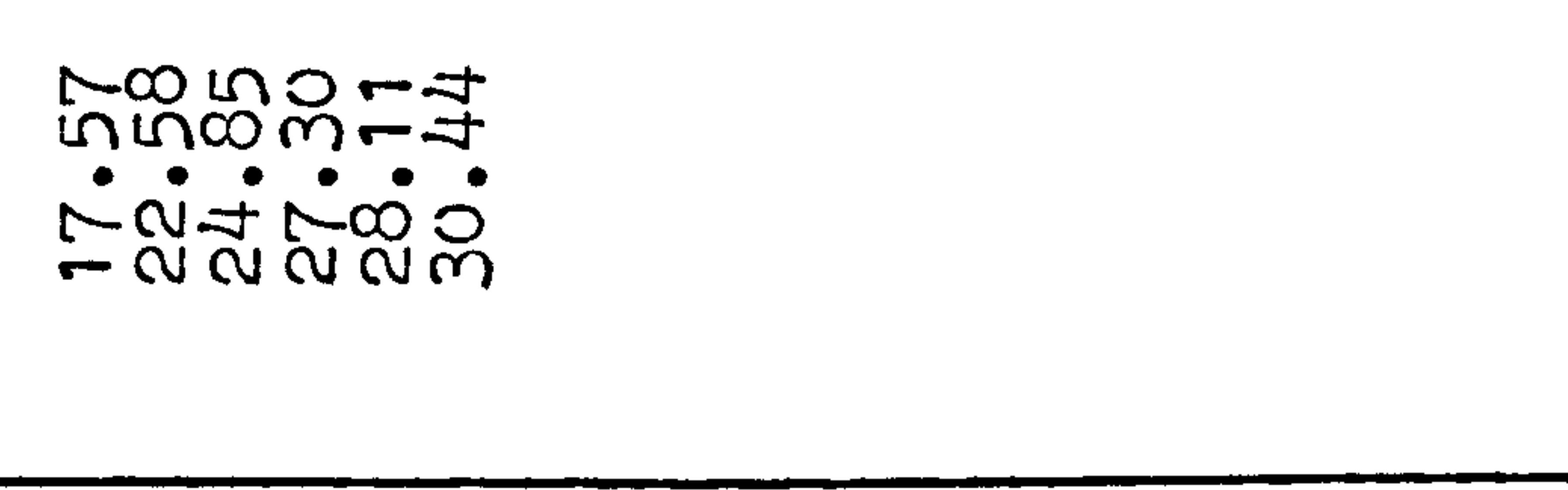 & 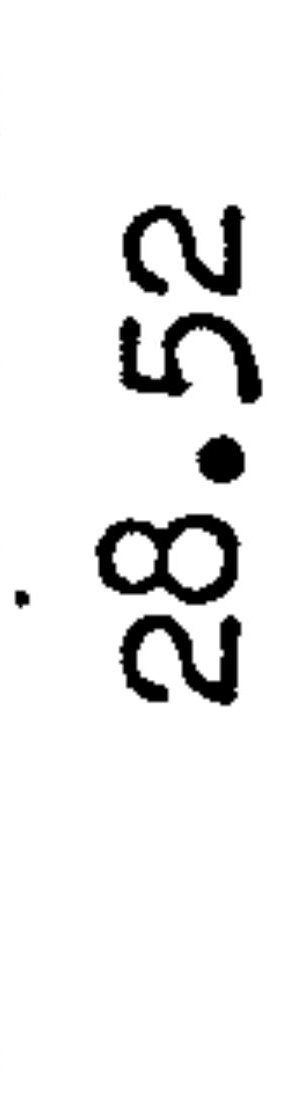 \\
\hline & 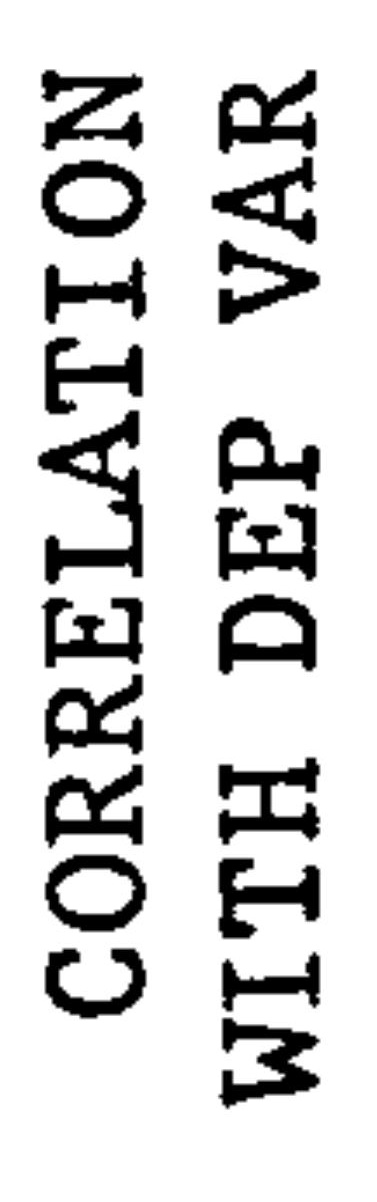 & 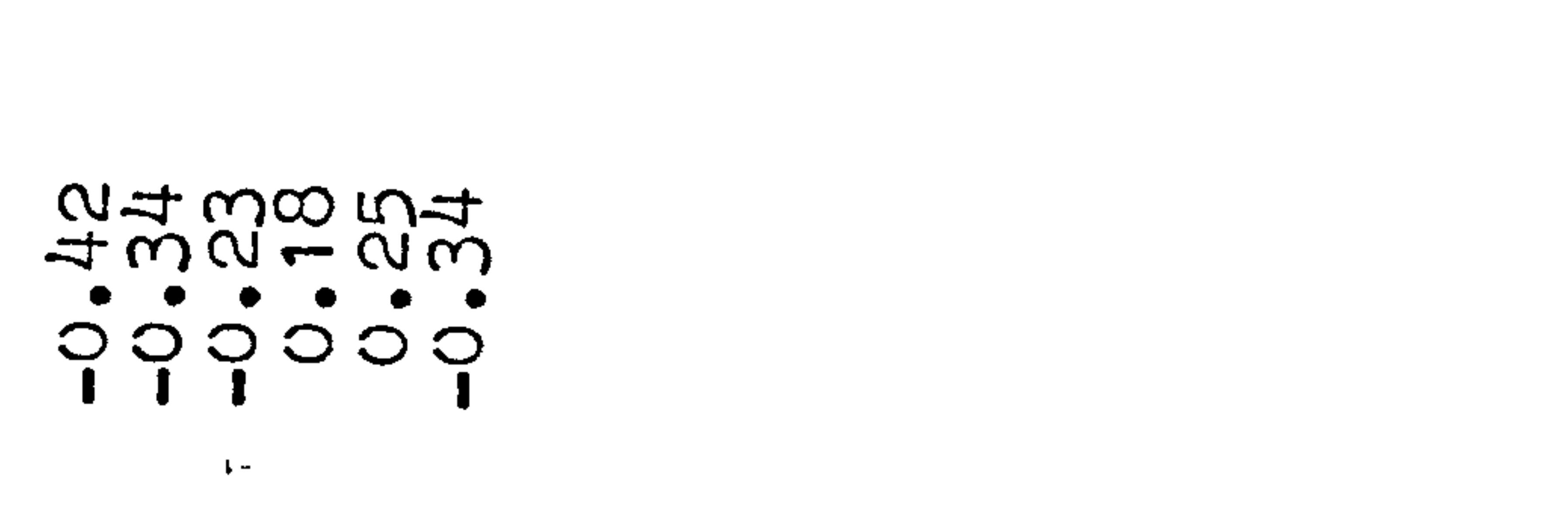 & \multirow{2}{*}{ 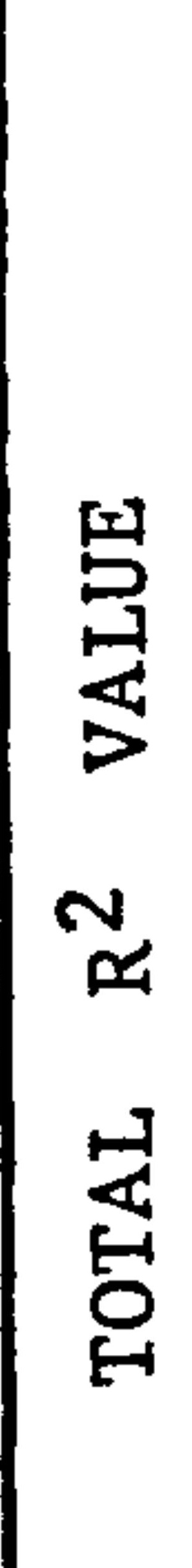 } \\
\hline & 獀。 & 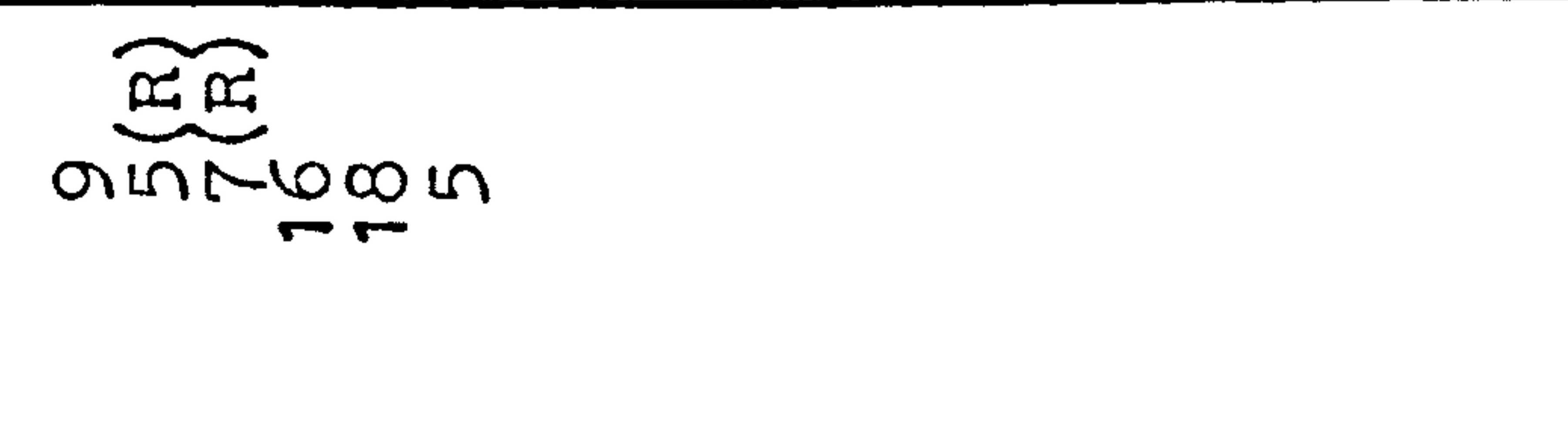 & \\
\hline \multirow{3}{*}{$\begin{array}{l}\text { II } \\
12 \\
0 \\
4 \\
\text { का } \\
0 \\
0 \\
\Sigma\end{array}$} & 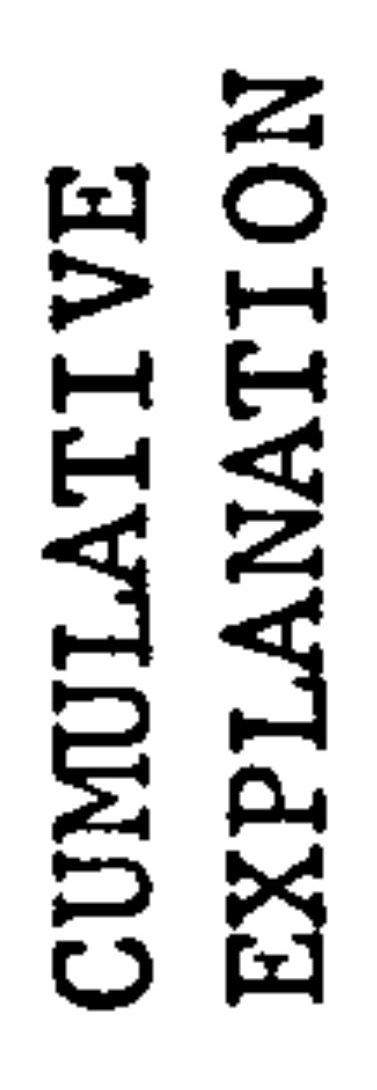 & 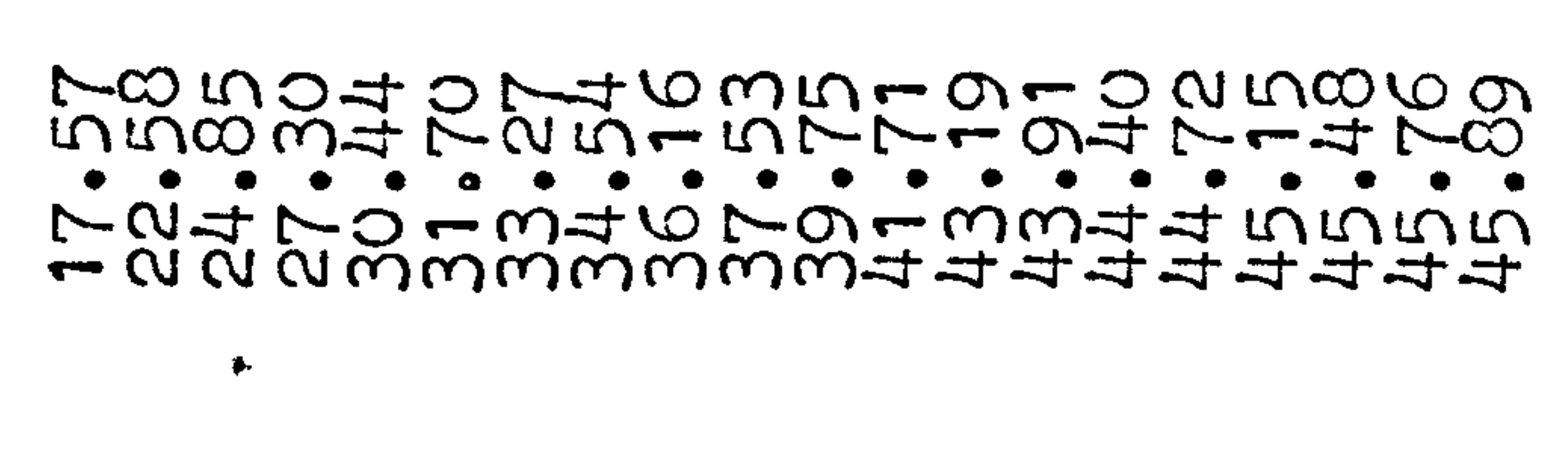 & $\begin{array}{l}\infty \\
\infty \\
\dot{f}\end{array}$ \\
\hline & 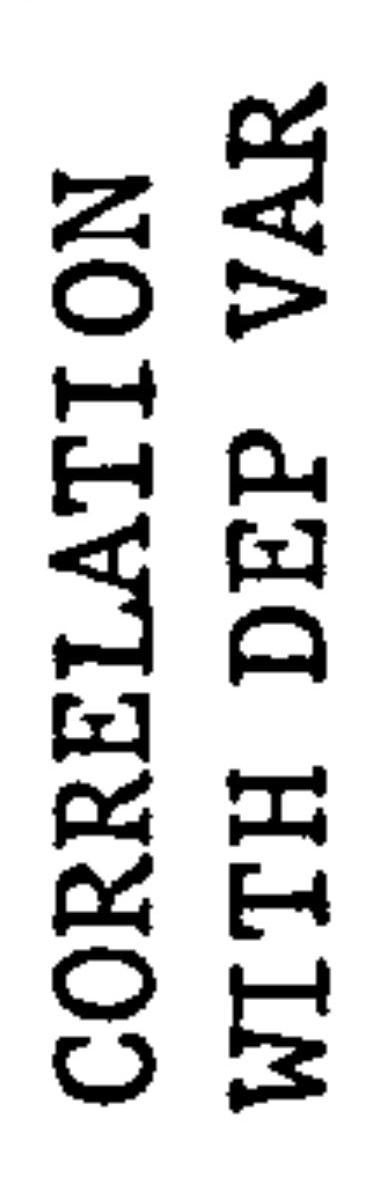 & 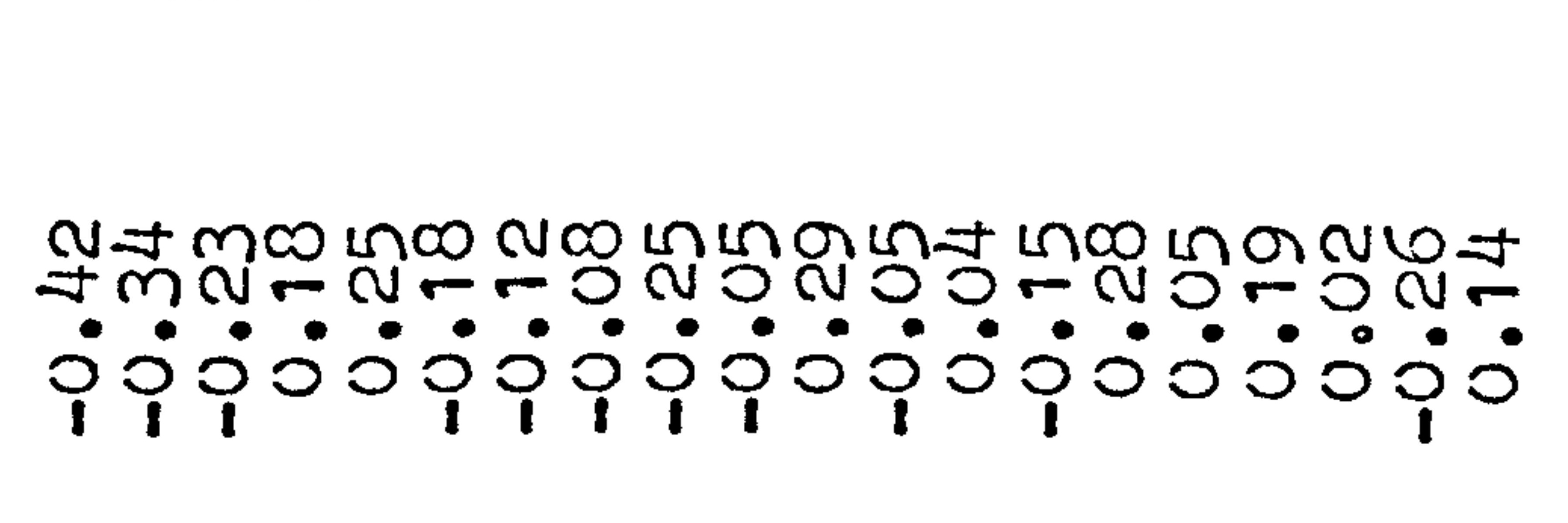 & \multirow{2}{*}{ 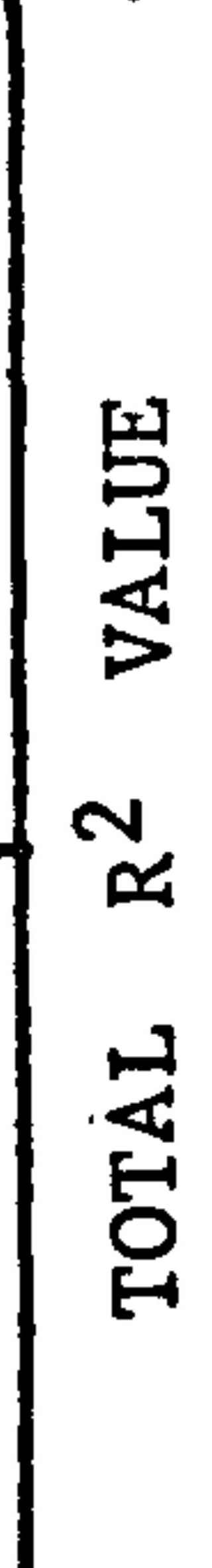 } \\
\hline & 四 & 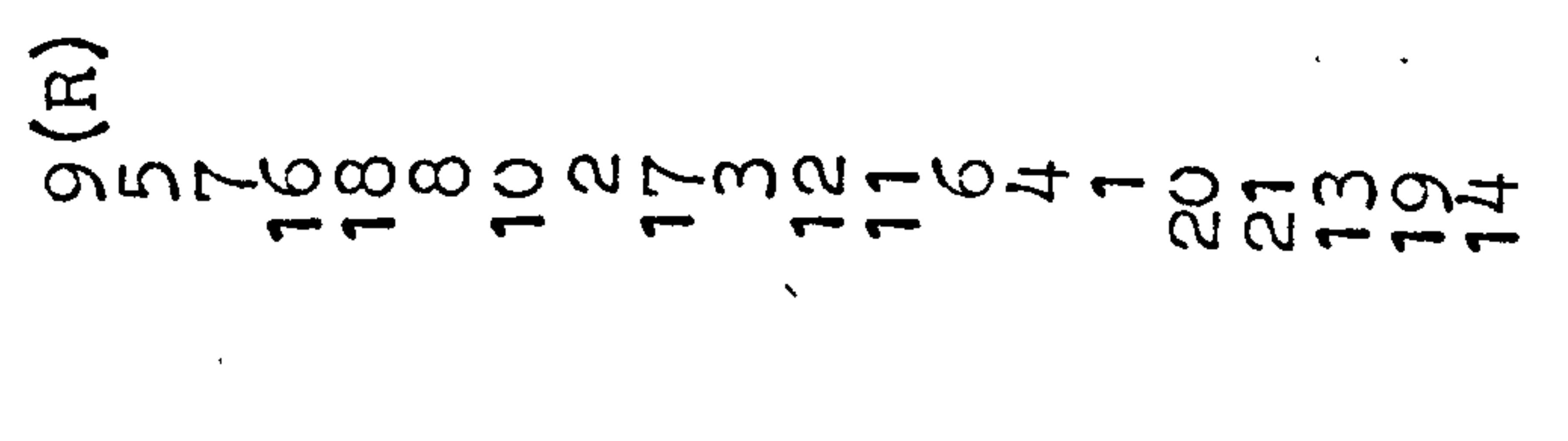 & \\
\hline
\end{tabular}


the CBS arees. The derived regression equation is given belor.

$$
Y_{C B_{1}}=4.79-0.152 X_{2}-0.209 Y_{10}+0.199 X_{18}
$$

but us was expected there was little improvenent in the overall sultebility of the model. The level of explanation was in fact recuced to $r^{2}=0.225$ although the variation about the regression plene was also recuced to, S.E.E. $=13.0 \%$. Basically however, especially since the overall regression sigrificence level vias only low $(F=4.54)$, it must once egain be stressed that little confidence should or can be placed on either of these last tro sets of regression equations.

\section{5) TOTHI PFDESTFIAN CASUALTIFS 1970 (TPEDTQ).}

The level of pedestrier cesucilties in eny urben area vas found once again to be highly related to the size and degree of interaction within that area. It can be seen from the derived equation given below that

$$
\begin{aligned}
Y_{1}= & 248.4+575.8 X_{1}-19.62 X_{3}-12.8 x_{10}+22.7 X_{15}-14.2 X_{16} \\
& -12.0 X_{17}-55.9 x_{18}
\end{aligned}
$$

the only significent variebles outside these size variebles were $X_{3}: \operatorname{coin} 7 \phi$ and $X_{10}: C I 7 \phi$, of which it would seem only the latter may be modifled in order to control the value of TPEDT 4 . The significence of $10 \% 7 \phi$ is of little surprise since the inverse relationship noted simply shows that es the level of car ownership increases, the number of pedestrien casualties decreases. The simple result therefore of verying pedestrien exposure. 
The regression ranking for TPED7 $\varnothing$ in Teble (9.3.12) shows the impact once egain of $X_{1}$ : INTACT7\%. This variable accounts for $96 \%$ of the total variction in TPED7\%, vith only $X_{18}:$ NPOP accounting for $\varepsilon$ percentage $>1,0$

The overall explanation level of the regression equation is approsimately $99 \%\left(r^{2}=0.988\right)$ end the variation about the regression plane ves $16.2 \%$. Thus although the variction in this dependent varieble was well expleined by this regression equation there was a fair emount of regression deviation. However, a stucy of the residual plots for TPED7 reverled no abnormalities, end when a logarithmic transformation was epplied there was a recuction in the level of explanation $\left(r^{2}=0.965\right)$ es well es a reduction in the regression varietion (4.36). For these reasons therefore this line of study was not persued any further.

When IPEDT/ was looked at in relaticn to the CBS ares. it was found that en even better relationship was derived with the level of explanation being raised to $r^{2}=0.992$, end the regression varience recuced to $10.1 \%$. The regression equation derived is given below and the close compariscn with the originel regression

$$
\begin{aligned}
I_{C B_{1}}= & 438.2+490.47 X_{1}-22.3 X_{2}-20.1 X_{4}+24.7 X_{15}+41.9 X_{17} \\
& -33.6 X_{18}+107.3 X_{20}
\end{aligned}
$$

equaticn is obvious, end cen be seen in Teble (9.5.8). There is one significant adition in this equation, end that is the introduction of $\mathrm{X}_{4}$ : SHI $\varnothing$ with on inverse relationship with TPED7申. 


\begin{tabular}{|c|c|c|c|}
\hline \multirow{3}{*}{ 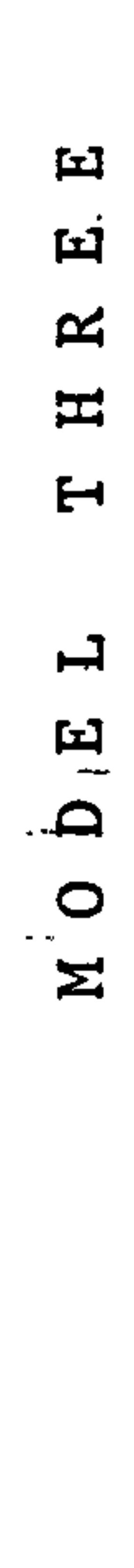 } & 贸总 & 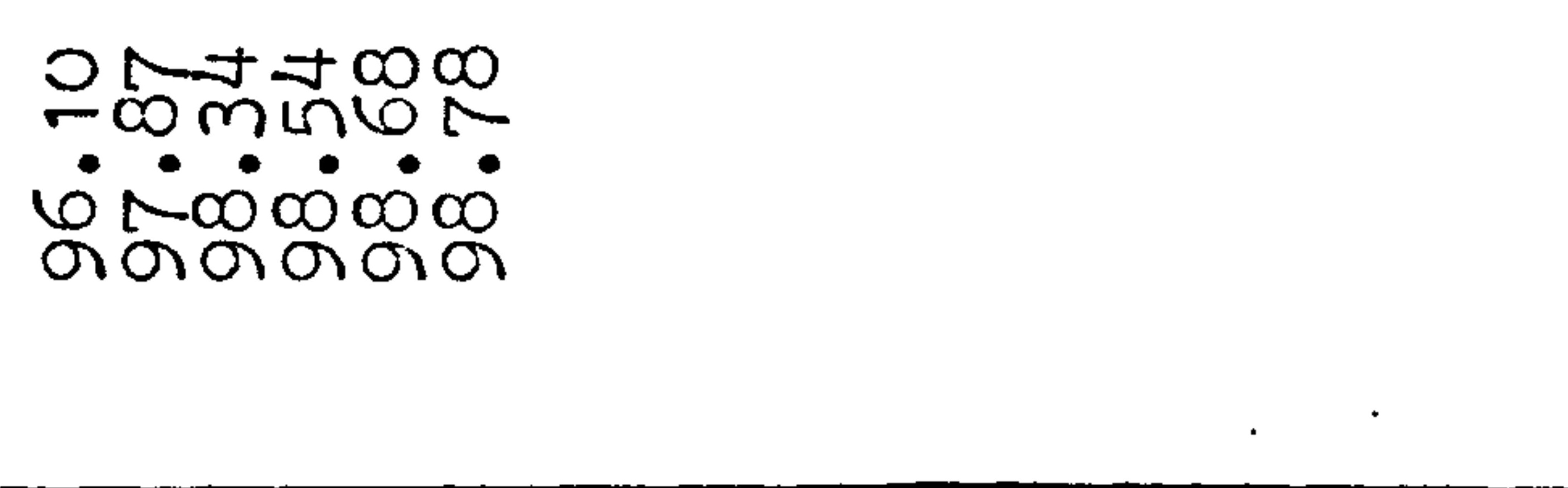 & $\stackrel{\infty}{\infty}$ \\
\hline & 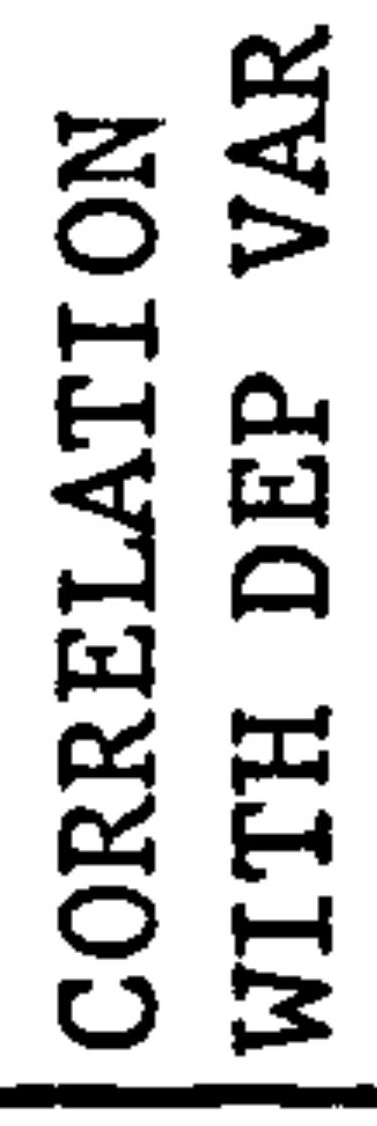 & 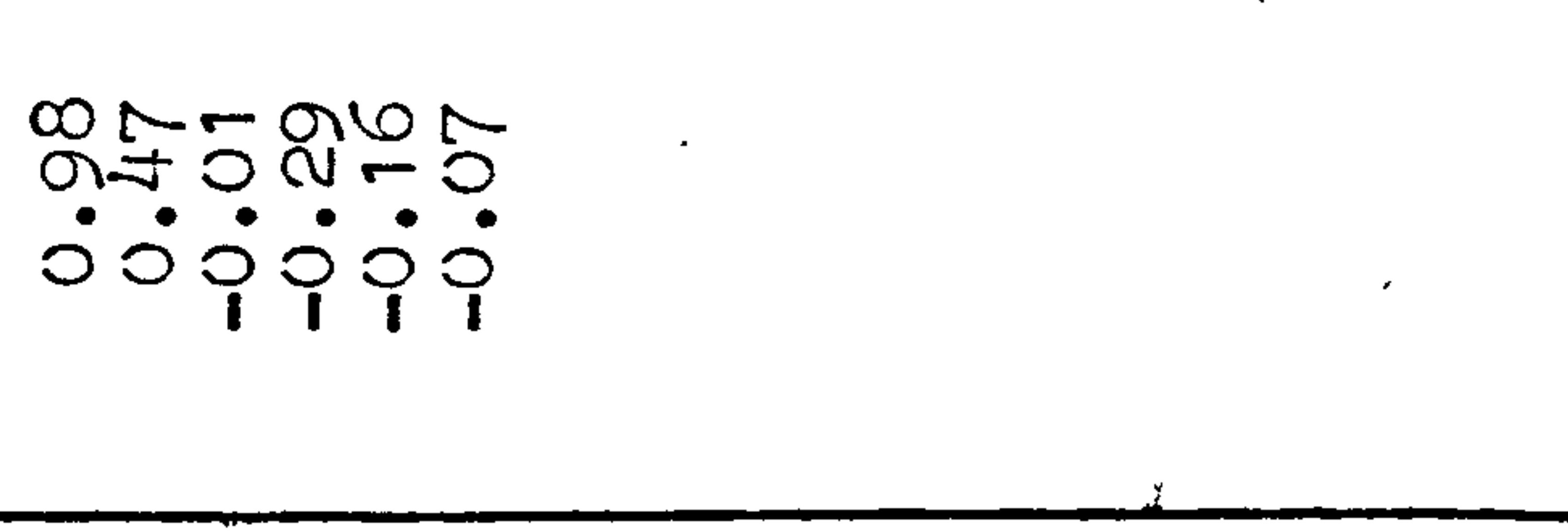 & \multirow[t]{2}{*}{ 憵 } \\
\hline & 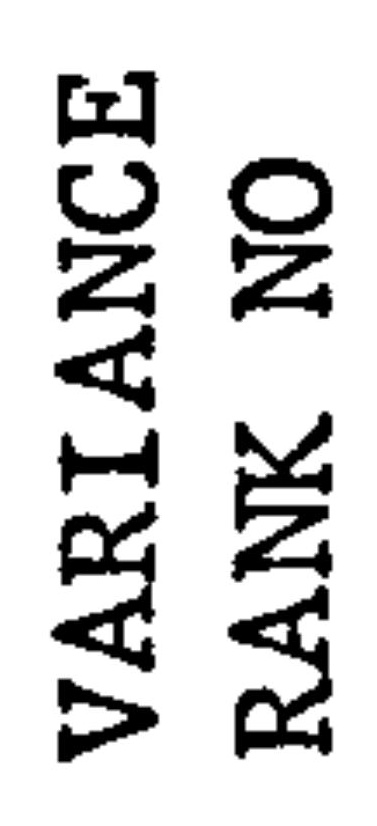 & - & \\
\hline \multirow{3}{*}{$\begin{array}{c}0 \\
3 \\
H \\
\\
H \\
a \\
D \\
0 \\
\Sigma \\
i\end{array}$} & 鼠总 & 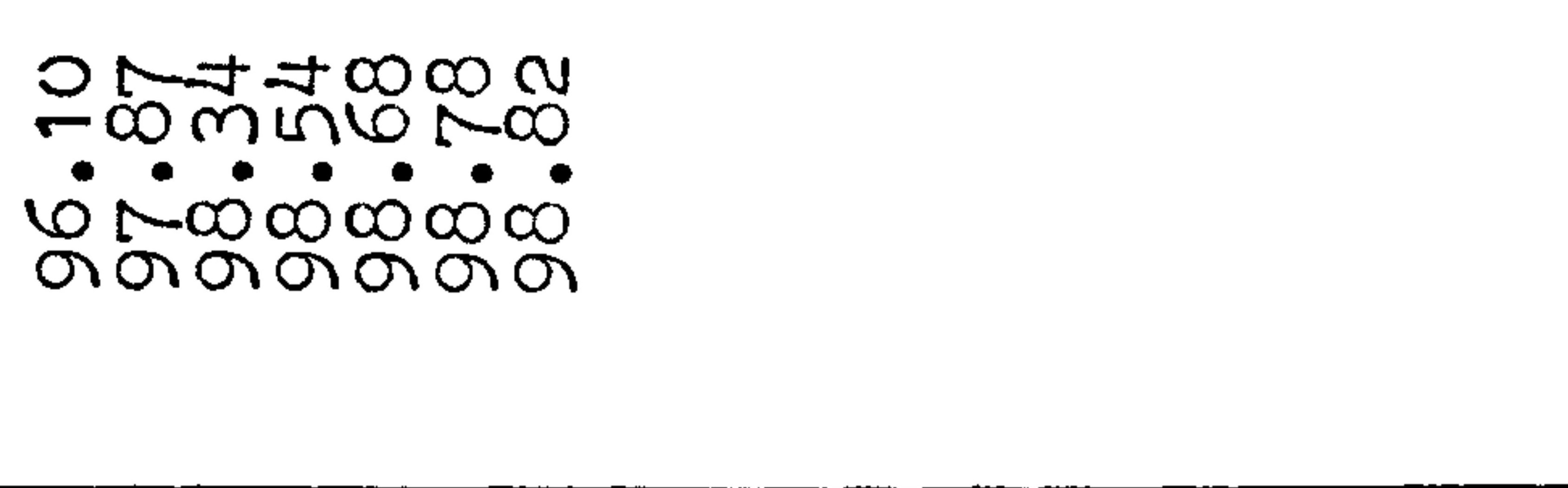 & $\begin{array}{l}\stackrel{\infty}{\infty} \\
\infty \\
\infty\end{array}$ \\
\hline & 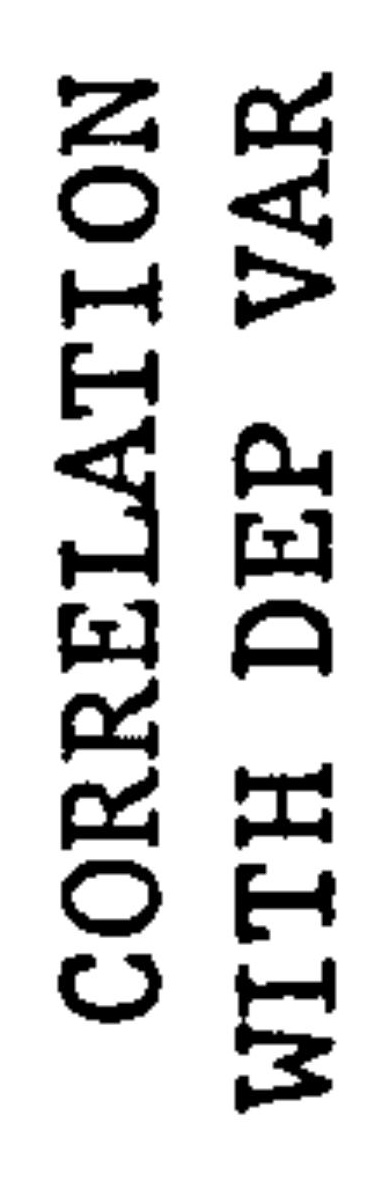 & 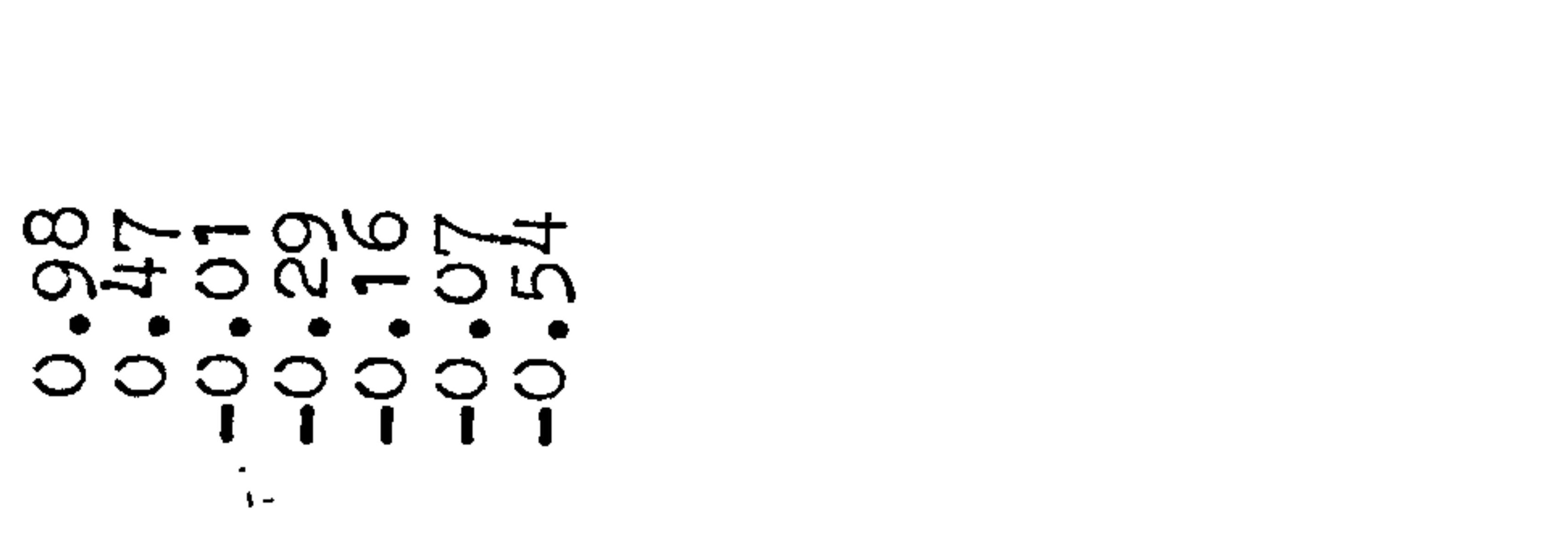 & \multirow[t]{2}{*}{ 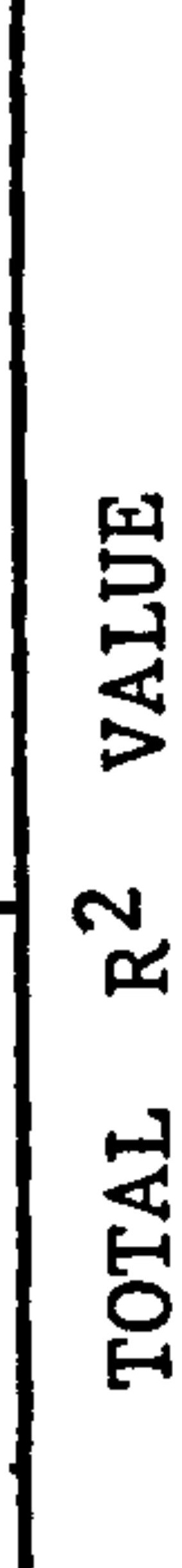 } \\
\hline & 留。 & 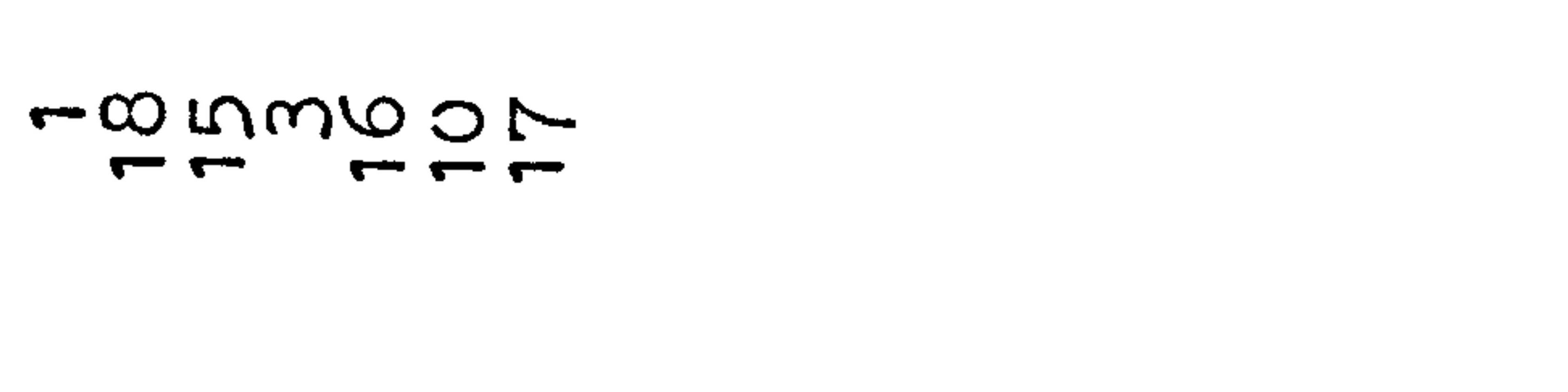 & \\
\hline \multirow{3}{*}{ 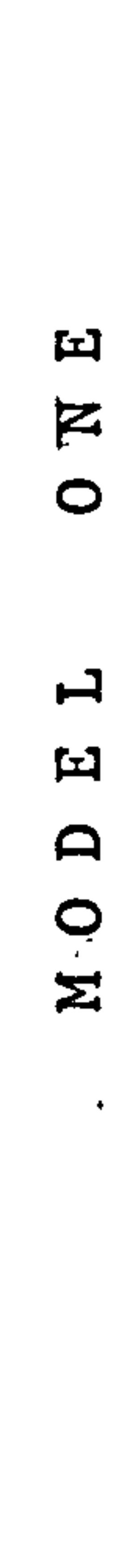 } & 思总 & 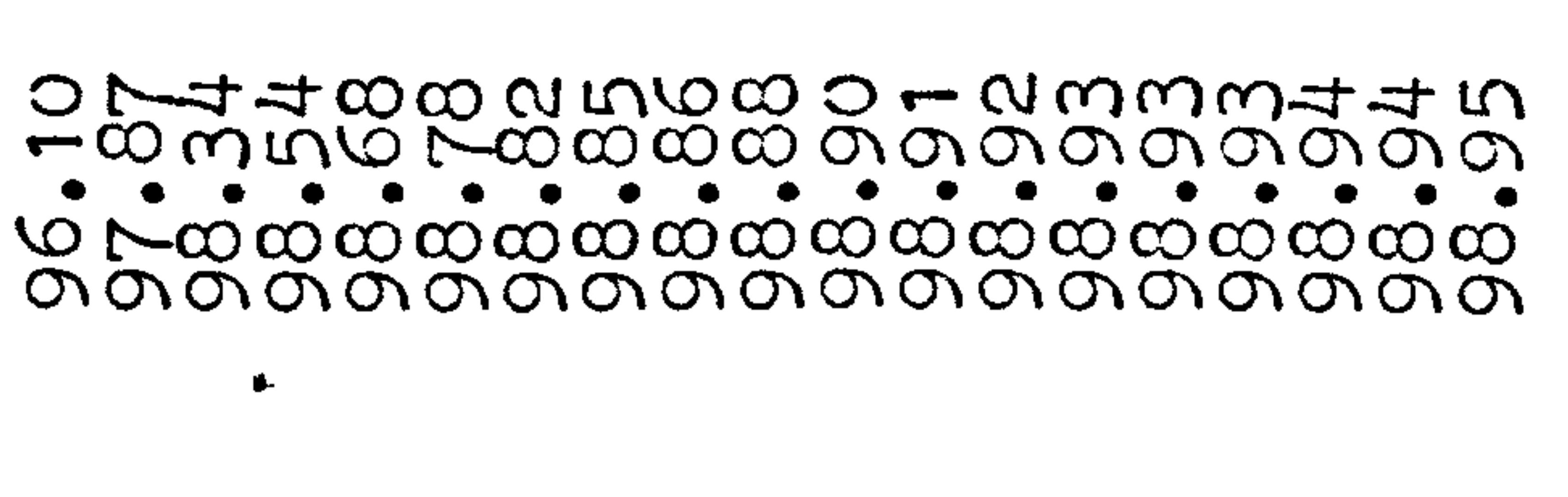 & مू \\
\hline & 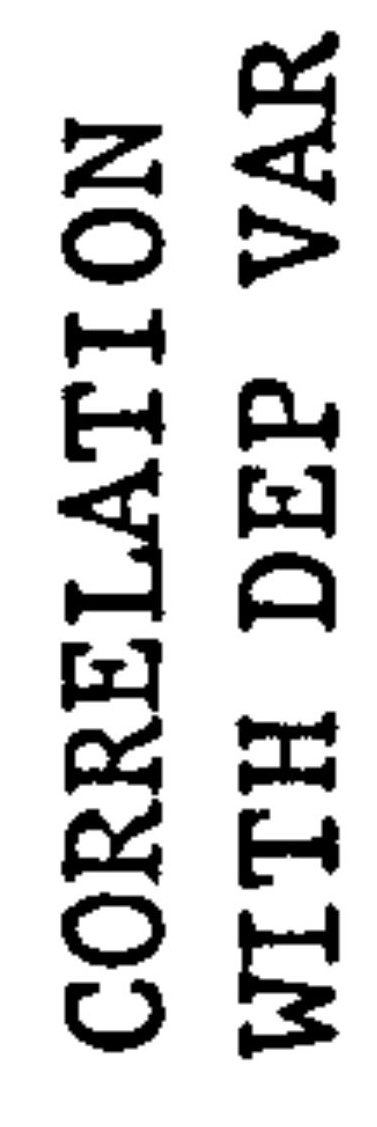 & 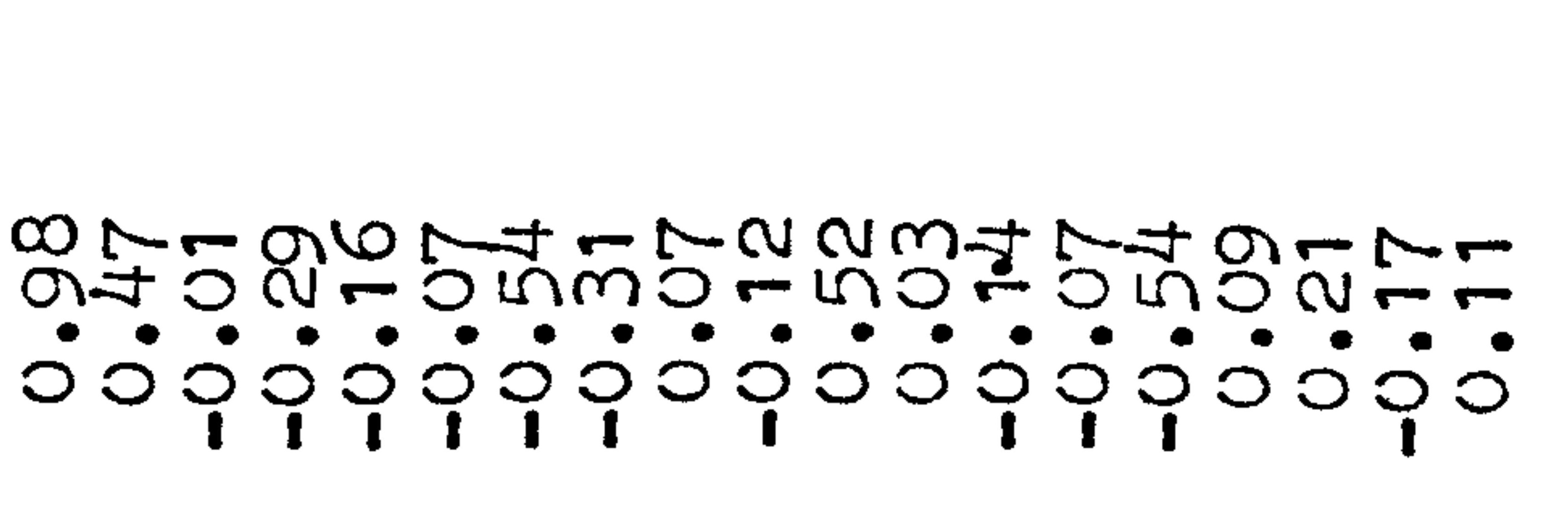 & \multirow{2}{*}{ 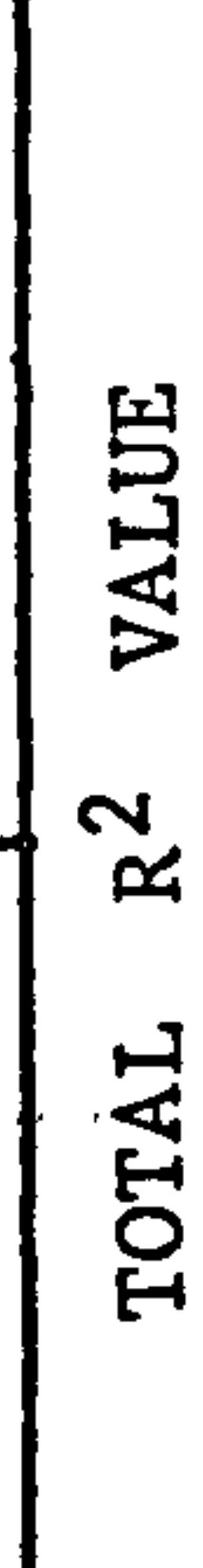 } \\
\hline & 思宗 & - & \\
\hline
\end{tabular}


Although the actual impact of SHI $7 \varnothing$ upon the level of pedestrien cesualties is very limited, it does indicate the marginal impact of such structurel veriebles. Its absence from the original 100 area regression equetion was in some ways surprising, but it woulc seem with hindsight that the impact of SHI7 $\not \varnothing$ is limited in the smaller less urtanised non-county boroughs, and conseguently was deemed insignificent in the total regression situation.

Sumarising therefore it woulc seem that TPED7Ø is mainly expleined by the one varieble INTECT 79 , as was the case with both $T A 7 \varnothing$ and TC7 $\varnothing$. Hoverer, it would also seem that the actual level of pedestrien accidents is also affected by the tho veriebles CI $7 \varnothing$. and COH $7 \emptyset^{\prime}$, with the third verieble SHI $7 \varnothing^{\prime}$ being significent when the influence of non-county borough areas is remored from the regression.

Although the level of explanation for all the regression equations related to TPED7 $\varnothing$ was consistently high, there still remained some regression varience which needs further study. With this thought in mind the impact of the size variebles was once again held constent, and the remaining variation studied in the following regression enalysis.

\section{6). TOTAI PFDFSTEIAN CASTUPTIFS PEP 103 POPUT,ATION 1970}

\section{(TPEIPPTQ)}

The most striking feature of this regression is that whilst the level of explenation for this dependont variable is not as high as those for the absolute dependent variables, it is much higher then those for the compareble variables TCPP7 snd TAPP7 7 . 
The $r^{2}$ value obtrined in this regression was 0.640 , end the regression verience was 16.8,

The regression ranking for TPEDPP7 $7 \varnothing$ is given in Table (9.3.1?) and from this and also the derived regression equation given below, it can be seen that the three size variables $X_{1}, X_{16}, X_{18}$ are all

$$
\begin{aligned}
I_{1}= & 1.64+0.11 x_{1}-0.13 x_{3}-0.14 x_{7}-0.06 x_{10}-0.11 x_{11} \\
& +0.10 x_{16}+0.09 x_{18}-0.15 x_{22}
\end{aligned}
$$

emongst the most importent variables, with the reminder mainly being physical structurel variebles. .

Looking at these significent variables it cen be seen that the one which accounts for the greatest emount of verietion in $\operatorname{TPELPP} 7 \varnothing$ is $\cos 7 \varnothing(32.26)$. As was true in the previous regression, the importance of this varieble lies in its deternination of pedestrien exposure, which must be reloted inversely.

The second variable in importence in terms of level of addi ticnel explenation is $X_{1}$ : INTACT7 which indicates that the level of pedestrian cesualties is not solely related to population size, but $\varepsilon l$ so the degree of interaction, which has not been fully accounted for by holding the population levels of different urben Erez.s constent.

The remaining variebles in this regression meenthile include

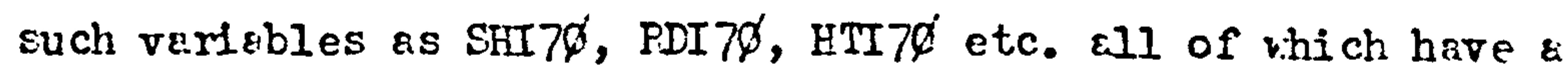


negative relationship with the dependent varieble, and which all account approximately for $2 \%$ of the variation.

The results of this regression inply that although the number of pedestrian casualties increases with the populaticn size of that urben area, the actual relationship is much more complex with severgl structural variables being able to modify this simple increase. When one compares these conclusions with those for TCPP7 $\varnothing$ and TAPP7 $\varnothing$, the most obvicus difference revolves around the fact that TPEDPP7 $\varnothing$ seems to be affected meinly by internal structural factors, whilst the other two variebles seen to be more affected by external influences such as the emount of through traffic. The implication here therefore is that what mas be suit able for one type of casurlty mey not suit the other type of casualty, end in some cases these two groups could be in direct conflict, with each other. Basicelly this difference cen perhaps be categorised by the fact that one needs a macro epproach whilst the other needs a. micro approach, which must be implemented through the direct study of, end applicetion of locel problems end remedies.

When IPECPP7 $\varnothing$ is studied in relation to the CBS arees only, the overall level of explenation is slightly reduced to $r^{2}=0.528$ but at the same time the variation about the regression plane is recuced to $14.0 \%$

The verigbles that are found to be significant in this CBS regression are very similer to those found in the original regression, al though as the derived regression shows below, there were some 
interesting modifications. For exemple the variable C0r.7 $\varnothing$ was

$$
\mathrm{Y}_{\mathrm{CB}_{1}}=1.92-0.1 \mathrm{CX}_{2}+0.19 \mathrm{X}_{3}+0.08 \mathrm{X}_{6}-0.15 \mathrm{X}_{13}-0.10 \mathrm{X}_{18}
$$

replaced by the varieble $\mathrm{X}_{18}: \nabla \mathrm{FI} 7 \not$, which however, measures virtually the seme thing. Similerly included in this equation

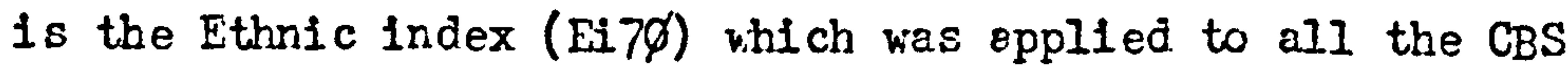
regressions. Although this variable is only just statistically significant, the recorded positive relationship with TPEDPP7 $\varnothing$ does perhaps emphasise the particuler problems of these immigrent sections of the population, and the adventeges which may accrue from further attention in this area of road safety propagenda end education.

\section{(7) DOTAL CESUALTIES PER $10^{6}$ VHHTCLE-NILFS 1970 (TCVM7\%)}

This varieble which relates total casuelties to velicle miles trevelled is the simplest exposure dependent varieble used In this reseerch. As was pointed out earlier in this report, the Inclusion of some measure of exposure has continually been proved to be vitel in research of this kind. For exemple, without exposure it was possible to conclude that young drivers are more probable to heve en accident due to inexperience, then eny other group of drivers. Yet recent research has shovn that perhaps if exposure retes are included this group of drivers is no more vulnerible then any other group. Accordingly, therefore this variable wes looked upon as being very importent in this research.

The regression ranking for TCVM7 $\varnothing$ is shown in Table (9.3.14) and the derived regression equation is presented belo:. 


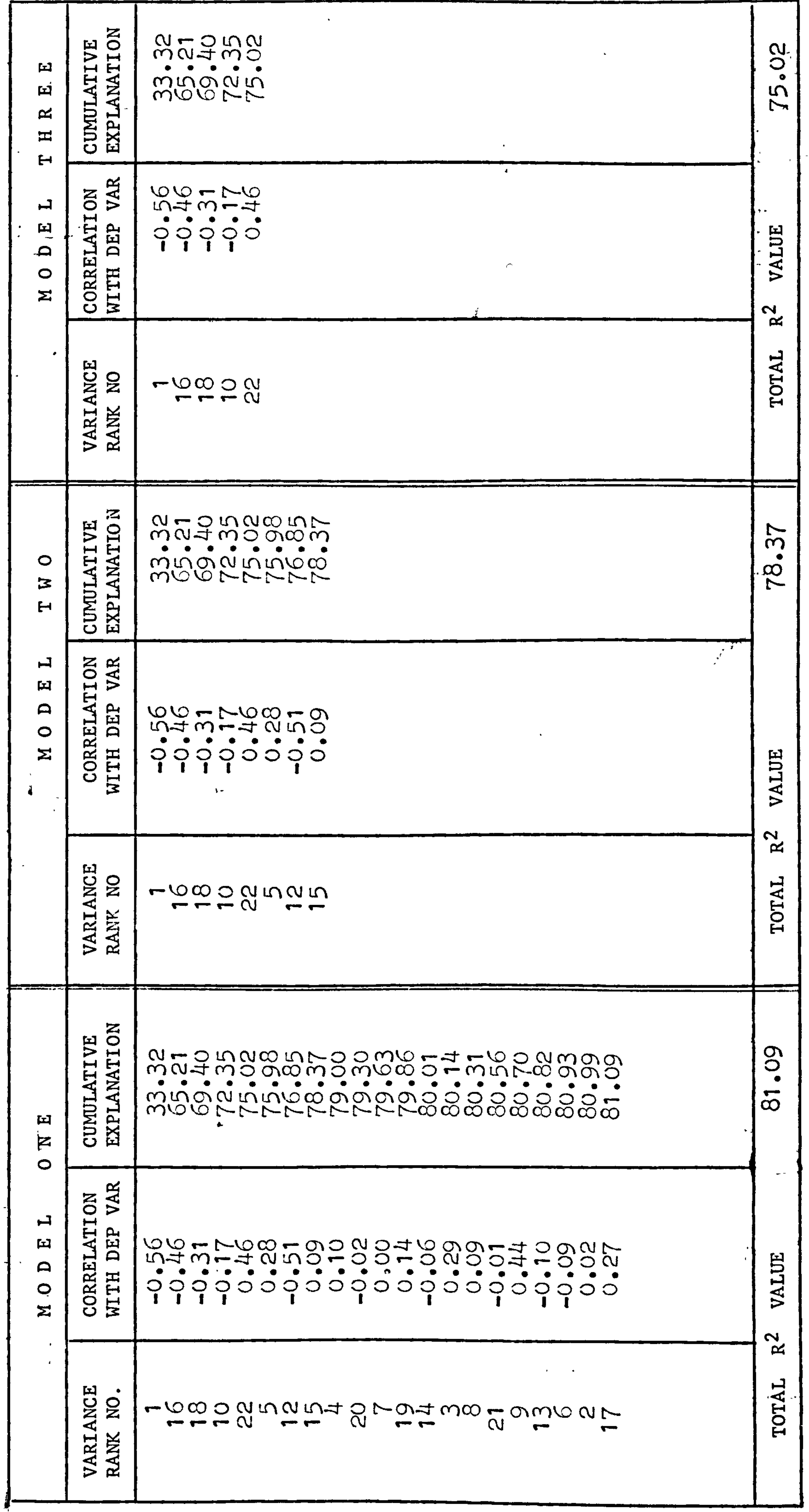




$$
\begin{aligned}
Y_{1}= & 18.83-8.02 x_{1}+1.70 x_{5}-2.47 x_{10}+5.44 x_{12}-2.61 x_{15} \\
& -9.33 x_{16}-4.56 x_{18}+3.96 x_{22}
\end{aligned}
$$

The level of explenation produced by this equation was reasoneble accounting for almost 79,6 of the total variation in TCVM7 $\not$. However, when the degree of regression variance wes calculzted it was found that S.E.E. expressed as a psrcentrge of the mean response, equelled the high volue of $34.5 \%$. In any situation such a velue vould alweys cast considereble doubt uoon the actrial model used in this regression. However, before moving on to this problem, it would be useful to have a quick detziled look at the variables introduced into this regression.

The most important verieble in explaining the veriation in

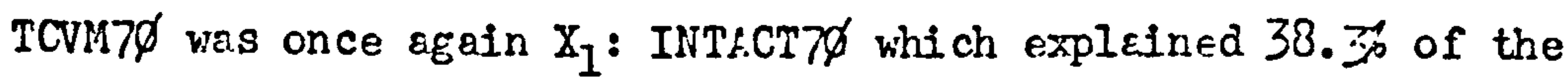
variation. This time however, the relationship derived between INTACT7 and the dependent variable was negative. That is, as the degree of interaction increases the volume of road casualties per vehicle-mile is decreased. Thus one comes to the situation that elthough the larger urban areas are more "exposed" (in terms of vehicle-miles trevelled) then smaller urben areas, these lareer areas are relatively more sefe. This point can also be seen in thet $\bar{Y}$ for $\varepsilon 11$ ICO sempled arens $=18.481$ yet $\bar{Y}$ for cnly CBS arees $=10.08$ : The logic behind this pronouncerent cennot be proved one wey or the other at present, but it cen be hypothesised that the lo:ser TCVN7 $\varnothing$ values are ascociated wi th the larger urben areas because of, 1) the higher levels of congestion and therefore 
lower speeds associated with these ereas and, 2) the higher levels of income associated with these areas with wich improvements can be made, both in terms of reconstruction end mejor network improvements, and also in terms of stringent locel solutions and degrees of traffic management.

Against the impact of INTACT7 $\not$ one must meenwhile balence the influence of two other variebles $X_{10}$ and $X_{22}$ which both account for approximately 38 of the variation in TCVH70. The former is the shape variable CI7 $\varnothing$ wich has its usuel inverse reletionship with the dependent variable, whilst the letter is the road density index ( $R D I 7 \varnothing)$ which is positively associated with TCVM7 $\varnothing$. Therefore since the meen v8lue of RII $7 \varnothing$ for CES areas is higher than that for all areas, this variable is affecting the value of TCMI7 in the opposite direction to INTACT7\%, and suiteble modification should tske place.

It was exgued above that because of the high degree of variation about the regression plene for this dependent variable, considerable doubt should be cast upon the viability of the model used. To collect furtber information about this problem, the residuel greph plots were studied in some detail, with especiel attention given to the plot between the derived residuals $\left(e_{i}\right)$ and the dependent variable TCVM7\%. This plot is show in Fig. (9.3.15), and from this it can be seen that there is some distinct reletionship between the two veriebles which can be described simply as parabolic. Thus the derived linear regression equation is underestimating the value of TCWM7 at both low and high values, 


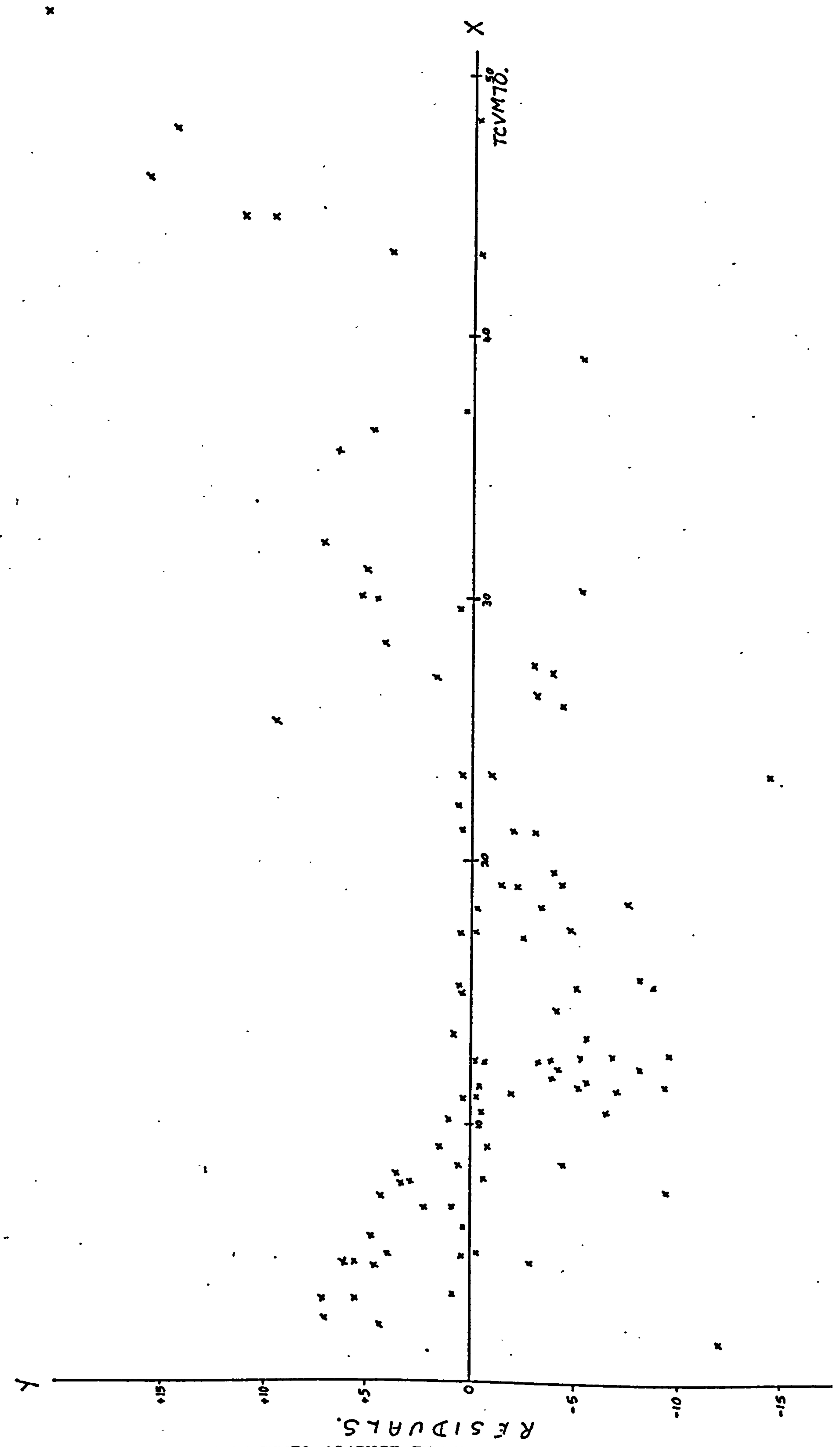

FIg. 9.3.15 PLOTT OF TCVM70 AGAINST THE RBGRESSION RESIDUALS 
whilst overestimeting at medium values. The probebility therefore is that the relationship between TCVMT end the various independent variebles is polynomial in nature rather than simple linear.

For these reasons it was decided to trensform the depandent variable TCVM7申. The eventual trensformation used was logarithric, and the result is given below;

$$
\begin{aligned}
\log Y_{1}= & 1.16-0.27 X_{1}+0.03 X_{5}-0.04 X_{10}+0.11 X_{12}-0.04 X_{15} \\
& -0.18 x_{16}-0.11 X_{18}-0.02 x_{19}+0.11 X_{22}
\end{aligned}
$$

It can be seen from this equation and elso Table (9.3.7), that there is very little difference between the tro sets of significant veriebles for the trensformed and non-trensformed equations. As regards the regression equetion itself however, there is considerable difference. In the first instence the level of explenation rises to almost $94 \%\left(r^{2}=0.937\right)$ and the variation about the regression plene is reduced to $7.8 \%$. Similerly when the residual plot for this trensformed regression is observed the perebollc trend noted earlier has been almost totelly removed, and the plot as shom in Fig. (9.3.16) is almost rencom. In attempting to explein this improvement one should immedictely look to the inojependent variable $X_{1}$ : INTACT7 sirce this verieble now eccounts for 66.27 of the totel variation in LNTCVM79. Thus it would seen that the inverse relationship noted previcusly betweon TCVI7 $7 \phi^{\circ}$ and INTACT7 $\phi^{\circ}$, is logerithmic in nature, suggesting that the improvements ebounding in the larger touns are not as good es was originally predicted, but which still do accrue. 


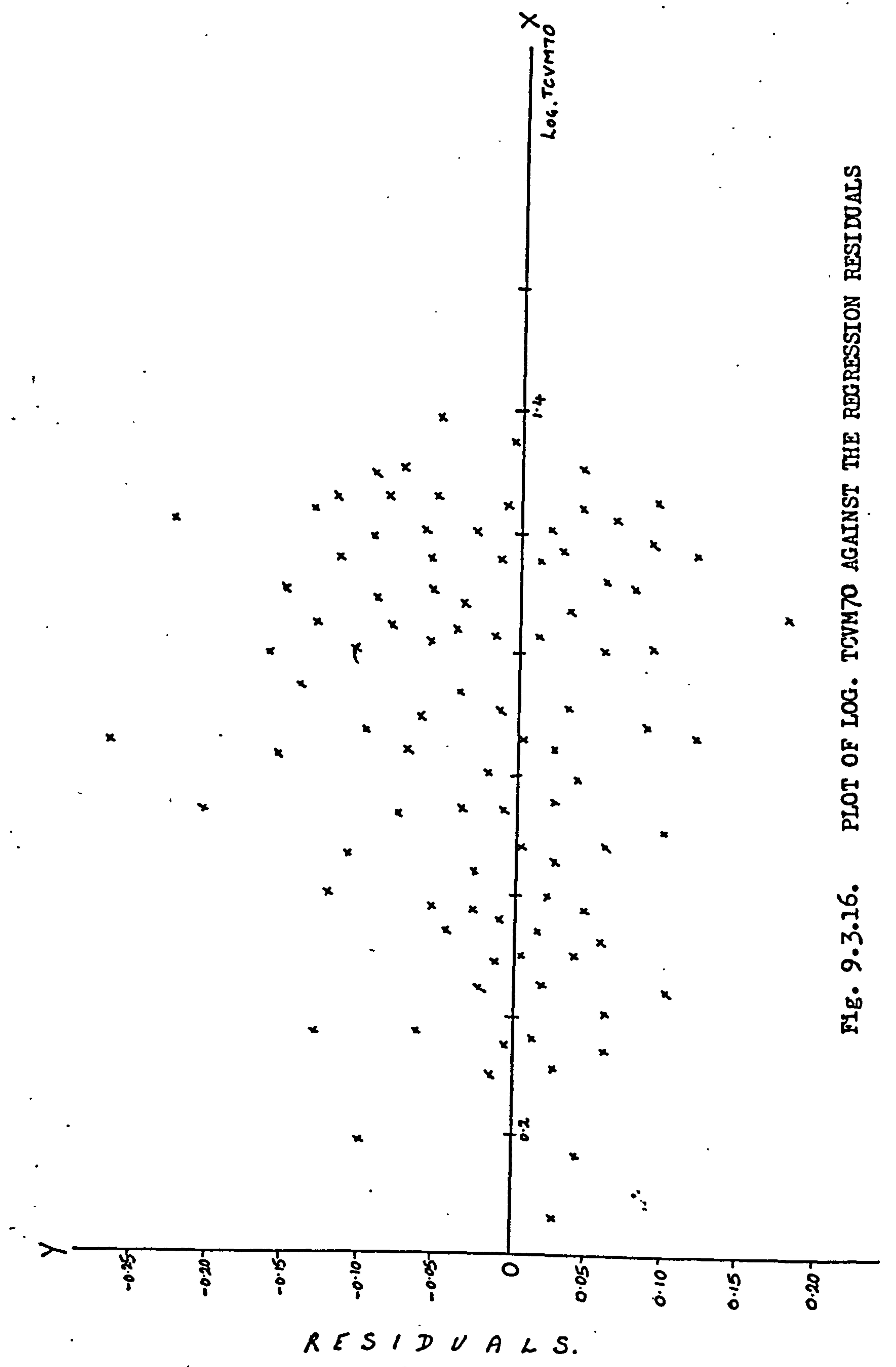


Before leaving this trensformed regression, it shoulo be noted that in this form the police voriable PPI7 $\left(\Sigma_{19}\right)$ once again becomes significent, indicating the influence of police action upon roed sefety levels, even though the influence may only be marginal.

Tuming to the regression for TCVM7 7 for only CES e reas, the derived equation is given below:

$$
\begin{aligned}
I_{C B_{i}}= & 10.08-2.75 X_{1}-2.45 X_{3}+0.86 X_{16}+3.46 X_{19} \\
& +4.26 X_{20}-1.15 X_{22}
\end{aligned}
$$

As can be seen the non-trensforned regression version was emplored here, and al though the goodness of fit left much to be desired (S.E.E. $\left.=23 . .^{\circ} \mathrm{B}\right)$, the level of explenation remeined fairly high $\left(r^{2}=0.875\right)$. Fron this regression there are perhaps three conclusions and comments which should be made:-

1) Although the variation cbout the regression plene remains high, the parebolic relationship noted for the full 100 sample regression no longer is obvious, indicoting that the relationship for these CBS areas is almost linear, and the logaritbmic relationship is only necessary when the smaller non-county borough areas are included.

2) The relationship between RLIT $7 \varnothing$ and TCVM7 for only CES areas is negative end not positive as nas the case for the 100 sample areas. Thus the impact of roed density would seem to have 
some kind of threshold value, ebove which congestion etc. seens to invert the relationship, such that at high values of RDI7\% the Impact upon TCWM $\not \varnothing$ is such that values of TCVM $\varnothing \varnothing$ decrease as $\mathrm{PDI} 7 \varnothing$ increases.

3) Once eggin the police veriable PPI7 $\varnothing$ is significent in the CDS areas perhaps indicating that the influence of police action is more successful in the lerger urben areas, here more manpower and instrumental devices are available. However, it should also be pointed out that these larger areas also provide a higher probability of escaping detection, which mey reduce the impact of PPI $7 \not$.

8) TOTAL ECCIDENTS PFR $10^{6}$ VFHICLE. MILES. 1970 (TAVM70)

This regression is once egain virtually icenticel to the preceding varieble, and accorlingly the arguments pertaining to TCII:C also apply here. The overall level of explenation for the regression shoin below wes $r^{2}=0.739$, with a regression varience (S.E.E.) of 39.2\%. The equation form vas;

$$
\begin{aligned}
I_{i}= & 14.89-4.17 X_{1}-1.94 X_{10}-1.47 X_{11}-1.59 X_{14}-5.74 X_{16} \\
& -3.80 X_{18}+1.99 X_{22}
\end{aligned}
$$

The regression renking for this varieble is shown in Teble (9.3.17) frow which it cen be seen that the set of significent variebles is very similar to those derived for TCVi $7 \varnothing$. This similarity also extends to the resicual plots and therefore the presumed logarithmic relationship between the independent variebles and TSVMT 7 . 


\begin{tabular}{|c|c|c|c|}
\hline \multirow{3}{*}{ 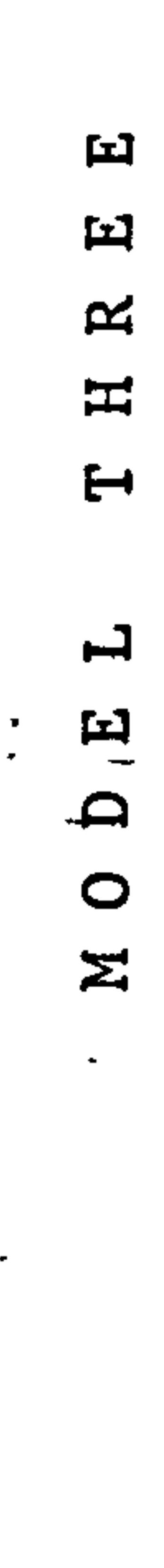 } & 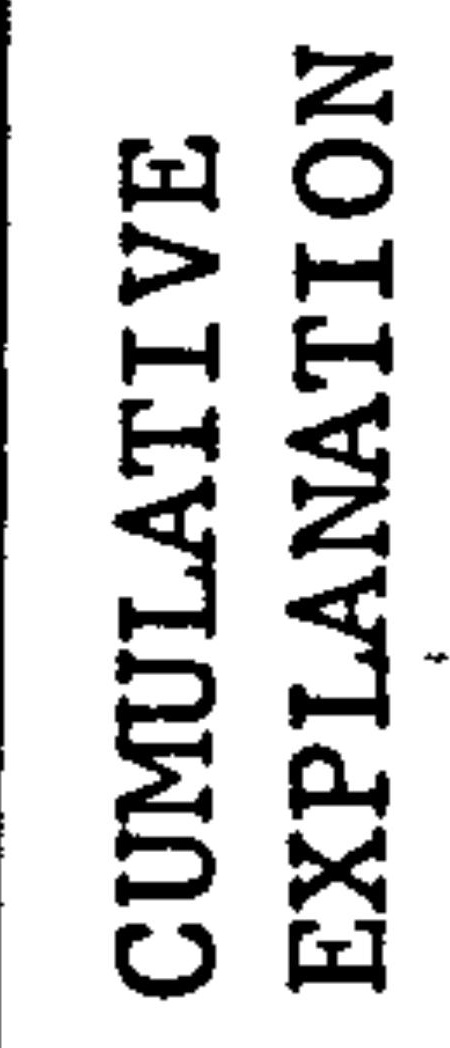 & 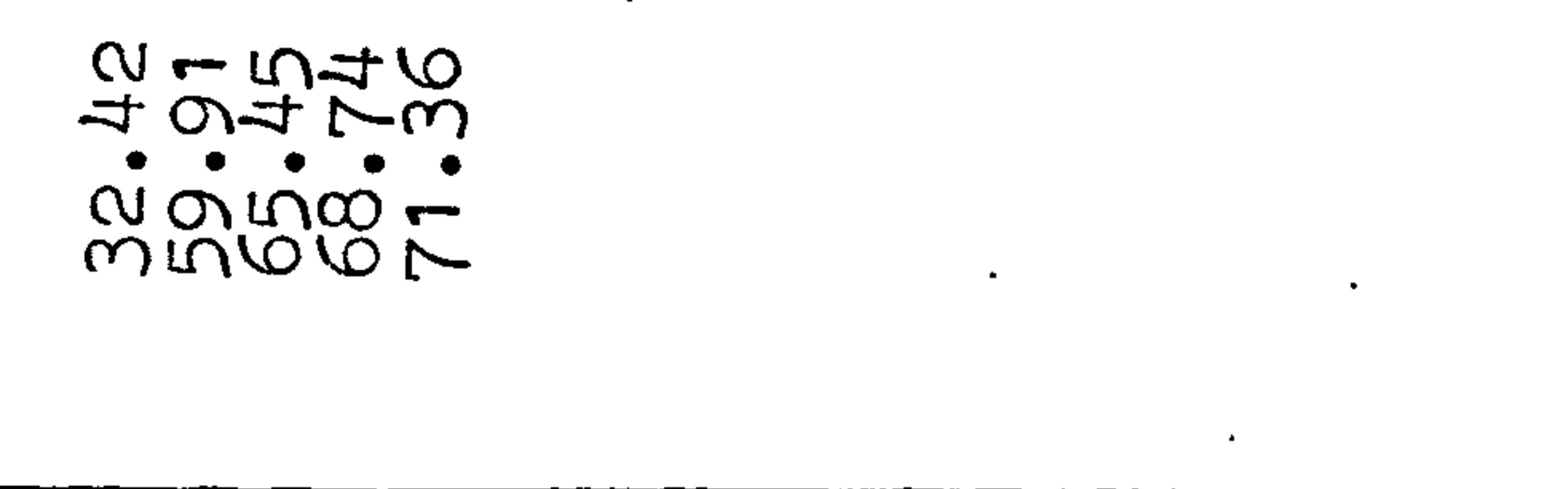 & 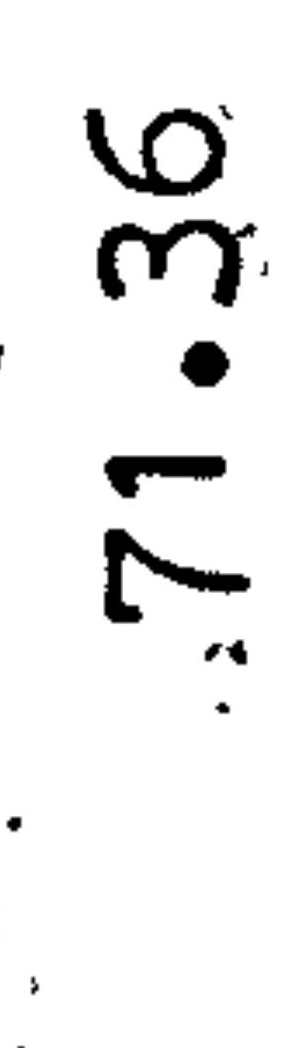 \\
\hline & 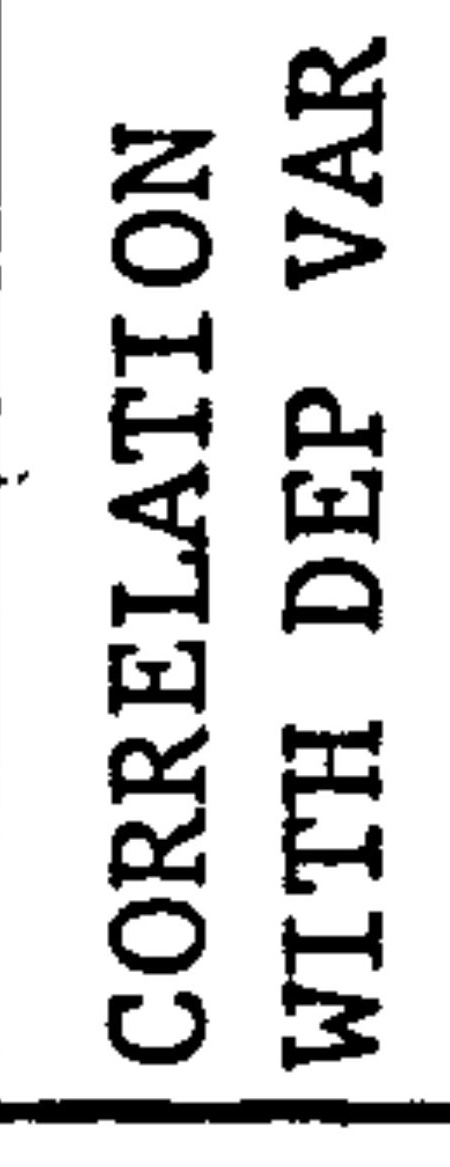 & 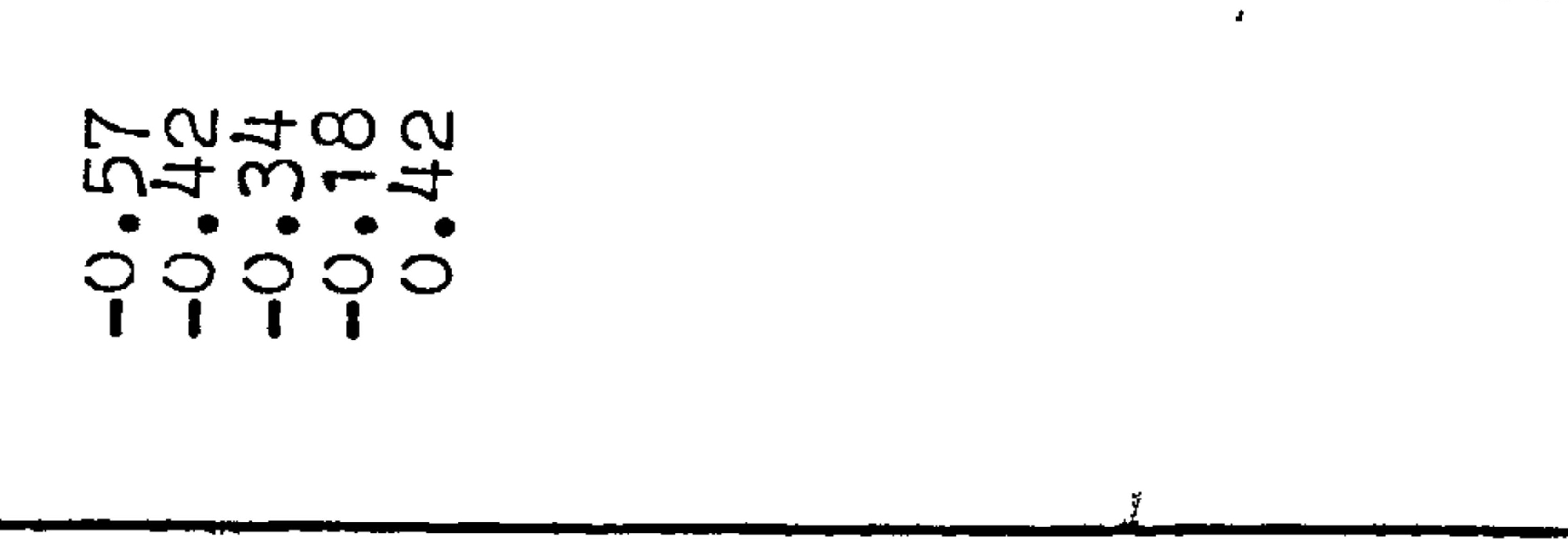 & \multirow{2}{*}{ 哇 } \\
\hline & 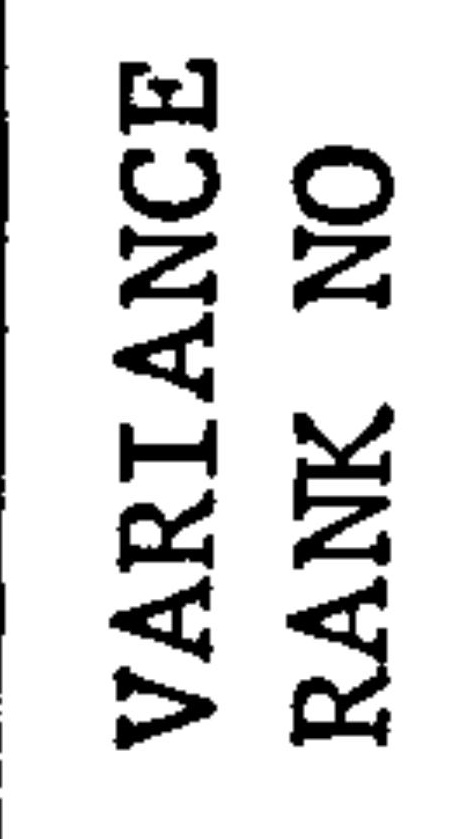 & $-6 \infty O N$ & \\
\hline \multirow{3}{*}{$\begin{array}{l}0 \\
3 \\
H \\
1 \\
1 \\
01 \\
0 \\
0 \\
\Sigma\end{array}$} & 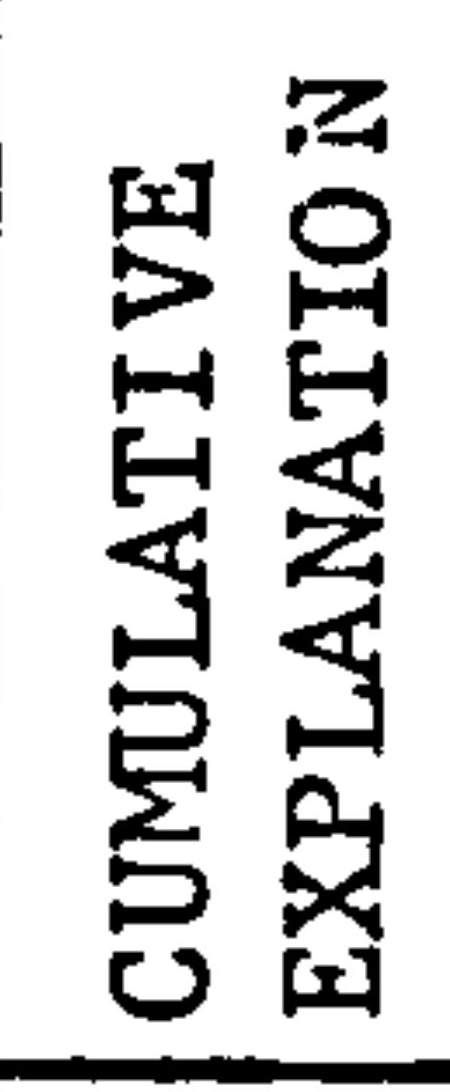 & 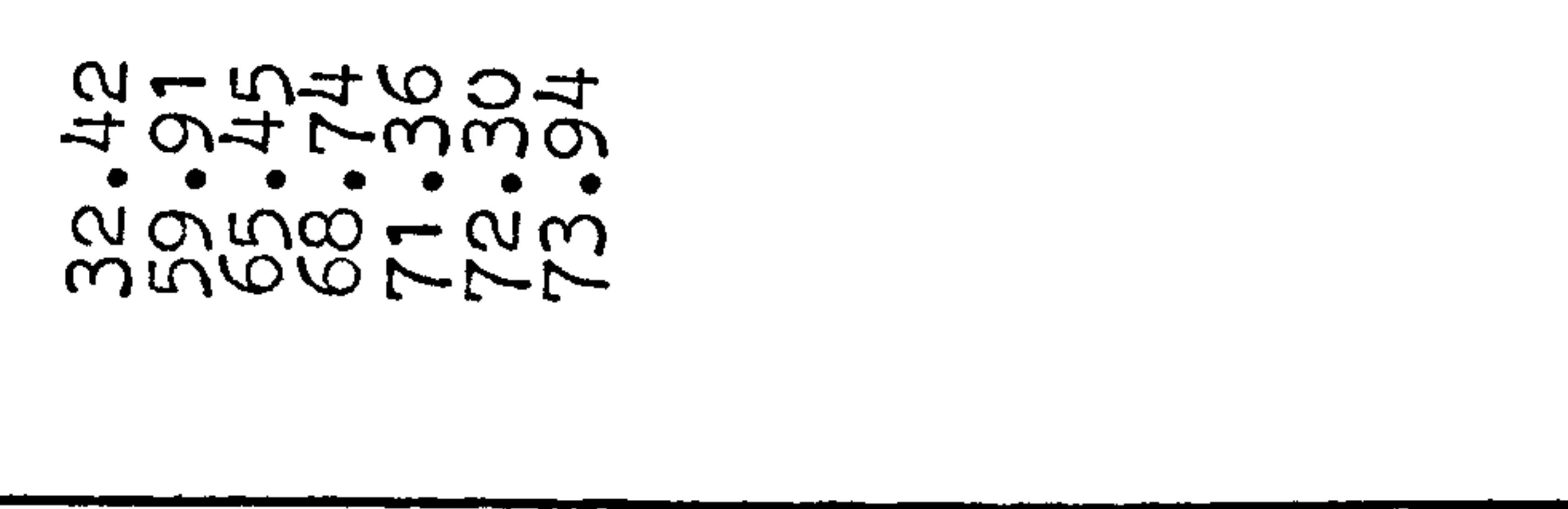 & $\begin{array}{l}\vec{\sigma} \\
\dot{n}\end{array}$ \\
\hline & 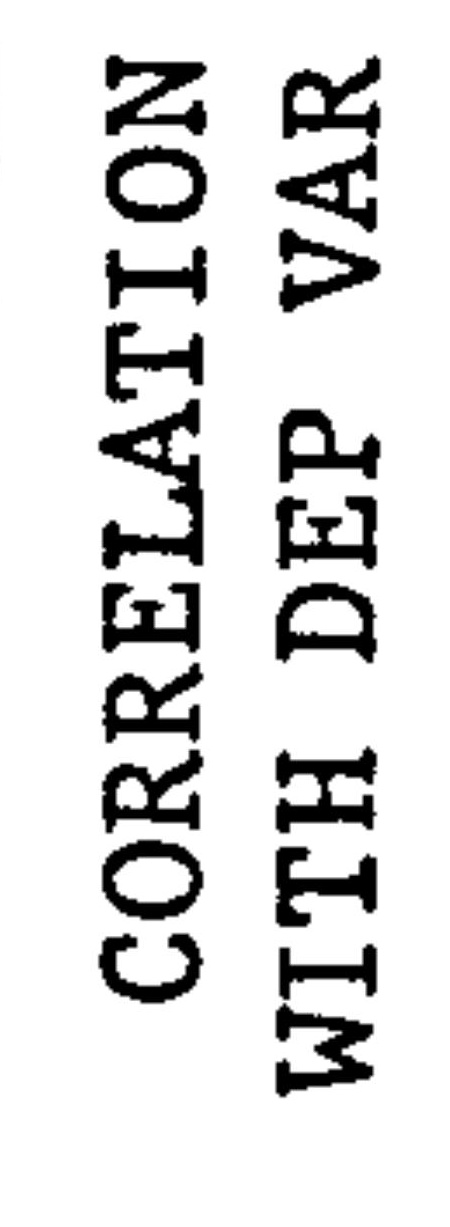 & 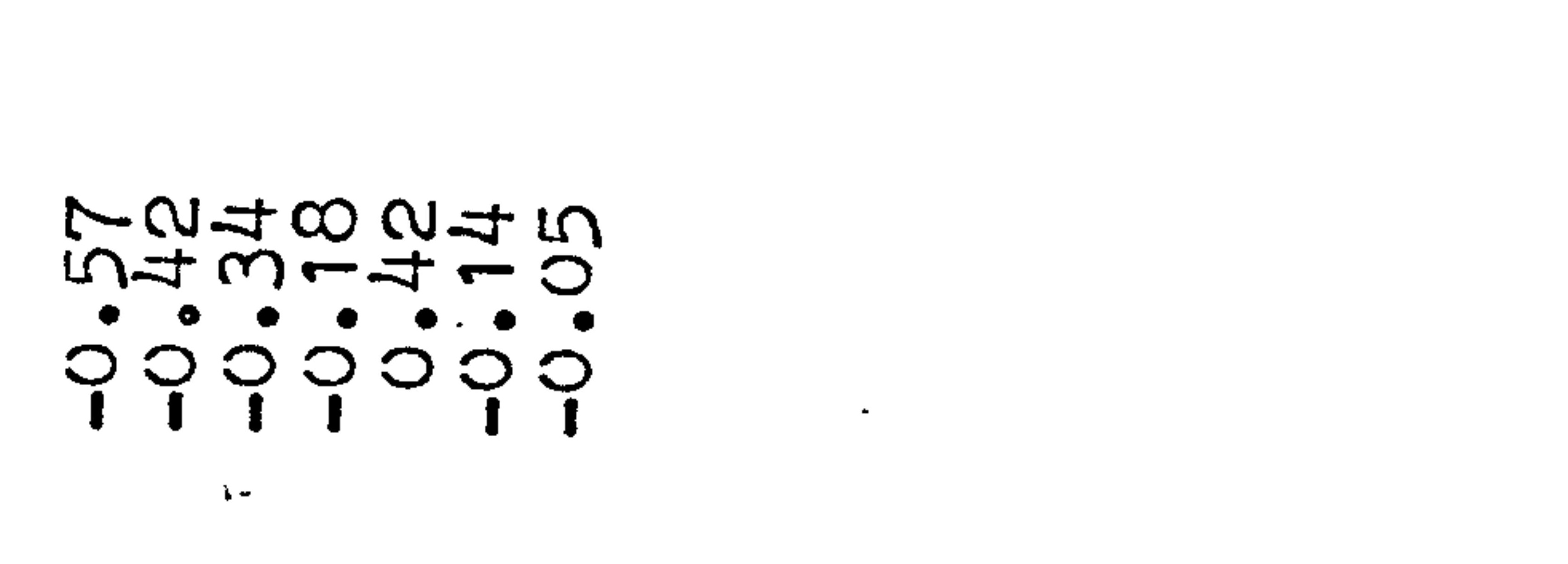 & \multirow{2}{*}{ 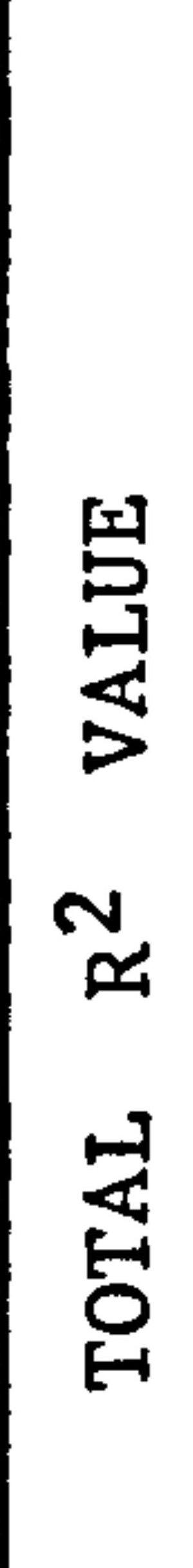 } \\
\hline & 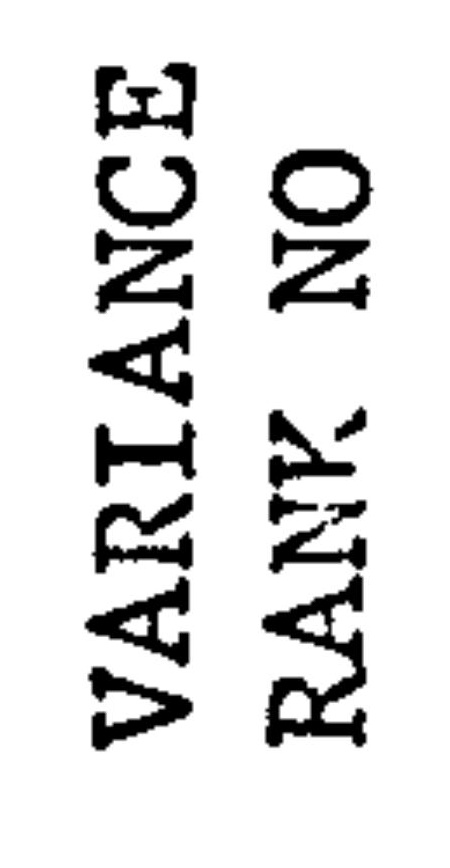 & 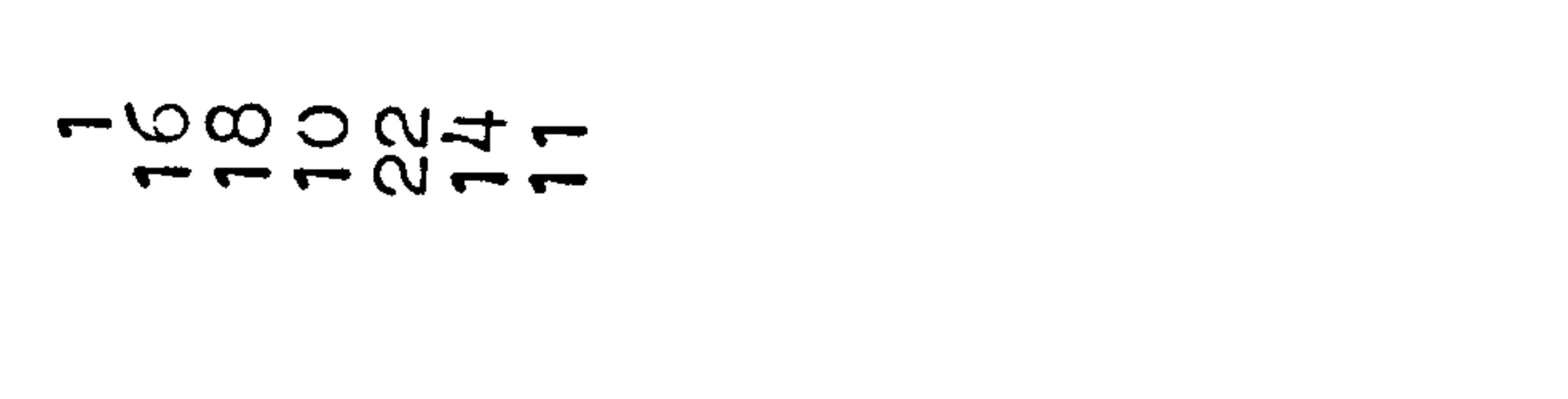 & \\
\hline \multirow{3}{*}{ 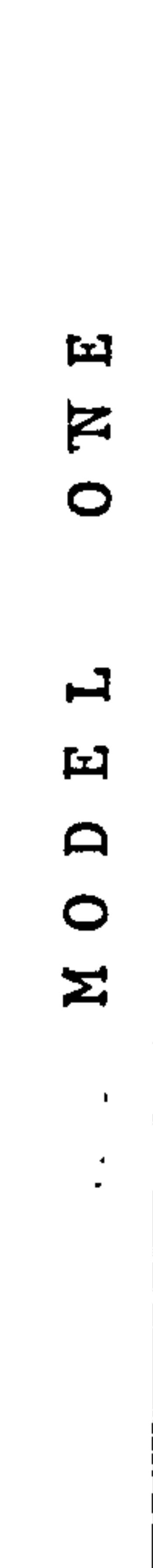 } & 号号 & 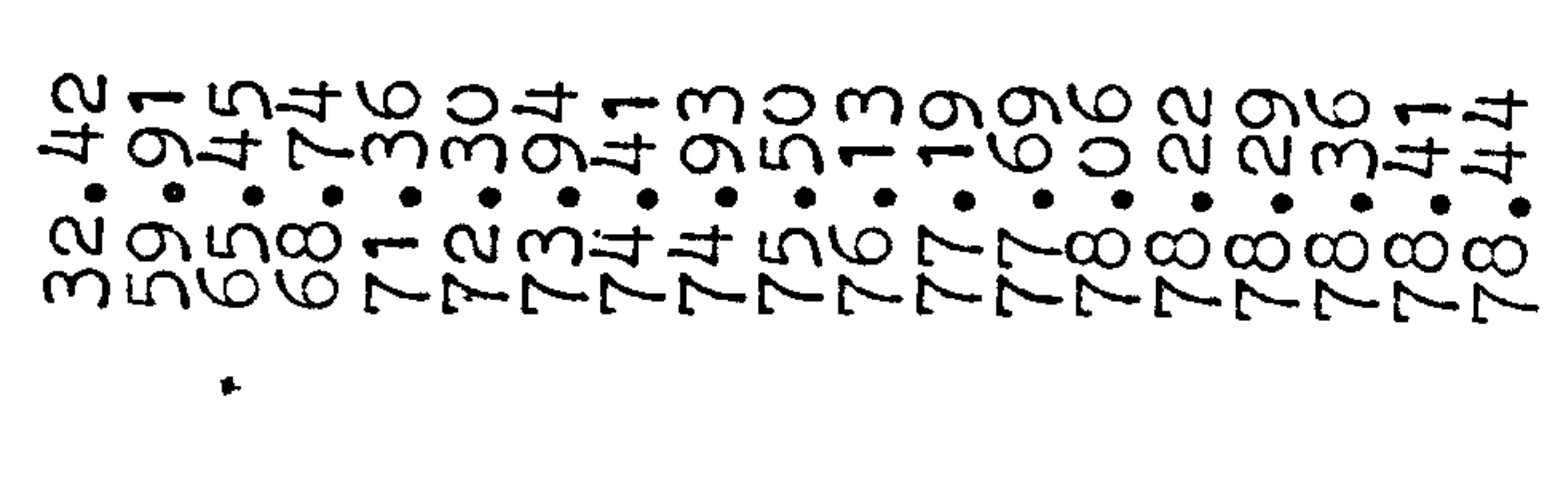 & 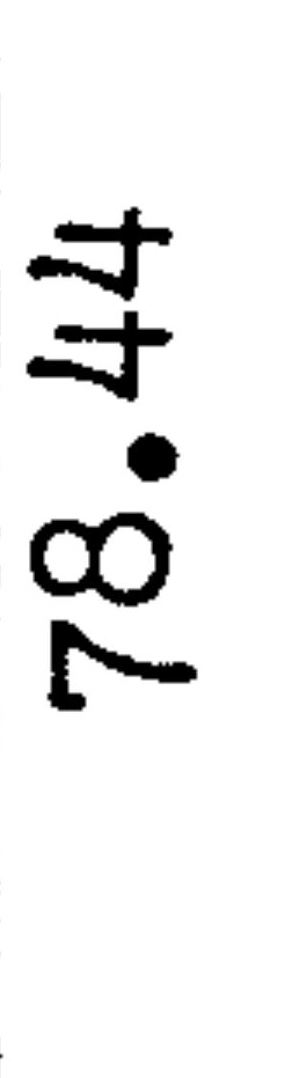 \\
\hline & 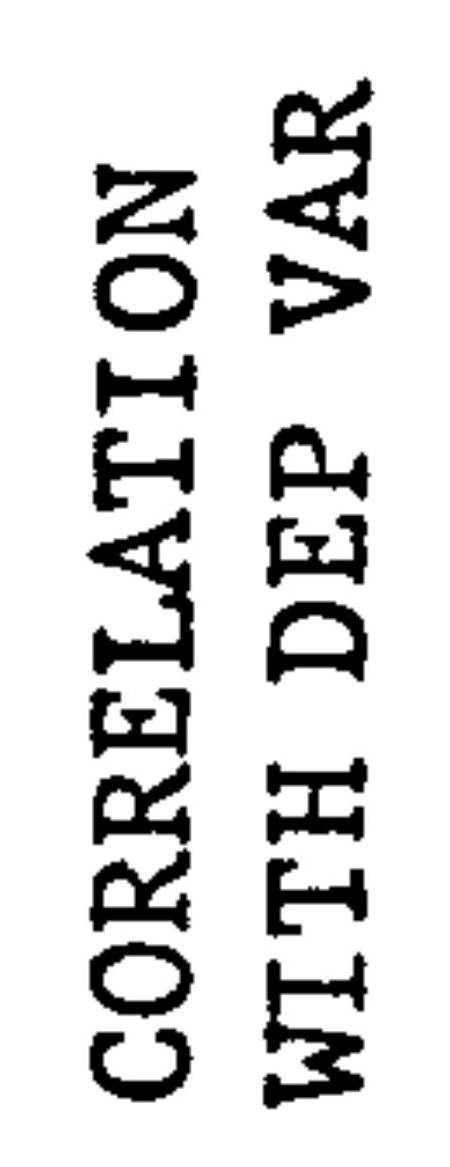 & 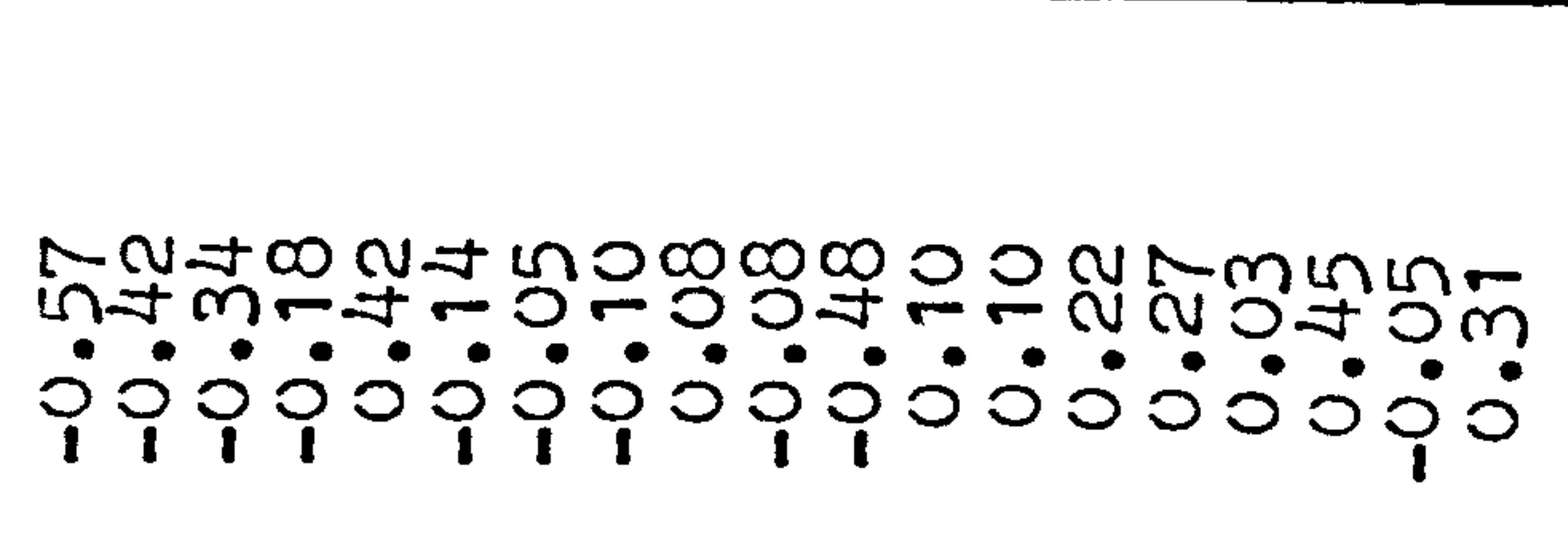 & \multirow{2}{*}{ 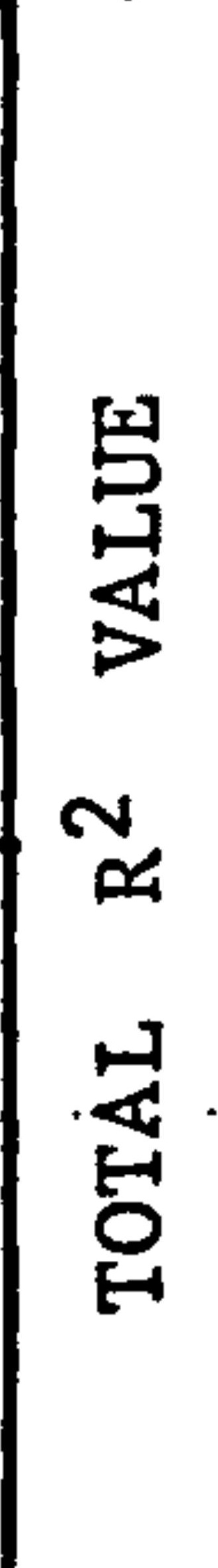 } \\
\hline & 罗完 & - & \\
\hline
\end{tabular}


As regards the regression against the $\mathrm{CBS}$ areas only, the level of explanation was increased to $90 \%\left(r^{2}=0.895\right)$ and the varience about the regression plene was reduced to $21.7 \%$. The regression is given below;

$$
\begin{aligned}
\mathrm{Y}_{C B_{1}}= & 7.94-1.58 \mathrm{X}_{1}-2.29 \mathrm{X}_{3}+0.62 \mathrm{X}_{11}-0.95 \mathrm{X}_{12}+0.68 \mathrm{X}_{16} \\
& +2.04 \mathrm{X}_{19}+3.08 \mathrm{x}_{20}-0.90 \mathrm{X}_{22}
\end{aligned}
$$

Once agein the similarity with TCWI7 is strikirg, with just two extra variables in the ecuation, TCI $\varnothing \varnothing$ end INLVI $\varnothing$, which relate to the shape of the road netrork and the age composition of the population stmucture. It is interesting that the variable introduced here was NAVI7\% and not IVI7 which would heve been an inatcation that young drivers are nore vulnerable to accidents than other age groups. As it stends, because of the introduction of NAVIT, the present data, and research, end one nust presume that when exposure varlables are introduced there is no differeace beticen any of the age groups in the population.

Besides these eight regressions described in some detail above, other reärescions provided some interesting results and are deserving of sone further attantion. This will be done in the next section of this report by grouping these variables where possible, in to honogencous units.

\section{(i) FATAL NID SEPIOUS RAGFESSTONS}

This group of regressions includes the four dependent 
varlables, TFS7 $\not$, TFSPP $\not \varnothing$, TFSVI $\not \varnothing$ and SR7 $\not$, und are all trjing to look at the incidence of the more serious casualties in different urben areas. The full list of results for tilese and other regressions is given in Appendix (3) and for the detalled rezressions, the reader is referred to that section of this report.

The absolute dependent variable TFS7\% exhibited characteristics sinilar to those described for other ebsolute variables. That is, the level of explanation was high $\left(r^{2}=0.950\right)$ but so was the regression variance $($ S.E. I. $=25.7 \%)$. Examination of the residual plots showed that the derived equation was over-predicting at the higher vulues of TFS7 $\not$. However, when the variable was transformed logarithnically, certain gains were made in that the regression varlance was reduced to $6.59 \%$. However, the overall gains were Iinited due to the fact that (i) the level of explanation was reduced to $91.6\left(r^{2}=0.907\right)$ and, (ii) the residual plots still showed considerable over-prediction at most levels.

of the variables tilat were introduced into these regressions, IVI 79 and KI $7 \not$ both increased wi th higher values of TFS7\%. Thet is when the incidence of young drivers within a population was high, there was a higher incidence of fatal and serious casualties, which could be a result of the postulated higher speeds of these ege groups.

As regards the other three regressions in this group, none of the levels of explanation were high with $r^{2}=0.534$ for TFSWM7 being the naximun value, and jet all the regression variances were 
high when expressed as a percentage of the mean response. Therefore the main conclusions which could be reached for this group of regressions was that the variation amongst the nuaber of fatal and serious casualties for different urban areas cennot really be accounted for by the structural varisbles. Accordingly, more detalled local work is necessary if the true relationships for these variables is to be found.

\section{(ii) PEDESTPIEN CASUMLTY REGRTSSIINS}

If the t*o pedestrian regressions mentioned earlier are discounted, this group also involves four dependent veriebles, TCPED7y, PEDCRT, PEDUT7\% and CPEDCR7ð.

As can be secn from the reaults of these regressions, the level of explanation tands to be on the low side end accoriingly verg little can be said definitely obout these results. It would seen, however, that the significent variables for these regressions relate to the social stending of the various urben erss, es well as the stendard of housing etc. noted in these urben ereas. Thus when dealing with the child pedestricn casual ties, such variables

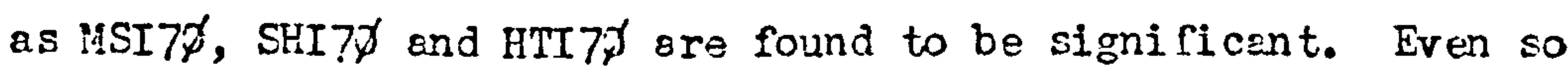
it would seen that the major causes for pedestrien casualties are once again related to micro features rather than the nacro features dealt with in this research. Hovever, because of the additiongl importence of ETT7 7 , it is interesting to look at these pedestrian variebles in a spatial context, as will be described later. 


\section{(iii) DRIVER AND RIDEP CASUALTIES}

The two absolute variables within this group TLRC7 9 and TYDE7 $\varnothing$ both exhibit very similar results. The levels of explanation are verJ high, being $r^{2}=0.959$ and 0.938 respectively, whilst the regression variances also prove to be relatively high (S.E. . $_{0}=23.2 \%$ and $28.0,0)$, indicating some degree of lack of fit. One of the interesting differences between the two however, is the appearince of PPI7, in tive regression for TDRC and not for TYDR7 . In the first place this obviously emphasises the importance of police control in relation to driver casualties, whilst at the seme time perhaps indicating that the impact of police intervention is much more marked emongst the groups of older driver and riders, than amongst young drivers. Hovever, this statenent must be qualified by the fact that the variable PPI69 is significent in the respective regression for 1969 (TIDP69), therefore one must decide upon one of two conclusions:- 1) Either PPI is not significent in 1970 as a result of a true temporal relationship, or 2) The significance of the varieble PPI is understeted in 1970.

of these tro byootheses the former seems the more plausible expecially when one considers that the influence of the 1967 foad Safetr Act was beginning to have a reduced iafluence by this period.

The other varlables in these tro regressions of eny significance were INTECTP which accounted for the major portion of the explenation in each regression, and $C O N 7 \phi$ and DENTh. The foraer had a positive relationship with the dependent variable ond was a measure 
of driver exposure, whllst DEiph had en inverse relationshlp perieps lndicating a reduction in eccident levels wh th an increase in congestion (end indi rectig a decrease in speeds).

Txo other regressions which can be included in this group are TLENA7f and DF.CB.7\%. In both of these wodels the level of explanation is only moderate th thalues for $r^{2}$ of 0.718 end 0.5-17 respcctively. Simllarly the regression deviations are 42.5: and 13.46, the larger of which could be explained by the parebolic residual plot noted when the residusls are plotted against TDER!17\%, ihlch indicates tivat a logarithilc relationship is nore eppropriate, as was the cree when desling with the other "vehlcle-alle" exposure varlebles.

of these too regressions the nore interesting 1avolves DFCR7P since most of the relationships noted in TCFMH7P epproxinate

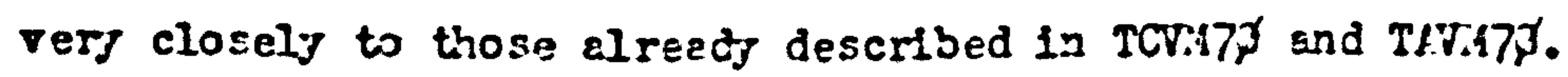

18 regards DPCR7g the list of sienlficent variebles is of considerable interost. Beeldes tio expected veriebles such es IliTACr7p end Coing, there ere also four other rarlebles included. The varleble CHSI7P was found to have an inverse relationchio W thin this regression. Thus es the amount of new development increases the number of driver and rider ceruelties as a proportion of all casualties, is reduced. Thls is consistent with the formor observation that thare was a positive reletionshlp betwenn CHSI7 end PEDiT7\%. The reasons for this are either that ned devolognent 1uproves the rood networis for drivers at the exponse of pedestrian 
safetj, or altematively induces more people to travel around on foot because of the impmved environnent, theroby increasing pedestrien exposure.

Also importent within this regression are the tro varisbles DOST $\varnothing$ and PI $7 \varnothing$. The former has a negative relationship with the dependent variable perhaps implying that as the amount of open space increases there are relatively more pedestrien and/or pedal cycle injuries, due to increased movenent. The RI7\% variable meanwhile has a high positive relationship with DRCR70, which could be an indirect inplication of including the riders of motor cycles and motor bikes ${ }^{12}$ in this dependent variable, as well as the direct result of increased road hazards due to inclenent veather.

\section{(iv) MISCFLLANDOUS}

of the remaining regressions, three will be described under this section. Tro of these TJUN7 $\not$ and TTRN7 $\varnothing$ describe virturily the same manoeuvre and therefore will be discussed tagether. For both of these the $r^{2}$ volue was high being 0.951 and 0.907 respectively, however tije regression deviations were also ressonably high being 29.37 and $26.8,5$. Within the two sets of significant variables tro appear of some intorest. Once again the police variable PPI? appears highly significant in both rogressions, shoring that police - action cen control both the absolute level of road crsualties, snd also that the fruits of their work are shom greatest in stopoing menoeuvres which are hazardous. The other importent variable was 
DVI70 which had a positive relationship with the dependent variable. Thus it would seen that if young drivers are more accident prone than other age groups, then this proneness is shom most in risk trking menoeuvres and at junctions. Hovever, since this varioble is not significsnt in the absolute variable regression, it could be that whilst young drivers are more accident prone at "risk" situations, they may equalise the situation by responding better in other potential accident situations.

The final regression to be mentioned is the one which tries to explain the reason for the number of casualties per accident in each urban area, TCTA7ð. Basically however, the results of this regression do little to help in this explanation, since the level of explanation is only $r^{2}=0.423$, al though the regression varlance is very good with S.E.E. $=5.51,6$.

The most importent variable in this regression is CHSI7 which is positively related to TCTA7\%. Thus the rederelopment of an erea vould seen to increase the incidence of driver accidents and now also the number of casualties per accident. This could be expleined by the fact that elther in such areas the incidence of car occupancy is higher, or alternatively the type of accidents are such that more people are injured in any accident. Thus it could be that the incidence of two, three or four car accidents is much higher in these areas instead of one car accidents . which nomally result in less cesualties. Similar reasons could also be put forward to explain the positive relationshis between Dos79 and TCTA79, with perheps the additional factor of higher speeds associated with such areas, being included. 
Having looked at the various regression equations derived during this stege of the analysis, it now becones necescary to study the variation in accident and casualty levels, within a spatial context. It ras expleined in the methodological section of this report that this spatial analysis was conducted through the use of the residuals from the regression equations modified into a Mean Safety Index, and introduced into a trend surface analysis. The following section of this report will therefore analyse the results of this spatial analysis.

\subsection{THE SPATTAL VARTATTON ANALYSTS}

It would have been possible to subject every regression equation to a trend surface analysis using the derived residuals as the input into the tread surface model. 13 However, since this would have proved both wasteful and inpractical, the number of regressions subjected to the enalysis was reduced to twenty, which were considered to be of the greater importance. The list of the 20 regressions used in the trend surface analysis is given in Table $(9.4 .1)$

13 Fal rburn and Robinson point out that the acturl calculation of the trend surface polinomials for irregulerly spaced data does not refer to the complete trend as defined by Grant (1957), but only to some unspecified portion of the complete trend. lccordingly these surfaces should be referred to as "partial trend surfeces." However, for convenience in this report such a distinction will be assumed to be understood, thereby needing no modification. 
1. TOTAL CASUALTIES

2. TOTAL ACCIDENTS

3. " FATAL AND SERIOUS CASUALties

4. " PEDESTRIAN CASUALTIES

5. $1^{\text {n DRIVER AND RIDER CASUALTIES }}$

6. " CHILD PEDEstrian CASUalties

7. " YOUNG DRIVER AND RIDER CASUALTIES

8. " ACCIDENTS ON UNCLASSIFIED ROADS

9. " ACCIDENTS ON CLASSIFIED ROADS

10. " Casualties PER $10^{3}$ poptlation

11. " ACC DENTS $n$ "

12. CASUALTT RATE PER $10^{6}$ VEHICLE MILES

13. ACCIDENT " " " "

14. TOTAL ACCIDENTS ON CLASSIFIED ROADS PER MILE OP CLASSIFIED ROAD

15. " " " UNCLASSIFIED " " " UNCIASSIFIED ROAD

16. TOTAL PEDESTRIAN CASUALTIES PER $10^{3}$ POPULATION

17. TOTAL PEDAL CYCLE ACCIDENTS PER $10^{3}$ PEDAL CYCLE WORK TRIPS

18. PEDESTRIAN CASUALTIES PER $10^{2}$ WALK WORK TRIPS

19. TOTAL DRIVER AND RIDER CASUALTIES PER $10^{6}$ VEHICIE MILES

20. TOTAL CASDALTIES/TOTAL ACCIDENTS.

TABLE 9.4.1. LIST OF THE 20 VARIABLES USED IN THE TREND SURFACE ANALYSIS. 
Assessment of the resultant trend surfaces can take several forms;

1) Obserration of the various surfaces produced, in order to discover the importance of independent variables, which have presiously been ignored.

2) Observe the deviations from the trend surface, for the sane reasons given above.

3) Observe the reduction in the sum of squares and therefore the percentage level of explanation. The significance of this reduction can further be tested using an infonnal analysis of variance test, as proposed by Anderson \& Bancroft. (1952).

4) Test the significance of the overall surface following the addition of each individual surface, through the construction of confidence levels, based on cumulative F-tables.

It is essential to understend the difference between these last two tests since the former represents the strength of the trend, whilst the latter which say, is represented by a high confidence for a linear surface, is interpreted as meaning, ".....sone flexbility in its angle and direction of dip but without sufficient freedon so that its direction of inclination could be completely reversed." (Krumbein 1963). In other words this last test is a test of the "reality" of the derived surface.

The percentege explanation level, due to the reduction in the sum of souares for the twenty regression variables, is given 


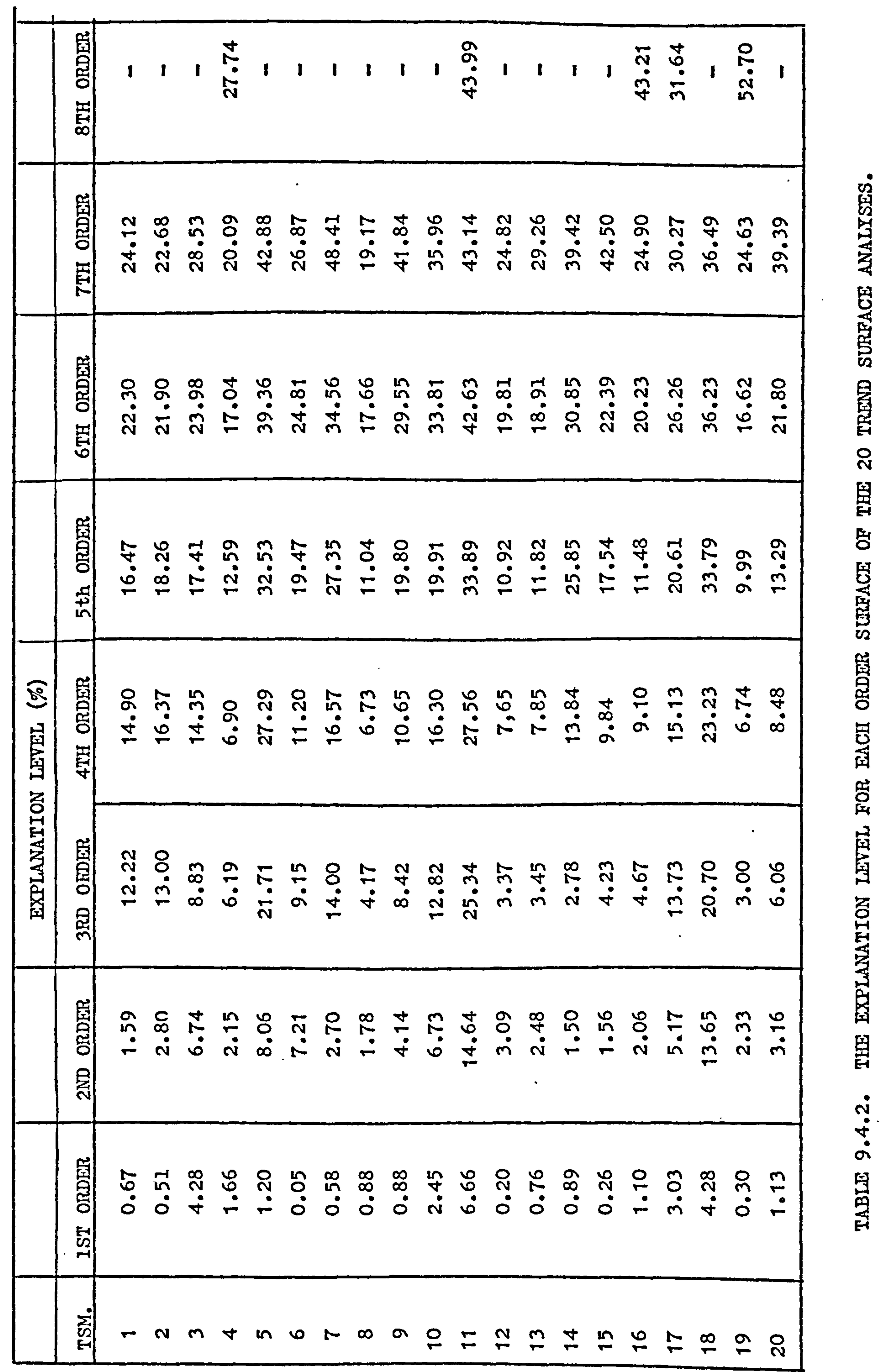




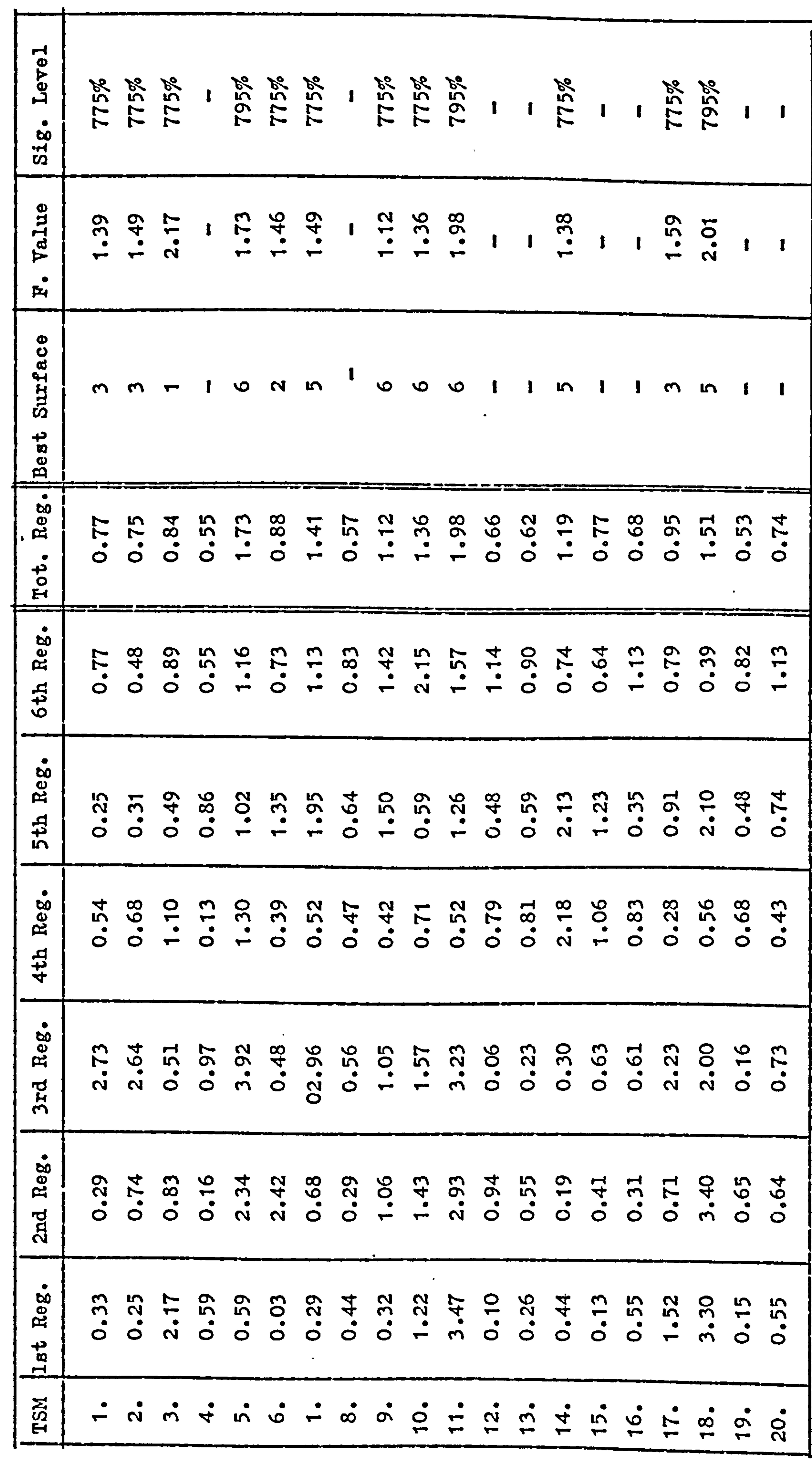

行 


\begin{tabular}{|c|c|c|c|c|c|c|}
\hline TSM & 1st Surf. & 2nd Surf. & 3rd Surf. & 4th Surf. & th Surf. & 6 th Surf \\
\hline 1. & 0.33 & 0.30 & 1.39 & 1.06 & 0.78 & 0.77 \\
2. & 0.25 & 0.54 & 1.49 & 1.19 & 0.88 & 0.75 \\
3. & 2.17 & 1.36 & 0.97 & 1.02 & 0.83 & 0.84 \\
4. & 0.59 & 0.41 & 0.66 & 0.45 & 0.57 & 0.55 \\
5. & 0.59 & 1.65 & 2.77 & 2.28 & 1.90 & 1.73 \\
6. & 0.03 & 1.46 & 1.01 & 0.77 & 0.96 & 0.88 \\
7. & 0.29 & 0.53 & 1.63 & 1.21 & 1.49 & 1.41 \\
8. & 0.44 & 0.34 & 0.44 & 0.44 & 0.49 & 0.57 \\
9. & 0.32 & 0.81 & 0.92 & 0.72 & 0.98 & 1.12 \\
10. & 1.22 & 1.36 & 1.47 & 1.18 & 0.98 & 1.36 \\
11. & 3.47 & 3.22 & 3.40 & 2.31 & 2.03 & 1.98 \\
12. & 0.10 & 0.60 & 0.35 & 0.50 & 0.49 & 0.66 \\
13. & 0.26 & 0.48 & 0.36 & 0.52 & 0.53 & 0.62 \\
14. & 0.44 & 0.29 & 0.29 & 1.38 & 1.38 & 1.19 \\
15. & 0.13 & 0.30 & 0.44 & 0.66 & 0.84 & 0.77 \\
16. & 0.55 & 0.40 & 0.49 & 0.61 & 0.51 & 0.68 \\
17. & 1.52 & 1.03 & 1.59 & 1.59 & 1.03 & 0.95 \\
18. & 3.30 & 2.97 & 2.61 & 1.84 & 2.01 & 1.51 \\
19. & 0.15 & 0.45 & 0.31 & 0.44 & 0.44 & 0.53 \\
20. & 0.55 & 0.59 & 0.64 & 0.57 & 0.61 & 0.74 \\
\hline D.F. & 2.97 & 5.94 & 9.90 & 14.85 & 20.79 & 27.72 \\
\hline
\end{tabular}

TABLE 9.4.4. SIGNIFICANCE TESTS FOR TEE COMPOUND SLRFACES OF THE TKEND STRFACE ANALYSIS (F. VALUES) 
In Table (9.4.2) whilst the results of the two sets of significence tests extended as far as the six-order surfaces, are given in Tables (9.4.3) and (9.4.4) respectively. Fron these tables it can be seen that whilst eight of these regression variobles fail to produce any surface which is significant at any level, the reaaining twelve heve only one surface which fails to exceed the 75: signiflcance level. In order to describe and analyse these spatial variations, therefore, each variable will be described independently where necessary, with special emphasis being placed upon the variable TC7 $\phi$.

\section{(1) TOTAL CASUALTIES TREND SURFACE ANALYSIS (1970)}

It has already been shown that the regression equation accounted for a high level of explanation within this dependent variable, and therefore except for one or tro values the range of the residuals for this varlable were not very high. However, in terns of the Mean Safety Index, the range was calculated between $300.000^{14}$ and 46.93 for Buxton and Ryde respectively. Ihen this variation was analysed within the trend surface analysis (TSY) 22. $00 \%$ of the variation was explained by the time the sixtin-order surfice had been rexched. Ho:rever, from the relevant tables it can be seen that the cumulative surfaces are only significant $(75<F<90$ \%) at the third-order surface, which accounts for only 12.22, of the total variation. None of the surfaces added after this surface

14 Although some calculated values for the Mean Safety Index (MSI) were higher than 300.00 , in order to keep calculations within mathenatical bounds a maximum linit of 300.00 was imposed in these instences. 
prove statistically significant, and are therefore possibly unreal surfaces, even though the strength of the surfaces are Increasing progressively. Therefore, for this variable, three surfaces are shown in FIgs. $(9.4 .5 ., 9.4 .6$. and 9.4.7) giving Ist, 3 rd and 6th order trends, of which the third surface should be the most important.

The linear trend which accounts for only 0.67 of the variation, and is insignificent at all levels, merely indicates en increasing trend in rond casualties in a general $S W-N E$ direction. Obviously however, because of the low strength and realit features littie confidence should be placed in this result at oll.

The third order surface neanwile, whilst sccounting for 12.22\% of the variation, also has en individuel surface significant $(90<\mathrm{F}<953)$, end a curnulative surface significance above the $F=75.5$ confidence level. 15

Observing this surface, where the contours are nerked in deviations of 5 from the 100.00 mean safety value, it cen be seen that the "minimax"16 form derived in the second order surface, has been modIfled into a compound minimax solution, with the two central crosspoints centred at central North Englend, and the "gateway" to the South-west peninsula (Fig. 9.4.5). Consequently it is possible to

15 fnotiner way in which to find the best fit surface is also availeble by finding the nininum residual mean sum of squeres

16 The"minimax" surface (Davis 1956) is one wherein tro exes cross at right-angles at a point whlch is the maximur value along one and the mininum elong the other. 


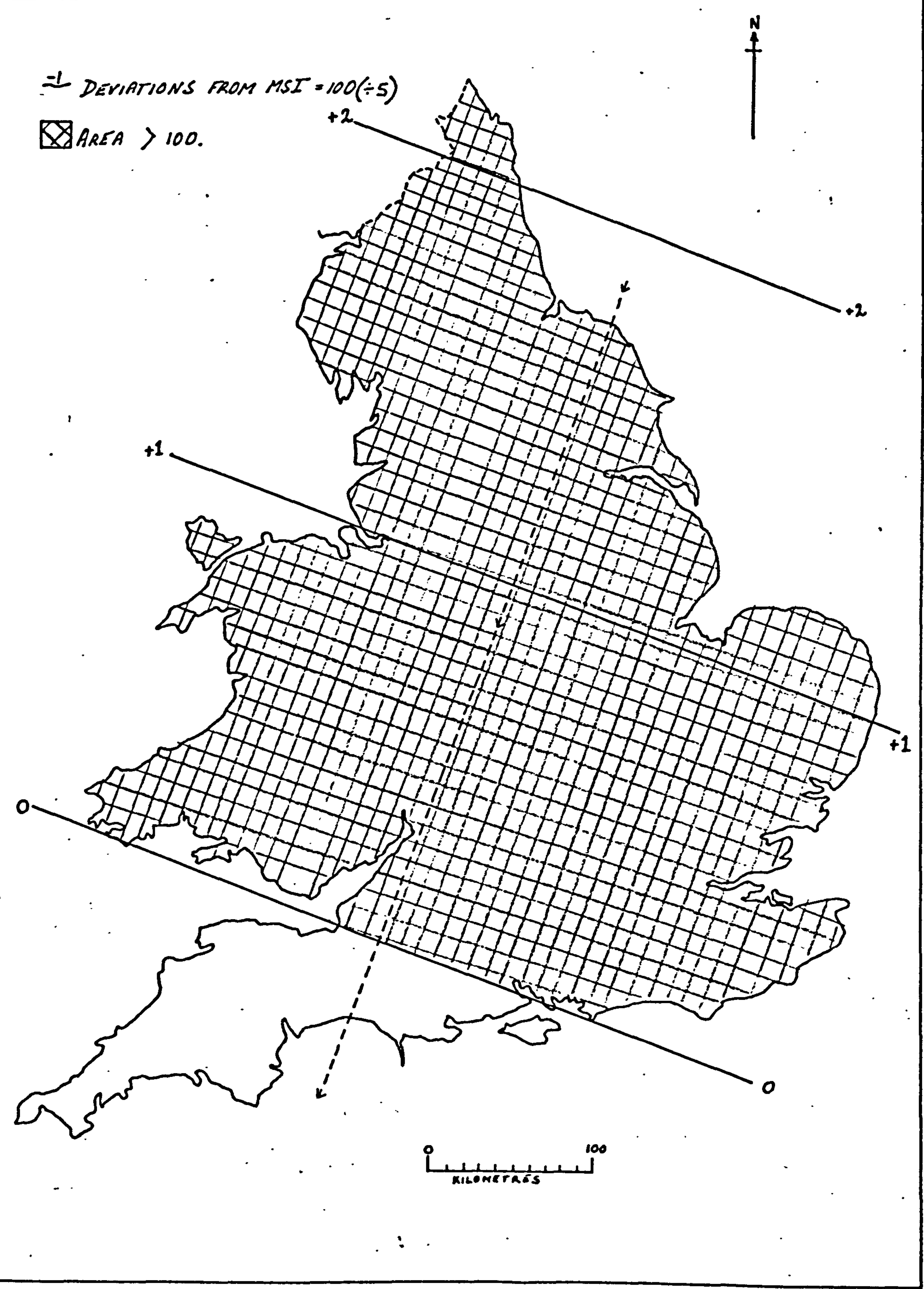

FIg. 9.4.5. LINEAR TREND SURFACE FOR TC7O 


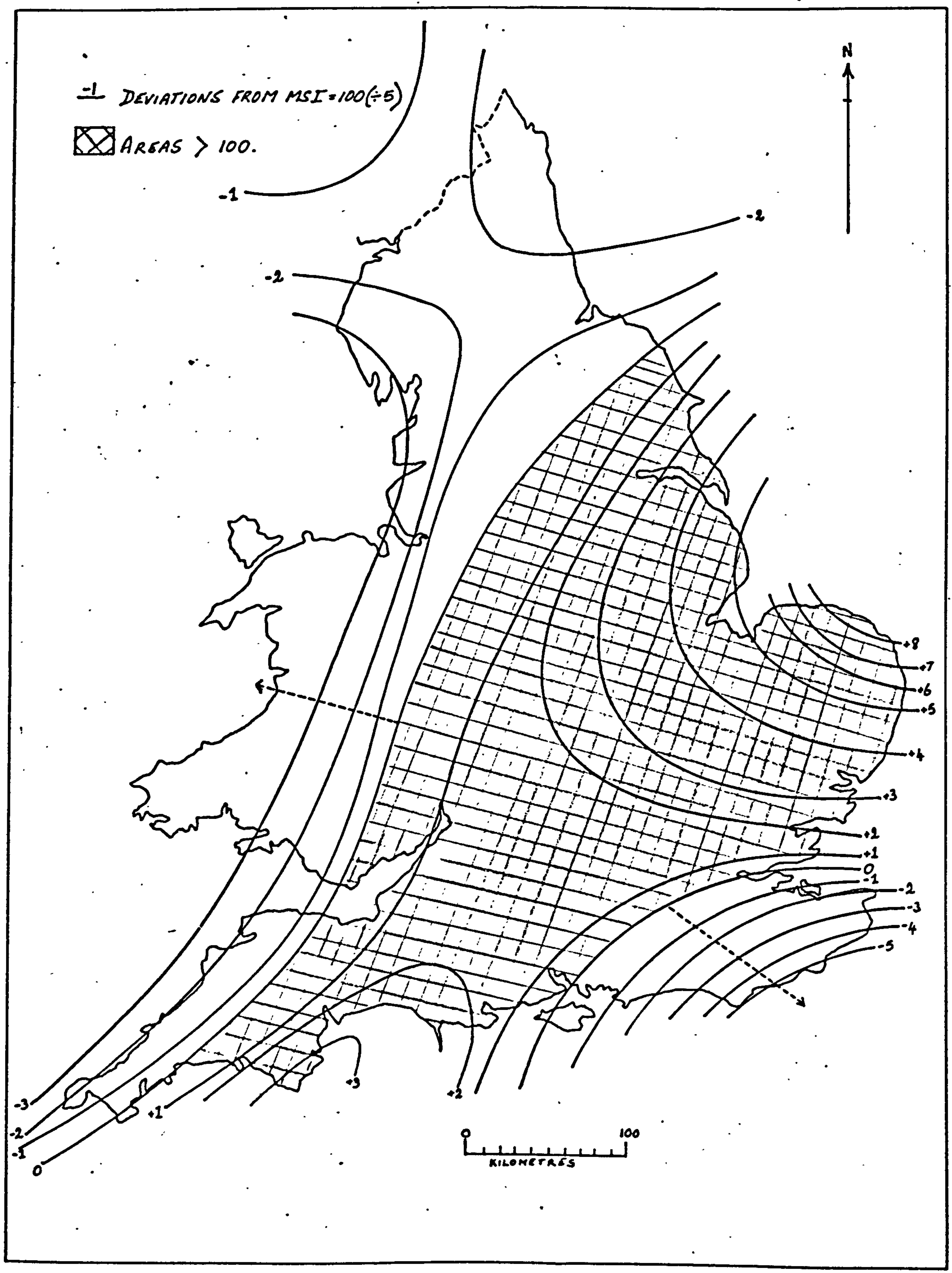

FIg. 9.4.6. CUBIC TREND SURFACE FOR TC7O 


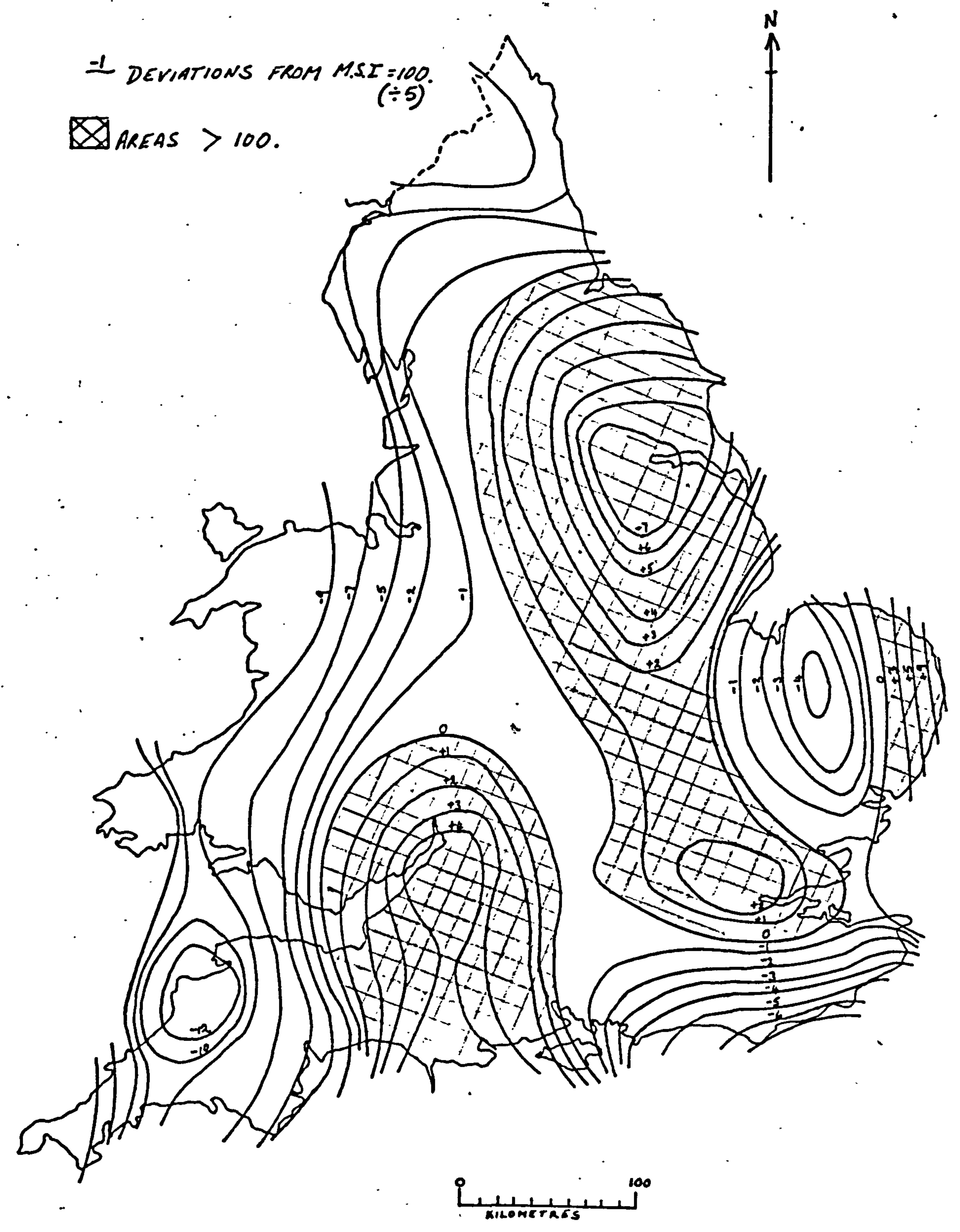

FIg. 9.4.7. SIXMH ORDER SURFACE FOR TCTO 
recognise four basic sub-regions:-

1) In area in the S.E. of Englend with a declining mean safety value as one moves in a S.E. direction.

2) In area along the east coast and extending inland as far as Sheffield and Coventry, which has a rapidly increasing set - of mean safety values, reaching 2 peak in the area of E. inglia.

3) A gently increasing surface rising from the west and Welsh coests into the edge of the industrial regions of the North and Midlands.

4) A rapidly rising surface from the west to the east coast of S.W. Englend, with a levelling off of the surface as it noves into the minimax centroid around Bath and Bristol.

In a geographical sense this derived cubic surface is very familiar on two counts. In the first instance it isolates five of the mejor sub-regions of England, the border lands of the North and Weles, the S.W. Peninsula, the S.E. region and the East Coast area. Similarly this surface also seems to follow somewhat, the transport axis ideclisation. That is, the four "legs" of the modified minimax solution seem to follow almost the same lines as the theoretical "industrial axes" of Englend, which run in a N.I.-S.H. N.H. - S.E. direction, Elong which the mejor lines of communication and trensport seem to flow.

If this relationship with the transport networiks is reclistic, as would seen reasonable, a further interesting feature of the 
surface can be seen. This concerns the location of the minimurn and maximus exes of the minimax solution. It can be seen that trsivel in a general N. $\%$ - S.E. direction is along the maximum axis. That is the centroid of the surface is the maximum value for this exis whether one moves in a N.W. direction or S.E. direction. Alternatively the minimum axis would seem to min in a S.k. - N.E. or eest direction, meaning that as one moves along this axis in either of these directions from the centroid aree, the values of the MSI increese. Remembering that this is $\theta$ surfece for 1970, it would seem to be incicatirg the N.H. - S.E. bies in the major transport netrork systems appliceble at that time. Similarly, the rising surface from both the east midlands end the urben conurbations of west Yorkshire, vould also seem to incicate the lack of satisfactory trensport facilities from these areas to the east coast ports of full end Grinsty which deal vith consideruble trade from these ares. These conclusions rould seen therefore to further justify the completion of the Trans- and E. Pennine motorways as well as the extension of the M5 motorrizy into S.W. England.

It was pointed out previously that the low order surfeces are generally deened to portrey the regional trend of the phenomena under stuiy therefore it would seem reasoneble also to consider the "deviations" from these derived surfaces as representing the variebility unexplained by the regionel generalisetions, cue to local abnormalities. Hovever, vith this varible, beckuse the explained varietion is very limited (12.2l), the residuals could elso indicate systenatic verietions which could heve been accounted 
for by higker order surfeces. The deviations from the cubic surfece for TC79 ere therefore show in Fig. (9.4.8). In this figle positive deviaticns are those where the values of the computed surfece are greater than the acturl value at that point. Therefore ereas with positive deviations have been over-predicted by the trend surfece. The converse is true for regative deviations, and so high negetive values are erees where the regional component fails to explain the high incidence of traffic conflicts.

Observing this deviaticns map, there are various features which are inmediately cobious and deserving of some further consideration, within the context of the regional trend. These features can be split into 5 groups:-

1) The most infortent feature of the deviations mep is the heevy concentretion of positire residuals in the Midlands region. Thus it seems that this region has been over-predicted by the regional trend, even though this area is on the edge of the centroid of the minimex surfece. It could be that this over-prediction is a direct result of being the node of the national netrork system, since increased attention has obviously been given to the setisfactory movement of these quantities of long distance, end through traffic, eround these urben areas. As a result, it would seem that these midland arees are able to cope vith the road safety problem better then would be expected according to the national Everage expectaticn.

2) A seccnd feature of tho residuals map is the group of negutive resicuals which control entry into the S.H. Peninsula, 


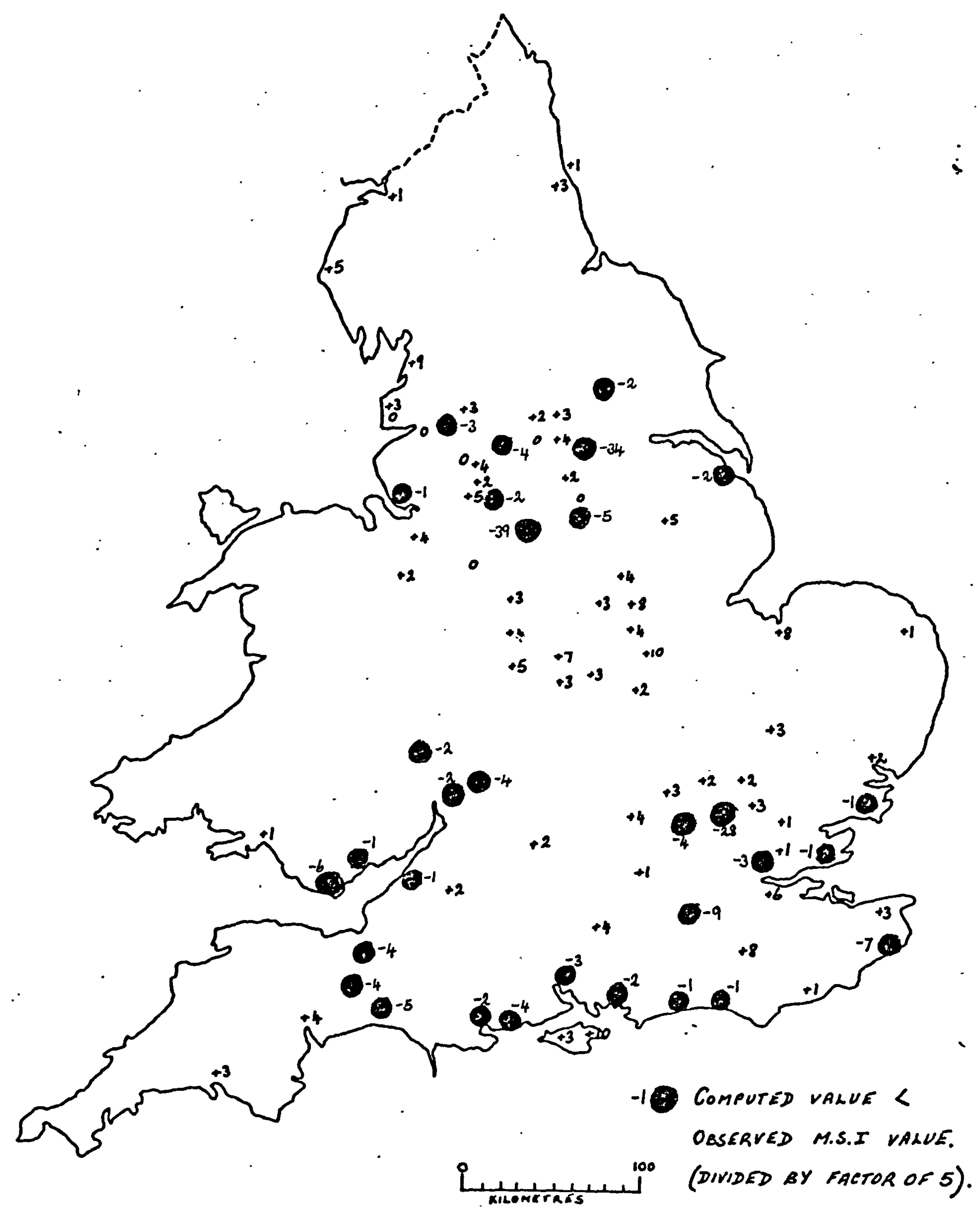

FI - 9.4.8 DEVIATIONS FFON THE CUBIC TREND SURFACE FOR TC7O 
both along the north and south coasts as well as the centril erees. Thus vibilst the regional trend showed the need for a better netwcrk syster in this area, the deviations show that the problem was underestinated by this regional trend. It is interesting to note that all the sampled town on the $A 38$ south of Biminghem have negative values, the implications of which needs no further emplificetion. \& further interesting point here hovever, is that once past this gatoway, the sompled toms have positive deviations, perheps implying thet the hieh casualty levels are not only related to traffic valumes, but elso the degree of congestion due to limited access into this \&ree. However, since the number of semplec points is very limitec at these points, no degree of certainty can be made upon such an assumption.

3) The third feature of the deviations mep is the ring of positive deviations eround Loncon, vithin which there epperss a smaller ring of negative velues. This suggests that there are perhops two patterns operating in this region. The inner region on the very outskirts of Loncion seems to be characterised by high MSI velues wich is the cpposite of the outer-ring, which incidentally inclucies the outer ring of new towns, end garden cities developed over the last thirty yeers. The result has been that the surface has tried to everkge these tro groups, end thereky over-predicts the outer ring of urben areas end under-predicts the inner ring. The obvious reason for these two rings and this feature in the resicual map is the disconcerting influence of London, which was not included in this research for that very reason. 
4) The fourth feature which needs mentioning here is the consistent string of negative values associeted with the coastal arees of south and south-cast Englend. This is probebly explained by the fact that this variable includes both driver and rider casuelties plus pedestrian casualties, yet this latter group has alreacy been shoun to be influenced more by local factors than regional trends. Therefore where high pedestrien levels are expected, as in these hollday resort areas, it is only natural for the regional trend to underestimate the incidence of casualties for these areas. This is also further modified by the ebnormal seasonal traffic variotions associated with these toms purely beceuse of their function. Thus the highest negative value for these areas is -7 for Dover, which is obviously related to its function as a cross-channel ferry port.

5) The final feature to be noted is the mixed residuals associated with the Lencashire and South Yorkshire conurbations, which fail to indicete even a mareinal local trend, except perhaps for the fact that as one moves east, there is a reletive increase in the number of negative values. Consecuently one can only assune that these areas are more influenced io locel enomelies than regional trends.

hlthough the 6th order-surfece fails to reach a satisfactory confidence level, it is worth observing since the explenation lerel has been increased to 22. Z3. This surfece is show in Fig. (9.4.7). As is only to be expected, this surface is much more complicated, but in many places it coes agree with or satisfy some of the features 
noted above as regards the deviations from the cubic surfece. The modifications and reglons produced in this 6 th order suriace cen best be cescribed as follows:-

(1) A circular high centred on the Bristol Channel erea which effectively blocks the approach to the S.W. by means of a ridge which extends across the area betwien Bristol end the Dorset coast. This area of high MSI values elso extends to the incustrial regions of $S$. Wales and the approaches to that area. Both of these modifications could have been predicted from the cubic surfece as argued ebove.

(2) The N.W. - S.E. transport axis is mointained as \& trough of low MSI velues between the highs of the S.W. and the N.E..

(3) A region of high MSI values centred upon York and the Humber estuary, end covering 0.11 of the N.E. and the east midlands.

(4) An expected smell high centred on the London region.

(5) An area of low MSI values centred near Kings Lynn, but increasing as one roves into the more easteriy a reas of East inglia.

(6) A gentiy declining surfece from both the welsh and North border lends.

(7) An aree of low values centred on the north Cornwall const and covering the major part of the S.W. peninsula. This is en interesting modification since it was al ready noted when discussing the areas past the entry to the S.W. that the deviations tended to be positive and it was postulated then that the areos of conflict 
might be restricted to a limited area, due to the congestion factor. Although this seems to be supported by this sixth-order surface 1 t must $s$ till be treated with come caution because of the low confidence value associated with this surface.

In conclusion therefore, it hould secm fair to stete that al though the emount of variation explained by these trend surfaces for $T C 7 \varnothing$ is only moderete, there would seen to be sone definite spatial (regional) trends which should be taken into account when stucying the road accident problem, and which can perhaps be related to the nationel trensport network systens and the function of different urben areas.

\section{(2) TOTAL DFIVFR AND RIDEP CASUALTY TFFND SURFACE ANALYSIS (1970) TDEC79}

It was suggested in the endysis of the previous variable TC7 that cne of the reasons for the leck of explanation in terms of a regionel trerd, could be the influence of the pedestrian casualties included within the totel number of casuel ties in eny urben area. It was further argued that this was due to the locel causation factors within the pedestrian casualty situation. Accordingly one vould expect, if this were true, that the varleble TDFC7 $\not \varnothing$ should exhibit a better fit and a surface more influenced by external factors when subjected to a trend surfece enelysis.

As regards the goodness of $\mathrm{fit}$, by the time the $6 \mathrm{tb}$ order surfece was derived, $39.7 \%$ of the total variation remaining from the regression on TIRC7 $\varnothing$ had been explained, end the resultent 
surface was highly significant $(F>95 \%)$. Similerly the cubic surfece, which can be used to observe the initial trend, eccounted for $21.7 \%$ of the variation end was eiso very highly significant $(F>99 \%)$. These two surfaces are shown in Fig $(9.4 .9)$ and Fig (9.4.12) respectively and vill be described in the following section.

The cubic surface obtained in this trend surface anelysis is In meny ways similer to that cescribed for $\mathrm{TC} 7 \mathrm{~d}$. Hovever, as was hypothesised there does seam to be a much better fit to external influences, as viell as a better overell fit. In fect the derived surface fits remarkedly well, on to the mejor national transport netrork system. Once egain sereral distinct regions cen be identified.

(1) A centrul region along the N.H. - S.E. Exis vith MSI values falling between 100.00 end 105.00 , extending approximately from Luton to the very north of Englend.

(ii) An area including S.E. England within which MSI vqlues decrease in a S.E. direction.

(iii) An area covering southern Englend and the beginning of the S.W. Peninsula, within which MSI values are ircreasing ir a southerly airection.

(iv) A rising surface which covers alnost all of eastem Englend, reaching peak in E. Anglia.

(v) A stesdily declining surface viestwards from the Welsh border lends. 


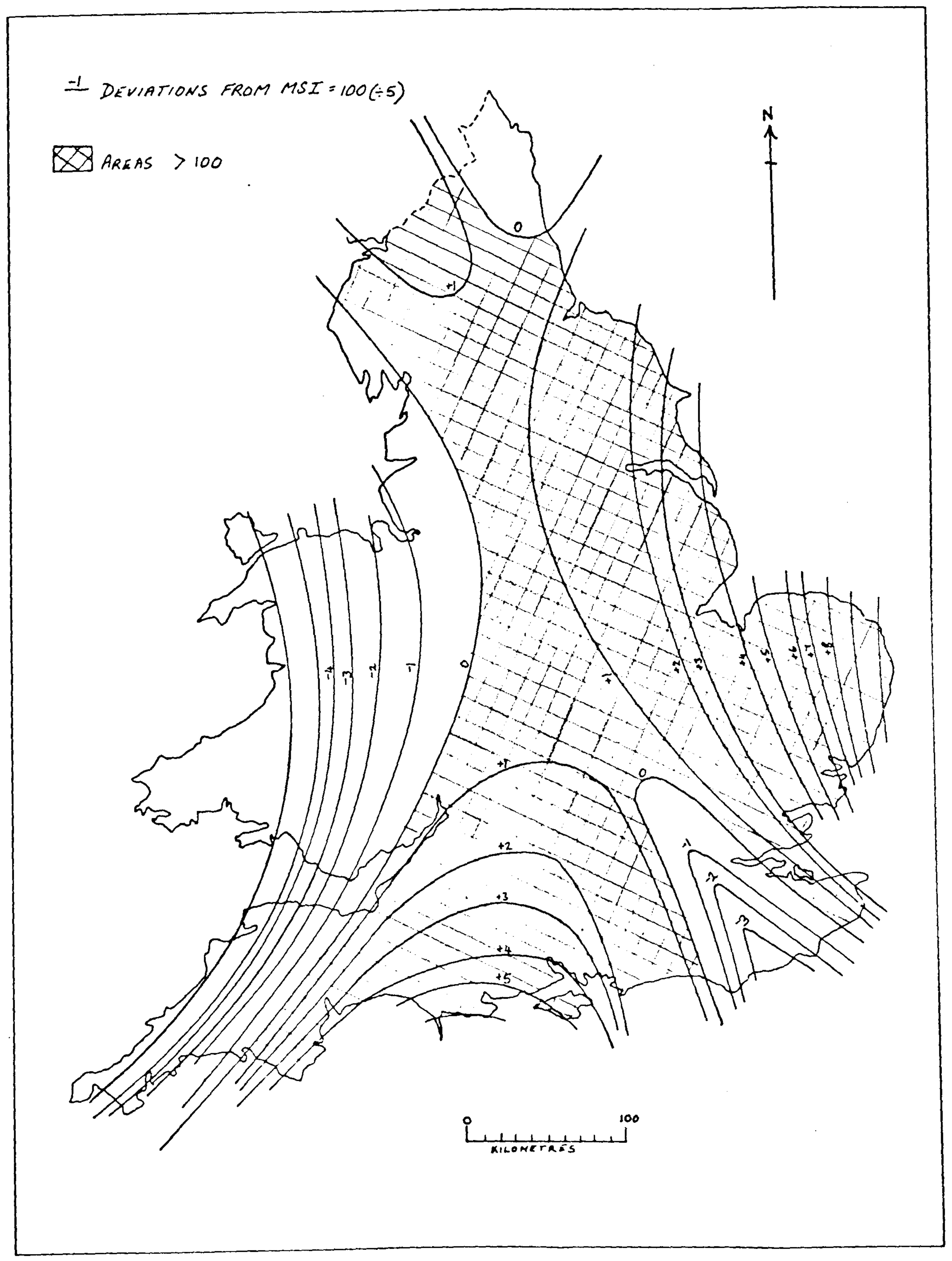

Fig. 9.4.9. CUBIC TREID SURFACE FOR TDRCTO 


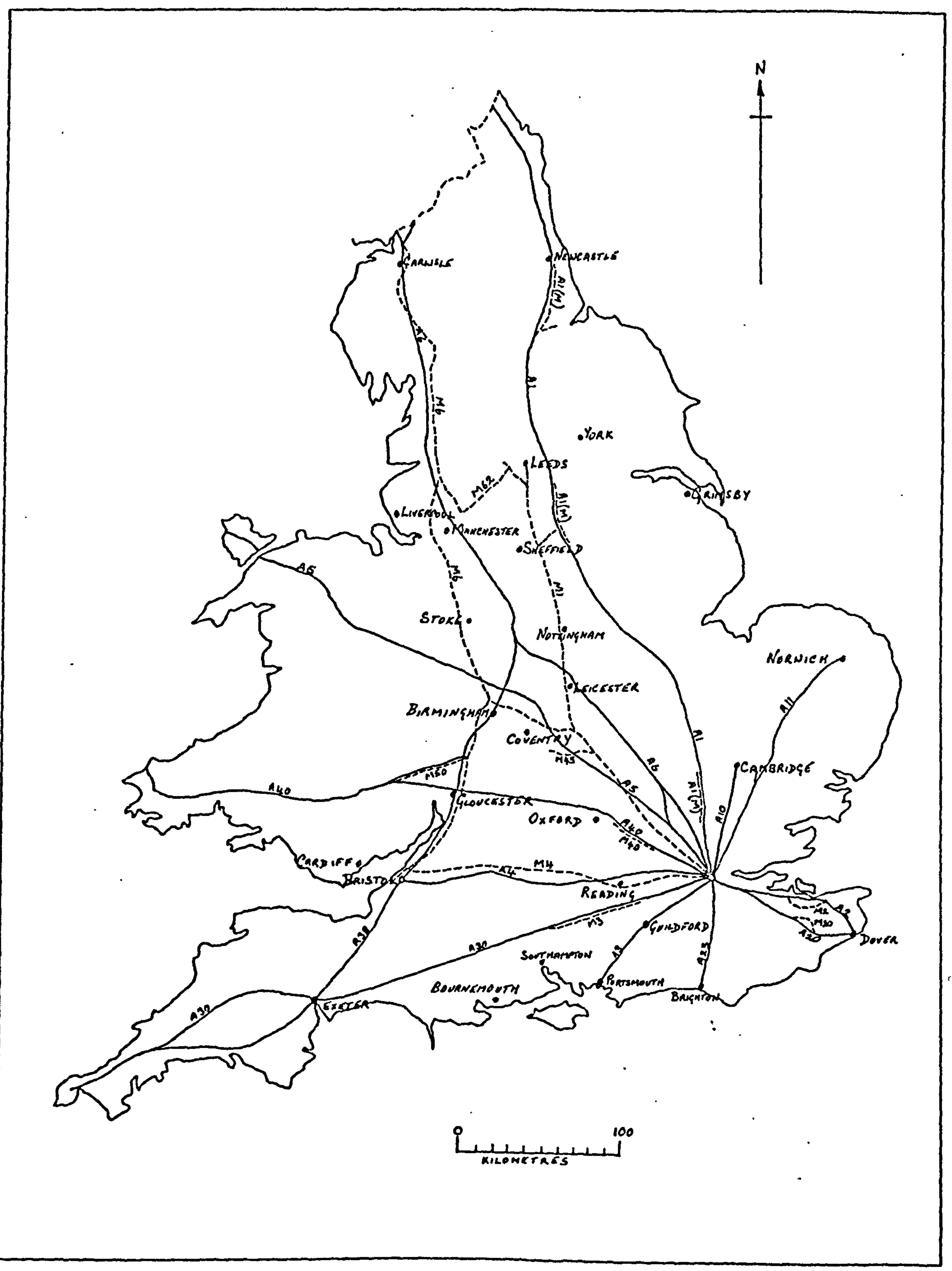

FIg. 9.4.10. THE TOAD NETMDRK STSTEM OF ENGLAND AND WALES. 
Since most of these regions are compareble to those described for $T C 7 \varnothing$, it is unnecessery to put forward the sime arguments here, except to sey that once agein the importence of the leck of major east-west communications and the problems of the S.K. Peninsula, are clearly elucidated. For means of comperison also, the major netrork highways are shom in Fig. (9.4.10).

The map of deviations from this cubic surface meanihile are not too easy to identify (Fig. 9.4.1I). However, certein fertures do apper.r to need to be cualified in higher order surfaces and these are listed below.

1) The cubic surface seems to be underestimating the MSI values especially in the S.E. Erce of Englend.

2) The areas around the Bristol Channel also seem to be underestimated and modifications to the surfece are needed here.

3) Whilst there is some over-prediction in the midlands area, it is nokhere near as uniform es with variable TC7\%.

4) The surface is definitely over-predicting in the N.W., and the Lenceshire conurbations in particular.

5) Although the surface rises towards the east coast, it is obvious fron the residuels that this rise shculd be much stecper.

6) One difference in this set of deviations and those obteired for TC7 which should be noted here, is that whereas for TC7 $\varnothing$ \&ll the soutrerr corst resorts had negative residuals, the deviations from this surface show a marked variation between the different 


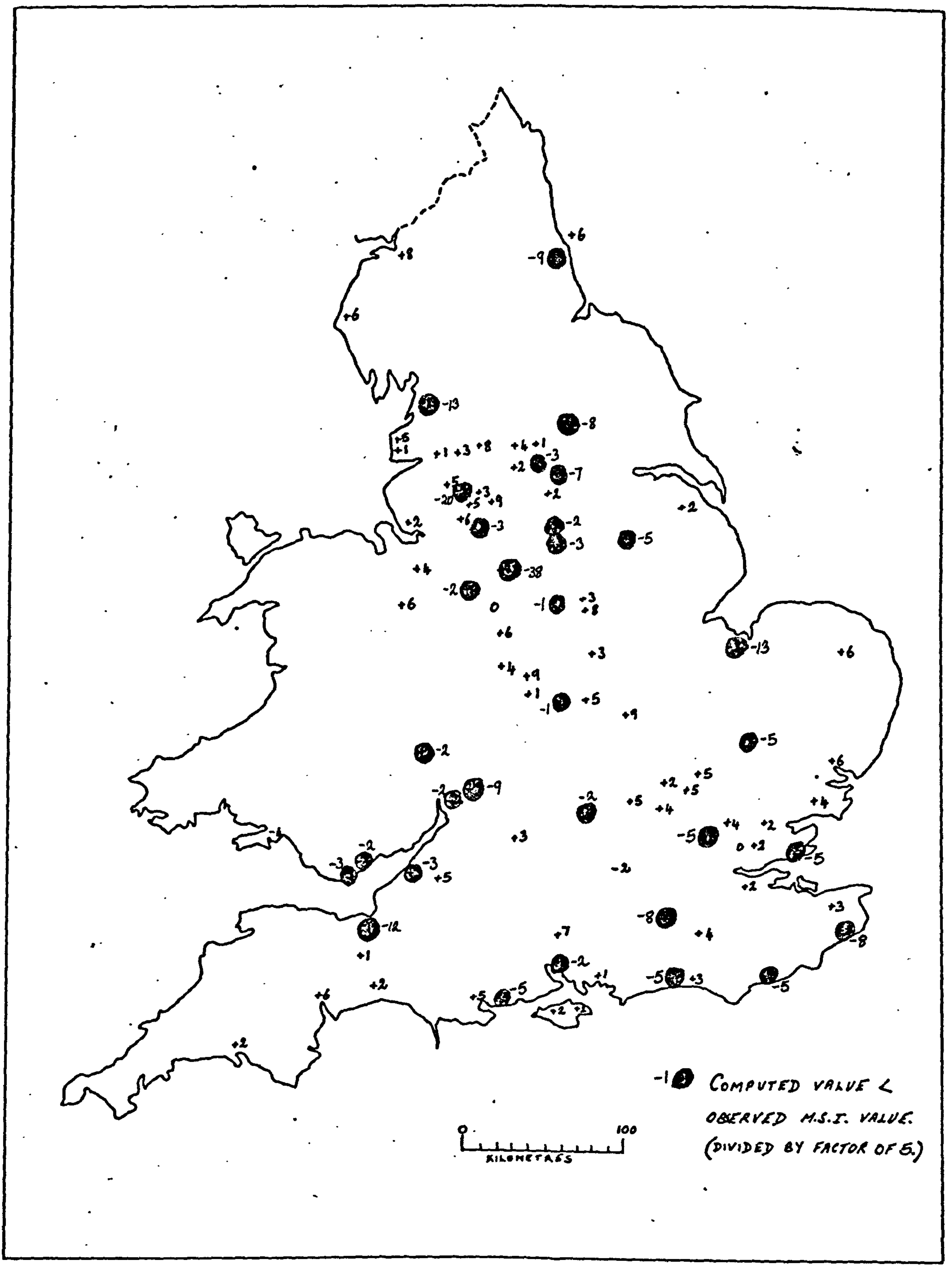

Fig. 9.4.11. DEVIATIONS FRDM THE CUBIC TREND SURFACE FOR TDRC7O 
resorts. Therefore it would seen that the arguments put forward previously concerning the signifcance of pedestrien casualties in these areas are justified.

Since the 6 th order surfece accounts for 397 of the variation in TIFC7 1 it would be assumed that a lot of these deviations mentioned above would be removed within that surfece. As can be seen from Fig. (9.4.12) this is very much the case with the central plateru being split into two groups, one being a 'low' and being centred over the southern midlands, and the other giving a gentle rise in the Lancashire conurbation area.

Similarly, the group of negative residuels around the Bristol Channel are removed by the introduction of a ridge into the north Devon area end extending into the rest Hampshire basin. Another rioge along the eastern coastline also helps to remove the negative velues in that area.

The general conclusions from this trend surface enalysis therefore must be similar to that for TC7\%. That is, the residuals from the regression TIDW7 would seem to be strongly related to the national road network system, and the function of certain urben areas. Hoverer, it must be pointed out that whilst the southern coast resorts do still provide some anomalies, the removal of the pedestrien cesuelties has reduced the major abnomalities of these areas, thereby enabling these areas to be satisfectorily incorporated within the trend surfeces. 


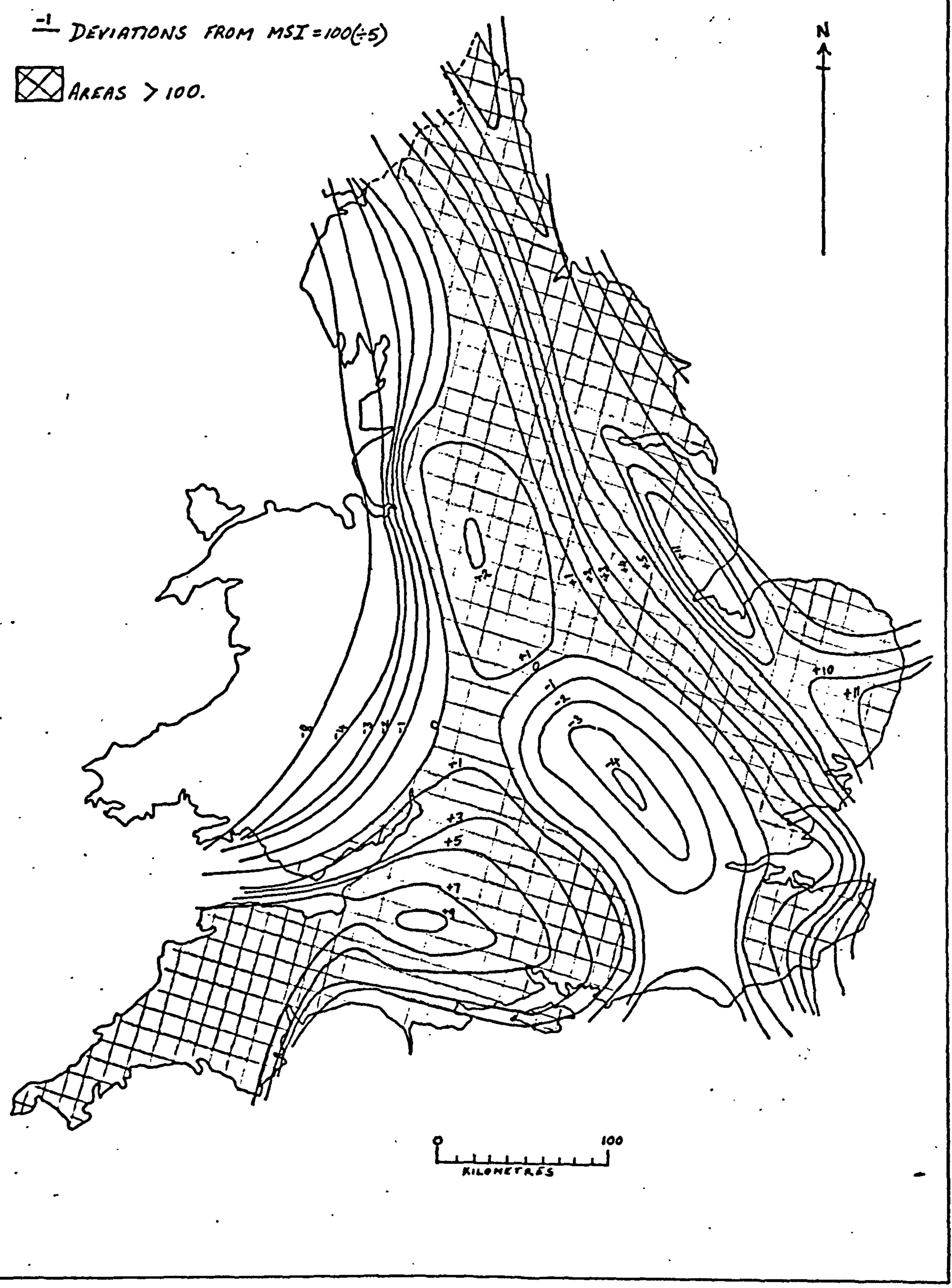

FIg. 9.4.12. SIXTH ORDER TREND SURFACE FOR TDRC7O 
(3) TOTLL ACCIDENTS PER $10^{3}$ POPULATION TPFAD SURFICE MYLYSIS 1970 (TAPP79)

If reference is nade back to the original regression results for this varisble, it will be seen that it was argued at that time that this variable measured the variation in road accidents once the size factor (population) had been removed. Similarly it was also shom that the structural variables accounted for a very low percentage of the total variation within the dependent variable (29:). Ho:vever, since one of the major independent variables introduced into the regression equation was that of ETTP it was postulated that perhaps a substential part of the remaining variation could be accounted for by spatial and regional variations, especially those also related to ETT7\%. This therefore is the main feature of Interest in looking at this trend surface analysis.

Fron the results obtained for TAPP7 it can be seen that the trend surface analysis was significant at all levels and by the time the 6 th order surface had been reached 43 of the variation in the variable had been accounted for, and the surface as a whole was highly significant. $(95<F<997)$. Similarly, the cubic surface bich accounted for 253 of the variation wes also significent with the calculated value of $F$ being significent at the 99.1 level. The cubic surface can therefore be observed as the more simplistic reglonal trend surfece.

The cubic surface thich is shom in Fig. (9:4.13) is so organIsed tinat the trends noted in the previous two trend surfece enalyses, are much more emphasised, within this variable. Thus the lon trough 


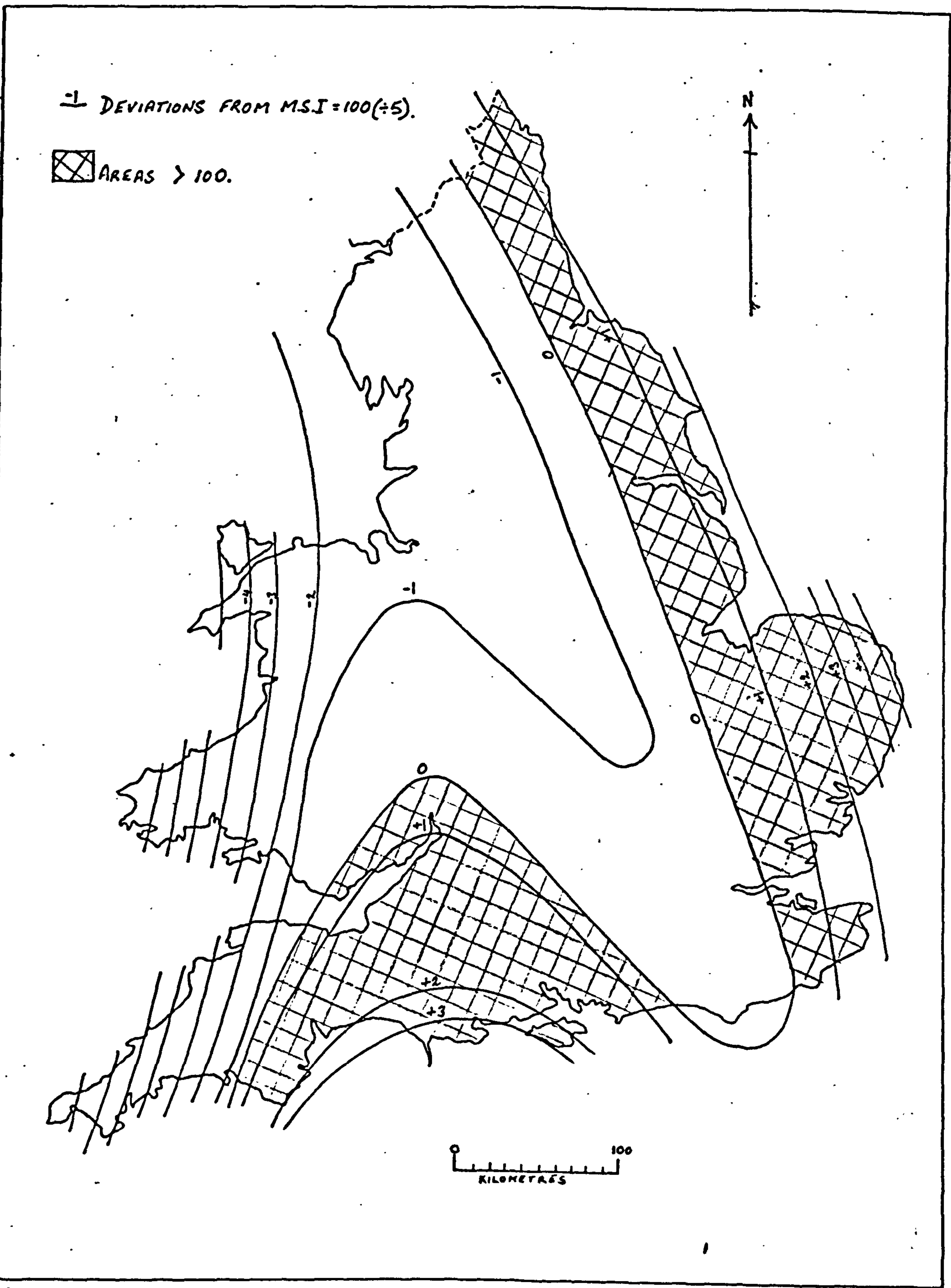

F1g. 9.4.13. CUBIC TREID SURFACE FOR TAPPTO 
which covers a mejor portion of Englend is again lined along the N.V. - S.E. Exis. Tovrards the eest of this area, the surfece rises rapidly towards the east coast region, xith considereble rises in East Anglia. There is also a similar rise in the surfece from the south miclends into the S.W. perinsule and onto the south coast area. It should be noted, however, that once the surface has moved into the S.H. peningula itself, the surface agein begins to fall fairly repialy. Thus once again the fertires of this surfece which should be noted are those which can be related to the major trensport netrork system, with the mein emphasis being on the unsatisfactory surface rises in an east-west direction end elso as one approaches the entrance to the S.li. peninsulz.

Observation of the residuals from this surface neanvile shows various features which nust be accounted for by eny higher order surfeces (FIE. 9.4.14).

(1) Uncier-prediction by the cubic surface for areas in the eastern half of Englend, including the south Yorkihire conurbations.

(ii) Under-prediction of most of the aress Eround London.

(iii) Under-prediction of the areas apprcachirg the scuttwest and also the south midlends.

This predominance of underestimation by the surface is gn Indication of the difference between aress of hich MSI values and those of low HSI values, which obviously cennot be eccounted for by the cubic surface. Similarly it would al so seem to be a direct 


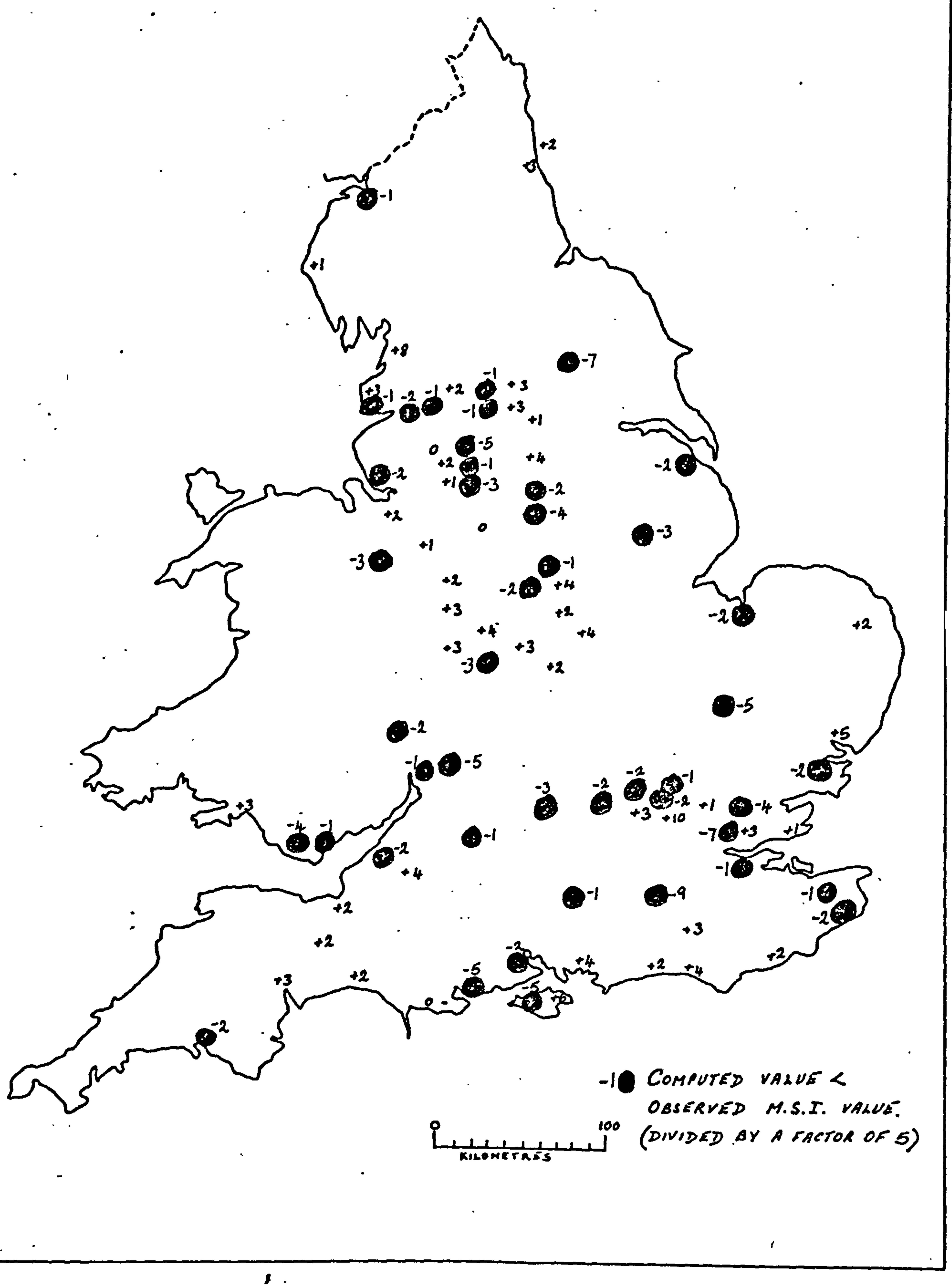

FIg. 9.4.14. DEVIATIONS FROM THE CUBIC TREND SURFACE FOR TAPPTO 
Indication of the impact of eny spatial variable such as road trensport.

Accordingly, the 6 th order surface which is shorn in Fig. (9.4.15) is considerably more complex although the major trend, the H.W. - S.E. trough still remeins as the centrel theme of the surface. The major modifications, as can be seen, are the introduction of new "highs" over centrel wales to account for the high velues for the industrial regions of South Wales, in particuler Cerdiff end Berry, and also over the eastern coastal region, in order to increase the high velues noted for this region of England. Although this surface greatly increases the level of explenation for TAPP7 $\varnothing$ it still falls to account for considereble variation as can be seen from the map of residuals for this surface. Howerer, it must be presumed that these reminIng variations are due to locel components within the regional trends, end os such cennot be expleined ut thin these trend surfece enelyses. In indication of these locel components cen cleerly be seen in the restduels for both the Lanceshire and Yorkshire conurbetions, where there is neither a predominance of negative nor positive velues which vould permit further regional explenetion for these aress.

The conclusion to be drakn from this enalysis therefore is that the postulates made regarding the importance of through truffic in the discussion on the original regression eauction, seem to be oerfectly valid. However, it would secm also that 


\section{DEVIATIONS FROM MSI = 100. (-5).}

QXarkas more THAN 100. 


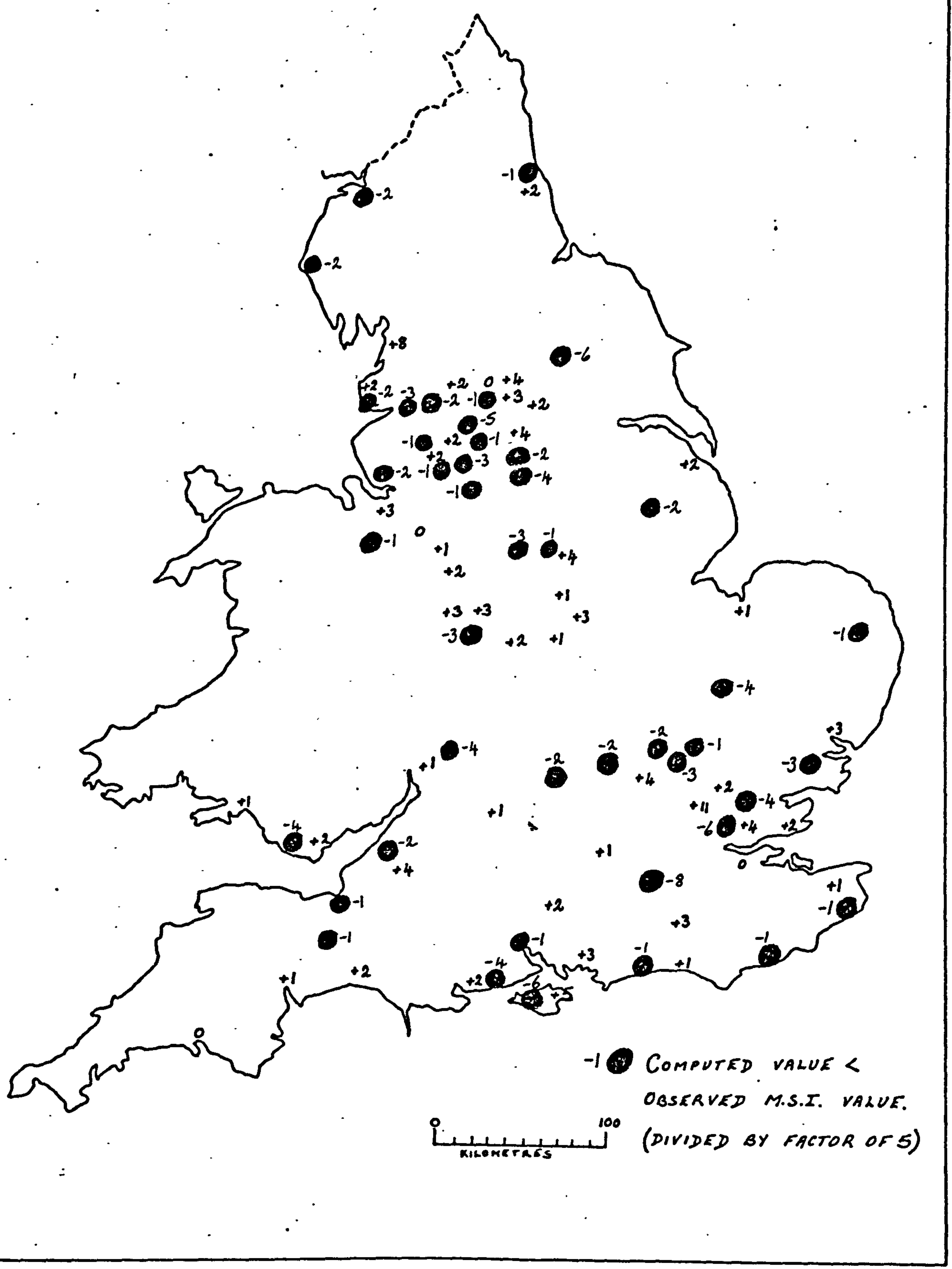

FIg. 9.4.16. DEVIATIONS FFOH THE SIXTH ORDER TREND SURFACE FOR TAPP7O 
most of the remaining variation in TAPP7 cen only be related to local factors, and as such cannot be accounted for within this cnalysis. Therefore once egein the situation is reached where further understending of the problem must erise from local studies of areas which cen be placed generally within the context of this research.

\section{(4) PEDESTPIAN CASUALTIES PEP $10^{2}$ VORK WLLK TRIPS TRHTD} AHALYSIS 1970: (TPEDWT7D)

It was stressed whilst looking at the results of the regression Enalysis that the volume of pedestrien casulties appeared to be dependent more upon local factors and arrengements, rather then regional or naticnal factors and trends. The results of these trend surface analsses rould seem to vindicate this line of argument since this verieble is the only pedestrien varieble which cen produce a surface khich is significant at any confidence level. From the relevant tables, it cen be seen that at the 5 th order surface, this surface accounts for approsimately 34,3 of the total variation in TPELNT7 $\varnothing$ and is significant at the 95\% level. It must be remembered however, that this variable is somewhat experimantel in nature due to the fact that the actual volume of pedestrien cesualties ras modified in order to take eccount of pedestrian exposure. The vollime of casualties has related to the number of work velk trips as given by the journey to work tables in the 1966 Census. Therefore $1 t$ vould be naive to essume that this variable is wi thout error, but then egain it vould seem reasonable to expect this variable to give some degree of indicotion in the relative risk of pedestrien casualties in different areas. 
The 5 th order surface for TPEDIIT/ is show in Fig. (9.4.17) and the most obvious feature of this figure is the lon values derived for the mialends region of Englend, centred on Birminghem and Coventry. In some wasys such en area of low velues is quite a surprise sirce with this region's high car ownership values one vould have expected the relative risk to pedestriens to be somewhat higher in these areas. The explanation to this secaing enomaly would eppear to be that because of the high levels of car cinership, it hes become necessery in these areas to find ways of accomodating and integrating these extra cars into the urban system, whilst also protecting both the environment and the pedestriens. The result has been the creation and building of better transport netrork systems in these ereas, and the simultonecus creation of pedestrian areas and facilities, in order to maintain the principle of single purpose thoroughways.

A second feature of this trend surface analysis is the wey all the major coastal resort areas are characterised by rising surfaces. The only exception to this role would seem to be elong the S.E. coast where the surface is felling. However, observation of the residuals man shows that this area includes negative values along the coastal area, indicating thet these areas are being uncerestimated. Wilst this is really of little surprise it does incicate that these recort ereas shoulc spend more time end money on the protection of the pedestrians in these ereas, who after all, are the main source of revenue for these toris.

Finelly, as regards this variable, the renainine point of interest is related to the deviations map for this 5 th order surface 


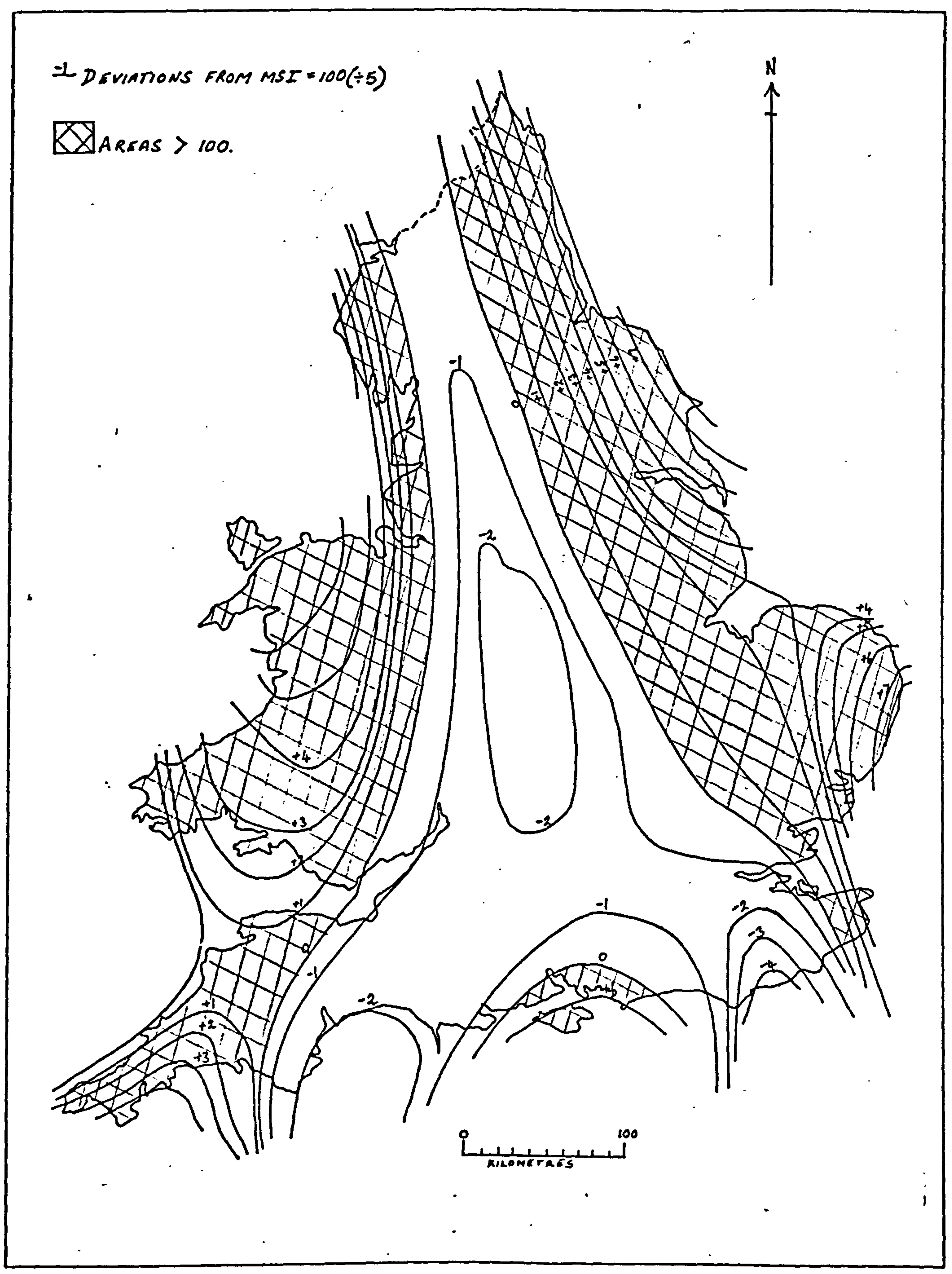

FIg. 9.4.17. FIFTH ORDER TREND SUFACE FOR PEDWT7O 
(FIg. 9.4.18). From this map one cen see that there is a high negative group of residuals around the edge of Loncion. Once again therefore it rould seen that the derlved reglonal trend Is unable to account for the areal inpact of the London conurbation, consezuently in most instences, the regional trend will underestirate values in these areis.

Sunnarisinf therefore, al though this variable nust be treated wh sone caution, it would seen that three inportsnt facts cen be derived fron this surface:-

(1) The rezion which has seemed to cope best with regards to the traffic/pedestrian conflict, and where the relutive risk to pedestriens is lorest, is the Midlands redion. Therefore it would seen reasonable to edrocete studies of these toms for a further understending of this problen.

(ii) As regaris relative pedestrian risk, it would seen that the coestal, and resort toins, have much that needs doing in order to reduce the level of pedestrian vulnerability.

(1ii) The aree surrounding London also has a high pedestrian rists value, end this includes the ring of new towns and garcen city areus.

The trend surfaces which have been described individually in this report have pinpointed the major features of the spatial analysis. The renaining trend surfaces either merely enphasise the trands alrexdy indicsted, or altematively are insignificent accoriling to the enalysis of variance test. However, shere the 


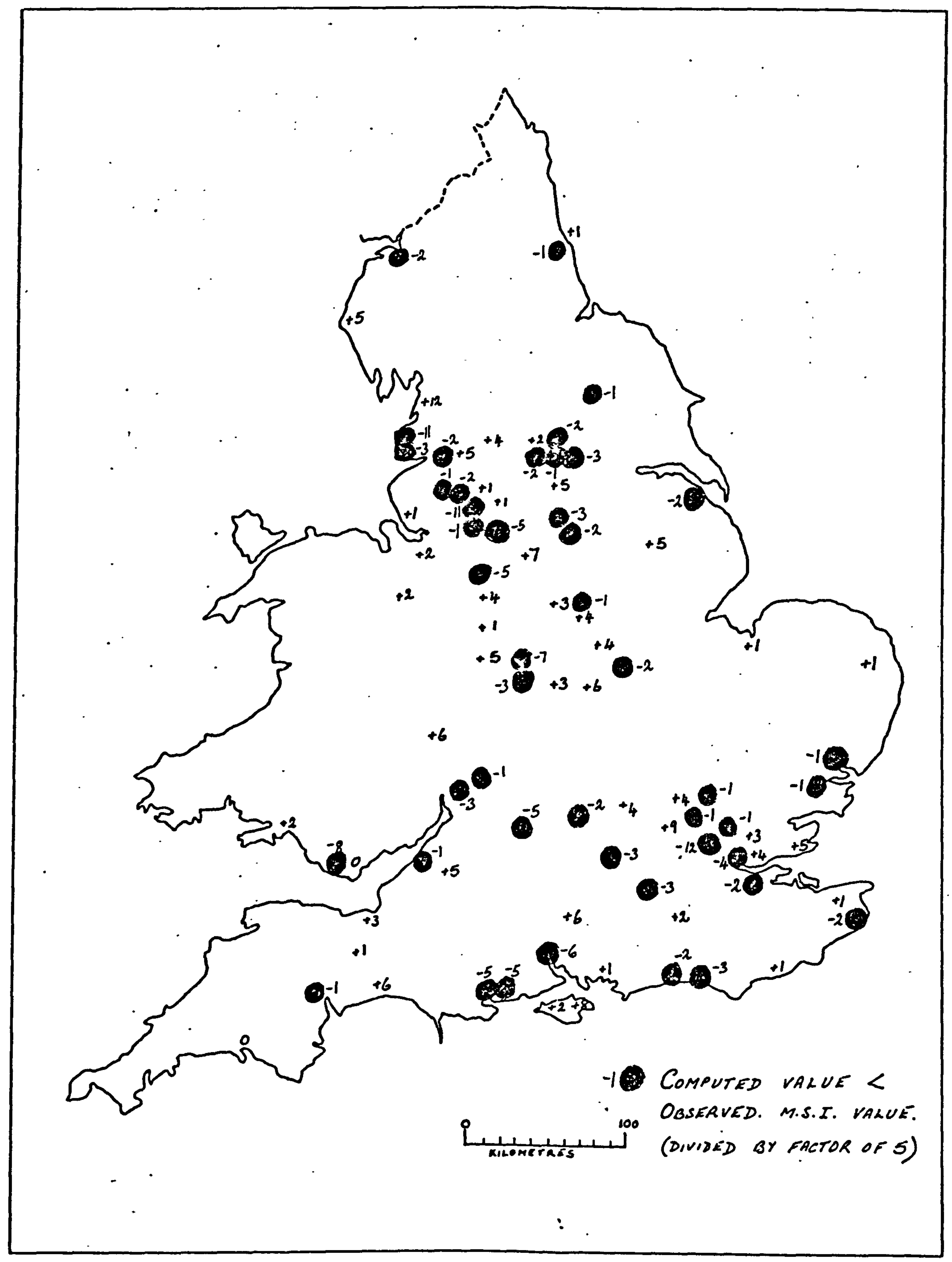

FIg. 9.4.13. DEVIATIONS FROM THE FIFTH ORDER TREND SURFACE FOR PEDWTTO 
trend surfaces heve proved significent at any surface, the relevant maps are show in Appendix 2, and for further information as regards these surfaces the reader is referred to that section of this report.

Before leaving this section of the study of the spatial variations it is pertinent at this point to look at the results of the calculation of the Meen Safety Index itself.

One of the major reasons for looking for, and at, these spatial variations as to look at regions and see if there were any specific probleas ralevint to that one region. However, at the same tine it is also possible to group toms according to their response to eny varlable in a non-spatial sonse. That is, torns can be grouped according to their actual MSI value. Once agkin the logic behind this approach is to see if certain groups of tows have sinilar problezs which can be solved accordingly.

Two methods of groubing the 100 sampled aress were tried, one which simply used tive value of the RSI, and thereby placed each area into a predeternined group, and the other which proved less reliable, and thich made use of a Q-mode factor inalysis.

l.ccording to the first node of analysis, it would have bean pessible to derive a grouping systen for every regression equation. Howerer, this was considered excessive and accordingly a grouping systen was atteined for only five regressions, which display the absolute levels of conflict and also some degree of exposure. Thus the five regression variables which were grouped accurding to their ISI values were:-

1) Totil Casualties 1970 
2) Total Fatal and Serious Cesual ties 1970

3) Total Pedestrian Casualties 1970

4) Total Cesualties for $10^{6}$ Vehicle-Nile 1970

5) Total Pedestrien Casualties $10^{2}$ york Walk Trios 1970

In additional grouping which was also included was that of the calculated HSI values from the trond surface analysis on the variable TC7\%. The logic here was that using these MSI values rould rexove the extemal througin traffic variable variation, thereby allowing a more realistic assessment of the group probiens of each urban aree. These groups are shoin in Tables (9.4.1.9) to Table $(9.4 .2 z)$.

As can be seen fron these tables, the distributions about 100.00 HSI velue, appear almost nomally distributed, wich is only to be expected considering their derivation. Therefore the groups (and constitunt parts) which are of most interest are those which occur at either end of the distribution, and are therefore shouing extrene resoonses to each of the regression variables. Thus as rezards this grouping procedure, the importent groups vere deened to be those with MSI values greater than 120.00, and less titan 80.00 . In the folloving section therefore, a quick sumrary of these groups will be given according to the individunl regression variable.

\section{1) TOTAL CASUATTIES 1970 - (MSI GROUPINGS)}

The urban areas grouped within the high MSI groups for this variable seen to be characterised by their very size. All. three 


\begin{tabular}{|c|c|c|}
\hline$\underset{\sim}{+}$ & 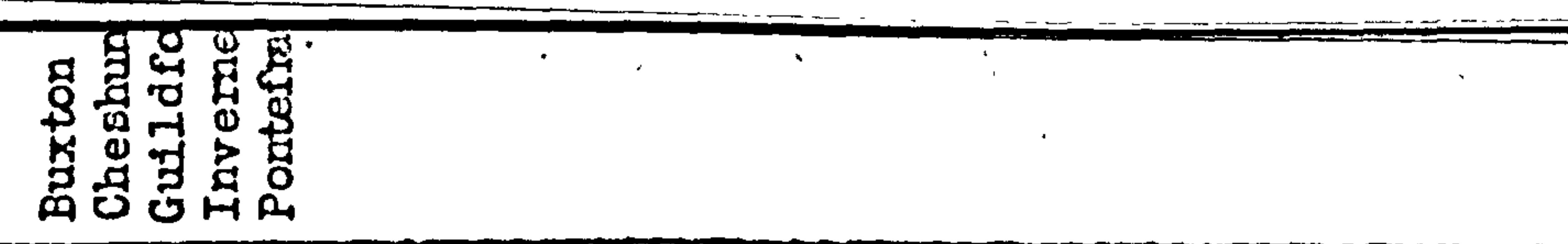 & \\
\hline 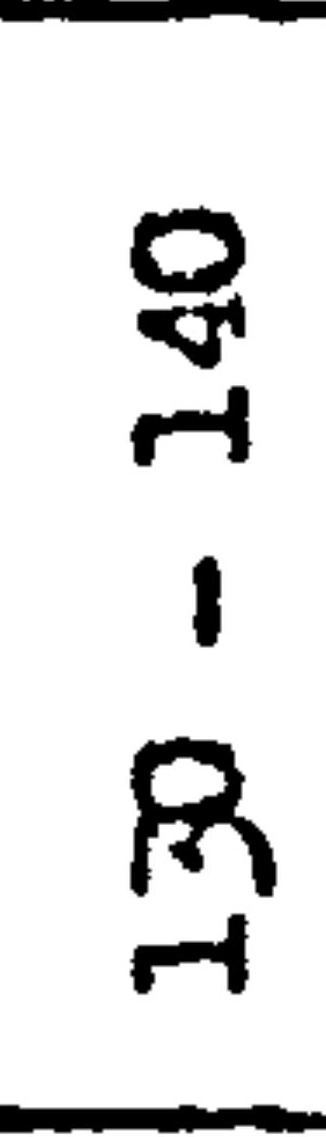 & $\begin{array}{l}\text { D. } \\
\end{array}$ & \\
\hline 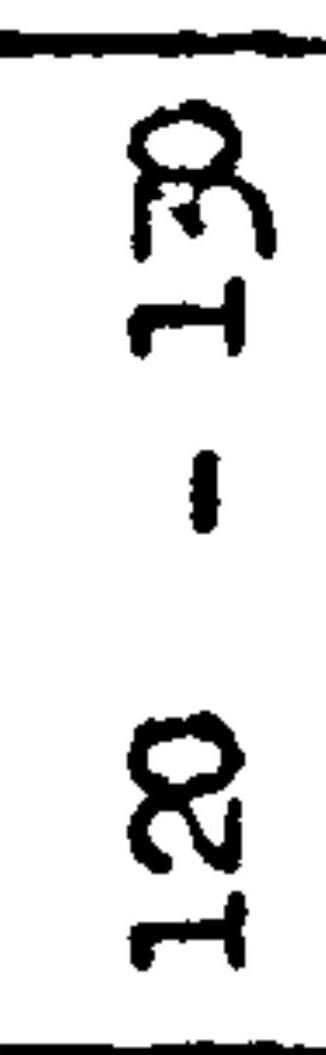 & 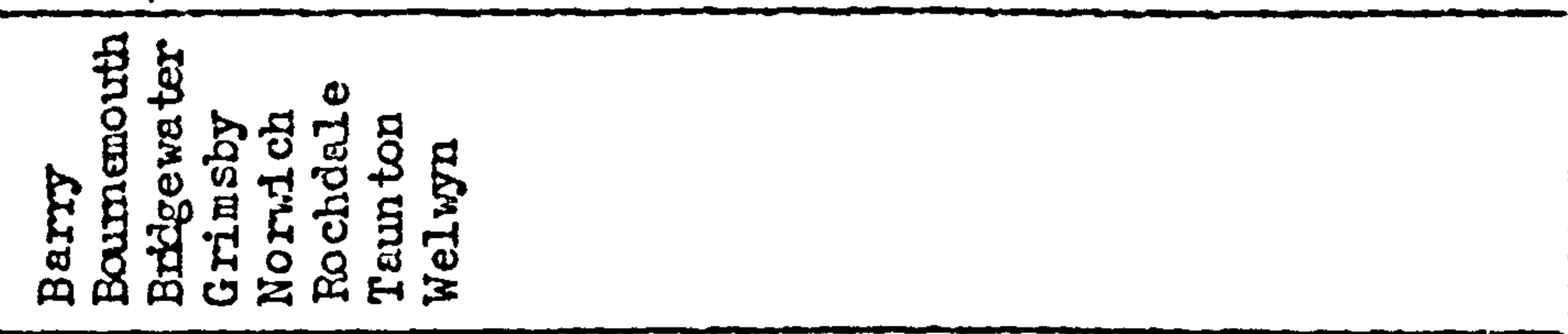 & \\
\hline 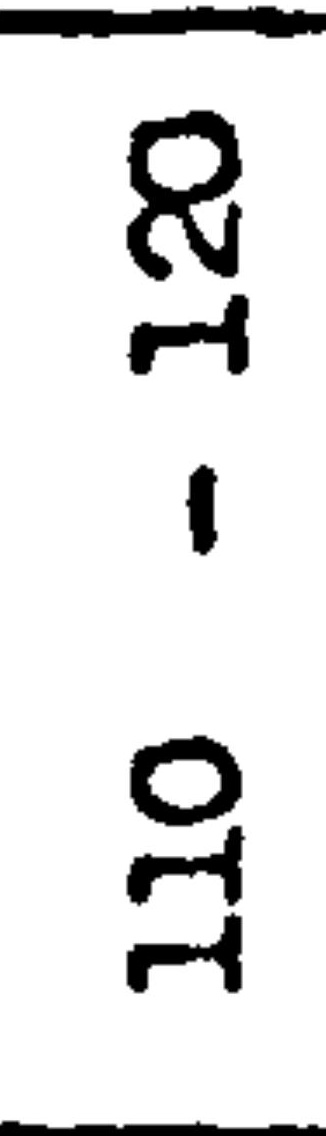 & 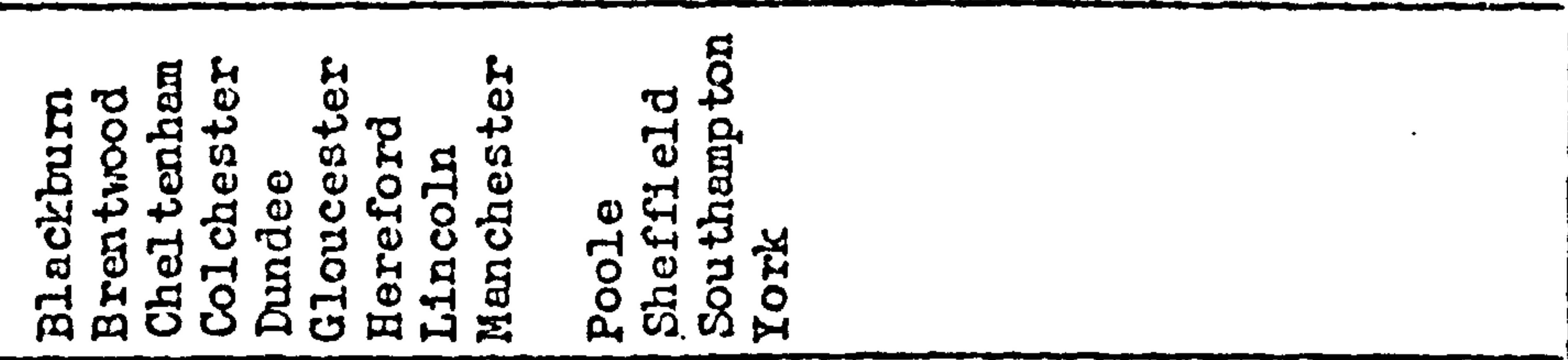 & \\
\hline \begin{tabular}{l}
$\stackrel{9}{7}$ \\
1 \\
8 \\
\hdashline
\end{tabular} & 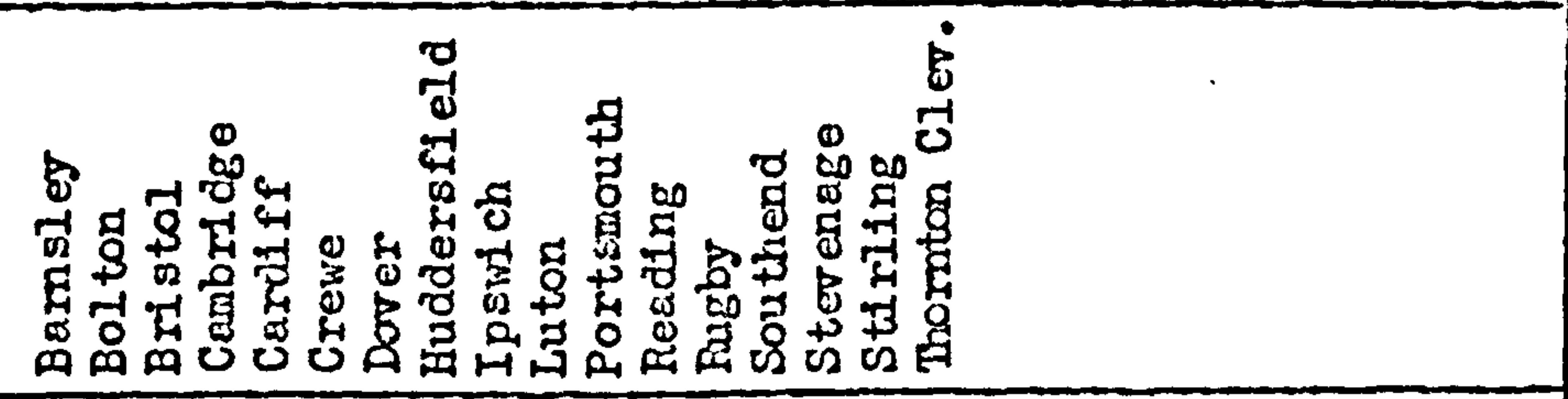 & \\
\hline 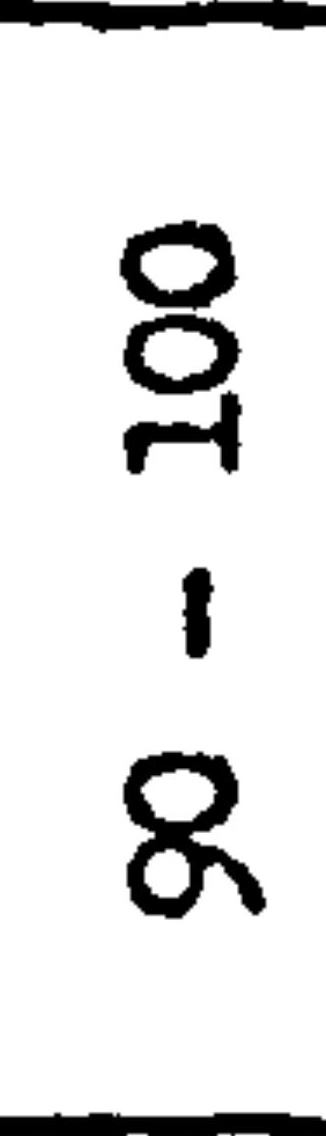 & 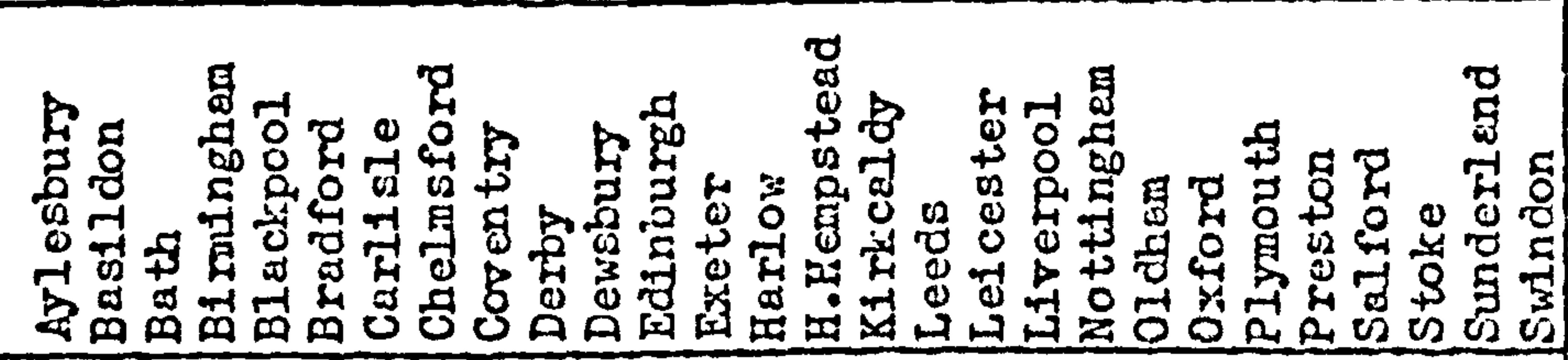 & \\
\hline $\begin{array}{l}8 \\
1 \\
8\end{array}$ & 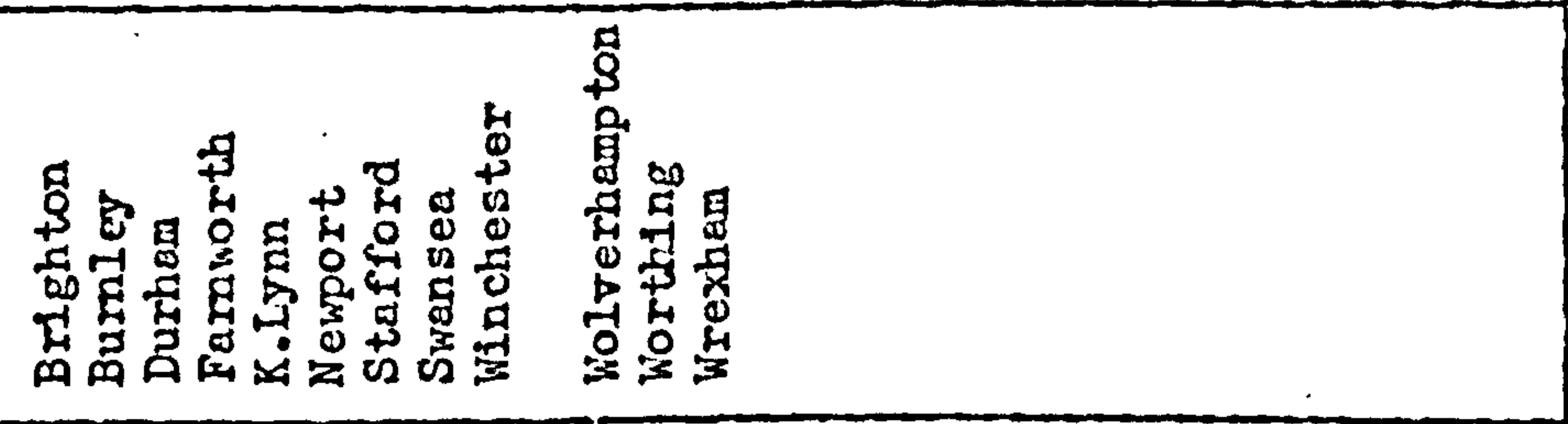 & \\
\hline $\begin{array}{l}8 \\
1 \\
2\end{array}$ & 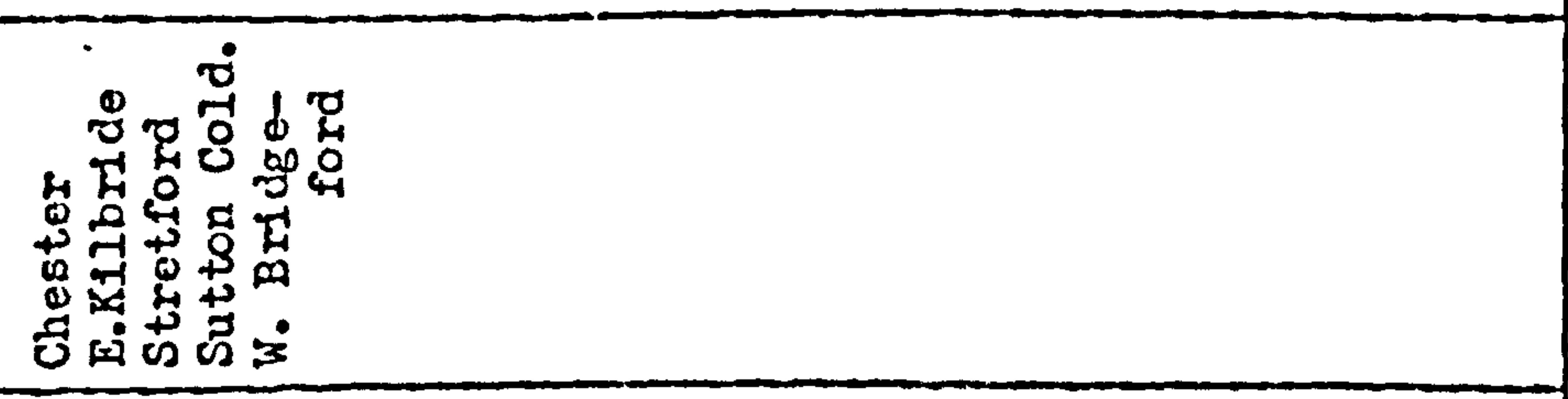 & \\
\hline $\begin{array}{l}8 \\
1 \\
8\end{array}$ & 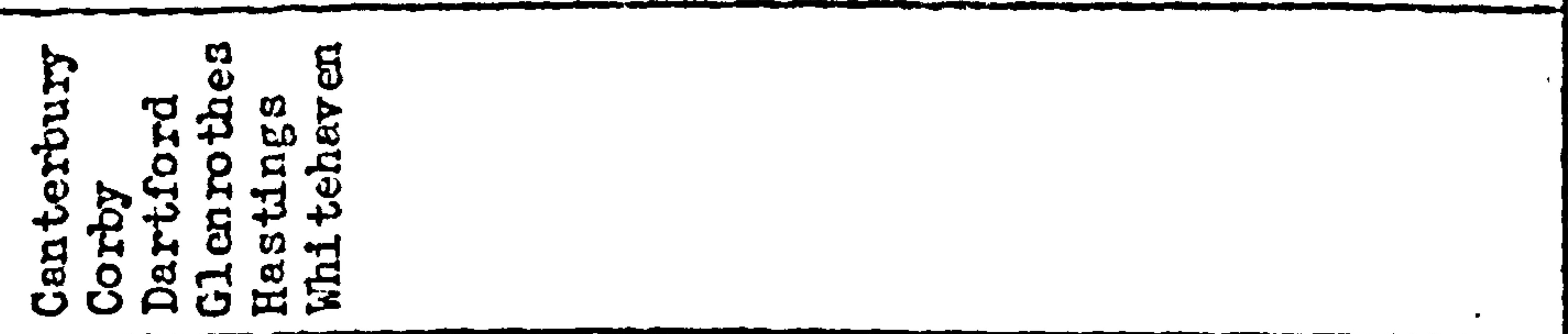 & \\
\hline $\begin{array}{l}8 \\
1 \\
8\end{array}$ & 点 & \\
\hline$R$ & 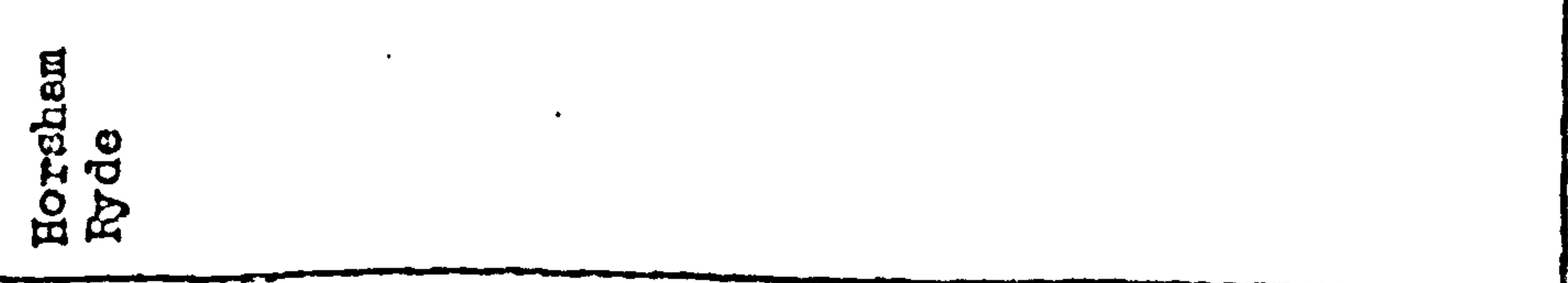 & \\
\hline
\end{tabular}


groups seem to be mainly composed of the lower sized urben area which also are towns which lie upon a mejor rosd traffic route. Thus in the top group one finds the torns Buxton and Guildford. A further charecteristic of this top group (with perhaps the exception of Inverness) is that these torms are malnly domitory to:ns around the najor conurbation arees of London, Yorkshire end Lencashire.

The $120.00-1 \pm 0.00$ group meanwile has a more varied set of to:ms then the other groups, with the result that it is almost imoossible to find any general characteristic for the whole group. Thus one finds that such toms as Boumfmouth and Bridgewater are in the saise group.

At the other end of the scale there is even less unifomity betiveen the varlous groups, al though once again it is obvious that cnly small to average sized to'ms are included within these values. Amongst the torms contrined within these groups two tows seen to stend out as unexpected constituents. These are Lancaster and Chester, with the forner having the lower value of the tro. One tentative hroothesis as to these low values could be the ring roed system which each hes developed recently, renoving unnecessary traffic from reglons of the toin centre. However, such hypotheses can only be proved after further research along these porticular lines.

Before leaving this variable it should be pointed out that whin these low value groups, there are two new tow developments and one toun (Corby) which hes elso been expanded under the aegis 


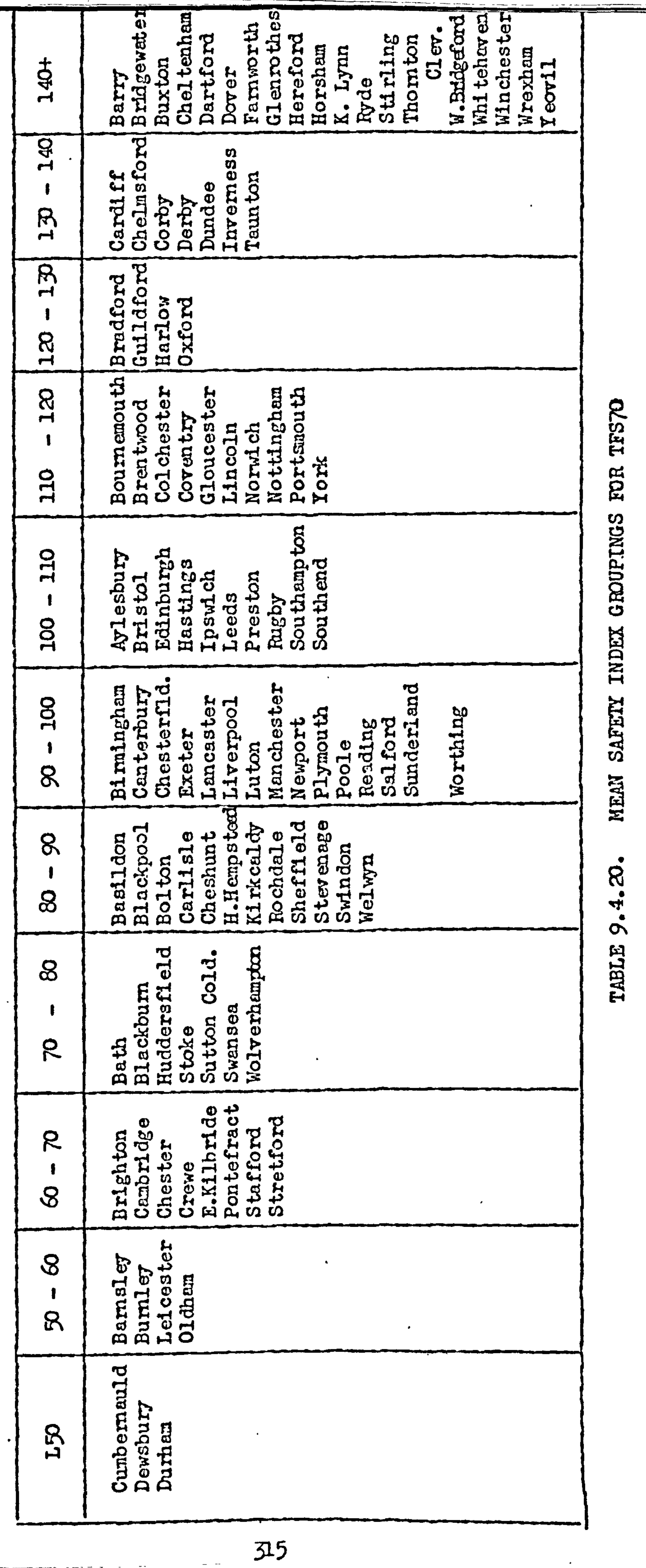


of a Development Corporation. This point however, will not be developed at this stage in the report, but is left until a later section dealing solely with the new town developments.

(2) TOTLL FETLL AND SFRIOUS CASTLLTIFS 1970 (YST GROUPINGS)

Once again the groupings noted within this variable prove very difficult to interpret ol though there are several features which ere deserving of note, simoly because of their eppearance at eny one location.

The first thing that should be said about these groupings is that the distribution is no longer normal, and the distribution of urban areas of differing size is much more rendon within the distribution. Thus Leicester and Barnsley are emongst the lowest values, whilst Cardiff and Derby are emongst the highest velues. However, it should be noted that the highest group once again mainly includes only small and medium sized urben areas.

If individual areas are observed further interesting infornation cen be derived. Thus if the location of Horshem and Fyde is noted in the groupings for TC7 7 and also for TFS7 $\varnothing$, it will be seen tizat whilst both are in the lowest values for all casualties, they are both in the highest group for fatal and serlous casuelties. Thus these tro areas con be said to exhibit 10, accident freauencies but high severity rates.

Perhaps the only groups which can be ldentified again within this varieble is the highest group with values of more then 140.00 . As with TC7\% this group seems to be made up of towns which lie on 


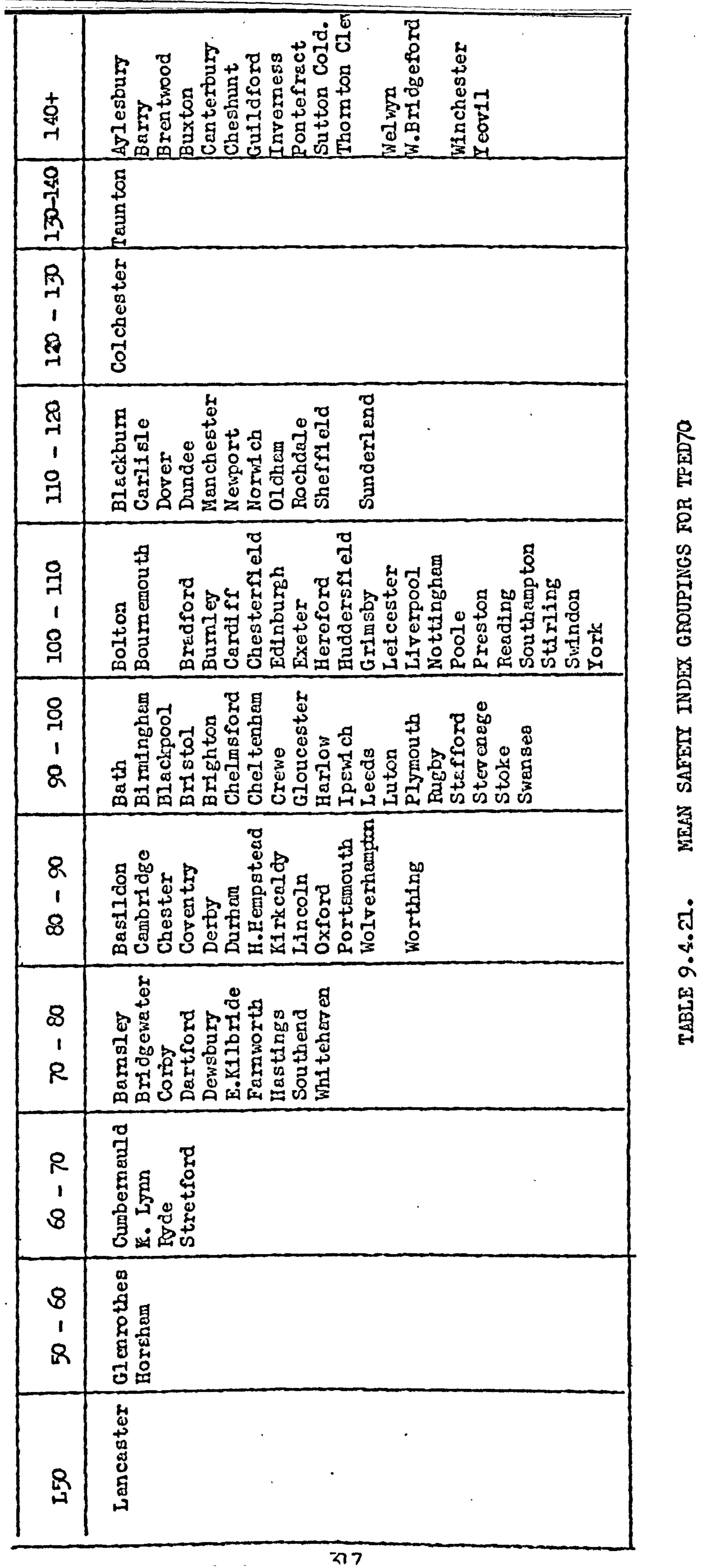


major trunk roads and are themselves relatively small. Accordi rely such toms rould seen to be unable to cope wi the the excessive denands made unon them by the increased traffic flows. Similerly, since this through traffic also tends to be of the high speed nature, such accidents tend to cause casual ties with higher degrees of severity.

\section{(3) TOTAL CASUALTIES PER $10^{6}$ VEHTCLE MTIES (MST GPOUPINGS)}

When the exposure varieble for total casualties is introduced, the groupings of urban areas appears totally haphazard. However, it should be recalled that this varieble within the regression model showed a considerable degree of lack of fit, especially at the higher and lower values. Consequently it is of no surprise when one finds a considerable number of large toms within the highest value group. Thus although it is impossible to make any statements about these groupings, it is obviously significant then some large to:ms finish with low MSI values, and in such cases these torns are identified as being in need of special crse studies. To:ms of this kind in the lowest group of MSI values include Bimingham, Sheffield and Dundee.

\section{(4) TOTAL PEDESTRIAN CASUATTIES (MST GPDUPINGS)}

The groupings attained with this varlable are very compareble to those obtoined for TC7 $\varnothing$ and TFS7 $\varnothing$ with just modifications for individual torms. Thus Salford which has a high grouping for this variable, is below the 100.00 mark for all casualties, with the result that there must be a relatively high number of pedestrian cssualties for that area.

The problen with this grouping, and the variable TPED7\% in general is that without some messure of exposure, very misleading 


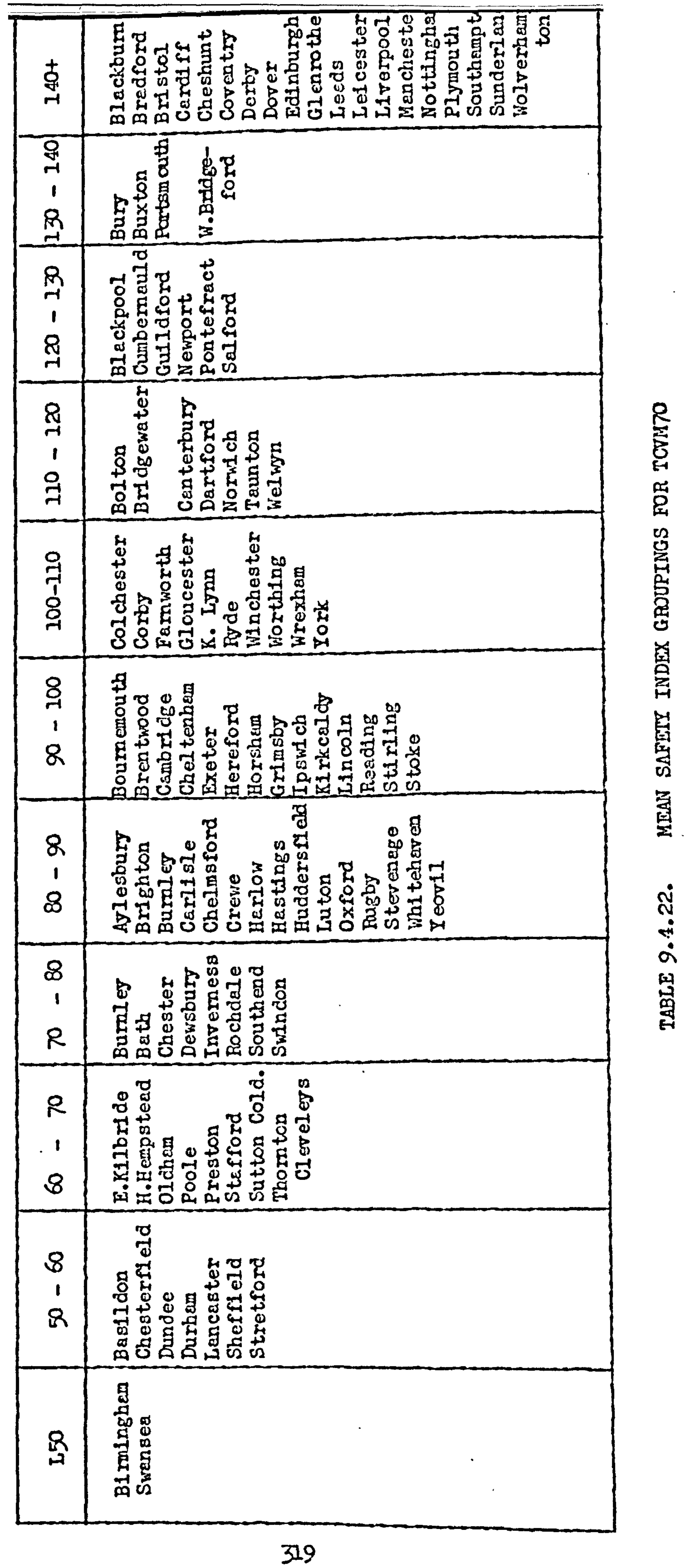


conclusions can be made. For example where the environment has been made more conducive to pedestrian movenent, more journeys mas be made on foot. The result on pedestrian casualties could be to increase the absolute volune of casualties thereby implying that the safety level for pedestrians had been reduced. In acturi fact, however, considering the increase in the volume of pedestrian movenent, it could be that the true change in the safety level for pedestrians is upwards. Therefore, when considering urban groupings it is best to consider those for total pedestrion casual ties in association with the pedestrien exposure variable given below.

\section{(5) TOTAL PEDESTPIAN CASUALTIES PER $10^{2}$ YOFK WALK TRTPS (HSI GROUPINGS)}

The major impact of introducing the exposure level is seen anongst some of the lerger urban areas, with the majority of the smaller toms remaining in their orizinal MSI group for the absolute variable. This movenent within the larger toins works in both directions with some increasing and others decreasing. Exanples of those areas lowering their MSI grouping are Leicester, Coventry, Bradford, 01dhem, Blackburn etc., whilst those raising their ISI groupings include Noraich, York and Bournemouth. It must be remenbered however, that the exposure introduced in this variable only includes "vork trips" and most of the towns which move to higher MSI groups are those who exhibit high pedestrien movezents for non-work trips. Thus these towns include the coastal resort torns and also the historic torns, which one would expect to have high pedestrian movencnts at all times of the 


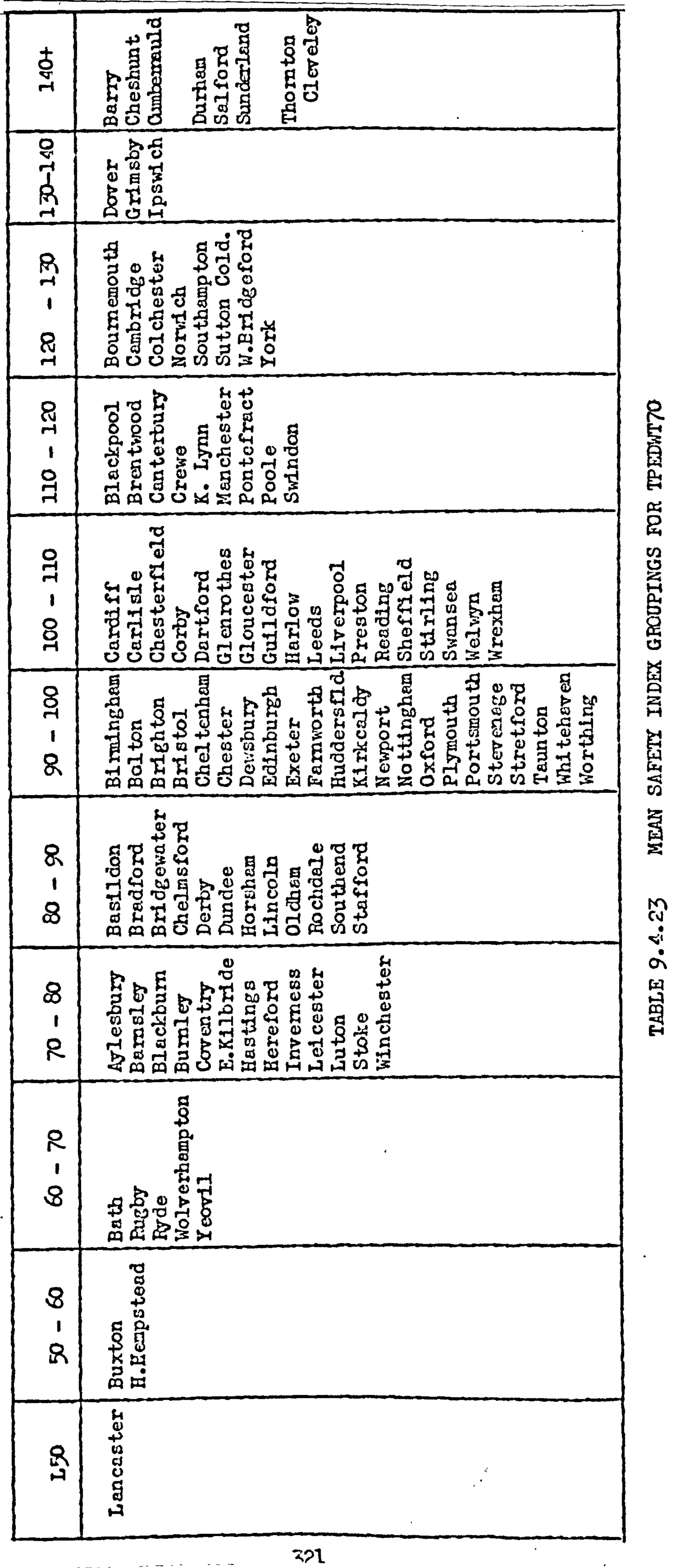


The second grouping method used involved the application of a Q-mode factor analysis technique upon the 20 groups of MSI values calculated for the trend surface analyses. In the Q-mode factor anelysis the data matrix is collapsed so that the rows are combined rather than the columns as in the normal R-mode factor analysis model. The result therefore in this context was to combine the urban areas according to their constituent MSI values. However, as was mentioned earlier the results from this approach proved less reliable for two basic reasons;-

1) The MSI values are such that several variables will create totally opposite MSI values due to the nature of the variable being used. Thus the composite factors which were derived would be almost average values of the MSI range.

2) Similarly little confidence can be placed in a factor analysis solution when there is such a divergence between the number of colurans and rows in the data matrix when the rovs are being combined. In such a situation the optimum kind of date matrix is obviously a square matrix.

Consequently. the results obtained by this technique are considered to be of somekhat dubious value and relevance. For that reason no results are presented here and the rnethod is left as a possible approach for future research.

The conclusions from these sets of urban groupings, therefore, are only very tentative, especially since it is only marginal to the main body of this research. However, the results do seem to suggest that there is some futare in this line of researcin if, and 
when some more sophisticated grouping techniques are used. However, the greatest use at present simply lies in the identification of certain groups and constituent urban menbers. Further developments must be the nore detalled study of individual groups and also individual urban areas within that group. With this thought in mind, therefore, it is worthwhile to leave this section of the analysis and look at the time series analysis.

\subsection{THE TIYE SERIES ANALYSIS}

The methodology used in this analysis has been described already in Chapter 8 of this report. Horever, in order to simplify matters, a simple relteration of the procedure will be epplied here.

Three variables; TC, TCPP and TCM, were studied in relation to their differing responses from 1966 to 1970 . Comparison between years was performed in tho ways, 1) Comparison of the overall regression explanation levels, 2) The varying importance of individual regression variables was stadied by means of comparing the relevant

coefficients. Since however, the results of the principal components analysis had differed for every year, in order to attain a reasonable comparison, it was necessary to return to the criginal date matrix. From this matrix variables were extracted which had been deemed significant by the step-ivise regression procedure, and where necessary were subjected to a logarithmic trensfornation. The results of this temporal analysis $: 111$ be presented below according to each of the three variables studied.

(i) TOTAL CASUALIIES TEUPORAL ANALYSIS

The five significant variables used in the enalysis for this 
dependent variable are show in Table (9.5.1), along with the derived bets coefficients (stendardised $b$ coefficients) for the years 1966 - 1970. Further results shown in Table $(9.5 .1)$ are for the regression equation conteining the transforned variables, which were necessary because of the lock of symetry in the original varieble distributions.

As can be seen from this table, the overall explenation level remained approxdnately consistent over this time period with a steady increase in the absolute $r^{2}$ velue from 0.954 in 1966 to 0.982 in 1970 , for the non-transformed regression model. As regerds the trensformed regression meanwhile, the range for the $r^{2}$ value is much less, with the peak of 0.967 appearing in 1970 and the mininum value being 0.951 in 1968 . Thus 1 t can be seen that whichever model is used the actual variation in the explanation level is very siall and seeningly insignificant. Consequentiy since the predominant variable in all of these regressions is the POP variable, one must presure that over this tine period the major contributing factor in the varietion in road casuelties between different urben areas is the actual size of these urben areas, end the degree of interaction within these areas. The importance of this variable con be further cualified by looking at the actial value of the beta coefficients. Thus in 1970, POP7 had a beta coefficient of 0.980 as related to the second most important . v.arleble PPI7申, which had a value of 0.048 .

In order to look at the temporal significence of the individual coefficients meanhile, it is necessary to construct confidence 


\begin{tabular}{|l|r|r|r|r|r|}
\hline VARIABLES & \multicolumn{5}{|c|}{ BETA COEFPICIENTS } \\
\hline POP70 & 1970 & 1969 & 1968 & 1967 & 1966 \\
SRI70 & 0.980 & 0.953 & 0.969 & 0.963 & 0.958 \\
CI70 & -0.013 & -0.009 & -0.032 & -0.003 & 0.001 \\
DVI70 & -0.041 & -0.062 & -0.053 & -0.051 & -0.042 \\
PF170 & 0.026 & 0.037 & 0.041 & 0.028 & 0.030 \\
$X_{0}$ & 0.047 & 0.082 & 0.038 & 0.045 & 0.049 \\
\hline$R^{2}$ & 682.486 & 601.024 & 1429.217 & 455.132 & 139.120 \\
\hline CI70 & 0.982 & 0.953 & 0.969 & 0.959 & 0.955 \\
LNF0F70 & -0.017 & -0.019 & -0.035 & -0.024 & -0.004 \\
LNSRI70 & 0.975 & 0.956 & 0.946 & 0.957 & 0.945 \\
LNDVI70 & -0.014 & -0.004 & -0.039 & -0.003 & -0.004 \\
LNFPI70 & 0.027 & 0.050 & 0.095 & 0.065 & 0.063 \\
$X_{0}$ & 0.028 & 0.073 & 0.032 & 0.035 & 0.064 \\
\hline$R^{2}$ & -2.350 & -2.487 & -1.672 & -2.092 & -2.272 \\
\hline & 0.967 & 0.962 & 0.951 & 0.965 & 0.962 \\
\hline
\end{tabular}

TABLE 9.5.1. TIME SERIES ANALISIS FOR SIMPLE AND TRANSFCRMED VARIABLES IN RELATION TO TOTAL CASUALTIES. 
regions around these coefficients. In order to do this, cne can make use of the simple $t$ test such that the confidence region is calculated by eppying the formula,

$$
\begin{aligned}
\text { c.f }= & b_{1} \pm S \cdot E\left(b_{1}\right) \cdot t_{(n)} \propto=0.005(1, z) \text { with } \\
& t(n-(k+1) \text { degrees of freedom. }
\end{aligned}
$$

where,

$b_{1}$ is the calculated value for the relevant $b$ coefficient

S. $E\left(b_{1}\right)$ = the standard error of the $b$ coefficient

$\mathrm{n}=$ the number of observations

$k=$ the number of independent variables.

Thus for the total casualties variable $t_{(94)} \alpha=0.005=2.62$, and $x=0.025=1.98$.

The confidence regions for all the independent variables in botis the trensformed and non-transformed regression models, are shom in Table (9.5.2) for 1970. The null hypotinesis being tested in this table is that the values for the $b$ coefficient for 1970 and 1966 are drawn from the same population, and consequently do not difier significantly. Thus it can only be stated that the values of these coefficients are significantly different if the 1956 value lies outside the confidence reglon for that same coefficient for 1970. At the some time it is also possible to test the individual significance of each variable within the regression by testing whether the confidence region includes the value of zero. If zero does fell within the confidence region then no confidence can be placed on the level or direction of the relationship indicated 


\begin{tabular}{|c|c|c|c|c|c|}
\hline VARIABLE & $\begin{array}{l}\text { B. COEFFICIENT } \\
(1970)\end{array}$ & $\begin{array}{l}\text { STANDARD } \\
\text { ERROR (b) }\end{array}$ & $\begin{array}{l}99 \% \text { CONFID. } \\
\text { LEVEL }\end{array}$ & $\begin{array}{l}\text { 95\% CONFID. } \\
\text { IEVEL }\end{array}$ & $\begin{array}{l}\text { B.COEFPIC } \\
\text { IENT 1966 }\end{array}$ \\
\hline POP & 0.006 & 0.00 & $0.00 *$ & 0.00 & 0.007 \\
\hline SRI & -252.253 & 303.14 & 794.23 & 600.22 & 13.703 \\
\hline CI & -600.088 & 209.48 & 547.58 & 414.77 & -736.268 \\
\hline DVI & 883.423 & 548.84 & 1437.96 & 1086.70 & 1477.861 \\
\hline PPI & 7.881 & 2.35 & 6.15 & 4.65 & 9.611 \\
\hline \multirow{5}{*}{ 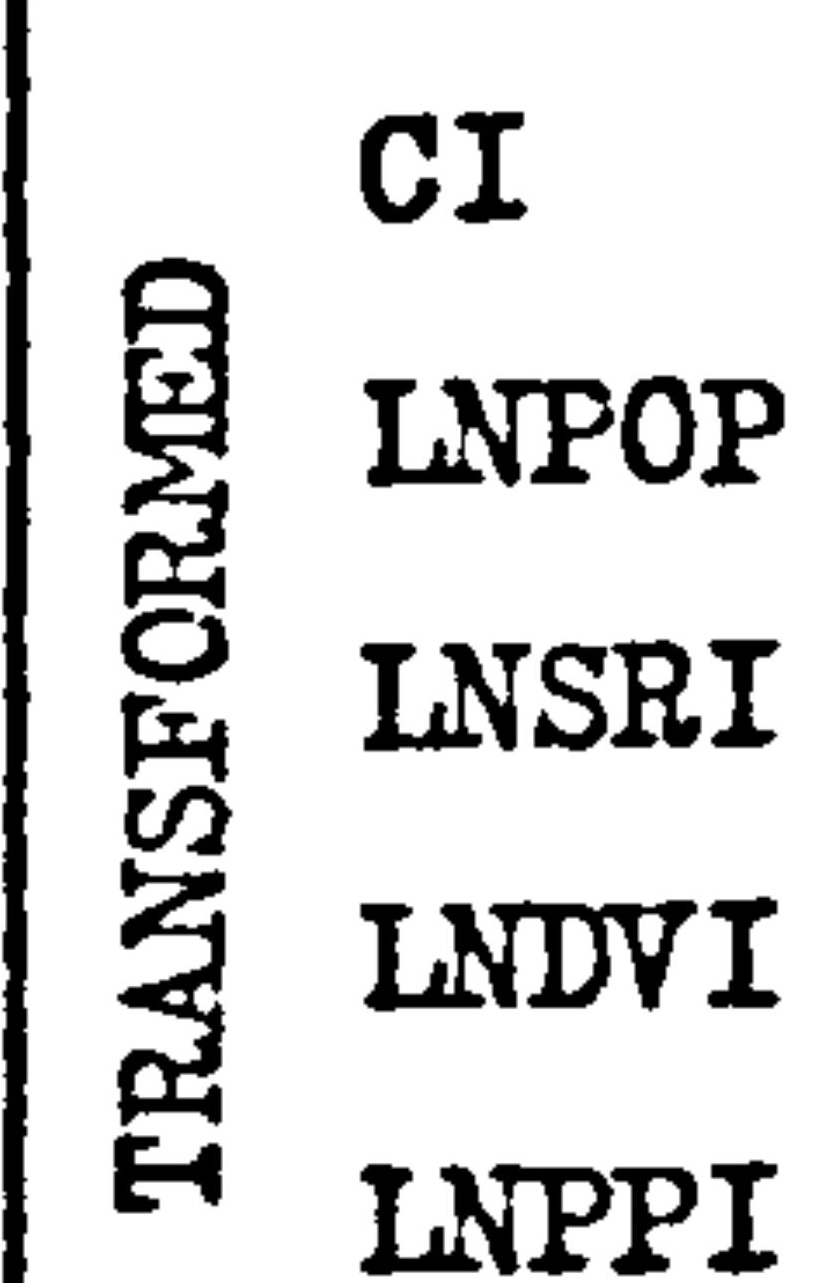 } & -0.107 & 0.12 & 0.314 & 0.238 & -0.029 \\
\hline & 1.069 & 0.02 & 0.052 & 0.040 & 1.041 \\
\hline & -0.499 & 0.79 & 2.070 & 1.564 & -0.150 \\
\hline & 0.169 & 0.14 & 0.367 & $0.277 *$ & 0.465 \\
\hline & 0.099 & 0.07 & 0.183 & 0.139 & 0.230 \\
\hline
\end{tabular}

* Significant Difference at that Confidence Level.

TABLE 9.5.2. CONFIDENCE INTERVALS FOR THE b. COEFPICIENTS WITHIN THE TIME SERIES ANALYSIS OF TOTAL CASUALTIES 
by the $b$ coefflcient, since the coefficient cannot be said to differ significantly from zero.

The results as indicated by this table reveal that for the two regressions TC7 and TCE6, only one variable POP, differed significantly between these two years. Similarly only four variables appeared to be significently different from zero, these being POP, CI, PPI ${ }^{17}$ and LNPOP. The implications from these results are that whilst the overall explonation level has renained reasonably ccnsistent over the period 1966 - 1970, the impact of the variable POP has chenged significantly during this same period. The direction of this change can be ascertained by referring back to the original coefficient values. From these it can be seen that in 1966 the populailon variable influenced the dependent variable less than in 1970. Thus it can be stated that wilst this independent variable has remained the major determinant of the value for the total casualties variable over this time period, the relative importance has increased with time. Thus in the earlier periods it rould seem that other varlables played a more important role in explaining the observed variaticn. Since this was not true of eny of the remeinine varielles in the regression, it becomes necessery to look at other variables which had not been incorporated due to the recomendations of the 1970 step-vise regression. Conseciuently, full

17 It is interesting to note thet this variable PPI is sigrificently different from zero since the di rection of this varieble is positive. This rowever, is totally opnosite to the results obteined in the major regression enelysis, ond one must $\varepsilon$ ssume that this is solely the result of the non-normality of this varieble in this regressior. This conclusion would seem to be supported by the lack of significence in transformed varieble IIIPPI. 


\begin{tabular}{|l|l|c|c|c|c|}
\hline \multicolumn{6}{|c|}{ ESTIMA TE OF THROUGH TRAFFIC } \\
\cline { 2 - 6 } & $\begin{array}{l}\text { B.COEFF- } \\
\text { ICIENT }\end{array}$ & $\begin{array}{c}\text { STANDARD } \\
\text { ERROR }\end{array}$ & $\begin{array}{c}99 \% \text { CCNF ID. } \\
\text { INIERTAL }\end{array}$ & $\begin{array}{c}95 \% \text { CONFID } \\
\text { INTERVAL }\end{array}$ & $\begin{array}{c}\text { SIGN IFICANCE } \\
\text { IETEL }\end{array}$ \\
\hline & & & & & \\
1970 & 2.247 & 1.359 & 3.561 & 2.690 & $190 \%$ \\
1969 & 5.589 & 2.358 & 6.178 & 4.669 & $95 \%$ \\
1968 & 8.854 & 1.889 & 4.949 & 3.740 & $95 \%$ \\
1967 & 6.942 & 2.310 & 6.052 & 4.574 & $99 \%$ \\
& 5.538 & 2.871 & 7.522 & 5.684 & $90 \%$ \\
\hline
\end{tabular}

TABLE 9.5.3. VARIATION IN THE INFLUENCE OF THE INDEFENEENT VARIABLE E.T.T. IN RESPECT TO TCTAL CA.SUALTIES 1966-1970 (SIGNIFICANT DIFFERENCE FROM ZERO). 
regressions were computed for each of the years and the significence levels of new veriebles notec; the result being that only cne variable eppeared to contribute anything to the explenation level, that being the variable ETT. The variations in this verieble are given in Te.ble (9.5.j) along with the relative significence of the coefficient values. It can be seen from this thet in 1967 the emount of through tryffic was significent et the $99:$ level from whence it has ceclined until in 1970 it is not even significant at the $90 \%$ confiderice 1evel. The conclusions to be made here therefore are that, over the period 1966 - 1970 the level of explenation of the dependent variable has remained fairly constent, but the impact of two variables has varied with time. That is as time has progressed from 1966, the impact of the estimate of through traffic veriable has decreased whilst the influence of the population variable has increased. Consequently, one must presume that over this period of tine, the problen caused by the volume of through traffic in urban areas has been satisfactorly reduced until the impact of this variable is only marginal.

\section{(ii) TOTAL CASUALTIES PER 103 POPULATLON TFYPORAL ANALYSIS}

The same procedure as used for the last variable was applied in this analysis except for the fact that only the years 1970,1959 and 1966 were calculated because of the unreliebility of the data for 1967 and 1968 due to considerable pollce re-organisation. The relevent data for this dependent variable are given in Table $(9.5 .4)$ and Table $(9 \cdot 5 \cdot 5)$. 


\begin{tabular}{|c|c|c|c|}
\hline \multicolumn{4}{|c|}{ BETA COEFFICIENTS } \\
\hline VARIABLES & 1970 & 1969 & 1966 \\
\hline POP & 0,079 & -0.006 & -0.020 \\
\hline DEN & -0.062 & -0.035 & -0.004 \\
\hline ETT & 0.268 & 0.413 & 0.277 \\
\hline CT & -0.130 & -0.173 & -0.053 \\
\hline DOS & 0.025 & -0.134 & -0.043 \\
\hline SH1 & -0.348 & -0.273 & -0.304 \\
\hline DVI & 0.079 & 0.156 & 0.230 \\
\hline cow & 0.203 & 0.289 & 0.224 \\
\hline$x_{0}$ & 6.057 & 5.483 & 3.725 \\
\hline $\mathrm{R}^{2}$ & 0.275 & 0.364 & 0.307 \\
\hline DEN & -0.147 & -0.072 & -0.010 \\
\hline EIT & 0.081 & 0.254 & 0.168 \\
\hline CI & -0.168 & -0.179 & -0.047 \\
\hline cow & 0.411 & 0.419 & 0.349 \\
\hline LNPOP & 0.259 & 0.132 & 0.005 \\
\hline LNSHI & -0.573 & -0.435 & -0.465 \\
\hline LNDOS & 0.060 & -0.131 & 0.025 \\
\hline LNDVI & 0.086 & 0.148 & 0.174 \\
\hline$x_{0}$ & 0.681 & 0.878 & 0.987 \\
\hline $\mathrm{R}^{\mathrm{z}}$ & 0.411 & 0.403 & 0.320 \\
\hline
\end{tabular}

TABLE 9.5.4. TIME SERIOUS ANALYSIS FCR SIMPLE AND TRANSFORMED VARIABLES IN RELATION TO TOTAL CASUALTIES PER $10^{3}$ POFULATion. 


\begin{tabular}{|c|c|c|c|c|c|}
\hline VARIABLE & $\begin{array}{l}\text { B. COEFPICIENT } \\
(1970)\end{array}$ & $\begin{array}{l}\text { STANDARD } \\
\text { ERROR (b) }\end{array}$ & $\begin{array}{l}\text { 99\% CONFID. } \\
\text { LEVEL }\end{array}$ & $\begin{array}{l}95 \% \text { CONFID. } \\
\text { LEVEL }\end{array}$ & $\begin{array}{l}\text { B.COHFFICI } \\
\text { ENT } 1966\end{array}$ \\
\hline POP & 0.000 & 0.000 & 0.000 & 0.000 & -0.000 \\
\hline DEN & -0.015 & 0.03 & 0.079 & 0.156 & -0.001 \\
\hline ETT & 0.018 & 0.01 & 0.026 & 0.020 & 0.026 \\
\hline CI & -2.094 & 1.51 & 3.956 & 2.990 & -1.077 \\
\hline DOS & 0.003 & 0.01 & 0.026 & 0.020 & -0.007 \\
\hline SHI & -0.016 & 0.01 & 0.026 & 0.020 & -0.017 \\
\hline DVI & 2.952 & 3.45 & $9.039 *$ & $6.831 *$ & 13.343 \\
\hline COW & 1.811 & 0.91 & 2.384 & 1.801 & 2.531 \\
\hline DEN & -0.003 & 0.003 & 0.008 & $0.006 *$ & -0.000 \\
\hline ETT & 0.000 & 0.0008 & 0.002 & 0.002 & 0.001 \\
\hline CI & -0.211 & 0.11 & 0.288 & 0.218 & -0.069 \\
\hline $\mathrm{COW}$ & 0.285 & 0.07 & 0.183 & $0.139 *$ & 0.284 \\
\hline LNFOP & 0.057 & 0.03 & 0.079 & 0.059 & 0.001 \\
\hline INSHI & -0.113 & 0.02 & 0.052 & 0.040 & -0.107 \\
\hline LNDOS & 0.012 & 0.02 & 0.052 & 0.040 & 0.006 \\
\hline LNDVI & 0.109 & 0.11 & 0.288 & 0.218 & 0.295 \\
\hline
\end{tabular}

* SIGNIFICANT DIPFERENCE AT THAT CCNFIDENCE LEVEL

TABLE 9.5.5. CONFIDENCE INTERVALS FOP, THE b COEFFICIENTS WITHIN THE TIME SERIES ANAIISIS OF TCTAL CASUALIIES PER $10^{3}$ POPOLATION. 
The second varieble of interest in this anelysis is the varieble COr. Besides being the second most important verieble in the regression series, COW, like INSHI, rould seen to have a varying impact uron the depencient varieble with time. Thus fron the beta coefficiert values one can sec that in 1970 CON had a value of 0.411 anc a velue of 0.349 in 1966 . However ance agein when reference is made to the significence tebles, it can be secn that whilst the varieble is significantiy different frem Zero, there is no evidence that the veriable has exerted any different influence at different time periods.

The verietle ETT is of interest once egain beceuse of the increese in the beta value as one moves backiards in time towards 1966. Thus the beta velue for 1970 of 0.081 is increesed to 0.168 in 1966. However as with the previous two variables, when ETT is noted rithin the significance tebles it cen be seen that statistically there is no difference between the values for 1966 and 1970 . Consccuently it rould be incorrect to assume eny chrnge in this veriatile vith time. In fact further stucy of the sigrificence table goes as far as to state that the varieble ETT is not even significent if thin the 1970 regression nociel even at the $95^{\circ}$ conficience level.

Summarlsing therefore one can sey that for the dependent varieble TCPP there hould seen to have becn no stetisticklly significent chenge in the variables end relationships achieved, curing the time period 1966 - 1970, since eny change in the coefficient values for eny of the inciependent variables could have cccured simply by chance at the $95^{\circ}$ conficience level. If it is therefore hypothesised that this dependent veriable gives the cacuel ty 
variation for urban areas once the size component has been relroved, it can also be stated that the impact of the structural variebles has remoined constant over thits time period, according to these results.

\section{(iii) TOTAL CASUAITIFS PFE $10^{6}$ VEHICIE BILFS TFYPOFAL ANELYSIS}

The previous two variebles included in this temporel enelysis heve both belonged to the "static" femily of road accident indicators. Therefore one of the further reasons for inclucing this depondent verieble in the temporal enalysis vis to stucy the impact of time upon an "exposure"varietle.

It vas pointed out in the section describing the results of the multiple regression that the best results for this varigile were cbtained wen the dependent varieble was subjected to a logerithmic transformation. The results in this analysis add further proof to this postulated logarithmic relationship, in terms of the level of explanation. Thus then the non-transformed veriebles are used the $r^{2}$ velue increases from 0.162 in 1966 to $0.194=r^{2}$ in 1970. When both the dependent and independent variebles are trensformed however, the range of $r^{2}$ values is from 0.910 in 1966 to 0.930 in 1970 . Consequentiy attention for this verieble is restricted to the transfomed regression nodel.

The consistent incresse in the level of explanation from 1966 to 1970 would seem at first to indicate some incresse in the explanatory nature of the incependent variebles used in this regression. However, the results given in the significarce tables $(9.5 .6)$ and (9.5.7) give no inaication of this variation with time. Instea 


\begin{tabular}{|c|c|c|c|}
\hline VARIABLES & & \multicolumn{2}{|c|}{ BETA CCEFPICIENTS } \\
\hline & 1970 & 1969 & 1966 \\
\hline POP & -0.503 & -0.408 & -0.471 \\
\hline DEN & $: 0.094$ & 0.042 & -0.014 \\
\hline CI & -0.220 & -0.181 & -0.149 \\
\hline CHSI & 0.126 & 0.130 & 0.009 \\
\hline $\mathbf{R I}$ & 0.063 & 0.195 & 0.123 \\
\hline $\mathrm{RDI}$ & -0.389 & -0.432 & -0.349 \\
\hline$x_{0}$ & 58.301 & 46.741 & 64.807 \\
\hline $\mathrm{R}^{2}$ & 0.494 & 0.480 & 0.462 \\
\hline DEN & 0.249 & 0.167 & 0.285 \\
\hline CI & -0.082 & -0.083 & -0.054 \\
\hline RI & -0.066 & -0.007 & -0.035 \\
\hline RDI & -0.274 & -0.254 & -0.272 \\
\hline LNFOP & -0.972 & -0.925 & -1.008 \\
\hline LNCESI & 0.077 & 0.066 & 0.030 \\
\hline$x_{0}$ & 5.423 & 5.237 & 5.606 \\
\hline $\mathrm{R}^{2}$ & 0.930 & 0.912 & 0.910 \\
\hline
\end{tabular}

TAELE 9.5.6. TIME SERIES ANALYSIS FOR SINFIE AND TRANSFORMED VARIABLES IN REIATION TO TOTAL CASUALTIES PER $10^{6}$ VEHICLE MILES. 


\begin{tabular}{|l|c|c|c|c|c|}
\hline VARIABIE & $\begin{array}{l}\text { B. CCEFP } \\
\text { ICIENT (1970) }\end{array}$ & $\begin{array}{l}\text { STANDARD } \\
\text { ERR.OR(b) }\end{array}$ & $\begin{array}{l}\text { 9S\% CONFID } \\
\text { ENCE LEVEI }\end{array}$ & $\begin{array}{l}95 \% \text { CONFID } \\
\text { ENCE IEVEL }\end{array}$ & $\begin{array}{l}\text { B CCEFF } \\
\text { ICIENT 1966 }\end{array}$ \\
\cline { 2 - 6 } PCP & -0.000 & 0.00 & 0.000 & 0.000 & 0.000 \\
CI & 0.270 & 0.49 & 1.284 & 0.970 & -0.043 \\
CHSI & -42.361 & 14.46 & 37.885 & 28.630 & -34.036 \\
RI & 0.968 & 0.61 & 1.598 & 1.208 & 0.073 \\
RDI & 0.124 & 0.16 & 0.419 & 0.317 & 0.286 \\
& -0.785 & 0.32 & 0.838 & 0.634 & -0.835 \\
DEN & 0.019 & 0.005 & 0.013 & 0.010 & 0.020 \\
CI & -0.413 & 0.14 & 0.367 & 0.277 & -0.267 \\
RI & -0.003 & 0.002 & 6.005 & 0.004 & -0.002 \\
RDI & -0.014 & 0.003 & 0.008 & 0.006 & -0.014 \\
LNFOP & -0.859 & 0.03 & 0.079 & 0.059 & -0.862 \\
LNCHSI & 0.460 & 0.13 & 0.472 & 0.356 & 0.173 \\
\hline
\end{tabular}

TABLE 9.5.7. CCNFIDENCE INTERVALS FOR THE B, COEFFICIENTS WITHIN THE TINE SERIES ANALYSIS OF TOTAL CASUALTIES PER $10^{6}$ VEHICLE MILES. 
these results suggest that both the increase in the $r^{2}$ velues, and also the generel relationships postulated within this regression, remain constant over time, end any chenges wich mes eppear are merely the result of chance randon variation. This car be stated at toth the $99:$ and $95 \%$ confidence level, since all the variebles within these regression models fell within the relerent confidence intervels. Although there vould seem to be no statistically significant oifference between the $b$ coefficients in a temporel sense, the significence tables do show that four of the incependent variakles ore cignificently different from zero at the $99 \%$ conficience level. Of these variables the major one would appear to be LNPOP which accounts for epproximetely 50:3 of the overall varietion in the dependent varieble, end this compares favouratiy w th the results obtained in the major regression enalysis. This is also true for the other significant variebles, nemely. DDN, CI, FDI and LNCHSI (at the 95: Ievel).

The major conclusions to be druxn from these temporal analyses can therefore be summarised as below:- 18

(i) The relationships between the dependent variables and independent variebles noted in the originel regression analysis eppears to be further justified by the results of the temporal fralysis, with only one varieble ETT, being inadequately represiented in the originel TC regression model.

18 Similer temporel enalyses vere carried out upon the date, when disaggregation hed been comoleted for County Borough areas end Non-County Borough ereas. Although in severrl instences there proved to be $\varepsilon b s o l u t e$ differerices between the coefficiont values for varibles, there wes no statistical siznifj cent chenges $\varepsilon$ t the $99, \%$ conficence level, over the period 1966 to 1970. Therefore the conclusions drelin from the results for the full 100 sempled arees e.re also 
(ii) The relationships noted in the major regression analyses appear to remain constant with time and do not significently differ in 1970 from 1066.

(iii) In terms of the total casualties dependent rarieble, It would seem that there has been on increase in the importence of the size variable (POP) as time has progressed from 1966 to 1970. This could perhaps indicate an increase in the relative importence of the human sub-system within the overall road accident system.

(iv) Also in terms of the total casualties dependent variable, there would eppear to have been a decrease in the relative imoortence of the variable related to through traffic (ETT) as time has progressed from 1966 to 1970. This would seem to irdicate a reduction in the level of problens caused by through trafflc rolumes during this time period, probably as a result of increased fecilities within urben arees for through treffic, end also because of improved exterral, naticnal transport facilities.

( $\nabla)$ The static nature of the relationships noted in these temporal enalyses, would seem to be on indictment of the present

18 contd.. ipplicable to these tro di segeregated groups once agein stressing the constency of the road eccident problem.

Further enalysis was elso conducted into the reletive response of the tro urben area groups vithin the same time period. Once egein the results proved insignificent end it could be concluded that there is no reason to suppose thet these two groups vere not drawn from the same population. Accordingly there would also appear to be no stetisticil reeson to support the hypothesised diseggregated dichotamous response for these two groups of urban areas. 
approach to road safety, end road safety enalysis. Thus el though the Ministry of Trensport notes that, "eny hopes that travel on the roads is getting safer are cuite mistaken," (FMSO 1967) in their recent edvisory publication, "Road Safety - A Fresh Approach," the point that has to be mede is, "If travel on the road is not getting sefer in spite of the enormous efforts being made by the Ministry and its associated bodies, something is seriously wrong somewhere." (Cohen 1968, p.122).

\subsection{THE STULY OF THE GFORTH OF POAD ACCIDENT CASUALTTES 1066 - 1970}

Although the temporel enelysis has enabled several conclusions to be made as regards the constency of the derived relationships with time, it vas also considered desirable to look at the actual retes of growth for these urben arees, in order to assess if eny further relationships could be uncovered.

In this section of the research, severel hypotheses were put forward and consequently tested. The most obvious of these wes, to what degree did the level of road eccident cesuelties in time $t+1$ depend upon the level of road accidents at tine $t$. As was mentioned in Cbapter 8 of this report, such a hypothesis can be rephrased so that one is testing whether towns of different size ond therefore, different road accident levels, heve accident Erovth levels which ere proportionaly equivalent. This cen be simply tested by using the regression model,

$$
\mathrm{x}_{\mathrm{t}+1}=\mathrm{a}+\mathrm{b} \mathrm{X}_{\mathrm{t}}+\mathrm{e}^{19}
$$

The results for this model are shown in $T \varepsilon b l e(9.5 .8)$ for $\varepsilon l l$

19 Refer to Chapter 8 


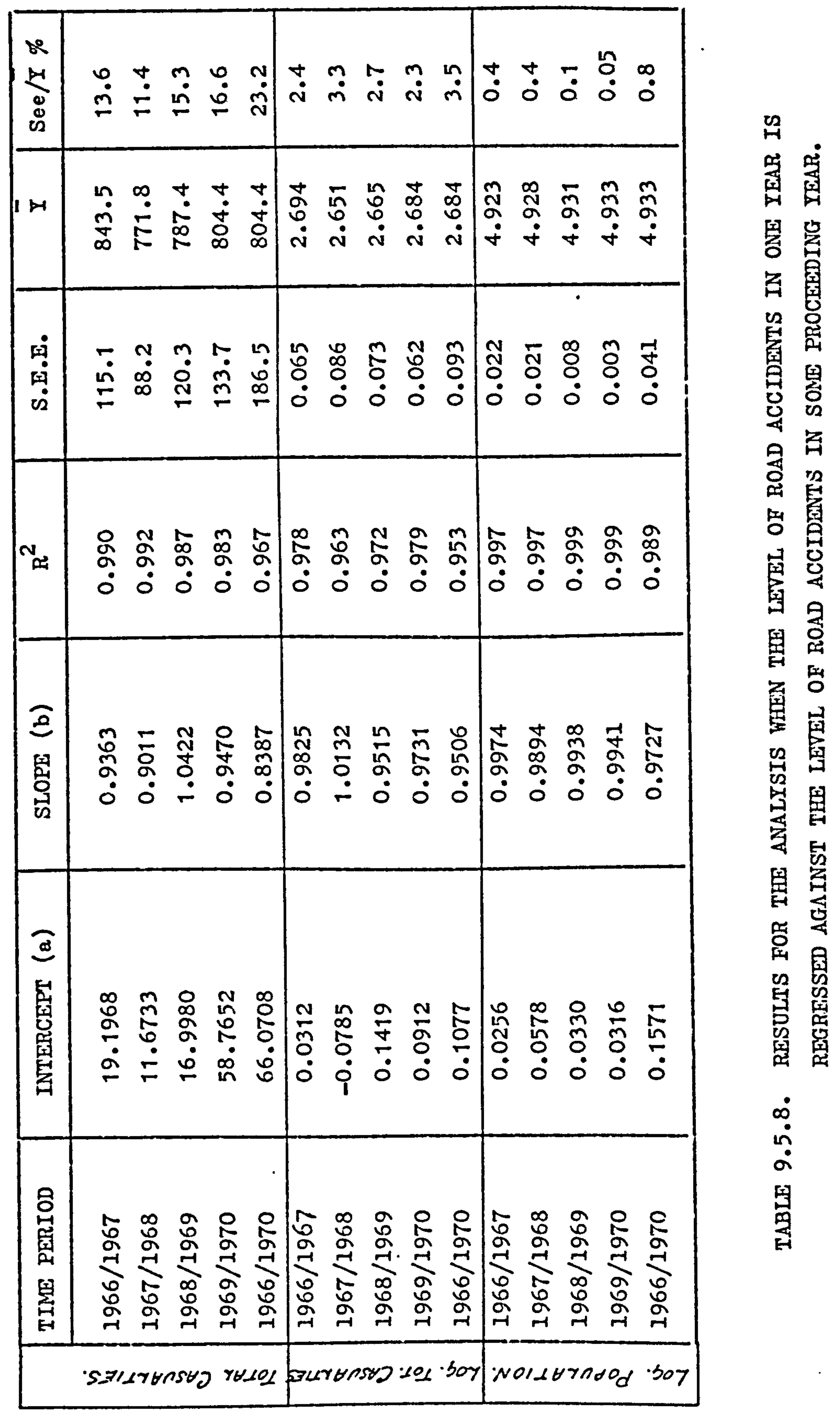


adjacent years for 1966 to 1970, end also for the period 1966 to 1970 itself. Similarly the results are shom for when total cesualties, log. total casualties, totel population, end log. total population, are used as variables within this regression model. From this teble it can be seen that for ell time periods the slope of the regression line as given by the b coefficient is virtually 1.0 and the level of explanation is very high. Now in the exceptional case of $b=1.0$, it would be acceptable to state that the absolute growth in road accident casualties is preportionate and independent of the original level of casualties. In this instence therefore one cen conclude that whilst the value of the $b$ coefficient indicates a virtual stochestic gronth process, the fact that most of the $b$ values are less than one rould seem to indicate thet smaller urben areas have growth rates which are proportionately greater then those for lareer urben areas. In other vords, there would seem to be \& weak negative reletionship between the gronth rete end the previous level of road accident casualties. It is necessery hovsver, to qualify this above conclusion by pointing out that the actual relationship is also affected by the verience about the regression line indicated by the error term $\left(e_{2}\right)$ within the regression equation. An indication of this varience is given by the Standard Error of Estimete which should be at a minimum level if the weak negative relationship noted above is not to be invalidated. Thus looking at the tabulated results once egrin it becomes obvious that the smallest variances ere associated with the logarithmically trensformed variables. This is of no surprise since the untrensformed variables both exhibit a 
strongly skewed distribution which affect the results and relationships accordingly. Since log. total casurlties produces the minimum degree of error, with no real reduction in the crerall level of explanation, it is this verieble which should be anelysed in sone further detail. The two features of interest are the values of the intercept and the $b$ coefficient.

The intercept can be regarded as indicating the overell chenge produced by the growth of rosd accident casuelties within the total population of urban areos, and which vould measure the vertical displecement of the curve, whose slope is defined by the b coefficient. Observing the velues of the intercept given in Table (9.5.9) it can be seen that 811 the values are positive exceot for the period 1967 - 1968 which has a value of -0.079. In fact the vole sequence of the intercept velues seems to indicate a quite convircing pattern. In the period 1966 - 1967 there would seem to have been a sterdy incresse in road casuelties rhich preceded the decline noted for the period 1967 - 1968. However, following this decline there then follows a two year period where casulties are increasing but at e decreasing rete. In other rorks, it voula seem that the decline during the 1967 - 1968 period was being accounted for, whilst also accommodating the overtll increase for these years noted by the 1966 - 1970 fleure. Although eny hypothesis put forwerd for this observed patterr must by nature be very tenuous, it is suggested here that perhaps there is more than a chance coincidence between the decline in casualties and the introduction of the 1967 Pond Sefety Act. Al though this line of thought connot be followed through in this resesrch, it is also suggested that before any 
definite conclusions cen be made in this direction other variebles, such as traffic volunes must be taken into consideretion. Howerer, since the results of the original regression analysis showed the impact of police action to be beneficial it roulc tentetively seen to be a reasonable postulate, and if so, a postulate rich woula benefit by temporal analysis to consider the lasting effect of such innovations.

Tumirg to the $b$ coefficient, there vould seem to be no temporel pattern as above, al though the $b$ cosfficient for 1967 1968 is the only value which is greeter then 1.0. Even so from the results available, it would seen possible to arrive at tro conclusions:-

(i) Since the error term is very small it would seem resscneble to accept the negative relationship between the gro:th in log. casurlties end the original level of log. casuslties, as being truely representetive of the real vorld situption.

(ii) There would seem to be $\varepsilon$ gredusl increase in this negative relationship with tine, even though the increase is not consistent.

The results shere the originel openir.g varieble was the populstion rerieble, proauce very similar conclusions, which although varying in minor detail in some places, correspond with those described above for the log. total casualties variable, and cen be seen in Table $(9.5 .8)$ 
A second way in which the growth of road casualties ${ }^{20}$ cen be compared to the original level of road casualties for each urban area, is by the use of the simple regression equation,

$$
G A(t . t+1)=a+b T C_{t}+e^{2 I}
$$

If the results from the previous regressions are correct then one would expect the results from this second eguction to contein very low end very insignificent values. As cen be seen from Table (9.5.9) this is exactly the case with very low levels of explenation, and b coefficient velues which closely approximete zero. Consequently tro conclusions would once again seem to be velid in this situation:-

(i) Beceuse of the horizontal nature of the derived recression it cen be concluded that there is no direct significant reletionship between the origiral road casualty level, and the growth rate of ce sual tics.

20 The gro:ith rate was celculeted by applicetion of the formule;

$$
G A(t . t+1)=\left(T C_{t+1}-T C_{t}\right) \cdot\left(\frac{T C_{t}+1+T C_{t}}{2}\right)^{-1}
$$

where, $G L(t . t+1)=$ the growth rate in casualties from time $t$ to $t+1$.

$\mathrm{TC}_{t} \quad=$ the totel number of cesualties at

This compound growth rate was used in orcer to counter the tendency for the results from a simple growth rote comoutation to be positively sceked, when nomslity is really desired.

21 A modification to this equation introduced the logarith miceliy trensformed verifble $l \mathrm{cg} T \mathrm{TC}_{t}$ in order to recuce the asjonetry of this distribution. 


\begin{tabular}{|c|c|c|c|}
\hline 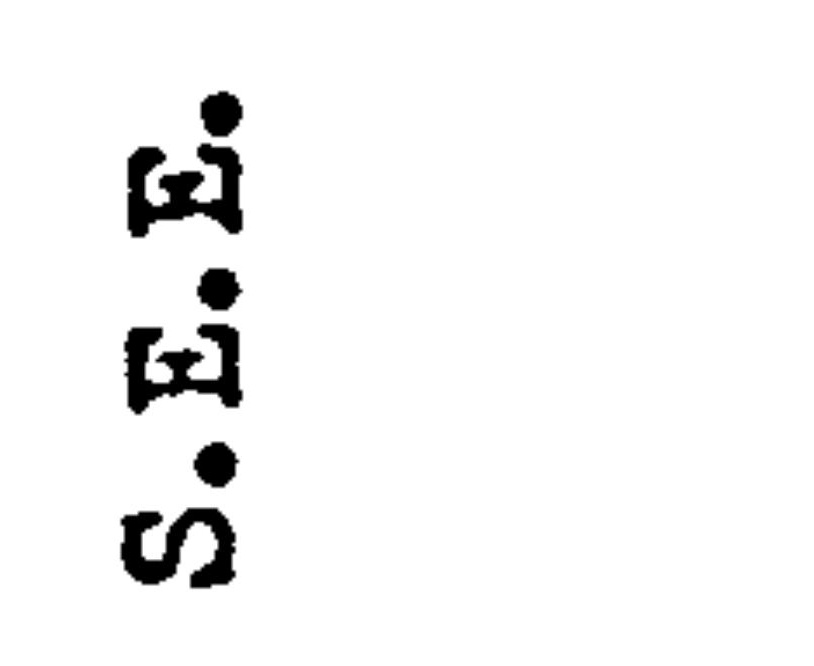 & 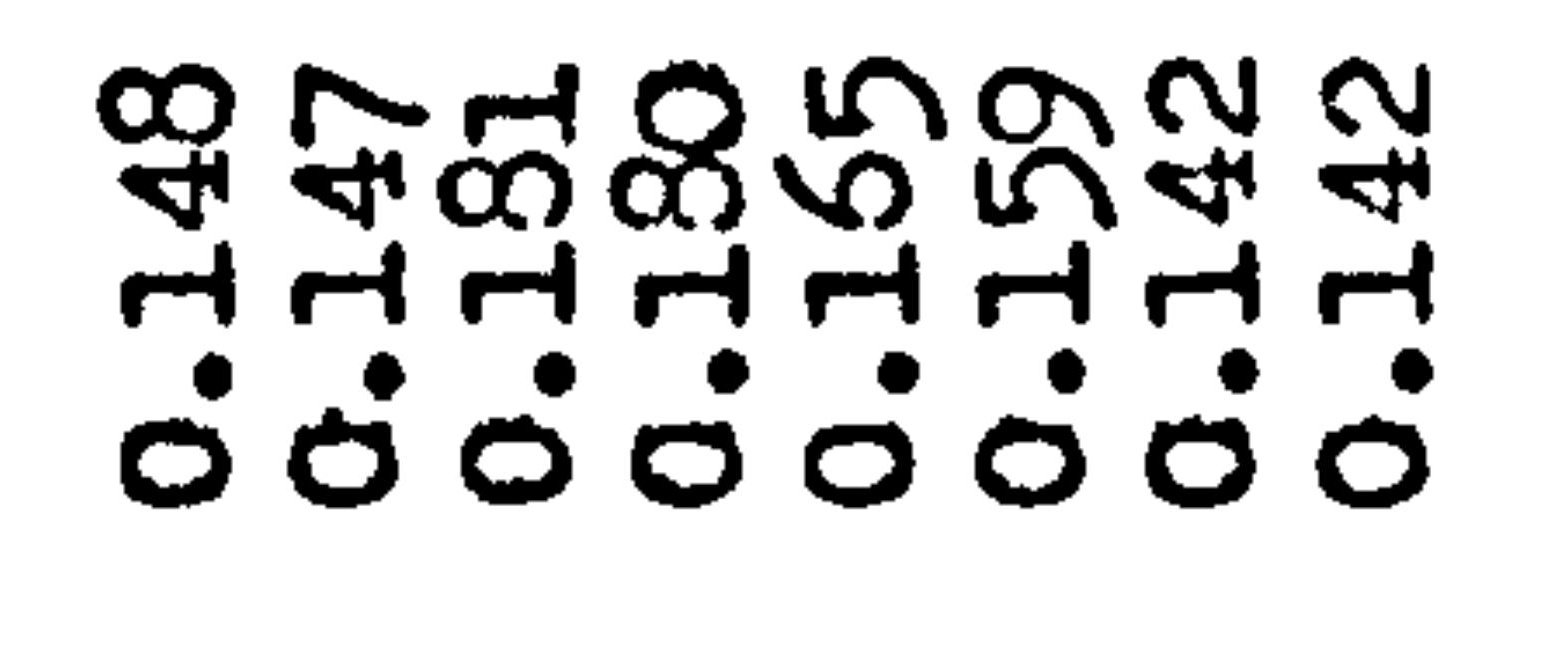 & $\begin{array}{l}\tilde{y} \\
\dot{0}\end{array}$ & $\begin{array}{l}\stackrel{8}{0} \\
\text { ؛ }\end{array}$ \\
\hline$\widetilde{N}_{\mathcal{~}}$ & 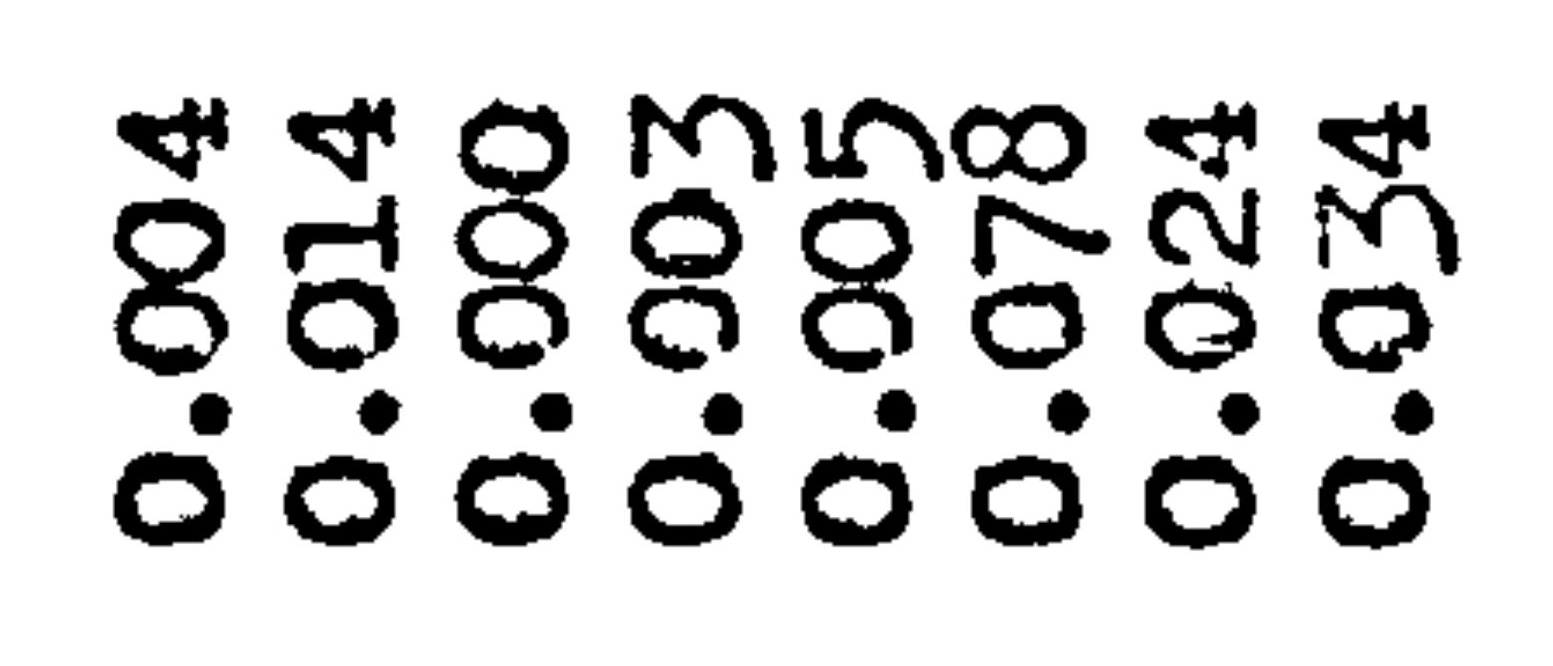 & $\begin{array}{l}\stackrel{o}{u} \\
\vdots \\
0\end{array}$ & 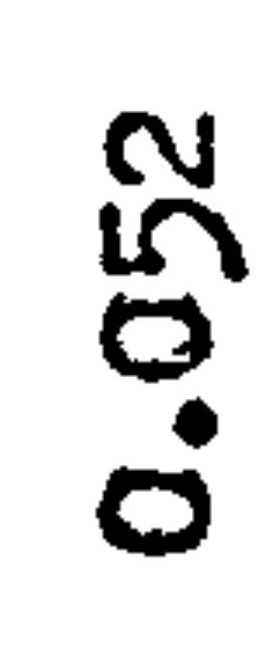 \\
\hline $\begin{array}{l}\text { 翼 } \\
\text { 号 } \\
\text { 新 }\end{array}$ & 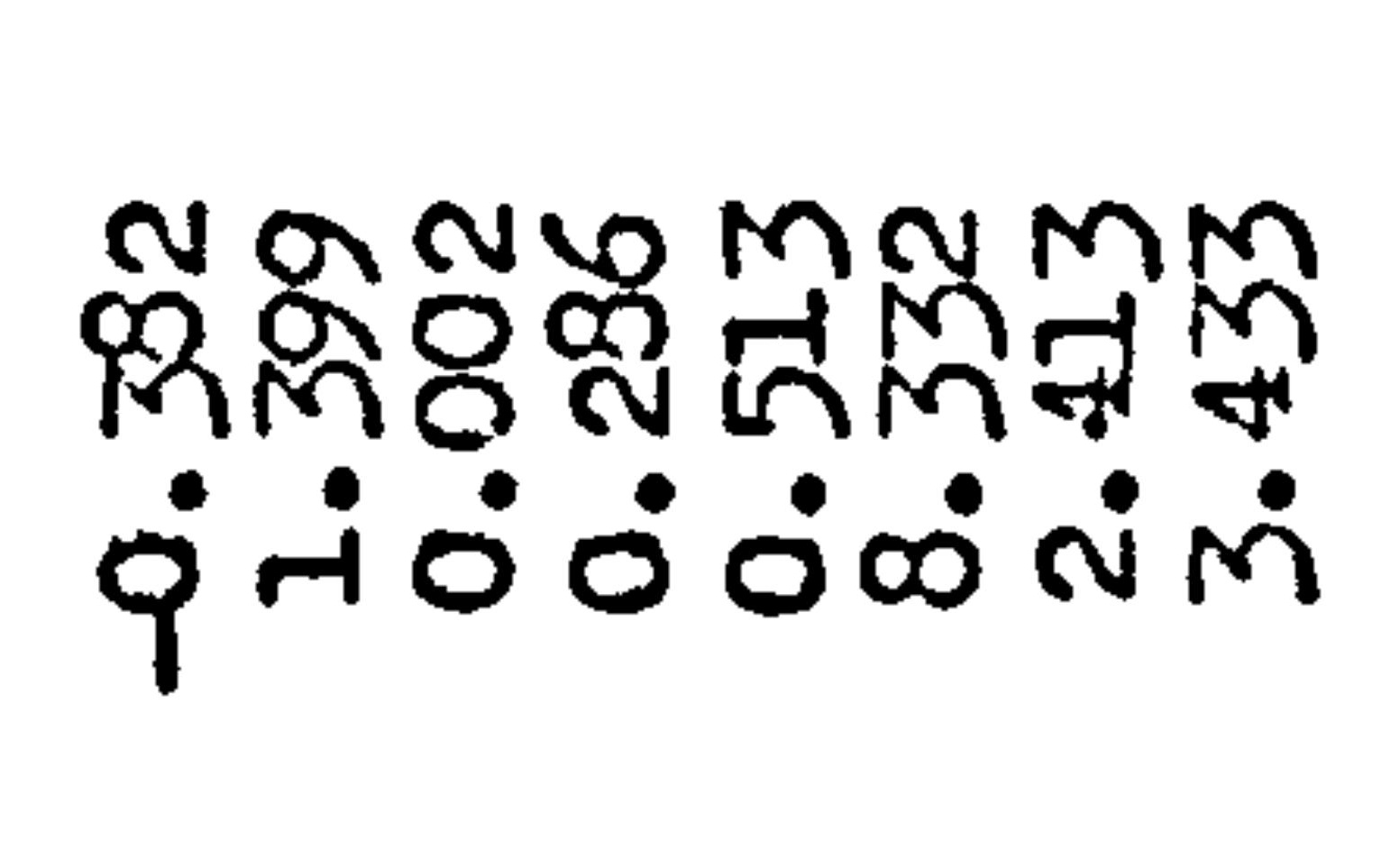 & $\begin{array}{l}\hat{\mathrm{n}} \\
\text { ஸे }\end{array}$ & $\begin{array}{l}\stackrel{\Re}{2} \\
\stackrel{0}{n}\end{array}$ \\
\hline 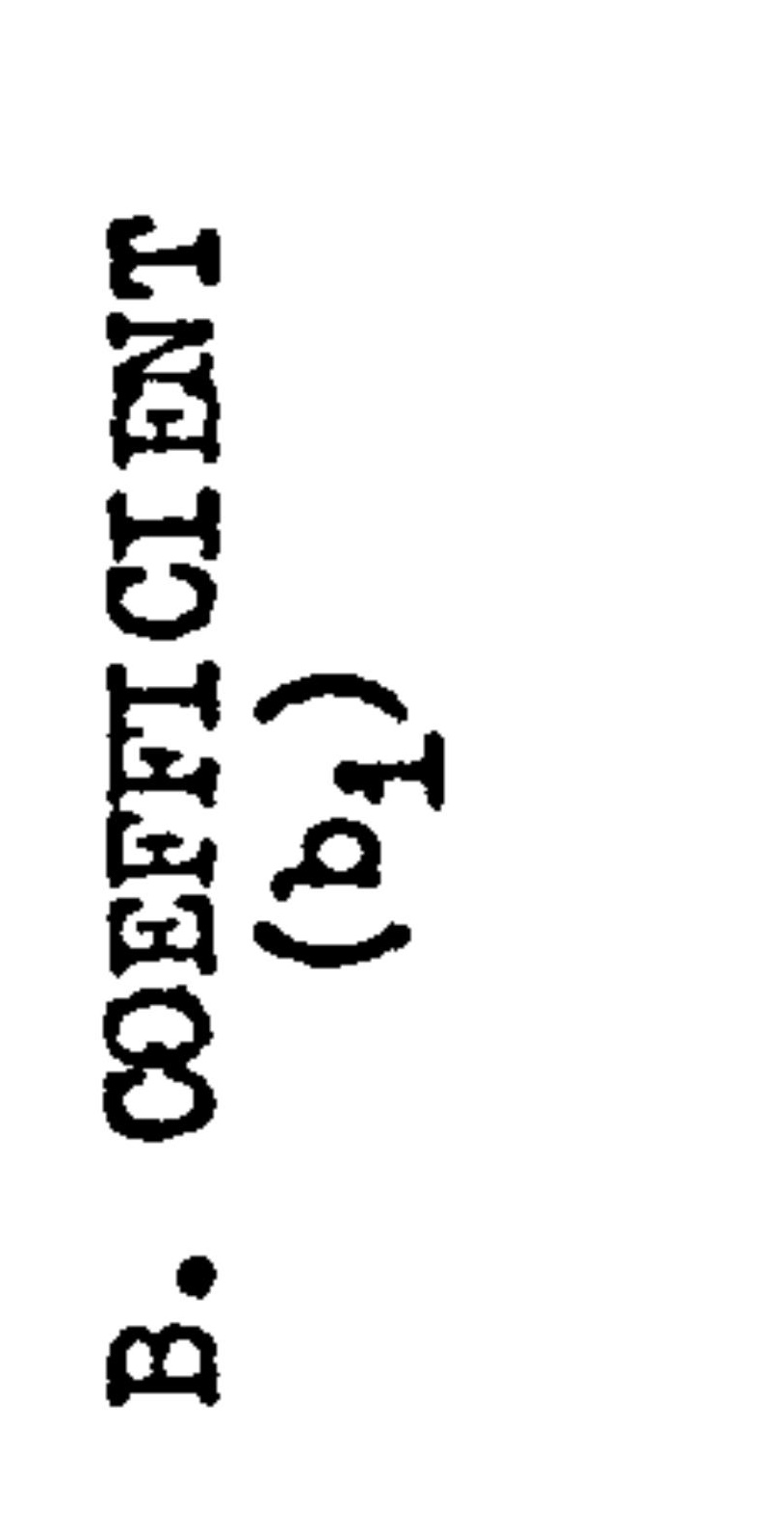 & 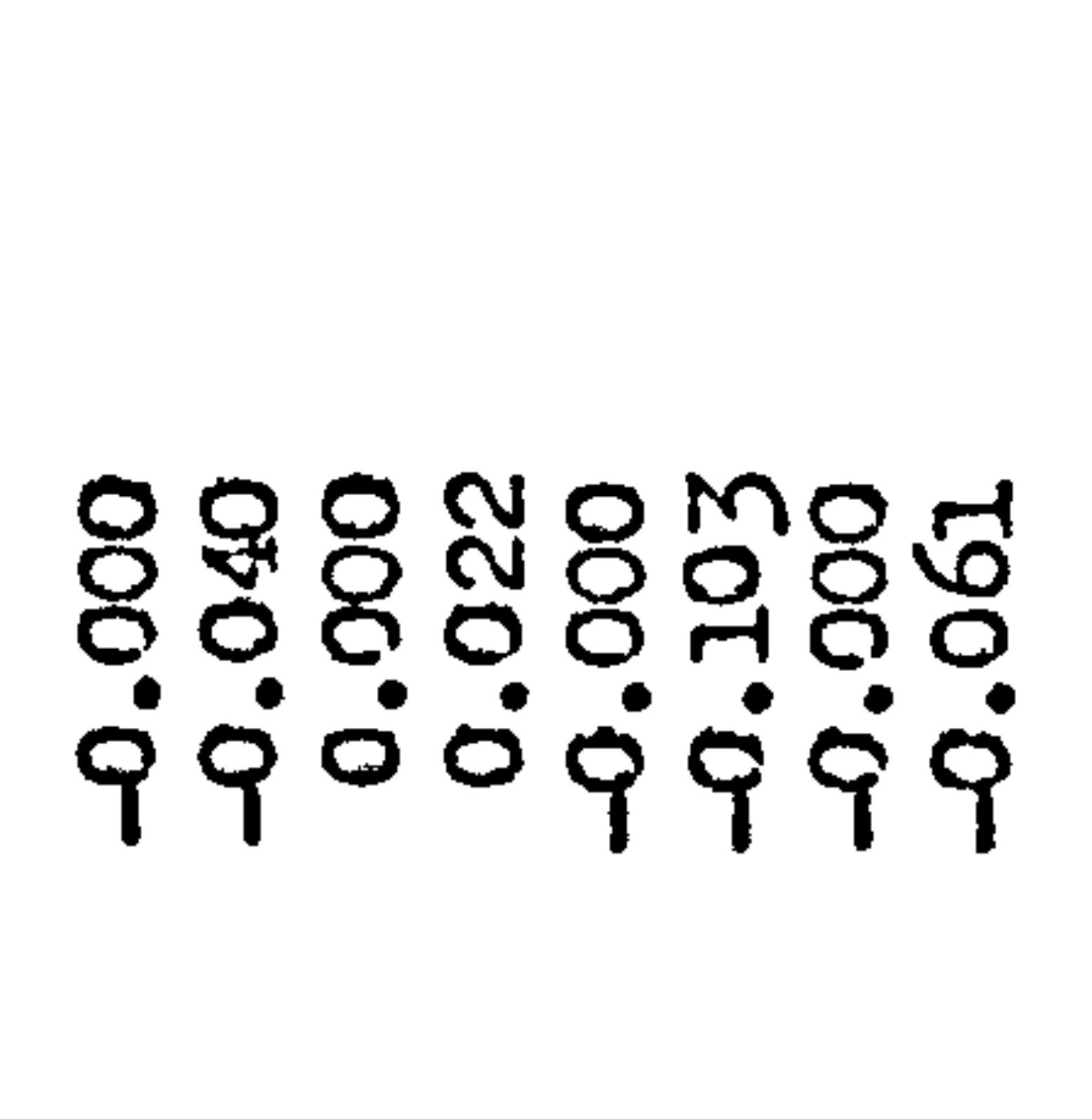 & $\dot{8}$ & $\begin{array}{l}7 \\
\dot{9}\end{array}$ \\
\hline 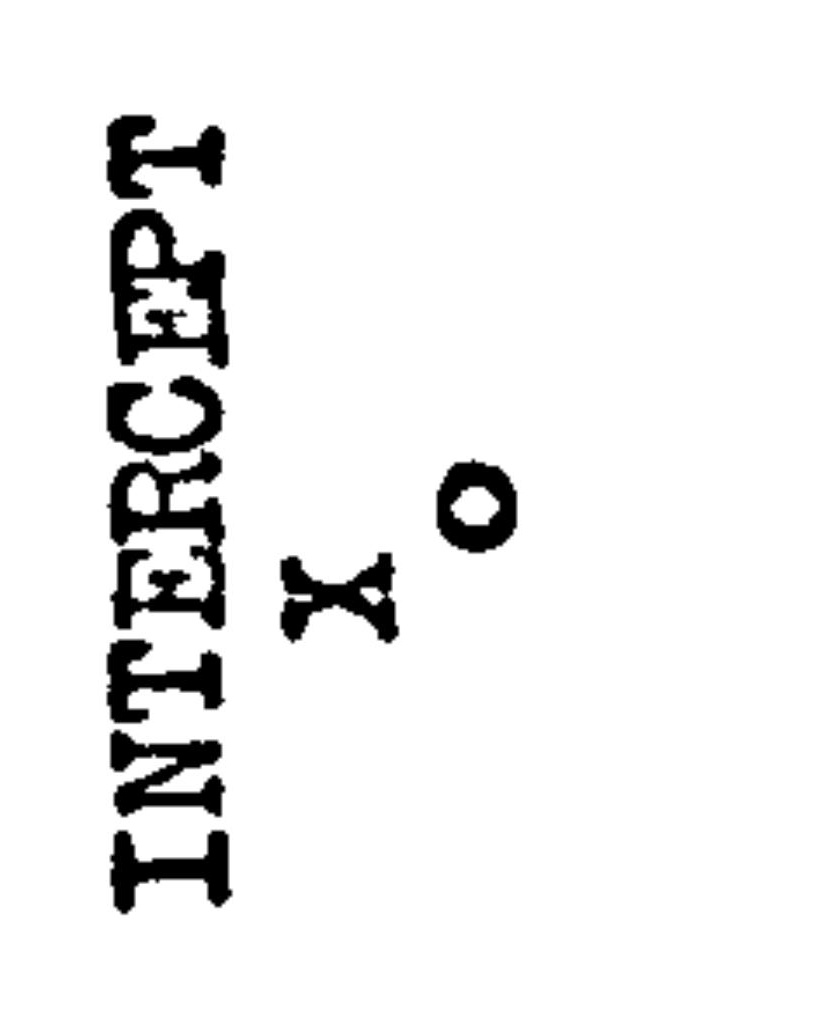 & 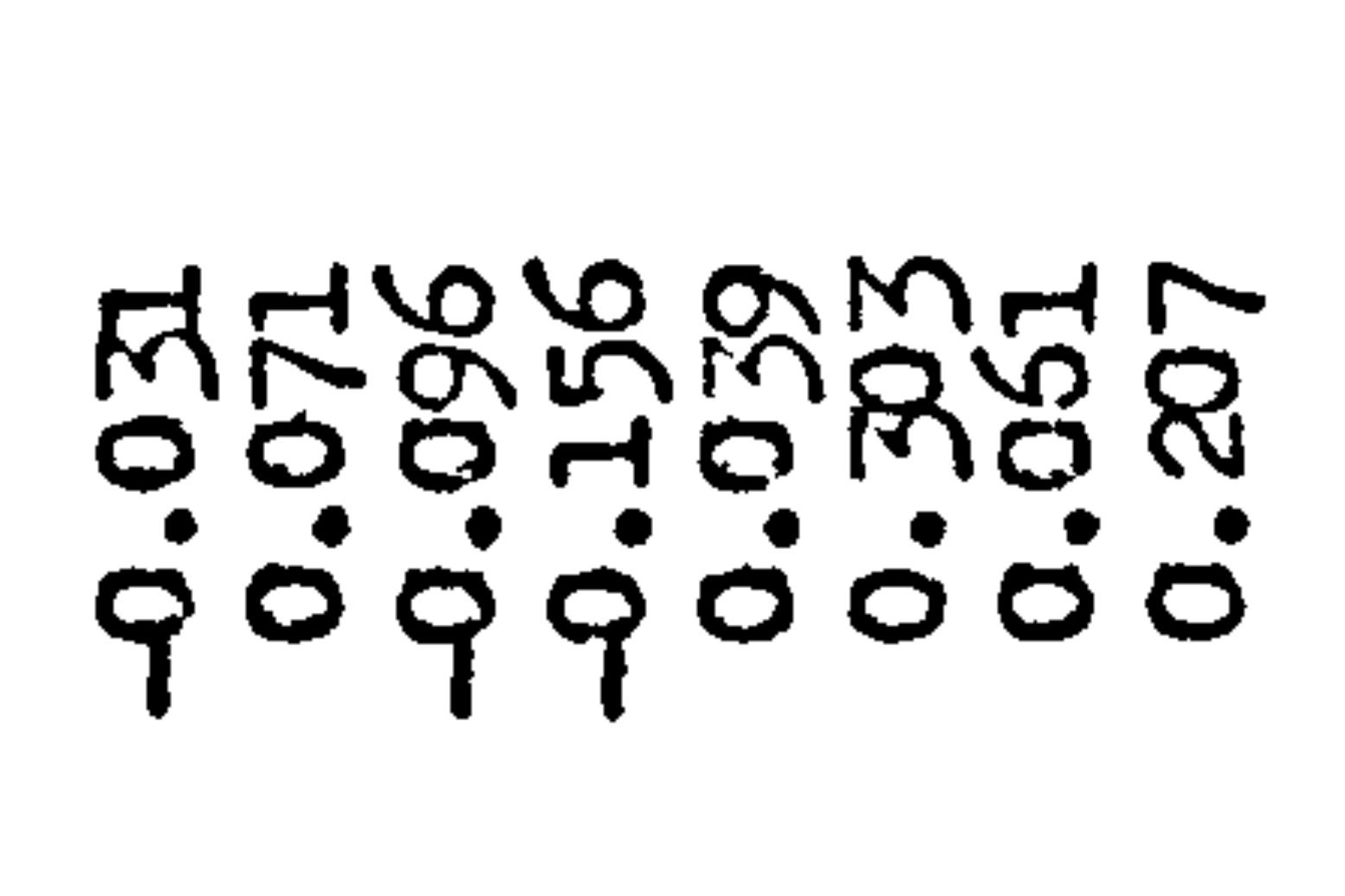 & $\begin{array}{l}\hat{n} \\
\stackrel{a}{q} \\
\dot{q}\end{array}$ & 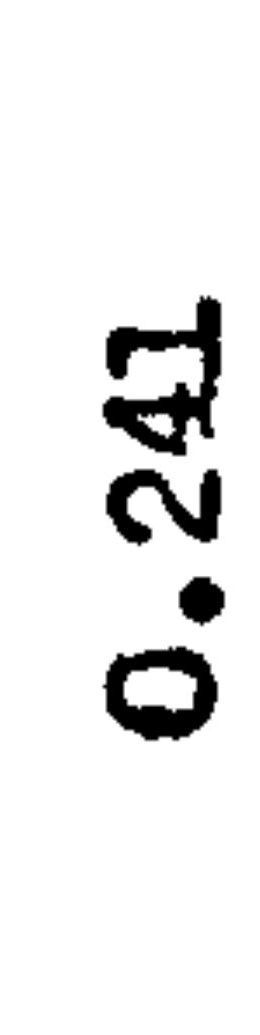 \\
\hline 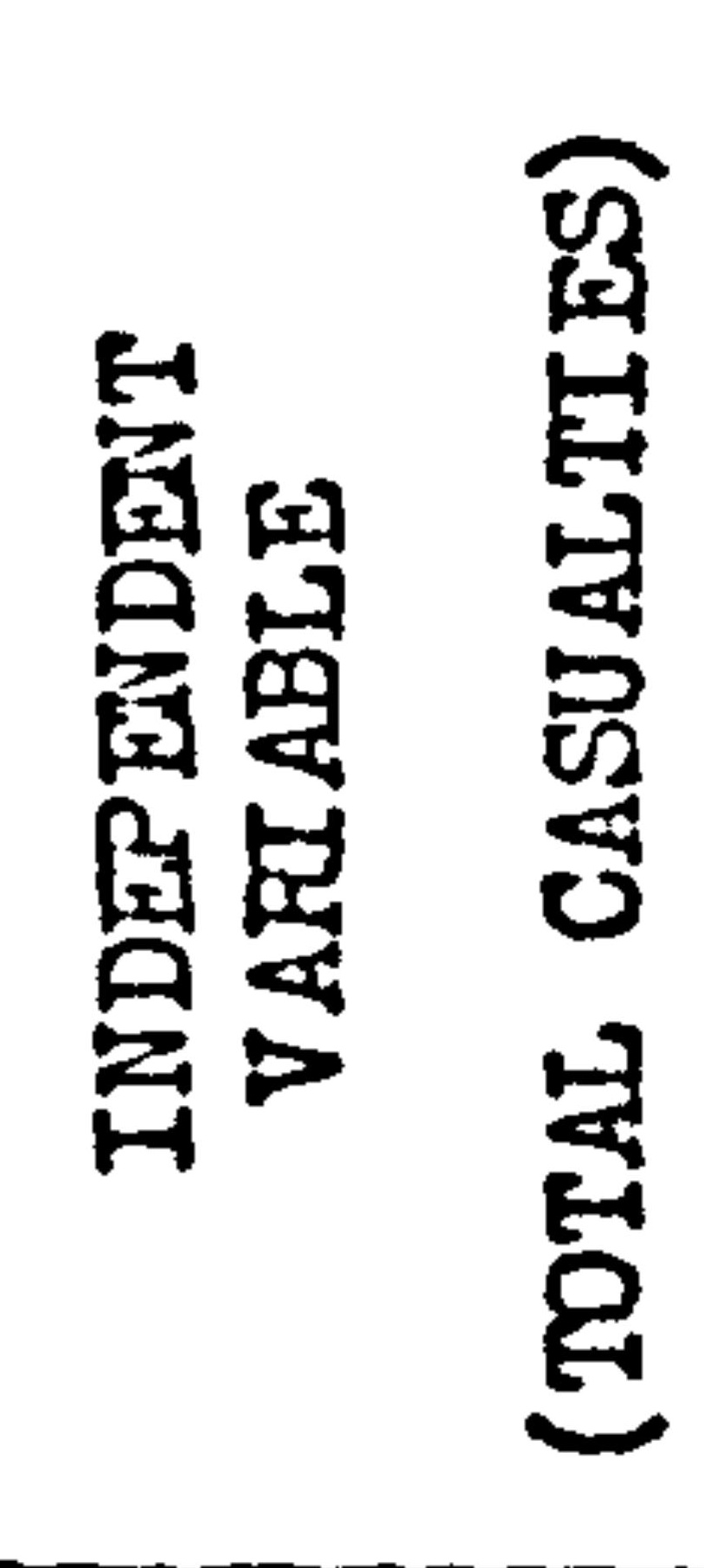 & 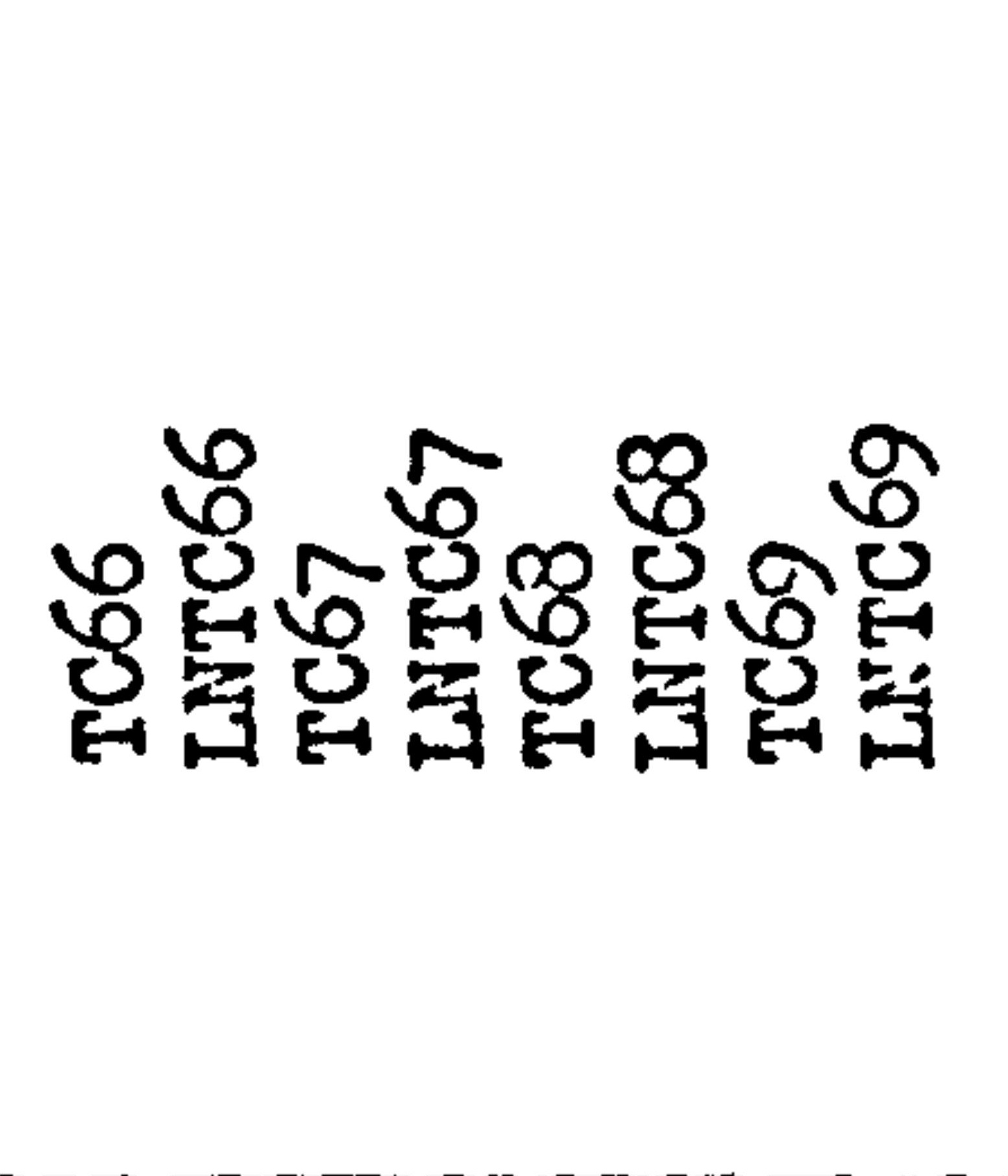 & ל้ & 莺 \\
\hline 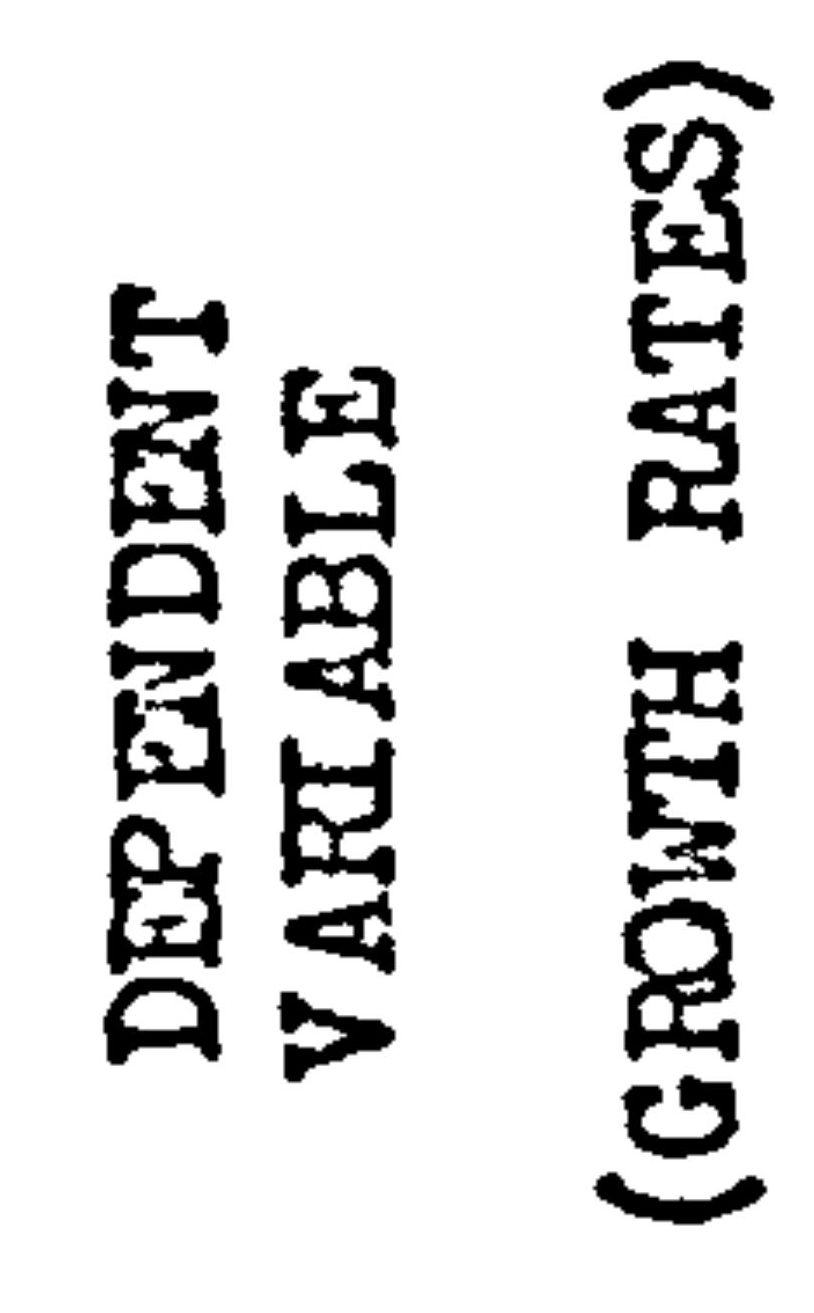 & 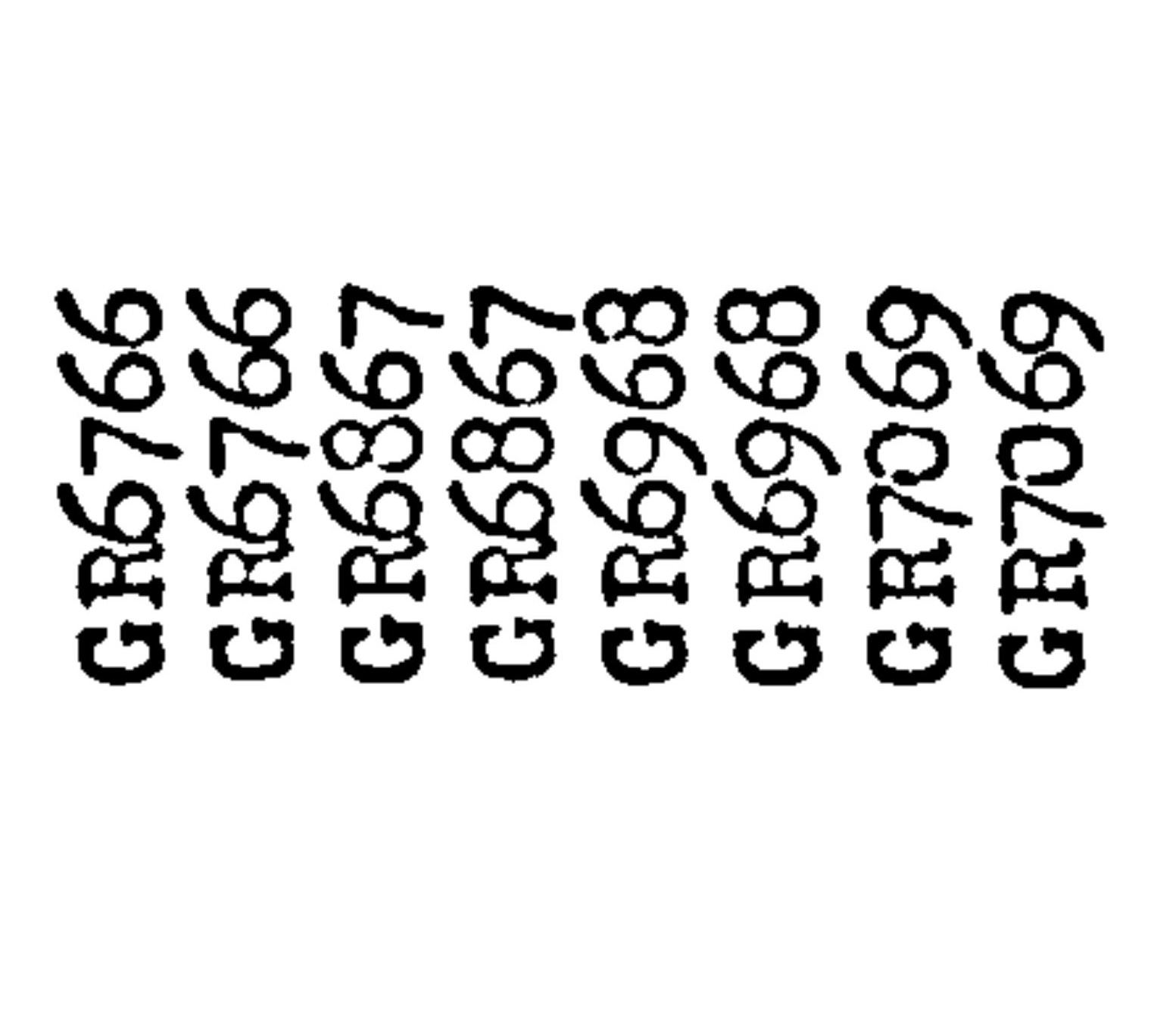 & 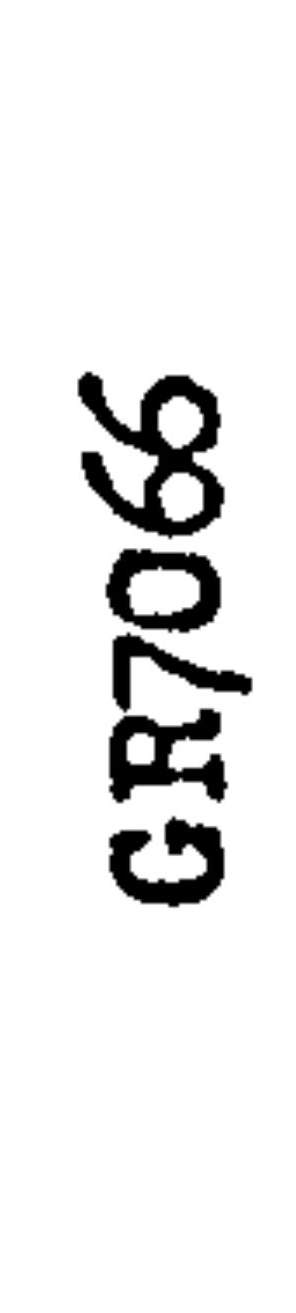 & 兽 \\
\hline
\end{tabular}


(ii) Although the magnitude of the $b$ coefficents ere very snall, since all the values are negative (except for the regressicn of $\mathrm{GA}_{1967}$ - 1968 on totel cesualties 1967), it woulc secm to be reasonable to assume that there is a weak inverse relationship between the level of road casualties and the followirg growth rates.

The leck of eny definite relationships in this anelysis therefore, suggests that further insight should be gained as to the actual grouth retes themselves. This can be done in two ways,

(i) By studying the growth rates for different years in terms of their basic statistics, and their grephic representations.

(ii) Through disaggregation in order to see if there is any significent difference in the growth rates for different sized urban areas.

The basic statistics for the computed growth rates are shown in Table (9.5.10) from wich it can be seen that thore is some variation between the velues for different yenrs. Thus for the first two sets of growth rates the mean vilue is negative with GA 1967 - 1968 heving both the higher meen value and also lower coefficient of veriation. The last two sets of grawth rates nearwhile both heve positive meen values, once sgain with the values increasing with time. The overall growth rete (GA, 1966 -1970) however, has a negrtive value, but also a high degrec of variction 


\begin{tabular}{|c|c|c|c|}
\hline $\begin{array}{c}\text { YEARS OF } \\
\text { GROWTH RATE }\end{array}$ & MEAN & STANDARD DEVIATION & $\begin{array}{c}\text { COEPPICIENT } \\
\text { OF VARIATION }\end{array}$ \\
\hline $1966-67$ & -0.038 & 0.147 & 393.1 \\
$1967-68$ & -0.096 & 0.180 & 188.3 \\
$1968-69$ & +0.030 & 0.165 & 558.3 \\
$1969-70$ & +0.044 & 0.144 & 323.2 \\
$1966-70$ & -0.061 & 0.214 & 351.7 \\
\hline
\end{tabular}

TABLE 9.5.10. CALCULATED BASIC STATISTICS FOR THE ANNUAL GROWTH RATES IN FOAD CASUALTIES FOR THE 100 URBAN AREAS. 
$(C V=351.7,6)$. Thus it can be seen thet once egein there would appear to be a significant break and change in the direction of groxth during the period $1967-1968$, during which time the 1967 Rosd Safety fict was introduced, and enforced. Before any conclusive statements can be made, however, it was necessary to see if there was eny statistically significont difference bet:een these growth rate meens. f. simple "c̈ifference between means" test was employed making use of the $t$ statistic ${ }^{22}$ The results of this anclysis are show in Teble $(9.5 .11)$ below and indicate that there is a significent difference betiveen the mean values for all yer.rs, except for those between 1969 and 1970. Thus it c×n be stated thet the variations in these meen values are not chence variations, end therefore the pattern they imply woulc seem to be a truely significant pattern. Similarly it would appear that the fluctuations in the growth rates betreen 1966 end 1969 are beginning to ever out, and perhaps retum to sone steady increase or decrease. It is impossible to state which direction future growth retes will follow beceuse of the very fluctuations, even though the 1966 - 1970 growth rate has a negrtive velue, and such information can only be obtrined by further future observations.

c2 The $t$ test used can be defined by:

$$
\begin{gathered}
t=\frac{\left(\bar{x}_{1}-\bar{x}_{2}\right)}{\hat{\sigma} \bar{x}_{1}-\bar{x}_{2}} \quad \text { where: } \\
\hat{\sigma} \bar{x}_{1}-\bar{x}_{2}=\sqrt{\frac{s_{1}^{2}+\frac{s_{2}^{2}}{N_{1}-1}}{N_{2}-1}} \text { with }\left(N_{1}+N_{2}-2\right) \text { degrees } \\
\text { of freedom }
\end{gathered}
$$


YEAS

\begin{tabular}{|c|c|c|c|c|}
\hline & $1966-1967$ & $1967-1968$ & $1968-19,69$ & $1969-1970$ \\
\hline $\begin{array}{r}1966-\overline{1967} \\
\end{array}$ & - & $2.48 \neq$ & $3.0 ? \$$ & 3.96 F⿻三丨 \\
\hline $\begin{array}{r}1967-\overline{1963} \\
19\end{array}$ & $2.48 \neq$ & - & 5.10 & 6.05 \\
\hline $\begin{array}{r}1968-\overline{6} \\
1969\end{array}$ & $3.02 \neq$ & 5.10 玤 & - & $0.68^{N S}$ \\
\hline $\begin{array}{r}1959- \\
1970\end{array}$ & 30,06 & 6.05 林 & $0.68^{\mathrm{NS}}$ & - \\
\hline
\end{tabular}

* = 't' is significent at 0.02 level

\#\# = 't' is significant at $0.01 \quad I \in \mathrm{vel}$

= 't' is significont at $0.001 \quad l \in v \in l$

NS $=$ liot significent.

Teble 9.5.11 Results of the 't' test used to test the significance of the difference bet:een the mean growth rate values for the years 1966 - 1370 .

Is a prelude to studying the growth rates in a diseggregated menner the 1966 - 1970 grouth rate was plotted Egairst the total gopulation level for exch urten area. This is shown in Fie (9.5.12) from which it cen be seen that whilst there seans to be a fair veriation cbout the mean velue of -0.06 , it also seeras as though the variance is reduced at higher population levels. Accorcingly it ras decided that the growth rates should be disaggregated into 
four groups based on the poplulation levels of $50,000,100,000$, 250,000 , and $250,000+$. Similarly since it was hoped to be able to conocre these groups, the growth rates were standardised such that;

$$
G_{z_{i}}=\frac{G_{1 n}-\bar{G}_{n}}{\sigma_{n}}
$$

where,

$$
\begin{aligned}
G_{Z_{1}}= & \text { the stendardised growth rate of the } i \text { th } \\
& \text { urban area within group } n . \\
\bar{G}_{n}= & \text { the mean value of group } n \\
\sigma_{n}= & \text { the standard deviation of group } n .
\end{aligned}
$$

As normal these standardi sed growth rates bill heve a mean value of zero and a standard deviation of 1. (Table 9.5.1j) The importance of these standardised growth rates lies in the fact that they place areas within a group, only respective to the other areas in that sane group. Thus two areas from different groups nay have totelly different absolute growth rates, but may be relatively placed within their respective eroups. If this is the case, then both areas will have similar standardised scorss, due to their relative locations within their groups. Obviously therefore the grestest value of these scores must lie in a study of their spatial variations.

However, before going on to make use of these standardised growth rates, the original disaggregated absolute growtil rates nave to be analysed. These original vilues and basic statistics ore shom for exch of the four groups in Table (9.5.1 3 ) and a plot of these 
1. Ayle sbury

2. Bury

3. Bridgewater

4. Buxton

5. Canterbury

6. Cheshunt

7. Corby

8. Cumbernaula

9. Dartford

10. Dover

11. Durham

12. Farnworth

13. Glenrothes

14. Hereford

15. Horsham

16. Inverness

17. K. Lynn

18. Lnncaster

19. Newport

20. Pontefract

21. Ryde

22. Stirling

23. Taunton

24. Thornton Cleveleys

25. Welwyn

26. W. Bridgeford

27. Whitehaven

28. Winchester

29. Wrexham

30. Yecril

$\overline{\mathrm{X}}=3.436$

$6=25.642$

$N=30$

\begin{tabular}{|c|c|}
\hline $\begin{array}{c}\text { ORIGINAL } \\
\text { GROKTH RATES }\end{array}$ & $\begin{array}{l}\text { STANDARDISED } \\
\text { GROWTH PATES }\end{array}$ \\
\hline-8.74 & -0.207 \\
\hline-1.76 & 0.065 \\
\hline-9.00 & -0.217 \\
\hline 3.70 & 0.278 \\
\hline-10.12 & -0.261 \\
\hline-3.26 & 0.007 \\
\hline-22.91 & -0.759 \\
\hline 73.77 & $3.011 *$ \\
\hline-10.05 & -0.258 \\
\hline 27.03 & $1.188 *$ \\
\hline-20.64 & -0.671 \\
\hline-19.46 & 0.625 \\
\hline 36.56 & $1.560 *$ \\
\hline-12.41 & -0.350 \\
\hline-4.15 & -0.028 \\
\hline 52.53 & $2.183 *$ \\
\hline 6.12 & 0.373 \\
\hline-42.86 & $-1.534 *$ \\
\hline 3.85 & 0.284 \\
\hline-16.77 & -0.520 \\
\hline-22.41 & -0.740 \\
\hline 14.33 & 0.693 \\
\hline 0.00 & 0.134 \\
\hline-38.78 & $-1.378 *$ \\
\hline$-14 \cdot 32$ & -0.424 \\
\hline-31.73 & $-1.103 *$ \\
\hline-22.71 & -0.752 \\
\hline-22.83 & -0.756 \\
\hline-12.21 & -0.342 \\
\hline 26.15 & $1.154 *$ \\
\hline
\end{tabular}

* greater than = 1 standard deviation

TABLE 9.5.13. THE GROUPED URBAN AREAS WITH THEIR ORIGINAL AND STANDARDISED GROWTH RATES. 
1. Barnsley

2. Bath

3. Brentwood

4. Burnley

5. Carlisle

6. Chelmsford

7. Cheltenham

8. Chester

9. Chesterfield

10. Colchester

11. Crewe

12. Durham

13. E. Kilbride

14. Exeter

15. Gloucester

16. Guildford

17. Harlow

18. Hastings

19. H. Hempstead

20. Grimsby

21. Kirkcaldy

22. Lincoln

23. Rochdale

24. Rugby

25. Stafford

26. Sterenage

27. Stretford

28. Sutton Cold.

29. Swind on

30. Worthing

\begin{tabular}{|c|c|}
\hline $\begin{array}{c}\text { ORIGINAL } \\
\text { GROWTH RATES }\end{array}$ & $\begin{array}{l}\text { STANDARDISED } \\
\text { GROWTH RATES }\end{array}$ \\
\hline-44.08 & $-2.033^{*}$ \\
\hline-15.35 & -0.421 \\
\hline-18.00 & -0.570 \\
\hline-25.41 & -0.985 \\
\hline 2.79 & 0.284 \\
\hline$-21 \cdot 32$ & -0.756 \\
\hline-1.94 & 0.332 \\
\hline-24.82 & -0.952 \\
\hline-11.31 & -0.194 \\
\hline-14.90 & -0.396 \\
\hline-29.44 & -0.819 \\
\hline 0.82 & 0.395 \\
\hline 25.00 & $1.844 *$ \\
\hline-14.34 & -0.364 \\
\hline 9.79 & 0.990 \\
\hline 30.39 & $2.146 *$ \\
\hline 17.99 & $1.453 *$ \\
\hline-6.42 & 0.080 \\
\hline-3.54 & 0.242 \\
\hline-2.50 & 0.301 \\
\hline-11.81 & -0.222 \\
\hline 3.80 & 0.654 \\
\hline 3.85 & 0.657 \\
\hline-19.61 & -0.660 \\
\hline-20.55 & -0.713 \\
\hline-6.92 & 0.052 \\
\hline-19.67 & -0.663 \\
\hline-0.78 & -.397 \\
\hline-4.03 & 0.215 \\
\hline-13.30 & -0.306 \\
\hline
\end{tabular}

$\overline{\mathrm{X}}=7.8537$

$6=17.815$

$N=30$ 
1. Basildon

2. Blackburn

3. Blackpool

4. Bolton

5. Bournemouth

6. Brighton

7. Cambridge

8. Derby

9. Dundee

10. Huddersfield

11. Ipswich

12. Luton

13. Norwich

14. Oldham

15. Oxford

16. Poole

17. Portsmouth

18. Preston

19. Reading

20. Salford

21. Southampton

22. Southend

23. Sunderland

24. Swansea

25. York

\begin{tabular}{|c|c|}
\hline $\begin{array}{l}\text { ORIGINAL GROWTH } \\
\text { RATES }\end{array}$ & $\begin{array}{l}\text { STANDARDISED } \\
\text { GROWTH RATES }\end{array}$ \\
\hline-9.37 & -0.095 \\
\hline-0.54 & 0.355 \\
\hline-30.05 & $-1.146 *$ \\
\hline-0.03 & -0.077 \\
\hline 10.83 & 0.933 \\
\hline-13.70 & -0.315 \\
\hline-14.54 & -0.358 \\
\hline 8,53 & 0.816 \\
\hline 16.82 & $1.238 *$ \\
\hline-6.42 & 0.055 \\
\hline-5.31 & 0.112 \\
\hline-4.67 & 0.144 \\
\hline-4.18 & 0.169 \\
\hline-39.92 & $-1.649 *$ \\
\hline-34.39 & $-1.367^{*}$ \\
\hline-6.40 & 0.056 \\
\hline-21.15 & -0.694 \\
\hline-20.18 & -0.644 \\
\hline-20.09 & -0.640 \\
\hline-4.30 & 0.163 \\
\hline-14.27 & -0.344 \\
\hline-17.87 & -0.527 \\
\hline 20.31 & $1.415 *$ \\
\hline 46.70 & $2.757^{*}$ \\
\hline-14.55 & -0.358 \\
\hline
\end{tabular}

$\overline{\mathrm{X}}=7.5096$

$6=19.660$

$\mathrm{N}=25$

* greater than = 1 standard deviation. 
1. Birmingham

2. Bradford

3. Bristol

4. Cardiff

5. Coventry

6. Edinburgh

7. Leeds

8. Leicester

9. Liverpool

10. Manchester

11. Nottingham

12. Plymouth

13. Sheifield

14. Stoke

15. Wolves

$$
\begin{aligned}
& \bar{X}=10.217 \\
& 6=17.692 \\
& N=15
\end{aligned}
$$

\begin{tabular}{|c|c|}
\hline $\begin{array}{c}\text { ORIGINAL GROWTH } \\
\text { RATES }\end{array}$ & $\begin{array}{c}\text { STANDARDISED } \\
\text { GROWTH RATES }\end{array}$ \\
\hline-13.45 & -0.183 \\
-10.74 & -0.030 \\
4.52 & 0.833 \\
4.21 & 0.815 \\
13.87 & $1.361^{*}$ \\
-4.25 & 0.337 \\
12.69 & $1.295 *$ \\
-30.77 & -1.162 \\
-32.28 & $-1.247^{*}$ \\
-23.23 & -0.736 \\
-24.30 & -0.796 \\
-9.98 & 0.013 \\
-7.99 & 0.126 \\
-18.03 & -0.442 \\
-13.52 & -0.187 \\
& \\
\hline & \\
\hline
\end{tabular}

* greater than = 1 standard deviation 


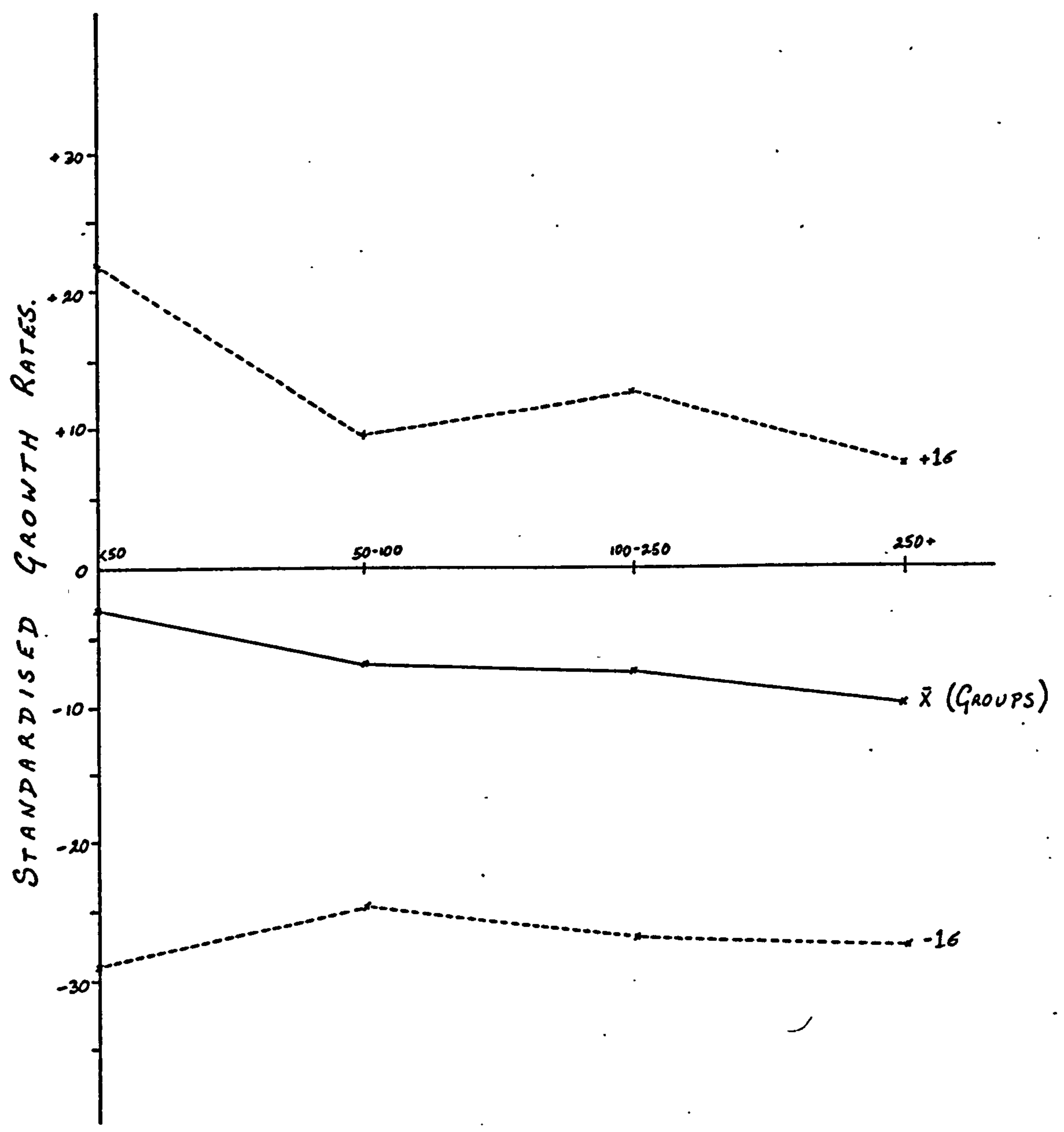

FIg. 9.5.14. PLOT OF STANDARDISED GROUP ROAD CASUALTY GROWTH RATES, MEANS AND STANDARD DEVIATIONS. 
statistics for each group is shorn in Fig. (9.5.14). It should be renembered that the reason for this disaggregation was to see if there actually was a different growth rate response for sneller urben areas, end also to see if the varience about the mean value sinilarly varied according to the size of the urban area. This last point can be simply tested by looking at both the graph plot in Fig. (9.5.I4) and also the coefficient of variation for each of the four groups. For both of these approaches it con be seen that the variance is by far the largest in the smallest population group. However, the other three groups do not seen to alter too much al though the smallest variance is associated vi th the largest. population group. Thus it can be stated that whilst the smaller urtan areas have a much greater variation in their growth rates, the degree of variation in the other grouns cennot be statistically differentiated even though there is a decressing trend as population size increases.

In order to test the hypothesis tilat each of the population groups has a different set of grouth rate values, the simple difference of means test was used again in order to see if the difference betireen the mean growth rates for each of the population groups was at all significant. The results for these tests are presented below in Table $(9.525)$ which shows that none of the group mean values are statistically significantly different fro'a each other at enj confidence level. 
GEOUPS

\begin{tabular}{|c|c|c|c|c|}
\hline & 1 & 2 & 3 & 4 \\
\hline 1 & - & $0.775 *$ & $0.654 \neq$ & $1.011 \neq$ \\
\hline 2 & $0.775 \neq$ & - & $0.055 \neq$ & $0.410 \neq$ \\
\hline 3 & $0.654 \neq$ & $0.065 \neq$ & - & $0.436 \neq$ \\
\hline 4 & $1.011 \neq$ & $0.110 \neq$ & $0.456 \neq$ & - \\
\hline
\end{tabular}

$$
\begin{aligned}
\text { DIF. } & =N_{1}+N_{2 / 2} \\
& =\text { INSIGNIFICANT 't' value }
\end{aligned}
$$

Taible 9.5.15 Results of the student's ' $t$ ' test used in order to test for any significsnt difference bet:reen the grouth rate neans for different urban groups. (1966 - 1970)

The t:o conclusions to be derived from these diseggregated approaches are therefore,

1) Although small uroan areas have a much larger variation - in groxth rates, there is no real discernible significrnt decrease as population levels increase for tive remining groups.

2) There is no statistical reason to presume thet smaller urban arous have different grontis rste characteristics to larger areas. The variations noted in their inean values could simply be the result of chence veriations. 
Although these results show that the diseggregetion of the urben areas does not improve the understanding of these growth rates, the disaggregation was maintrined in respect of the stendardised growth rates. As has already bean indicated the greatest use of these scores is in a spatial analysis. However, it should always be remenbered that a tain with a high score does not mean that its percentage rate of grovth was high compared to the national average, but that it was high according to the variation within its respective group. The spatial variation of these stendardised growth rates are sho:m in Fig. $(9.5 .15)$ with urban areas plotted according to their deviation fron the mean value. Four groups of deviations are marked on either side of the mean vulue and these cen be interpreted as:

1) $\pm 0.56=$ average growth rates.

2) $0.5<G<0.756$ = moderate growth rates.

3) $0.75<G<1.006=$ high growth rates.

4) $\geqslant 1.006=$ exceptional growth rates.

From this plotted spatial veriation severel features become imnediately obvious and therefore desorving of further attention. These can be sumarised o.s below:-

1) Although there are only eight sampled points in Scotland, all of these points, except for Edinburgh, have values above the mean and five hrve values which exceed plus one standard deviation, which perheps incicates the groving rosd accident problen in this region. Hoverer, it Iust also be pointed out that these eight points include the tirree Scottish new toins of Cumbermald, Glenrothes and E. Kilbride which heve been continuing to grow during this poriod 


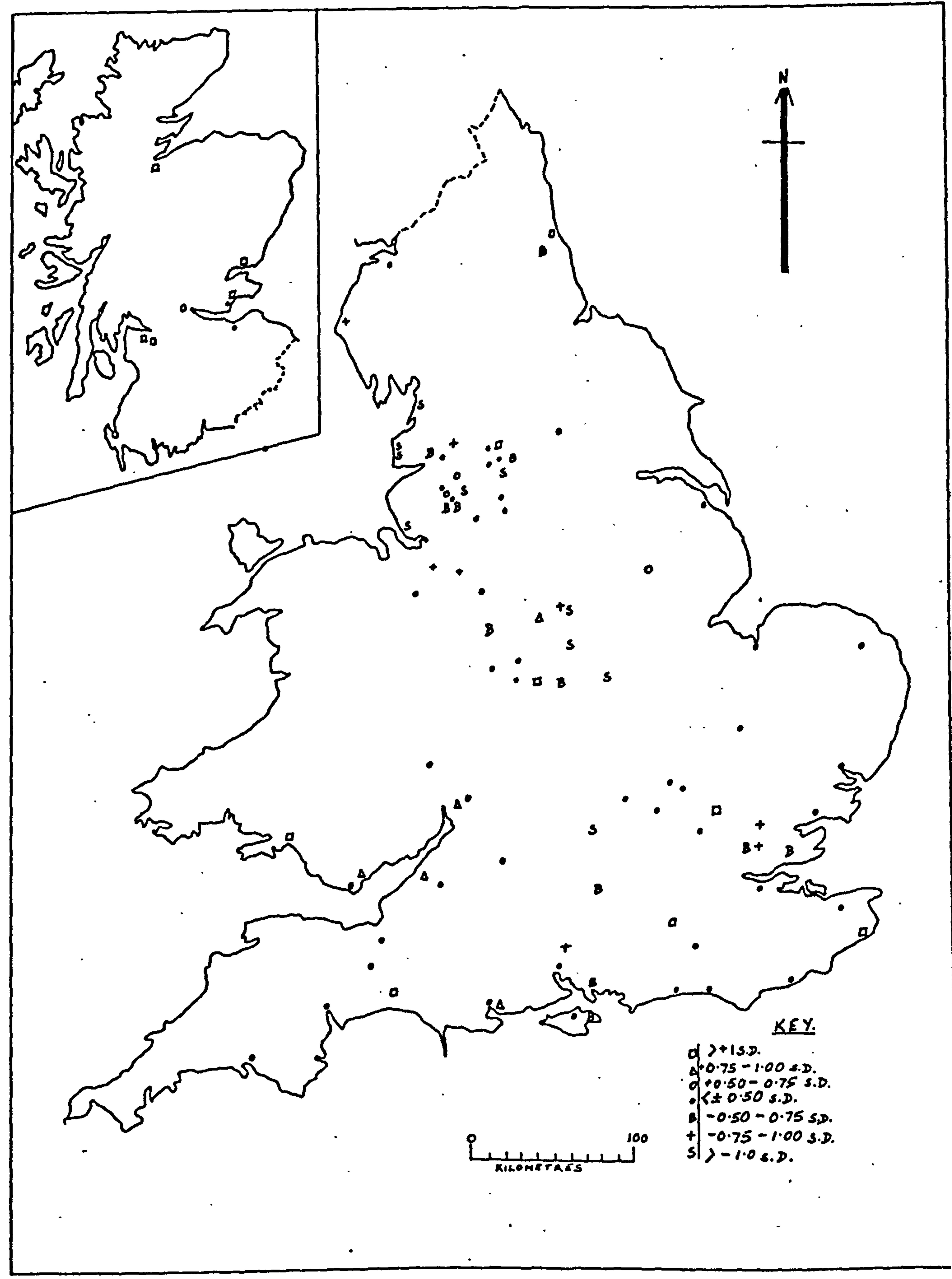

F1g. 9.5.15. MAP OF THE SPATIAL DISTRLBUTION OF GROUP STANUARDISED POAD CASUALTI GROITH RATES. 
and therefore perhaps should be dealt yith as excepticnal cases.

2) It would seen thet most of the sampled ares in the Northwest of Englend have less tinen average rates of growth, with only Femworth and Rochdale heving above average values. Since one of the factors which hes continually been reappearing is the volums of through treffic, these low values could be due to the improving rogd and motorsay systems in that area.

3) It was noted in the spatial enalysis using trend surfece teciniques, that the area around the gateway to the S.W. peninsula alviys had underestimated values. A similar situation is also revealed in this enalysis, with urben areas in tilis region and South hales having either average grouth rates or above average growth values. Consequently the argunents put forward in the prevlous spatial analysis vould seen to be verifled by this present enalysis.

4) Al though it was noted earlier that the urben aress around London were ususlly underestimated in respect of their levels of accldent casurlties etc., the results of this analysis seen to be less critical of that region. Only tro urben areas in the proxinity to London have growth rates which are wove averge, these being Harlo: and Guildford. The remainder have either average groith rates or belo: everage rates. With reference to previous results, therefore it must be concluded that al though these aress tend to have higher accident casualty levels then the netional 'norn,' the rato of grouth within these areas is no higher and often lover then in other arees of the country. 
5) Finally this analysis pinpoints certein anomaly urben areas with high rates of grorth which are out of charecter wi th the other urban areas in that region, and wich are therefore in need of some special attention. Besides the t:o aress previously mentioned, Guildford end Harlow, similar urben areas include Boumemouth, Dover, Leeds, Sunderland end Swansea.

This then concludes the presentation of the results from this research. However, before drawing all the conclusions together, since the research was initiated to look at the influence of urban plenning proposels, it will be useful to look at the results with particular reference to those areas specifically designed with roed sefety in mind. Thet is the new town areas included wi thin the 100 sempled areas. 


\section{Chapter 10 THE NEW TOWNS AREAS - A CASE ASSESSIIENT}

\subsection{INTPDDICTION}

One of the major assumptions in new torn developments is that through urban planning proposals and comprehensive planning in particular, it is possible to create an urben environment which is conducive to road safety both from the engineering point of view as well as the psychological point of view. Implicit in this statenent therefore is the argunent that the type and design of the urben structure of an area cen influence the level of road accident casualties in that area. Howerer, to date, this assumption has never been testod cuentitatively, except as in the simplistic tenas used by the Cumbernould Development Corporation. Unless this assuration is true meanihile, considerable amounts of money coula heve been expended, for which the return is unacceptable. Furthermore if such an approach is found to be unsatisfactory, then it could be argued that a more satisfactory approach to road safety hes been iznored, or remained uninvestiga.ted, purely as a result of a lack of scientific rigour and investigation. Consequentiy this section of this report attempts to look at the response of the six new to:n areas included within the 100 sanpled areas, by means of the results obteined through the proposed nethodological approsch adrocated in this research. The six areas studied here are; Harlow N.T., Hemel Hempstead N.T., Stevenege N.T., Cumbernauld, East Rllbride and Glenroties which conbine new towns of both the first end second generations. The assossment of these arens will be facilitatod by unaking use of the mean safety indices 
for these areas, and also by observing the significant road accident casual growtin rates for the time period 1966 - 1970.

\subsection{ASSESSHEAT OF THE HEAIN SAFETI INDICES}

The simplest way of looking at these mean safety indices is by observing the response of these nex torns in relation to some of the more importent dependent variables used in the regression analyses. These MSI values are shown in Table (10.2.1) and will be continuously referred to in this section of the report.

\section{(i) TOTAL CASUALTIFS 1970}

It can be seen from the results in the table that whilst five of the new torm areas heve MSI values of less then 100.0 in most the ectual deviation from this expected value is only marginal and in the case of Cumbernauld N.T., the MSI value is well over 100.0 (MSI $=139.33)$. It is also interesting to note that the three older new to:nstare all within eight MSI units of the expected value, wilst the remaining newer toms ${ }^{2}$ have much higher deviation MSI velues from the expected. When these MSI velues are compared with those derived for other areas it becomes obvious that the new toms response is not as good as would be expected. In severul instances torms of a similar size, which have not been planned, exhibit a better response. For exemple, Hastings, Horsham and Lencaster all have MSI values around the 50.0 mark. 3

1 Harlow, Henel Hemptead and Stevenage.

2 Excluding Cumbernauld.

3 For further examples of non-planned urban arees see Tables $(9.4 .19$ to 9.4 .23$)$. 


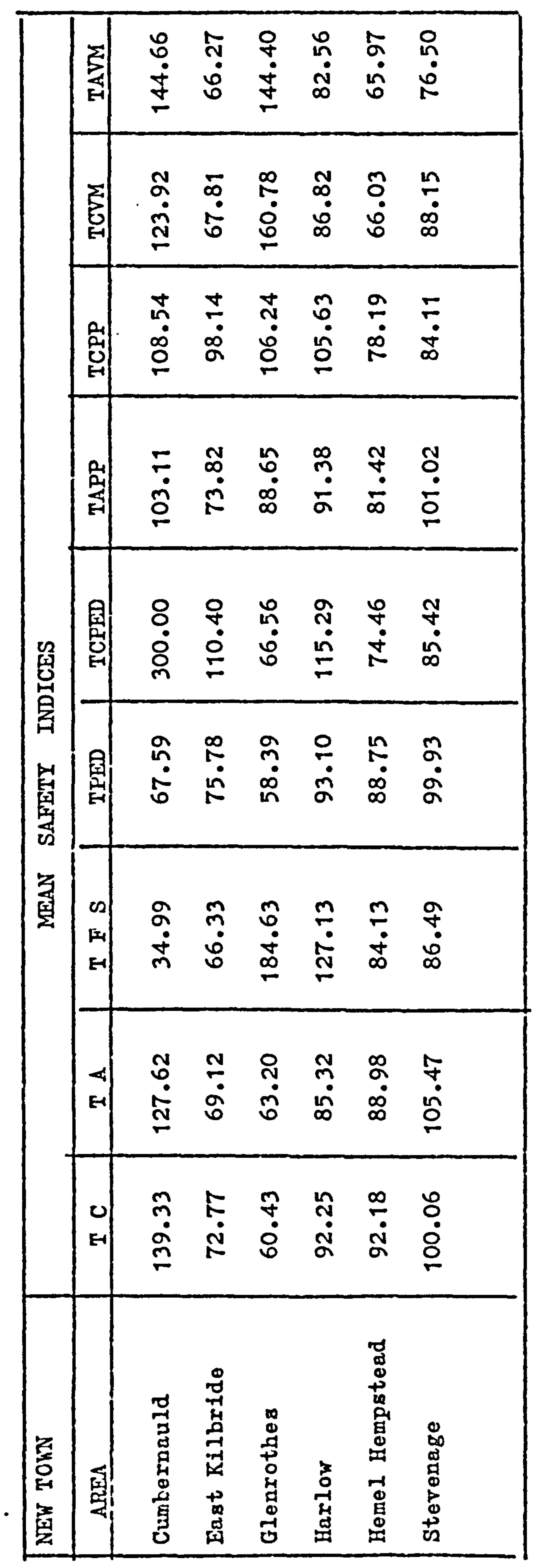

옹

急

悹

畐

国

오

点

瓷

昜

$a$

号

恣

密

思

官 
Another dependent variable which adds further information to $T C 7 \varnothing$ is the total casualties variable for 1966. The importrnt fact to be gained from this variable is that whilst the MSI values for the new to:n areas remain in the same relative position with each other, in terms of absolute value, they are substantially less. 4 Thus the two MSI values for Harlow in 1966 end 1970 are 70.08 end 92.25 respectively, and for Glenrothes 40.02 and 60.43 . This fact should be compared with the fact that the three comparable toms mentioned previously el ther remain virtually constant or decrease from 1966 $1970^{5}$, a general decrease which has already been discussed in terns of the growth rates 1966 - 1970 . Consequently the tempting conclusion to reach in accord with this data is that whilst these new torns may exhibit favoureble accident response rates in their early years of development, they seen to tend towards the national "norn" irrespective of the average national growth rates during that same period of time. If this is true then it would seem to suggest that the new to:ms improved environment is only effective within the early stgges of develooment.

Before leaving this variable some comment must be made about the apparent uncomplinentary results obtained for Cumbernauld. It was pointed out in the discussion on the areal units used in this research that where the new towns were concerned the unit used was the admialstretive unit. In most of these cases the adninistrative unit and the area of the New Town Corporation are almost identical.

4 Once again however, Cumbernauld is the exception to the rule.

5 The tir values for Lincaster ere $74.36(1966)$ and $51.3(1970)$ end for Hastines, $76.00(19,66)$ and $65.98(1970)$. 
However, in the case of Cumbernauld, this is not so since the audnistrative unit covers a much greater area then the new toxn. In order to see bow large en influence this hed on the ultimate MSI value for Cumbernauld, data was fed into the derived regression model for TC7ð, which was based on infornation provided by Cumbermauld Development Corporation end therefore related solely to the new town area. The resultant MSI value for this new town area was 85.80 . Consequently although the results for Cumbernauld vill continue to be presented, it must be ranembered that the MSI values relate to the adninistrative unit of Cumbernauld D.C. snd not solely the new town area. For this reason connents on the Cumbernauld results will be very linited.

The results for the dependent varieble TAT $\varnothing$ are almost identical to those for TC7\%, end therefore will not be discussed in any detall. The only significant point to be made is that except for Stevenage and Glenrothes, the MSI values relating to this varieble are lower than those for TC7 $\phi$, thus suggesting that these new tom areas have more casualties per accident then is the national norn.

\section{(1i) TOTAL FATAT END SERIOUS CASUALTIFS 1070}

The implications of this veriable are much more difficult to discem than the previous variebles because the response varies from one to enother new toim. Glenrothes and Harlow exhibit high MSI values indicating that the accidents in these areas are more serious than would normally be expected. However, since both of these areas exhibit below average MSI values for TC7 $\varnothing$ it would 
seen that whilst the overall level of road casual ties is reduced the remaining accidents (and therefore casualties) are much more serious. This is en interesting observation from a cost-benefit point of view since it must be doubtful whether the advantages gained from a reduction in total casualties outweighs the disadventages derived from the high number of serious casualties ane to the high financial (as well as human) costs associated with such accidents.

The remalning new toms meanwhile appear to exhibit low MSI values for this varieble, and therefore it cen be said that these areas have been more successful in reducing the number of serious accidents rather then totel accidents. Wi thout further detailed study the reason for this reduction cannot be assertained but it must be presumed that the cause is two-fold. In the first instence the removal of through traffic and high speed traffic to the peripheral areas must have affected this casualty level. Secondly, it must also be presumed that the level of fatal and serious casualties has been affected by the rosd system within the urben area itself.

\section{(iii) TOTAL PEDPSTPIEN CASUAITIES 1970}

If the urben environment of the new towns is to achieve its desired ein of a safe environment for those poople living within that urben area then one of the weys in which this safety level can be expressed is through the number of pedestrien casualties within these arees. In respect of this variable the response of the new town areas is very good with all six exhibiting HSI values of less than 100.0. However, what is perheps of Ereater interest is the 
fact that the three newer new torns, heve nuch lower MSI values then the other three older new torms. In fact the response of these older areas is not as good as would have been hoped with values vell into the 90.0 lepel. Tro conclusions can be made here, either of wich could prove to be valid. In the first instence, it could be concluded that the second generation new torns heve developed to:n plens which offer much higher levels of sefety to their populations than do the earlier new torns. Alternatively It could also be argued that the higher levels in the earlier new to:ms is merely a function of time. That is, like the observation made in respect of TC7\%, it could be that as these new torn developments age, their safety responses tend towards the national norm. The only way to solve this dilenma is through more tenporal enalysis of this variable.

\section{(iv) TOTAT, CHILD PEDESTRIAN CASUALTIES 1970}

In the context of safety for the inhabitents of an urban area, this variable is just as important as the previous variable for total pedestrien casualties. However, whilst the response for TPED $7 \not$ was good, the response to this veriable varied from aree to area. Three of the new terns had values exceeding 100.0 (Cumberauld, E. Xilbride and Harlor) whilst the remeinder had very good response rates, with Stevenage having the highest MSI value of 85.42 . Of the three aress with poor response rates Cunbernauld can be dismissed for the reasons forwarded earlier, whilst there would seem no logical reuson for the other two areas. For whilst the MSI value for TPED7申 for Harlow was near 100.0, it 
did remain below the expected value. Thus it can be stated that in both these areas the facilities for child safety and perhaps the urben structure as a whole is unsatisfectory from the point of this type of casualty. Obviously therefore there is some need to investigate this problem in these areas and perhaps there is some added need for child rosd safety education in order to try end reinedy the situation.

\section{(v) TOTAL ACCIDFITS PFR 103 POPULLTION 1970}

It was argued during the analysis of the mejor regression models that if the size and interaction variables accounted for such $a$ high proportion of the variation in the absolute dependent voriobles, then this variable which holds the size component constent is a true indicator of the possible effect of urban structure. In these ne: toin areas one would expect therefore that if these areas influence the level of roed accident casualties at all, then there would be some low MSI values associated with this variable. From the table it can be seen hovever, that whilst the majority of HSI values are below the expected level, the overall deviations are only small, with the lowest value being 73.82 for East Kilbride. Sinilarly when these results are compared to those for the related veriable TCPP7, it can be seen that these results are even worse, al though it must be pointed out that the above average values for Glenrothes and Harlon, are consistent with the high casualty/ accident rates noted prevlously for these areas. However, the conclusion must remain that the response of these new toin areas to these tho variebles is nowhere near as good as vould have been expected or desired. 


\section{(vi) MOTAL CASULLTIES PER $10^{6}$ VEHICLE MILES 1970}

The final variables to be examined in relation to the new tow areas are the two exposure variebles TCVM7 $\varnothing$ and TAVM $\not \varnothing$. However, since the results for these two variables are so similar, connent will be restricted to the forner. hs can be seen from the tabled results the response to these variables is good except in the case of Glenrothes, with values as 10 w as 66.03 for Hemel Hempstead and 67.81 for East Kilbride. Whilst these results could be indicating, therefore, that the poor results for the majority of dependent variables in these new to:m areas are due to the iack of exposure in the variables themselves, it must once again be noted that other areas continue to procuce response rates which ere as good, if not better than those obtuincd for the rew touns. Thus Dindec, Chesterfield end Stretford have values of 56.91, 57.41 and 56.07-respectively. Consecuently it would seen to be rether naive to try end explein the relatively poor results for the new to:n areas on this fact alone. Sinilarly since these poor results are fairly constent for wichever varieble is chosen, it rould seem to be reasoneble to assume thet these results are a true reflection of the actuel performance of these ares.

\subsection{ASSFCCPRT OF TEE GFOTH EATES FOP TEE HET TD:N AFFAS 1966 - 1070}

Although it is difficult to arrive ut eny speciric conclusions concerning the functioning of these new torns through these growth rates, it has beer mentioned in the previous section the there vould seem to be a movencht towerds the nationel zivergge in these areas according to time from inception, and with little regord to 
the averege netional growth rates. For this resson it was deemed useful to look at these growth rates and compere then with other ereas. However, it must be rememberec thet in the case of the more recont new torn areas this cen only be a qualitetive assessment beceuse of the fact that they are etill groving and are therefore not a completed unit.

The absolute growth rates end the stenciarcised growth rates for these arees are shom in Table (10.3.1). From this it cun be secn thet four of the sire areas heve high positive ebsolute grorth rates, with the remaining tro having only small negative ebsclute grouth rates, wich incidentelly ere both less than their respective group meen value growth rate. Consecuently when one observes the stendardised growth rates it is also secn that ell the arees have a positive deviation value, four of which are greater then plus one stridard deviation.

The implicetions of these results are ouite importent in tems of essessing the success of the nev tom areas since several of the hypotheses put forvard in the previous section appear to be totally vindicetec. In the first instence it is cbvious that during a period when the overe. Il national situation had averkge negative growth rates, these new tom areas continued, on the whole, to have positive grovth rates. If the new town areas were to be as successful $\varepsilon s$ was hoped, it is doubtful if this rould be the cese.

Seconcly, end perhaps more importent these above averate grouth rates r.culd seem to verify the postulate put forvard that these new 


\begin{tabular}{|l|c|c|c|}
\hline $\begin{array}{l}\text { NEW TCWN } \\
\text { AREA }\end{array}$ & $\begin{array}{c}\text { GROhTH RATE } \\
\text { 1966-1970 (10 })\end{array}$ & $\begin{array}{c}\text { MEAN VALUE FOR } \\
\text { ASSOCIATED GROUP (SIZE) }\end{array}$ & $\begin{array}{c}\text { STANDARDISED } \\
\text { GROWTH RATE }\end{array}$ \\
\hline Cumbernauld & +73.77 & -3.436 & 3.011 \\
East Kilbride +25.00 & -7.854 & 1.844 \\
Glenrothes & +36.56 & -3.436 & 1.560 \\
Harlow & +17.99 & -7.854 & 1.453 \\
Hemel Hemp- & -3.54 & -7.854 & 0.242 \\
stead & & & \\
Stevenage & -6.92 & & \\
\hline
\end{tabular}

TABLE 10.3.1 GROWTH RATES FOR THE NEW TOWN AREAS (1966-1970) 
tokn erees, after en eerly successful pcriod as regards road safety, appear to be gracually moving towards the national norm and losing the adventeges that they originally enjoyed. Even teking in to account the fact that these areas are still growing in some instences, this must still remain true oue to the size of the deviations from the meen growth rates, wich cbviously take this fact into account.

\section{TO'NI}

30.1 SUIWEFI OF TFE NEW/PESPCNSE FATFS

It was argued in the introduction to this chapter, that if it wes possible to influence the level of rosd eccident casualties, this must be indicetec. In the new tom aress. However, the results put formerd in this chepter do not seen to support this point of $\nabla 1$ ur, end in severel instences it has been shoin that the response of the new towns is sometimes vorse than the national roral. As a whole these results seen to lead to five conclusions as regaras the new torn areas, and these ere sumnerised below.

1) Allowing for 2 certein degree of variction, the new towns seem in general to exhibit response rates which are belor the expected level. However, the size of this deviation in respect to the national norm, end elso other similer sized urban arees, is not $\varepsilon$ s greet $\varepsilon s$ would be expected for these areas, considering the reasens for their incepticn.

2) The nev toin arees co seem to have created en environment which results in ccnsiderable sevings in the number of pedestrien cesualties, end therefore from the point of view of the inhabitants of these areas they are justified develocments. 
3) The rew tom areas eppear to have their best response rates during the early years of their developnent. However, 8.fter $\varepsilon$ certain period of time, it would $\varepsilon \mathrm{cen}$ that these advantages E.re eroded and as a result, of high growth rates, tend towgrds the national "norn."

4) The level of these growth rates is both independent of the national everege growth rate as well as the acturl time period.

5) The response retes of these new tokn arees do not support the argument that the level of road accident casualties cen be controlled by comprebensive plenning and modifications of the urben structure, but instead seem to indicate that the road accident system is a homaeostatic system which meinteins a constent opereting environment in the face of external fluctuations. That is it is a system which resists eny alteration in environmental conditions end exhibits a gradual return to equilibrium or steady-stete behaviour after such an alteration. Consecuently, a certein omount of coubt must be placed upon the justification of new town developnent solely from a roed safety point of view. 
ChaDter 11. CONCLOSTONS END PCSSIBIIITIES FOP FUTUFF FFSEAFCH

\subsection{CONCLUSTONS}

It has been continually emphesised within this report that the major need within road accident enalysis is the creaticn and applicetion of a more cuantitative, scientific approach in order to essess the achievements and progress of road safety proposals. Accoriingly, therefore this research has tried to put forward such \& methodologicel epproach which enebles the resesrcher to stucy verietions in the volume of road accident casualties, both in e spatial and temporal dimension.

Thilst the development end epplication of such en epproach has been the mejor purpose of this research, enalysis of the data, and the urban structure sub-system, has olso enabled certain conclusions to be dram pertaining to these sections of the rod accident problem. That is, it was possible to study the level of influence these structurel variebles exerted upon the observed volune of road accidents in any cne urban area. In most instences these conclusions have been discussed in the relevent sections of the text of this report, but in order to echieve some overall assessment, it becomes necessery to drain ell these conclusions together, end thence corment upon then es a whole.

Pertieps the mejor conclusion which cen be drim from the results of this research is that in most instences, it yould seen that the mejor determinants of the volume of roed accidents observed Within any urbon area, are those factors which are related to the 
human end psychological sub-systems. Put the opposite way arcund, one cen therefore state that the impact of the structural sub-system upon the level of road accidents vould seem to be marginel in the shortterm end almost negligible in the long term. This sub-system would appear however, to be instrumental in determining the way in which road accident casulties are allocated between the varicus types of accidents, and persons (users) injured.

The implications of this conclusion are quite importent as regards the total approech to road safety. In many weys it also sems to vindicate the rork and suggestions of Cohen (1968), by implying that the majcr road accident problems ere psychological, rather then engineering, in nature. Similarly it would seem that structurel chenges are only successfui whilst they renain "unfemilie.r" with, as the saying goes, feniliarity breeding contempt. That is, whilst a new road or junction, or urbin structure mey in the short term lead to a reduction in road accidents, in the long term with en increased understending of the new structure, the level of accidente mey increase once more, simply as a humen response to the improved, safer, environment. Therefore in th:e phraseology of Cohen, it would seem that in order to understend the road accident problem any further, one should be trying to understend the psychologicel factors inherent within the "bio-robot"model with perhaps slightly less emphasis on the various enginecring factors.

The results of the various regrassion anclyses besicies emphesising this humen dilemm, also pin-pointed tho other major factors, which have a significant impact upon the level of roed accident cesuelties. Perheps the more importent of these two factors is the 
importence of the police activity variables. The results obtained for these variables positively show the significsnce of police action in mainteining or reducing road accident levels. Al though it is difficult to indicate eny single ceusel chain, it must be postuleted thet the importence of police action is most useful as a simple deterrent to conscious disobedience of the various road safety (traffic) laws, and as such, should be wldely encourged by ell sectors of the community.

The second major conclusion to be drein from these regression models, which is strongly supported by the trend surfece enelyses, is the unquestionable importence of the degree of through treffic variable. In fact this latter enelysis shows how in most instinces, the inportence of this variabla is under-emphesised by the regression models. This can be shom by the fact that all the trend surfaces derived from the relevent regression residuals follow cuite remarkably the mejor road network systems of this country, whilst also indicating the further iustification for better efst-west trinsport communicetions. Similerly with reference to the time series enclysis, it rould also seen that the importance of these improvenents will be most noticeable in relction to the smeller "en route" towns which heve not yet been provided uf th adecuate facilities to deal with the present and future volumes of external traffic. Until such improvements are provided in these ares, these smaller toins nould seen to be about to increase their road accident problem at a proportionally faster rate than most of the larger urben areas, where It is possibly reasonable to postale te that some ecuilibrium, saturetion level, is slowly being obtained. 
A further conclusion to be drem from this time series analysis, especially with reference to the new tom areas, is that from the date and results obtained in this research, it would seem reasonable to postulate that the road eccident system, as regards the structural. variables, is a homaeostetic system which is always trying to revert back to its equilibrium or steady state beheviour, following some structurel fluctuations. If this is true then it would seem that sone major change is necessary, probably in the psychological atti tude of individuals, before any permanent chenge in the road accident pattern cen be achieved. Consecuently it nould seem that where any piece-meal improvements are operative, the benefits which hove been ochieved are, or will be of very marginal value. In respect of the new tows therefore, one should not look for lerge improvements in the level of road accidents, and raad safety in general. Similarly al though roed safety is only one aspect of the aims of new tow developments, from this point of view one must elso plece several reservations upon the actial success rates of these urben arees, and perheps also further financial justification should be encourcged before any future nev town areas are advocated.

These then are the major conclusions to be drem from this research al though several other importent results are argued within the relevent sections of the main text of this renort. However, before terminating this report some coment must briefly be made concerring the possible direction of future reserch. 


\subsection{FUTUFF, FESFAFCI DEV ETOPHENTS}

Because of the very nature of this research, as a basic introductory study, the lincs of possible future research must be regarded as being of the utrost importance. As a result tuo possible general lines of progress are suggested here.

The results of this research have continually indicated the importence of the humen, psychologicel sub-systers and the need for a greater uncerstending of the humen being in respect to the motor vehicle. If systems enalysis is therefore ultimately to be applied succesfully to roed accident analysis, it is obviously essential to open this sub-system end study the relationships between the various elements found within that sub-system. That is, one of the greatest reeds at the present time is a better understending of the humen component in rosd accident causation.

The second major trend for future research, ond perhaps the more importent as regerds this present research, is the extension of the overview epproach, to individual units. That is, so far it has only been possible to combine, or group urben areas according to their eggregete responses, end their cverell veriation. What is now needed is the individual study, in some depth, of the verious indivicluel urben areas which are shom to be representative of a certein group of urben aress. By this meens the subjective epproach norrally used in selecting arecs for deteiled study, cen now be repleced by a more objective epprosch based on previous enelysis end computetion. However, it must once gefin be emphasised 
that before such enalysis cen teke plece, perhaps it would be useful to epply more sophisticated groupirg technicues than those used in this analysis, probebly once again making use of multidimensional stetisticnl techniciues.

Working along the same lines of thought, the results of the trend surface analyses also indicate urban areas (and in some cases regions) which shov abnomel responses to specific sections of the road accident problem. Therefore once agein it shoulc be possible to take these individusl areas and subject them to intense scrutiny as regerds these specific problems. This should be cione in order to discover the cause of these ancmilies, and therefore perhaps understend rosd accident inter-relctionships more fully.

\section{A final possibility for future research is the extension of} the study of the various noted reletionships over time. This should be done by the extensive monitoring of accidents either at the locel or national level, in order to obtein suiteble temporel data which con be enalysed with greater confidence dus to the smaller levels of error. The results of such vork, extended over a longer period of time then used in this research, would give volueble information as regerds the changing influence of various voriables, and therefore more informetion es to the type of $n$ nture of the roed rccident systrm.

In generel therefore the suggestions nigde here os regards future reserch include the further colloction of date, end the study of element inter-relctionships, in order to understand the road accident probler somewht bettor, whilst at the scme time enabling the structuring of the road accident systen. As has been reitersted on severil 
occasions in this report, until such a situation has been reached, no degree of prediction or evaluetion con be accepted with any degree of certeinty, and road accident resecrch must remain vithin its present constrining limitations of piece-meal, unscientific \&dvencesent. 
ABERCROMBIF SIP P., (1933) Tovn and Country Plenning. B.CKOFF R.L., S.K. GUPTA End J.S. MINAS (1962) Scientific method: optimising applied research dcalsions. New York.

MDERSON R.L. and T.A. BANCPOFT (1952) Statistical Theory in Reseerch. New York: HoGran-Hill. ANDEESON B.J., S. EFLANDER and J. CUSTAVSSON (1065) Appendiy to the applicetion of temporery rord speed limits in sweden 1961-62. Ministry of Communications, Stockholm.

ASHBY W.F. (1953) An introduction to cybernetics (biley Science Editions) New York.

ASHBY Y.R. (19.56)

BAMACK J.E. (19,62)

BAFTLETT M.C. (1950)

BEPFY B.J.L. (19,58)

BICKAOPE $(1063)$

BLAIR D.T. end T.H. ELISS (1967) The measurement of shape in geogrephy: An oppraisal of methods and tecbnicues. Bulletin of quentitetive date for geogrephers No. 11. Dept. of Geogriphy, Nottingram University. 
BOHLIN N.I. (1967)

BORCHERT J.P. (1961)

BUCHANAI C. (1965)

EUIGE K. (1966)

CARSDLL J.P. (1953)

CHILDE V.G. (1936)

CHOFLEY R.J. end P. HEGGETT (1965) Trend-surface mapping in geographical research. Trens. Inst. Br. Geogr. 37, 47-67.

CHUPCERAN C.\%. (1961) Prediction and optimel decision. New Jersey. of Relationships between fccidents and the Geonetric and Traffic Charecteristics of the Inter-stete System. Bureau of Public Poads, U.S. Pept. of Trensportetion, Washington D.C.

CLAFK P.J. (1956) Grouping in Spatiel Distributions, Science Vol. 123, $73-374$.

CLIFF A.D. and ORD J.K. (1970) Spatial autocorrelation: A reviev of existing and new measures with applicstions. Econ. Googr. 46, $269-292$. 
COHEN and PFFSTON (1968) fccident ceusation and prevention. COLFOl T. end BUXBAOH R.C. (1968) Hotor Vehicle Inspection end Motor Vehicle fccident Mortelity. Im. J. Public Health $58.1090-1099$.

COVFRDALE and COLPITTS (1967) Report on en Evaluation of Motor Vehicle Inspection, New York. CUMBEFNAULD DEVELOPMENT COFPOBATION (1967) Report on Foed sccicients. CUEFI L. (1966) A Note on Spatial Association. The Professional Geogrepher. Vol. 18. 97 - 99.

DACFY H.F. (1967) Description of line patterns. Northwestern University, Studies in Geography 1इ. $277-287$. DAVIES 0.L. (1963) (Ed.) The Design end Analysis of Industriel Experiments. Loncon.

DAYSON R.F.F. (1971) Current Costs of Ford Accicents in G.E. Foad Research Leb. Report 396. DEPAFTHENT OF THE EIVIFONIENT (1972) Foed Accidents 1970. H.M.S.O. DHFYMES P.J. (1970) Econonetrics: Stetisticel Founditions and fpplications. Herper \& Fow.

DICEIMSCN F.E. (1947) City, region ard regionalism: a geogrephical contribution to human ecology. Ioncion. IRAPFR N.F. and EITH H. (1966) Apriled Fegression Analysis. New York. DUWCAN O.D. et el. (1961) Stetistical Geogrephy: Problems in fnalyzing Areal Dete. New York.

IUTN J.R. (1970) Treffic Census Results for 1970 . Foad Fesearch Lab. Feport 428.

EFLENDER S. (1971)

A review of some statistical models used in eutomobile insurince and in rosd sccident studies. Accident Analysis end Prevention $\quad \vdots \quad 45-75$. 
EPLANDER S.; GUSTAVSSON J, and LAEUSSON E. (1968) Some investigations on the relationship between road accidents and estimeted traffic. Accid. Anal ie Prev. 1. $17-64$.

FHIFBAIN K.I. end FOBINSON G. (1967) Toms end Trend-Surfaces in Gippslend, Victoriz. Australien Geographical Studies $5.125-134$.

GENSLER H.C. (1966)

GORDON J.E. (1949)

GOULD P.P. (1966)

HAGGETT P. $(19,55)$

HAFILN H.H. (1960)

HARFIS P. (1971)

HAFNEY D. (1959)

HENDFICKSCN K.E. erd hHITE P.0. (1964) Pronax: a quick metrod for

HEREMIANI P.G. (1968)

HOME OFFICE (1971) rotation to oblicque simple structure. Br. Jour. Statist. Psychol. 17. 65-70.

Power stecring cars in accioients. ACIF Eulletin No. 9. Comell Aero Líb., Euffelo, N.Y.

The Epideniology of fccidents. fmer. Jour. of Pub. Heal th 39. $504-515$. On Nentel Maps. Iiscussion Peper No. S. Michigen Inter-University Comaunity of Mathematical Geogrephers. Locetionel Inalysis in Hugen Geography, New York. Modern Factor Enalysis, Chicago. Ford Acciònt Tabulation Lengurge. (Fattle) Foad Reserrch Lab. Report 337. Explenation in Geogrephy, London. Forecasts of Vehtele Omersipip in Counties and County Boroughs in Great Britain. Focd Research Lab. Report 200 . Criminal Stats. England \& Wales (Cind. 5020) 
HO:AE OFFTCE (1971 - 72)

HODGE G. (1965)

HOSST P. (1941)

JEFFEPS J.N.R. (1957)

JOFG MISEN N.0. (1969)
Offences Felating to Hotor Vehicles. (H.C. 451).

The Prediction of Trade Centre Viability in the Grest Plains. Papers, The Regional

Science Association 15. $87-115$.

Prediction of Personal Adjustment.

Social Science Research Council Bulletin 43. Two Case Studies in the Applicrtion of Principal Component fnelysis. Applied Statistics, 16. $225-236$.

A ilodel for Forecasting Traffic Accidents. Paper presented to the O.C.D. .. Symposium on the use of Statistical Methods in tire Analysis of Foad Accidents. (F.R.I.Cronthome) Report 10.

KAISER H.F. and DICKIHN K.\%.(1959) Analy tical Determination of Common Factors - unpublished manuscript.

KATZ A. (1971) To:vards a Methodology of Traffic Sefety Messurement and Progren Evalurtion. iccid. Anal. Se Prev. 3. $15-43$.

KENDALL M.G. (1957)

A Course in Multivariate finalysis.

KING L.J. (1969)

Statistical Analysis in Geography.

KLIR J. and VAL CH $_{1}$. (1967) Cybemetic Modelling, London. KFISIBEIN H.C. $(1953)$

Confidence Intervals on Low Order Polynomial

Trend Surfaces. Jour. of Geo-physical Research $68.5869-78$.

KPUNBBEIN Y.C. and GRAYBILT F.A. (1965) An Introduction to Statisticel Models in Geoloz, New York. 
LLABE C.G. (1957) Statistical Methods and Formulae, London.

LAMLES D.N. and HAXNELL A.E. (1971) Factor Analysis as a Statistical Method (2ind Ed.) London.

IIKERT R. (1950)

The Dual Function of Statistics. Jour. fmer. Statist. Assoc. $55.1-7$.

LOVIFY I.S. (1365)

A short course in nodel design. J. Lmer. Inst. Plenners 77. No. $2158-165$.

MACKAY G.14. et al. (1959) Cause end effects of Traffic Accidents. Dept. of Transp. End Environmental Plenning. University of Bimingham.

MASSEY I.F. (19,65) Principal Components Regression in Exploratory Statistical Pesearch. J. Lmer. Stailist. Assoc. $50 \cdot 234-250$

MCCARIY H.H., HOOK J.C. S: KNOS D.S. (1956) The Heasurement of Association in Industrial Geography. Dept. of Geosrsphy, University of Iovia.

MCOUTCHEDN R.H. and SHEPIAN H.H. (1959) The Influence of Periodic Motor Vehicle Inspection on Mechenical Condition. J. Safety Research 1. $184-192$ HCFAFIIND R.A. (1963) A critigue of accident research. Innals of the New York Acrdery of Sciences 107, hrt. 2. $686-695$.

MOGLADE F.S. end ABERCFDIBIE S.A. (1955) Accident classification for research Durposes. Traff. Quarterly $19(4)$

HILT, J.S. (1874) Systen of Logic. IINTSTEI OF TFANSPOET (1957) Hightray Statistics, H.I1.S.O. MTNISTEY OF TENISPOFI (1967) Ford Safety - A Fresh Approach. H.M.S.O. 
HOKGAN J.N. (1957)

Who uses seat belts? Behavioural

Sciences 12. $463-465$.

EUNT P.i. and WEBSTFR F.V. (1968) A study of rood triffic crossing the cordons round the central areas of elght torns with populations ranging froin 13,000 to 8 million. Poad Research Lab. Report 209.

NADER R. (1965) "Unsafe at eny speed."

ORGANISATION FOR ECONO!IICS CO-OPERATION AND DEVETOPAEIT (1969) SyMEOSIUM on the use of statistical methods in the enalysis of road accidents. Paris.

PERAITO A. (1970) Conceptualisstion and use of road safety and traffic engineering foraulas. Traff. quarterly $25 .(3) 429-446$.

PFUNDT K. (1959) Three difficulties in the comparison of accident rates. Accid. Inal. \& Prev. 1. $253-260$.

POOLE M.A. and O'FAPRELI P.N. (1970) The assumptions of the linen regression model. Trans. Instit. of Er. Geogr. No. 52.

RAPAPOET A. (1967) Research on the elcoholic driver: A critique in Selzer, Gikes and Huellse. The Prevention of Highway Injury. Univ. of Michigen.

REGISTRAR GENEFLL'S OFIICE (1951) Census Returns. REGISTRLR GE'ERHL'S OFFICE (1956) Census Returns REGISTPAR GEVIEFAL'S OFFICE (1971) Consus Returns. FECHT J.C. (1966) Multiple Fegression of the Effects of Safety Activities on the Traffic Acciont Pettem. National Safety Council, Chicreo 
REMPLER S.A. ind BLOMGUIST N. (19,56) Index I. JHmförelse mellan motorfordonsbestend, trafikintensitet och polis sapporterade vHg trafikolyckor; ars - och menadsvis inom hola landet utan uppdelning pa olika olycirstjper. Stocirholm REIPLER S. A. end WESTEPGREN K. (1956) Utrecklingen av polisrapporterade Vugtrafikolyckor 1950 - 1964. Stati sti cxa forsiningsg ruppen. Stockholm.

RIDLEY T.M. end TURNER E.D. (1958) Value of Traffic Heragenent: A reply. J. Trensp. Economics end Policy II $267-583$. ROBERTSON J.S.; RYAN G.A. Ind MACLEAN A.J. (1956) Traffic Accidents in Adelaide, South Australia. A.R.R.B. Special Report No. I.

ROBINSON A.H. (1956)

The Necessity of Welghting Velues in Correlation of Areal Data. Annals Assoc. of Amer. Geogr. $46.233-236$.

P.OBINSON A.H., LINDSEPG J.B., end BRTNKMAN L.T. (1961) A Correlation and Fegression Anelysis Applied to Fural Farm Population Densities in the Grest Plains. Annals Assoc. of Amer. Geogr. 51. $211-221$.

PDBSON B.T. (197Z)

Urban Growth. In Approach. London.

RiDSEN, R. (1057) Optimality Principles in Biology. Loncion.

SKILIING H. (1954) An operational view. Americen Scientist, 52. $388 \mathrm{~A}-396 \mathrm{~A}$.

SMAISES A.E. (1047) The analysis and delimitetion of urben fields. Geography 32. 151 - 161. 
SIEED R.J. (1949)

SIEED R.J. (1972)
Some statisticel aspects of road sefety research. J. Royal Statist. Soc. Series A. (general) Pert 1. The usefulness of formulge in traffic encineering and rosd sefety. Accid. Anel. and Prov. 4. $303-112$.

SMEED R.J. and JFFFCOAT G.0.(1969) Internrtional Comperison of Poad Accident statistics. Peper presented to the O.C.D.E. Symposium on the use of statisticel methods in the enalysis of road accidents (R.R.I. Crowtiome). Report No. 34.

SIIEED R.J. and JEFTCOATE G.0. (1970) Effects of chenges in motorisation in various countries on the number of road fatelities. Traff. Fngng. Control 12. (Z) $150-151$

STONE H. I.D. (1914) The principals of urben traffic.

STOTT P.F. (1968) Report from London. Traff. Engng. \& Control 9 $592-595$

SUCHALN E.A. (1961)

A conceptional enelissis of the accident phenomenon. Social Problens 8, 24I - 253.

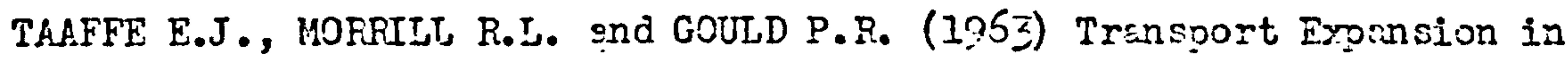
Underdeveloped Countries: A Comparative Analycis. Geographical Review 5z, 503-529. TA'ABUFPI T.N. (1969) Wrong-Wey Driving Accidents sre Reduced. Highway Res. Rec. No. ?2. Highway Res. Board, Washington D.C. 
TANNER J.C. (1958)

THOMIS E.N. (I950)
A problen in the combination of accident frecuencies. Blonetrike 45. $331-342$. Maps of Residuals from Regressions: Their Cheracteristics and uses in Geogrephic Reserrch. Monograph No. 2, Dept. of Geogrephy, Unit. of Iowr.

THOMAS E.N., and ANDERSON D.I. (1965) Addi tionel coments on weighting values in correletion enelysis of areel data. Annal. Assoc. of Amer. Geogrephers 55, $492-505$

THOMPSON G.H. (1951)

THDMSON, J.M. (1968)

THUPSTONE L.L. (1947)

TISDALE H. (1942)

TOBLER W.R. (1966)

TEIPP H.A. (1942)

WEBER H. (1953)

XHITLEN E.H.T. (1959)
The Factoriol Analysis of Humen Ability, London.

The value of traffic managenent. Jour. Transp. Econ. End Policy II, 3- 22. Multiple Factor Analysis, Chicago. The process of urbanisation. Social Forces $>0$, ZII - ZI16.

Nunerical Map Generalisetion and Notes on the Analysis of Goorrephicel Distributions. Discussion Paper No. 3. Michigan Interstete University Community of Mathematic: I Geogrsphers Tom Planning and Fond Traffic. The Cito. Nev York. Composition trends in a grenite: modal variation and ghost stratigrephy in pert of the Donegal granite Eire. J. Geophys. Res. 64. $8 z 5-849$. 
WOHL M. (1969)

WONG S.T. (1953)
Putting the enalysis. and evaluation of traffic safety measures into perspective. Accid. Anal. end Prev. 1, 77 - 101. 1. multi-variate statistical model for predicting mean annual flood in New Englend. Annals, Assoc. of hmer. Geogr.5z. 298 - 311. 
APPENDIX 1

THE TOWN CLASSIFICATION INDEX 
Appendix 1. THE TOSN CLASSIFICATTON INDEX

The derivation of the town classification index has already been explained (prge 113), and therefore the only important point to reiterate at this point is that the index is a compound variable consisting of the product of Haggett's shape index and Clark's network structure. Consecuently this compound index enables one to observe the type of network system present within our existing urban areas. In order to extend this idea the T.C.I. variable was plotted against Haggett's shape index. (FIg. 12.1.1.).

As can be seen from this diagram the Haggett shape index can be divided ints three regions:-

i) $0.20-0.40$ which can be said to tend towards linearlty,

2) $0.40-0.83$ random.

3) $0.83-1.00$ which can be said to tend towards circularity.

Similarly since Clark's work shows that the number of nearest nelghbour points cen indicate the kind of netrork structure, it also becomes possible to divide each of the afore-mentioned three groups (shape) into five further groups, according to the T.C.I. values. The limiting values for each of the network grids were:-
1) Hanhattan $\geqslant 0.75$
2) Rendom $\quad 0.55$
3) Redial $\leqslant 0.45$

and therefore the calculated T.C.I. Ilmits for the shape group $0.20-0.40$ cen be given as:-
1) Manhatten $0.05-0.1050$
2) Random $0.0660-0.1386$
3) Padisl $0.1100-0.2310$ 


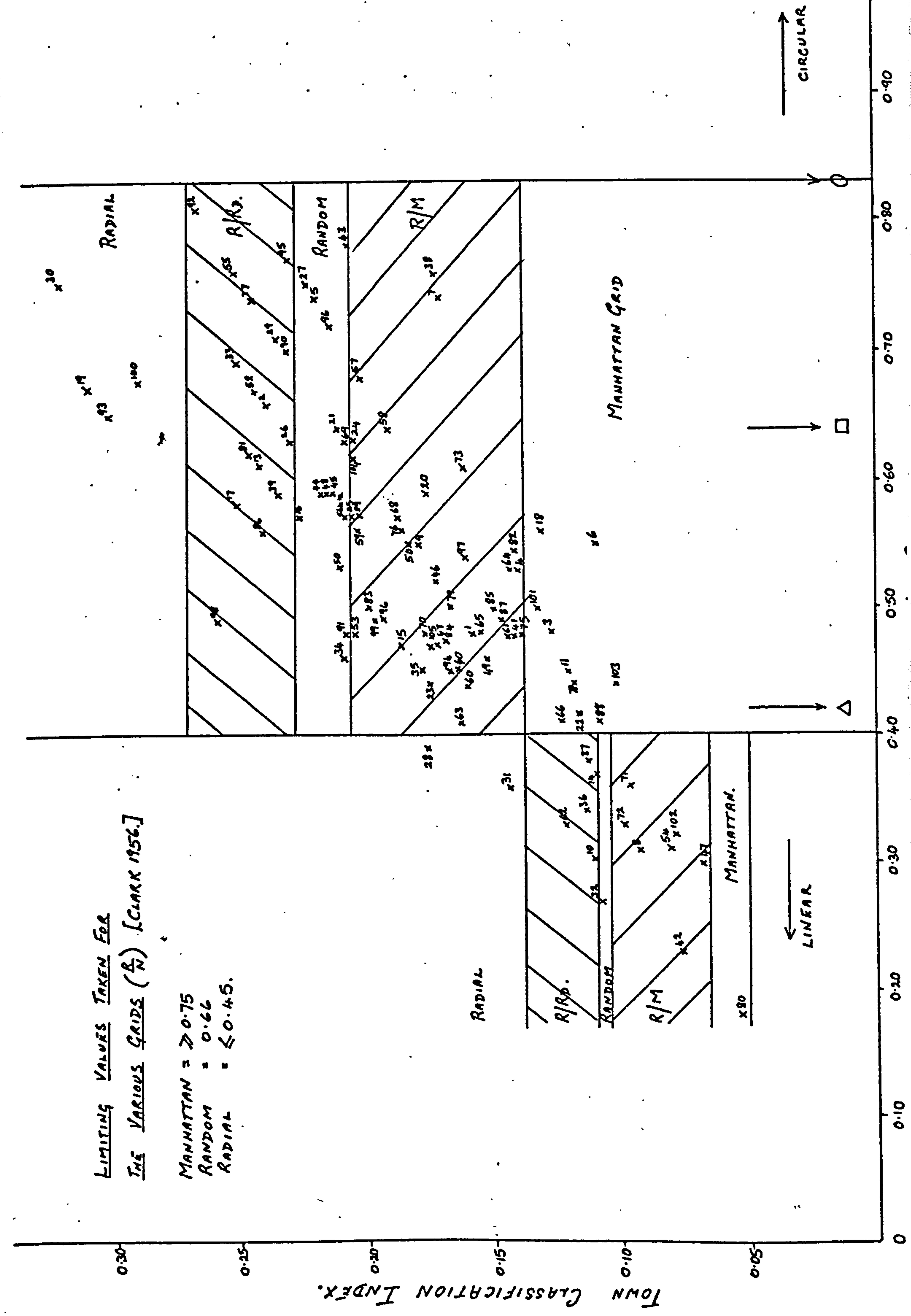


Correspondingly, when the towns are plotted upon this graph framework one is able to study these areas according to both their shape and kind of netirork structure (Fig. 12.1.1.).

The most obvious feature of this graph plot is the seeningly linear relationshlp, which is of little surprise, since it simply means that the shape of the urban area becomes more circular there is a positive tendency to develop a radial network system. However what is of more interest is the manner in which the netrork systems vary within each shape group. Thus within the lower shape group Southend has a distinct Menhattan grid whilst Manchester would seem to have a strong tendency towards a radial network.

Wh thin the midale shape range group, there is once again a wide divergence. Thus Crewe, Canterbury and York all hare strong radial netrork systems willst Swansea, Birmingham and Cambridge would seen to have Manhattan grid systems.

Although this line of research is only marginal to the project reported here, it is suggested that as a descriptive device this index and method of representation could perhaps repay further investigation. 
APPENDIX 2

SIGNIFICENT TREND SURFACE MAPS 


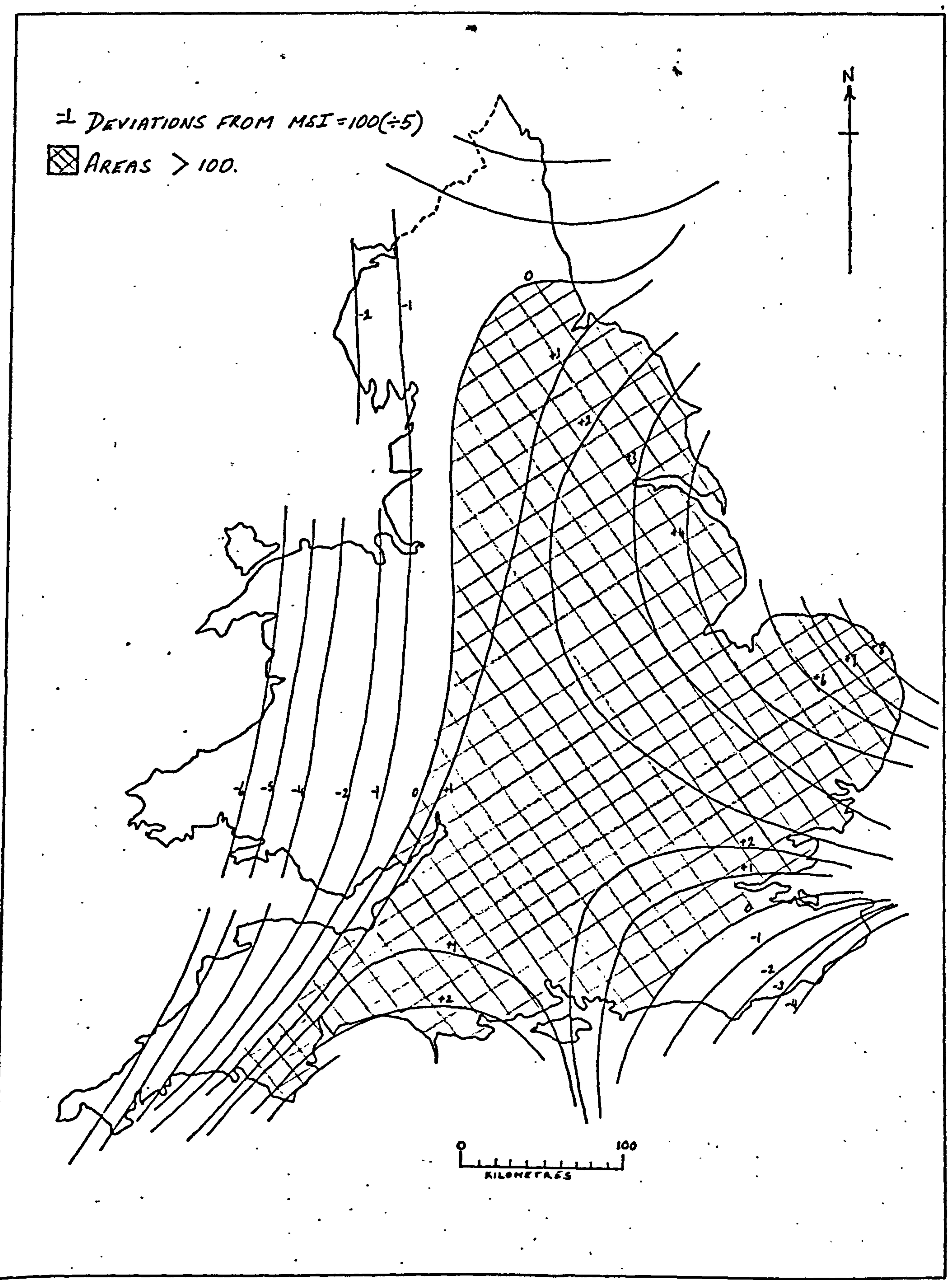

CUBIC SURFACE FOR TAT $\phi(\alpha=>75 \%)$. 
$=1$ DEVIATIONS FROM MSI $=100(\div 5)$

$\otimes_{A R E A}>100$.

. 
IL DEVIATIONS FROM MSI $=100(\div 5)$

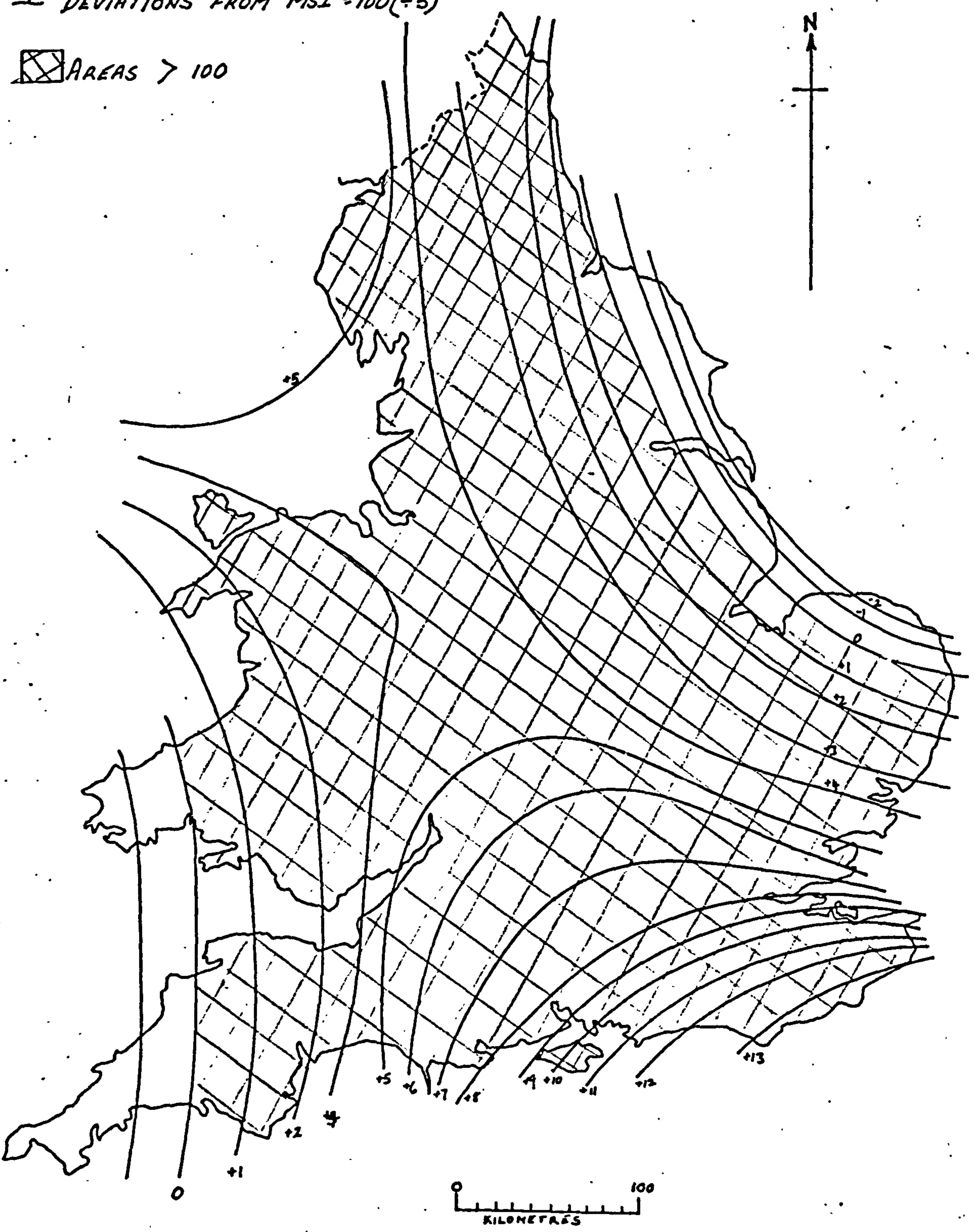

QuADRATIC SURFACE FOR TCPEDT $\phi(\alpha=>75 \%)$. 


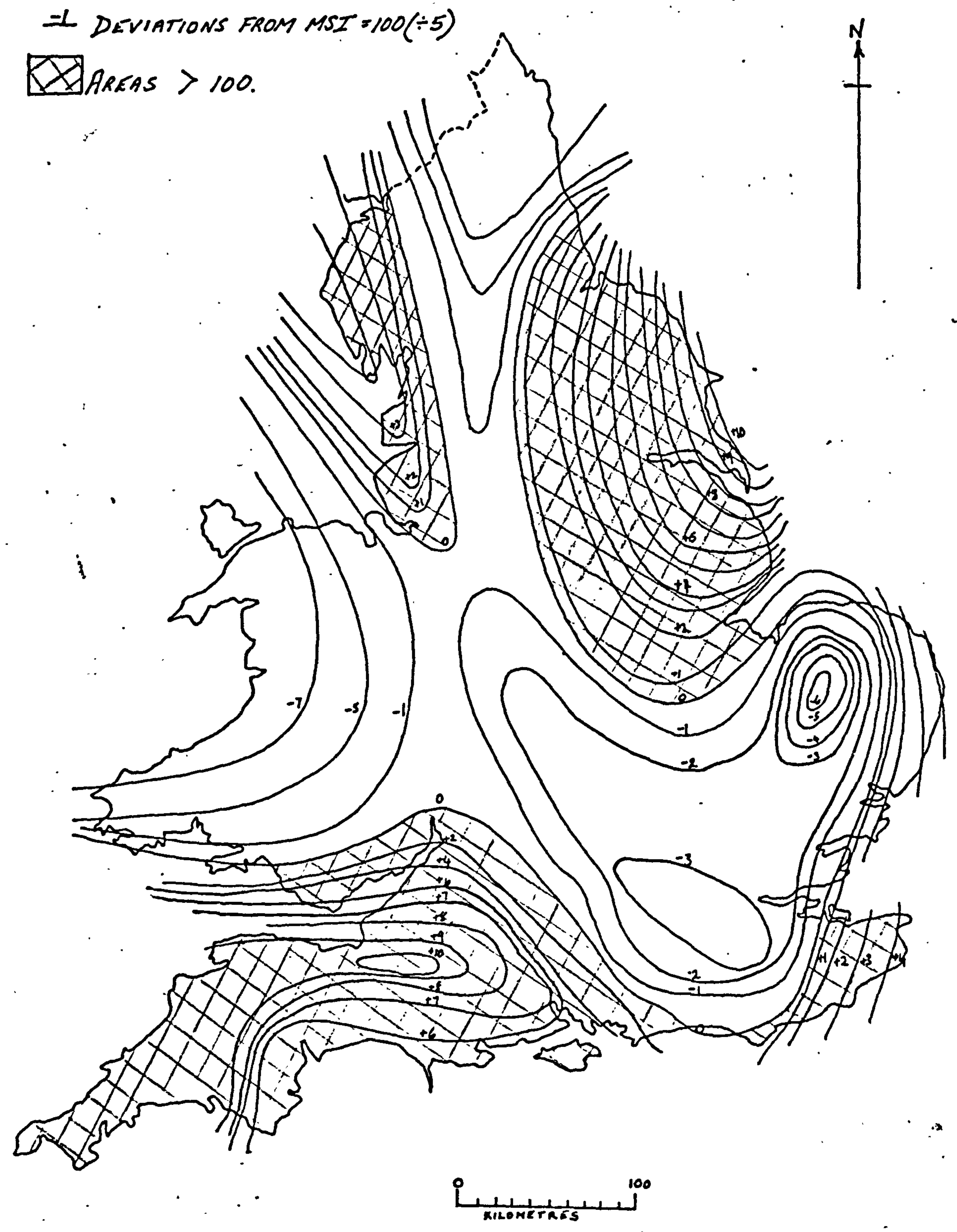

SIXTH ORDER SURFACE FOR TYDRTQ $(\alpha=775 \%)$ 


\section{$=1$ DEVIATIONS FROM MSI = $100(\div 5)$.}

Xarkas > 100 .
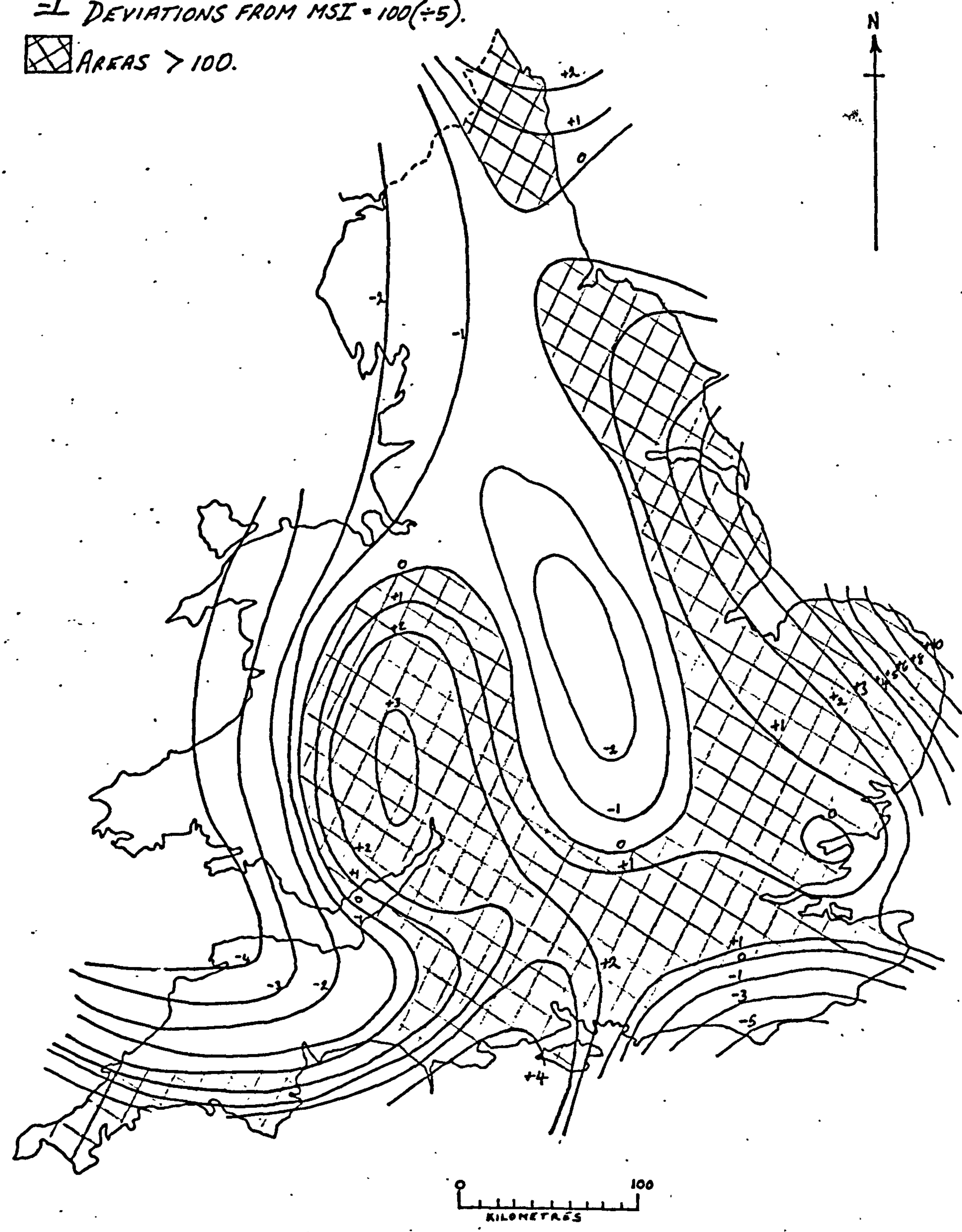

SIXTH ORDER SURFACE FOR TCPPT $\phi(\alpha=>75 \%)$ 


\section{$\angle$ DeVIATIONS FROM MSI $=100(\div 5)$}

AREAS $>100$.
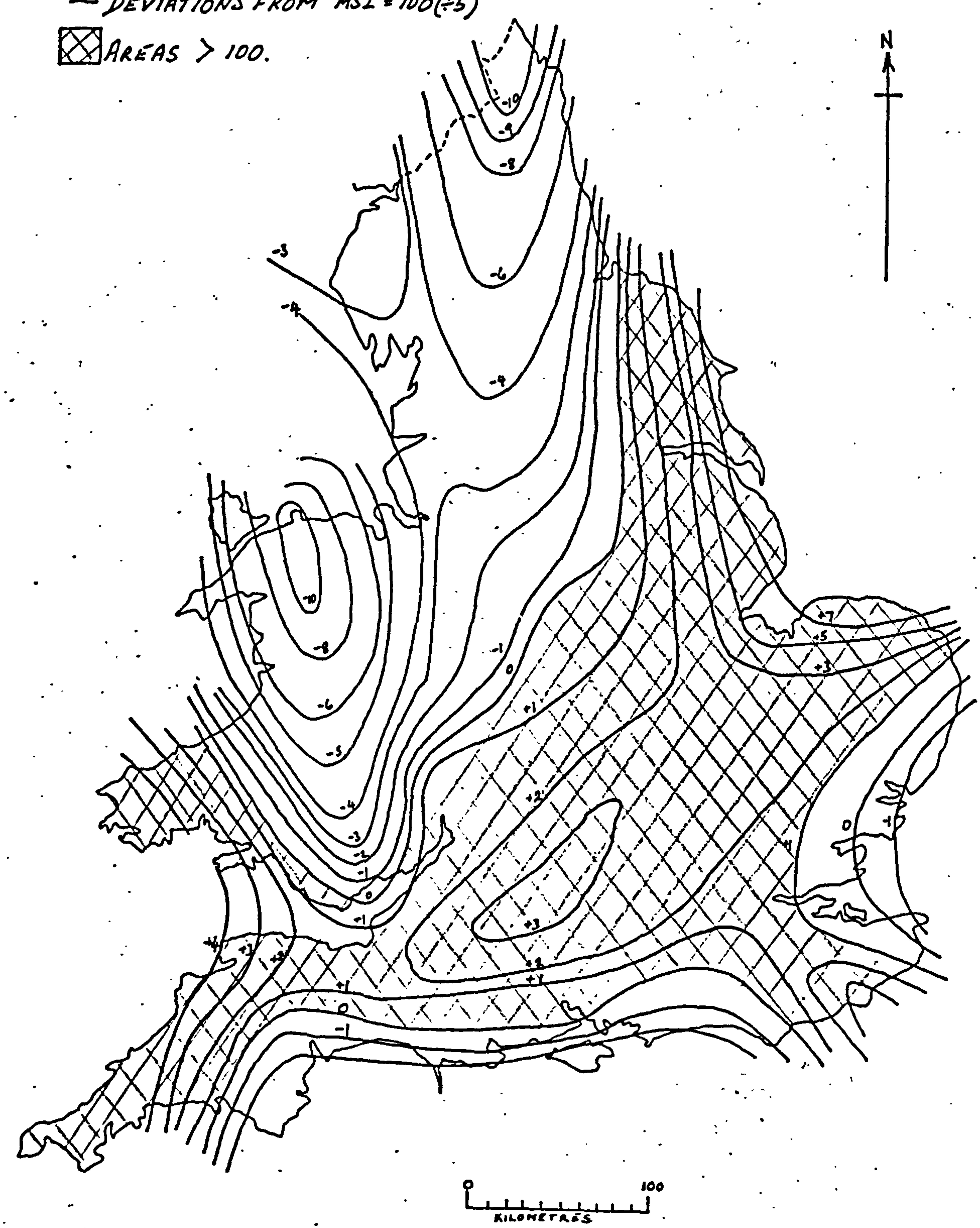


\section{DEVIATIONS AROM MST $=100(\div 5)$}

\section{X}
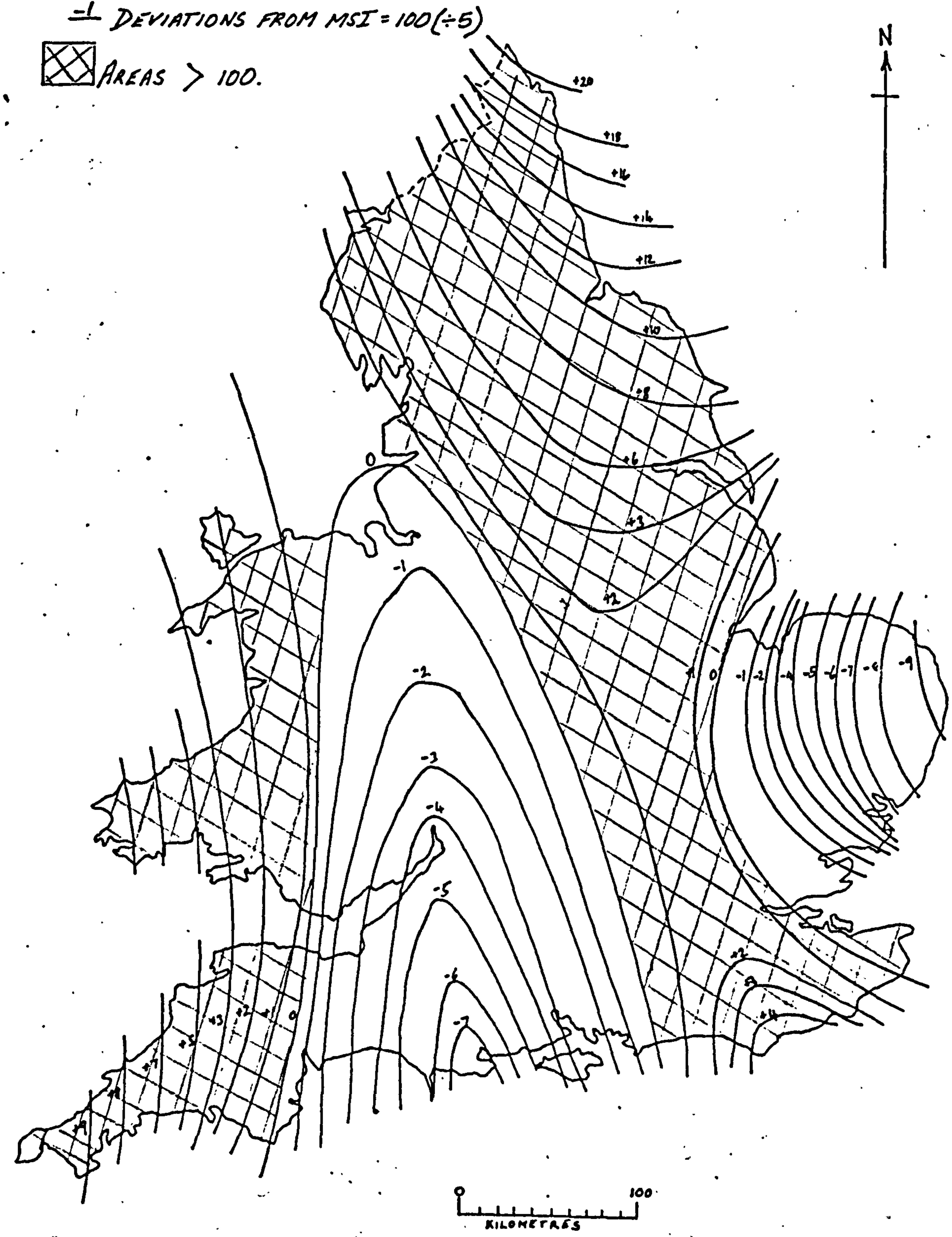

CuBIC SURFACE FOR TPCWTT $\phi(\alpha=775 \%)$. 
APPENDIX 3

MULTIPLE REGRESSION RESULTS 


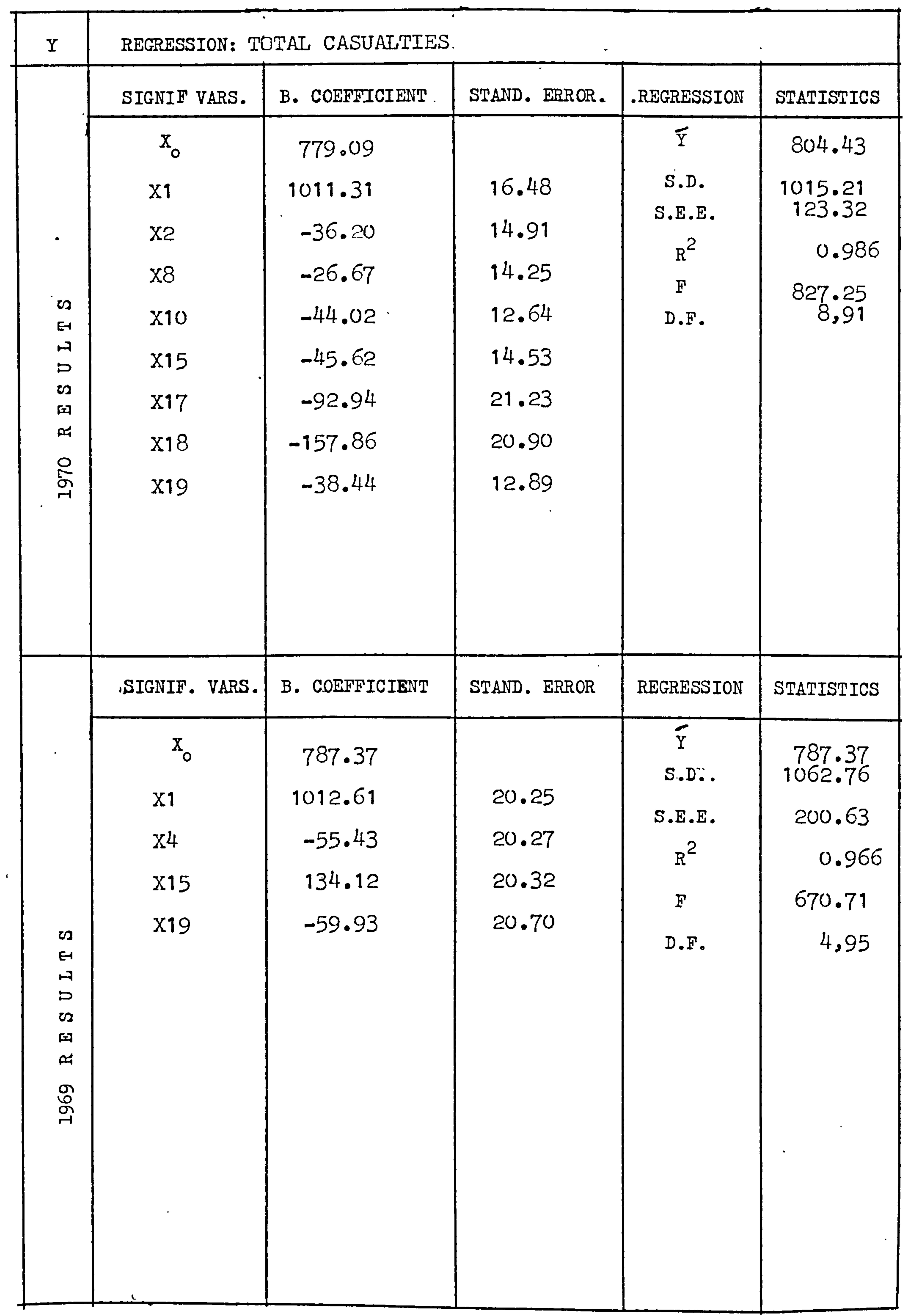




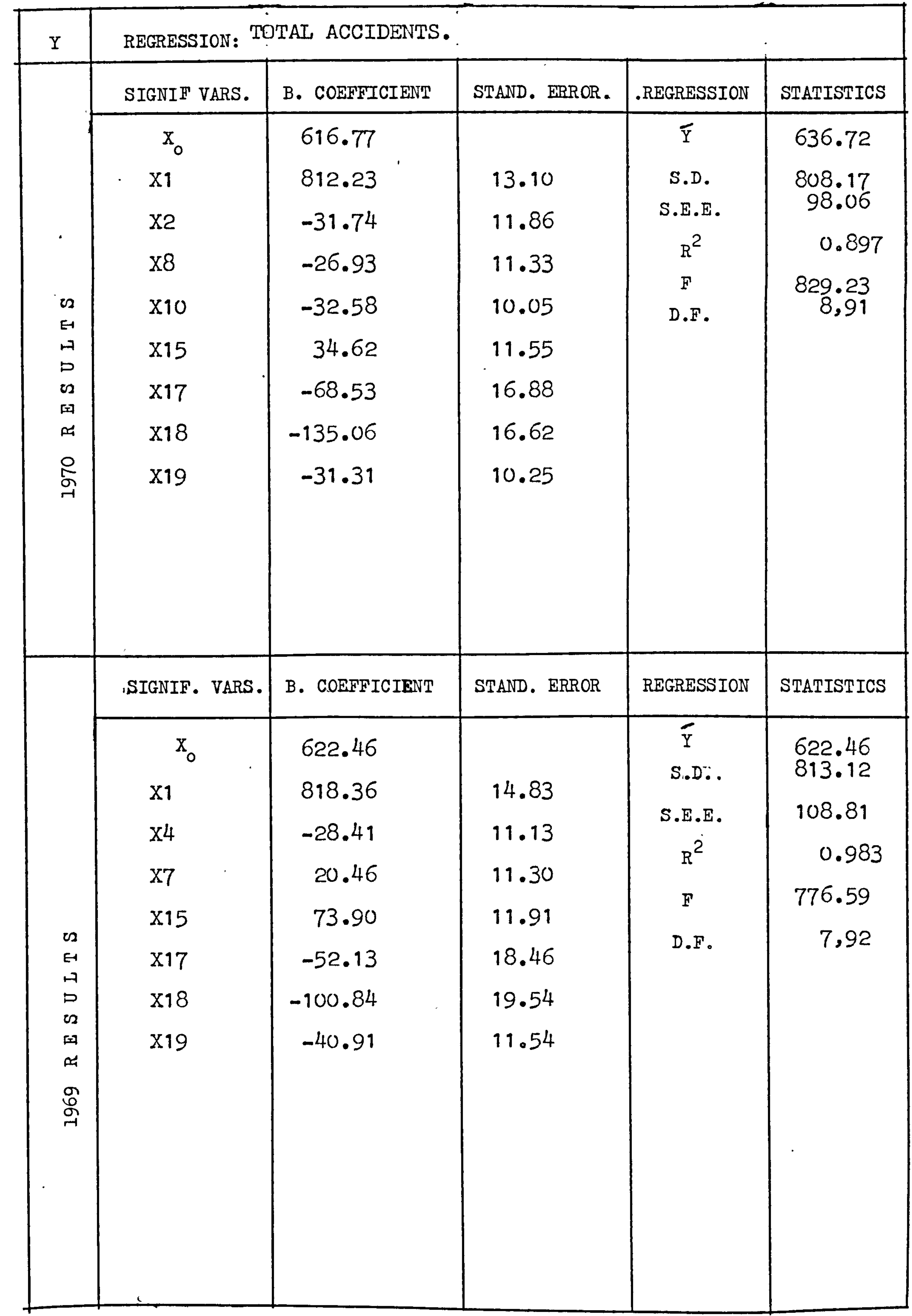




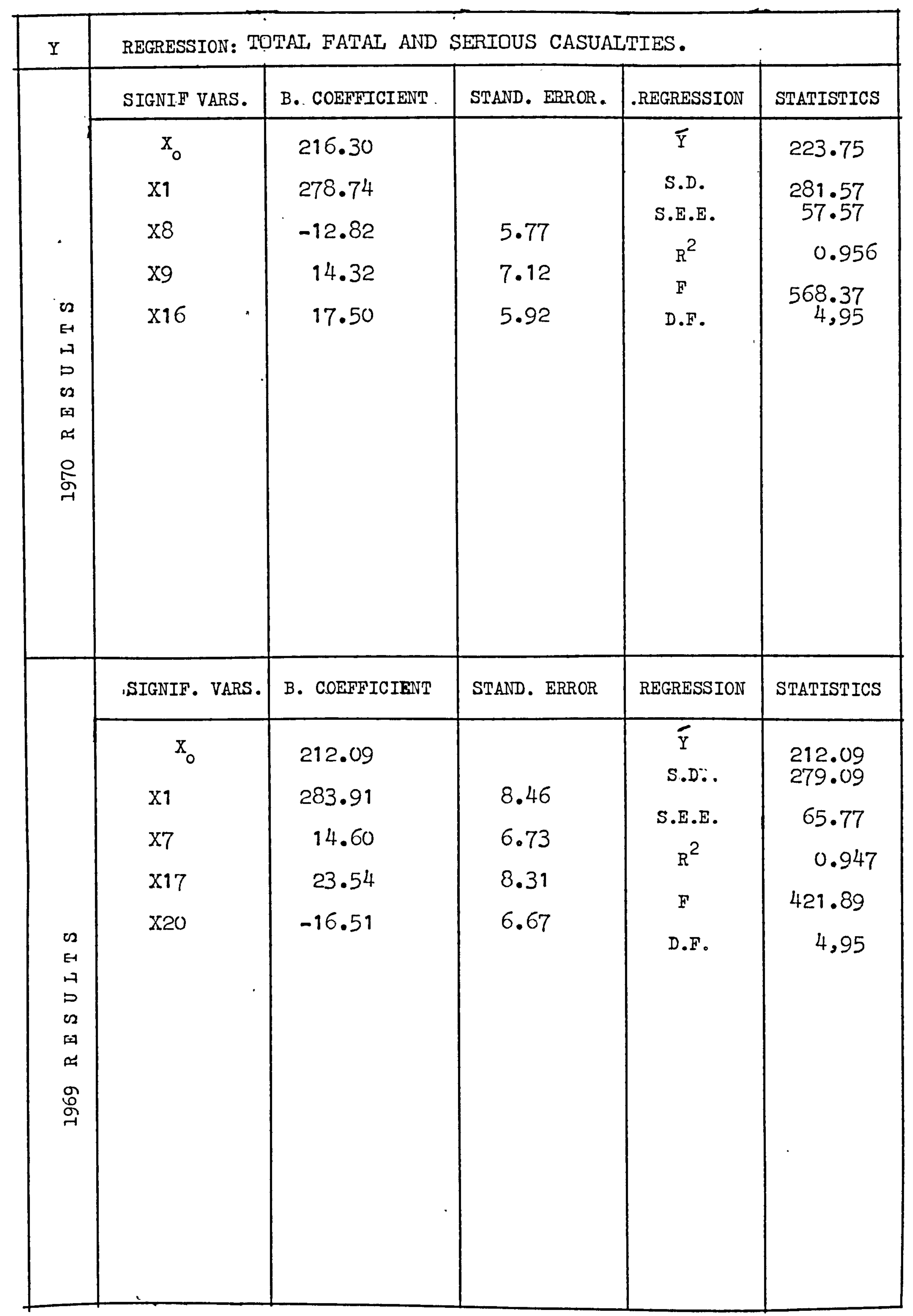




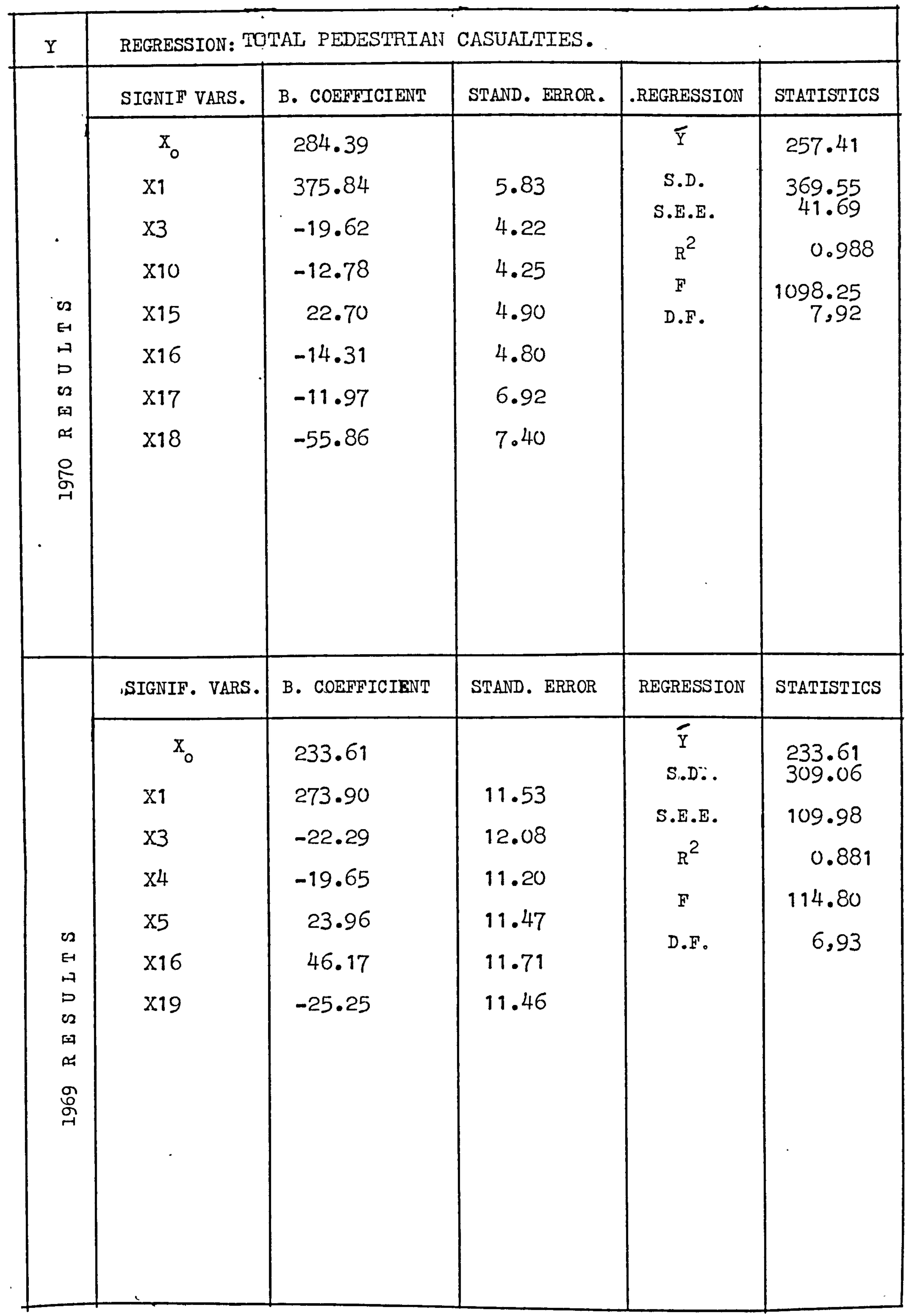




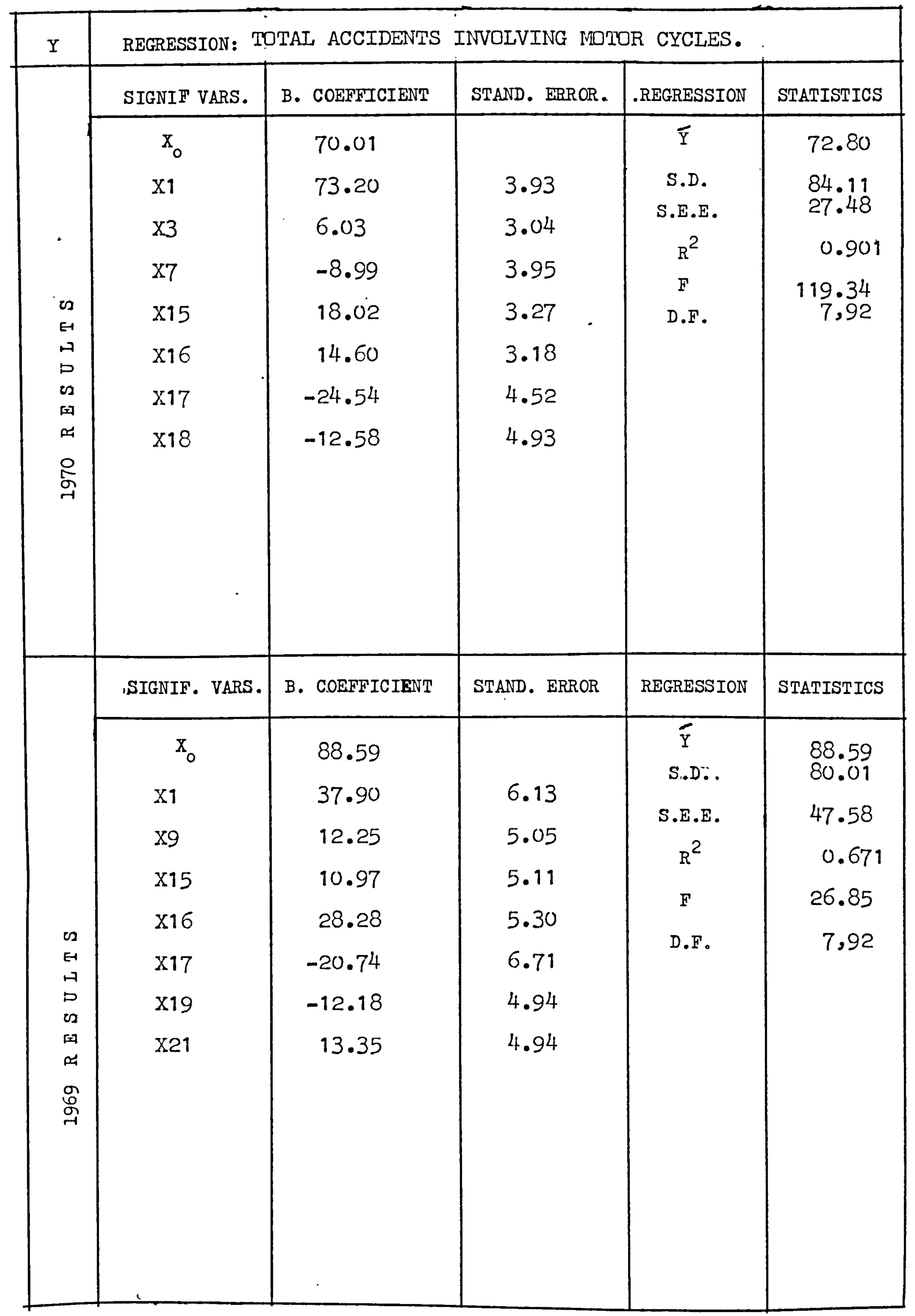




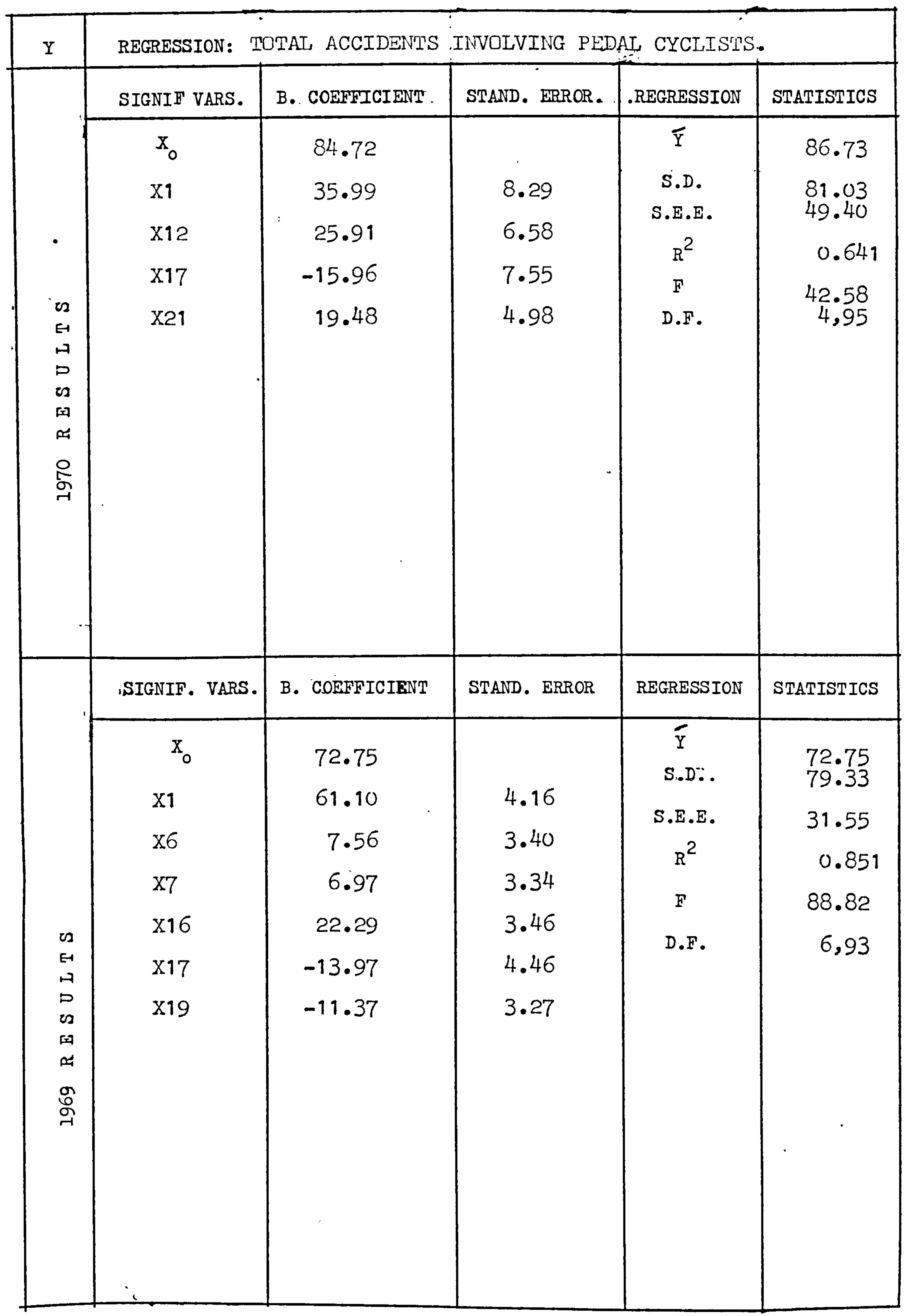




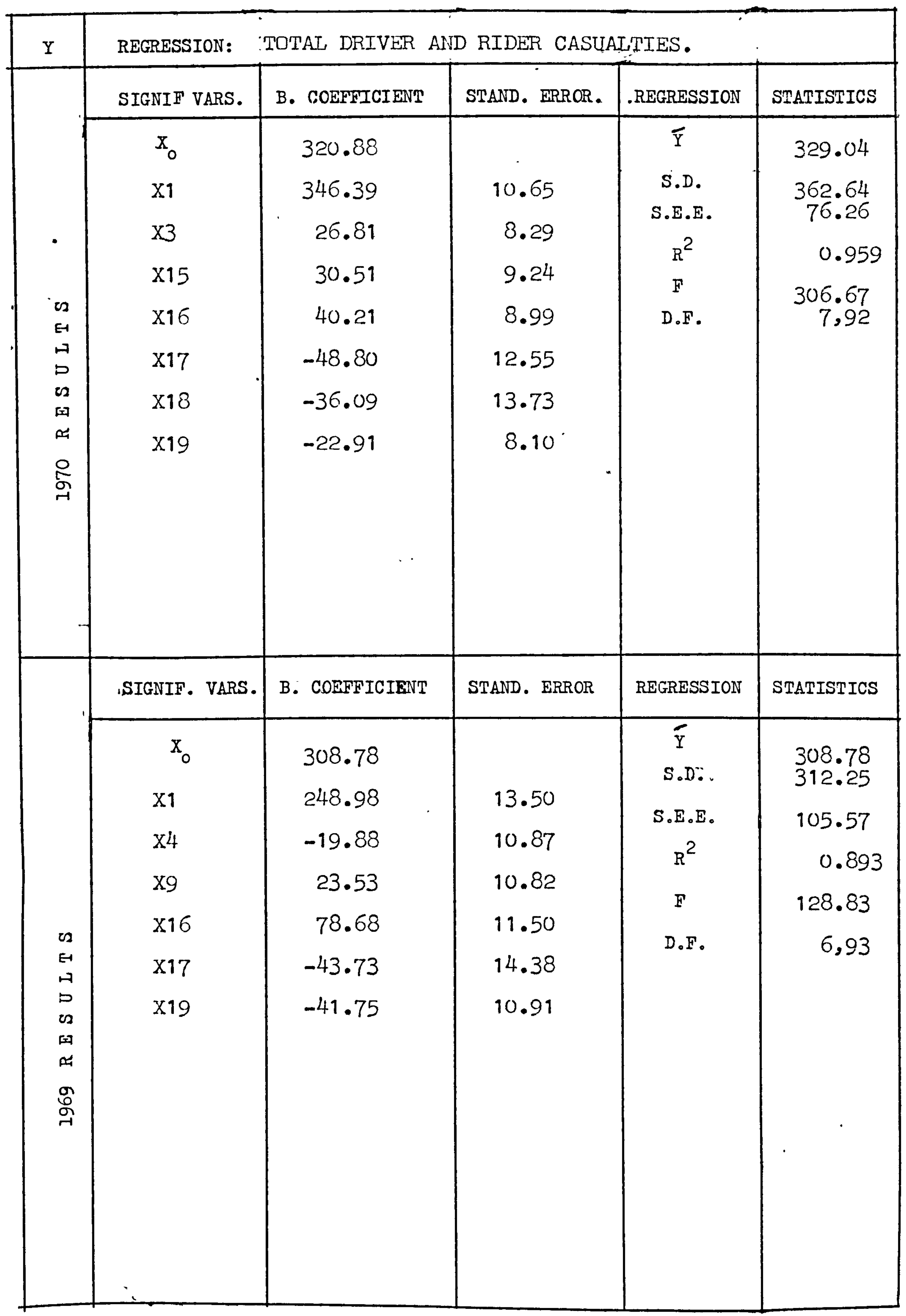




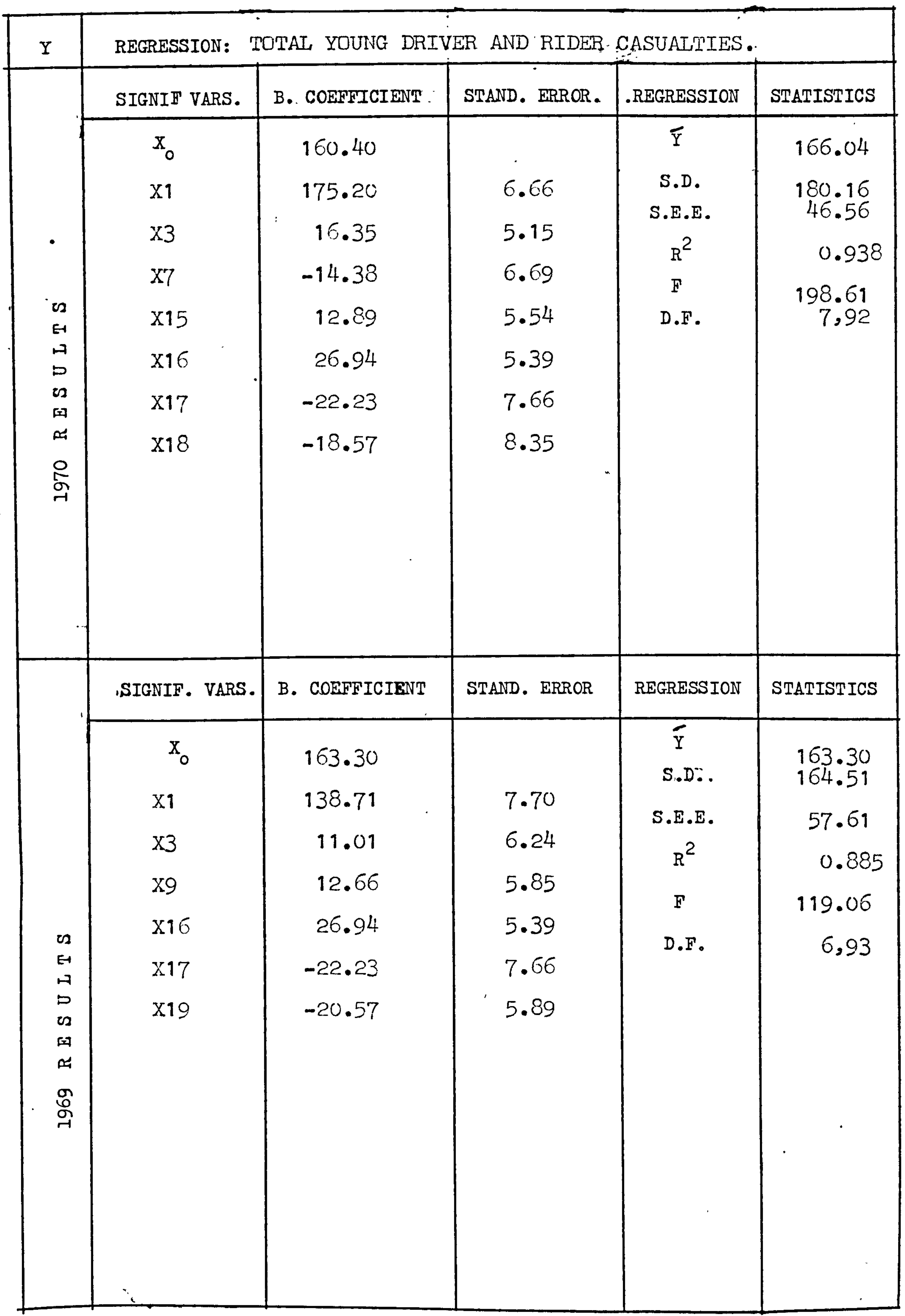




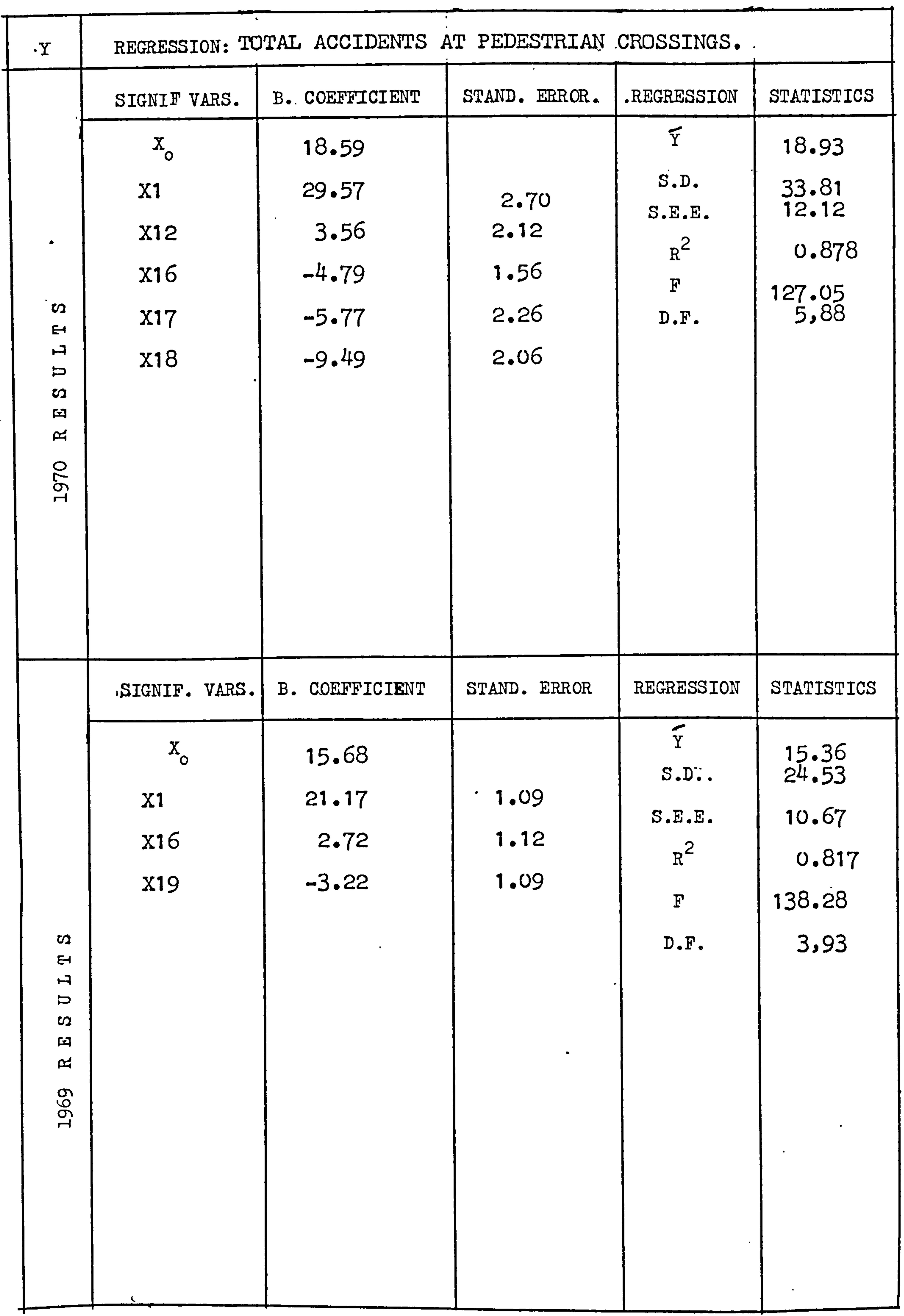




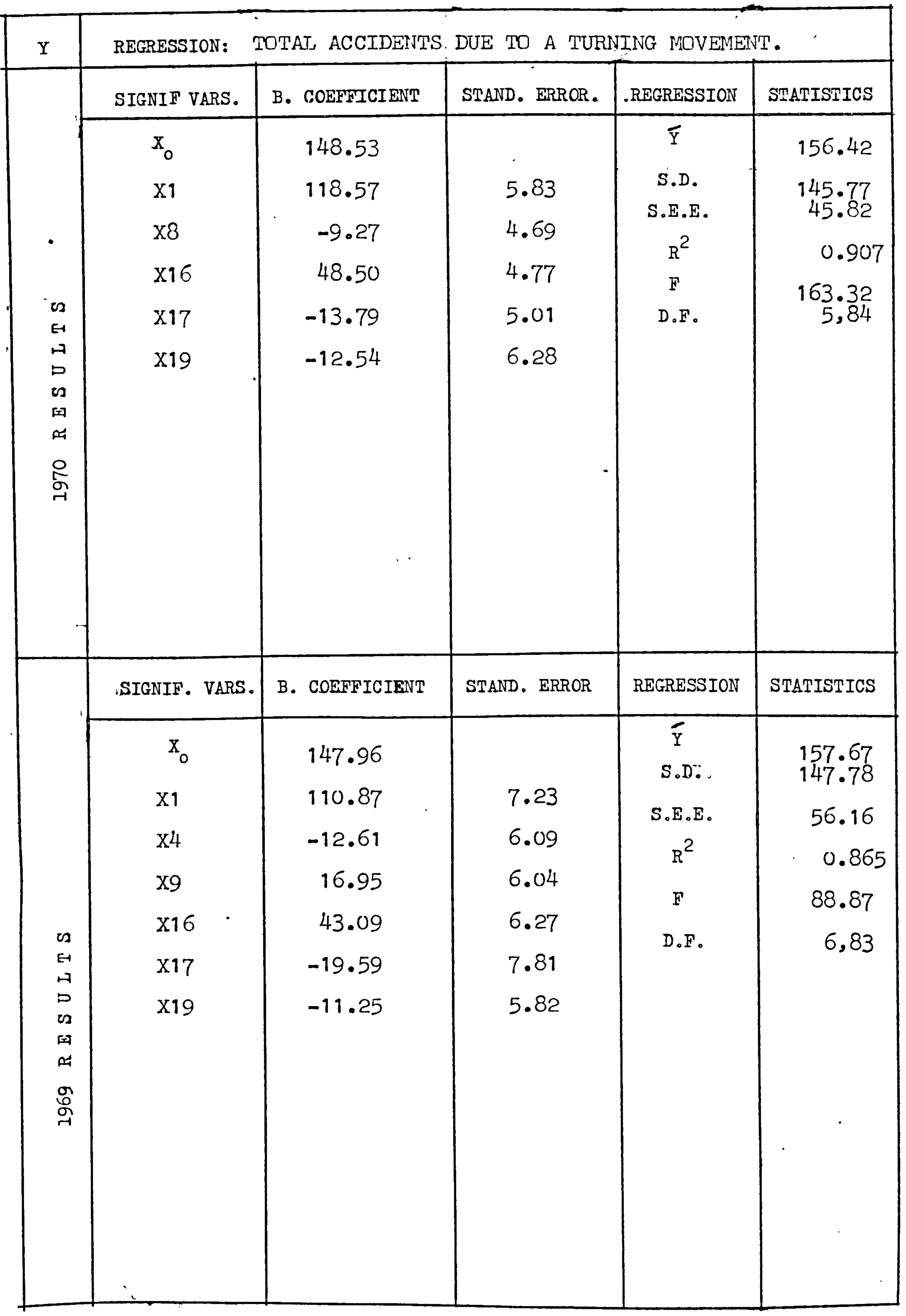




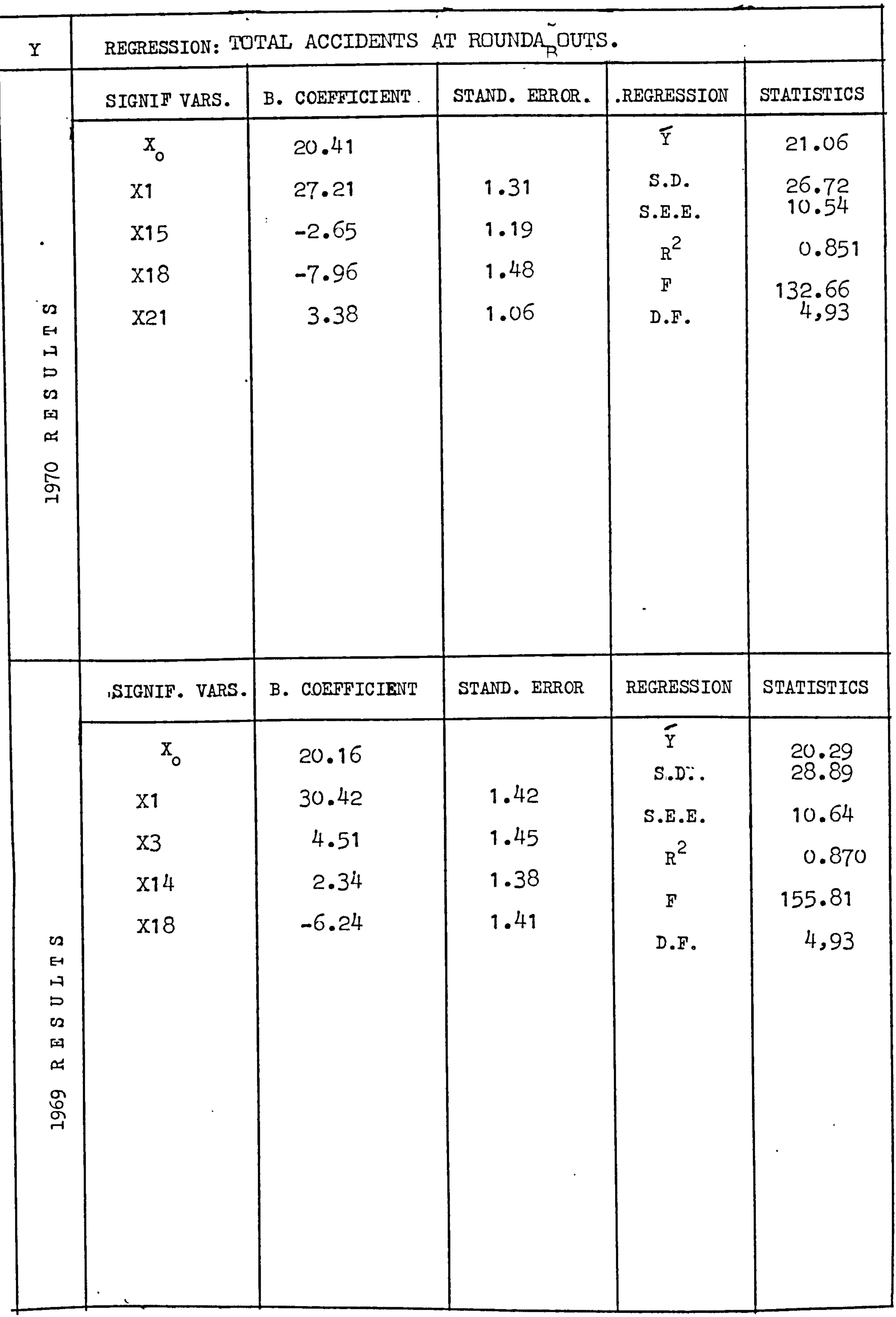




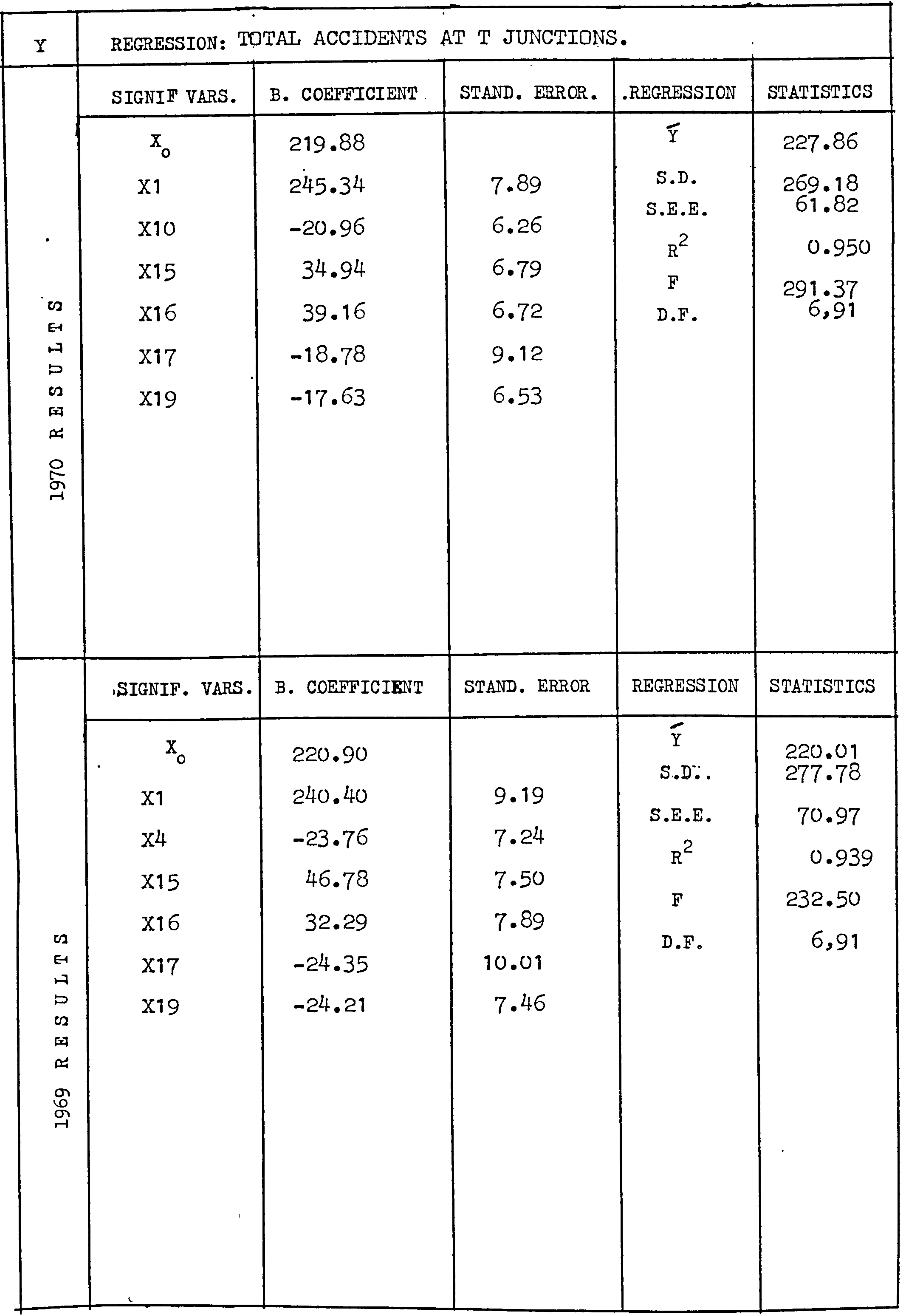




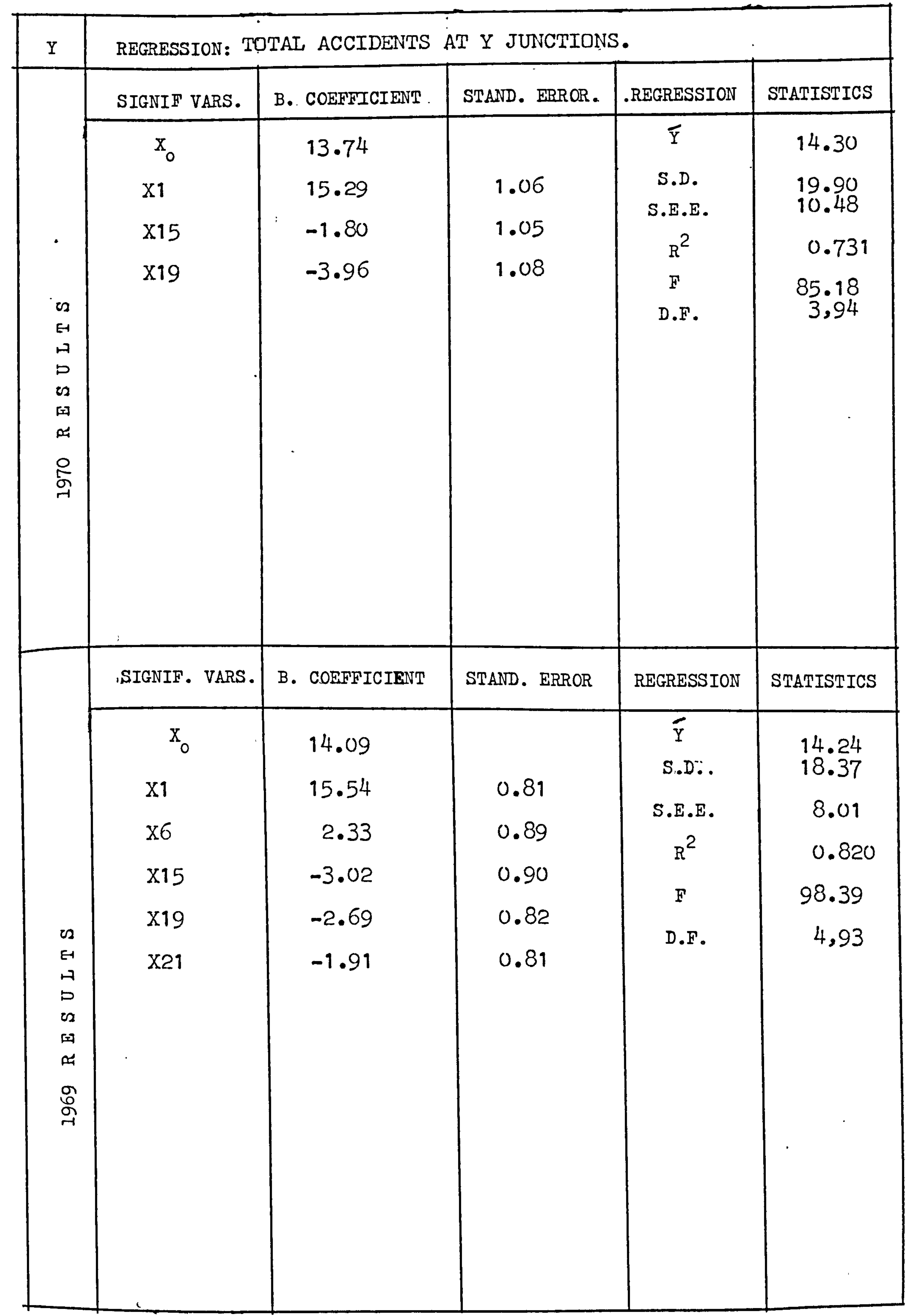




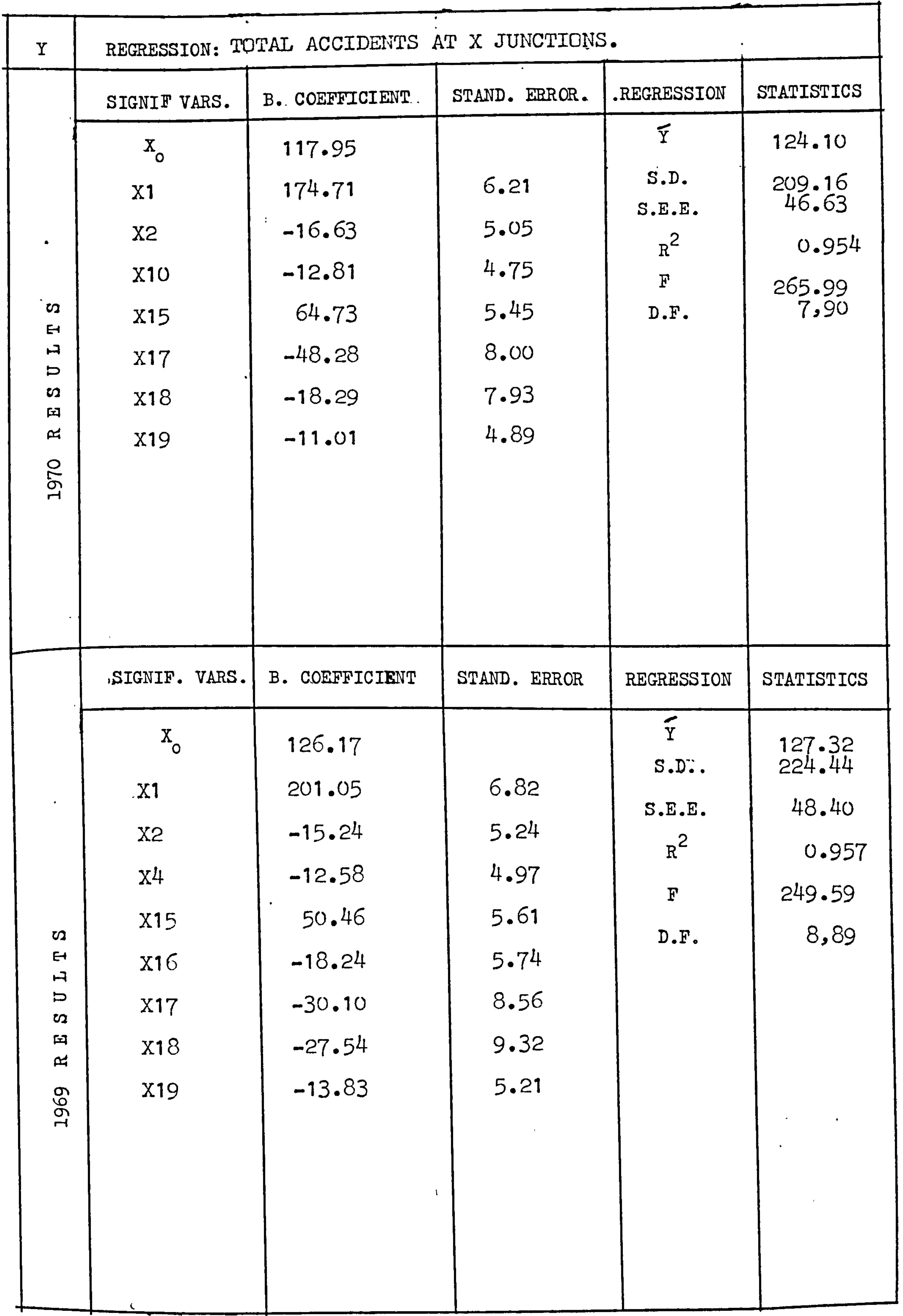




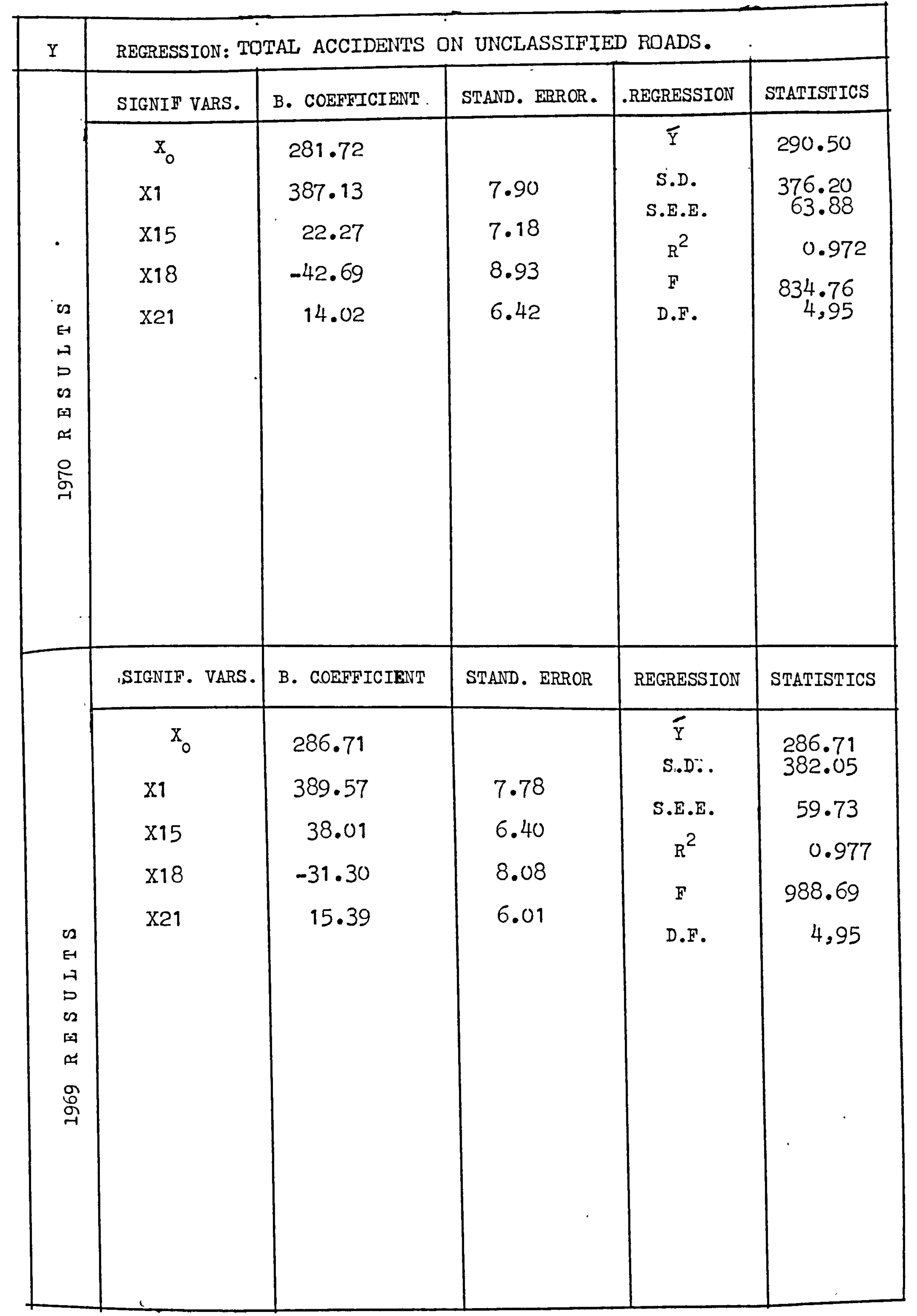




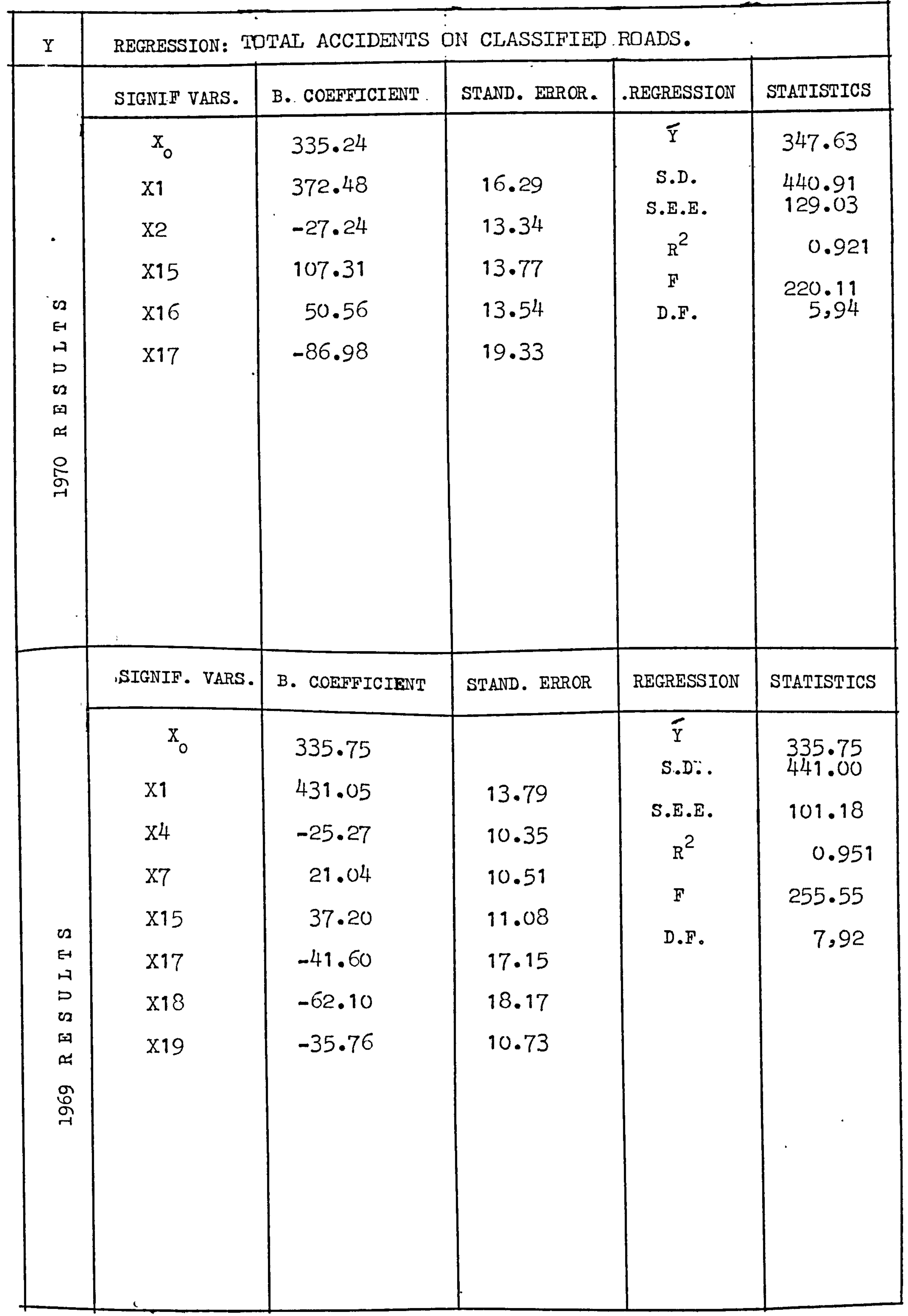




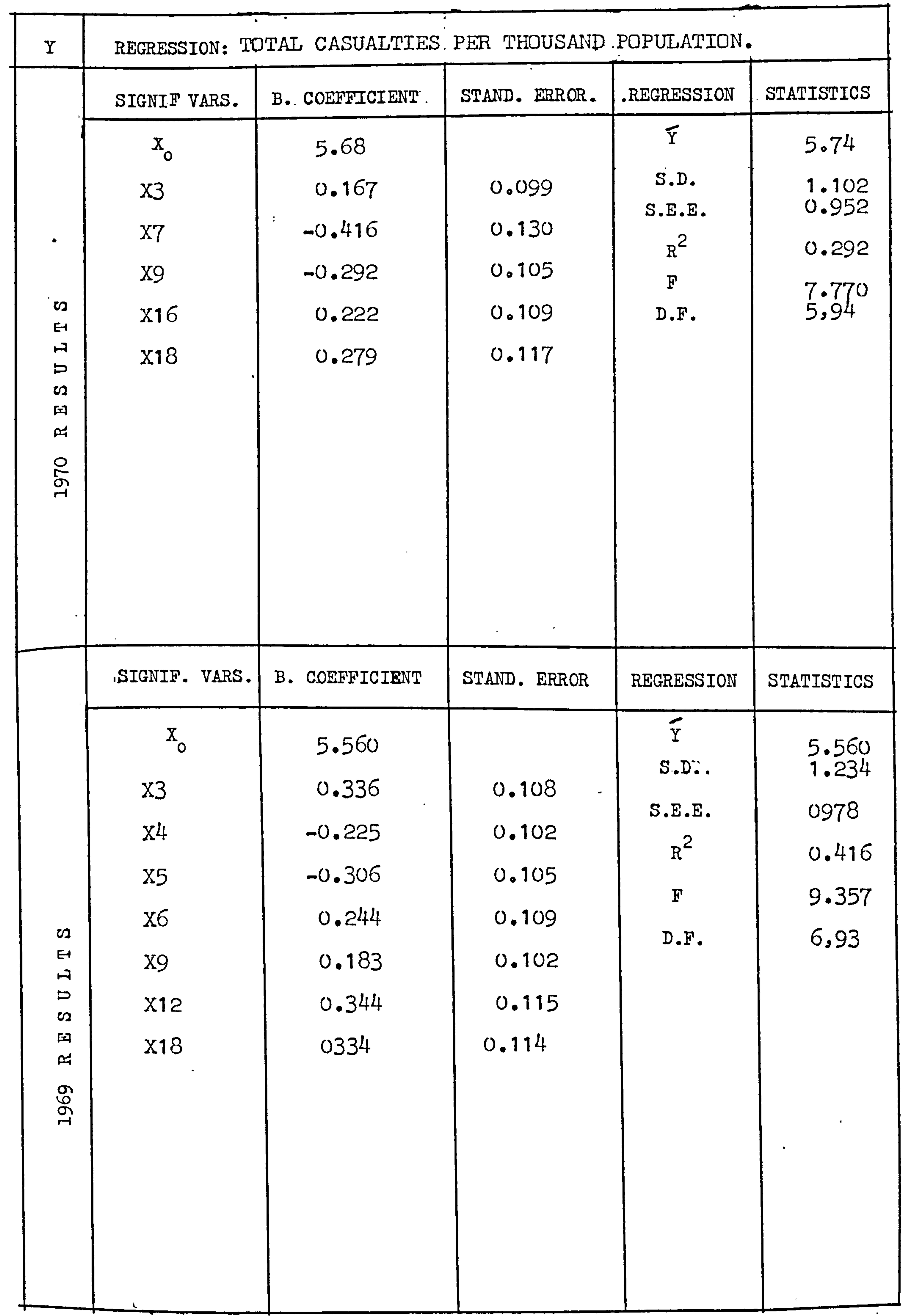




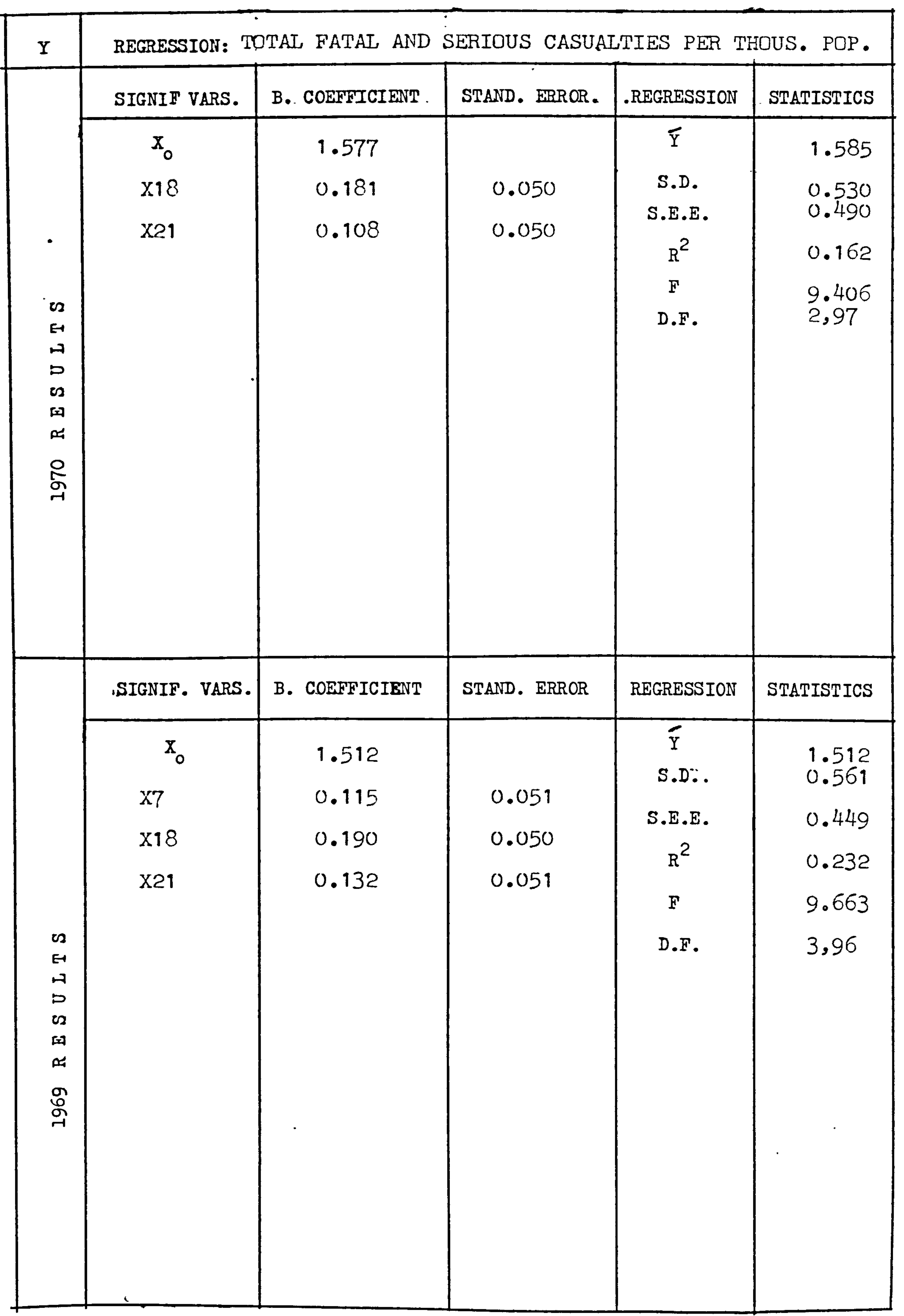




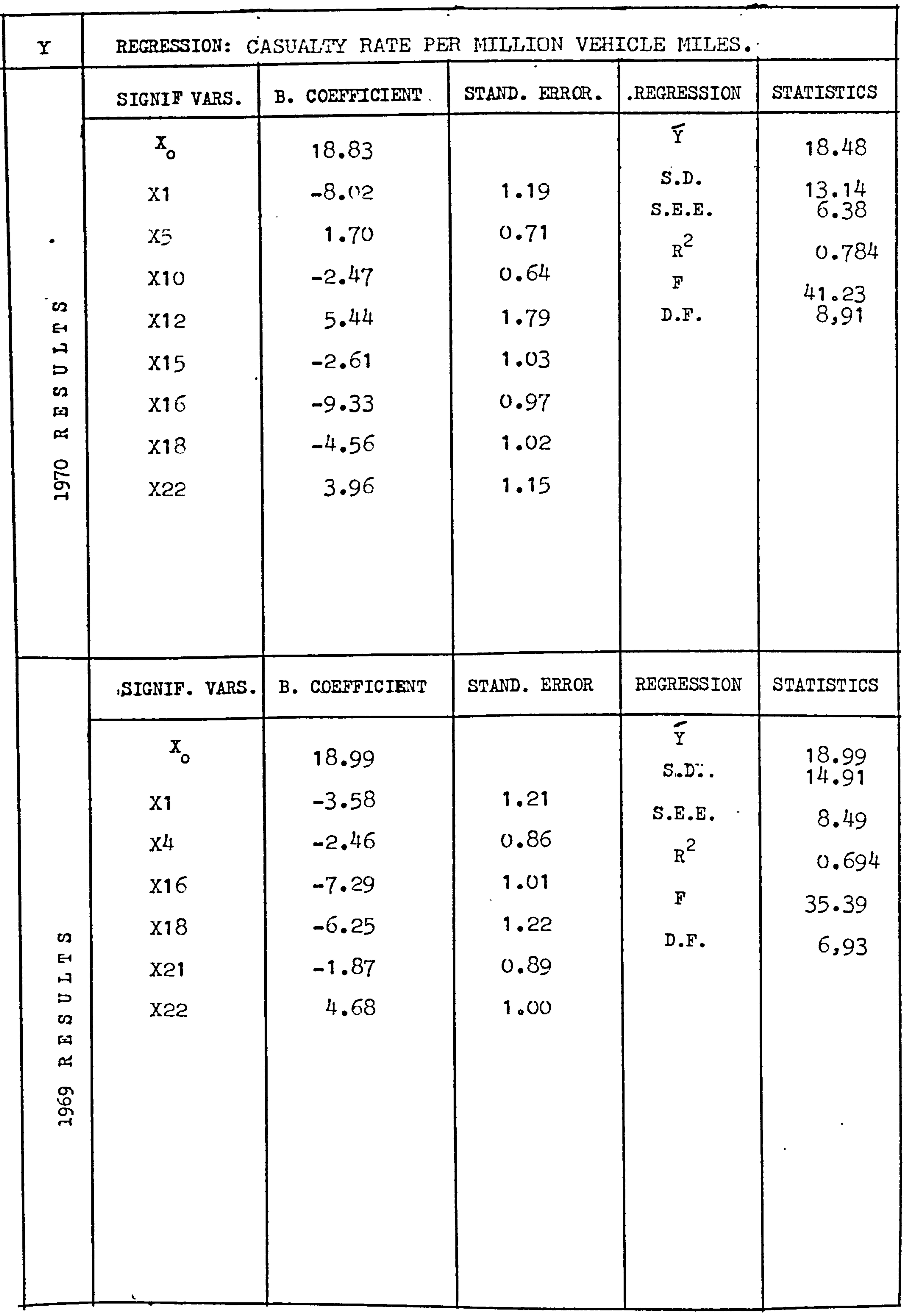




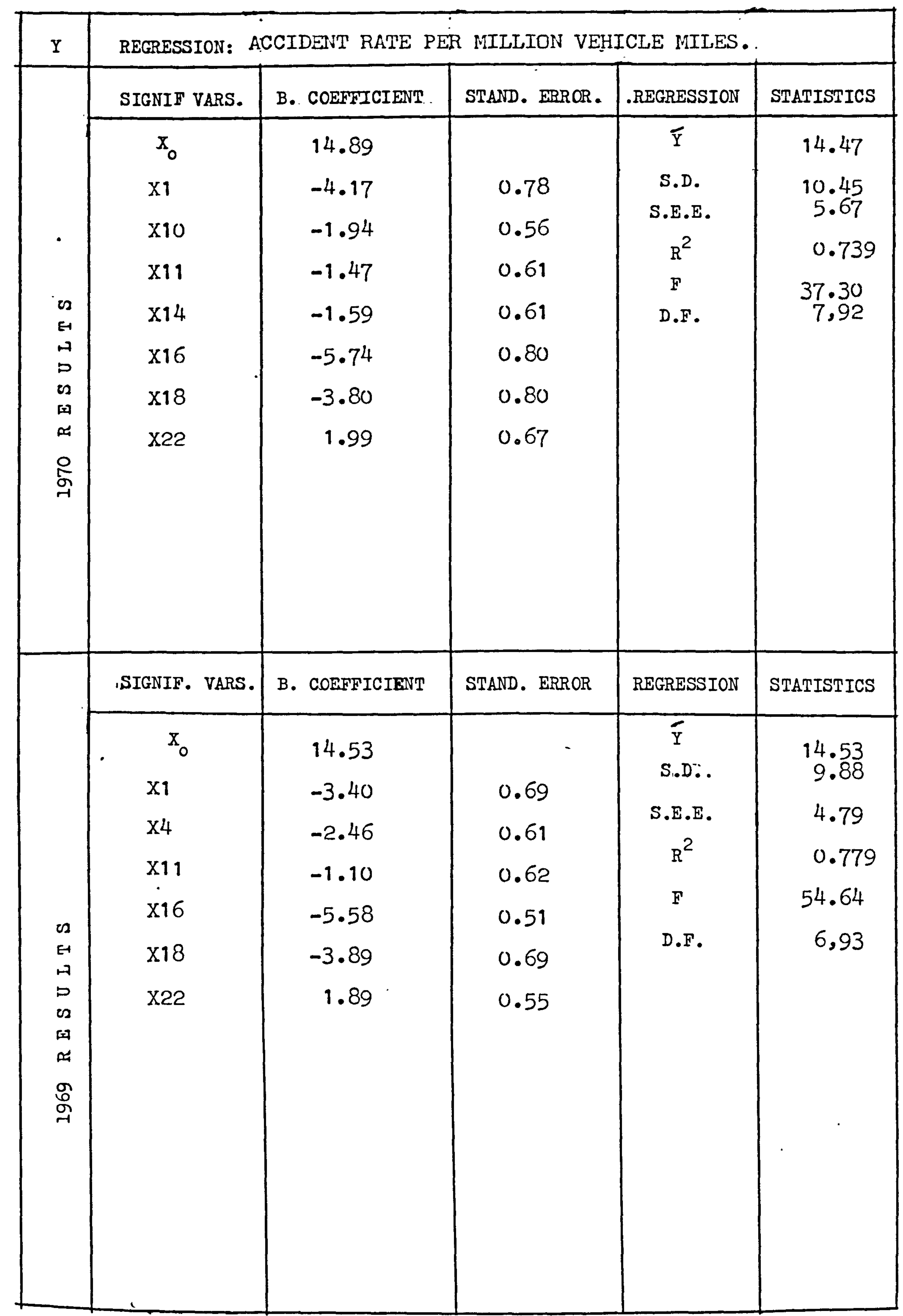




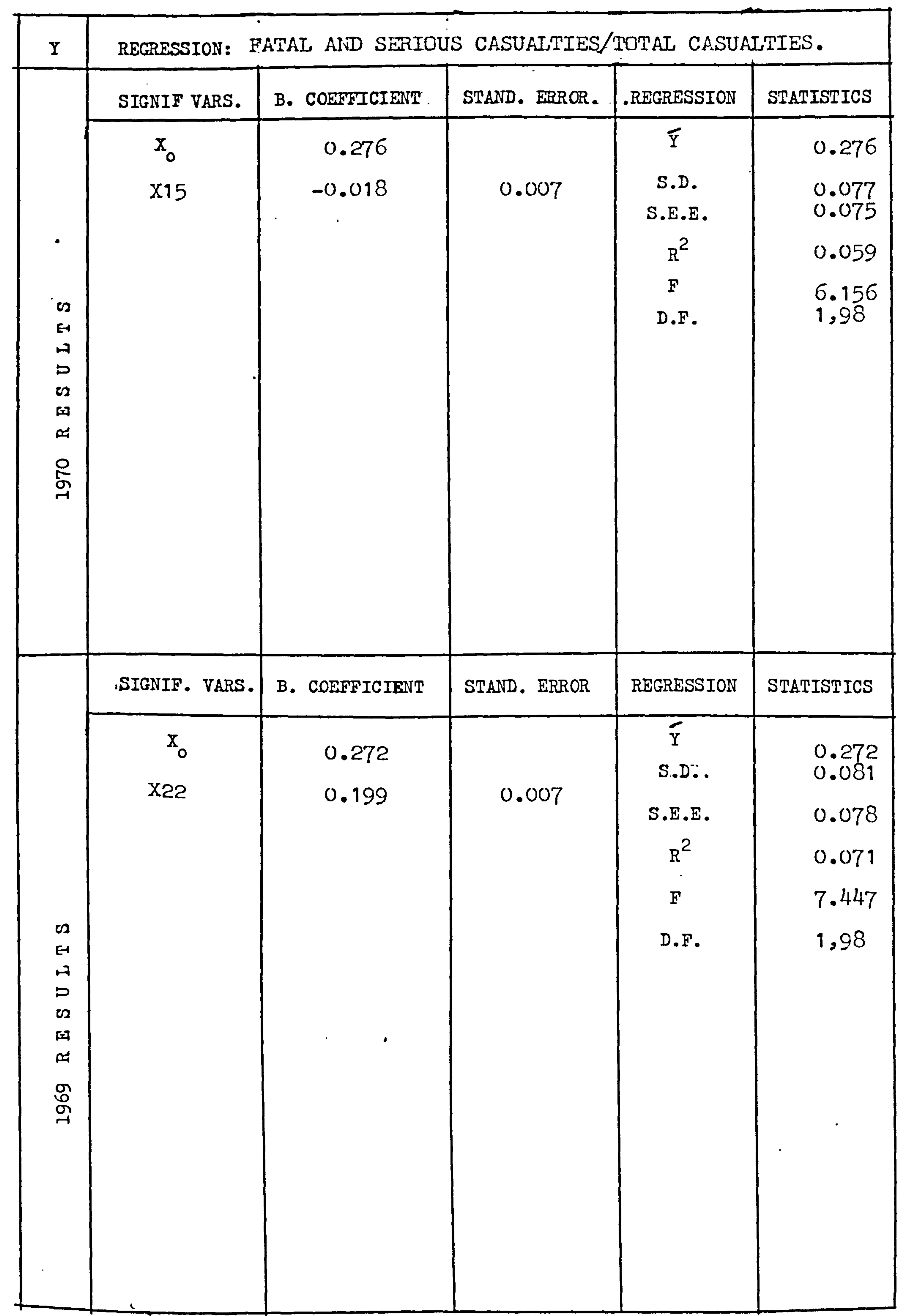




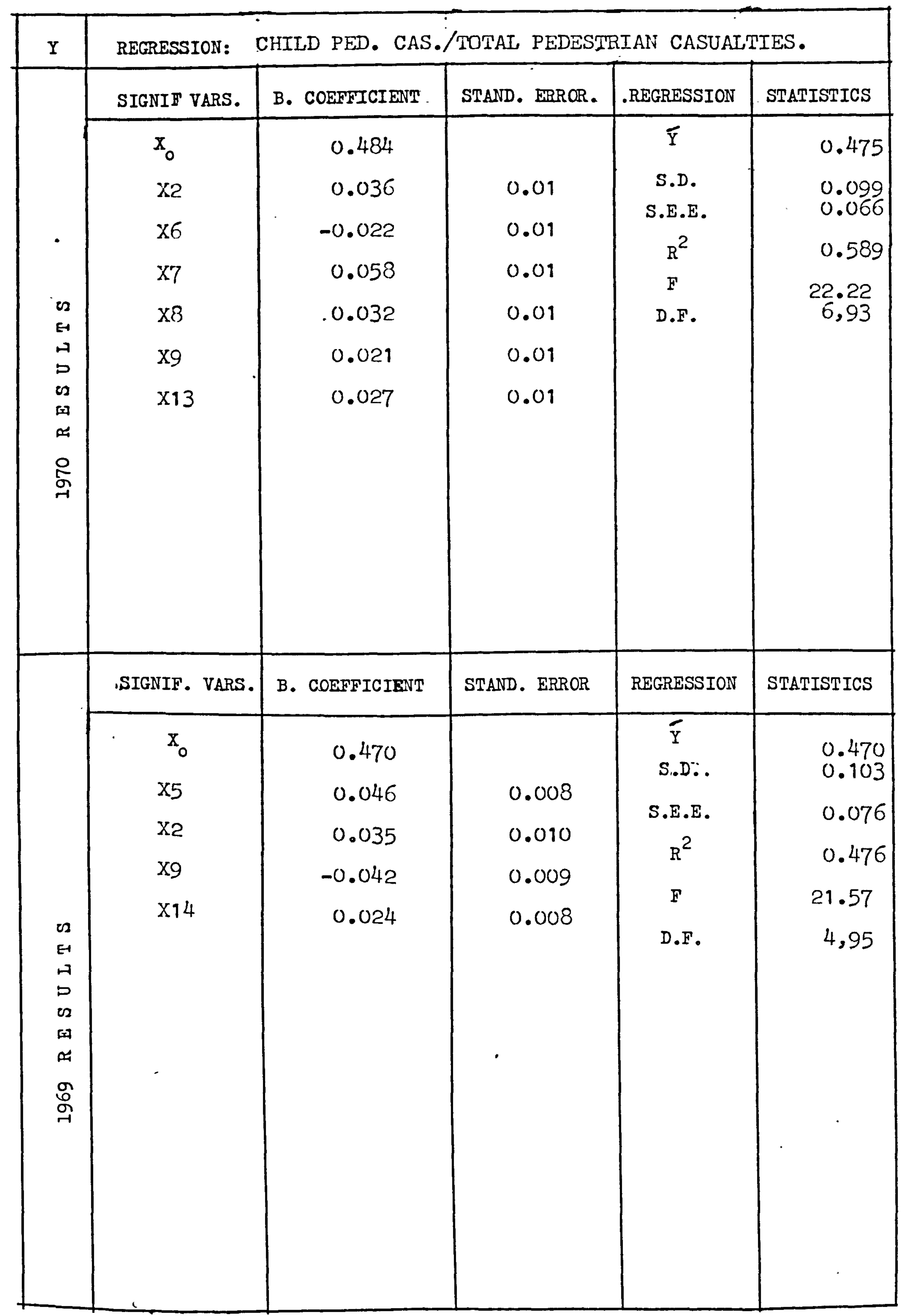




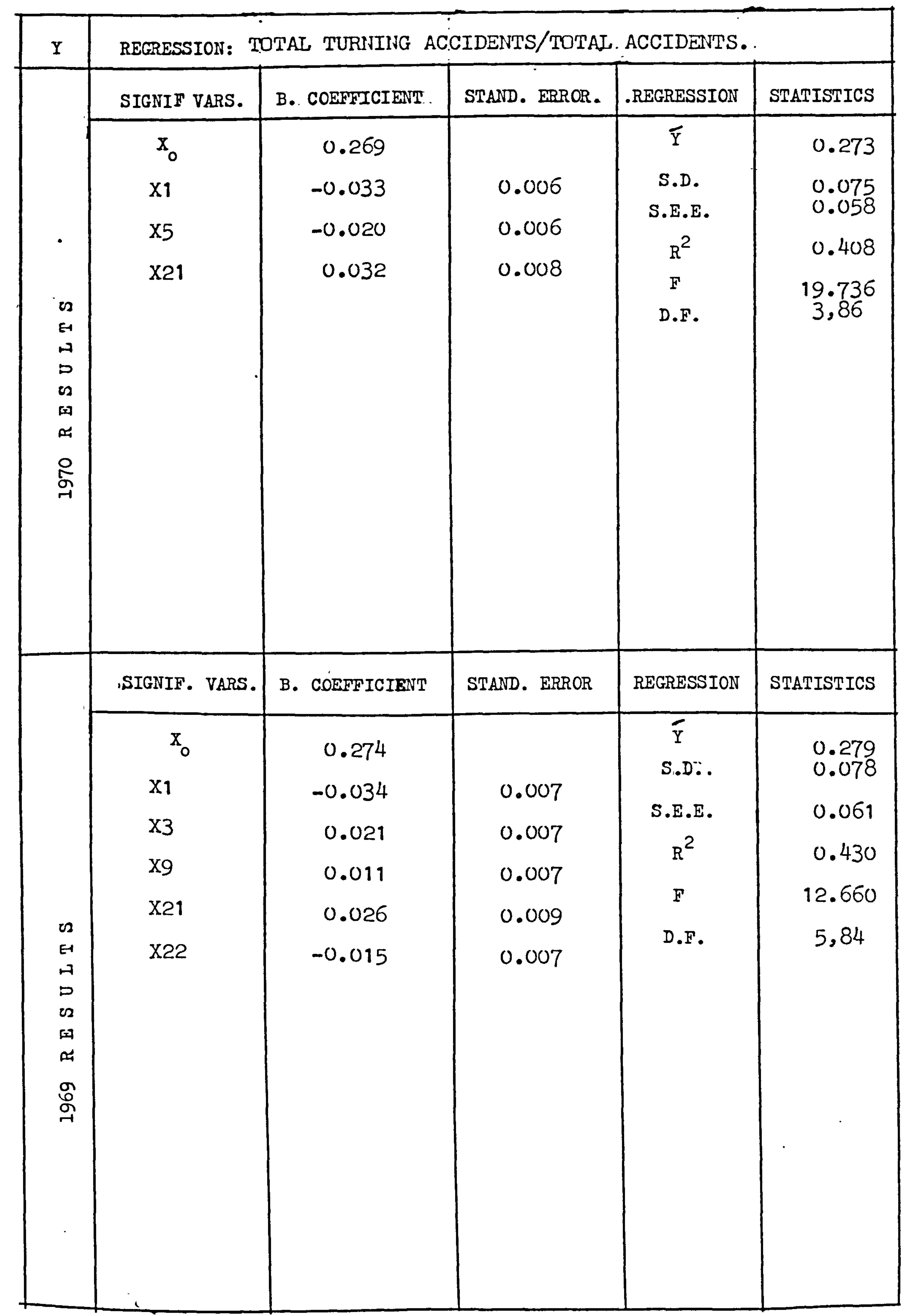




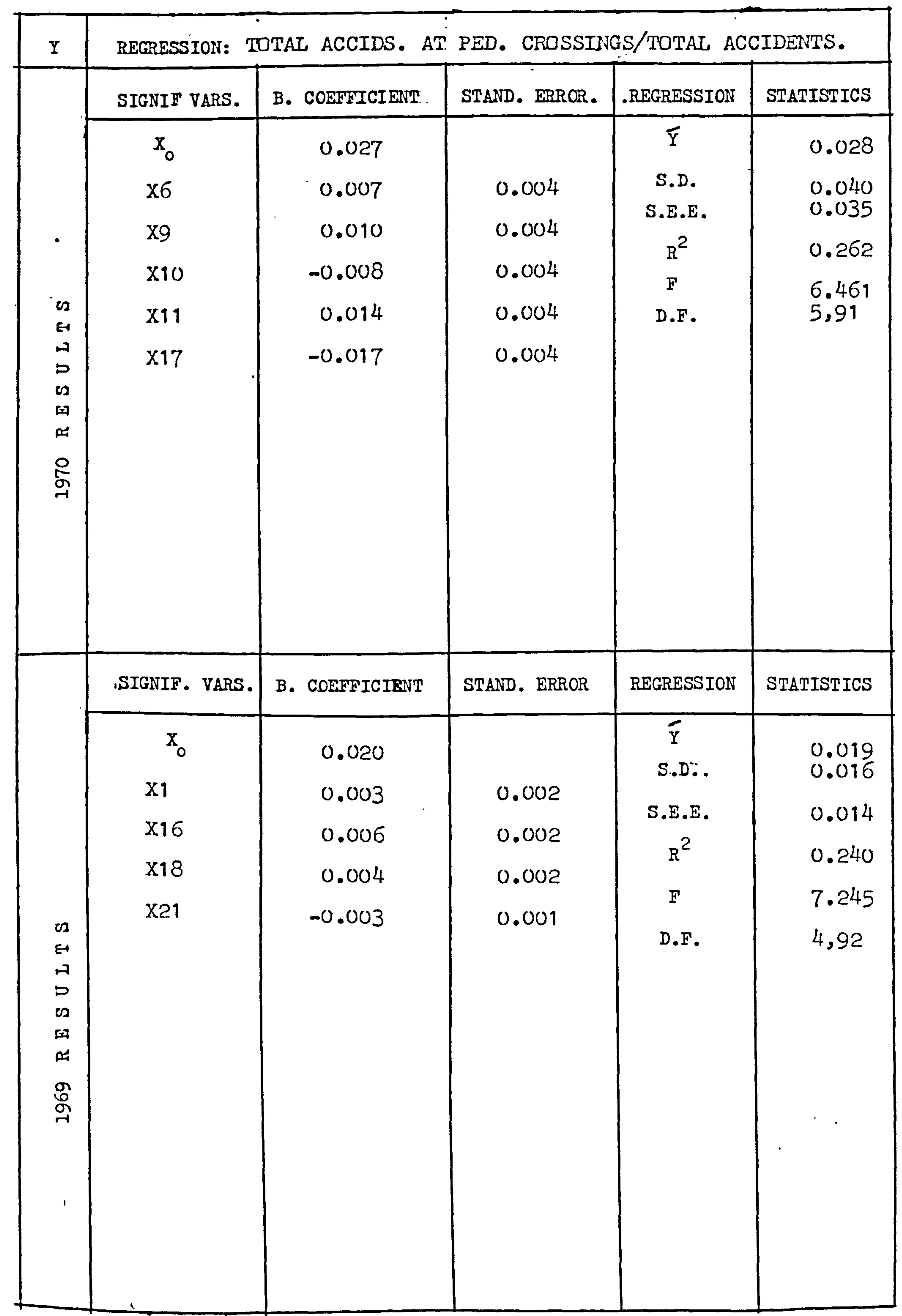




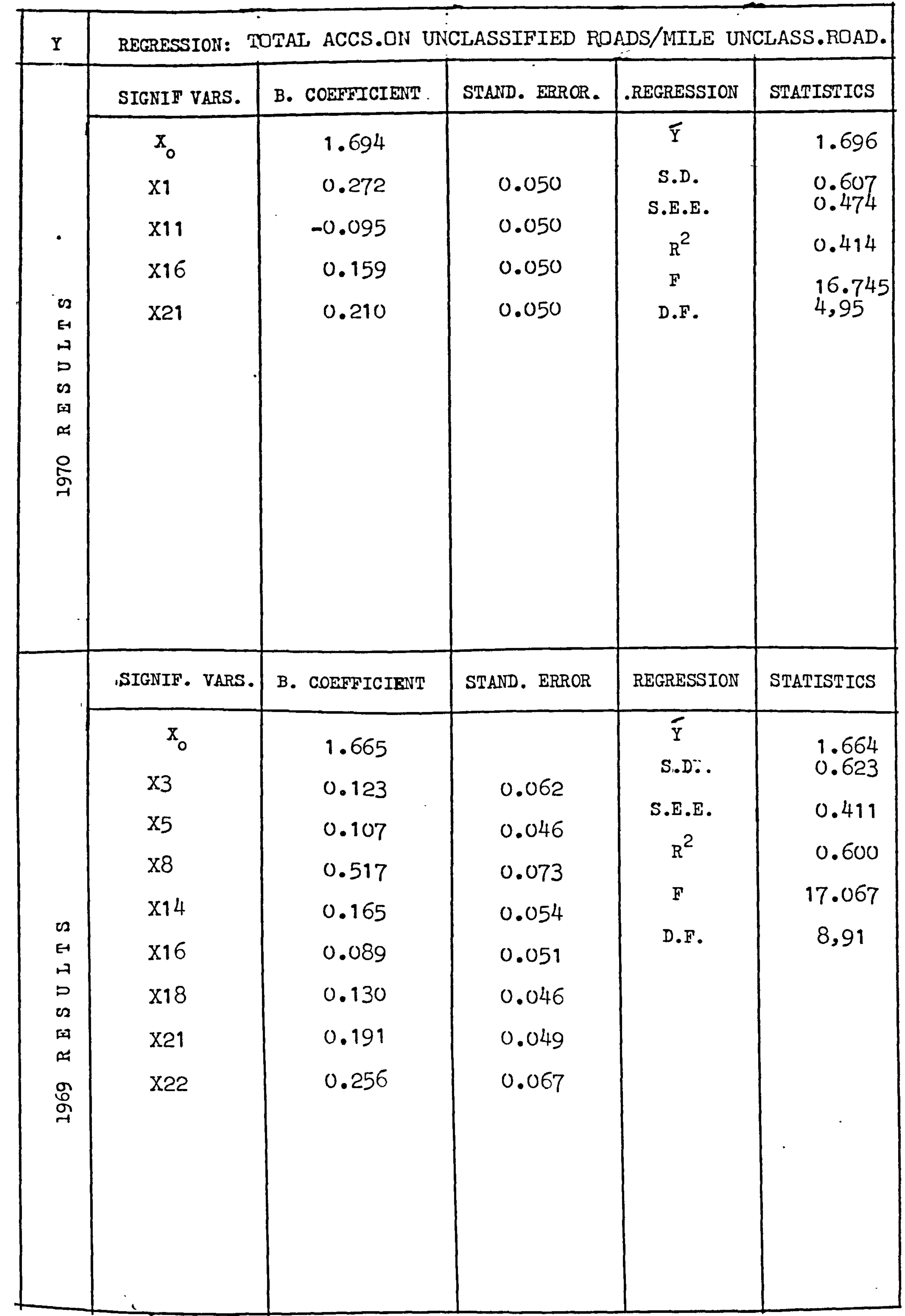




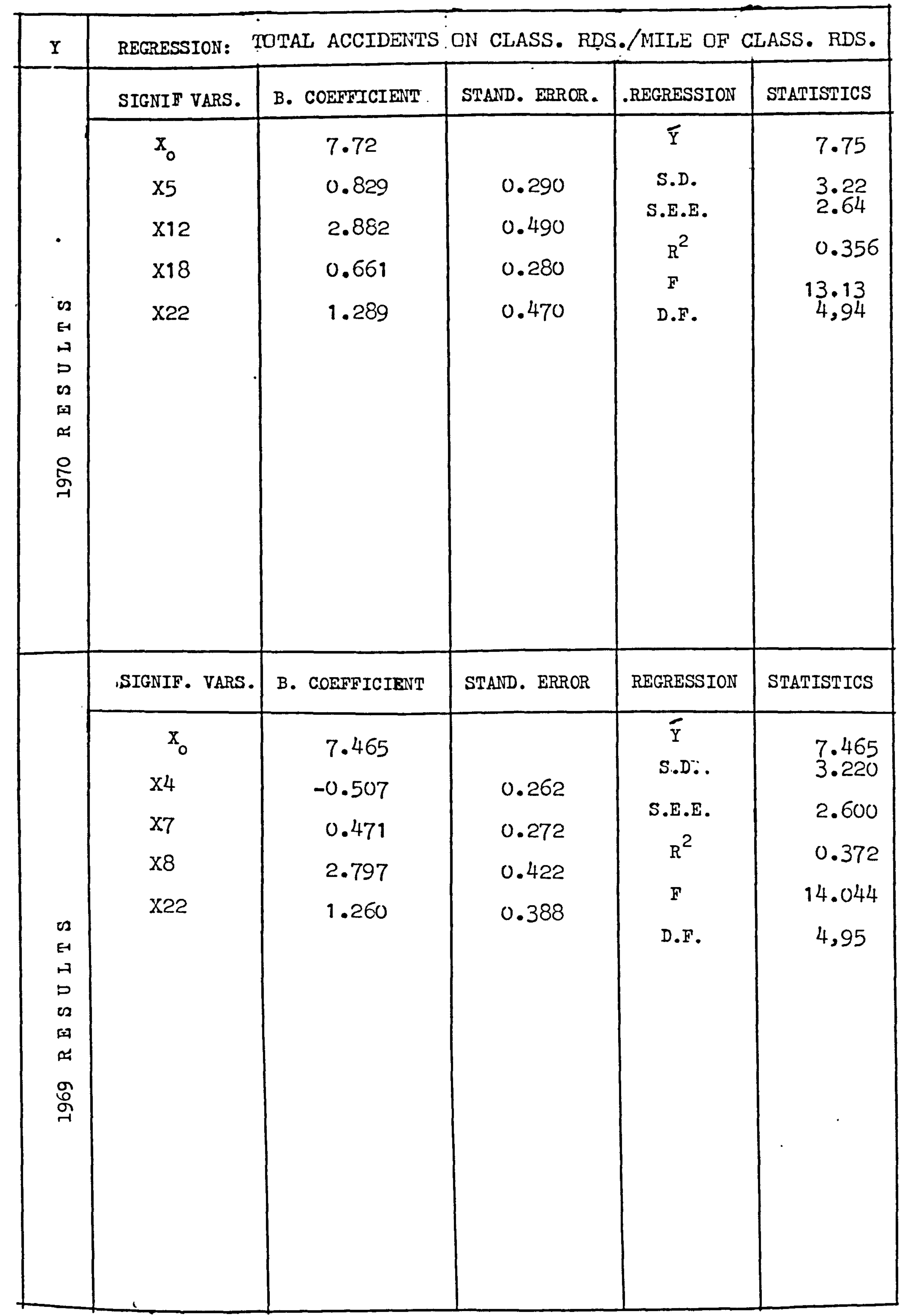




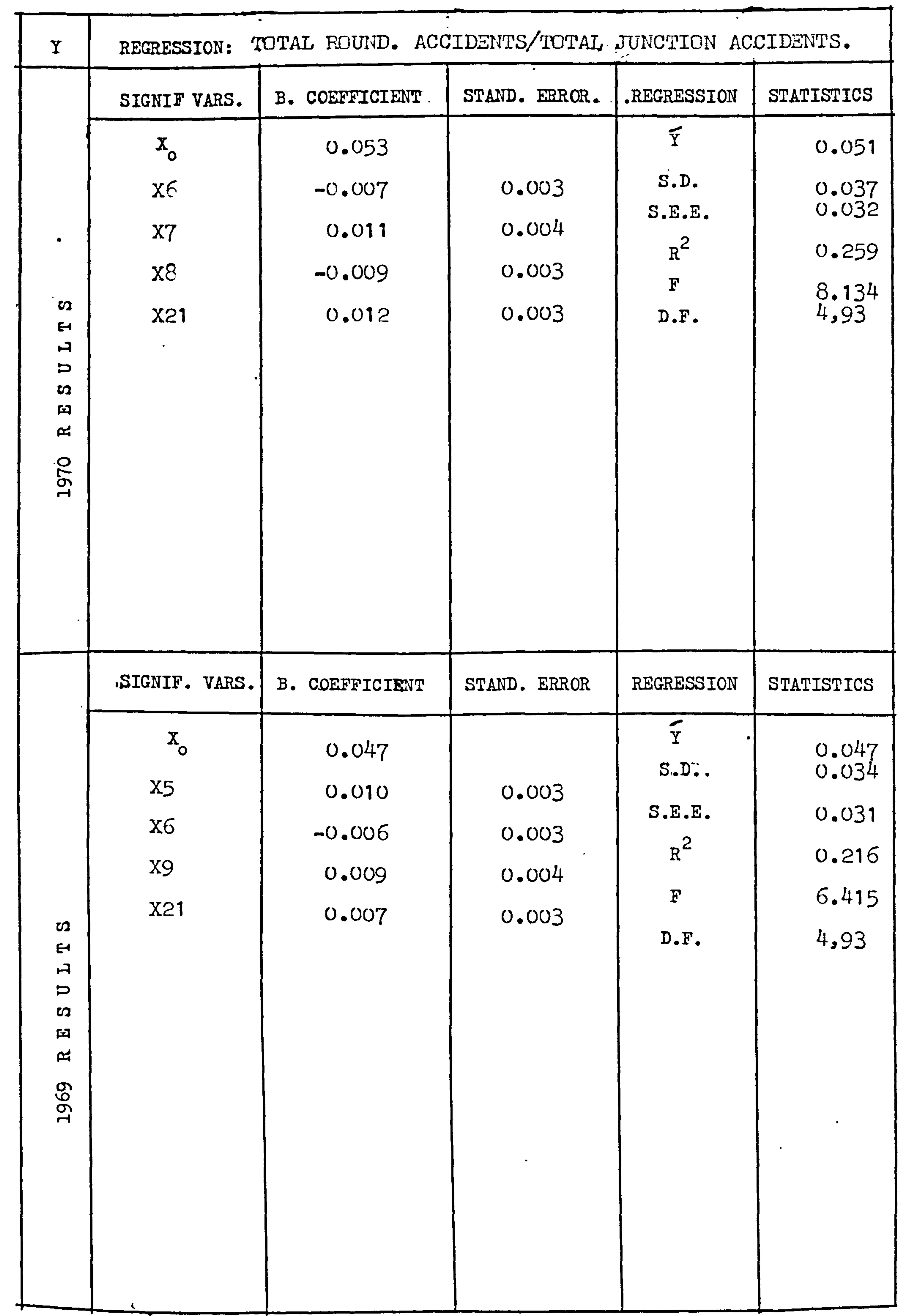




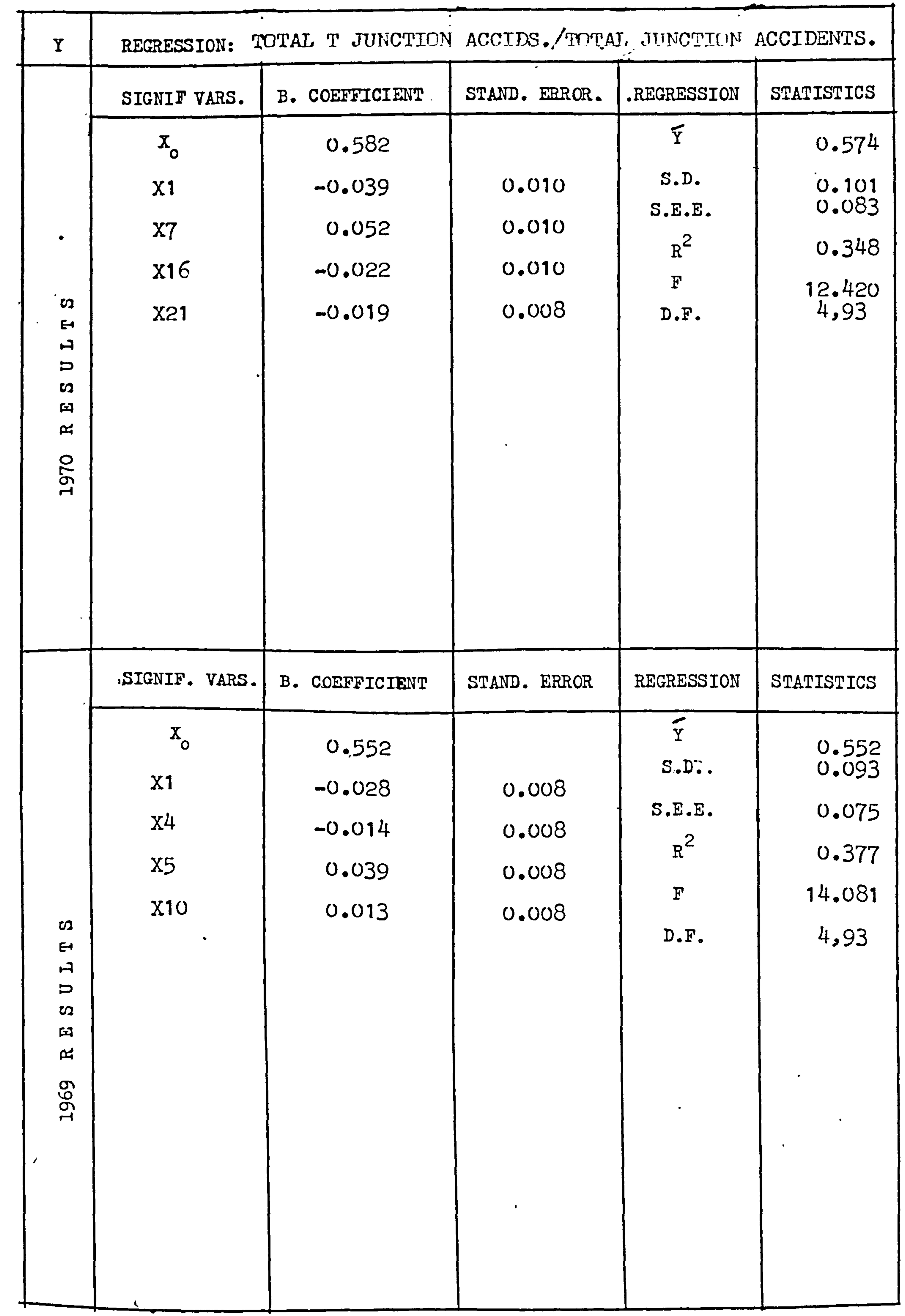




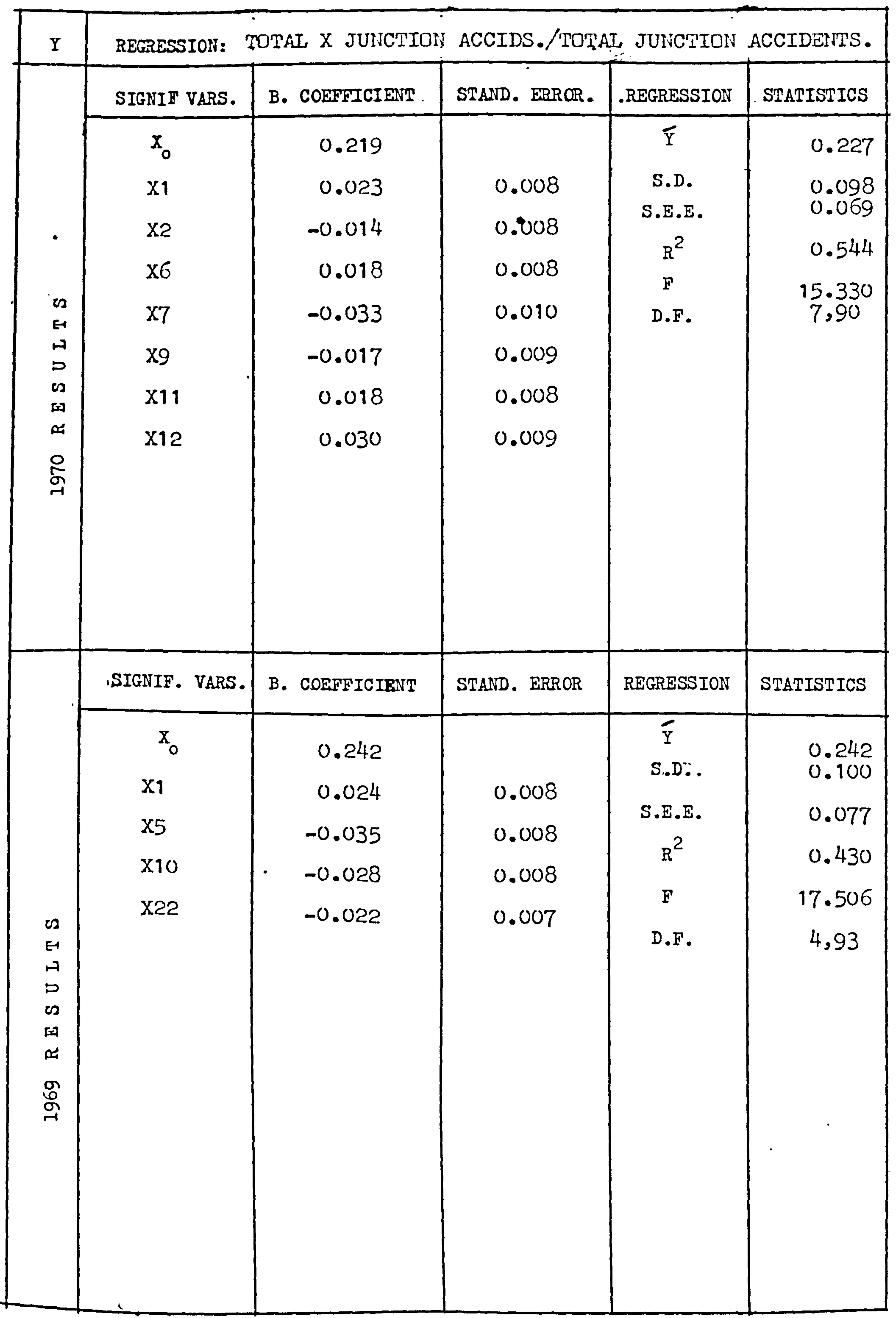




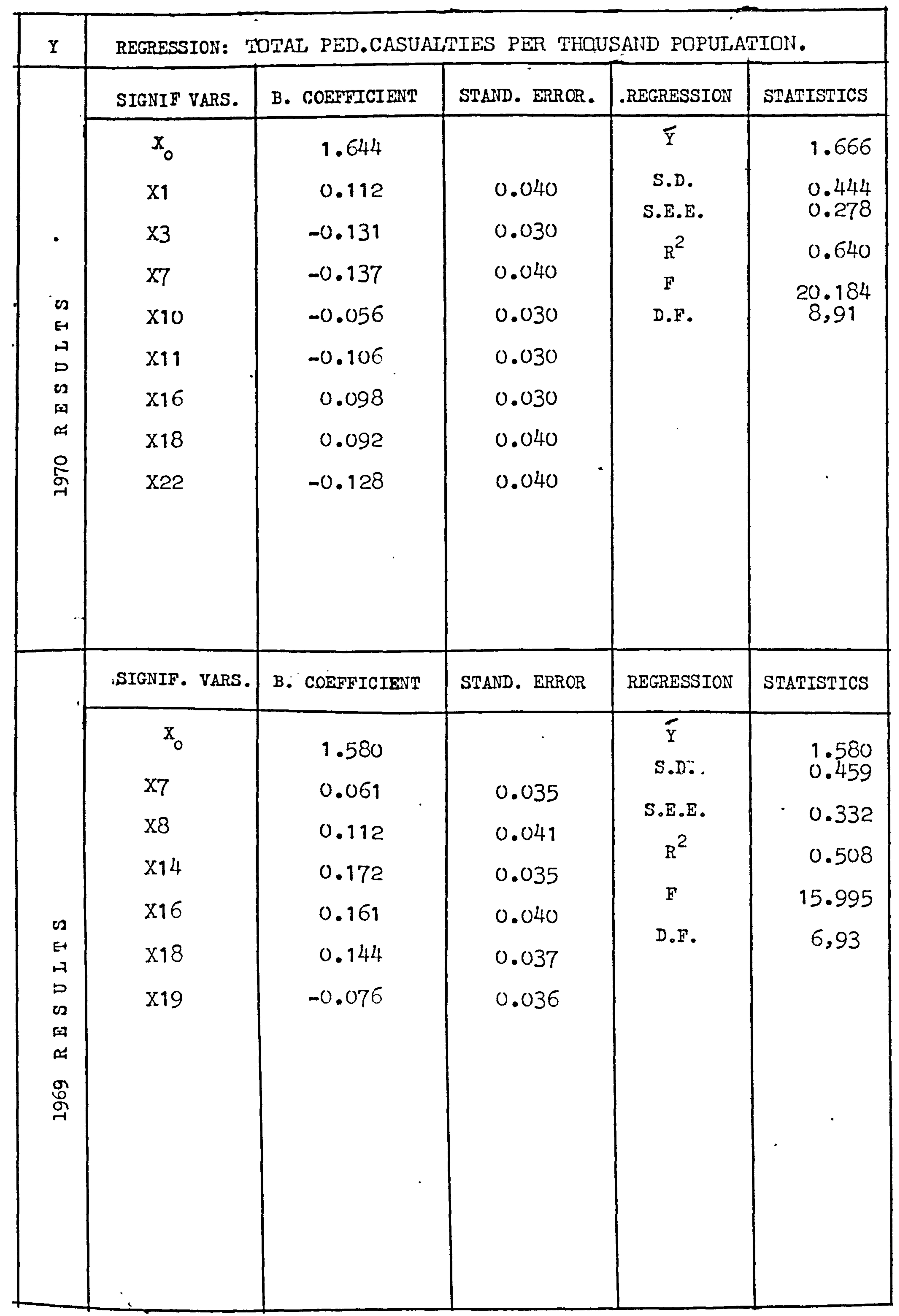




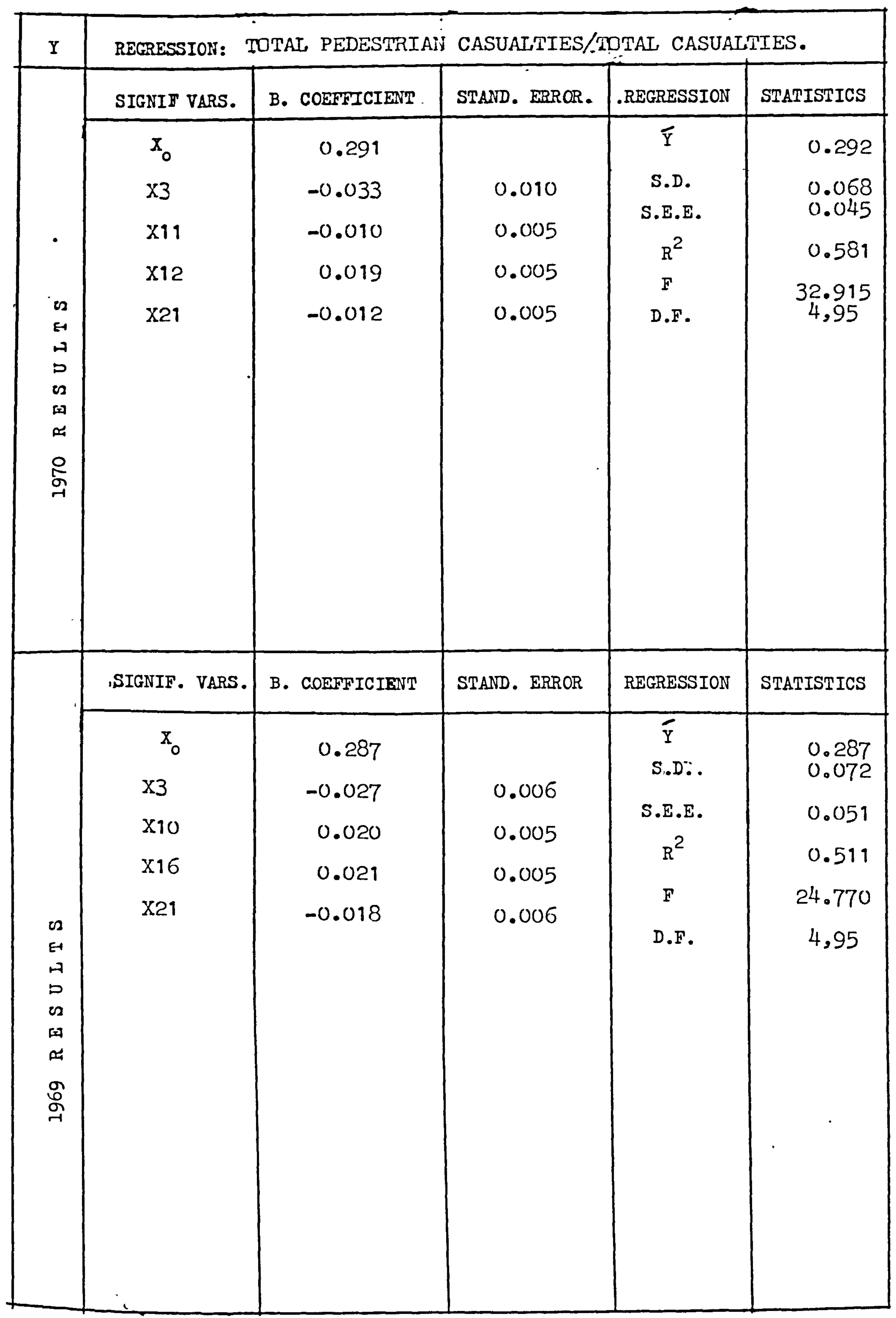




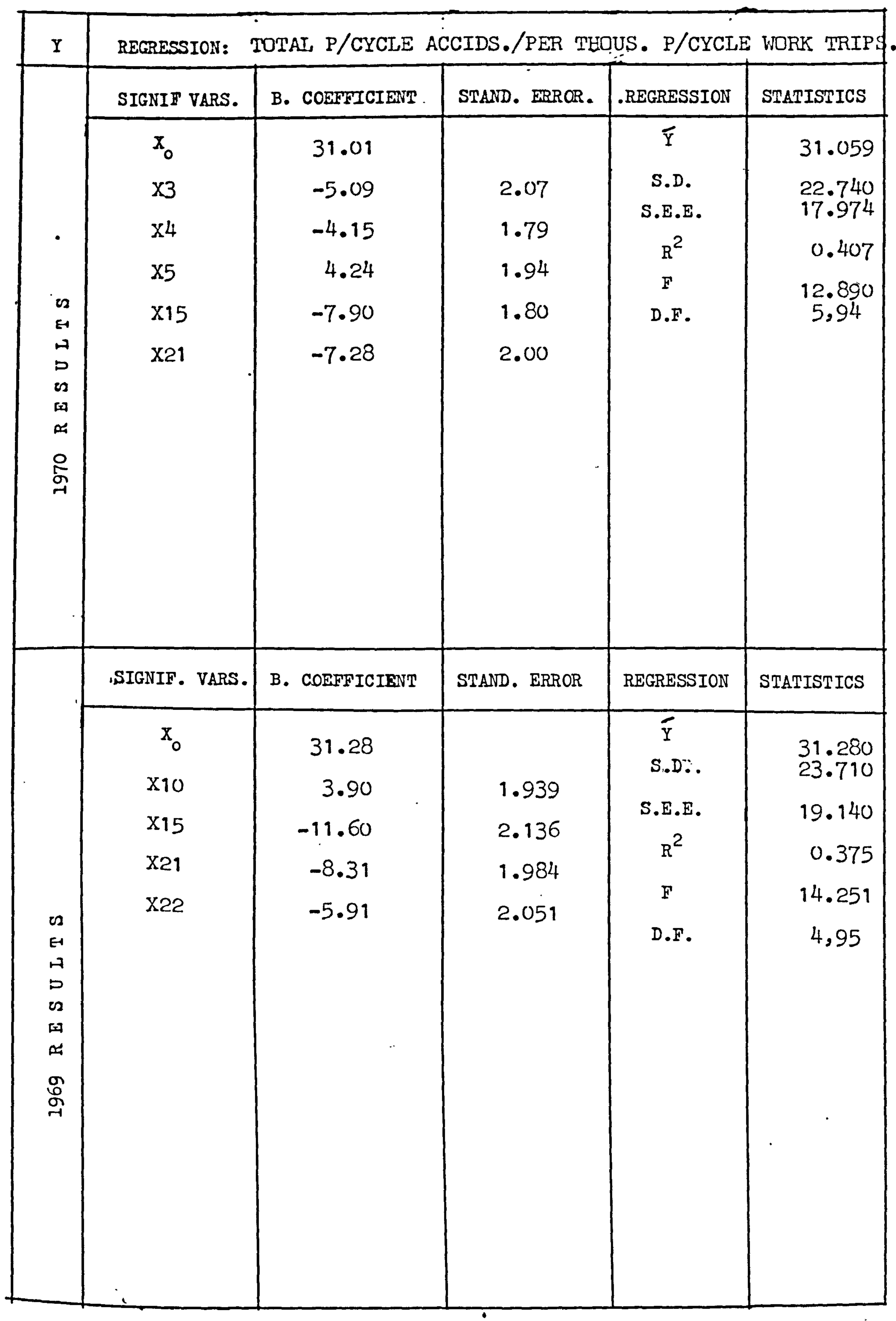




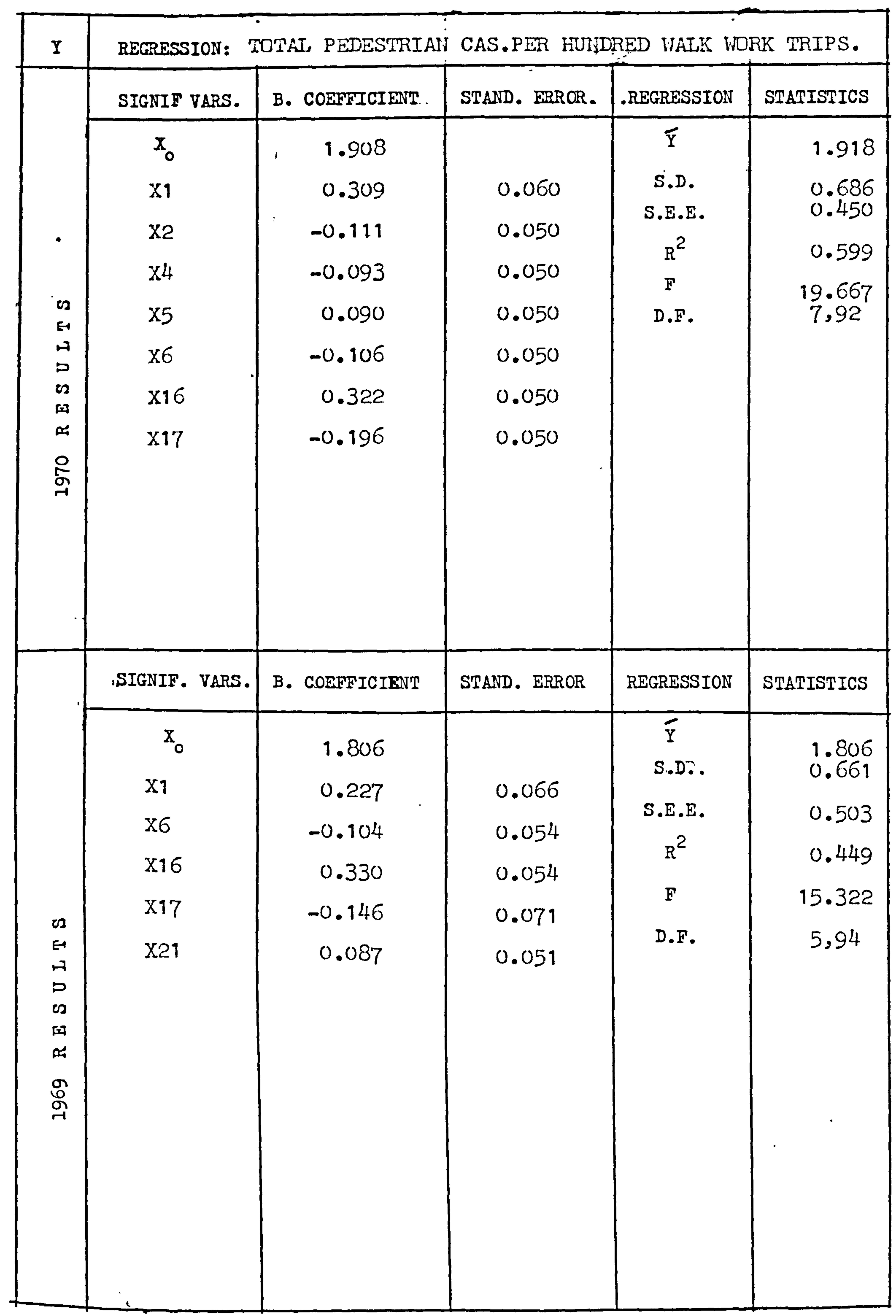




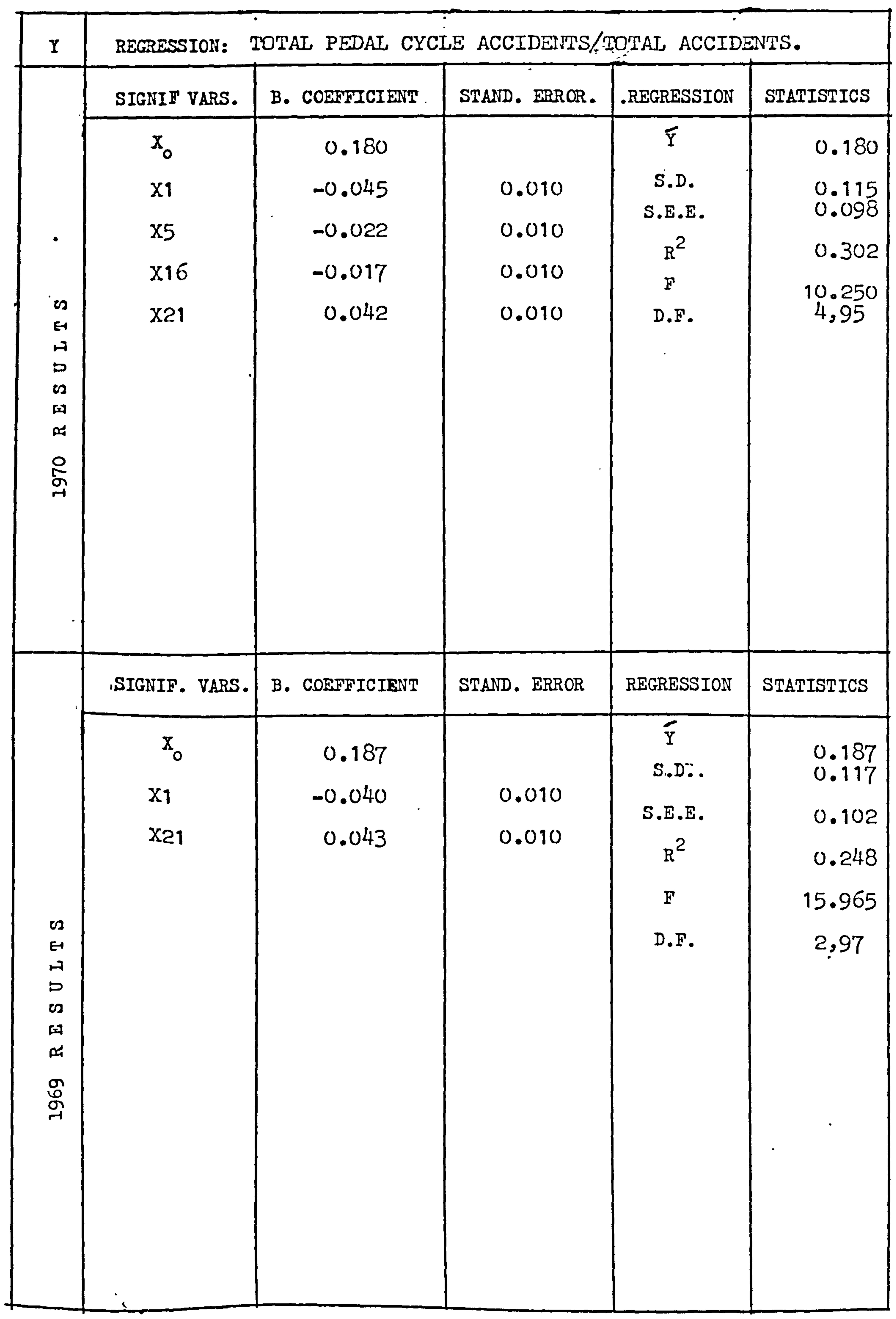




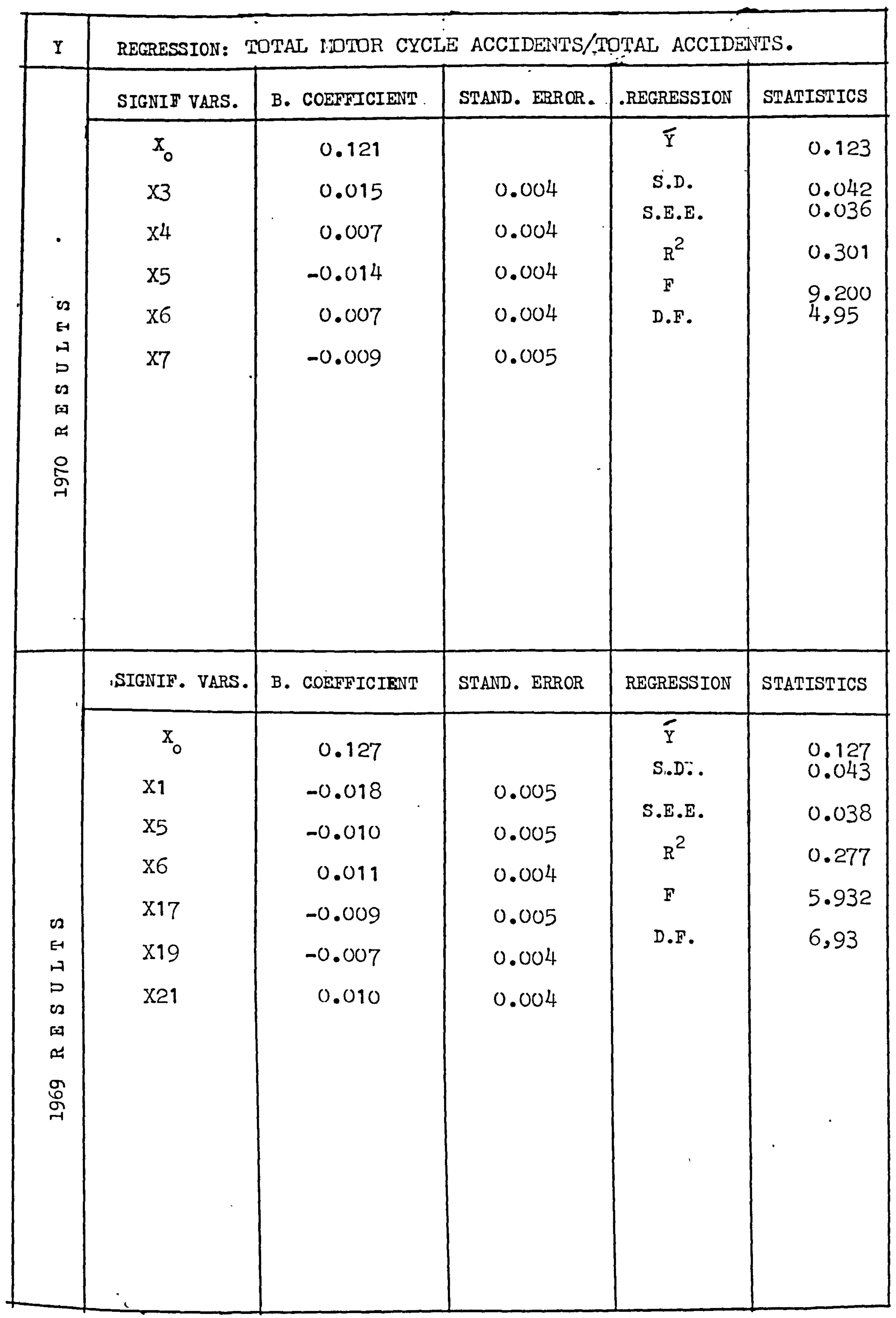




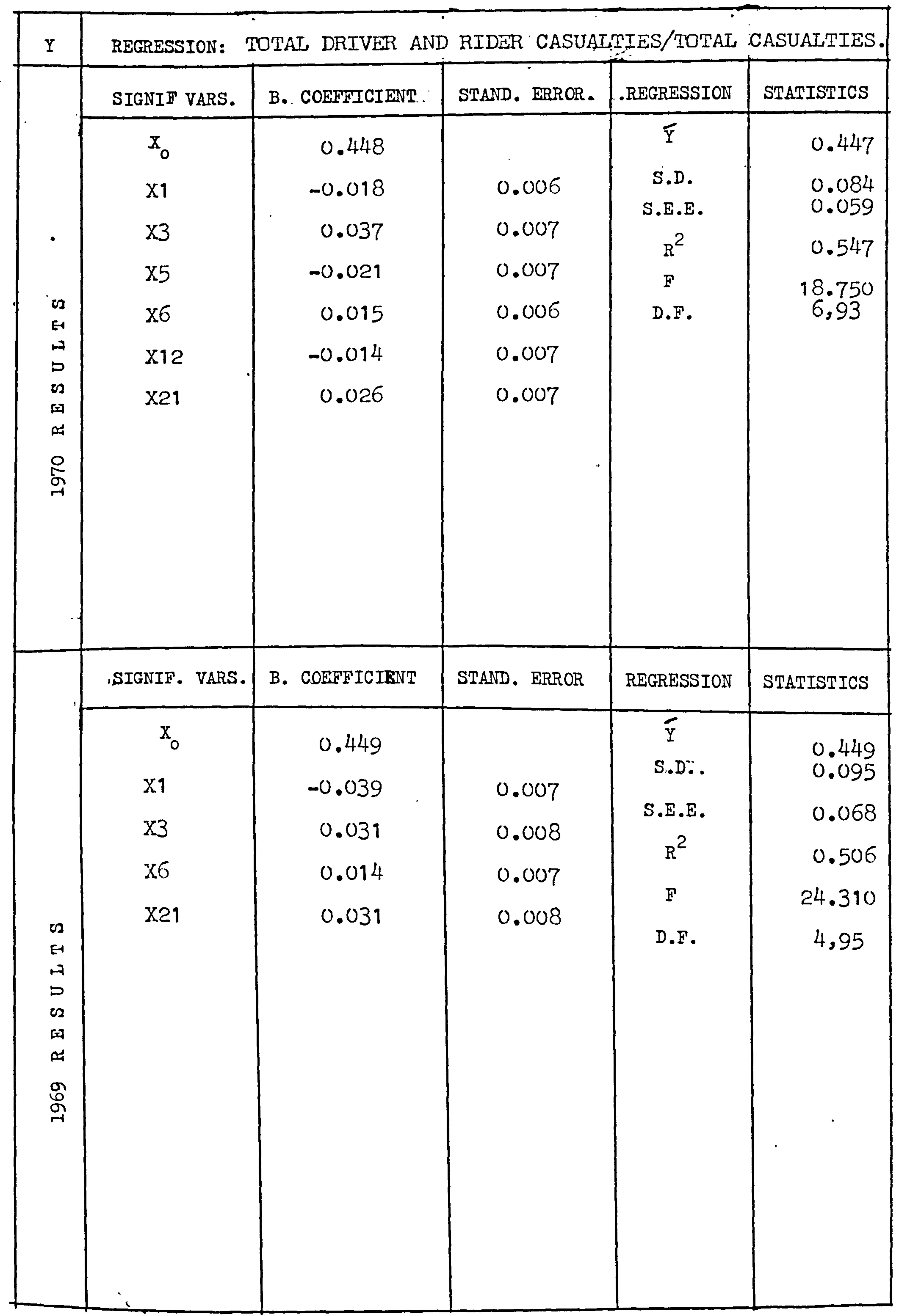




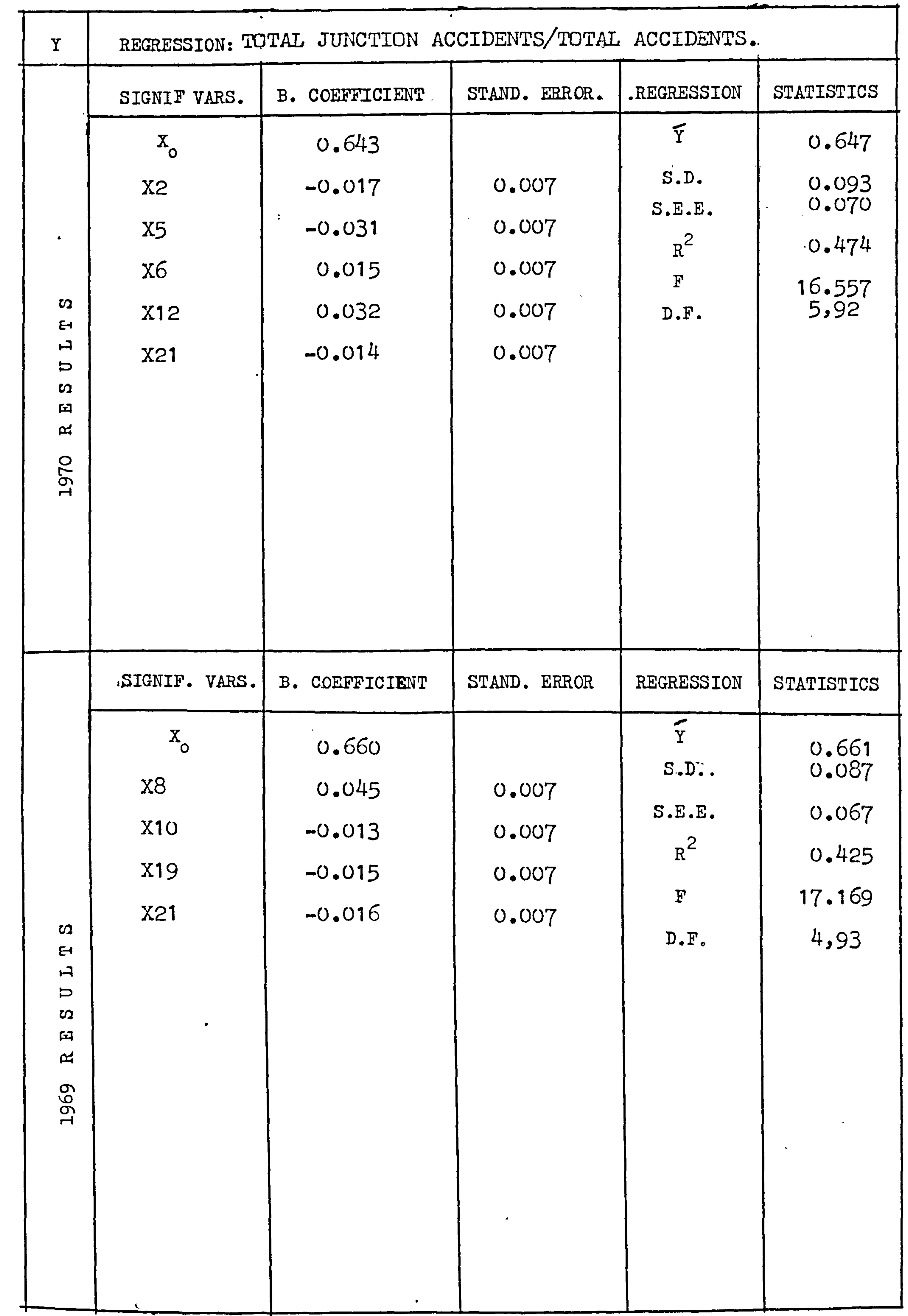


The euthor wishes to express his gratitude to all those people who have helped in the completion and presentation of this research, both as regards acadenic and financial consider ations, wh thin the Departnent of Civil Engineering, Salford Unifersity.

In particular the author would like to thank Dr. S. Raymond for his unswerving support throughout this research and also Mr. R. Thomas for his often invaluable advice as regards the statistical sections of this research.

The author would also like to express his gretitude to the Transport and Road Research Laboratory for the provision of most of the data as regerds road accident statistics.

Finally, the author would also like to thank Mrs. F. Ashburn for her total comitinent to the art of typing, without which the typing of this manuscript could here been long delayed. 